Prepared for the U.S. Department of Energy

under Contract DE-AC05-76RL01830

\title{
Operations \& Maintenance Best Practices - A Guide to Achieving Operational Efficiency (Release 3.0)
}

GP Sullivan

R Pugh
AP Melendez

WD Hunt

August 2010

Pacific Northwest

NATIONAL LABORATORY

Proudly Operated by Battelle Since 1965 


\title{
DISCLAIMER
}

United States Government. Neither the United States Government nor any agency thereof, nor Battelle Memorial Institute, nor any of their employees, makes any warranty, express or implied, or assumes any legal liability or responsibility for the accuracy, completeness, or usefulness of any information, apparatus, product, or process disclosed, or represents that its use would not infringe privately owned rights. Reference herein to any specific commercial product, process, or service by trade name, trademark, manufacturer, or otherwise does not necessarily constitute or imply its endorsement, recommendation, or favoring by the United States Government or any agency thereof, or Battelle Memorial Institute. The views and opinions of authors expressed herein do not necessarily state or reflect those of the United States Government or any agency thereof.

\author{
PACIFIC NORTHWEST NATIONAL LABORATORY \\ operated by \\ BATTELLE \\ for the \\ UNITED STATES DEPARTMENT OF ENERGY \\ under Contract DE-AC05-76RL01830 \\ Printed in the United States of America \\ Available to DOE and DOE contractors from the \\ Office of Scientific and Technical Information, \\ P.O. Box 62, Oak Ridge, TN 37831-0062; \\ ph: (865) 576-8401, fax: (865) 576-5728 \\ email: reports@adonis.osti.gov \\ Available to the public from the National Technical Information Service, \\ U.S. Department of Commerce, 5285 Port Royal Rd., Springfield, VA 22161 \\ ph: (800) 553-6847, fax: (703) 605-6900 \\ email: orders@ntis.fedworld.gov \\ online ordering: http://www.ntis.gov/ordering.htm
}

This document was printed on recycled paper.

$(8 / 00)$ 


\title{
Operations \& Maintenance Best Practices - A Guide to Achieving Operational Efficiency (Release 3.0)
}

\author{
GP Sullivan ${ }^{(a)}$ \\ R Pugh \\ AP Melendez \\ WD Hunt
}

August 2010

Prepared for

Federal Energy Management Program

U.S. Department of Energy

under Contract DE-AC05-76RL01830

Pacific Northwest National Laboratory

Richland, Washington 99352

(a) Efficiency Solutions, LLC 



\section{Preface}

This Operations and Maintenance (O\&M) Best Practices Guide was developed under the direction of the U.S. Department of Energy's Federal Energy Management Program (FEMP). The mission of FEMP is to facilitate the Federal Government's implementation of sound, costeffective energy management and investment practices to enhance the nation's energy security and

environmental stewardship. Each of these activities is directly related to achieving requirements set forth in:

- The Energy Policy Act of 2005, which established a number of energy and water management goals for Federal facilities and fleets and also amended portions of the National Energy Conservation Policy Act (NECPA).

- Executive Order 13423, Strengthening Federal Environmental, Energy, and Transportation Management (signed in January 2007). This set more challenging goals than EPAct 2005 and superseded existing executive orders 13123 and 13149.

- The Energy Independence and Security Act of 2007, which further established energy, water, and building commissioning management goals and requirements and also amended portions of EPAct 2005 and NECPA. EISA was signed into law in December 2007.

- Executive Order 13514, Federal Leadership in Environmental, Energy and Economic Performance (signed in October of 2009) directs Federal agencies to further address energy, water, and operational efficiency beyond E.O. 13423 with targeted goals and actions.

Release 3.0 of this guide provides updates to Release 2.0 in the areas of $O \& M$ technologies, equipment performance, and costs. This new release also addresses water use and the impacts that recommended $O \& M$ practices can have on water efficiency.

Overall, this guide highlights O\&M programs targeting energy and water efficiency that are estimated to save $5 \%$ to $20 \%$ on energy bills without a significant capital investment. Depending on the Federal site, these savings can represent thousands to hundreds-of-thousands dollars each year, and many can be achieved with minimal cash outlays. In addition to energy/resource savings, a well-run O\&M program will:

- Increase the safety of all staff, as properly maintained equipment is safer equipment.

- Ensure the comfort, health, and safety of building occupants through properly functioning equipment providing a healthy indoor environment.

- Confirm the design life expectancy of equipment is achieved.

- Facilitate the compliance with the above-mentioned Acts and Orders as well as Federal legislation such as the Clean Air Act and the Clean Water Act, as well as expected carbon mitigation legislation.

The focus of this guide is to provide the Federal O\&M/Energy manager and practitioner with information and actions aimed at achieving these savings and benefits. 



\section{Acknowledgments}

This report is the result of numerous people working to achieve a common goal of improving operations and maintenance and energy/water efficiency across the Federal sector. The authors wish to acknowledge the contribution and valuable assistance provided by the staff of the Federal Energy Management Program (FEMP). Specifically, we would like to thank Ab Ream and Shawn Herrera, FEMP Program Managers, for their leadership and support of the FEMP Operations and Maintenance program.

In addition, the authors would like to recognize Bill Sandusky of the Pacific Northwest National Laboratory (PNNL) for his continued commitment and recognition of the resource savings potential of O\&M to the Federal sector. Also from PNNL, Eric Richman and Carol Jones, and Hayden McKay of Hayden McKay Lighting Design, Inc. for their work on the Lighting section of this document.

Beth Shearer, of Beth Shearer and Associates, provided a conscientious review of material provided in this version of the document. She provided invaluable comments and suggestions to improve the quality of the document.

Finally, the authors would like to extend their appreciation to PNNL's document production team - Dave Payson and Elaine Schneider - for the conscientious, team-oriented, and high quality assistance they brought to this version of the document. 



\section{Contents}

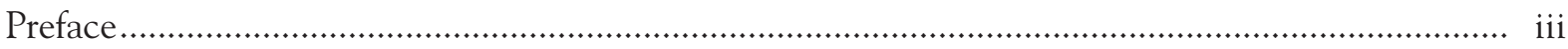

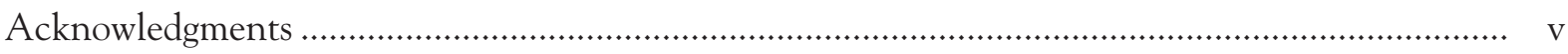

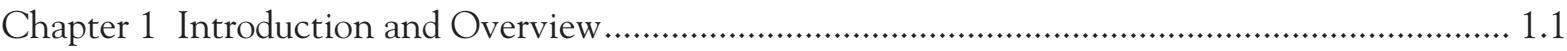

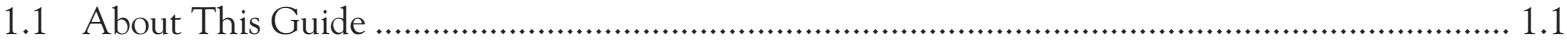

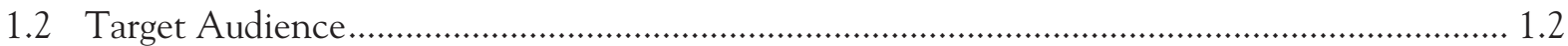

1.3 Organization and Maintenance of the Document ................................................................. 1.2

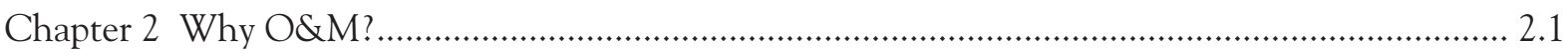

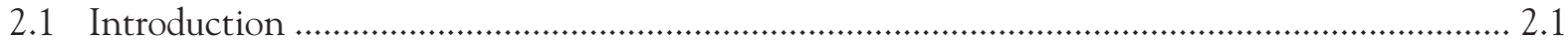

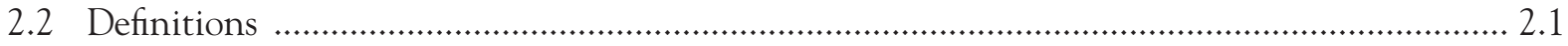

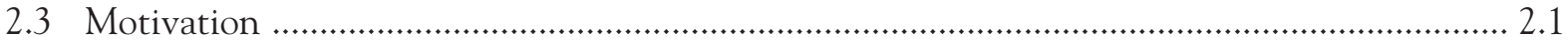

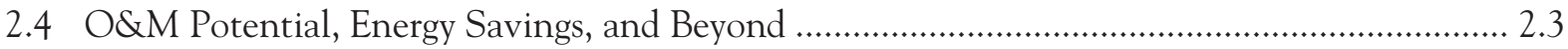

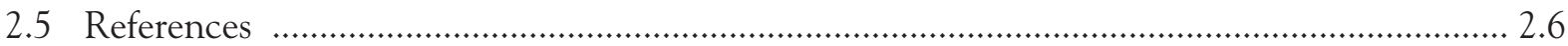

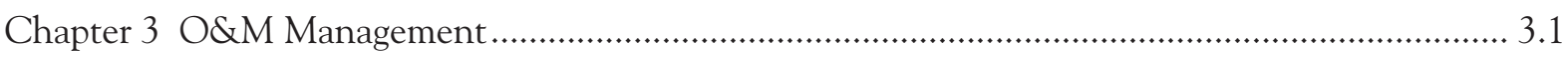

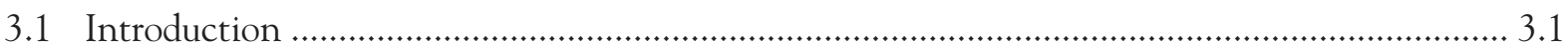

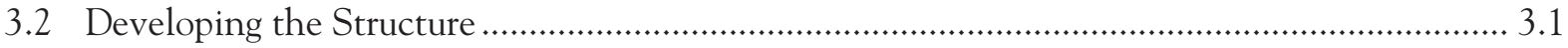

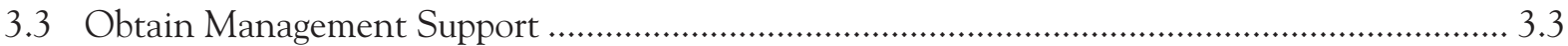

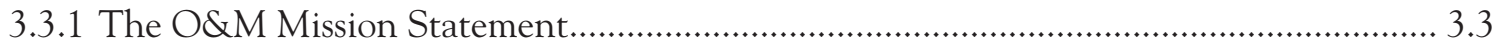

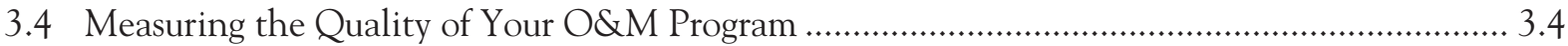

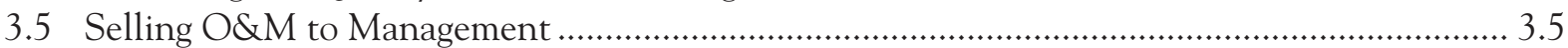

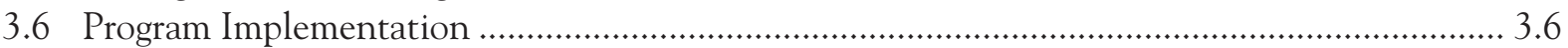

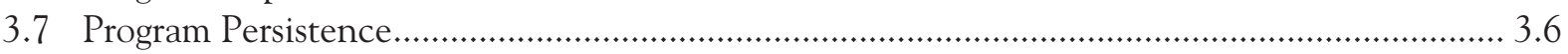

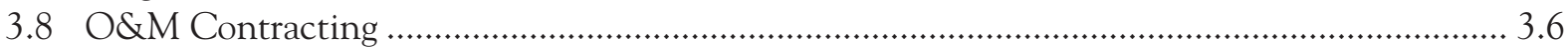

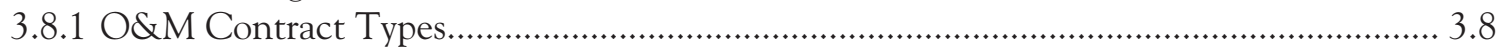

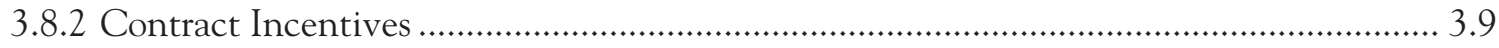

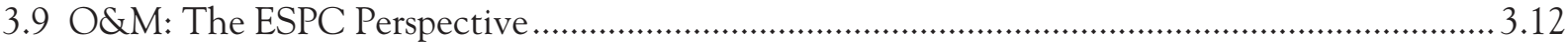

3.9.1 O\&M Needs for Verified and Persistent Savings ............................................................... 3.12

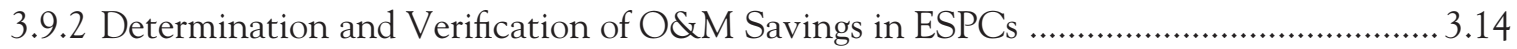

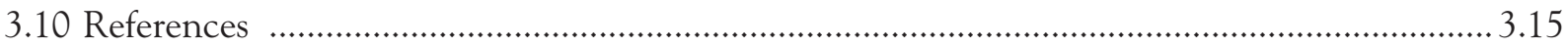

Chapter 4 Computerized Maintenance Management System ....................................................... 4.1

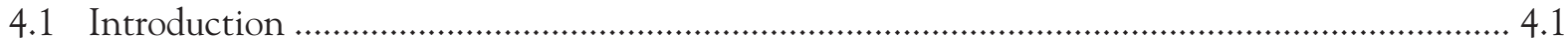

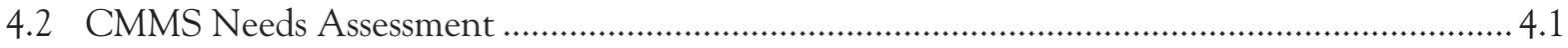

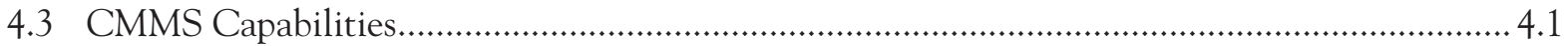

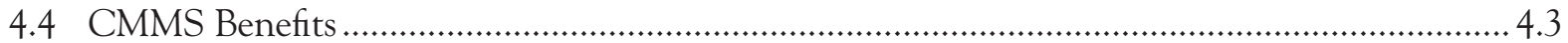

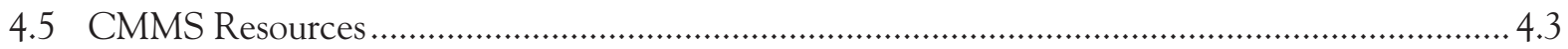

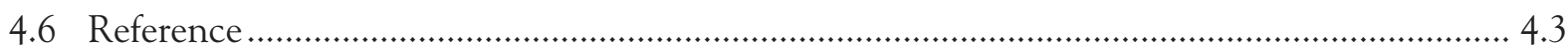


Chapter 5 Types of Maintenance Programs ….............................................................................. 5.1

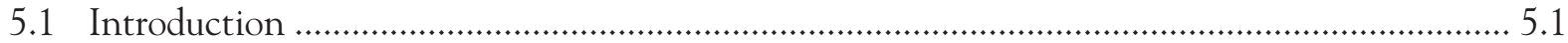

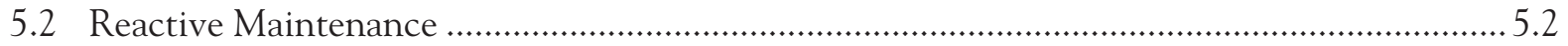

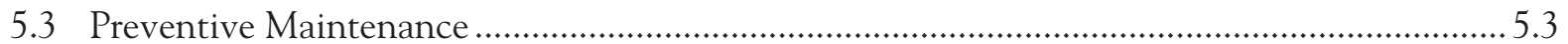

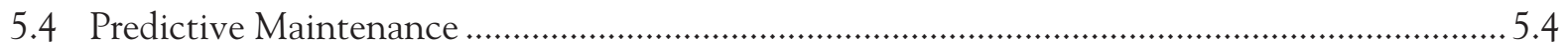

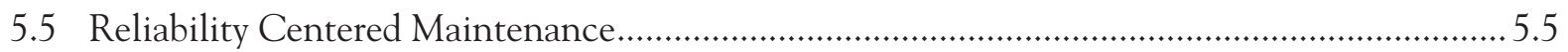

5.6 How to Initiate Reliability Centered Maintenance.................................................................. 5.6

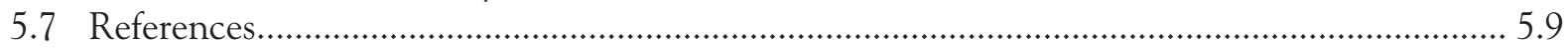

Chapter 6 Predictive Maintenance Technologies ........................................................................... 6.1

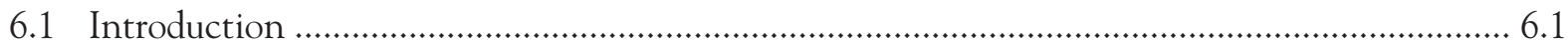

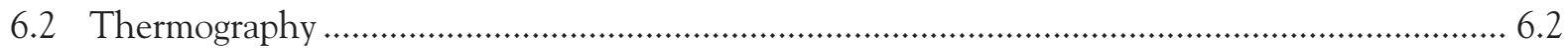

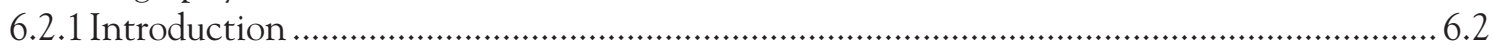

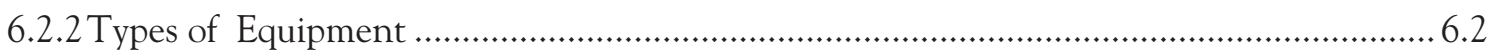

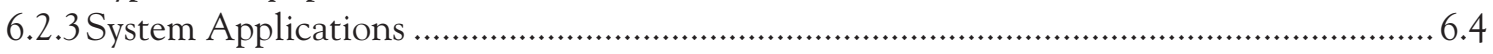

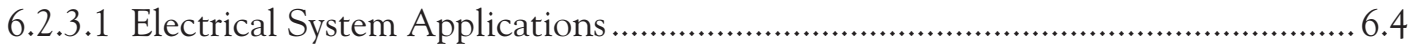

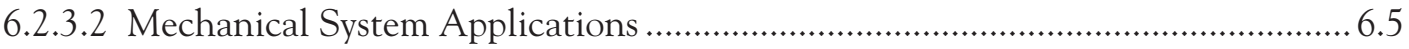

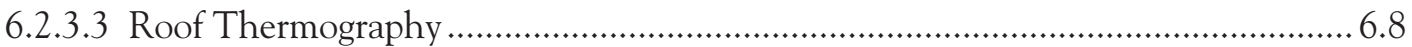

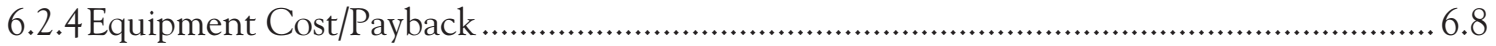

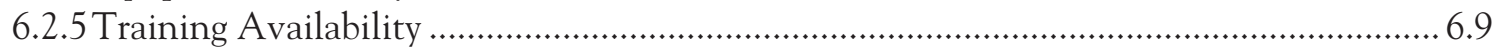

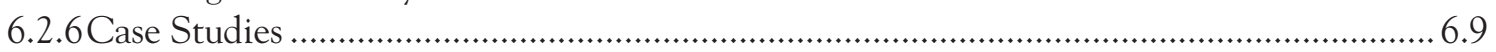

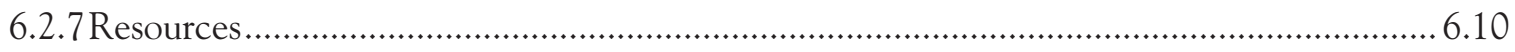

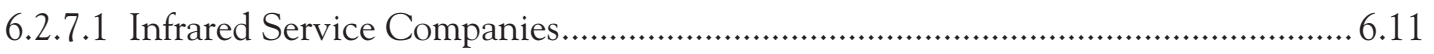

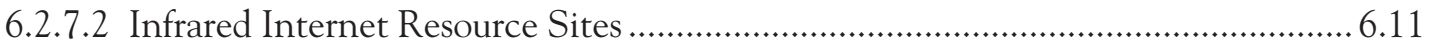

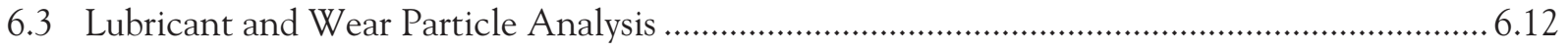

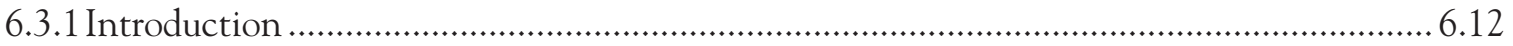

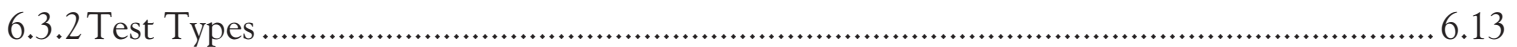

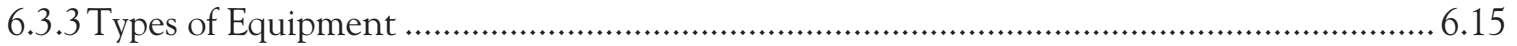

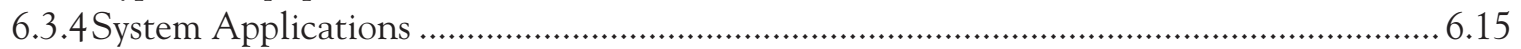

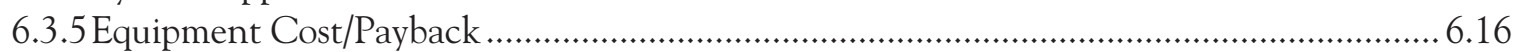

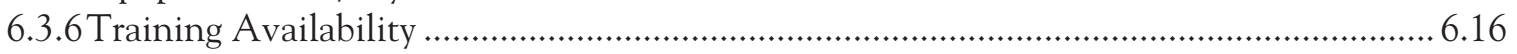

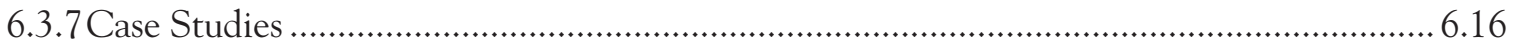

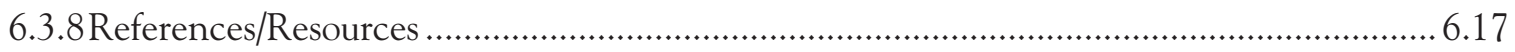

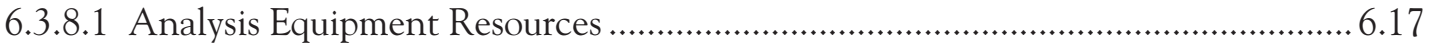

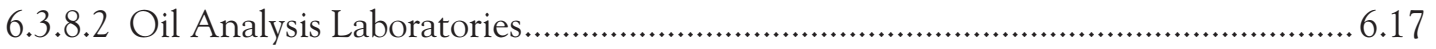

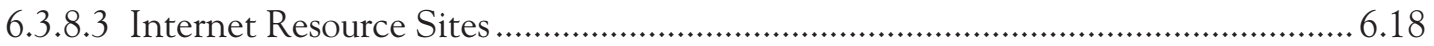

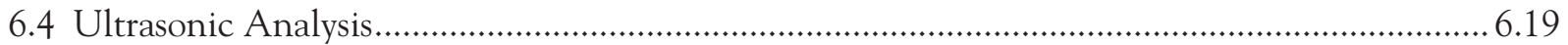

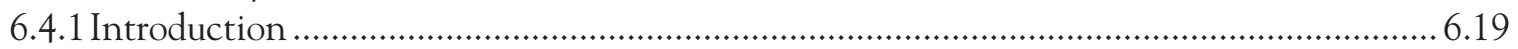

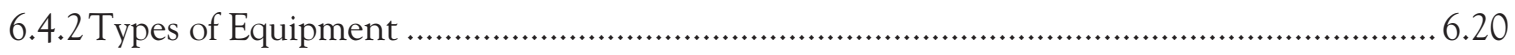

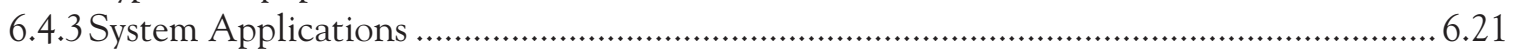

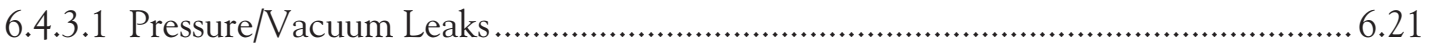

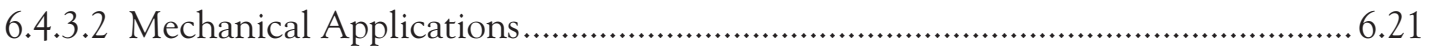

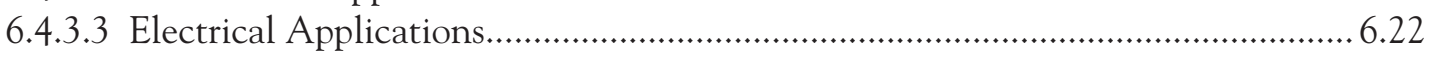

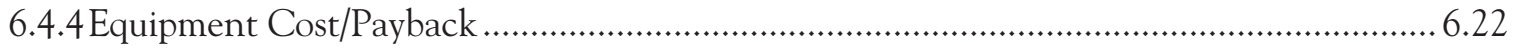

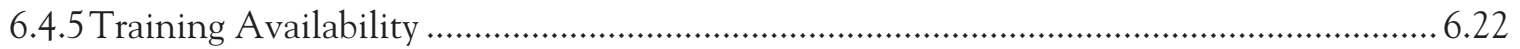

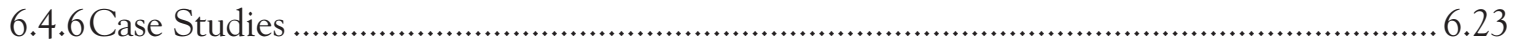

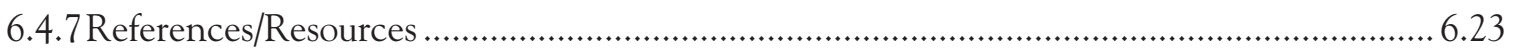




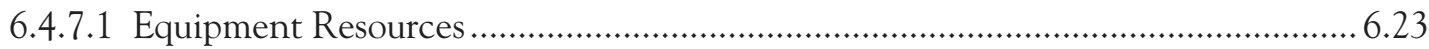

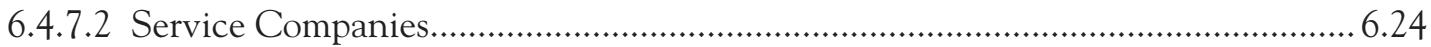

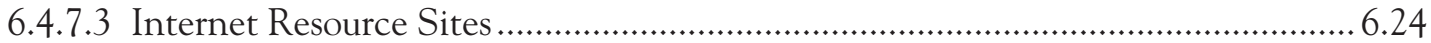

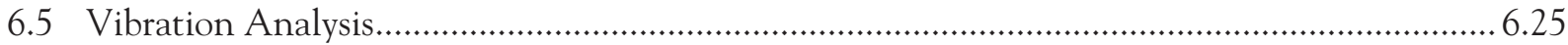

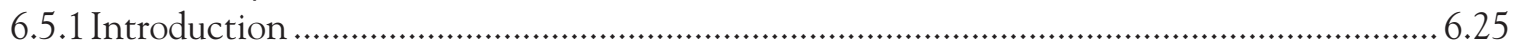

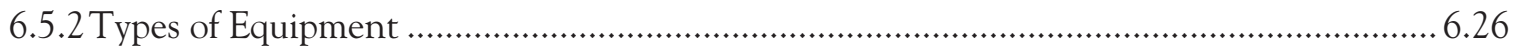

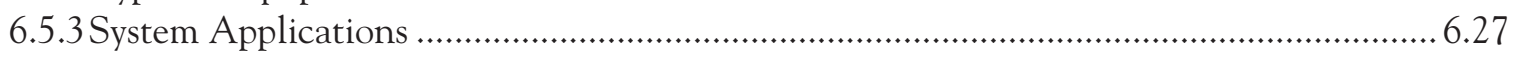

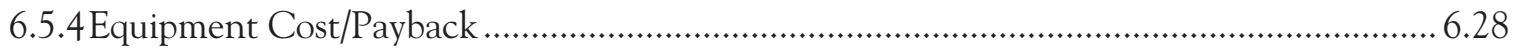

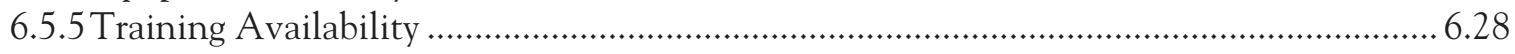

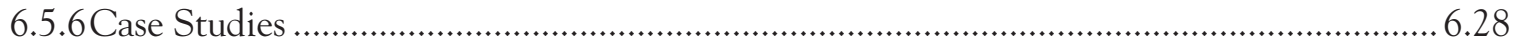

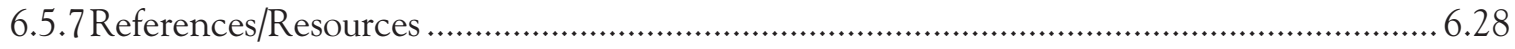

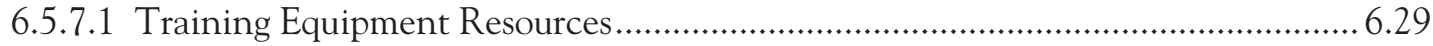

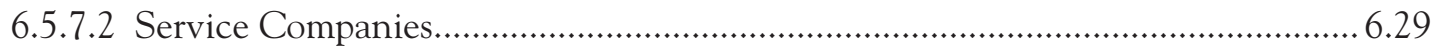

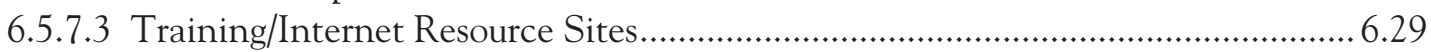

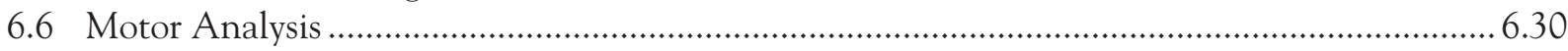

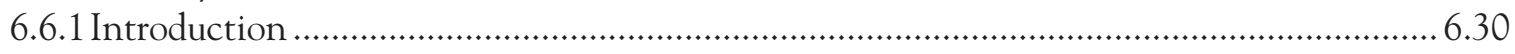

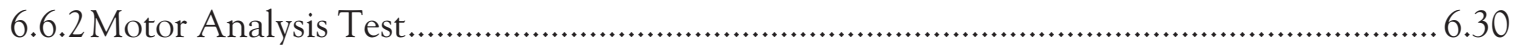

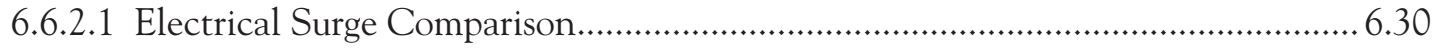

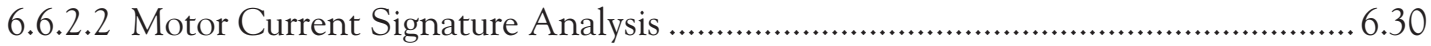

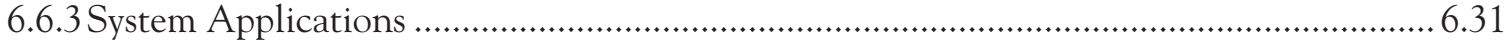

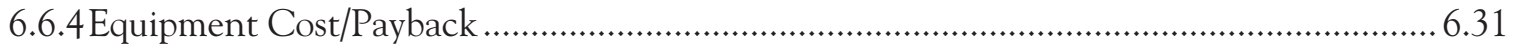

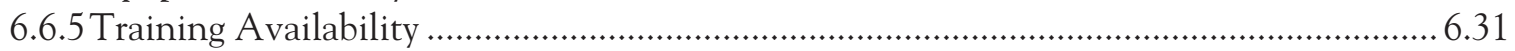

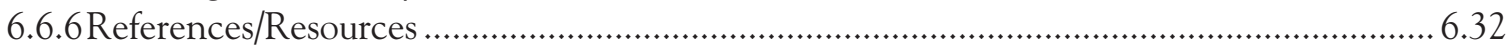

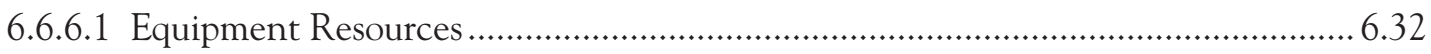

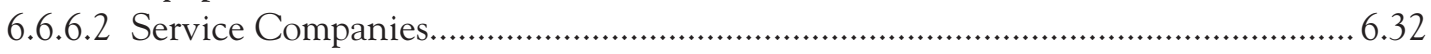

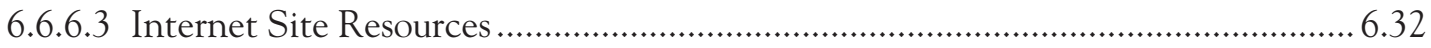

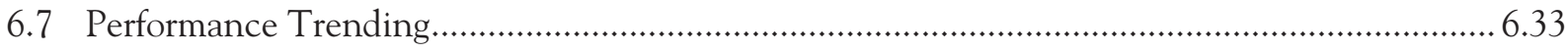

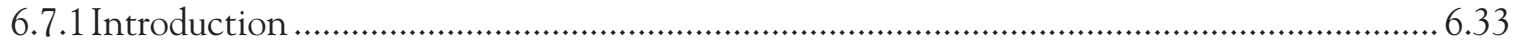

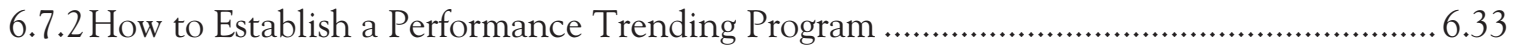

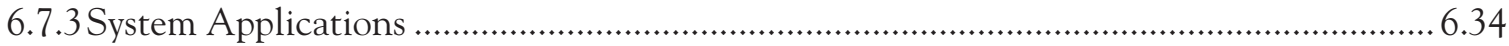

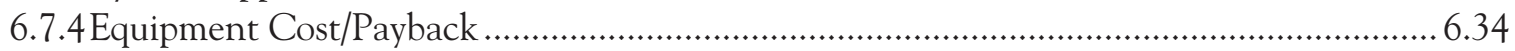

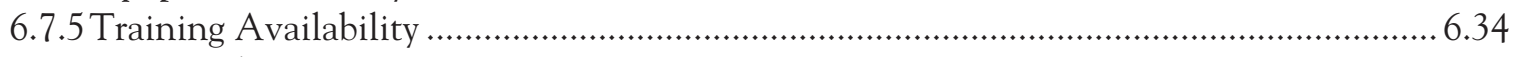

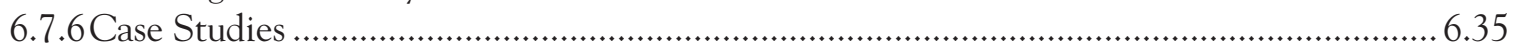

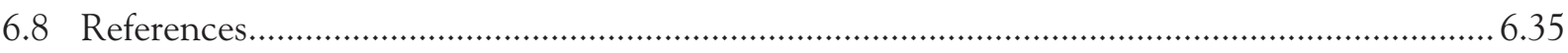

Chapter 7 Commissioning Existing Buildings.......................................................................... 7.1

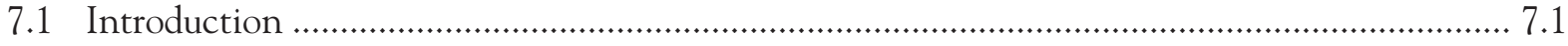

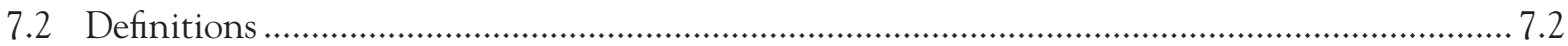

7.3 Typical Findings from Existing Building Commissioning …................................................... 7.4

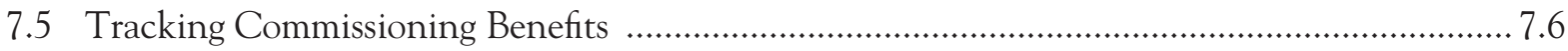

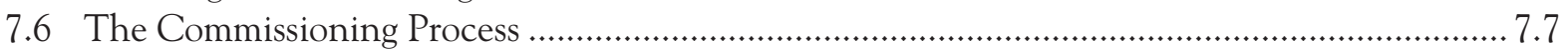

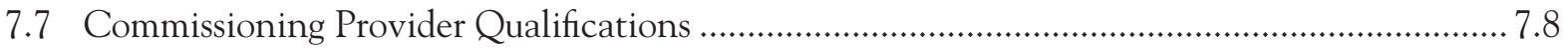

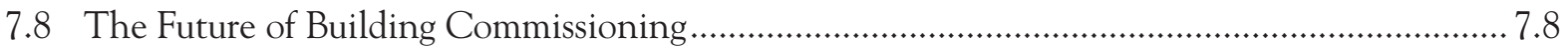

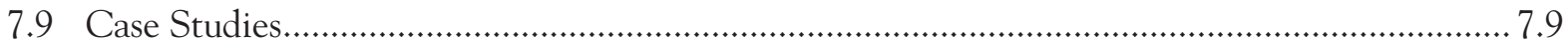

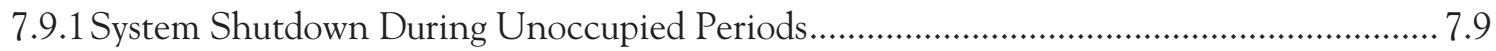

7.9.2 In-House Recommissioning at a DOE National Laboratory ............................................ 7.10 


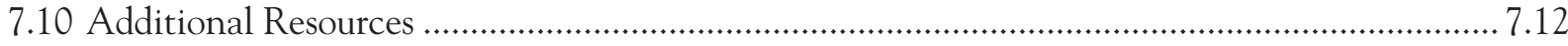

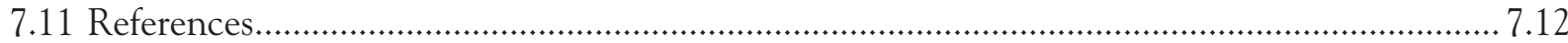

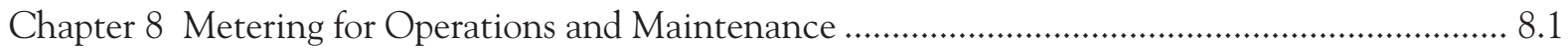

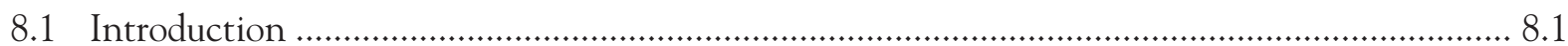

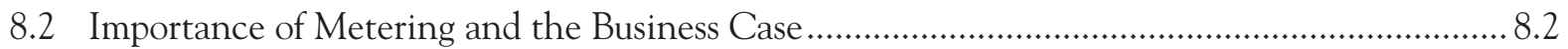

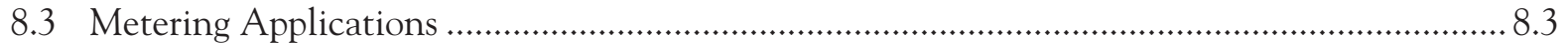

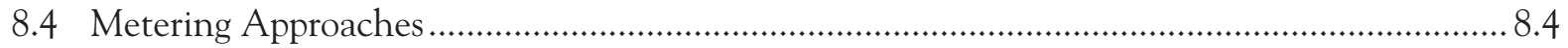

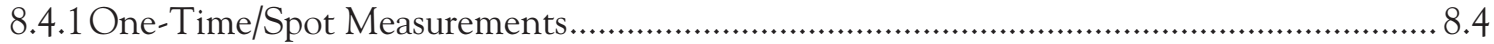

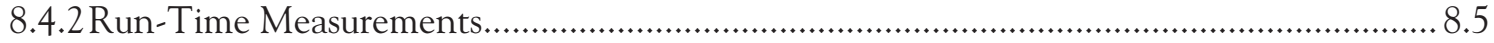

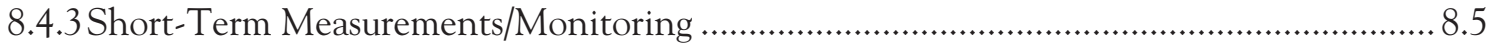

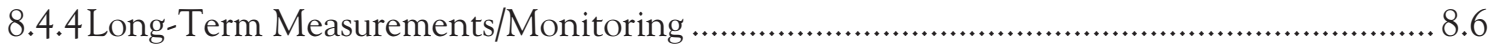

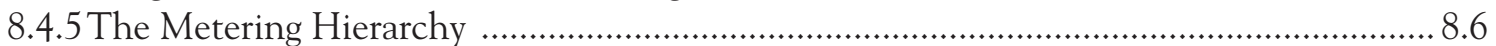

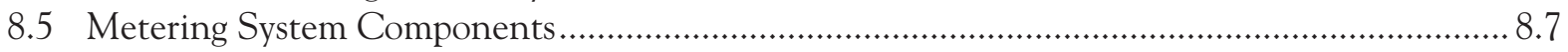

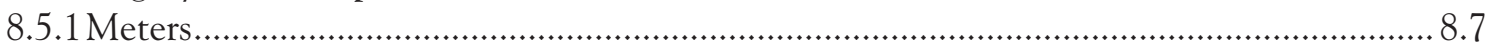

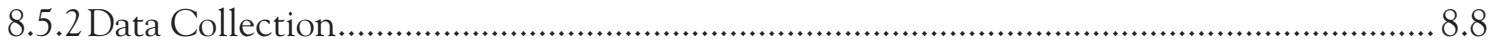

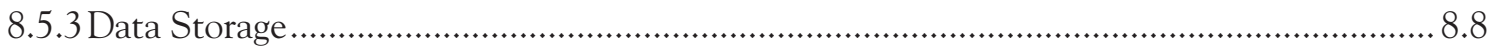

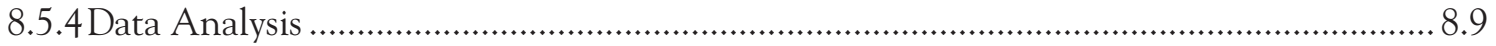

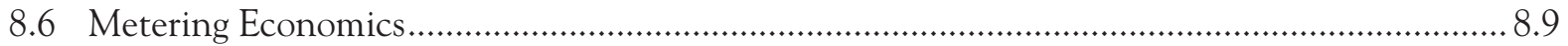

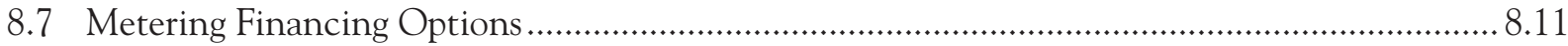

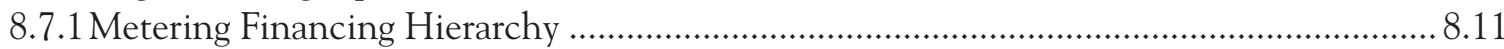

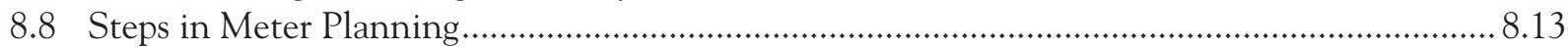

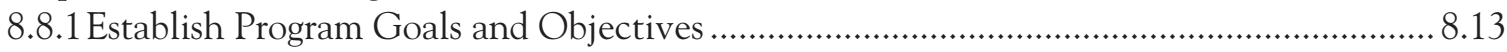

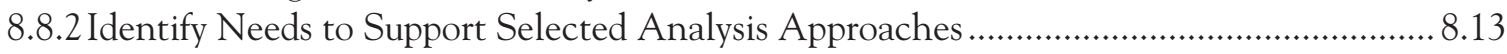

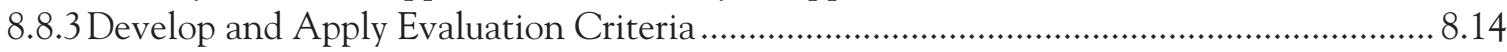

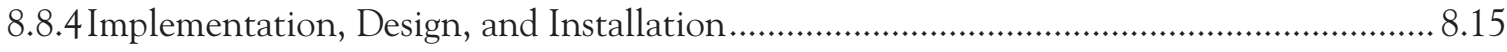

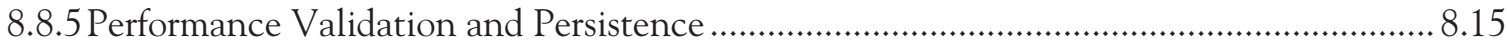

8.9 Case Study - General Services Administration's Kastenmeier Federal Courthouse ..................8.15

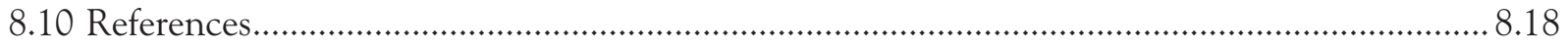

Chapter 9 O\&M Ideas for Major Equipment Types ............................................................................. 9.1

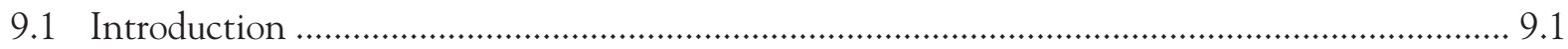

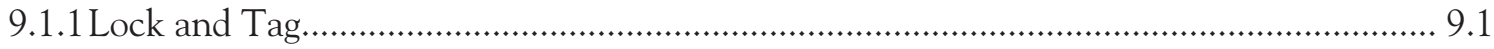

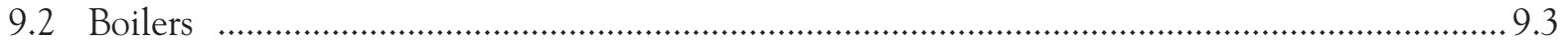

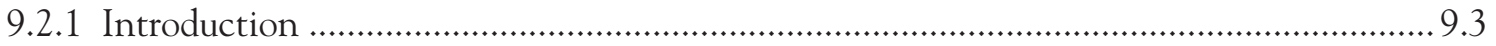

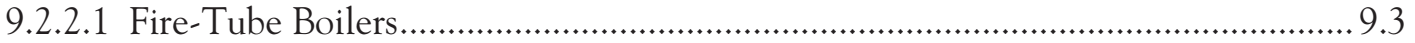

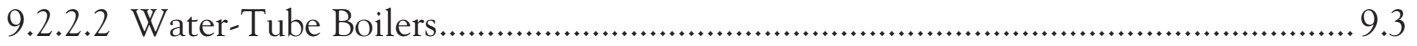

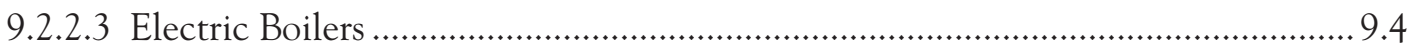

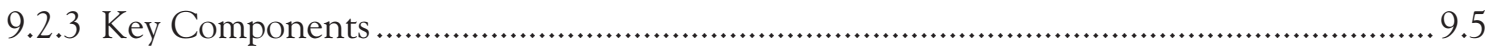

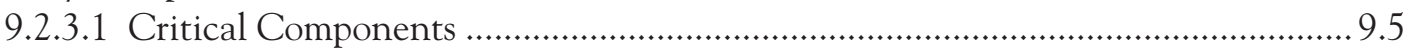

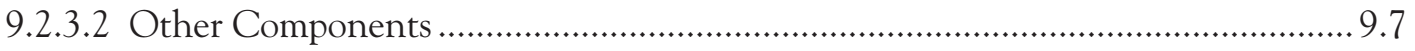

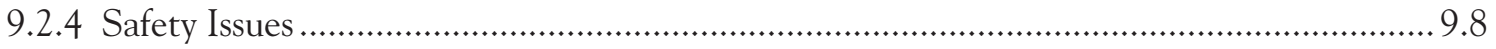

9.2.5.1 Efficiency, Safety, and Life of the Equipment...................................................... 9.9

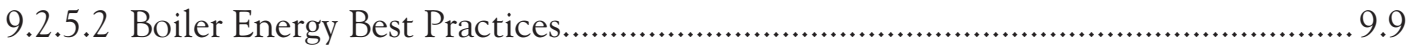

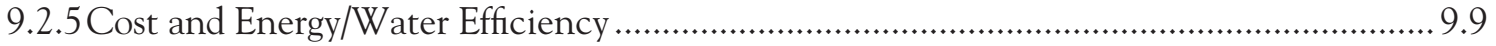

9.2.5.1 Efficiency, Safety, and Life of the Equipment......................................................9.

9.2.5.2 Boiler Energy Best Practices............................................................................. 9.9 


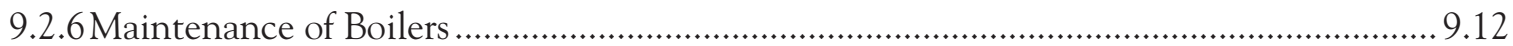

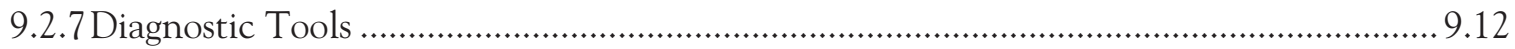

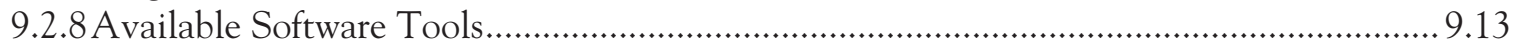

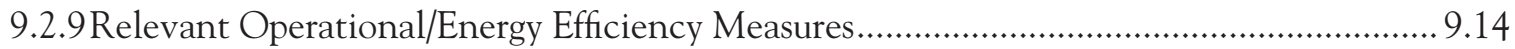

9.2.9.1 Boiler Measure \#1: Boiler Loading, Sequencing, Scheduling, and Control.........9.14

9.2.9.2 Boiler Measure \#2: Boiler Combustion Efficiency .............................................. 9.17

9.2.9.3 Boiler Measure \#3: Trending Boiler Stack Temperature....................................9.20

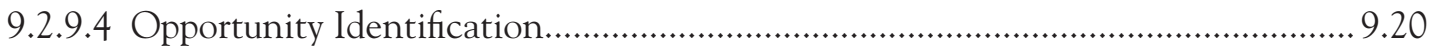

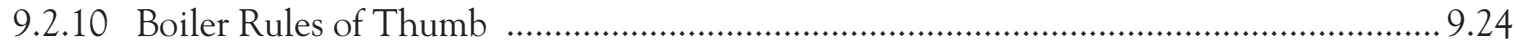

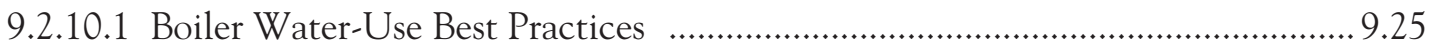

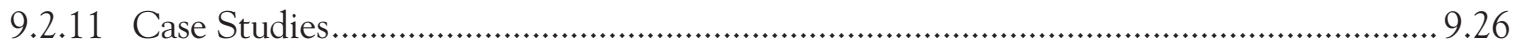

9.2.12 Boiler Checklist, Sample Boiler Maintenance Log, and Water Quality Test ...............9.26

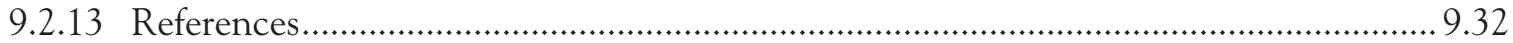

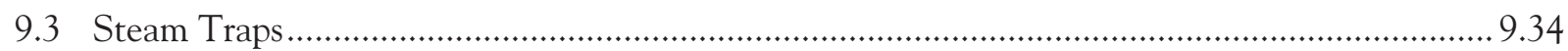

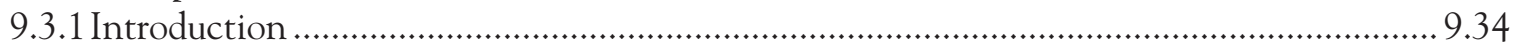

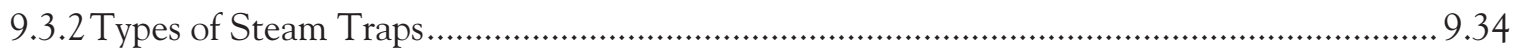

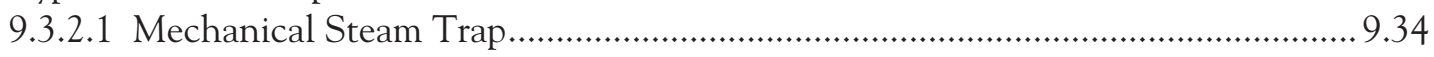

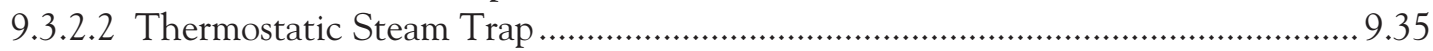

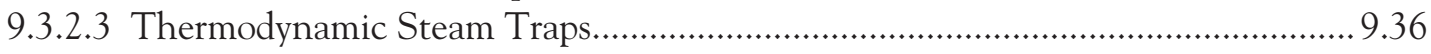

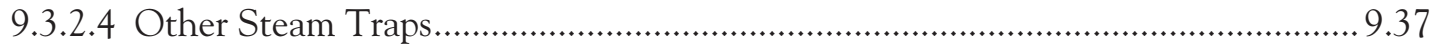

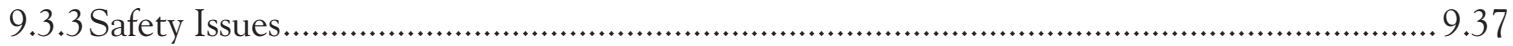

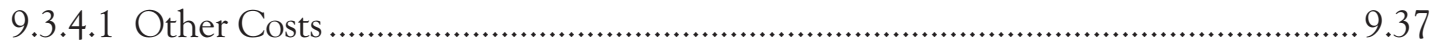

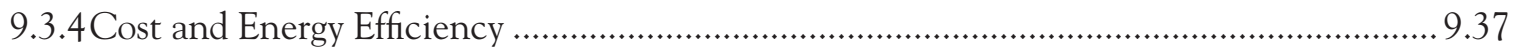

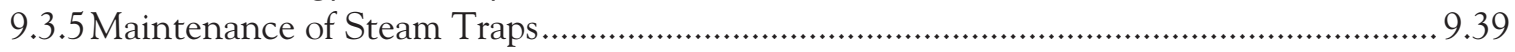

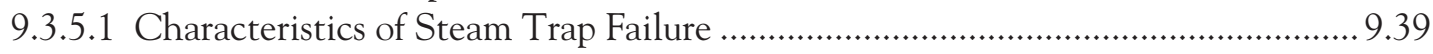

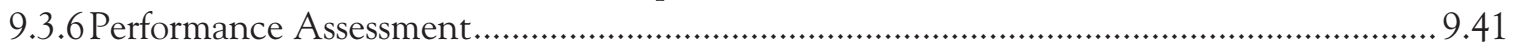

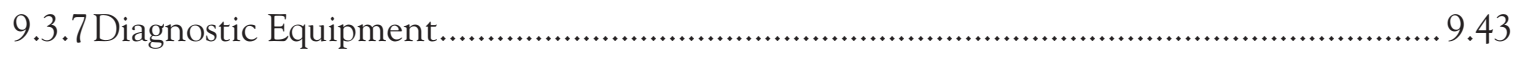

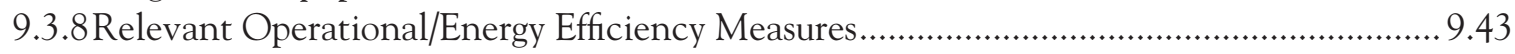

9.3.8.1 Steam Trap Water-Use Best Practices.................................................................. 9.45

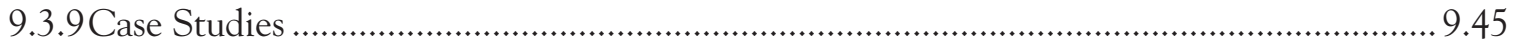

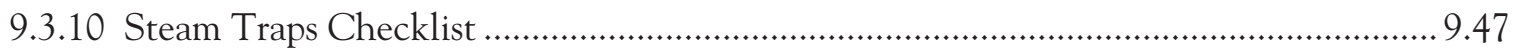

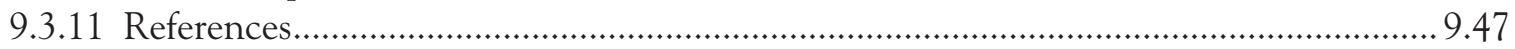

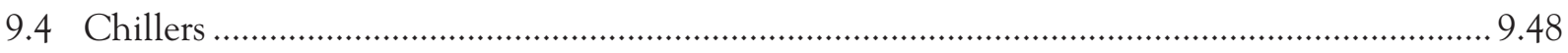

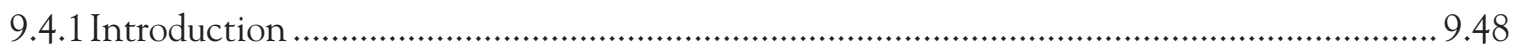

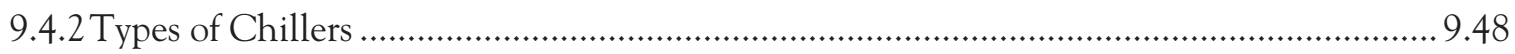

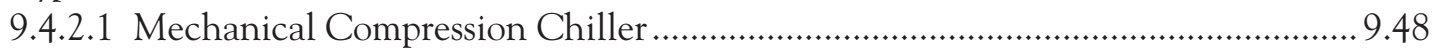

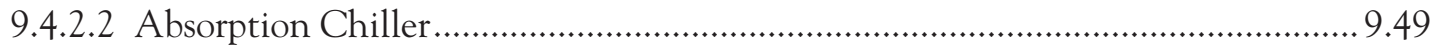

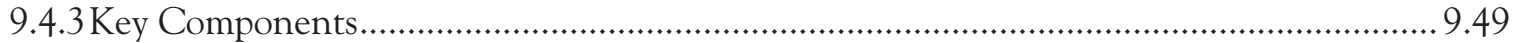

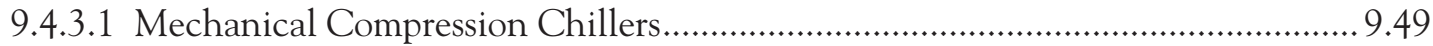

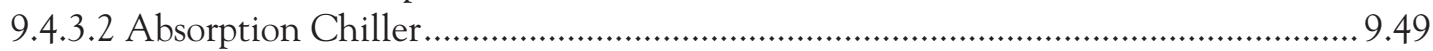

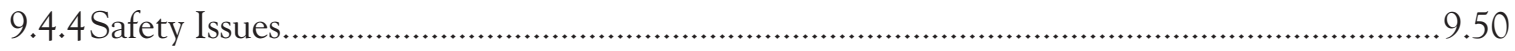

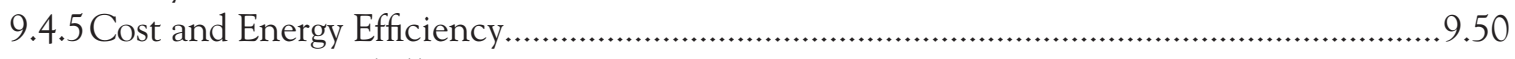

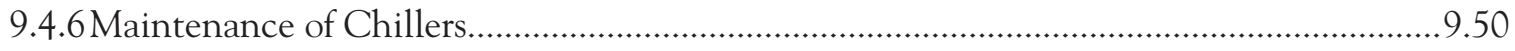

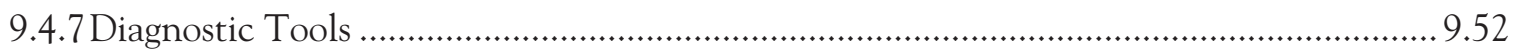

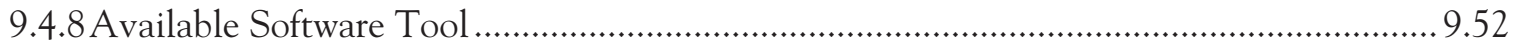

9.4.9Relevant Operational/Energy Efficiency Measures ...............................................................5. 9.53

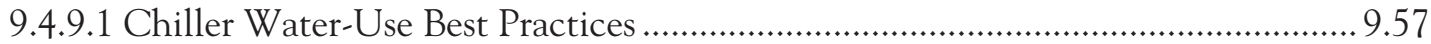

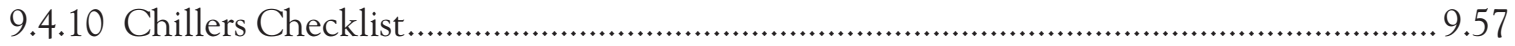

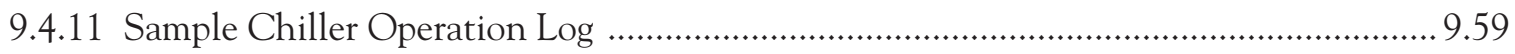




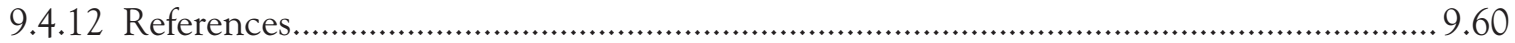

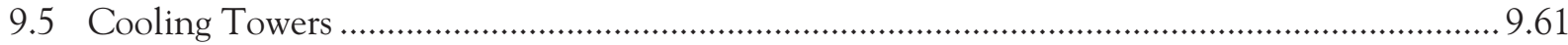

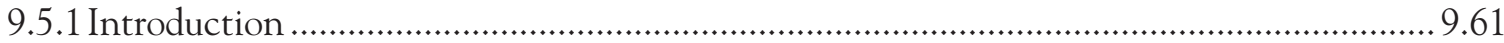

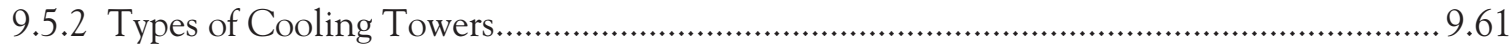

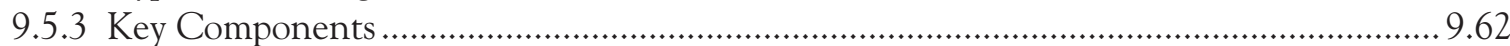

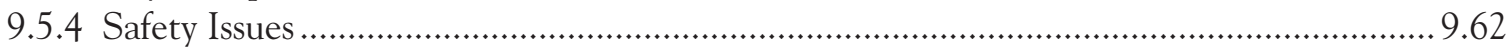

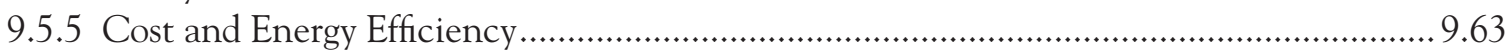

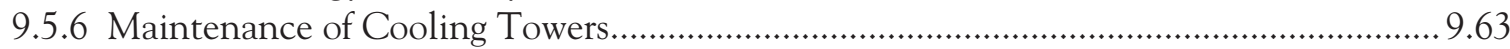

9.5.7 Common Causes of Cooling Towers Poor Performance ..................................................6.64

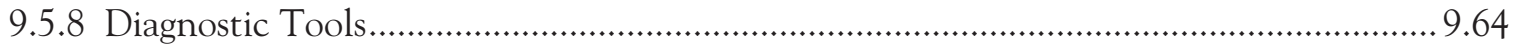

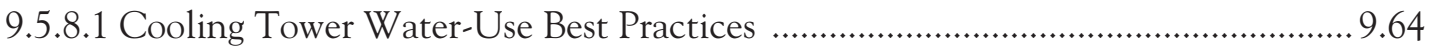

9.5.8.2 Operations and Maintenance Opportunities ...............................................................6...6

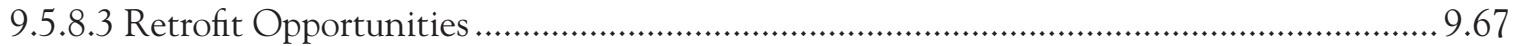

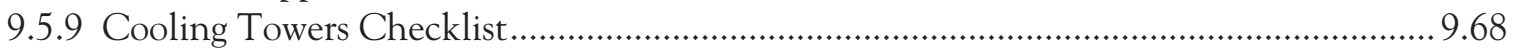

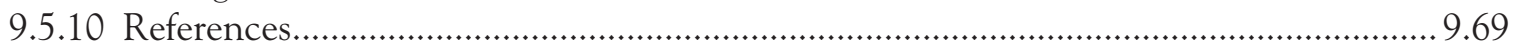

9.6 Energy Management/Building Automation Systems ........................................................... 9.70

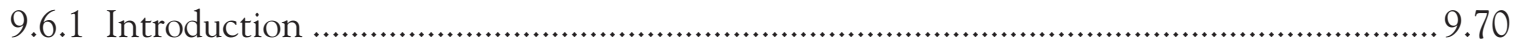

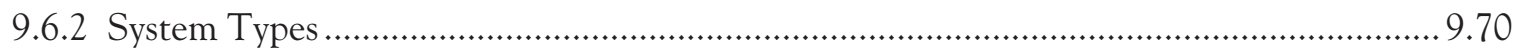

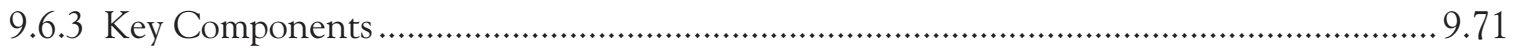

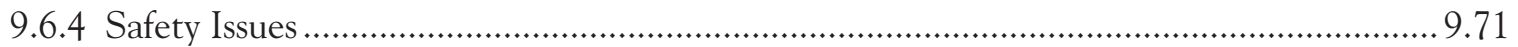

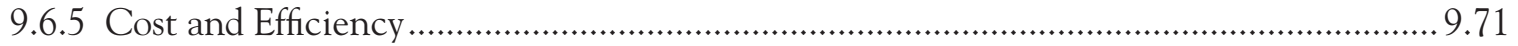

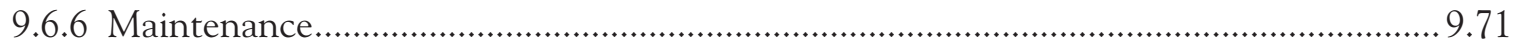

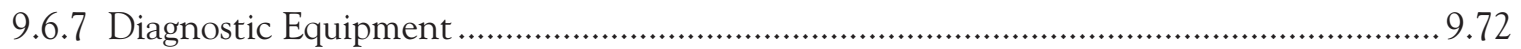

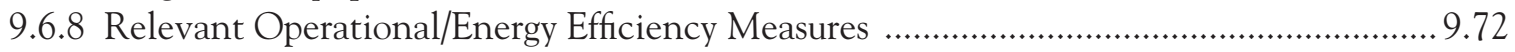

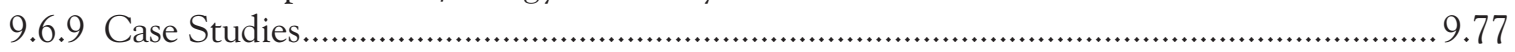

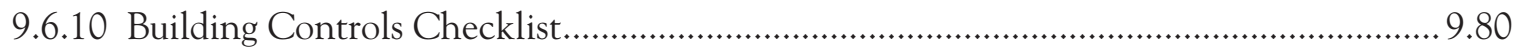

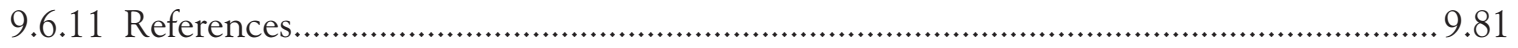

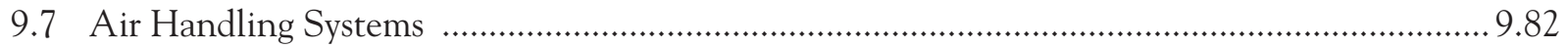

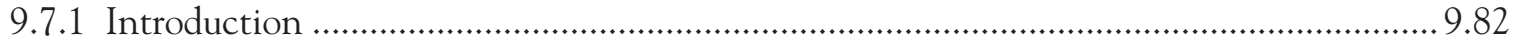

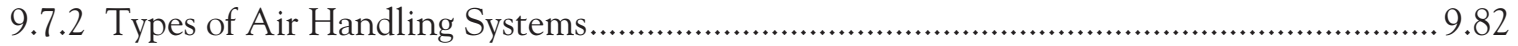

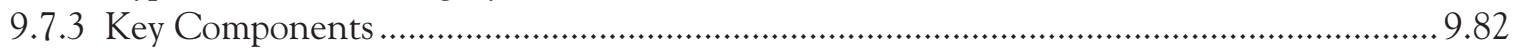

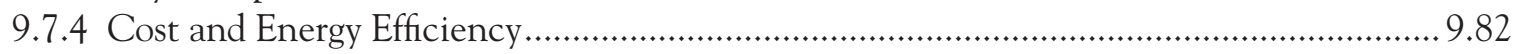

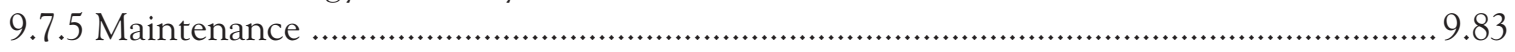

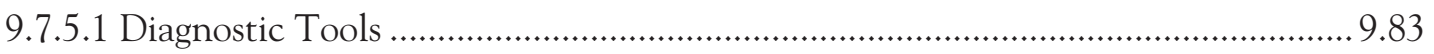

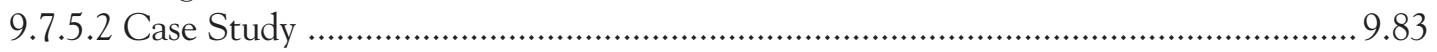

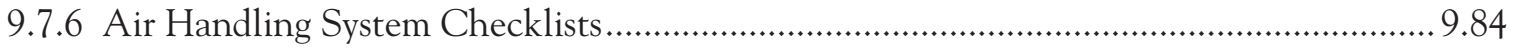

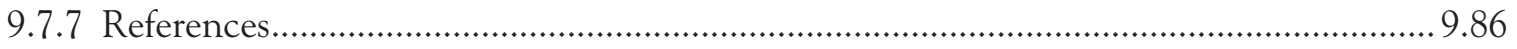

9.8 Fans

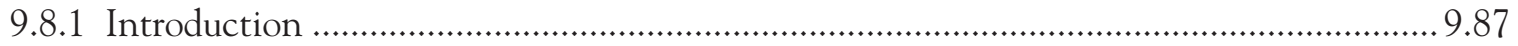

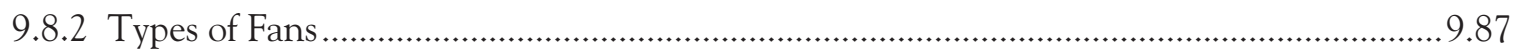

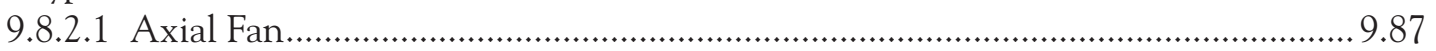

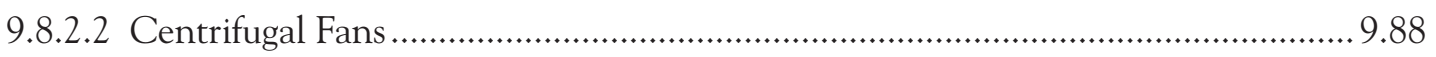

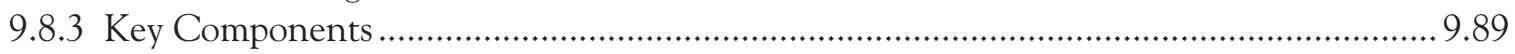

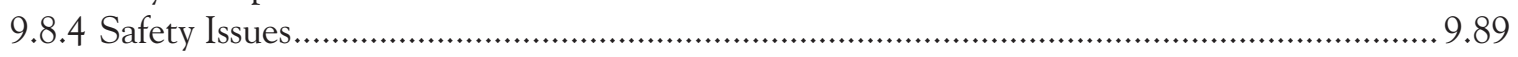

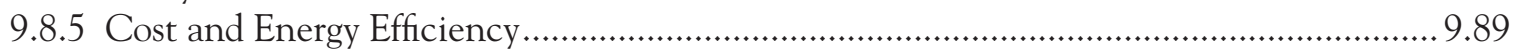

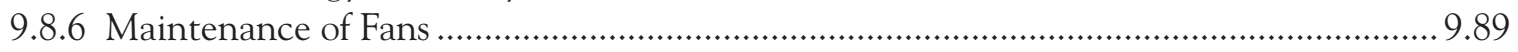

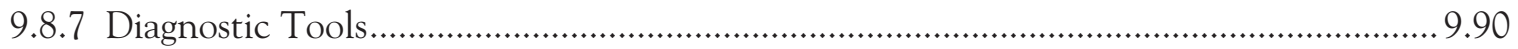

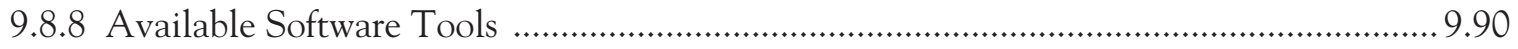


9.8.9 Relevant Operational/Energy Efficiency Measures ....................................................... 9.91

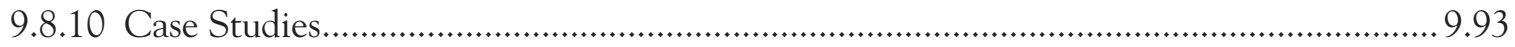

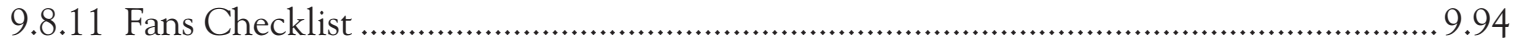

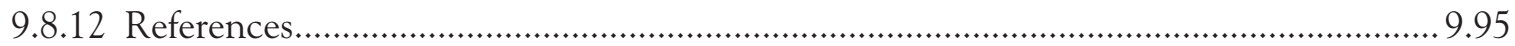

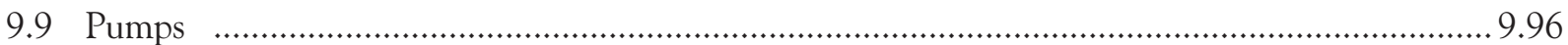

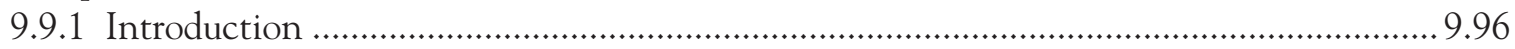

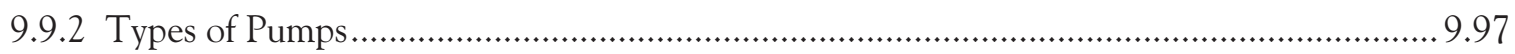

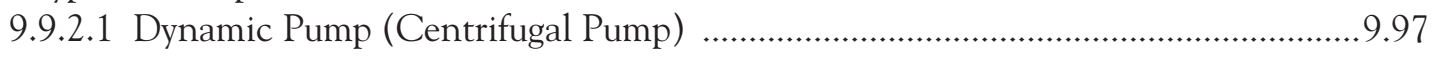

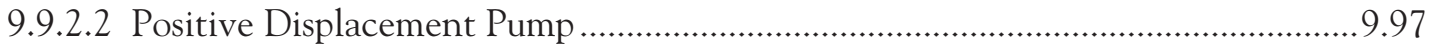

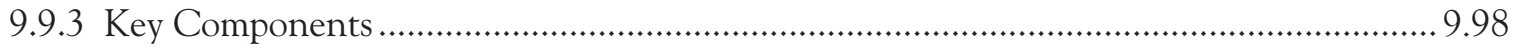

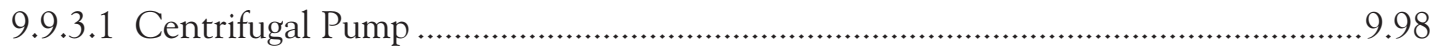

9.9.3.2 Positive Displacement Pumps ................................................................................9..98

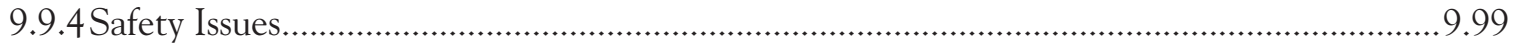

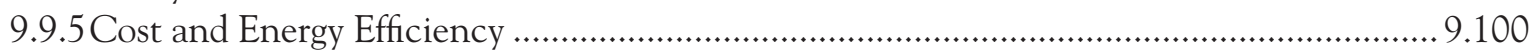

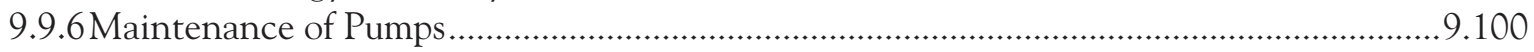

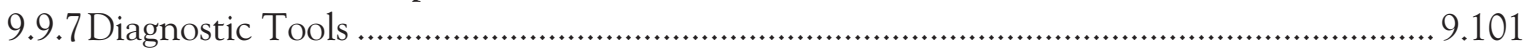

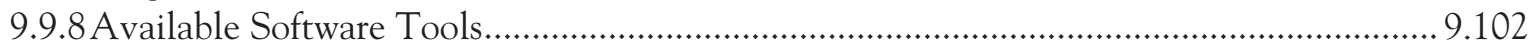

9.9.9Relevant Operational/Energy Efficiency Measures .......................................................... 9.102

9.9.9.1Pump System Water-Use Best Practices ................................................................ 9.105

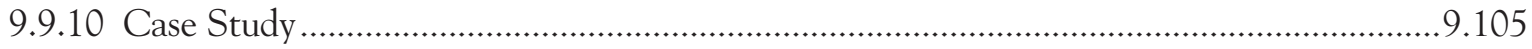

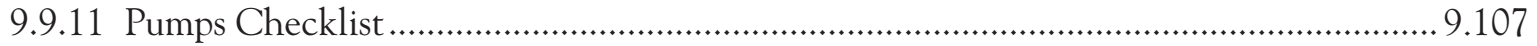

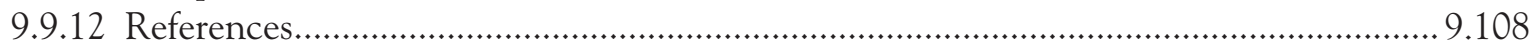

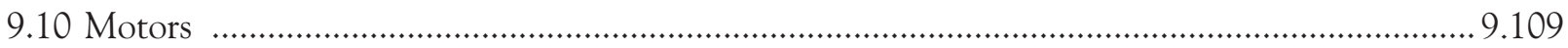

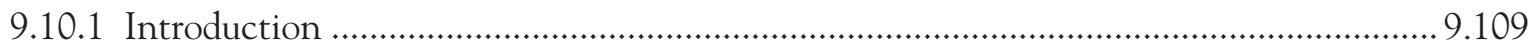

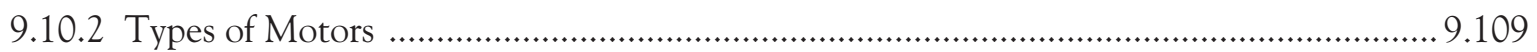

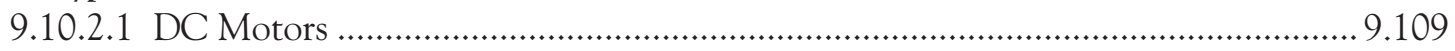

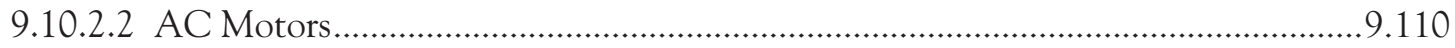

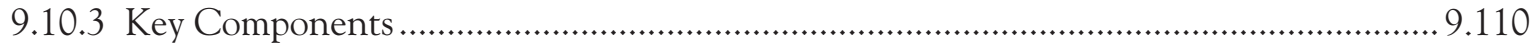

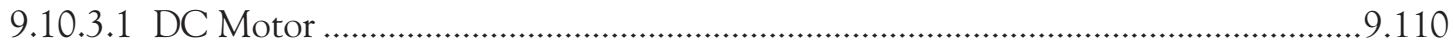

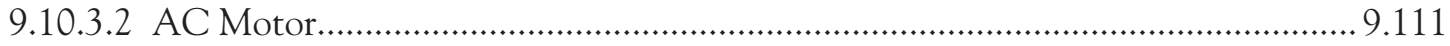

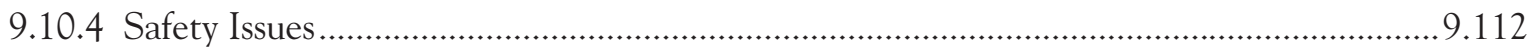

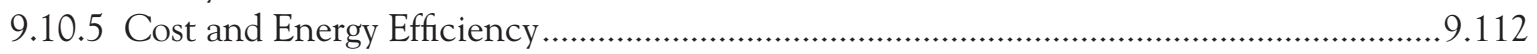

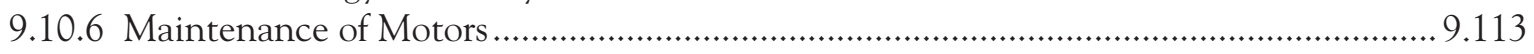

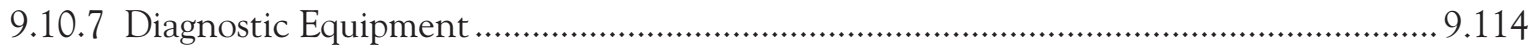

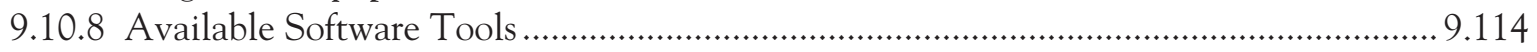

9.10.9 Relevant Operational/Energy Efficient Measures …..................................................... 9.115

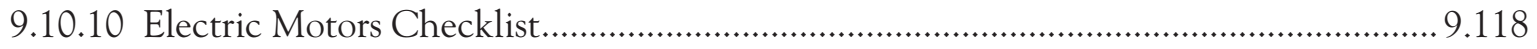

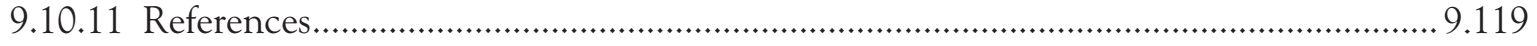

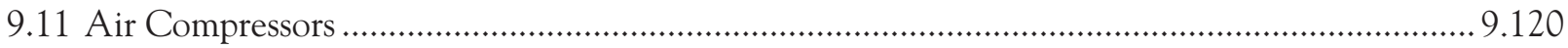

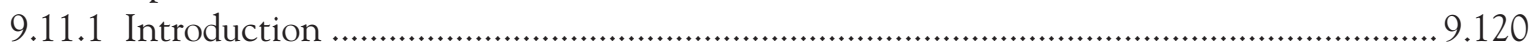

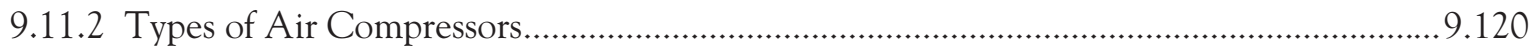

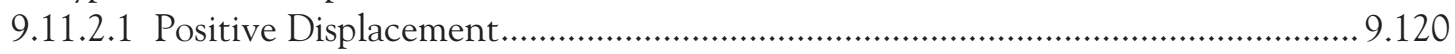

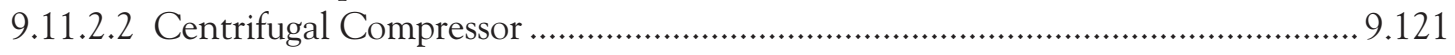

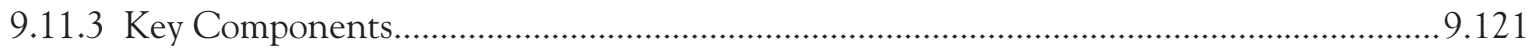

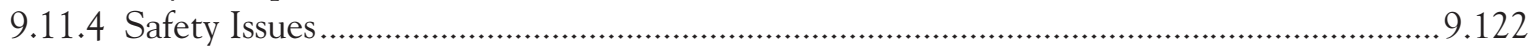

9.11.4.1 General Safety Requirements for Compressed Air.............................................9.122

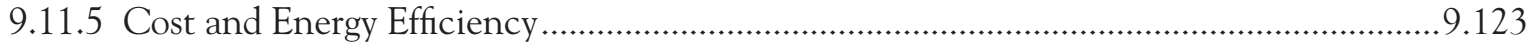

9.11.5.1 Identify the Electrical Cost of Compressed Air................................................... 9.123 
9.11.5.2 Waste Heat Recovered from Compressors can be Used for Heating .....................9.124

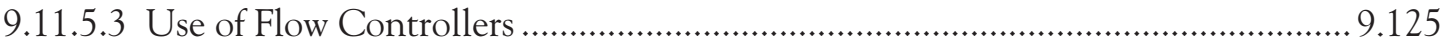

9.11.5.4 Importance of Maintenance to Energy Savings.....................................................125

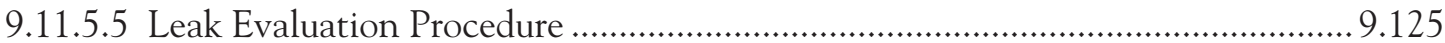

9.11.6 Maintenance of Air Compressors.............................................................................126

9.11.6.1 General Requirements for a Safe and Efficient Air Compressor .........................9.126

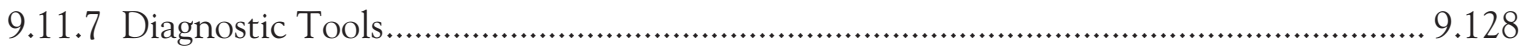

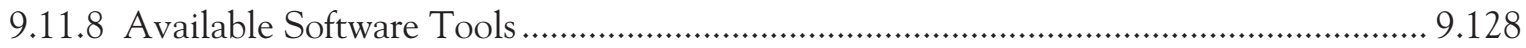

9.11.9 Relevant Operational/Energy Efficiency Measures ......................................................... 9.129

9.11.9.1 Air Compressor Water-Use Best Practices..................................................... 9.129

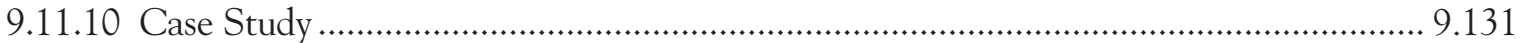

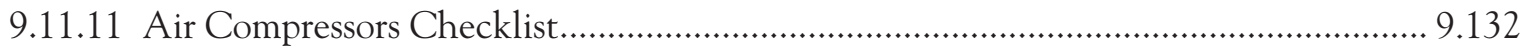

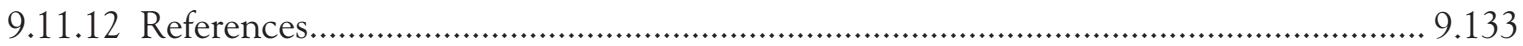

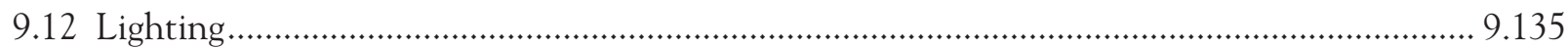

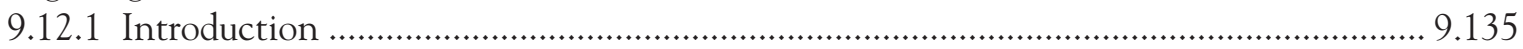

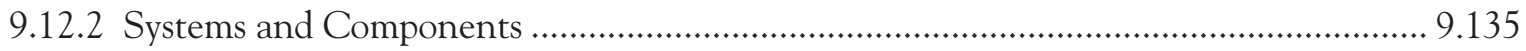

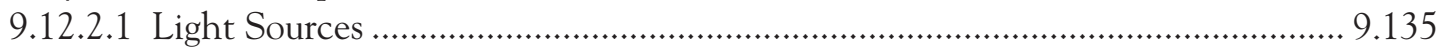

9.12.2.2 Ballasts, Transformers, and Power Packs........................................................... 9.138

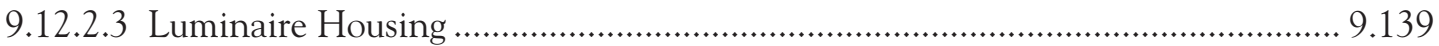

9.12.2.4 Lighting Control Devices ............................................................................... 9.140

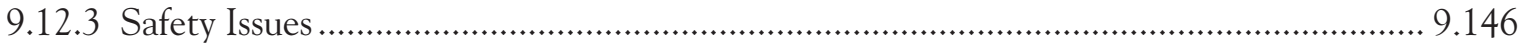

9.12.3.1 Electrical and Equipment Safety …….......................................................... 9.146

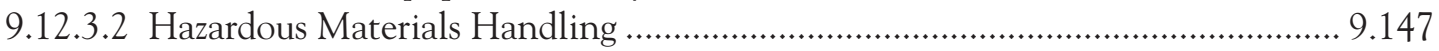

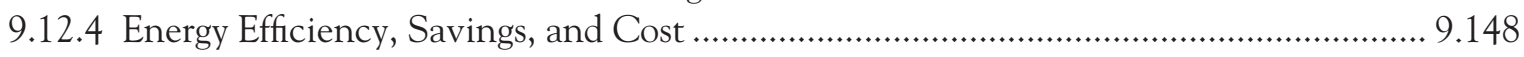

9.12.4.1 Planned versus Reactive Maintenance............................................................ 9.148

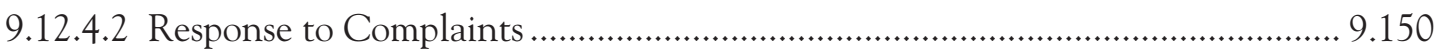

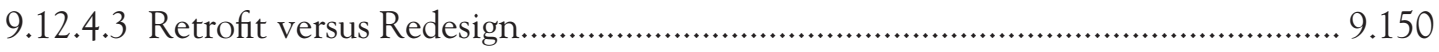

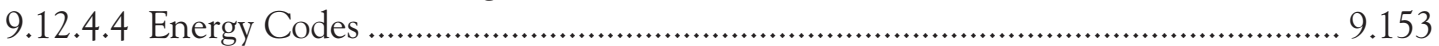

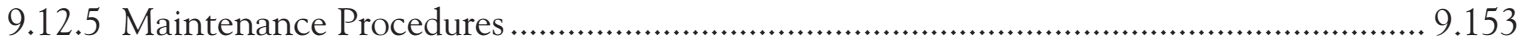

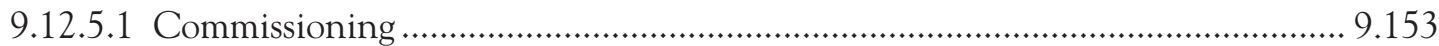

9.12.5.2 Common Causes of Poor Performance ……....................................................... 9.154

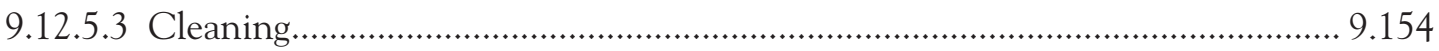

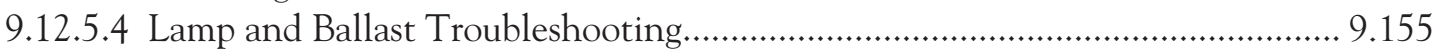

9.12.5.5 Lighting Controls Calibration and Troubleshooting ........................................ 9.156

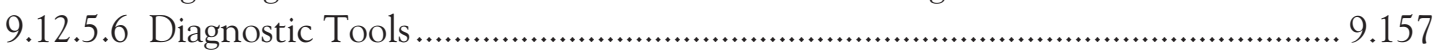

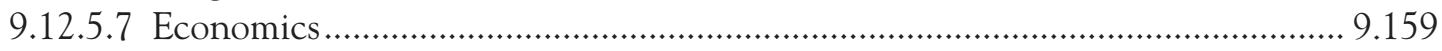

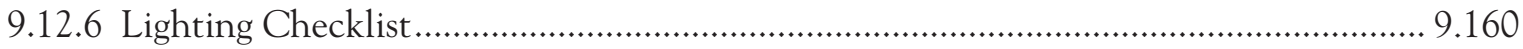

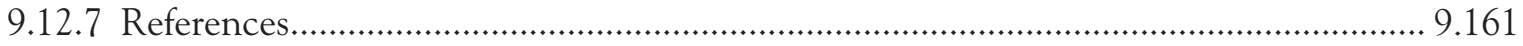

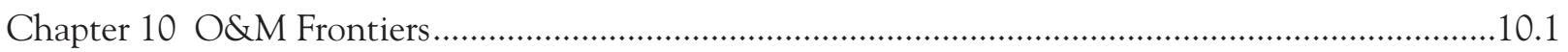

10.1 ACRx Handtool/Honeywell HVAC Service Assistant ..........................................................10.1

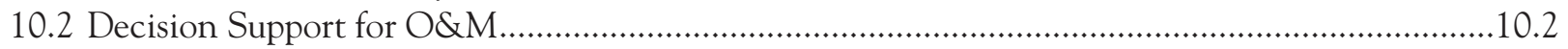

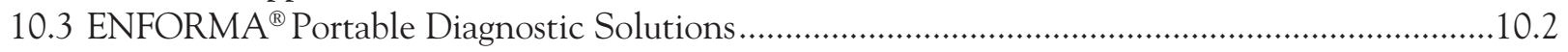

10.4 Performance and Continuous Re-Commissioning Analysis Tool ...............................................10.3

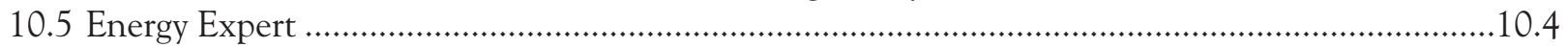

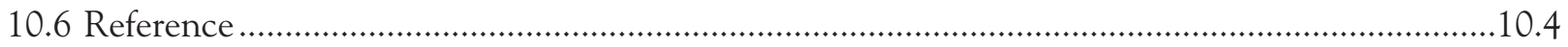

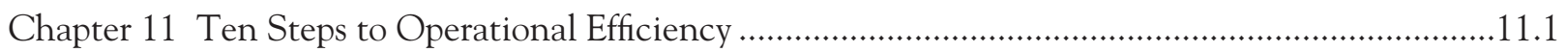


Appendix A - Glossary of Common Terms .............................................................................. A.1

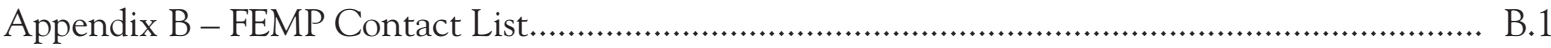

Appendix C - Resources for Energy and Facilities Professionals.................................................. C.1

Appendix D - Suggestions for Additions or Revisions ............................................................. D. 1

\section{Figures}

2.4.1 Effect of adequate and timely maintenance and repairs on the service life ........................ 2.5

5.1.1 Component failure rate over time for component population .......................................... 5.1

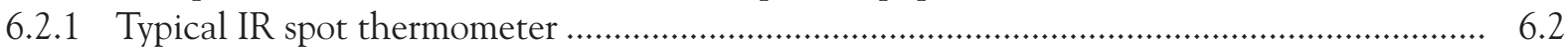

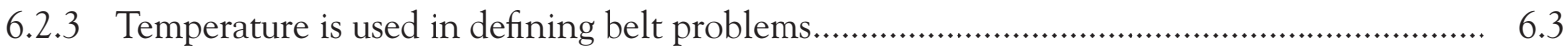

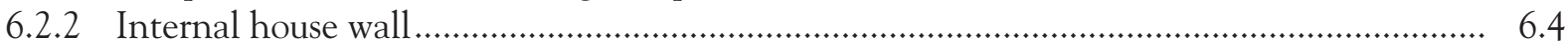

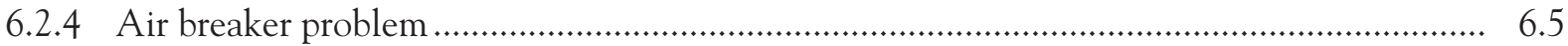

6.2.5 Overloaded contacts show different temperature profiles indicating one contact seeing much greater load, a potentially unsafe situation............................................... 6.5

6.2.6 IR scans of multiple electric motors can highlight those with hot bearings indicting

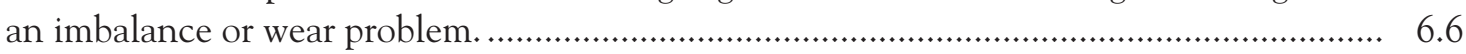

6.2.7 Possible gearbox problem indicated by white area defined by arrow ................................. 6.6

6.2.8 Seized conveyer belt roller as indicated by elevated temperatures in belt/roller.................. 6.6

6.2.9 Inoperable steam heaters seen by cooler blue areas when compared to the operating

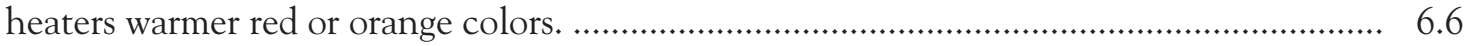

6.2.11 When trended, IR scans of single bearings provide a useful indicator of wear and

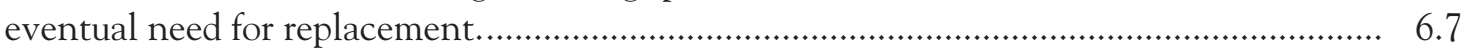

6.2.10 IR scans of boiler can highlight those areas where the refractory has broken down leading to costly heat loss................................................................................... 6.7

6.2.12 Steam or hot water distribution system leaks and/or underground line location can

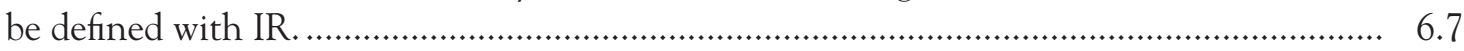

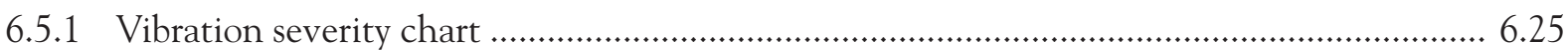

6.5.2 FFT - Example of graph breaking down vibration level at different frequencies ................ 6.26

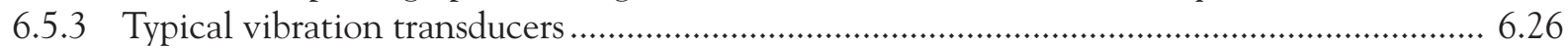

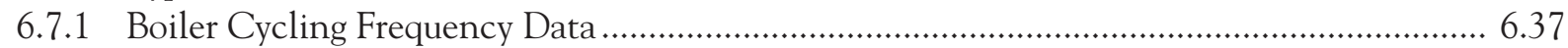

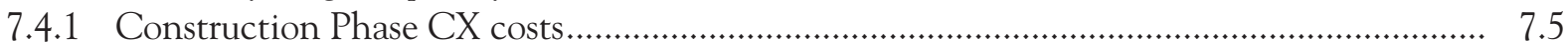

7.9.1 Whole-building electricity use before and after night shutdown program........................ 7.10

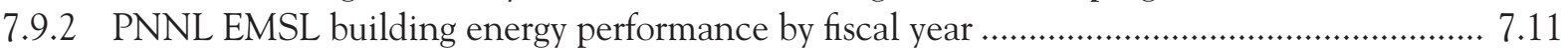

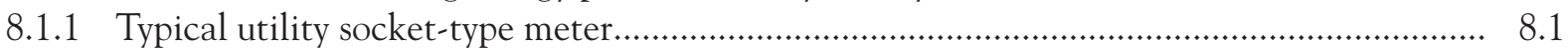

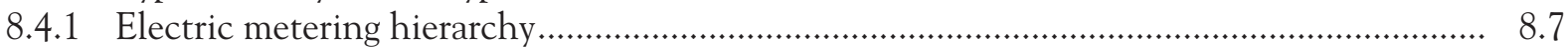

8.5.1 Typical electrical sub panel used in long-term monitoring ......................................... 8.8

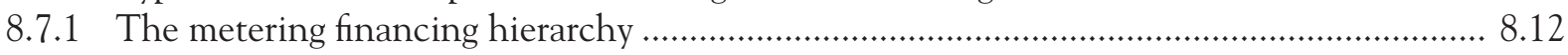

8.8.1 Development process for meter system planning …......................................................... 8.14 
8.9.1 Installed wireless monitoring system for WBE-based system............................................ 8.17

8.9.2 Sample screen capture for a generic building showing an alarm or high-energy

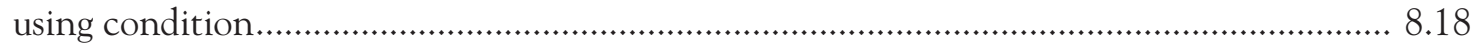

8.9.3 Data from the monitoring device provides a comparison of 2 days of electricity................ 8.18

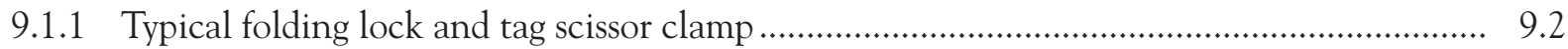

9.2.1 Horizontal return fire-tube boiler............................................................................... 9.3

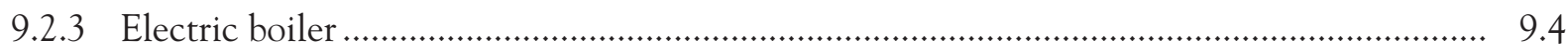

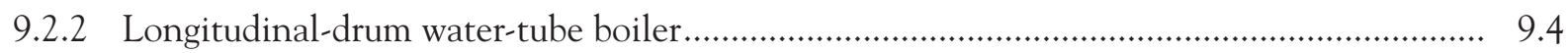

9.2.4 Adapted from 1999 National Board of Boiler and Pressure Vessel Inspectors

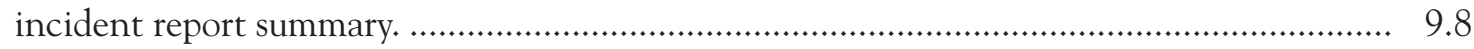

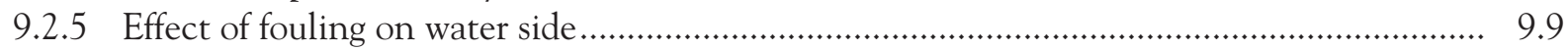

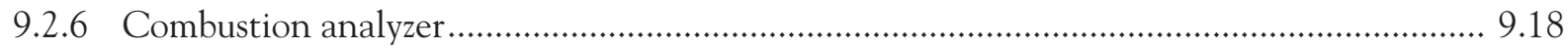

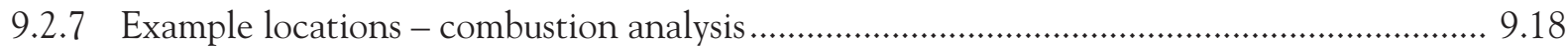

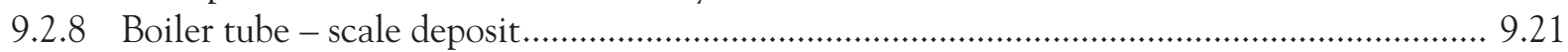

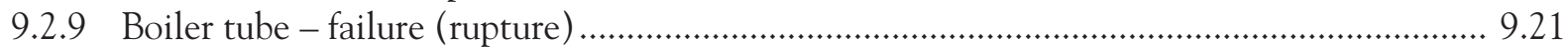

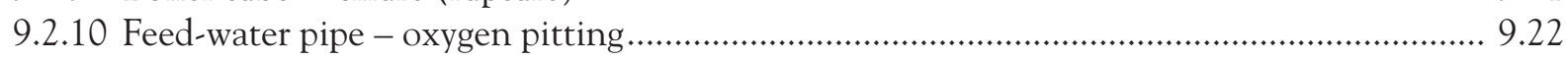

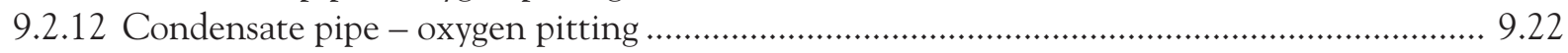

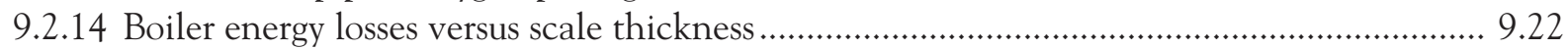

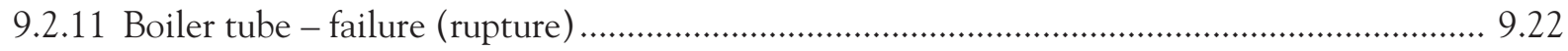

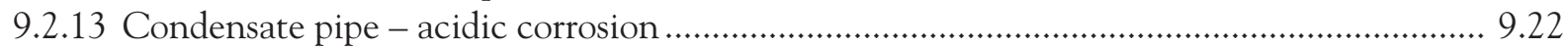

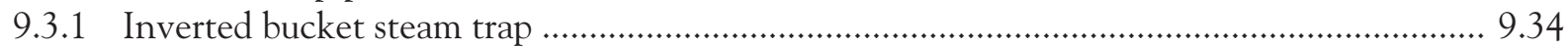

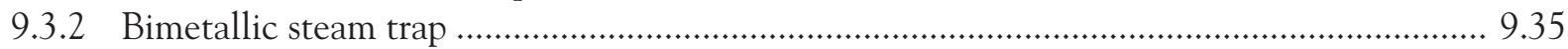

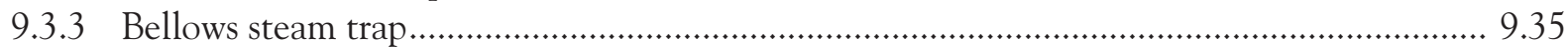

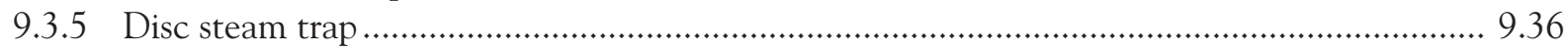

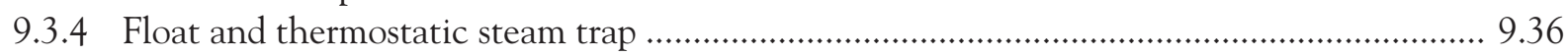

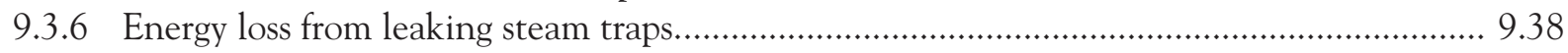

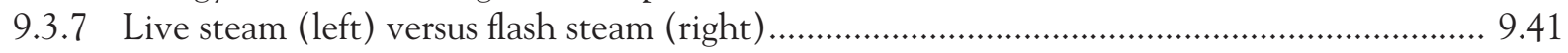

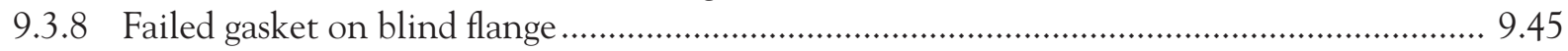

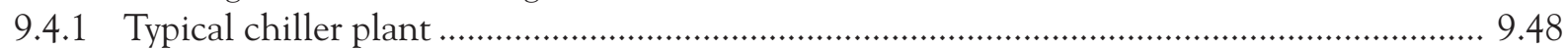

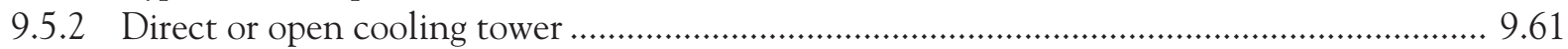

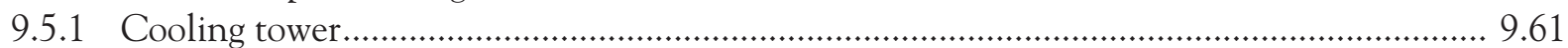

9.6.1 General Services Administration's Custom House, Philadelphia, PA ................................. 9.77

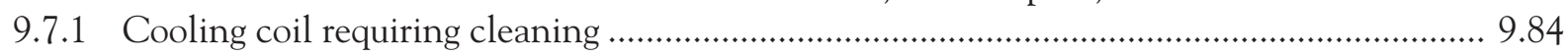

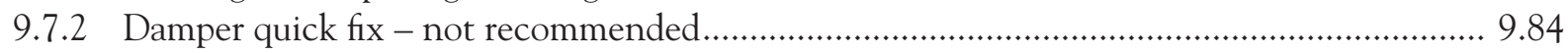

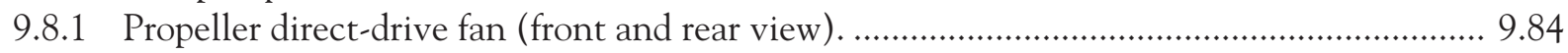

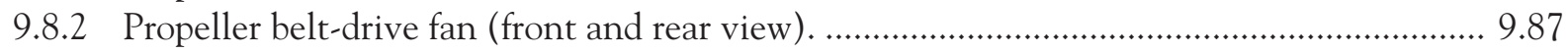

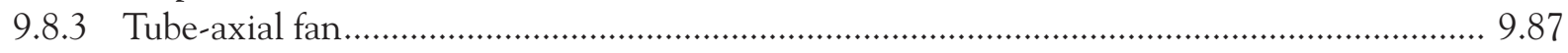

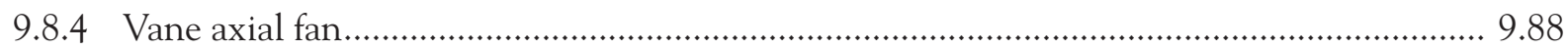

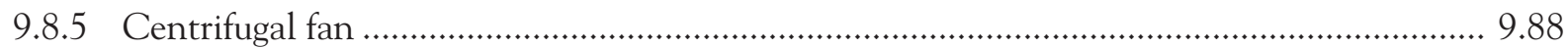

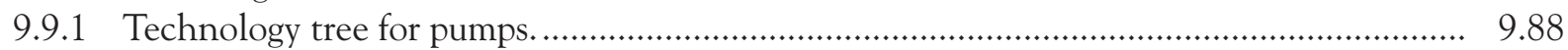

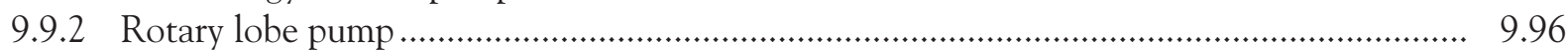

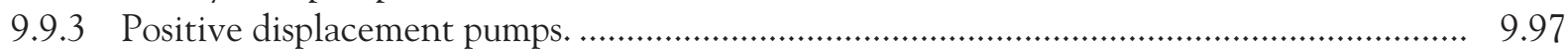

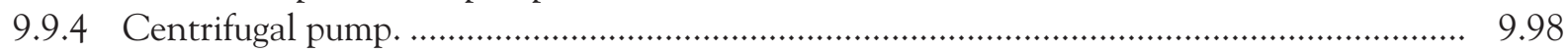

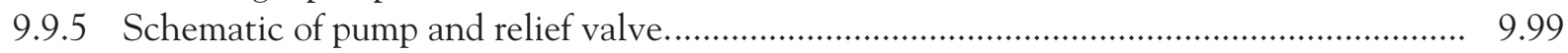

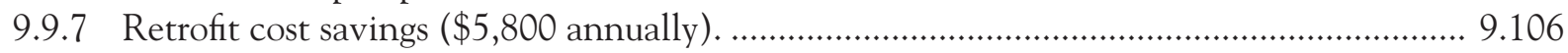

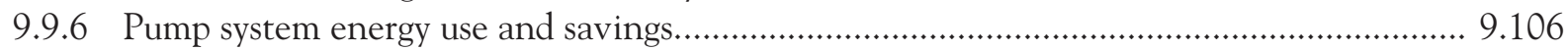




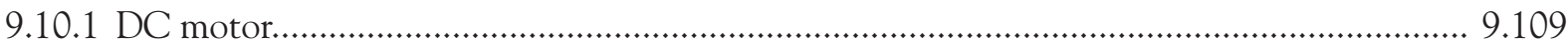

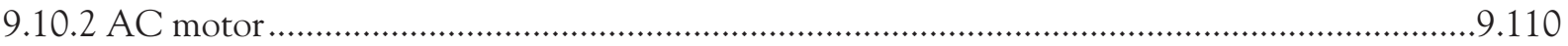

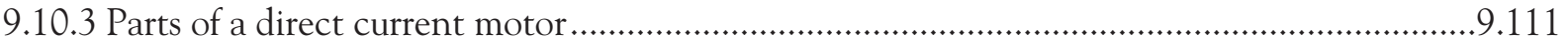

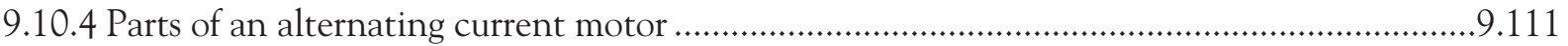

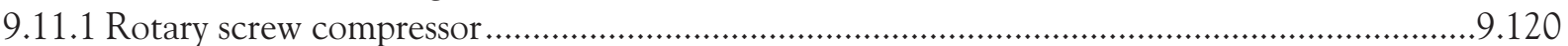

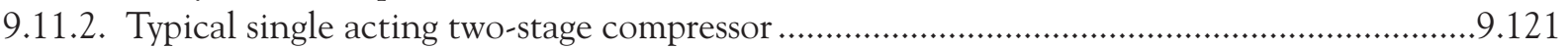

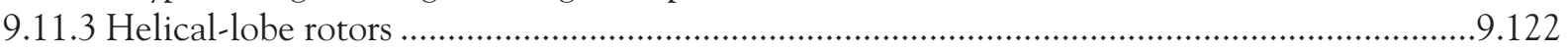

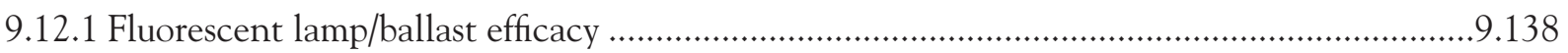

9.12.2 Wall-box occupancy sensor uses hidden internal dip-switches to set manual-on, auto-off.

9.12.3 Photosensor and fluorescent dimming ballast for continuous daylight dimming .................9.145

9.12.4 Repair and rewiring must be done by a licensed electrician. .............................................9.146

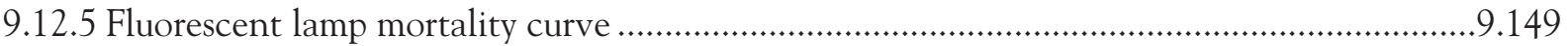

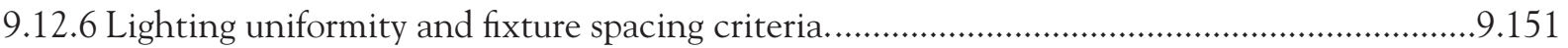

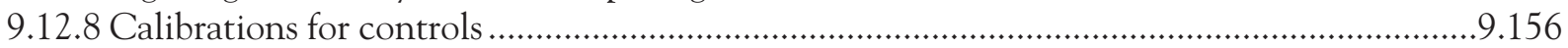

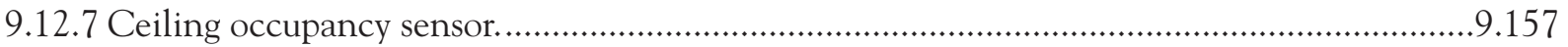

\section{Tables}

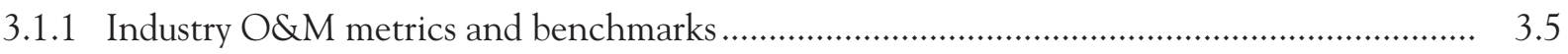

3.2.2 Overview of key $O \& M$ issues, timing, and supporting documents ................................... 3.13

5.5.1 Reliability centered maintenance element applications ..................................................... 5.6

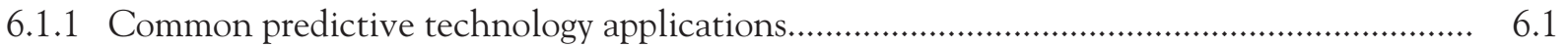

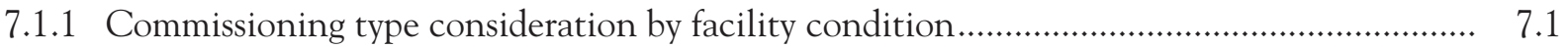

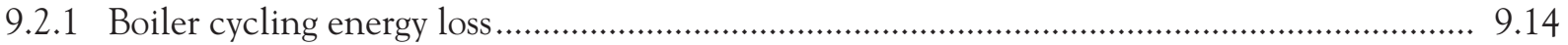

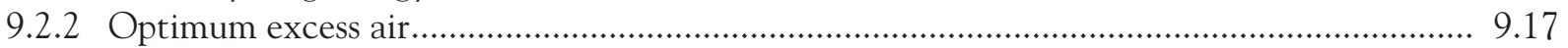

9.2.3 Recommended limits for boiler-water concentrations .................................................. 9.21

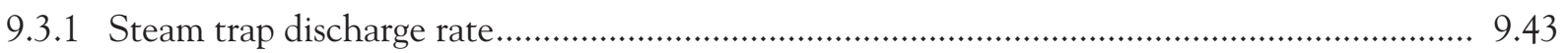

9.6.1 Custom House demand reduction and savings 2005-2006 ............................................ 9.79

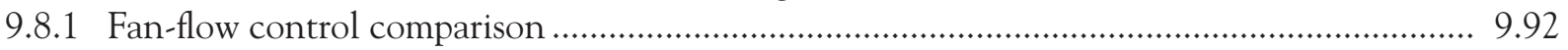

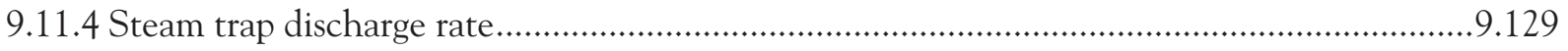

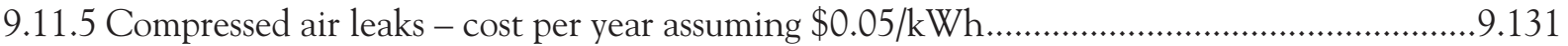





\section{Chapter 1 Introduction and Overview}

The purpose of this guide is to provide you, the Operations and Maintenance (O\&M)/Energy manager and practitioner, with useful information about $O \& M$ management, technologies, energy and water efficiency, and cost-reduction approaches. To make this guide useful and to reflect your needs and concerns, the authors met with O\&M and Energy managers via Federal Energy Management Program (FEMP) workshops. In addition, the authors conducted extensive literature searches and contacted numerous vendors and industry experts. The information and case studies that appear in this guide resulted from these activities.

It needs to be stated at the outset that this guide is designed to provide information on effective $\mathrm{O} \& \mathrm{M}$ as it applies to systems and equipment typically found at Federal facilities. This guide is not designed to provide the reader with step-by-step procedures for performing $O \& M$ on any specific piece of equipment. Rather, this guide first directs the user to the manufacturer's specifications and recommendations. In no way should the recommendations in this guide be used in place of manufacturer's recommendations. The recommendations in this guide are designed to supplement those of the manufacturer, or, as is all too often the case, provide guidance for systems and equipment for which all technical documentation has been lost.

As a rule, this guide will first defer to the manufacturer's recommendations on equipment operation and maintenance.

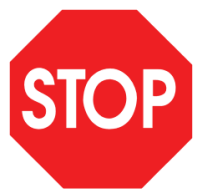

\section{Actions and activities recommended in this guide should only be attempted by trained and certified personnel. If such personnel are not available, the actions recommended here should not be initiated.}

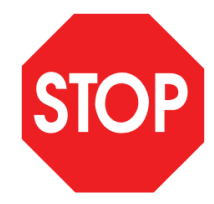

\subsection{About This Guide}

This guide is designed to serve as a resource for $O \& M$ management and technical staff. It does not try to represent the universe of $O \& M$-related material. Rather, it attempts to:

- Provide needed background information on why O\&M is important and the potential for savings from good O\&M.

- Define the major O\&M program types and provide guidance on the structure of a good $O \& M$ program.

- Provide information on state-of-the-art maintenance technologies and procedures for key equipment.

- Identify information sources and contacts to assist you in getting your job done. 


\subsection{Target Audience}

O\&M/Energy managers, practitioners, and technical staff represent the prime focus of this document. However, a competent O\&M program requires the participation of staff from five welldefined areas: Operations, Maintenance, Engineering, Training, and Administration. While a given site may not have all five of these areas as separate entities, these functions are provided for within the organization. It is these staff that are targeted.

A successful O\&M program requires cooperation, dedication, and participation at all levels and cannot succeed without everyone involved understanding the basic principles and supporting the cause.

\subsection{Organization and Maintenance of the Document}

It is the intention of the authors to update this guide periodically as new O\&M procedures and technologies are developed and employed. This guide can be found on the FEMP Web site at http://wwwl.eere.energy.gov/femp/operations_maintenance/om_bpguide.html.

The guide consists of eleven chapters. This chapter provides an introduction and an overview. Chapter 2 provides the rationale for "Why O\&M?" Chapter 3 discusses O\&M management issues and their importance. Chapter 4 examines Computerized Maintenance Management Systems (CMMS) and their role in an effective O\&M program. Chapter 5 looks at the different types of maintenance programs and definitions. Chapter 6 focuses on maintenance technologies, particularly the most accepted predictive technologies. Chapter 7 describes the building commissioning process and how it contributes to effective O\&M. Chapter 8 covers the topic of metering and its applications for improved operations and efficiency. Chapter 9 explores O\&M procedures for the predominant equipment found at most Federal facilities and, where applicable, provides calculation procedures for estimating energy savings. Chapter 10 describes some of the promising O\&M technologies and tools on the horizon to increase O\&M efficiency. Chapter 11 provides ten steps to initiating an operational efficiency program.

The O\&M environment is in a constant state of evolution and the technologies and vocabularies are ever expanding. Therefore, a glossary of terms is presented in Appendix A. Appendix B provides a list of Federal contacts for training and assistance. Appendix $C$ includes a list of organizations and trade groups that have interest or are related to O\&M. And finally, Appendix D is a form that can be used to submit suggestions or revisions to this guide.

Again, we designed this to be a useful document, and we welcome your input to help us keep it current. Please feel comfortable to make suggestions for changes, additions, or deletions using the form found in Appendix D. 


\section{Chapter 2 Why O\&M?}

\subsection{Introduction}

Effective O\&M is one of the most cost-effective methods for ensuring reliability, safety, and energy efficiency. Inadequate maintenance of energy-using systems is a major cause of energy waste in both the Federal Government and the private sector. Energy losses from steam, water and air leaks, uninsulated lines, maladjusted or inoperable controls, and other losses from poor maintenance are often considerable. Good maintenance practices can generate substantial energy savings and should be considered a resource. Moreover, improvements to facility maintenance programs can often be accomplished immediately and at a relatively low cost.

\subsection{Definitions}

Operations and Maintenance are the decisions and actions regarding the control and upkeep of property and equipment. These are inclusive, but not limited to, the following: 1) actions focused on scheduling, procedures, and work/systems control and optimization; and 2) performance of routine, preventive, predictive, scheduled and unscheduled actions aimed at preventing equipment failure or decline with the goal of increasing efficiency, reliability, and safety.

Operational Efficiency represents the life-cycle, cost-effective mix of preventive, predictive, and reliability-centered maintenance technologies, coupled with equipment calibration, tracking, and computerized maintenance management capabilities all targeting reliability, safety, occupant comfort, and system efficiency.

\subsection{Motivation}

In October of 2009, EO 13514 was signed into law. This order directs Federal agencies to further address energy, water, and operational efficiency beyond E.O. 13423.

The key energy- and operational-efficiency-related provisions in the Executive Order are as follows:

- Federal agencies must enhance efforts toward sustainable buildings and communities. Specific requirements include the implementation of high-performance sustainable Federal building design, construction, operation and management, maintenance, and deconstruction.

- Pursuing cost-effective, innovative strategies (e.g., highly reflective and vegetated roofs) to minimize consumption of energy, water, and materials.

- Managing existing building systems to reduce the consumption of energy, water, and materials, and identifying alternatives to renovation that reduce existing asset-deferred maintenance costs.

- Reducing potable water consumption intensity $2 \%$ annually through FY 2020 , or $26 \%$ by the end of FY 2020, relative to a FY 2007 baseline.

- Reducing agency industrial, landscaping, and agricultural water consumption 2\% annually, or 20\% by the end of FY 2020, relative to a FY 2010 baseline.

- Identifying, promoting, and implementing water reuse strategies consistent with state law that reduce potable water consumption. 
While applicable only to Department of Energy facilities, DOE Order 430.2B was issued in February 2008 clearly outlining the requirements and responsibilities for managing DOE facilities. The relevance of this Order lies in forward-thinking and highlights DOE's commitment to energy and resource efficiency.

The key energy- and operational-efficiency-related provisions in the DOE Order are as follows:

- By FY 2015, reduce energy intensity by no less than 30\% on average across the entire Department, relative to the Department's energy use in FY 2003. Energy intensity means energy consumption per gross square foot of building space, including industrial and laboratory facilities.

- By FY 2015, reduce potable water use by no less than $16 \%$, relative to the Department's potable water use in FY 2007.

- Install advanced electric metering systems at all Department sites in accordance with the DOE metering plan for site monitoring of electric energy. Standard metering systems for steam, natural gas, and water must also be installed and centrally monitored at all Department sites for steam, natural gas, and water consumption. Advanced meters are defined as having the capability to measure and record interval data (at least hourly for electricity) and communicate the data to a remote location in a format that can be easily integrated into an advanced metering system.

- Use standardized operations and maintenance $(O \& M)$ and measurement and verification $(M \& V)$ protocols coupled with real-time information collection and centralized reporting capabilities.

While effective, some feel that capital upgrades are not
always the most cost-effective solution. Indeed, the authors
of this guide contend that low-cost/no-cost O\&M measures
(including activities referred to as retrocommissioning
or retuning) should be the first energy savings measure
considered. O\&M measures should be considered prior to
the installation of energy conservation measures for the
following reasons:

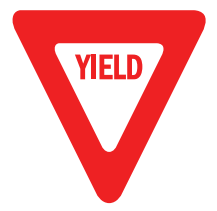

- Typically, O\&M measures are low-cost or no-cost in nature.

- Many O\&M measures are easily installed by in-house personnel.

- O\&M measures can have immediate payback.

- These measures rarely require the design time, bid preparation, evaluation, and response compared to capital projects that can take up to a year to implement. 


\section{Is an Energy Savings Performance Contract Being Considered? (Haasl and Sharp 1999)}

Some level of retrocommissioning (i.e., O\&M best practices) is usually appropriate if you are considering any type of energy savings agreement such as an energy savings performance contract. There are two primary reasons for performing retrocommissioning before obtaining an energy-savings agreement. First, the low-cost energy savings gained from retrocommissioning remains with the building (the owner gets all of the savings) and does not become part of the financial agreement; second, retrocommissioning optimizes the existing equipment so the most appropriate capital measures are selected and financed through the agreement.

A good reason for doing retrocommissioning as part of an energy-savings agreement is to ensure that the performance of new equipment is not hindered because it interfaces with older equipment, components, or systems that are malfunctioning. Even when commissioning is specified for the new equipment, it often stops short of looking at the systems with which the new equipment interfaces or examining how it integrates with other systems or equipment that may affect its performance. This is especially true for energy management control systems. Because controls are an area where many difficulties and misunderstandings occur between building owners and performance contractors, it is a good idea to specify commissioning for both the new and existing equipment that may affect the performance of the new equipment.

When retrocommissioning is performed before the energy-savings agreement or energy savings performance contract is finalized, it is important to inform the contractor about the retrocommissioning activities and give him or her a copy of the final report. If the contractor is not informed and energy bills from prior years are used to help determine the energy baseline, the baseline may be inaccurate. This may cause the cost savings upon which the financing is based to be significantly less than expected, leading to disagreements and even legal battles.

Retrocommissioning performed up front to capture the low-cost savings may not be a wise choice if the savings from the retrocommissioning do not remain with the building but, instead, go into a general fund. In this case, the "low-cost/no-cost" improvements should be part of the performance contract. In this way, a portion of the savings stays with the building as part of the financial arrangement. Integrating the retrocommissioning measures into the energy-savings agreement is a way to capture the savings as part of the investment repayment. The amount invested can be increased when the savings estimates are higher. Moreover, the savings gained from bundling these measures with the capital upgrades-especially if some of the upgrades are marginally cost-effective (i.e., good value but with long paybacks) - help to increase the overall viability and attractiveness of the energy savings performance contract funding.

\subsection{O\&M Potential, Energy Savings, and Beyond}

It has been estimated that O\&M programs targeting energy efficiency can save $5 \%$ to $20 \%$ on energy bills without a significant capital investment (PECI 1999). From small to large sites, these savings can represent thousands to hundreds-of-thousands of dollars each year, and many can be achieved with minimal cash outlays.

The need for effective building O\&M is illustrated in Figure 2.4.1, which shows how, over time, the performance of a building (and its components) will eventually degrade in two scenarios one with and one without "normal" maintenance. Of interest in the figure is the prolonged service life achieved through effective O\&M. Not shown in this figure is the additional benefit of reduced building (energy) operating costs resulting from effectively maintaining mechanical and electrical equipment (e.g., lighting; heating, ventilation, and air conditioning [HVAC]; controls; and on-site generation).

Beyond the potential for significant cost and energy/resource savings, an O\&M program operating at its peak operational efficiency has other important implications: 


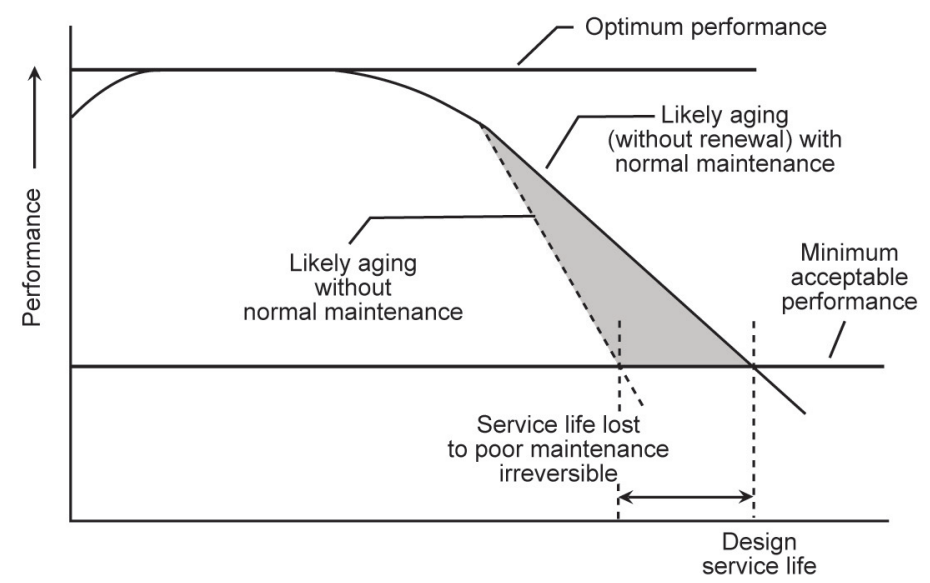

Figure 2.4.1. Effect of adequate and timely maintenance and repairs on the service life of a building (National Research Council 1998).

- A well-functioning $O \& M$ program is a safe $O \& M$ program. Equipment is maintained properly mitigating any potential hazard arising from deferred maintenance.

- In most Federal buildings, the O\&M staff are responsible for not only the comfort, but also the health and safety of the occupants. Of increasing productivity (and legal) concern are indoor air quality (IAQ) issues within these buildings. Proper O\&M reduces the risks associated with the development of dangerous and costly IAQ situations.

When Marion County, Florida, officials realized their new county courthouse was making hundreds of employees sick, they did more than send the workers to the doctor, they sued the builder/ operator of the building for bad air and won a \$14.2 million judgment (Ewell 1996).

- Properly performed O\&M ensures that the design life expectancy of equipment will be achieved, and in some cases exceeded. Conversely, the costs associated with early equipment failure are usually not budgeted for and often come at the expense of other planned O\&M activities.

- An effective O\&M program more easily complies with Federal legislation such as the Clean Air Act and the Clean Water Act as well as expected carbon management legislation.
O\&M measures cost approximately 20 times less and achieve roughly the same energy savings as retrofit measures.

- A well functioning O\&M program

is not always answering complaints, rather, it is proactive in its response and corrects situations before they become problems. This model minimizes callbacks and keeps occupants satisfied while allowing more time for scheduled maintenance.

Two recent DOE/FEMP-sponsored programs have highlighted both the opportunity and the cost effectiveness of $\mathrm{O} \& \mathrm{M} /$ low-cost energy efficiency measures; these programs were the Energy Savings Expert Teams (ESET) and Energy Efficiency Expert Evaluations (E4). Both programs were designed to respond to the need for immediate, cost-effective energy savings. From the post evaluations, the following findings were highlighted: 
A demonstration focused on O\&M-based energy efficiency was conducted at the U.S. Department of Energy Forrestal Building in Washington, D.C. (Claridge and Haberl 1994). A significant component to this demonstration was metering and the tracking of steam use in the building. Within several months, $\$ 250,000$ per year in steam leaks were found and corrected. These included leaks in a steam converter and steam traps. Because the building was not metered for steam and there was not a proactive O\&M program, these leaks were not detected earlier, nor would they have been detected without the demonstration. The key lessons learned from this case study were:

- O\&M opportunities in large buildings do not have to involve complex engineering analysis.

- Many O\&M opportunities exist because building operators may not have proper documentation that hindered day-to-day actions.

- Involvement and commitment by building administrators is a key ingredient for a successful O\&M program.

\section{Energy Savings Expert Teams - ESET (Hunt 2007):}

- To realize the same benefits (energy savings), equipment retrofits cost approximately 20-times more than low-cost O\&M measures

- Dollars saved per dollars invested (calculated values):

o OEBM projects: 3.83 (simple payback 0.26 years)

o Retrofit projects: 0.19 (simple payback 5.26 years)

- Overall program cost-effectiveness for measures implemented (as of May 2007)

- includes retrofit, O\&M measures and program administration/delivery

o Annual energy savings: 202,512 MMBtu

o Annual cost savings: $\$ 1,731,780$

o Total program cost: $\$ 1,795,000$

o Simple payback: 1.0 years

\section{Energy Efficiency Expert Evaluations - E4 (Hail 2008):}

- Calculated savings range from 3\% to over 40\%, average savings $15 \%$.

- Dollars saved per dollars invested (calculated values):

o OEMM projects (defined as <\$5,000): 14.9 (simple payback 0.07 years)

o Retrofit projects (defined as $>\$ 5,000$ ): 0.7 (simple payback 1.5 years)

- Overall program cost effectiveness for measures implemented (as of December 2008), includes retrofit, O\&M measures and program administration/delivery

o Annual cost savings: $\$ 584,000$

o Total program cost: $\$ 800,000$

o Simple payback: 1.4 years 


\subsection{References}

Claridge, J. and D. Haberl. 1994. Can You Achieve 150\% of Predicted Retrofit Savings? Is it Time for Recommissioning? American Council for an Energy Efficiency Economy (ACEEE), Summer Study on Energy Efficiency in Buildings, Volume 5, Commissioning, Operation and Maintenance. ACEEE, Washington, D.C.

Clean Air Act. 1986. Public Law 88-206, as amended, 42 USC 7401 et seq.

Clean Water Act. 1997. Public Law 95-217, as amended, 91 Stat. 1566 and Public Law 96-148, as amended.

DOE Order 430.2B. Departmental Energy, Renewable Energy and Transportation Management. Issued February 27, 2008.

E.O. 13423. Strengthening Federal Environmental, Energy, and Transportation Management. Signed January 24, 2007.

E.O 13514. Federal Leadership in Environmental, Energy, and Economic Performance.

Signed October 5, 2009.

Ewell, C. 1996. Victims of 'Sick Buildings' Suing Builders, Employers. Knight-Ridder News Service.

Haasl, T. and T. Sharp. 1999. A Practical Guide for Commissioning Existing Buildings. ORNL/TM1999/34, Oak Ridge, Tennessee.

Hail, J. 2008. Benefits of the 2007 Energy Efficiency Expert Evaluations (E4). Presentation to the Federal Energy Management Program, December 2009. Pacific Northwest National Laboratory, Richland, Washington.

Hunt, D. 2007. Energy Savings Expert Team (ESET) Benefits Assessment. Presentation to the Federal Energy Management Program, May 2007. Pacific Northwest National Laboratory, Richland, Washington.

National Research Council (NRC). 1998. Stewardship of Federal Facilities; A Proactive Strategy for Managing the Nation's Public Assets. National Academy Press, Washington, D.C.

PECI. 1999. Operations and Maintenance Assessments. Portland Energy Conservation, Inc. Published by U.S. Environmental Protection Agency and U.S. Department of Energy, Washington, D.C. 


\section{Chapter 3 O\&M Management}

\subsection{Introduction}

O\&M management is a critical component of the overall program. The management function should bind the distinct parts of the program into a cohesive entity. From our experience, the overall program should contain five very distinct functions making up the organization: Operations, Maintenance, Engineering, Training, and Administration-OMETA.

Beyond establishing and facilitating the OMETA links, O\&M managers have the responsibility of interfacing with other department managers and making their case for ever-shrinking budgets. Their roles also include project implementation

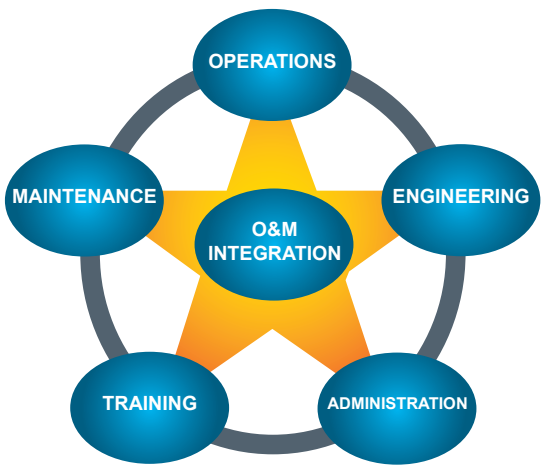
functions as well as the need to maintain persistence of the program and its goals.

\subsection{Developing the Structure}

Five well-defined elements of an effective O\&M program include those presented above in the OMETA concept (Meador 1995). While these elements, Operations, Maintenance, Engineering, Training, and Administration, form the basis for a solid O\&M organization, the key lies in the well-defined functions each brings and the linkages between organizations. A subset of the roles and responsibilities for each of the elements is presented below; further information is found in Meador (1995).

\section{Operations}

- Administration - To ensure effective implementation and control of operation activities.

- Conduct of Operations - To ensure efficient, safe, and reliable process operations.

- Equipment Status Control - To be cognizant of status of all equipment.

- Operator Knowledge and Performance - To ensure that operator knowledge and performance will support safe and reliable plant operation.

\section{Maintenance}

- Administration - To ensure effective implementation and control of maintenance activities.

- Work Control System - To control the performance of maintenance in an efficient and safe manner such that economical, safe, and reliable plant operation is optimized.

- Conduct of Maintenance - To conduct maintenance in a safe and efficient manner.

- Preventive Maintenance - To contribute to optimum performance and reliability of plant systems and equipment. 
- Maintenance Procedures and Documentation - To provide directions, when appropriate, for the performance of work and to ensure that maintenance is performed safely and efficiently.

\section{Engineering Support}

- Engineering Support Organization and Administration - To ensure effective implementation and control of technical support.

- Equipment Modifications - To ensure proper design, review, control, implementation, and documentation of equipment design changes in a timely manner.

- Equipment Performance Monitoring - To perform monitoring activities that optimize equipment reliability and efficiency.

- Engineering Support Procedures and Documentation - To ensure that engineer support procedures and documents provide appropriate direction and that they support the efficiency and safe operations of the equipment.

\section{Training}

- Administration - To ensure effective implementation and control of training activities.

- General Employee Training - To ensure that plant personnel have a basic understanding of their responsibilities and safe work practices and have the knowledge and practical abilities necessary to operate the plant safely and reliably.

- Training Facilities and Equipment - To ensure the training facilities, equipment, and materials effectively support training activities.

- Operator Training - To develop and improve the knowledge and skills necessary to perform assigned job functions.

- Maintenance Training - To develop and improve the knowledge and skills necessary to perform assigned job functions.

\section{Administration}

- Organization and Administration - To establish and ensure effective implementation of policies and the planning and control of equipment activities.

- Management Objectives - To formulate and utilize formal management objectives to improve equipment performance.

- Management Assessment - To monitor and assess station activities to improve all aspects of equipment performance.

- Personnel Planning and Qualification - To ensure that positions are filled with highly qualified individuals.

- Industrial Safety - To achieve a high degree of personnel and public safety. 


\subsection{Obtain Management Support}

Federal O\&M managers need to obtain full support from their management structure in order to carry out an effective maintenance program. A good way to start is by establishing a written maintenance plan and obtaining upper management approval. Such a management-supported program is very important because it allows necessary activities to be scheduled with the same priority as other management actions.

Management reports should not assign blame for poor maintenance and inefficient systems, but rather to motivate efficiency improvement through improved maintenance.

Approaching $\mathrm{O} \& \mathrm{M}$ by equating it with increased productivity, energy efficiency, safety, and customer satisfaction is one way to gain management attention and support.

When designing management reports, the critical metrics used by each system should be compared to a base period. For example, compare monthly energy use against the same month for the prior year, or against the same month in a particular base year (for example, 1985). If efficiency standards for a particular system are available, compare your system's performance against that standard as well. Management reports should not assign blame for poor maintenance and inefficient systems, but rather to motivate efficiency improvement through improved maintenance.

\subsubsection{The O\&M Mission Statement}

Another useful approach in soliciting management buy-in and support is the development an O\&M mission statement. The mission statement does not have to be elaborate or detailed. The main objective is to align the program goals with those of site management and to seek approval, recognition, and continued support. Typical mission statements set out to answer critical questions - a sample is provided below:

- Who are we as an organization - specifically, the internal relationship?

- Whom do we serve - specifically, who are the customers?

- What do we do - specifically, what activities make up day-to-day actions?

- How do we do it - specifically, what are the beliefs and values by which we operate?

- Finally, how do we measure success - what metrics do we use, (e.g., energy/water efficiency, safety, dollar savings, etc.?)

A critical element in mission statement development is involvement of upper management and facility staff alike. Once involved with the development, there will be "ownership" which can lead to compliance (facility staff) and support (management). 


\subsection{Measuring the Quality of Your O\&M Program}

Traditional thinking in the O\&M field focused on a single metric, reliability, for program evaluation. Every O\&M manager wants a reliable facility; however, this metric alone is not enough to evaluate or build a successful O\&M program.

Beyond reliability, O\&M managers need to be responsible for controlling costs, evaluating and implementing new technologies, tracking and reporting on health and safety issues, and expanding their program. To support these activities, the $O \& M$ manager must be aware of the various indicators that can be used to measure the quality or effectiveness of the O\&M program. Not only are these metrics useful in assessing effectiveness, but also useful in cost justification of equipment purchases, program modifications, and staff hiring.

Below are a number of metrics that can be used to evaluate an O\&M program. Not all of these metrics can be used in all situations; however, a program should use of as many metrics as possible to better define deficiencies and, most importantly, publicize successes.

- Capacity factor - Relates actual plant or equipment operation to the full-capacity operation of the plant or equipment. This is a measure of actual operation compared to full-utilization operation.

- Work orders generated/closed out - Tracking of work orders generated and completed (closed out) over time allows the manager to better understand workloads and better schedule staff.

- Backlog of corrective maintenance - An indicator of workload issues and effectiveness of preventive/predictive maintenance programs.

- Safety record - Commonly tracked either by number of loss-of-time incidents or total number of reportable incidents. Useful in getting an overall safety picture.

- Energy use - A key indicator of equipment performance, level of efficiency achieved, and possible degradation.

- Inventory control - An accurate accounting of spare parts can be an important element in controlling costs. A monthly reconciliation of inventory "on the books" and "on the shelves" can provide a good measure of your cost control practices.

- Overtime worked - Weekly or monthly hours of overtime worked has workload, scheduling, and economic implications.

- Environmental record - Tracking of discharge levels (air and water) and non-compliance situations.

- Absentee rate - A high or varying absentee rate can be a signal of low worker morale and should be tracked. In addition, a high absentee rate can have a significant economic impact.

- Staff turnover - High turnover rates are also a sign of low worker morale. Significant costs are incurred in the hiring and training of new staff. Other costs include those associated with errors made by newly hired personnel that normally would not have been made by experienced staff. 
While some metrics are easier to quantify than others, Table 3.1.1 below can serve as a guide for tracking and trending metrics against industry benchmarks (NASA 2000).

Table 3.1.1. Industry O\&M metrics and benchmarks

\begin{tabular}{|l|l|r|}
\hline Metric & \multicolumn{1}{c|}{ Variables and Equation } & Benchmark \\
\hline Equipment Availability & $\%=\frac{\text { Hours each unit is avaialbe to run at capacity }}{\text { Total hours during the reporting time period }}$ & $>95 \%$ \\
\hline Schedule Compliance & $\%=\frac{\text { Total hours worked on scheduled jobs }}{\text { Total hours scheduled }}$ & $>90 \%$ \\
\hline $\begin{array}{l}\text { Emergency Maintenance } \\
\text { Percentage }\end{array}$ & $\%=\frac{\text { Total hours worked on emergency jobs }}{\text { Total hours worked }}$ & $<10 \%$ \\
\hline $\begin{array}{l}\text { Maintenance Overtime } \\
\text { Percentage }\end{array}$ & $\%=\frac{\text { Total maintenance overtime during period }}{\text { Total regular maintenance hour during period }}$ & $<5 \%$ \\
\hline $\begin{array}{l}\text { Preventive Maintenance } \\
\text { Completion Percentage }\end{array}$ & $\%=\frac{\text { Preventive maintenance actions completed }}{\text { Preventive maintenance actions scheduled }}$ & $>90 \%$ \\
\hline $\begin{array}{l}\text { Preventive Maintenance } \\
\text { Budget/Cost }\end{array}$ & $\%=\quad \frac{\text { Preventive maintenance cost }}{\text { Total maintenance cost }}$ & $15 \%-18 \%$ \\
\hline $\begin{array}{l}\text { Predictive Maintenance } \\
\text { Budget/Cost }\end{array}$ & $\%=\quad \frac{\text { Preventive maintenance cost }}{\text { Total maintenance cost }}$ & $10 \%-12 \%$ \\
\hline
\end{tabular}

\subsection{Selling O\&M to Management}

To successfully interest management in O\&M activities, O\&M managers need to be fluent in the language spoken by management. Projects and proposals brought forth to management need to stand on their own merits and be competitive with other funding requests. While evaluation criteria may differ, generally some level of economic criteria will be used. O\&M managers need to have a working knowledge of economic metrics such as:

- Simple payback - The ratio of total installed cost to first-year savings.

- Return on investment - The ratio of the income or savings generated to the overall investment.

- Net present value - Represents the present worth of future cash flows minus the initial cost of the project.

- Life-cycle cost - The present worth of all

\section{Life-Cycle Cost Training}

Take advantage of LCC workshops offered by FEMP. Each year, FEMP conducts a 2-hour televised workshop on life-cycle cost methods and the use of BLCC (Building Life-Cycle Cost) software programs. In some years, two-day classroom workshops are offered at various U.S. locations.

More information can be found at: http://wwwl. eere.energy.gov/femp/program/lifecycle.html costs associated with a project.

FEMP offers life-cycle cost training along with its Building Life-Cycle Cost (BLCC) computer program at various locations during the year - see Appendix B for the FEMP training contacts. 


\subsection{Program Implementation}

Developing or enhancing an $O \& M$ program requires patience and persistence. Guidelines for initiating a new $\mathrm{O} \& \mathrm{M}$ project will vary with agency and management situation; however, some steps to consider are presented below:

- Start small - Choose a project that is manageable and can be completed in a short period of time, 6 months to 1 year.

- Select troubled equipment - Choose a project that has visibility because of a problematic history.

- Minimize risk - Choose a project that will provide immediate and positive results. This project needs to be successful, and therefore, the risk of failure should be minimal.

- Keep accurate records - This project needs to stand on its own merits. Accurate, if not conservative, records are critical to compare before and after results.

- Tout the success - When you are successful, this needs to be shared with those involved and with management. Consider developing a "wall of accomplishment" and locate it in a place where management will take notice.

- Build off this success - Generate the success, acknowledge those involved, publicize it, and then request more money/time/resources for the next project.

\subsection{Program Persistence}

A healthy O\&M program is growing, not always in staff but in responsibility, capability, and accomplishment. O\&M management must be vigilant in highlighting the capabilities and accomplishments of their O\&M staff.

Finally, to be sustainable, an O\&M program must be visible beyond the O\&M management. Persistence in facilitating the OMETA linkages and relationships enables heightened visibility of the O\&M program within other organizations.

\subsection{O\&M Contracting}

Approximately $40 \%$ of all non-residential buildings contract maintenance service for heating, ventilation, and air conditioning (HVAC) equipment (PECI 1997). Discussions with Federal building mangers and organizations indicate this value is significantly higher in the Federal sector, and the trend is toward increased reliance on contracted services.

In the O\&M service industry, there is a wide variety of service contract types ranging from fullcoverage contracts to individual equipment contracts to simple inspection contracts. In a relatively new type of O\&M contract, called End-Use or End-Result contracting, the O\&M contractor not only takes over all operation of the equipment, but also all operational risk. In this case, the contractor agrees to provide a certain level of comfort (space temperature, for instance) and then is compensated based on how well this is achieved. 
From discussions with Federal sector O\&M personnel, the predominant contract type is the fullcoverage contract (also referred to as the whole-building contract). Typical full-coverage contract terms vary between 1 and 5 years and usually include options for out-years.

Upon review of several sample O\&M contracts used in the Federal sector, it is clear that some degree of standardization has taken place. For better or worse, some of these contracts contain a high degree of "boiler plate." While this can make the contract very easy to implement, and somewhat uniform across government agencies, the lack of site specificity can make the contract ambiguous and open to contractor interpretation often to the government's disadvantage.

When considering the use of an O\&M contract, it is important that a plan be developed to select, contract with, and manage this contract. In its guide, titled Operation and Maintenance Service Contracts (PECI 1997), Portland Energy Conservation, Inc. did a particularly good job in presenting steps and actions to think about when considering an O\&M contract. A summary of these steps are provided below.

\section{Steps to Think About When Considering an O\&M Contract}

- Develop objectives for an O\&M service contract, such as:

- Provide maximum comfort for building occupants.

- Improve operating efficiency of mechanical plant (boilers, chillers, cooling towers, etc.).

- Apply preventive maintenance procedures to reduce chances of premature equipment failures.

- Provide for periodic inspection of building systems to avoid emergency breakdown situations.

- Develop and apply a screening process. The screening process involves developing a series of questions specific to your site and expectations. The same set of questions should be asked to perspective contractors and their responses should be rated.

- Select two to four potential contractors and obtain initial proposals based on each contractor's building assessments. During the contractors' assessment process, communicate the objectives and expectations for the O\&M service contract and allow each contractor to study the building documentation.

- Develop the major contract requirements using the contractors' initial proposals. Make sure to include the requirements for documentation and reporting. Contract requirements may also be developed by competent in-house staff or a third party.

- Obtain final bids from the potential contractors based on the owner-developed requirements.

- Select the contractor and develop the final contract language and service plan.

- Manage and oversee the contracts and documentation.

- Periodically review the entire contract. Build in a feedback process.

The ability of Federal agencies to adopt the PECI-recommended steps will vary. Still, these steps do provide a number of good ideas that should be considered for incorporation into Federal maintenance contracts procurements. 


\subsubsection{O\&M Contract Types}

There are four predominant types of $O \& M$ contracts. These are: full coverage contracts, fulllabor contracts, preventive-maintenance contracts, and inspection contracts. Each type of contract is discussed below (PECI 1997).

Full-Coverage Service Contract. A full-coverage service contract provides 100\% coverage of labor, parts, and materials as well as emergency service. Owners may purchase this type of contract for all of their building equipment or for only the most critical equipment, depending on their needs. This type of contract should always include comprehensive preventive maintenance for the covered equipment and systems. If it is not already included in the contract, for an additional fee the owner can purchase repair and replacement coverage (sometimes called a "breakdown" insurance policy) for the covered equipment. This makes the contractor completely responsible for the equipment. When repair and replacement coverage is part of the agreement, it is to the contractor's advantage to perform rigorous preventive maintenance on schedule, since he or she must replace the equipment if it fails prematurely.

Full-coverage contracts are usually the most comprehensive and the most expensive type of agreement in the short term. In the long term, however, such a contract may prove to be the most cost-effective, depending on the owner's overall $O \& M$ objectives. Major advantages of fullcoverage contracts are ease of budgeting and the fact that most if not all of the risk is carried by the contractor. However, if the contractor is not reputable or underestimates the requirements of the equipment to be insured, the contractor may do only enough preventive maintenance to keep the equipment barely running until the end of the contract period. Also, if a company underbids the work in order to win the contract, the company may attempt to break the contract early if it foresees a high probability of one or more catastrophic failures occurring before the end of the contract.

Full-Labor Service Contract. A full-labor service contract covers 100\% of the labor to repair, replace, and maintain most mechanical equipment. The owner is required to purchase all equipment and parts. Although preventive maintenance and operation may be part of the agreement, actual installation of major plant equipment such as a centrifugal chillers, boilers, and large air compressors is typically excluded from the contract. Risk and warranty issues usually preclude anyone but the manufacturer installing these types of equipment. Methods of dealing with emergency calls may also vary. The cost of emergency calls may be factored into the original contract, or the contractor may agree to respond to an emergency within a set number of hours with the owner paying for the emergency labor as a separate item. Some preventive maintenance services are often included in the agreement along with minor materials such as belts, grease, and filters.

This is the second most expensive contract regarding short-term impact on the maintenance budget. This type of contract is usually advantageous only for owners of very large buildings or multiple properties who can buy in bulk and therefore obtain equipment, parts, and materials at reduced cost. For owners of small to medium-size buildings, cost control and budgeting becomes more complicated with this type of contract, in which labor is the only constant. Because they are responsible only for providing labor, the contractor's risk is less with this type of contract than with a full-coverage contract. 
Preventive-Maintenance Service Contract. The preventive-maintenance (PM) contract is generally purchased for a fixed fee and includes a number of scheduled and rigorous activities such as changing belts and filters, cleaning indoor and outdoor coils, lubricating motors and bearings, cleaning and maintaining cooling towers, testing control functions and calibration, and painting for corrosion control. Generally the contractor provides the materials as part of the contract. This type contract is popular with owners and is widely sold. The contract may or may not include arrangements regarding repairs or emergency calls.

The main advantage of this type of contract is that it is initially less expensive than either the full-service or full-labor contract and provides the owner with an agreement that focuses on quality preventive maintenance. However, budgeting and cost control regarding emergencies, repairs, and replacements is more difficult because these activities are often done on a time-andmaterials basis. With this type of contract the owner takes on most of the risk. Without a clear understanding of PM requirements, an owner could end up with a contract that provides either too much or too little. For example, if the building is in a particularly dirty environment, the outdoor cooling coils may need to be cleaned two or three times during the cooling season instead of just once at the beginning of the season. It is important to understand how much preventive maintenance is enough to realize the full benefit of this type of contract.

Inspection Service Contract. An inspection contract, also known in the industry as a "fly-by" contract, is purchased by the owner for a fixed annual fee and includes a fixed number of periodic inspections. Inspection activities are much less rigorous than preventive maintenance. Simple tasks such as changing a dirty filter or replacing a broken belt are performed routinely, but for the most part inspection means looking to see if anything is broken or is about to break and reporting it to the owner. The contract may or may not require that a limited number of materials (belts, grease, filters, etc.) be provided by the contractor, and it may or may not include an agreement regarding other service or emergency calls.

In the short-term perspective, this is the least expensive type of contract. It may also be the least effective-it's not always a moneymaker for the contractor but is viewed as a way to maintain a relationship with the customer. A contractor who has this "foot in the door" arrangement is more likely to be called when a breakdown or emergency occurs. The contractor can then bill on a time-and-materials basis. Low cost is the main advantage to this contract, which is most appropriate for smaller buildings with simple mechanical systems.

\subsubsection{Contract Incentives}

An approach targeting energy savings through mechanical/electrical (energy consuming) O\&M contracts is called contract incentives. This approach rewards contractors for energy savings realized for completing actions that are over and above the stated contract requirements.

Many contracts for O\&M of Federal building mechanical/electrical (energy consuming) systems are written in a prescriptive format where the contractor is required to complete specifically noted actions in order to satisfy the contract terms. There are two significant shortcomings to this approach:

- The contractor is required to complete only those actions specifically called out, but is not responsible for actions not included in the contract even if these actions can save energy, improve building operations, extend equipment life, and be accomplished with minimal additional effort. Also, this approach assumes that the building equipment and maintenance lists are complete. 
- The burden to verifying successful completion of work under the contract rests with the contracting officer. While contracts typically contain contractor reporting requirements and methods to randomly verify work completion, building $O \& M$ contracts tend to be very large, complex, and difficult to enforce.

One possible method to address these shortcomings is to apply a provision of the Federal Acquisition Regulations (FAR), Subpart 16.404 - Fixed-Price with Award Fees, which allows for contractors to receive a portion of the savings realized from actions initiated on their part that are seen as additional to the original contract:

Subpart 16.404 — Fixed-Price Contracts With Award Fees.

(a) Award-fee provisions may be used in fixed-price contracts when the government wishes to motivate a contractor and other incentives cannot be used because contractor performance cannot be measured objectively. Such contracts shall -

(1) Establish a fixed price (including normal profit) for the effort. This price will be paid for satisfactory contract performance. Award fee earned (if any) will be paid in addition to that fixed price; and

(2) Provide for periodic evaluation of the contractor's performance against an award-fee plan.

(b) A solicitation contemplating award of a fixed-price contract with award fee shall not be issued unless the following conditions exist:

(1) The administrative costs of conducting award-fee evaluations are not expected to exceed the expected benefits;

(2) Procedures have been established for conducting the award-fee evaluation;

(3) The award-fee board has been established; and

(4) An individual above the level of the contracting officer approved the fixed-price-award-fee incentive.

Applying this approach to building mechanical systems O\&M contracts, contractor initiated measures would be limited to those that

- require little or no capital investment,

- can recoup implementation costs over the remaining current term, and

- allow results to be verified or agreed upon by the government and the contractor.

Under this approach, the contractor bears the risk associated with recovering any investment and a portion of the savings.

In the past, The General Services Administration (GSA) has inserted into some of its mechanical services contracts a voluntary provision titled Energy Conservation Award Fee (ECAF), which allows contractors and sites to pursue such an approach for O\&M savings incentives. The ECAF model language provides for the following: 
An energy use baseline will be furnished upon request and be provided by the government to the contractor. The baseline will show the 3-year rolling monthly average electric and natural gas use prior to contract award.

- The government will calculate the monthly electric savings as the difference between the monthly energy bill and the corresponding baseline period.

- The ECAF will be calculated by multiplying the energy savings by the monthly average cost per kilowatt-hour of electricity.

- All other contract provisions must be satisfied to qualify for award.

- The government can adjust the ECAF for operational factors affecting energy use such as fluctuations in occupant density, building use changes, and when major equipment is not operational.

Individual sites are able to adapt the model GSA language to best suit their needs (e.g., including natural gas savings incentives). Other agencies are free to adopt this approach as well since the provisions of the FAR apply across the Federal Government.

Energy savings opportunities will vary by building and by the structure of the contract incentives arrangement. Some questions to address when developing a site specific incentives plan are:

- Will metered data be required or can energy savings be stipulated?

- Are buildings metered individually for energy use or do multiple buildings share a master meter?

- Will the baseline be fixed for the duration of the contract or will the baseline reset during the contract period?

- What energy savings are eligible for performance incentives? Are water savings also eligible for performance incentives?

- What administrative process will be used to monitor work and determine savings? Note that overly rigorous submittal, approval, justification, and calculation processes will discourage contractor participation.

Since the contract incentives approach is best suited for low cost, quick-payback measures, O\&M contractors should consider recommissioning/value recommissioning actions as discussed in Chapter 7.

An added benefit from the contract incentives process is that resulting operations and energy efficiency improvements can be incorporated into the $O \& M$ services contract during the next contract renewal or re-competition since (a) the needed actions are now identified, and (b) the value of the actions is known to the government. 


\subsection{O\&M: The ESPC Perspective}

With the prevalence of Energy Savings Performance Contracts (ESPCs) in the Federal sector, some guidance should be offered from the $O \& M$ perspective. This guidance takes two forms. First, the need for high-quality and persistent O\&M for ESPC projects to assure savings are met. Second, the opportunities $O \& M$ provides for enhanced efficiency of new and existing equipment and systems.

\subsubsection{O\&M Needs for Verified and Persistent Savings (LBNL 2005)}

In Federal ESPCs, proper O\&M is critical to the maintaining the performance of the installed equipment and to the achievement (and persistence) of the guaranteed energy savings for the term of the ESPC.

Inadequate $O \& M$ of energy-using systems is a major cause of energy waste, often affects system reliability and can shorten equipment life. Proper O\&M practices are a key component in maintaining the desired energy savings from an ESPC and minimizing the chance of unexpected repair and replacement issues arising during the ESPC contract term. Further, to ensure longterm energy and cost savings, unambiguous allocation of responsibility for O\&M and repair and replacement $(R \& R)$ issues, including reciprocal reporting requirements for responsible parties, are vital to the success of an ESPC.

Either the ESCO or the government (or the government's representative) may perform O\&M activities on equipment installed as part of an ESPC. However, the ESCO is ultimately responsible for ensuring the performance of new equipment installed as part of the ESPC throughout the duration of the ESPC contract term. The government is typically responsible for existing equipment.

\section{One Illustrative Scenario: Why O\&M reporting is important for ESPC Projects}

At one ESPC site, a disagreement during the performance period was seriously exacerbated due to the allocation of O\&M responsibilities and the lack of reporting required on O\&M conducted.

The primary cost saving measure implemented by the ESCO was an upgrade to the central chiller plant. The ESCO installed one new chiller (out of two), and two new distribution pumps (out of four). The ECM did not upgrade the existing cooling tower and distribution system. Due to project economics, the site elected to operate and maintain the entire chilled water system, including the new equipment. The ESPC contract did not require the site to document or report O\&M activities to the ESCO.

After project acceptance, several problems with the chiller plant arose. In one instance, both chillers went out of service due to high head pressure. The ESCO asserted that the event was due to improper operations and lack of adequate maintenance by site personnel, and had voided the warranty for the new chiller. The site contended that the system was not properly commissioned and had design problems.

Since the site had not maintained any O\&M records, they had no foundation to win the dispute. The site's contracting officer was obligated to continue full payments to the ESCO even though systems were not operating properly. After much contention, the ESCO eventually got the system working properly.

Lessons Learned:

- O\&M documentation on ECMs is essential to minimizing disputes.

- If feasible, have ESCO accept O\&M responsibilities.

- Proper commissioning is essential prior to project acceptance. 
In an ideal scenario, the ESCO will both operate and perform all maintenance activities on equipment installed in an ESPC project. In many cases, however, it is not practical for the ESCO to carry out these activities. Often, the site is accustomed to performing O\&M and the cost of reallocating these responsibilities may not be feasible within the ESPC contract term, since services must be paid from savings. In other instances, limited site access or other issues may make government $O \& M$ preferable.

A critical factor in the success of an ESPC is to ensure that the O\&M plan for new equipment relates well to the O\&M approach for existing equipment. This is especially true when new and existing equipment are located in the same facility or when existing equipment has a potential effect on the operation or savings achieved by new equipment. Clear definition of roles and responsibilities for $O \& M$ contribute toward proper coordination of $O \& M$ activities for new and existing equipment. In doing so, the chance of customer dissatisfaction, accusations and potential litigation during the ESPC contract term are minimized.

From the ESPC perspective, Table 3.2.2 below presents an overview of the key O\&M issues, the timing or stage in the process which it needs to be addressed and the relevant supporting documents for more information. All listed documents can be found on the FEMP ESPC web site at:

http://wwwl .eere.energy.gov/femp/financing/espcs.html.

Table 3.2.2. Overview of key O\&M issues, timing, and supporting documents

\begin{tabular}{|c|c|c|}
\hline Key O\&M Topics & ESPC Stage & Reference Documents \\
\hline $\begin{array}{l}\text { 1. Describe overall responsibility for the operation, maintenance, } \\
\text { repair, and replacement at the project level }\end{array}$ & $\begin{array}{l}\text { Initial and Final } \\
\text { Proposals }\end{array}$ & $\begin{array}{l}\text { Section } 3 . b, 3 . c, 3 . d \text { of the Risk/ } \\
\text { Responsibility Matrix; Sections } \\
\text { C.6, C.7, C. } 8 \text { of IDIQ }\end{array}$ \\
\hline $\begin{array}{l}\text { 2. Describe responsibility for the operation, maintenance, repair, } \\
\text { and replacement of each ECM. }\end{array}$ & Final Proposal & Sections C.6, C.7, C.8 of IDIQ \\
\hline $\begin{array}{l}\text { 3. Define different conditions under which Repair and } \\
\text { Replacement }(R \& R) \text { work will be performed, who will be } \\
\text { liable, and the source of funds for performing } R \& R \text { activities. }\end{array}$ & Final Proposal & Section C.8 of IDIQ \\
\hline $\begin{array}{l}\text { 4. Define reporting requirement for } O \& M \text { activities and its } \\
\text { frequency. }\end{array}$ & Final Proposal & $\begin{array}{l}\text { IDIQ; M\&V Plan Outline } \\
\text { (Sections 2.4.1, 3.8.8) }\end{array}$ \\
\hline 5. Submission of the ECM-specific O\&M checklists by the ESCO. & Final Proposal & $\begin{array}{l}\text { Recommended, but not } \\
\text { required by IDIQ contract }\end{array}$ \\
\hline $\begin{array}{l}\text { 6. ESCO provides O\&M training \& submits the Operations and } \\
\text { Maintenance Manual for ECMs, including: } \\
\text { - New written operations procedures; } \\
\text { - Preventive maintenance work procedures and checklists. }\end{array}$ & Project Acceptance & $\begin{array}{l}\text { IDIQ Attachment 2: Sample } \\
\text { Checklist/Schedule of Post- } \\
\text { Award Reporting Requirements } \\
\text { and Submittals } \\
\text { Sections C. } 6.3 \text { and C. } 7.4 \text { of IDIQ }\end{array}$ \\
\hline $\begin{array}{l}\text { 7. Government (or ESCO) periodically reports on maintenance } \\
\text { work performed on ECMs }\end{array}$ & $\begin{array}{l}\text { Performance } \\
\text { Period }\end{array}$ & Section C.7.3 of IDIQ \\
\hline $\begin{array}{l}\text { 8. Identification of O\&M issues that can adversely affect savings } \\
\text { persistence; Steps to be taken to address the issue }\end{array}$ & $\begin{array}{l}\text { Performance } \\
\text { Period }\end{array}$ & $\begin{array}{l}\text { Annual Report (Sections } 1.5 \\
2.5 .1,2.5 .2,2.5 .3) ; \text { Project } \\
\text { specific O\&M checklists }\end{array}$ \\
\hline
\end{tabular}




\subsubsection{Determination and Verification of O\&M Savings in ESPCs}

O\&M and other energy-related cost savings are allowable in Federal ESPCs, and are defined as reduction in expenses (other than energy cost savings) related to energy and water consuming equipment. In fact, an analysis of annual measurement and verification $(M \& V)$ reports from 100 ongoing Super ESPC projects showed that 21\% of the reported savings were due to reductions in O\&M costs (LBNL 2007). These energy-related cost savings, which can also include savings on $R \& R$ costs, can constitute a substantial portion of a project's savings, yet $O \& M$ and $R \& R$ cost savings are often not as diligently verified or reviewed as energy savings.
10 CFR $\S 436.31$. Energy cost savings means a reduction in the cost of energy and related operation and maintenance expenses, from a base cost established through a methodology set forth in an energy savings performance contract, utilized in an existing Federally owned building or buildings or other Federally owned facilities as a result of $-(1)$ The lease or purchase of operating equipment, improvements, altered operation and maintenance, or technical services...

Source: Title 10, Code of Federal regulation part 436 Subpart B - Methods and Procedures for Energy Savings Performance Contracting.

Energy-related cost savings can result from avoided expenditures for operations, maintenance, equipment repair, or equipment replacement due to the ESPC project. This includes capital funds for projects (e.g., equipment replacement) that, because of the ESPC project, will not be necessary. Sources of energy-related savings include:

- Avoided current or planned capital expense,

- Transfer of responsibility for O\&M and/or R\&R to the ESCO, and

- Avoided renovation, renewal, or repair costs as a result of replacing old and unreliable equipment.

Methods for estimating O\&M savings resulting from changes to equipment have not been developed for the FEMP or IPMVP M\&V Guidelines. However, the general rule to follow is that any savings claimed from $O \& M$ activities must result in a real decrease in expenditures. $O \& M$ budget baselines cannot be based on what the agency should be spending for proper $O \& M$; baseline expenditures must be based on what the agency is spending. The agency's O\&M expenditures after implementation need to decrease for savings to be considered real.

Determining the appropriate level of effort to invest in the $M \& V$ of energy-related cost saving is the same as for energy cost savings: The level of $M \& V$ rigor will vary according to (a) the value of the project and its expected benefits, and (b) the risk in not achieving the benefits. A graded approach towards measuring and verifying $O \& M$ and $R \& R$ savings is advised. There is one primary method for calculating O\&M savings, which is detailed below.

The most common approach for calculating energy-related cost savings involves the same concepts as those used for determining energy savings: Performance-period labor and equipment costs are subtracted from adjusted baseline values, as shown in the equation below.

\section{OEGM Cost Savings $=[$ Adjusted Baseline OEBM Costs $]-[$ Actual OEGM Costs $]$}


This method is appropriate for most projects, and is especially simple to apply to those that include elimination of a maintenance contract or reduction in government staff. For other projects, costs for replacement parts can often be determined from purchase records and averaged to arrive at an annual baseline value. Labor costs for particular services may be more difficult to quantify since service records may not be representative or may lack sufficient detail. For example, parts costs for replacement light bulbs, ballasts, or steam traps are relatively easy to quantify from purchase records. Labor costs to replace lamps, ballasts, or steam traps are more difficult to quantify because time spent on these specific tasks may not be well documented. In addition, labor reductions on these specific tasks may not qualify as "real savings" if labor expenditures do not decrease. Although the agency receives value in the sense that labor is freed up to perform other useful tasks, this value may not result in cost savings that can be paid to the ESCO.

Baseline O\&M costs should be based on actual budgets and expenditures to the greatest extent practical. This essentially "measures" the baseline consumption of these parts or services. Estimated expenditures should be avoided if at all possible. In cases where such information is not available and must be estimated, parts and labor costs can be derived from resources such as R.S. Means or other methods. Estimated expenditures should be adjusted to reflect any site-specific factors that would affect costs.

A more complete discussion of this topic can be found at the main ESPC web site located at: http://wwwl.eere.energy.gov/femp/financing/espcs.html.

\subsection{References}

LBNL 2005. Planning and Reporting for Operations $\mathfrak{E}$ Maintenance in Federal Energy Saving Performance Contracts. Lawrence Berkeley National Laboratory, Berkeley, California. Available at: http://ateam.lbl.gov/mv/.

LBNL 2007. How to Determine and Verify Operating and Maintenance (OEBM) Savings in Federal Energy Savings Performance Contracts. Lawrence Berkeley National Laboratory, Berkeley, California. Available at: http://ateam.lbl.gov/mv/.

Meador, R.J. 1995. Maintaining the Solution to Operations and Maintenance Efficiency Improvement. World Energy Engineering Congress, Atlanta, Georgia.

NASA. 2000. Reliability Centered Maintenance Guide for Facilities and Collateral Equipment. National Aeronautics and Space Administration, Washington, D.C. February 2000.

PECI. 1997. Operations and Maintenance Service Contract. Portland Energy Conservation, Inc., Portland, Oregon. 



\section{Chapter 4 Computerized Maintenance Management System}

\subsection{Introduction}

A computerized maintenance management system (CMMS) is a type of management software that performs functions in support of management and tracking of $O \& M$ activities.

\subsection{CMMS Needs Assessment}

In determining the need for a CMMS, facility managers should assess their current mode of operation. Key questions to ask include:

- Do you have an effective way to generate and track work orders? How do you verify the work was done efficiently and correctly? What is the notification function upon completion?

- Are you able to access historical information on the last time a system was serviced, by whom, and for what condition?

- How are your spare-parts inventories managed and controlled? Do you have either excess inventories or are you consistently waiting for parts to arrive?

- Do you have an organized system to store documents (electronically) related to $O \& M$ procedures, equipment manuals, and warranty information?

- When service staff are in the field what assurances do you have that they are compliant with all life, health and safety issues (e.g., lock and tag) and are using the right tools/equipment for the task?

- How are your assets, i.e., equipment and systems, tracked for reporting and planning?

If the answers to these questions are not well defined or lacking - you may consider investigating the benefits a well implemented CMMS may offer.

\subsection{CMMS Capabilities}

CMMS systems automate most of the logistical functions performed by maintenance staff and management. CMMS systems come with many options and have many advantages over manual maintenance tracking systems. Depending on the complexity of the system chosen, typical CMMS functions may include the following:

- Work order generation, prioritization, and tracking by equipment/component.

- Historical tracking of all work orders generated which become sortable by equipment, date, person responding, etc.

- Tracking of scheduled and unscheduled maintenance activities.

- Storing of maintenance procedures as well as all warranty information by component.

- Storing of all technical documentation or procedures by component. 
- Real-time reports of ongoing work activity.

- Calendar- or run-time-based preventive maintenance work order generation.

- Capital and labor cost tracking by component as well as shortest, median, and longest times to close a work order by component.

- Complete parts and materials inventory control with automated reorder capability.

- PDA interface to streamline input and work order generation.

- Outside service call/dispatch capabilities.

Many CMMS programs can now interface with existing energy management and control systems (EMCS) as well as property management systems. Coupling these capabilities allows for conditionbased monitoring and component energy use profiles.

While CMMS can go a long way toward automating and improving the efficiency of most O\&M programs, there are some common pitfalls. These include the following:

- Improper selection of a CMMS vendor. This is a site-specific decision. Time should be taken to evaluate initial needs and look for the proper match of system and service provider.

- Inadequate training of the O\&M administrative staff on proper use of the CMMS. These staff need dedicated training on input, function, and maintenance of the CMMS. Typically, this training takes place at the customer's site after the system has been installed.
As reported in A.T. Kearney's and Industry Week's survey of 558 companies that are currently using a computerized maintenance management system (DPSI 1994), companies reported an average of:

$28.3 \%$ increase in maintenance productivity

$20.1 \%$ reduction in equipment downtime

$19.4 \%$ savings in lower material costs

$17.8 \%$ reduction in maintenance, repairs, operation (MRO) inventory

14.5 months average payback time.

- Lack of commitment to properly implement the CMMS. A commitment needs to be in place for the start up/implementation of the CMMS. Most vendors provide this as a service and it is usually worth the expense.

- Lack of commitment to persist in CMMS use and integration. While CMMS provides significant advantages, they need to be maintained. Most successful CMMS installations have a "champion" of its use who ushers and encourages its continued use.

\section{Considerations for CMMS Evaluation and Selection}

- Have all relevant in-house staff (particularly field staff) been involved with the assessment of need, desired capabilities, and usability of proposed system?

- Does the product meet all of the needs as assessed?

- "Feature overload" is a common complaint of active CMMS users. Are you purchasing more than you need or have the capability to manage?

- Does the product offer module expansion as your system or needs grow?

- If needed, how well does the system integrate with other facility/energy management or accounting systems?

- How long has the vendor been in business? Do they have references for similar installations they could provide?

- How does the vendor provide technical assistance?

- How are product upgrades accomplished, and at what cost? 


\subsection{CMMS Benefits}

One of the greatest benefits of the CMMS is the elimination of paperwork and manual tracking activities, thus enabling the building staff to become more productive. It should be noted that the functionality of a CMMS lies in its ability to collect and store information in an easily retrievable format. A CMMS does not make decisions, rather it provides the O\&M manager with the best information to affect the operational efficiency of a facility.

Benefits to implement a CMMS include the following:

- Detection of impending problems before a failure occurs resulting in fewer failures and customer complaints.

- Achieving a higher level of planned maintenance activities that enables a more efficient use of staff resources.

- Affecting inventory control enabling better spare parts forecasting to eliminate shortages and minimize existing inventory.

- Maintaining optimal equipment performance that reduces downtime and results in longer equipment life.

\subsection{CMMS Resources}

The Internet provides a great resource for identifying CMMS vendors. A simple search under "CMMS" provides links to the many vendors and the resources they offer.

\section{CMMS and EMCS (Energy Management and Control System) Integration}

As technology improves and both of these systems develop capabilities, opportunities for integration exist. A good example is with air filtration systems. Traditionally, air filters are changed as part of a time-based PM activity - filters may get changed every 3 months, needed or not. Newer filtration systems made use of pressure sensors to calculate a need based filter change out. Many of these systems communicate back though an existing EMCS and notify the system monitor of differential pressure limit/alarm and the need for a filter change.

The opportunity and capability now exists to "port" this same differential pressure limit from the EMCS directly to the CMMS. This development affords a level of real-time maintenance management, whereby the filter change notification becomes an automatically generated work order scheduled based on need. In addition, this particular filter item is removed from inventory and a re-order paced if necessary. While this example highlight a simple air filter integration capability, the same logic applies to many other systems and equipment for which time-based maintenance can be replaced with need-based maintenance.

\subsection{Reference}

DPSI. 1994. Uptime for Windows Product Guide, Version 2.1. DPSI, Greensboro, North Carolina. 



\section{Chapter 5 Types of Maintenance Programs}

\subsection{Introduction}

What is maintenance and why is it performed? Past and current maintenance practices in both the private and government sectors would imply that maintenance is the actions associated with equipment repair after it is broken. The dictionary defines maintenance as follows: "the work of keeping something in proper condition; upkeep." This would imply that maintenance should be actions taken to prevent a device or component from failing or to repair normal equipment degradation experienced with the operation of the device to keep it in proper working order. Unfortunately, data obtained in many studies over the past decade indicates that most private and government facilities do not expend the necessary resources to maintain equipment in proper working order. Rather, they wait for equipment failure to occur and then take whatever actions are necessary to repair or replace the equipment. Nothing lasts forever and all equipment has associated with it some predefined life expectancy or operational life. For example, equipment may be designed to operate at full design load for 5,000 hours and may be designed to go through 15,000 start and stop cycles.

The need for maintenance is predicated on actual or impending failure - ideally, maintenance is performed to keep equipment and systems running efficiently for at least design life of the component(s). As such, the practical operation of a component is time-based function. If one were to graph the failure rate a component population versus time, it is likely the graph would take the "bathtub" shape shown in Figure 5.1.1. In the figure the Y axis represents the failure rate and the X axis is time. From its shape, the curve can be divided into three distinct: infant mortality, useful life, and wear-out periods.

The initial infant mortality period of bathtub curve is characterized by high failure rate followed by a period of decreasing failure. Many of the failures associated with this region are linked to poor design, poor installation, or misapplication. The infant mortality period is followed by a nearly constant failure rate period known as useful life. There are many theories on why components fail in this region, most acknowledge that poor $\mathrm{O} \& \mathrm{M}$ often plays significant role. It is also generally agreed

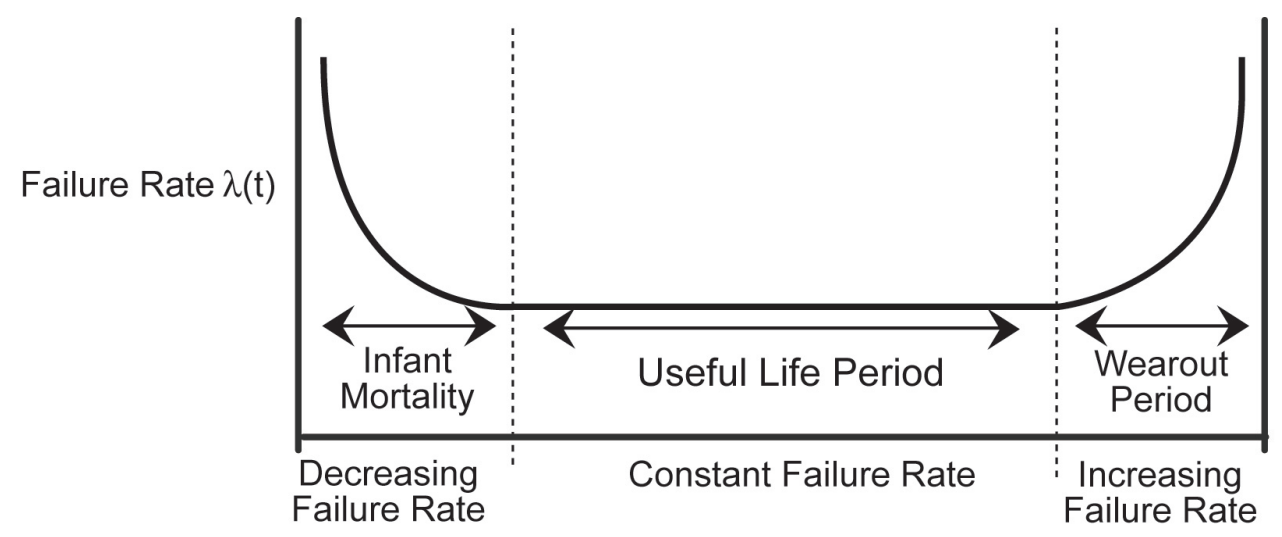

Figure 5.1.1. Component failure rate over time for component population 
that exceptional maintenance practices encompassing preventive and predictive elements can extend this period. The wear-out period is characterized by a rapid increasing failure rate with time. In most cases this period encompasses the normal distribution of design life failures.

The design life of most equipment requires periodic maintenance. Belts need adjustment, alignment needs to be maintained, proper lubrication on rotating equipment is required, and so on. In some cases, certain components need replacement, (e.g., a wheel bearing on a motor vehicle) to ensure the main piece of equipment (in this case a car) last for its design life. Anytime we fail to perform maintenance activities intended by the equipment's designer, we shorten the operating life of the equipment. But what options do we have? Over the last 30 years, different approaches to how maintenance can be performed to ensure equipment reaches or exceeds its design life have been developed in the United States. In addition to waiting for a piece of equipment to fail (reactive maintenance), we can utilize preventive maintenance, predictive maintenance, or reliability centered maintenance.

\subsection{Reactive Maintenance}

Reactive maintenance is basically the "run it till it breaks" maintenance mode. No actions or efforts are taken to maintain the equipment as the designer originally intended to ensure design life is reached. Studies as recent as the winter of 2000 indicate this is still the predominant mode of maintenance in the United States. The referenced study breaks down the average maintenance program as follows:

- $>55 \%$ Reactive

- $31 \%$ Preventive

\section{Advantages}

- Low cost.

- Less staff.

\section{Disadvantages}

- Increased cost due to unplanned downtime of equipment.

- Increased labor cost, especially if overtime is needed.

- Cost involved with repair or replacement of equipment.

- Possible secondary equipment or process damage from equipment failure.

- Inefficient use of staff resources.

- $12 \%$ Predictive

- $2 \%$ Other.

Note that more than $55 \%$ of maintenance resources and activities of an average facility are still reactive.

Advantages to reactive maintenance can be viewed as a double-edged sword. If we are dealing with new equipment, we can expect minimal incidents of failure. If our maintenance program is purely reactive, we will not expend manpower dollars or incur capital cost until something breaks. Since we do not see any associated maintenance cost, we could view this period as saving money. The downside is reality. In reality, during the time we believe we are saving maintenance and capital cost, we are really spending more dollars than we would have under a different maintenance approach. We are spending more dollars associated with capital cost because, while waiting for the equipment to break, we are shortening the life of the equipment resulting in more frequent replacement. We may incur cost upon failure of the primary device associated with its failure causing the failure of a secondary device. This is an increased cost we would not have experienced if our maintenance program was more proactive. Our labor cost associated with repair will probably be 
higher than normal because the failure will most likely require more extensive repairs than would have been required if the piece of equipment had not been run to failure. Chances are the piece of equipment will fail during off hours or close to the end of the normal workday. If it is a critical piece of equipment that needs to be back on-line quickly, we will have to pay maintenance overtime cost. Since we expect to run equipment to failure, we will require a large material inventory of repair parts. This is a cost we could minimize under a different maintenance strategy.

\subsection{Preventive Maintenance}

Preventive maintenance can be defined as follows: Actions performed on a time- or machine-run-based schedule that detect, preclude, or mitigate degradation of a component or system with the aim of sustaining or extending its useful life through controlling degradation to an acceptable level.

The U.S. Navy pioneered preventive maintenance as a means to increase the reliability of their vessels. By simply expending the necessary resources to conduct maintenance activities intended by the equipment designer, equipment life is extended and its reliability is increased. In addition to an increase in reliability, dollars are saved over that of a program just using reactive maintenance. Studies indicate that this savings can amount to as much as $12 \%$ to

$18 \%$ on the average. Depending on the facilities current maintenance practices, present equipment reliability, and facility downtime, there is little doubt that many facilities purely reliant on reactive maintenance could save much more than $18 \%$ by instituting a proper preventive maintenance program.

While preventive maintenance is not the optimum maintenance program, it does have several advantages over that of a purely reactive program. By performing the preventive maintenance as the equipment designer envisioned, we will extend the life of the equipment closer to design. This translates into dollar savings. Preventive maintenance (lubrication, filter change, etc.) will generally run the equipment more efficiently resulting in dollar savings. While we will not prevent equipment catastrophic failures, we will decrease the number of failures. Minimizing failures translate into maintenance and capital cost savings. 


\subsection{Predictive Maintenance}

Predictive maintenance can be defined as follows: Measurements that detect the onset of system degradation (lower functional state), thereby allowing causal stressors to be eliminated or controlled prior to any significant deterioration in the component physical state. Results indicate current and future functional capability.

Basically, predictive maintenance differs from preventive maintenance by basing maintenance need on the actual condition of the machine rather than on some preset schedule. You will recall that preventive maintenance is time-based. Activities such as changing lubricant are based on time, like calendar time or equipment run time. For example, most people change the oil in their vehicles every 3,000 to 5,000 miles traveled. This is effectively

\section{Advantages}

- Increased component operational life/availability.

- Allows for preemptive corrective actions.

- Decrease in equipment or process downtime.

- Decrease in costs for parts and labor.

- Better product quality.

- Improved worker and environmental safety.

- Improved worker morale.

- Energy savings.

- Estimated $8 \%$ to $12 \%$ cost savings over preventive maintenance program.

\section{Disadvantages}

- Increased investment in diagnostic equipment.

- Increased investment in staff training.

- Savings potential not readily seen by management. basing the oil change needs on equipment run time. No concern is given to the actual condition and performance capability of the oil. It is changed because it is time. This methodology would be analogous to a preventive maintenance task. If, on the other hand, the operator of the car discounted the vehicle run time and had the oil analyzed at some periodicity to determine its actual condition and lubrication properties, he/she may be able to extend the oil change until the vehicle had traveled 10,000 miles. This is the fundamental difference between predictive maintenance and preventive maintenance, whereby predictive maintenance is used to define needed maintenance task based on quantified material/equipment condition.

The advantages of predictive maintenance are many. A well-orchestrated predictive maintenance program will all but eliminate catastrophic equipment failures. We will be able to schedule maintenance activities to minimize or delete overtime cost. We will be able to minimize inventory and order parts, as required, well ahead of time to support the downstream maintenance needs. We can optimize the operation of the equipment, saving energy cost and increasing plant reliability. Past studies have estimated that a properly functioning predictive maintenance program can provide a savings of $8 \%$ to $12 \%$ over a program utilizing preventive maintenance alone. Depending on a facility's reliance on reactive maintenance and material condition, it could easily recognize savings opportunities exceeding 30\% to 40\%. In fact, independent surveys indicate the following industrial average savings resultant from initiation of a functional predictive maintenance program:

- Return on investment: 10 times

- Reduction in maintenance costs: $25 \%$ to $30 \%$

- Elimination of breakdowns: $70 \%$ to $75 \%$

- Reduction in downtime: $35 \%$ to $45 \%$

- Increase in production: $20 \%$ to $25 \%$. 
On the down side, to initially start into the predictive maintenance world is not inexpensive. Much of the equipment requires cost in excess of $\$ 50,000$. Training of in-plant personnel to effectively utilize predictive maintenance technologies will require considerable funding. Program development will require an understanding of predictive maintenance and a firm commitment to make the program work by all facility organizations and management.

\subsection{Reliability Centered Maintenance}

Reliability centered maintenance (RCM) magazine provides the following definition of RCM: "a process used to determine the maintenance requirements of any physical asset in its operating context."

Basically, RCM methodology deals with some key issues not dealt with by other maintenance programs. It recognizes that all equipment in a facility is not of equal importance to either the process or facility safety. It recognizes that equipment design and operation differs and that different equipment will have a higher probability to undergo failures from different degradation mechanisms than others. It also approaches the structuring of a maintenance program recognizing that a facility does not have unlimited financial and personnel resources and that the use of both need to be prioritized and optimized. In a nutshell, RCM is a systematic approach to evaluate a facility's equipment and resources to best mate the two and result in a high degree of facility reliability

\section{Advantages}

- Can be the most efficient maintenance program.

- Lower costs by eliminating unnecessary maintenance or overhauls.

- Minimize frequency of overhauls.

- Reduced probability of sudden equipment failures.

- Able to focus maintenance activities on critical components.

- Increased component reliability.

- Incorporates root cause analysis.

Disadvantages

- Can have significant startup cost, training, equipment, etc.

- Savings potential not readily seen by management. and cost-effectiveness. RCM is highly reliant on predictive maintenance but also recognizes that maintenance activities on equipment that is inexpensive and unimportant to facility reliability may best be left to a reactive maintenance approach. The following maintenance program breakdowns of continually top-performing facilities would echo the RCM approach to utilize all available maintenance approaches with the predominant methodology being predictive.

- $<10 \%$ Reactive

- $25 \%$ to $35 \%$ Preventive

- $45 \%$ to $55 \%$ Predictive.

Because RCM is so heavily weighted in utilization of predictive maintenance technologies, its program advantages and disadvantages mirror those of predictive maintenance. In addition to these advantages, RCM will allow a facility to more closely match resources to needs while improving reliability and decreasing cost. 
Table 5.5.1 below highlights guidance on RCM development by equipment application (adapted from NASA 2000). It is important to both define the equipment criticality and cost of down-time when determining the optimal mix of maintenance elements. Once defined, the equipment can be prioritized in the developing a functional RCM program.

Table 5.5.1. Reliability centered maintenance element applications

\begin{tabular}{|l|l|l|}
\hline \multicolumn{2}{|c|}{ Reliability Centered Maintenance Hierarchy } \\
\hline Reactive Element Applications & Preventive Element Applications & Predictive Element Applications \\
\hline $\begin{array}{l}\text { Small parts and equipment } \\
\text { Non-critical equipment }\end{array}$ & Equipment subject to wear & Equipment with random failure patterns \\
\hline $\begin{array}{l}\text { Equipment unlikely to fail } \\
\text { Redundant systems }\end{array}$ & Equipment with known failure patterns & Equipment not subject to wear \\
\hline & Manufacturer recommendations & $\begin{array}{l}\text { Systems which failure may be induced by } \\
\text { incorrect preventive maintenance }\end{array}$ \\
\hline
\end{tabular}

\subsection{How to Initiate Reliability Centered Maintenance}

The road from a purely reactive program to a RCM program is not an easy one. The following is a list of some basic steps that will help to get moving down this path (NASA 2000).

1. Develop a Master equipment list identifying the equipment in your facility.

2. Prioritize the listed components based on importance or criticality to operation, process, or mission - see text box

\section{Maintenance Priority Matrix for RCM Development}

\section{Priority}

Weighting Description Application

1 Emergency Life, health, safety risk-mission criticality

2 Urgent Continuous operation of facility at risk

3 Priority Mission support/project deadlines

4 Routine Prioritized: first come/first served

5 Discretionary Desired but not essential

6 Deferred Accomplished only when resources allow

highlighting priority scheme.

\section{Comparison of Four Maintenance Programs (Piotrowski 2001)}

\section{Reactive Maintenance (Breakdown or Run-to-Failure Maintenance)}

Basic philosophy

- Allow machinery to run to failure.

- Repair or replace damaged equipment when obvious problems occur.

Cost: $\$ 18 / \mathrm{hp} / \mathrm{yr}$

This maintenance philosophy allows machinery to run to failure, providing for the repair or replacement of damaged equipment only when obvious problems occur. Studies have shown that the costs to operate in this fashion are about $\$ 18$ per horsepower (hp) per year. The advantages of this approach are that it works well if equipment shutdowns do not affect production and if labor and material costs do not matter. 
3. Assign components into logical groupings.

4. Determine the type and number of maintenance activities required and periodicity using:
a. Manufacturer technical manuals
b. Machinery history
c. Root cause analysis findings - Why did it fail?
d. Good engineering judgment

5. Assess the size of maintenance staff.

6. Identify tasks that may be performed by operations maintenance personnel.

7. Analyze equipment failure modes and impacts on components and systems.

8. Identify effective maintenance tasks or mitigation strategies.

The references and resources provided below are by no means all-inclusive. The listed organizations are not endorsed by the authors of this guide and are provided for your information only. To locate additional resources, the authors of this guide recommend contacting relevant trade groups, databases, and the world-wide web.

\section{An Introduction to Reliability and Maintainability Engineering}

By: Charles E. Ebeling

Published by: McGraw Hill College Division

Publication date: September 1996

\section{Maintenance Engineering Handbook}

By: Lindley R. Higgins, Dale P. Brautigam, and R. Keith Mobley (Editor)

Published by: McGraw Hill Text, 5th Edition

Publication date: September 1994

\section{Condition-Based Maintenance and \\ Machine Diagnostics}

By: John H. Williams, Alan Davies, and

Paul R. Drake

Published by: Chapman \& Hall

Publication date: October 1994

\section{Maintenance Planning and Scheduling}

Handbook

By: Richard D. (Doc) Palmer

Published by: McGraw Hill

Publication date: March 29, 1999

\author{
Maintainability and Maintenance Management \\ By: Joseph D. Patton, Jr. \\ Published by: Instrument Society of America, \\ 3rd Revision \\ Publication date: February 1994 \\ Reliability-Centered Maintenance \\ By: John Moubray \\ Published by: Industrial Press, 2nd Edition \\ Publication date: April 1997 \\ Reliability-Centered Maintenance \\ By: Anthony M. Smith \\ Published by: McGraw Hill \\ Publication date: September 1992.
}




\section{Preventive Maintenance (Time-Based Maintenance)}

Basic philosophy

- Schedule maintenance activities at predetermined time intervals.

- Repair or replace damaged equipment before obvious problems occur.

\section{Cost: $\$ 13 / \mathrm{hp} / \mathrm{yr}$}

This philosophy entails the scheduling of maintenance activities at predetermined time intervals, where damaged equipment is repaired or replaced before obvious problems occur. When it is done correctly, studies have shown the costs of operating in this fashion to be about $\$ 13$ per hp per year. The advantages of this approach are that it works well for equipment that does not run continuously, and with personnel who have enough knowledge, skills, and time to perform the preventive maintenance work.

\section{Predictive Maintenance (Condition-Based Maintenance)}

Basic philosophy

- Schedule maintenance activities when mechanical or operational conditions warrant.

- Repair or replace damaged equipment before obvious problems occur.

\section{Cost: $\$ 9 / \mathrm{hp} / \mathrm{yr}$}

This philosophy consists of scheduling maintenance activities only if and when mechanical or operational conditions warrant-by periodically monitoring the machinery for excessive vibration, temperature and/or lubrication degradation, or by observing any other unhealthy trends that occur over time. When the condition gets to a predetermined unacceptable level, the equipment is shut down to repair or replace damaged components so as to prevent a more costly failure from occurring. In other words, "Don't fix what is not broke." Studies have shown that when it is done correctly, the costs to operate in this fashion are about $\$ 9$ per hp per year. Advantages of this approach are that it works very well if personnel have adequate knowledge, skills, and time to perform the predictive maintenance work, and that it allows equipment repairs to be scheduled in an orderly fashion. It also provides some lead-time to purchase materials for the necessary repairs, reducing the need for a high parts inventory. Since maintenance work is only performed when it is needed, there is likely to be an increase in production capacity. 


\title{
Reliability Centered Maintenance (Pro-Active or Prevention Maintenance)
}

\author{
Basic philosophy
}

- Utilizes predictive/preventive maintenance techniques with root cause failure analysis to detect and pinpoint the precise problems, combined with advanced installation and repair techniques, including potential equipment redesign or modification to avoid or eliminate problems from occurring.

\section{Cost: $\$ 6 / \mathrm{hp} / \mathrm{yr}$}

This philosophy utilizes all of the previously discussed predictive/preventive maintenance techniques, in concert with root cause failure analysis. This not only detects and pinpoints precise problems that occur, but ensures that advanced installation and repair techniques are performed, including potential equipment redesign or modification, thus helping to avoid problems or keep them from occurring. According to studies, when it is done correctly, operating in this fashion costs about $\$ 6$ per hp per year. One advantage to this approach is that it works extremely well if personnel have the knowledge, skills, and time to perform all of the required activities. As with the predictive-based program, equipment repairs can be scheduled in an orderly fashion, but additional improvement efforts also can be undertaken to reduce or eliminate potential problems from repeatedly occurring. Furthermore, it allows lead-time to purchase materials for necessary repairs, thus reducing the need for a high parts inventory. Since maintenance work is performed only when it is needed, and extra efforts are put forth to thoroughly investigate the cause of the failure and determine ways to improve machinery reliability, there can be a substantial increase in production capacity.

\subsection{References}

NASA. 2000. Reliability Centered Maintenance Guide for Facilities and Collateral Equipment. National Aeronautics and Space Administration, Washington, D.C.

Piotrowski, J. April 2, 2001. Pro-Active Maintenance for Pumps, Archives, February 2001, Pump-Zone.com [Report online]. Available URL: http://www.pump-zone.com. Reprinted with permission of Pump-Zone.com. 



\section{Chapter 6 Predictive Maintenance Technologies}

\subsection{Introduction}

Predictive maintenance attempts to detect the onset of a degradation mechanism with the goal of correcting that degradation prior to significant deterioration in the component or equipment. The diagnostic capabilities of predictive maintenance technologies have increased in recent years with advances made in sensor technologies. These advances, breakthroughs in component sensitivities, size reductions, and most importantly, cost, have opened up an entirely new area of diagnostics to the O\&M practitioner.

As with the introduction of any new technology, proper application and TRAINING is of critical importance. This need is particularly true in the field of predictive maintenance technology that has become increasingly sophisticated and technology-driven. Most industry experts would agree (as well as most reputable equipment vendors) that this equipment should not be purchased for in-house use if there is not a serious commitment to proper implementation, operator training, and equipment monitoring and repair. If such a commitment cannot be made, a site is well advised to seek other methods of program implementation-a preferable option may be to contract for these services with an outside vendor and rely on their equipment and expertise.

Table 6.1.1 below highlights typical applications for some of the more common predictive maintenance technologies. Of course, proper application begins with system knowledge and predictive technology capability - before any of these technologies are applied to live systems.

Table 6.1.1. Common predictive technology applications (NASA 2000)

\begin{tabular}{|c|c|c|c|c|c|c|c|c|c|c|c|c|}
\hline Technologies & 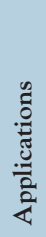 & : & 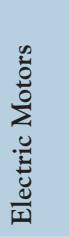 & 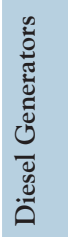 & 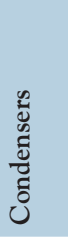 & 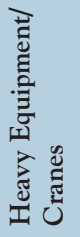 & 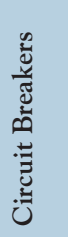 & $\frac{\stackrel{8}{\frac{\pi}{\pi}}}{j}$ & 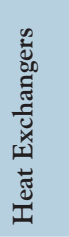 & 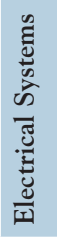 & & 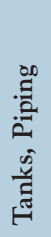 \\
\hline Vibration Monitoring/Analysis & & $\mathrm{X}$ & $\mathrm{X}$ & $\mathrm{X}$ & & $\mathrm{X}$ & & & & & & \\
\hline Lubricant, Fuel Analysis & & $\mathrm{X}$ & $\mathrm{X}$ & $\mathrm{X}$ & & $\mathrm{X}$ & & & & & $\mathrm{X}$ & \\
\hline Wear Particle Analysis & & $\mathrm{X}$ & $\mathrm{X}$ & $\mathrm{X}$ & & $\mathrm{X}$ & & & & & & \\
\hline Bearing, Temperature/Analysis & & $\mathrm{X}$ & $\mathrm{X}$ & $\mathrm{X}$ & & $\mathrm{X}$ & & & & & & \\
\hline Performance Monitoring & & $\mathrm{X}$ & $\mathrm{X}$ & $\mathrm{X}$ & $\mathrm{X}$ & & & & $\mathrm{X}$ & & $\mathrm{X}$ & \\
\hline Ultrasonic Noise Detection & & $\mathrm{X}$ & $\mathrm{X}$ & $\mathrm{X}$ & $\mathrm{X}$ & & & $\mathrm{X}$ & $\mathrm{X}$ & & $\mathrm{X}$ & \\
\hline Ultrasonic Flow & & $\mathrm{X}$ & & & $\mathrm{X}$ & & & $\mathrm{X}$ & $X$ & & & \\
\hline Infrared Thermography & & $\mathrm{X}$ & $\mathrm{X}$ & $\mathrm{X}$ & $\mathrm{X}$ & $\mathrm{X}$ & $\mathrm{X}$ & $\mathrm{X}$ & $\mathrm{X}$ & $\mathrm{X}$ & $\mathrm{X}$ & \\
\hline Non-destructive Testing (Thickness) & & & & & $\mathrm{X}$ & & & & $\mathrm{X}$ & & & $\mathrm{X}$ \\
\hline Visual Inspection & & $\mathrm{X}$ & $\mathrm{X}$ & $\mathrm{X}$ & $\mathrm{X}$ & $\mathrm{X}$ & $\mathrm{X}$ & $\mathrm{X}$ & $\mathrm{X}$ & $\mathrm{X}$ & $\mathrm{X}$ & $\mathrm{X}$ \\
\hline Insulation Resistance & & & $\mathrm{X}$ & $\mathrm{X}$ & & & $\mathrm{X}$ & & & $\mathrm{X}$ & $\mathrm{X}$ & \\
\hline Motor Current Signature Analysis & & & $\mathrm{X}$ & & & & & & & & & \\
\hline Motor Circuit Analysis & & & $\mathrm{X}$ & & & & $\mathrm{X}$ & & & $\mathrm{X}$ & & \\
\hline Polarization Index & & & $\mathrm{X}$ & $\mathrm{X}$ & & & & & & $\mathrm{X}$ & & \\
\hline Electrical Monitoring & & & & & & & & & & $\mathrm{X}$ & $\mathrm{X}$ & \\
\hline
\end{tabular}




\subsection{Thermography}

\subsubsection{Introduction}

Infrared (IR) thermography can be defined as the process of generating visual images that represent variations in IR radiance of surfaces of objects. Similar to the way objects of different materials and colors absorb and reflect electromagnetic radiation in the visible light spectrum ( 0.4 to 0.7 microns), any object at temperatures greater than absolute zero emits IR energy (radiation) proportional to its existing temperature. The IR radiation spectrum is generally agreed to exist between 2.0 and 15 microns. By using an instrument that contains detectors sensitive to IR electromagnetic radiation, a two-dimensional visual image reflective of the IR radiance from the surface of an object can be generated. Even though the detectors and electronics are different, the process itself is similar to that a video camera uses to detect a scene reflecting electromagnetic energy in the visible light spectrum, interpreting that information, and displaying what it detects on a liquid crystal display (LCD) screen that can then be viewed by the device operator.

Because IR radiation falls outside that of visible light (the radiation spectrum to which our eyes are sensitive), it is invisible to the naked eye. An IR camera or similar device allows us to escape the visible light spectrum and view an object based on its temperature and its proportional emittance of IR radiation. How and why is this ability to detect and visualize an object's temperature profile important in maintaining systems or components? Like all predictive maintenance technologies, IR tries to detect the presence of conditions or stressors that act to decrease a component's useful or design life. Many of these conditions result in changes to a component's temperature. For example, a loose or corroded electrical connection results in abnormally elevated connection temperatures due to increased electrical resistance. Before the connection is hot enough to result in equipment failure or possible fire, the patterns are easily seen through an IR imaging camera, the condition identified and corrected. Rotating equipment problems will normally result in some form of frictional change that will be seen as an increase in the component's temperature. Faulty or complete loss of refractory material will be readily seen as a change in the components thermal profile. Loss of a roof's membrane integrity will result in moisture that can be readily detected as differences in the roof thermal profile. These are just a few general examples of the hundreds of possible applications of this technology and how it might be used to detect problems that would otherwise go unnoticed until a component failed and resulted in excessive repair or downtime cost.

\subsubsection{Types of Equipment}

Many types of IR detection devices exist, varying in capability, design, and cost. In addition, simple temperature measurement devices that detect IR emissions but do not produce a visual image or IR profile are also manufactured. The following text and pictures provide an overview of each general instrument type.

Spot Radiometer (Infrared Thermometer) - Although not generally thought of in the world of thermography, IR thermometers use the same basic principles as higher end equipment to define an object's temperature based on IR emissions. These devices do not provide any image representative of an object's thermal profile, but rather a value representative of the temperature of the object or area of interest. 
Infrared Imager - As indicated earlier, equipment capabilities, design, cost, and functionality vary greatly. Differences exist in IR detector material, operation, and design. At the fundamental level, IR detection devices can be broken down into two main groups imagers and cameras with radiometric capability. A simple IR imager has the ability to detect an object's IR emissions and translate this information into a visual image. It does not have the capability to analyze and quantify specific temperature values. This type of IR detection device can be of use when temperature values are unimportant and the object's temperature profile (represented by the image) is all that is needed to define a problem. An example

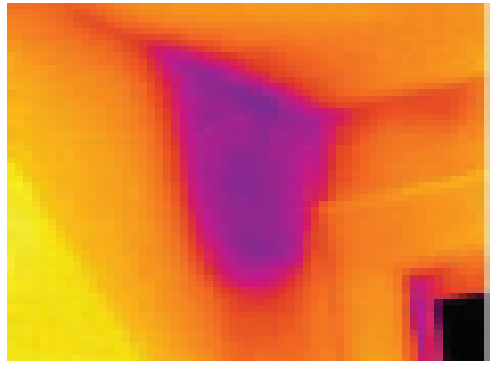

Figure 6.2.2. Internal house wall. Note dark area indicating cooler temperatures because of heat loss. of such an application would be in detecting missing or inadequate insulation in a structure's envelope. Such an application merely requires an image representative of the differences in the thermal profile due to absence of adequate insulation. Exact temperature values are unimportant.

IR cameras with full radiometric capability detect the IR emissions from an object and translate this information into a visible format as in the case of an imager. In addition, these devices have the capability to analyze the image and provide a temperature value corresponding to the area of interest. This capability is useful in applications where a temperature value is important in defining a problem or condition. For example, if an image indicated a difference between a pulley belt temperature and an ambient temperature, the belt may have worn, be the wrong size, or indicate a misalignment condition. Knowing the approximate temperature differences would be important in determining if a problem existed.
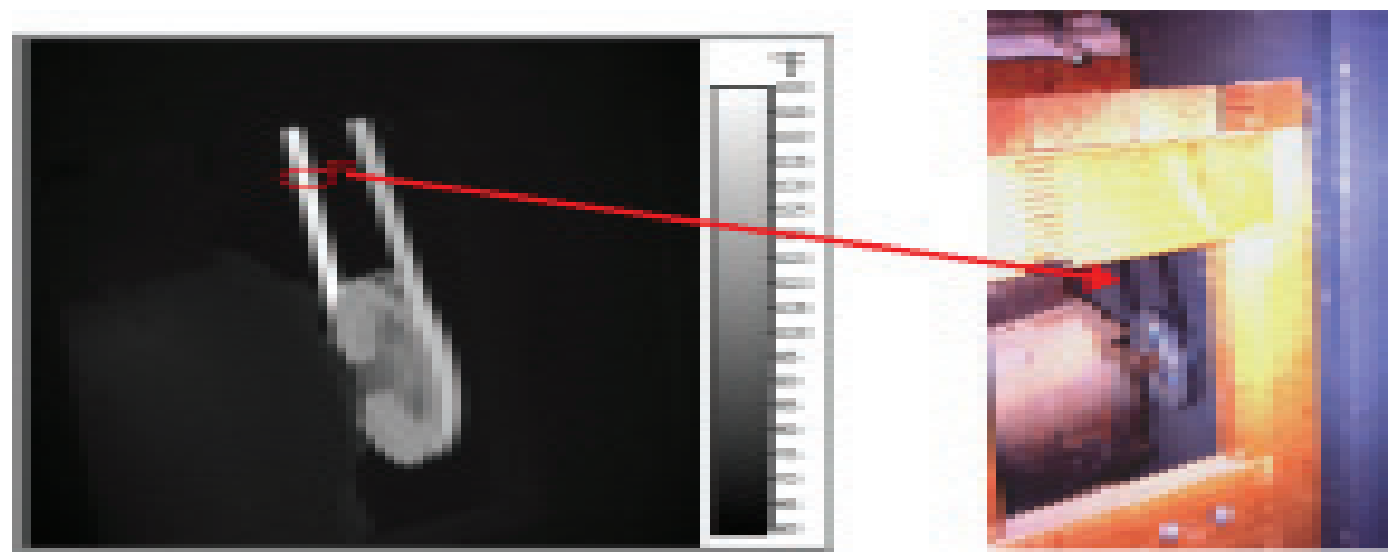

Figure 6.2.3. Temperature is used in defining belt problems. Figure shows a belt temperature of $149^{\circ} \mathrm{F}$, and ambient temperature of $67^{\circ} \mathrm{F}$ for a difference of $82^{\circ} \mathrm{F}$. The difference should be trended over time to determine slippage that would be indicated by a higher temperature difference. 


\subsubsection{System Applications}

\subsubsection{Electrical System Applications}

The primary value of thermographic inspections of electrical systems is locating problems so that they can be diagnosed and repaired. "How hot is it?" is usually of far less importance. Once the problem is located, thermography and other test methods, as well as experience and common sense, are used to diagnose the nature of the problem. The following list contains just a few of the possible electrical system-related survey applications:

- Transmission lines

- Splices

- Shoes/end bells

- Inductive heating problems

- Insulators

- Cracked or damaged/tracking

- Distribution lines/systems

- Splices

- Line clamps

- Disconnects

- Oil switches/breakers

- Capacitors

- Pole-mounted transformers

- Lightning arrestors

- Imbalances

- Substations

- Disconnects, cutouts, air switches

- Oil-filled switches/breakers (external and internal faults)

- Capacitors

- Transformers

- Internal problems

- Bushings

- Oil levels

- Cooling tubes

- Lightning arrestors

- Bus connections

- Generator Facilities

- Generator

- Bearings

- Brushes

- Windings

- Coolant/oil lines: blockage

- Motors

- Connections

- Bearings

- Winding/cooling patterns

- Motor Control Center

- Imbalances
- In-Plant Electrical Systems

- Switchgear

- Motor Control Center

- Bus

- Cable trays

- Batteries and charging circuits

- Power/Lighting distribution panels
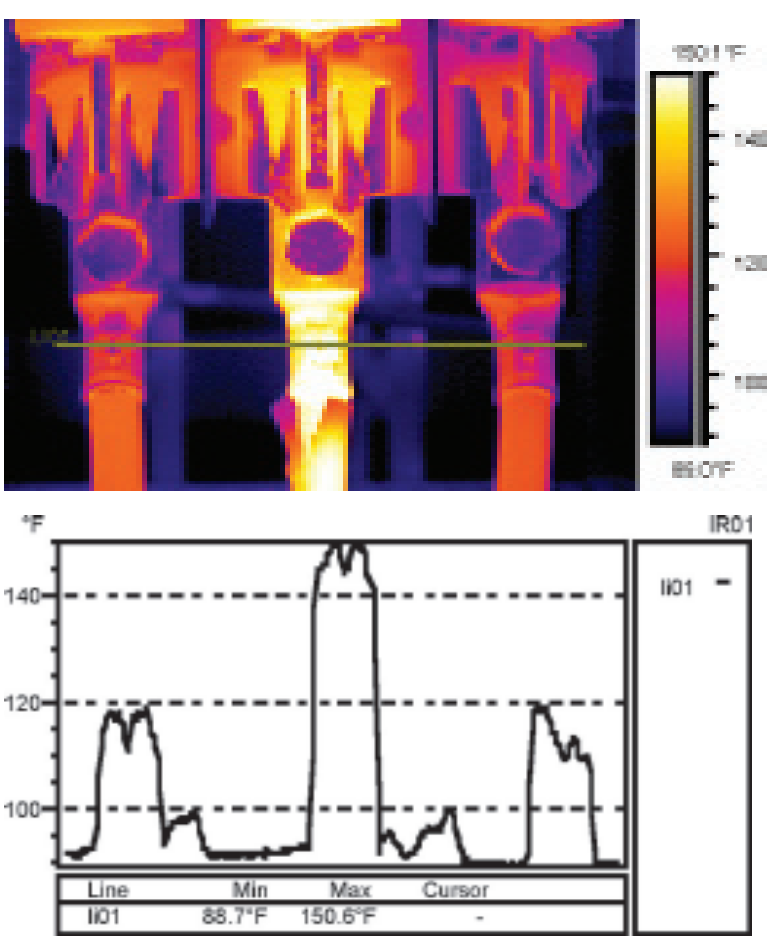

Software analysis tools can quantify and graphically display temperature data. As shown above, the middle conductor/connection is a much higher temperature indicating a loose connection. 


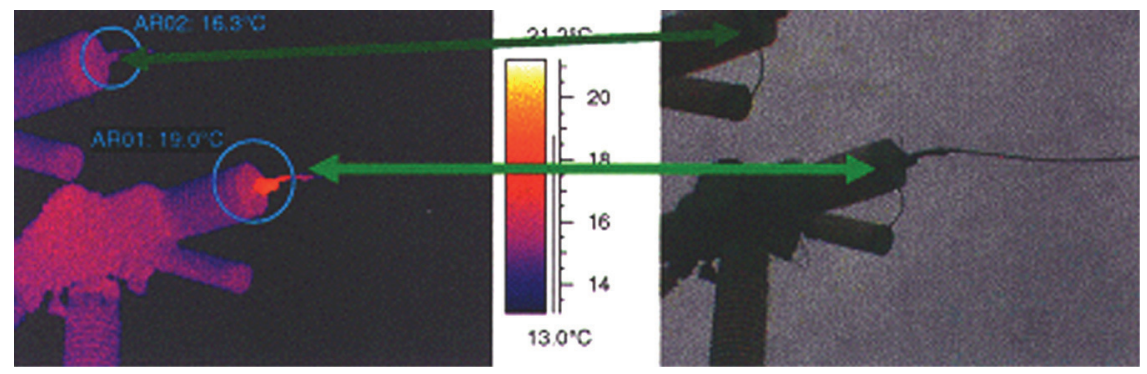

Figure 6.2.4. Air breaker problem. Highlighted by temperature difference between two different breakers. Likely caused by poor connection.

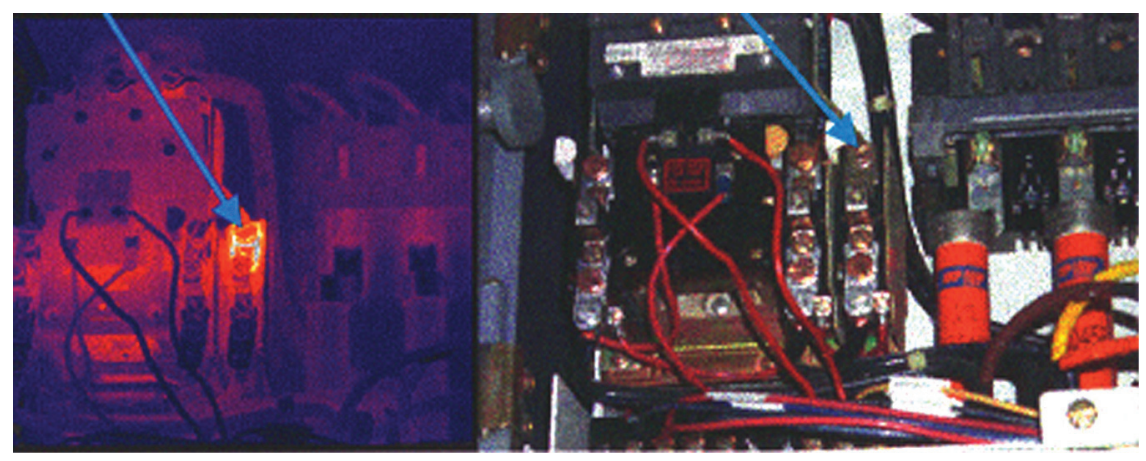

Figure 6.2.5. Overloaded contacts show different temperature profiles indicating one contact seeing much greater load, a potentially unsafe situation.

\subsubsection{Mechanical System Applications}

Rotating equipment applications are only a small subset of the possible areas where thermography can be used in a mechanical predictive maintenance program. In addition to the ability to detect problems associated with bearing failure, alignment, balance, and looseness, thermography can be used to define many temperature profiles indicative of equipment operational faults or failure. The following list provides a few application examples and is not all inclusive:

- Steam Systems

- Boilers

- Refractory

- Tubes

- Traps

- Valves

- Lines

- Heaters and furnaces

- Refractory inspections

- Tube restrictions

- Fluids

- Vessel levels

- Pipeline blockages
- Environmental

- Water discharge patterns

- Air discharge patterns

- Motors and rotating equipment

- Bearings

- Mechanical failure

- Improper lubrication

- Coupling and alignment problems

- Electrical connections on motors

- Air cooling of motors 


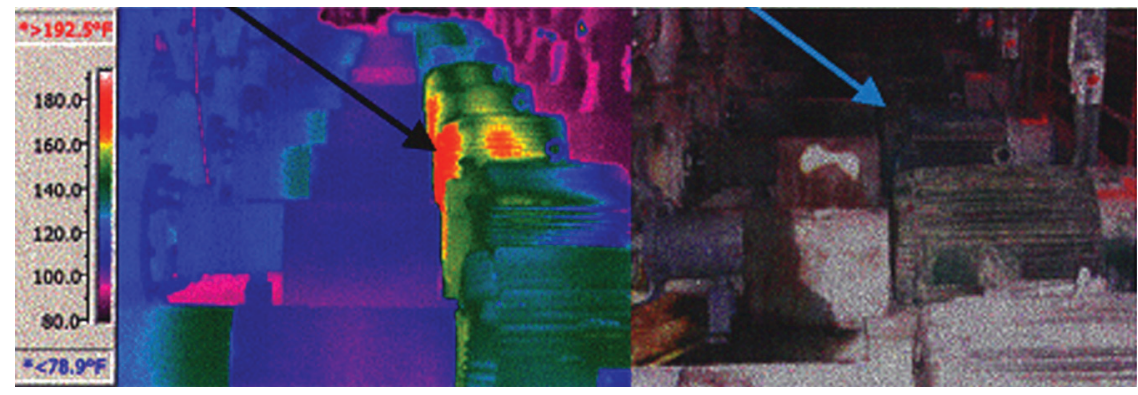

Figure 6.2.6. IR scans of multiple electric motors can highlight those with hot bearings indicting an imbalance or wear problem.

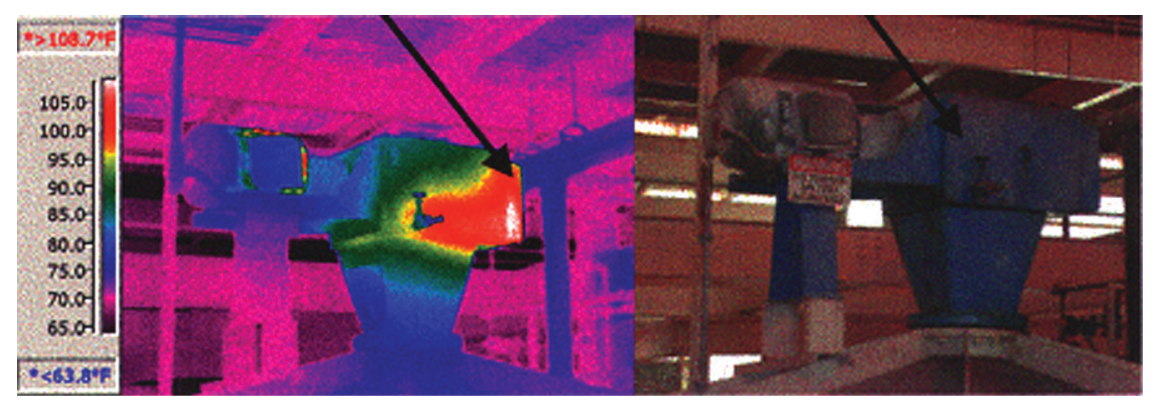

Figure 6.2.7. Possible gearbox problem indicated by white area defined by arrow. Design drawings of gearbox should be examined to define possible cause of elevated temperatures.

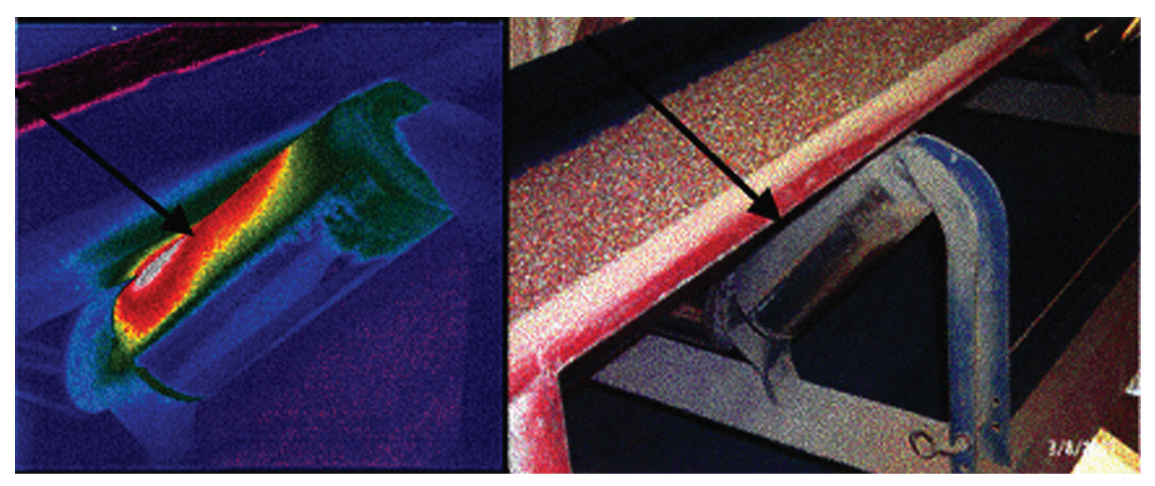

Figure 6.2.8. Seized conveyer belt roller as indicated by elevated temperatures in belt/roller contact area.

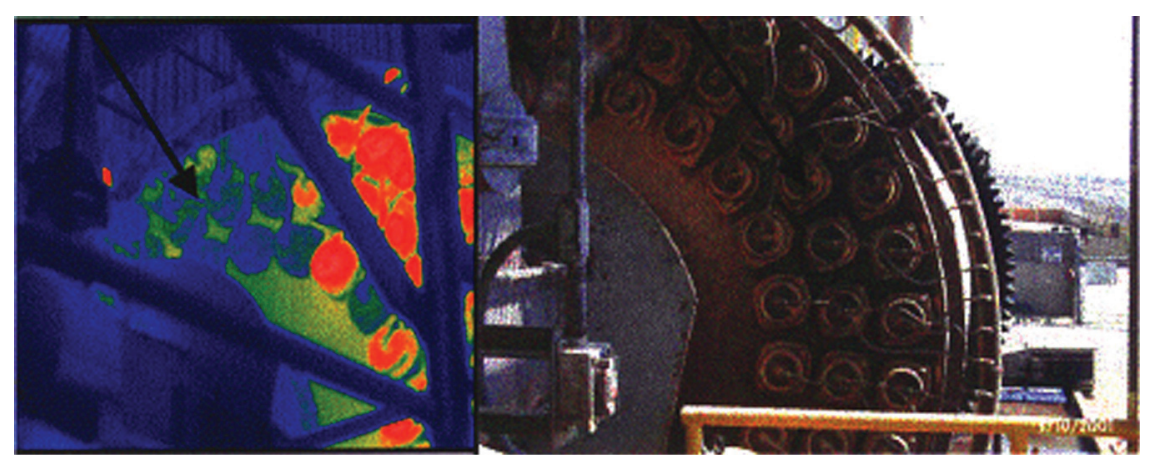

Figure 6.2.9. Inoperable steam heaters seen by cooler blue areas when compared to the operating heaters warmer red or orange colors. 


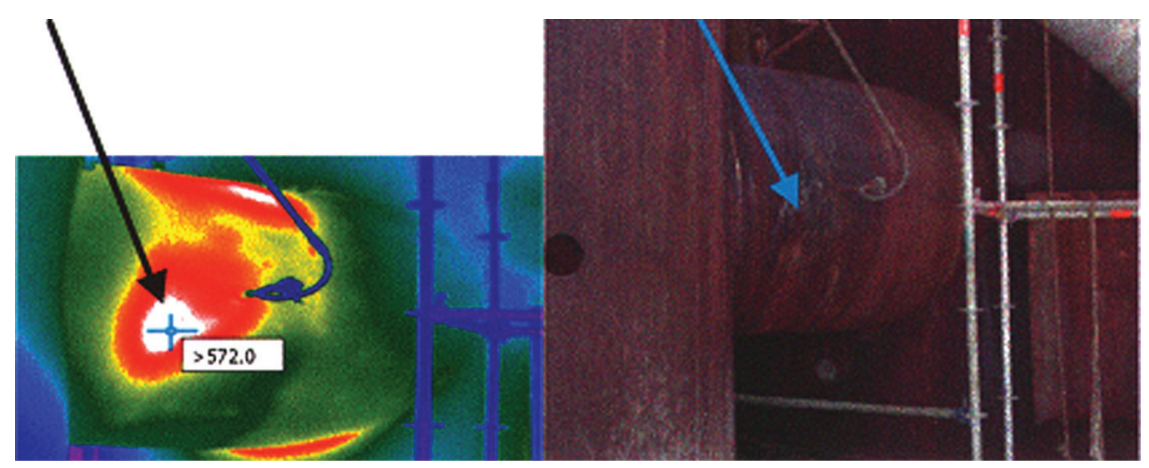

Figure 6.2.10. IR scans of boiler can highlight those areas where the refractory has broken down leading to costly heat loss.
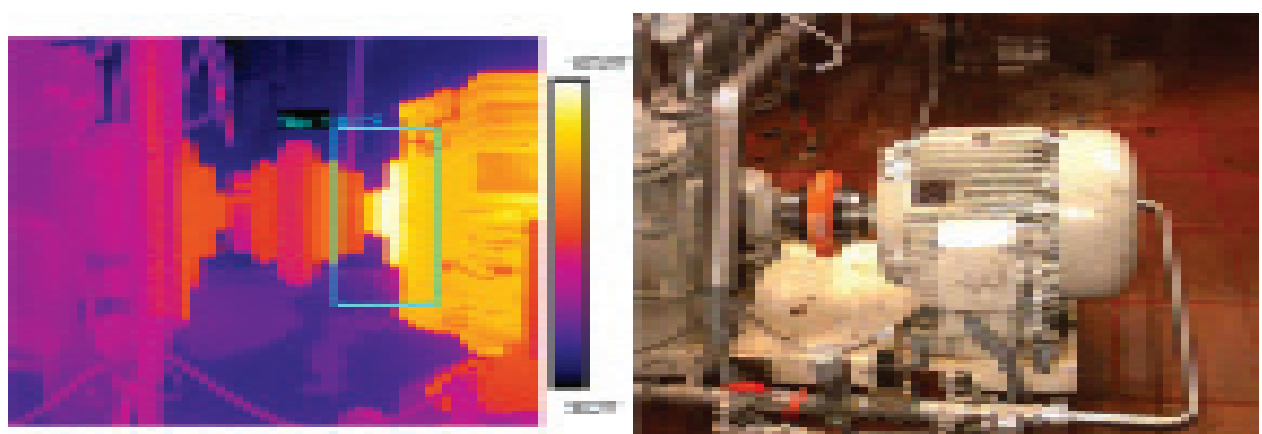

Figure 6.2.11. When trended, IR scans of single bearings provide a useful indicator of wear and eventual need for replacement.

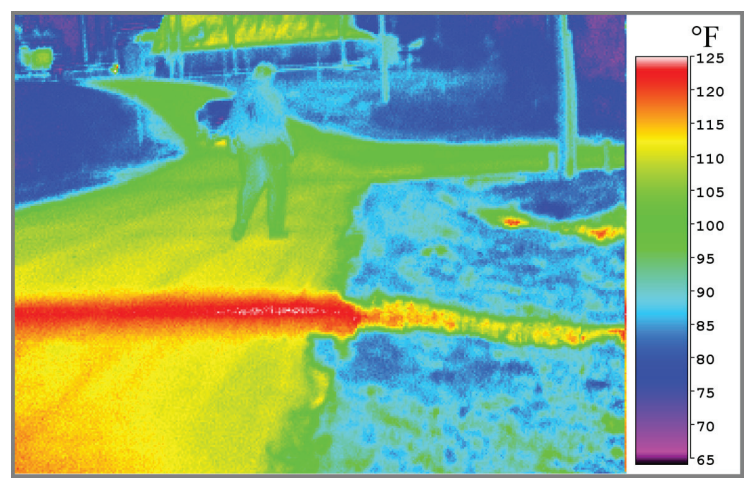

Figure 6.2.12. Steam or hot water distribution system leaks and/or underground line location can be defined with $I R$. 


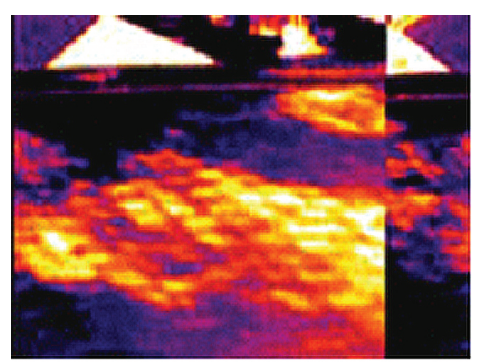

These images show elevated temperatures of roof insulation due to difference in thermal capacitance of moisture-laden insulation.
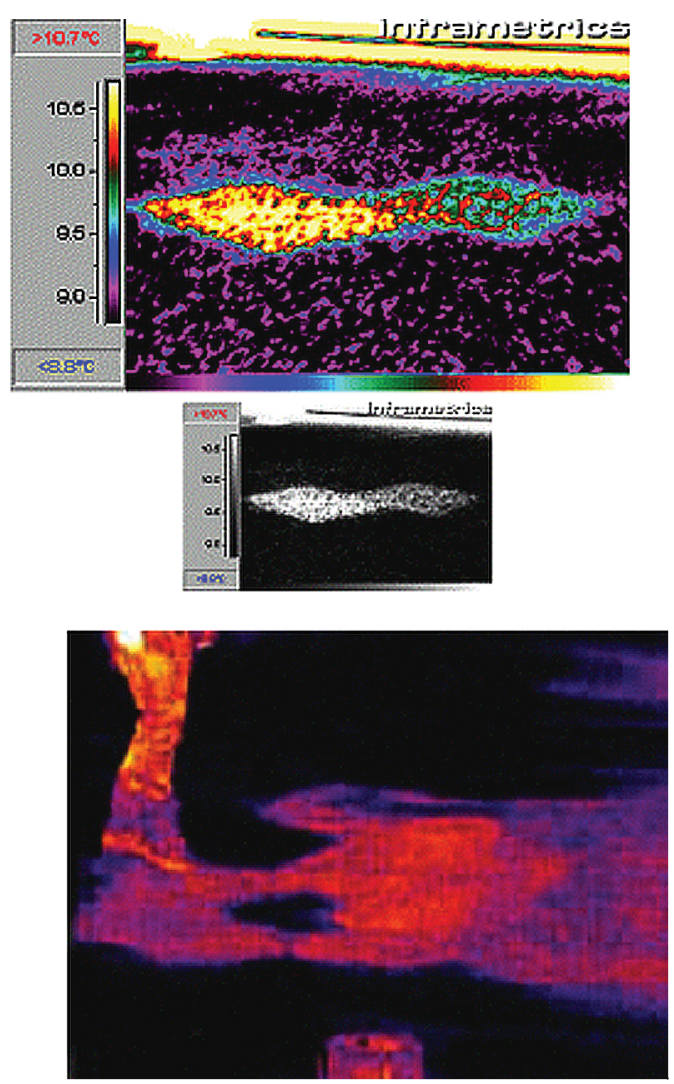

IR thermography is a powerful tool for locating roof leaks. As shown in the images, lighter colored regions indicate areas of potential leakage.

\subsubsection{Roof Thermography}

The old adage "out of sight, out of mind" is particularly true when it applies to flat roof maintenance. We generally forget about the roof until it leaks on our computers, switchgear, tables, etc. Roof replacement can be very expensive and at a standard industrial complex easily run into the hundreds of thousands of dollars. Depending on construction, length of time the roof has leaked, etc., actual building structural components can be damaged from inleakage and years of neglect that drive up repair cost further. Utilization of thermography to detect loss of a flat roof's membrane integrity is an application that can provide substantial return by minimizing area of repair/replacement. Roof reconditioning cost can be expected to run less than half of new roof cost per square foot. Add to this the savings to be gained from reconditioning a small percentage of the total roof surface, instead of replacement of the total roof, and the savings can easily pay for roof surveys and occasional repair for the life of the building with change left over.

\subsubsection{Equipment Cost/Payback}

As indicated earlier, the cost of thermography equipment varies widely depending on the capabilities of the equipment. A simple spot radiometer can cost from $\$ 500$ to $\$ 2,500$. An IR imager without radiometric capability can range from $\$ 7,000$ to $\$ 20,000$. A camera with full functionality can cost from $\$ 18,000$ to $\$ 65,000$. Besides the camera hardware, other program costs are involved. 
Computer hardware, personnel training, manpower, etc., needs to be accounted for in the budget. Below is a listing of equipment and program needs recommended by a company recognized as a leader in the world of IR program development:

- Level I thermographic training

- Level II thermographic training

- Ongoing professional development

- IR camera and accessories

- Report software

- Laptop computer

- Color printer

- Digital visual camera

- Personal Protective Equipment (PPE) for arc flash protection

Payback can vary widely depending on the type of facility and use of the equipment. A production facility whose downtime equates to several thousands of dollars per hour can realize savings much faster than a small facility with minimal roof area, electrical distribution network, etc. On average, a facility can expect a payback in 12 months or less. A small facility may consider using the services of an IR survey contractor. Such services are widely available and costs range from $\$ 600$ to $\$ 1,200$ per day. Contracted services are generally the most cost-effective approach for smaller, less maintenanceintensive facilities.

\subsubsection{Training Availability}

Training for infrared thermography is available through a variety of system manufacturers and vendors. In addition, the American Society of Non-destructive Testing (ASNT) has established guidelines for non-destructive testing (NDT) (Level I, II, or III) certification (NASA 2000). These three levels are designed to take the student from Level I - where the student is competent with equipment function and use, to Level II - where the student is fully capable and experienced and can complete diagnostics and recommendations, to Level III - where the student is fully experienced to supervise and teach Level I and II students.

\subsubsection{Case Studies}

\section{IR Diagnostics of Pump}

A facility was having continual problems with some to its motor and pump combinations. Pump bearings repeatedly failed. An IR inspection confirmed that the lower thrust bearing was warmer than the other bearing in the pump. Further investigation revealed that the motor-pump combination was designed to operate in the horizontal position. In order to save floor space, the pump was mounted vertically below the motor. As a result, the lower thrust bearing was overloaded leading to premature failure. The failures resulted in a $\$ 15,000$ repair cost, not including lost production time ( $\$ 30,000$ per minute production loss and in excess of $\$ 600$ per minute labor). 


\section{IR Diagnostics of Steam Traps}

Steam trap failure detection can be difficult by other forms of detection in many hard to reach and inconvenient places. Without a good trap maintenance program, it can be expected that 15\% to $60 \%$ of a facility's traps will be failed open. At $\$ 3 / 1,000 \mathrm{lb}$ (very conservative), a $1 / 4$-in. orifice trap failed open will cost approximately $\$ 7,800$ per year. If the system had 100 traps and $20 \%$ were failed, the loss would be in excess of $\$ 156,000$. An oil refinery identified $14 \%$ of its traps were malfunctioning and realized a savings of $\$ 600,000$ a year after repair.

\section{IR Diagnostics of Roof}

A state agency in the northeast operated a facility with a 360,000 square foot roof area. The roof was over 22 years old and experiencing several leaks. Cost estimates to replace the roof ranged between $\$ 2.5$ and $\$ 3$ million. An initial IR inspection identified 1,208 square feet of roof requiring replacement at a total cost of $\$ 20,705$. The following year another IR inspection was performed that found 1,399 square feet of roof requiring replacement at a cost of $\$ 18,217$. A roof IR inspection program was started and the roof surveyed each year. The survey resulted in less than 200 square feet of roof identified needing replacement in any one of the following 4 years (one year results were as low as 30 square feet). The total cost for roof repair and upkeep for the 6 years was less than $\$ 60,000$. If the facility would have been privately owned, interest on the initial $\$ 3$ million at $10 \%$ would have amounted to $\$ 300,000$ for the first year alone. Discounting interest on $\$ 3$ million over the 5-year period, simple savings resulting from survey and repair versus initial replacement cost ( $\$ 3$ million to $\$ 60,000$ ) amount to $\$ 2,940,000$. This figure does not take into account interest on the $\$ 3$ million, which would result in savings in excess of another $\$ 500,000$ to $\$ 800,000$, depending on loan interest paid.

\subsubsection{Resources}

The resources provided below are by no means all-inclusive. The listed organizations are not endorsed by the authors of this guide and are provided for your information only. To locate additional resources, the authors of this guide recommend contacting relevant trade groups, databases, and the world-wide web.

\section{FLIR Systems}

Boston, MA

Telephone: 1-800-464-6372

Web address: www.flirthermography.com

Mikron Instrument Company, Inc. Oakland, NJ

Telephone: (201) 405-0900

Web address: www.irimaging.com

\author{
Raytek \\ Santa Cruz, CA \\ Telephone: 1-800-227-8074 \\ Web address: www.raytek-northamerica.com \\ Electrophysics \\ Fairfield, NJ \\ Telephone: (973) 882-0211 \\ Web address: www.electrophysics.com
}




\subsubsection{Infrared Service Companies}

Hartford Steam Boiler

Engineering Services

Telephone: (703) 739-0350

Web address: www.hsb.com/infrared/

American Thermal Imaging

Red Wing, MN

Telephone: (877) 385-0051

Web address: www.americanthermalimaging.com

Infrared Services, Inc.

5899 S. Broadway Blvd.

Littleton, CO 80121

Voice: (303) 734-1746

Web address: www.infrared-thermography.com

Snell Thermal Inspections

U.S. wide

Telephone: 1-800-636-9820

Web address: www.snellinspections.com

\subsubsection{Infrared Internet Resource Sites}

Academy of Infrared Thermography

(www.infraredtraining.net)

- Level I, II, and III certification information and training schedule

- Online store (books, software, videos)

- Online resources (links, image gallery, message board)

- Communication (classifieds, news, industry-related information

- Company profile and contact information

\section{Snell Infrared (Snellinfrared.com)}

- Training and course information

- Industry links

- IR library

- Newsletter

- Classifieds

- IR application information 


\subsubsection{Introduction}

One of the oldest predictive maintenance technologies still in use today is that of oil analysis. Oil analysis is used to define three basic machine conditions related to the machine's lubrication or lubrication system. First is the condition of the oil, that is, will its current condition lubricate per design? Testing is performed to determine lubricant viscosity, acidity, etc., as well as other chemical analysis to quantify the condition of oil additives like corrosion inhibitors. Second is the lubrication system condition, that is, have any physical boundaries been violated causing lubricant contamination? By testing for water content, silicon, or other contaminants (depending on the system design), lubrication system integrity can be evaluated. Third is the machine condition itself. By analyzing wear particles existing in the lubricant, machine wear can be evaluated and quantified.

In addition to system degradation, oil analysis performed and trended over time can provide indication of improperly performed maintenance or operational practices. Introduction of contamination during lubricant change-out, improper system flush-out after repairs, addition of improper lubricant, and improper equipment operation are all conditions that have been found by the trending and evaluation of oil analysis data.

Several companies provide oil analysis services. These services are relatively inexpensive and some analysis laboratories can provide analysis results within 24 hours. Some services are currently using the Internet to provide quick and easy access to the analysis reports. Analysis equipment is also available should a facility wish to establish its own oil analysis laboratory. Regardless of whether the analysis is performed by an independent laboratory or by in-house forces, accurate results require proper sampling techniques. Samples should be taken from an active, low-pressure line, ahead of any filtration devices. For consistent results and accurate trending, samples should be taken from the same place in the system each time (using a permanently installed sample valve is highly recommended). Most independent laboratories supply sample containers, labels, and mailing cartons. If the oil analysis is to be done by a laboratory, all that is required is to take the sample, fill in information such as the machine number, machine type, and sample date, and send it to the laboratory. If the analysis is to be done on-site, analytical equipment must be purchased, installed, and standardized. Sample containers must be purchased, and a sample information form created and printed.

The most common oil analysis tests are used to determine the condition of the lubricant, excessive wearing of oil-wetted parts, and the presence of contamination. Oil condition is most easily determined by measuring viscosity, acid number, and base number. Additional tests can determine the presence and/or effectiveness of oil additives such as anti-wear additives, antioxidants, corrosion inhibitors, and anti-foam agents. Component wear can be determined by measuring the amount of wear metals such as iron, copper, chromium, aluminum, lead, tin, and nickel. Increases in specific wear metals can mean a particular part is wearing, or wear is taking place in a particular part of the machine. Contamination is determined by measuring water content, specific gravity, and the level of silicon. Often, changes in specific gravity mean that the fluid or lubricant has been contaminated with another type of oil or fuel. The presence of silicon (usually from sand) is an indication of contamination from dirt. 


\subsubsection{Test Types}

- Karl Fischer Water Test - The Karl Fischer Test quantifies the amount of water in the lubricant.

Significance: Water seriously damages the lubricating properties of oil and promotes component corrosion. Increased water concentrations indicate possible condensation, coolant leaks, or process leaks around the seals.

- ICP Spectroscopy - Measures the concentration of wear metals, contaminant metals, and additive metals in a lubricant.

Significance: Measures and quantifies the elements associated with wear, contamination, and additives. This information assists in determining the oil and machine condition.

The following guide highlights the elements that may be identified by this test procedure. Also provided are brief descriptions explaining where the particles came from for engines, transmissions, gears, and hydraulic systems.

\begin{tabular}{|c|c|c|c|c|}
\hline \multicolumn{5}{|c|}{ Spectrometer Metals Guide } \\
\hline Metal & Engines & Transmissions & Gears & Hydraulics \\
\hline Iron & $\begin{array}{l}\text { Cylinder liners, rings, gears, } \\
\text { crankshaft, camshaft, valve } \\
\text { train, oil pump gear, wrist } \\
\text { pins }\end{array}$ & $\begin{array}{l}\text { Gears, disks, housing, } \\
\text { bearings, brake bands, } \\
\text { shaft }\end{array}$ & $\begin{array}{l}\text { Gears, bearings, shaft, } \\
\text { housing }\end{array}$ & Rods, cylinders, gears \\
\hline Chrome & $\begin{array}{l}\text { Rings, liners, exhaust } \\
\text { valves, shaft plating, } \\
\text { stainless steel alloy }\end{array}$ & Roller bearings & Roller bearings & Shaft \\
\hline Aluminum & $\begin{array}{l}\text { Pistons, thrust bearings, } \\
\text { turbo bearings, main } \\
\text { bearings (cat) }\end{array}$ & Pumps, thrust washers & Pumps, thrust washers & Bearings, thrust plates \\
\hline Nickel & $\begin{array}{l}\text { Valve plating, steel alloy } \\
\text { from crankshaft, camshaft, } \\
\text { gears from heavy bunker- } \\
\text { type diesel fuels }\end{array}$ & $\begin{array}{l}\text { Steel alloy from roller } \\
\text { bearings and shaft }\end{array}$ & $\begin{array}{l}\text { Steel alloy from roller } \\
\text { bearings and shaft }\end{array}$ & \\
\hline Copper & $\begin{array}{l}\text { Lube coolers, main and rod } \\
\text { bearings, bushings, turbo } \\
\text { bearings, lube additive }\end{array}$ & $\begin{array}{l}\text { Bushings, clutch plates } \\
\text { (auto/ powershift), } \\
\text { lube coolers }\end{array}$ & Bushings, thrust plates & $\begin{array}{l}\text { Bushings, thrust plates, } \\
\text { lube coolers }\end{array}$ \\
\hline Lead & $\begin{array}{l}\text { Main and rod bearings, } \\
\text { bushings, lead solder }\end{array}$ & $\begin{array}{l}\text { Bushings (bronze } \\
\text { alloy), lube additive } \\
\text { supplement }\end{array}$ & $\begin{array}{l}\text { Bushings (bronze } \\
\text { alloy), grease } \\
\text { contamination }\end{array}$ & Bushing (bronze alloy) \\
\hline Tin & $\begin{array}{l}\text { Piston flashing, bearing } \\
\text { over-lay, bronze alloy, } \\
\text { babbit metal along with } \\
\text { copper and lead }\end{array}$ & Bearing cage metal & $\begin{array}{l}\text { Bearing cage metal, } \\
\text { lube additive }\end{array}$ & \\
\hline Cadmium & $\mathrm{N} / \mathrm{A}$ & $\mathrm{N} / \mathrm{A}$ & $\mathrm{N} / \mathrm{A}$ & N/A \\
\hline Silver & $\begin{array}{l}\text { Wrist pin bushings } \\
\text { (EMDs), silver solder (from } \\
\text { lube coolers) }\end{array}$ & $\begin{array}{l}\text { Torrington needle } \\
\text { bearings (Allison } \\
\text { transmission) }\end{array}$ & $\mathrm{N} / \mathrm{A}$ & $\begin{array}{l}\text { Silver solder (from lube } \\
\text { coolers) }\end{array}$ \\
\hline Titanium & $\begin{array}{l}\text { Gas turbine bearings/hub/ } \\
\text { blades, paint (white lead) }\end{array}$ & $\mathrm{N} / \mathrm{A}$ & $\mathrm{N} / \mathrm{A}$ & $\mathrm{N} / \mathrm{A}$ \\
\hline Vanadium & $\begin{array}{l}\text { From heavy bunker-type } \\
\text { diesel fuels }\end{array}$ & $\mathrm{N} / \mathrm{A}$ & $\mathrm{N} / \mathrm{A}$ & $\mathrm{N} / \mathrm{A}$ \\
\hline
\end{tabular}


Spectrometer Metals Guide (contd)

\begin{tabular}{|c|c|c|c|c|}
\hline \multicolumn{5}{|c|}{ Contaminant Metals } \\
\hline Silicon & $\begin{array}{l}\text { Dirt, seals and sealants, } \\
\text { coolant inhibitor, lube } \\
\text { additive } \\
\text { (15 ppm or less) }\end{array}$ & $\begin{array}{l}\text { Dirt, seals and } \\
\text { sealants, coolant } \\
\text { inhibitor, lube additive } \\
\text { ( } 15 \text { ppm or less) }\end{array}$ & $\begin{array}{l}\text { Dirt, seals and } \\
\text { sealants, coolant } \\
\text { additive, lube additive } \\
\text { (15 ppm or less) }\end{array}$ & $\begin{array}{l}\text { Dirt, seals and sealant, } \\
\text { coolant additive, lube } \\
\text { additive } \\
\text { (15 ppm or less) }\end{array}$ \\
\hline Sodium & $\begin{array}{l}\text { Lube additive, coolant } \\
\text { inhibitor, salt water } \\
\text { contamination, wash } \\
\text { detergents }\end{array}$ & $\begin{array}{l}\text { Lube additive, coolant } \\
\text { inhibitor, salt water } \\
\text { contamination, wash } \\
\text { detergents }\end{array}$ & $\begin{array}{l}\text { Lube additive, } \\
\text { saltwater } \\
\text { contamination, } \\
\text { airborne contaminate }\end{array}$ & $\begin{array}{l}\text { Lube additive, coolant } \\
\text { inhibitor, saltwater } \\
\text { contamination, } \\
\text { airborne contaminate }\end{array}$ \\
\hline \multicolumn{5}{|c|}{ Multi-Source Metals } \\
\hline Molybdexznum & $\begin{array}{l}\text { Ring plating, lube additive, } \\
\text { coolant inhibitor }\end{array}$ & $\begin{array}{l}\text { Lube additive, coolant } \\
\text { inhibitor }\end{array}$ & $\begin{array}{l}\text { Lube additive, coolant } \\
\text { inhibitor, coolant } \\
\text { inhibitor, grease } \\
\text { additive }\end{array}$ & $\begin{array}{l}\text { Lube additive, coolant } \\
\text { inhibitor }\end{array}$ \\
\hline Antimony & Lube additive & Lube additive & Lube additive & Lube additive \\
\hline Manganese & Steel alloy & Steel alloy & Steel alloy & Steel alloy \\
\hline Lithium & N/A & $\begin{array}{l}\text { Lithium complex } \\
\text { grease }\end{array}$ & $\begin{array}{l}\text { Lithium complex } \\
\text { grease }\end{array}$ & Lithium complex grease \\
\hline Boron & $\begin{array}{l}\text { Lube additive, coolant } \\
\text { inhibitor }\end{array}$ & $\begin{array}{l}\text { Lube additive, coolant } \\
\text { inhibitor }\end{array}$ & $\begin{array}{l}\text { Lube additive, coolant } \\
\text { inhibitor }\end{array}$ & $\begin{array}{l}\text { Lube additive, coolant } \\
\text { inhibitor }\end{array}$ \\
\hline \multicolumn{5}{|c|}{ Additive Metals } \\
\hline Magnesium & $\begin{array}{l}\text { Detergent dispersant } \\
\text { additive, airborne } \\
\text { contaminant at some sites }\end{array}$ & $\begin{array}{l}\text { Detergent dispersant } \\
\text { additive, airborne } \\
\text { contaminant at some } \\
\text { sites }\end{array}$ & $\begin{array}{l}\text { Detergent dispersant } \\
\text { additive, airborne } \\
\text { contaminant at some } \\
\text { sites }\end{array}$ & $\begin{array}{l}\text { Detergent dispersant } \\
\text { additive, airborne } \\
\text { contaminant at some } \\
\text { sites }\end{array}$ \\
\hline Calcium & $\begin{array}{l}\text { Detergent dispersant } \\
\text { additive, airborne } \\
\text { contaminant at some sites, } \\
\text { contaminant from water }\end{array}$ & $\begin{array}{l}\text { Detergent dispersant } \\
\text { additive, airborne } \\
\text { contaminant at some } \\
\text { sites, contaminant } \\
\text { from water }\end{array}$ & $\begin{array}{l}\text { Detergent dispersant } \\
\text { additive, airborne } \\
\text { contaminant at some } \\
\text { sites, contaminant } \\
\text { from water }\end{array}$ & $\begin{array}{l}\text { Detergent dispersant } \\
\text { additive, airborne } \\
\text { contaminant at some } \\
\text { sites, contaminant from } \\
\text { water }\end{array}$ \\
\hline Barium & $\begin{array}{l}\text { Usually an additive from } \\
\text { synthetic lubricants }\end{array}$ & $\begin{array}{l}\text { Usually an additive } \\
\text { from synthetic } \\
\text { lubricants }\end{array}$ & $\begin{array}{l}\text { Usually an additive } \\
\text { from synthetic } \\
\text { lubricants }\end{array}$ & $\begin{array}{l}\text { Usually an additive } \\
\text { from synthetic } \\
\text { lubricants }\end{array}$ \\
\hline Phosphorus & Anti-wear additive (ZDP) & $\begin{array}{l}\text { Anti-wear additive } \\
\text { (ZDP) }\end{array}$ & $\begin{array}{l}\text { Anti-wear additive } \\
\text { (ZPD), EP additive } \\
\text { (extreme pressure) }\end{array}$ & $\begin{array}{l}\text { Anti-wear additive } \\
\text { (ZDP) }\end{array}$ \\
\hline Zinc & Anti-wear additive (ZDP) & $\begin{array}{l}\text { Anti-wear additive } \\
\text { (ZDP) }\end{array}$ & $\begin{array}{l}\text { Anti-wear additive } \\
\text { (ZPD) }\end{array}$ & $\begin{array}{l}\text { Anti-wear additive } \\
\text { (ZDP) }\end{array}$ \\
\hline
\end{tabular}

\section{Test Types (contd)}

- Particle Count - Measures the size and quantity of particles in a lubricant.

Significance: Oil cleanliness and performance. An increase in particle size and gravity is an indication of a need for oil service.

- Viscosity Test - Measure of a lubricant's resistance to flow at a specific temperature.

Significance: Viscosity is the most important physical property of oil. Viscosity determination provides a specific number to compare to the recommended oil in service. An abnormal viscosity $( \pm 15 \%)$ is usually indicative that lubricant replacement is required. 
- Fourier transform (FT)-IR Spectroscopy - Measures the chemical composition of a lubricant.

Significance: Molecular analysis of lubricants and hydraulic fluids by FT-IR spectroscopy produces direct information on molecular species of interest, including additives, fluid breakdown products, and external contamination.

- Direct Read Ferrography - Measures the relative amount of ferrous wear in a lubricant.

Significance: The direct read gives a direct measure of the amount of ferrous wear metals of different size present in a sample. If trending of this information reveals changes in the wear mode of the system, then action is required.

- Analytical Ferrography - Allows analyst to visually examine wear particles present in a sample.

Significance: A trained analyst visually determines the type and severity of wear deposited onto the substrate by using a high magnification microscope. The particles are readily identified and classified according to size, shape, and metallurgy.

- Total Acid Number - Measures the acidity of a lubricant.

Description: Organic acids, a by-product of oil oxidation, degrade oil properties and lead to corrosion of the internal components. High acid levels are typically caused by oil oxidation.

\subsubsection{Types of Equipment}

Although independent laboratories generally perform oil analysis, some vendors do provide analysis equipment that can be used on-site to characterize oil condition, wear particles, and contamination. These devices are generally composed of several different types of test equipment and standards including viscometers, spectrometers, oil analyzers, particle counters, and microscopes. On-site testing can provide quick verification of a suspected oil problem associated with critical components such as water contamination. It can also provide a means to quickly define lubricant condition to determine when to change the lubricant medium. For the most part, detailed analysis will still require the services of an independent laboratory.
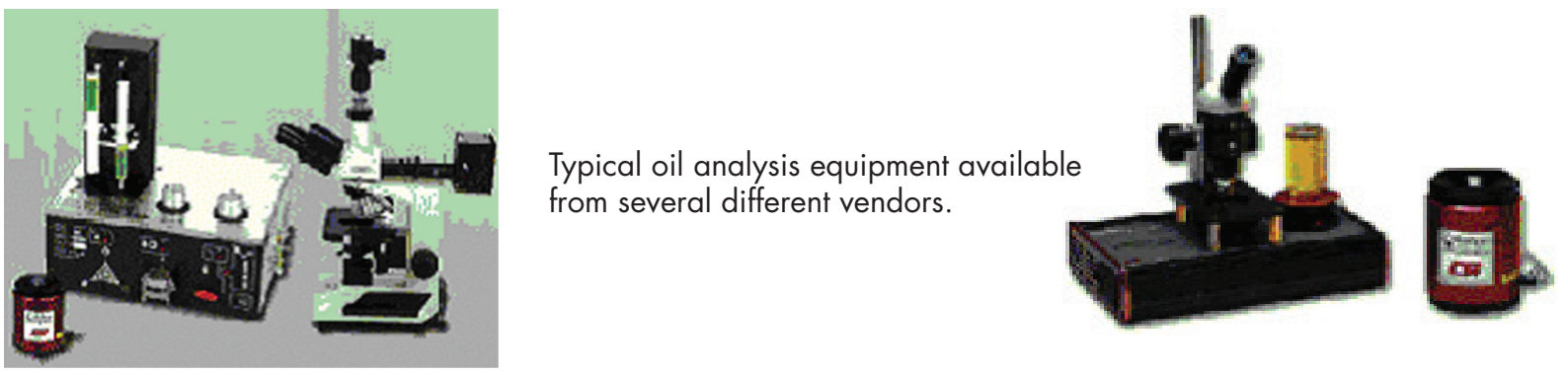

\subsubsection{System Applications}

All machines with motors $7.5 \mathrm{hp}$ or larger, and critical or high-cost machines should be evaluated for routine lubricating oil analysis (NASA 2000) from monthly to quarterly. All hydraulic systems, except mobile systems, should be analyzed on a quarterly basis. Mobile systems should be considered for analysis based upon the machine size and the cost effectiveness of performing the analysis. Generally speaking, it is more cost effective in mobile equipment to maintain the hydraulic fluid based on the fluid condition. However, for small systems, the cost to flush and replace the hydraulic fluid on a time basis may be lower than the cost to analyze the fluid on a routine basis. Typical equipment applications include: 
- Turbines

- Boiler feed pumps

- Electrohydraulic control (EHC) systems

- Hydraulics

- Servo valves

- Gearboxes

- Roller bearings

- Anti-friction bearings

- Any system where oil cleanliness is directly related to longer lubricant life, decreased equipment wear, or improved equipment performance

\subsubsection{Equipment Cost/Payback}

For facilities utilizing a large number of rotating machines that employ circulating lubricant, or for facilities with high dollar equipment using circulating lubricant, few predictive maintenance technologies can offer the opportunity of such a high return for dollars spent. Analysis for a single sample can run from $\$ 15$ to $\$ 100$ depending on the level of analysis requested - samples are typically sent through the mail to the testing center. Given the high equipment replacement cost, labor cost, and downtime cost involved with a bearing or gearbox failure, a single failure prevented by the performance of oil analysis can easily pay for a program for several years.

\subsubsection{Training Availability}

Training for lubricant and wear particle analysis typically takes place via vendors. Because the analysis is usually conducted by outside vendors at their location, training consists of proper sampling techniques (location and frequency) as well as requisite sample handling guidance.

\subsubsection{Case Studies}

\section{Reduced Gear Box Failure}

Through oil analysis, a company determined that each time oil was added to a gear reducer, contamination levels increased and this was accompanied by an increase in bearing and gear failures. Further examination determined that removing the cover plate to add oil allowed contamination from the process to fall into the sump. Based on this, the system was redesigned to prevent the introduction of contamination during oil addition. The result was a reduction in bearing/gearbox failure rates.

\section{Oil Changes When Needed}

A major northeast manufacturer switched from a preventive maintenance approach of changing oil in 400 machines using a time-based methodology to a condition-based method using in-house oil analysis. The oil is now being changed based on its actual condition and has resulted in a savings in excess of $\$ 54,000$ per year. 


\section{Oil Changes and Equipment Scheduling}

A northeast industrial facility gained an average of 0.5 years between oil changes when it changed oil change requirements from a preventive maintenance time-based approach to changing oil based on actual conditions. This resulted in greater than a $\$ 20,000$ consumable cost in less than 9 months.

A large chemical manufacturing firm saved more than $\$ 55,000$ in maintenance and lost production cost avoidance by scheduling repair of a centrifugal compressor when oil analysis indicated water contamination and the presence of high ferrous and non-ferrous particle counts.

\subsubsection{References/Resources}

The references and resources provided below are by no means all-inclusive. The listed organizations are not endorsed by the authors of this guide and are provided for your information only. To locate additional resources, the authors of this guide recommend contacting relevant trade groups, databases, and the world-wide web.

\subsubsection{Analysis Equipment Resources}

Computational Systems, Inc./

Emerson Process Management

Knoxville, TN

Telephone: (865) 675-2400

Fax: (865) 218-1401

Web address: www.compsys.com

Reliability Direct, Inc.

League City, TX

Telephone: 1-888-710-6786

Fax: (281) 334-4255

Web address: www.reliabilitydirect.com

Spectro, Inc.

Industrial Tribology Systems

Littleton, MA

Telephone: (978) 486-0123

Fax: (978) 486-0030

E-Mail: Info@SpectroInc.com

Web address: www.spectroinc.com

\subsubsection{Oil Analysis Laboratories}

Computational Systems, Inc./

Emerson Process Management

Knoxville, TN

Telephone: (865) 675-2400

Fax: (865) 218-1401

Web address: www.comsys.com

Polaris Laboratories

Indianapolis, IN

Telephone: (877) 808-3750

Fax: (317) 808-3751

Web address: www.polarislabs $1 . c o m$

Analysts, Inc.

Locations throughout the U.S.

Telephone: (800) 336-3637

Fax: (310) 370-6637

Web address: www.analystsinc.com

LubeTrak

Sandy, UT

Telephone: 1-866-582-3872 (Toll Free)

Web address: www.lubetrak.com 


\subsubsection{Internet Resource Sites}

www.testoil.com

- Sample report

- Free oil analysis

- Industry-related articles

- Test overview

- Laboratory services

- Training services

www.compsys.com

- Laboratory service

- Technical articles

- Application papers

- Sample report

- Training services

- Technical notes www.natrib.com

- Technical articles

- Case studies

- Newsletters

- Application notes 


\subsection{Ultrasonic Analysis}

\subsubsection{Introduction}

Ultrasonic, or ultrasounds, are defined as sound waves that have a frequency level above $20 \mathrm{kHz}$. Sound waves in this frequency spectrum are higher than what can normally be heard by humans. Non-contact ultrasonic detectors used in predictive maintenance detect airborne ultrasound. The frequency spectrums of these ultrasounds fall within a range of 20 to $100 \mathrm{kHz}$. In contrast to IR emissions, ultrasounds travel a relatively short distance from their source. Like IR emissions, ultrasounds travel in a straight line and will not penetrate solid surfaces. Most rotating equipment and many fluid system conditions will emit sound patterns in the ultrasonic frequency spectrum. Changes in these ultrasonic wave emissions are reflective of equipment condition. Ultrasonic detectors can be used to identify problems related to component wear as well as fluid leaks, vacuum leaks, and steam trap failures. A compressed gas or fluid forced through a small opening creates turbulence with strong ultrasonic components on the downstream side of the opening. Even though such a leak may not be audible to the human ear, the ultrasound will still be detectable with a scanning ultrasound device.

Ultrasounds generated in vacuum systems are generated within the system. A small percentage of these ultrasonic waves escape from the vacuum leak and are detectable, provided the monitoring is performed close to the source or the detector gain is properly adjusted to increase detection performance. In addition to system vacuum or fluid leaks, ultrasonic wave detection is also useful in defining abnormal conditions generated within a system or component. Poorly seated valves (as in the case of a failed steam trap) emit ultrasounds within the system boundaries as the fluid leaks past the valve seat (similar to the sonic signature generated if the fluid was leaking through the pipe or fitting walls). These ultrasounds can be detected using a contact-type ultrasonic probe.

Ultrasonic detection devices can also be used for bearing condition monitoring. According to National Aeronautics and Space Administration (NASA) research, a 12-50x increase in the amplitude of a monitored ultrasonic frequency $(28$ to $32 \mathrm{kHz}$ ) can provide an early indication of bearing deterioration.

Ultrasonic detection devices are becoming more widely used in detection of certain electrical system anomalies. Arcing/tracking or corona all produce some form of ionization that disturbs the air molecules around the equipment being diagnosed and produces some level of ultrasonic signature. An ultrasonic device can detect the high-frequency noise produced by this effect and translate it, via heterodyning, down into the audible ranges. The specific sound quality of each type of emission is heard in headphones while the intensity of the signal can be observed on a meter to allow quantification of the signal.

In addition to translating ultrasonic sound waves into frequencies heard by the human ear or seen on a meter face, many ultrasonic sound wave detectors provide the capability to capture and store the detectors output. Utilizing display and analysis software, a time waveform of the ultrasonic signature can then be visually displayed. This functionality increases the technology's capability to capture and store quantifiable data related to a components operating condition. Ultrasonic signature information can then be used to baseline, analyze, and trend a component's condition. In contrast to a technician's subjective analysis of a component's condition using an audio signal, many ultrasonic anomalies indicative of component problems are more easily defined using a signature profile. The following images of ultrasonic time waveforms from two identical gearboxes illustrate how ultrasonic 
signature data storage and analysis can be used to quantify machine condition. Gearbox "1" waveform shows an ultrasonic signature anomaly that may be attributable to missing or worn gear teeth, while Gearbox "2" signature shows a flat profile.

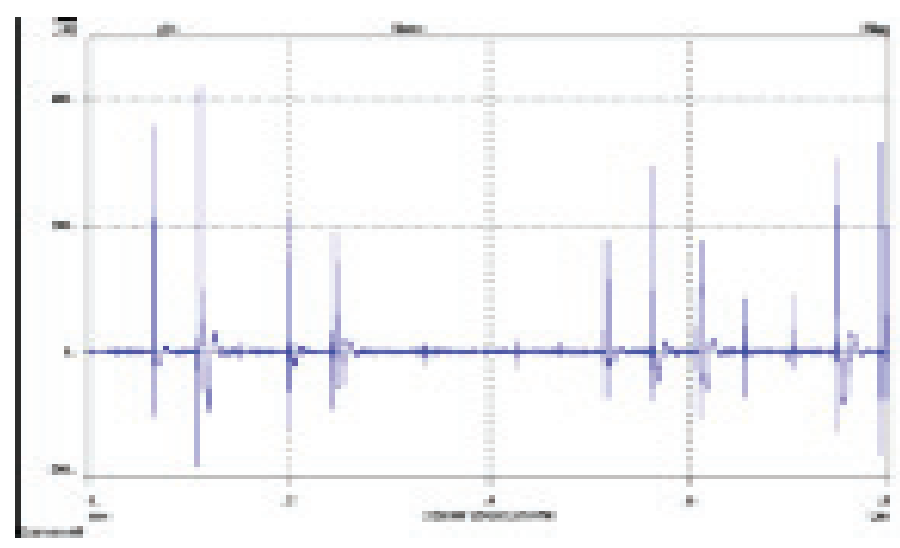

Gearbox 1

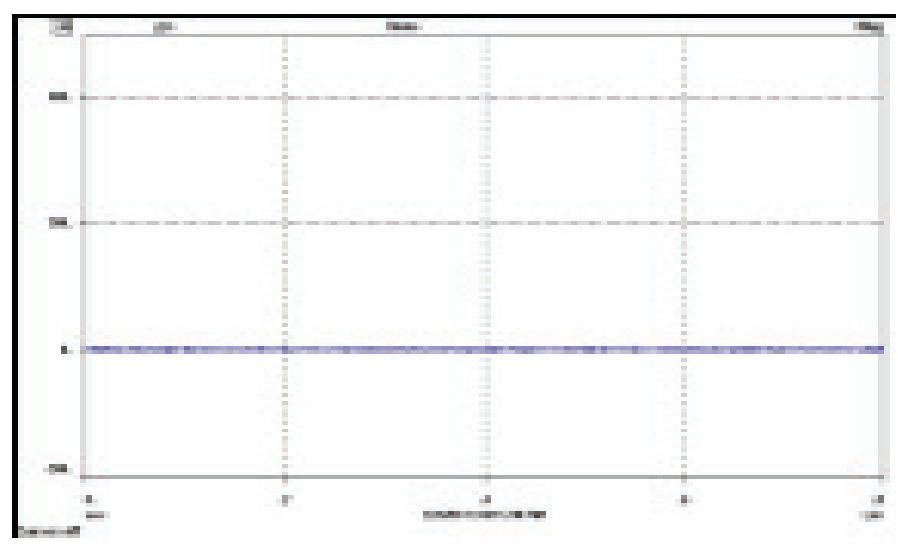

Gearbox 2

Generally, this type of diagnosis can be performed on a standard personal computer (PC). The programs not only provide the spectral and time series views of the ultrasonic signature but enable users to hear the translated sound samples simultaneously as they are viewing them on the PC monitor.

\subsubsection{Types of Equipment}

Ultrasonic analysis is one of the less complex and less expensive predictive maintenance technologies. The equipment is relatively small, light, and easy to use. Measurement data are presented in a straightforward manner using meters or digital readouts. The cost of the equipment is moderate and the amount of training is minimal when compared to other predictive maintenance technologies. The picture to the right shows a typical ultrasonic detection device.

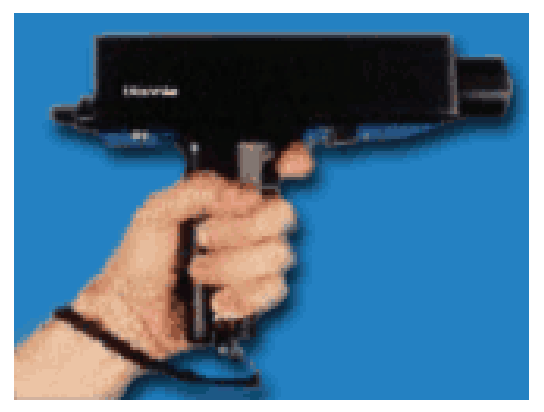

Typical hand-held ultrasonic detector 
Since ultrasounds travel only a short distance, some scanning applications could present a safety hazard to the technician or the area of interest may not be easily accessible. In these applications, the scanning device is generally designed with a gain adjust to increase its sensitivity, thereby allowing scanning from a greater distance than normal. Some ultrasonic detectors are designed to allow connection of a special parabolic dish-type sensing device (shown at right) that greatly extends the normal scanning distance.

\subsubsection{System Applications}

\subsubsection{Pressure/Vacuum Leaks}

- Compressed air

- Oxygen

- Hydrogen

- Heat exchangers

- Boilers

- Condensers

- Tanks

- Pipes

- Valves
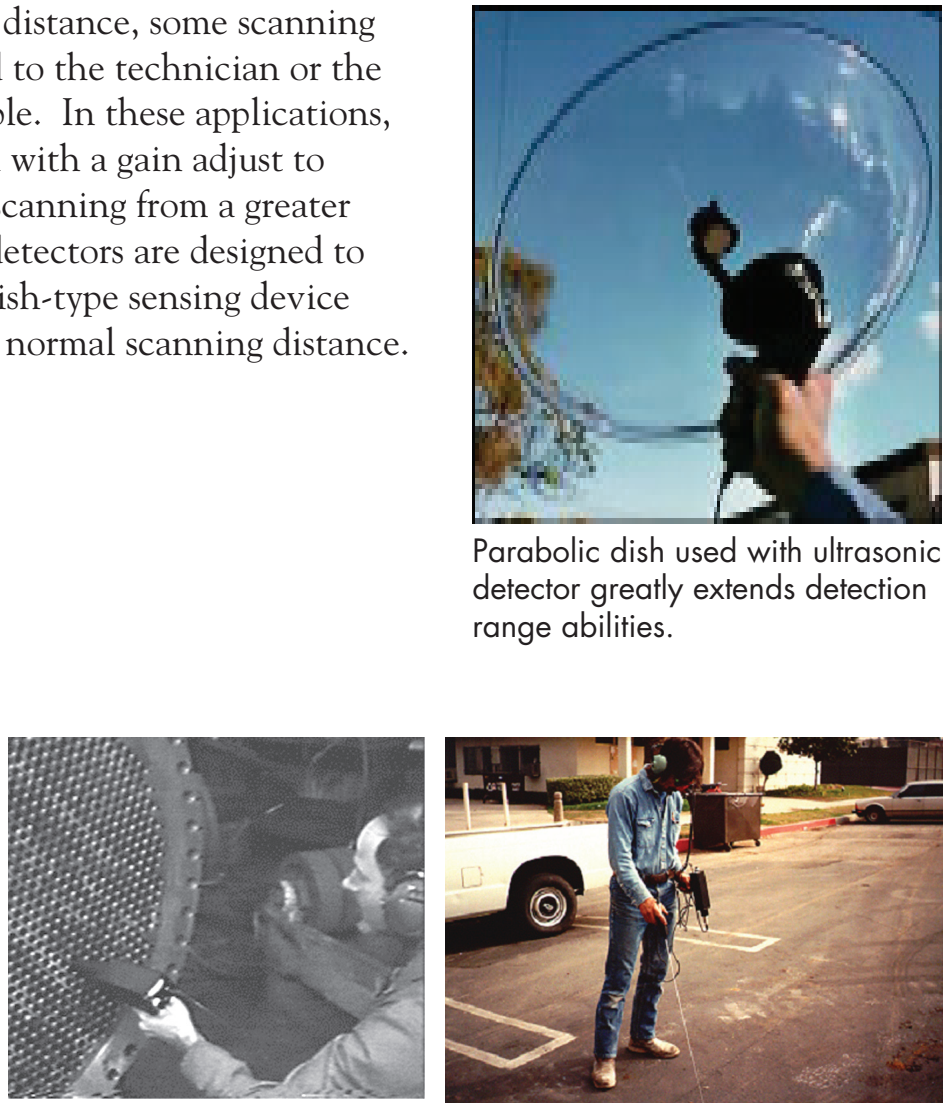

Parabolic dish used with ultrasonic detector greatly extends detection range abilities.

Ultrasonic detection can be used to locate underground system leaks and detect heat exchanger tube leakage.

- Steam traps.
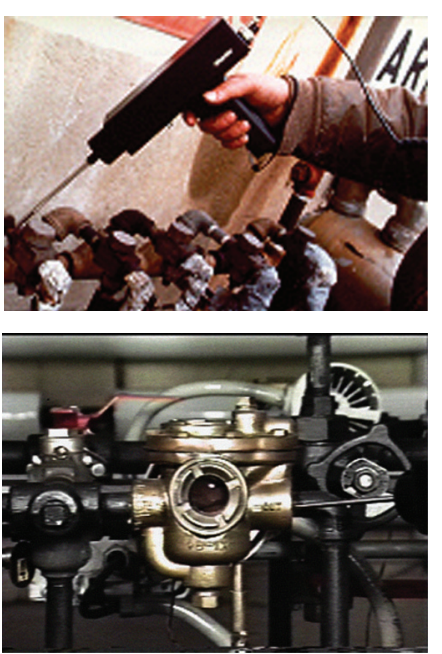

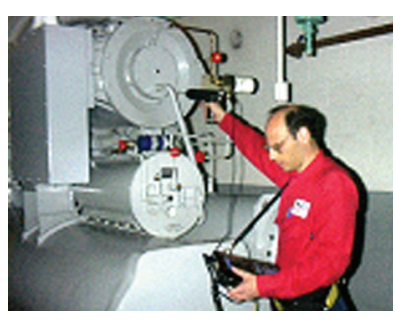

From steam trap faults and valve leakage to compressor problems, ultrasonic detection can be used to find a variety of problems that generate ultrasonic signatures.

\subsubsection{Mechanical Applications}

- Mechanical inspection

- Bearings

- Lack of lubrication

- Pumps

- Motors

- Gears/Gearboxes

- Fans

- Compressors

- Conveyers. 


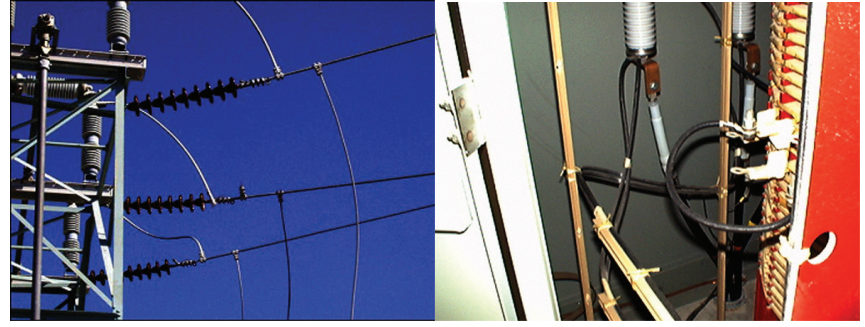

Mechanical devices are not the only sources of ultrasonic emission. Electrical equipment will also generate ultrasonic waves if arcing/tracking or corona are present.

\subsubsection{Electrical Applications}

- Arcing/tracking/corona

- Switchgear

- Transformers

- Insulators

- Seals/Potheads

- Junction boxes

- Circuit breakers.

\subsubsection{Equipment Cost/Payback}

As indicated earlier, ultrasonic analysis equipment cost is minimal when compared to other predictive maintenance technologies. A typical handheld scanner, software, probes, will cost from $\$ 750$ to $\$ 10,000$ - depending on the type, accuracy and features. The minimal expense combined with the large savings opportunities will most often result in an equipment payback period of 6 months or less.

\subsubsection{Training Availability}

Training for ultrasonic analysis is available through a variety of system manufacturers and vendors. Depending on your needs, consider training that will qualify you for the American Society of Non-destructive Testing (ASNT) various levels of certification. Generically, these levels take the following form:

Level I - the student is competent with equipment function and use; Level II - the student is fully capable and experienced and can complete diagnostics and recommendations; Level III - the student is fully experienced to supervise and teach Level I and II student.

\section{Steam Trap Applications \\ (NASA 2000):}

Steam traps should be monitored on the downstream side of the trap using the test equipment's contact mode. Each type of steam trap produces a distinct sound as briefly described below. It is recommended that users receive training and then gain experience in a controlled environment before diagnosing operating systems.

Typical ultrasonic signatures will include and opening and closing sound characterized by steam rushing sound followed by a period of relative quiet. Many types of traps fail in the open position, producing a continuous, rushing sound. Common trap types and their diagnostic signatures include:

Inverted Bucket: A normal trap sounds as if it is floating; a failed trap sinks, producing a continuous flow noise.

Float and Thermostatic (Continuous Load): Flow and noise associated with these traps are usually modulated as the trap opens and closes. Failed traps are normally cold and silent.

Thermostatic: Ultrasonic testing results of this type of trap vary. The signatures produced by these traps can be continuous or intermittent depending on the type. It is best to reference a properly functioning trap for a baseline signature for comparison. 


\subsubsection{Case Studies}

\section{Ultrasound Detects Compressed Air Leaks}

A northeast industrial plant was experiencing some air problems. The facility's two compressors were in the on mode for an inordinate amount of time, and plant management assumed a third compressor was needed, at a cost of $\$ 50,000$. Instead, the foundry invested less than $\$ 1,000$ in contracting an outside firm to perform an ultrasound inspection of its air system. In a single day, the ultrasound technician detected 64 air leaks accounting for an estimated total air loss of $295.8 \mathrm{cfm}$ (26\% of total system capacity). Considering it cost approximately $\$ 50,014$ per year (calculated at $\$ .04 / \mathrm{kilowatt} /$ hour) to operate the two air compressors, at a total of $1,120 \mathrm{cfm}$, correcting this air loss saved the plant $\$ 13,000$ per year. In addition, the plant avoided having to spend another $\$ 50,000$ on another air compressor, because after the leaks were found and repaired, the existing compressors were adequate to supply demand.

A Midwest manufacturer saved an estimated $\$ 75,900$ in annual energy costs as a result of an ultrasound survey of its air system. A total of 107 air leaks were detected and tagged for repair. These leaks accounted for an air loss of 1,031 cfm, equal to $16 \%$ of the total $6,400 \mathrm{cfm}$ produced by the air compressors that supply the facility.

\section{Steam Trap Monitoring (NASA 2000)}

Implementation of a steam trap monitoring program often has significant financial benefit. Initial steam trap surveys in the petrochemical industry revealed that $34 \%$ of the steam traps inspected had failed, mostly in the open position. For facilities with a periodic steam trap monitoring program, the following distribution of degradations were discovered during each survey:

- Five steam leaks (other than traps) per 150 traps

- Two leaking valves per 150 traps

- Twenty of the 150 traps leak

Building off these findings - one trap (failed open) with a $1 / 4$ inch orifice will lose roughly $500 \mathrm{MBtu} /$ year (at $25 \mathrm{psi}$ ) if undiscovered. With a cost of steam at $\$ 7.50$ per MBtu, a boiler efficiency of $75 \%$ and a system energized for $50 \%$ of the year, the annual cost savings of detecting this leak is $\$ 2,500$. This one leak could justify the purchase of an ultrasonic detector - and this is likely one of many leaks to be found.

\subsubsection{References/Resources}

The references and resources provided below are by no means all-inclusive. The listed organizations are not endorsed by the authors of this guide and are provided for your information only. To locate additional resources, the authors of this guide recommend contacting relevant trade groups, databases, and the world-wide web.

\subsubsection{Equipment Resources}

\author{
UE Systems \\ Elmsford, NY \\ Telephone: (914) 592-1220 or \\ 1-800-223-1325 \\ Fax: (914) 347-2181 \\ Web address: www.uesystems.com
}

CTRL Systems, Inc.

Westminster, MD

Telephone: (877) 287-5797

Web address: www.ctrlsys.com 
Specialized Diagnostic Technologies, Inc. SDT North America

Cobourg, Ontario

Canada

Telephone: 1-800-667-5325

Web address: www.sdtnorthamerica.com

Superior Signal Company

Spotswood, NJ

Telephone: 1-800-945-TEST(8378) or (732) 251-0800

Fax: (732) 251-9442

Web address: www.superiorsignal.com

\subsubsection{Service Companies}

Mid-Atlantic Infrared Services, Inc.

Bethesda, MD

Telephone: (301) 320-2870

Web address: www.midatlanticinfrared.com

\section{UE Systems, Inc.}

Telephone: (914) 592-1220 or 1-800-223-1325 (Toll Free)

Fax: (914) 347-2181

Web address: www.vesystems.com

Leek Seek

Telephone: TX: (512) 246-2071

CA: (909) 786-0795

FL: (727) 866-8118

Web address: www.leekseek.com

\subsubsection{Internet Resource Sites}

www.vesystems.com

- Technology overview

- Training

- Links

- Sound demos

www.superiorsignal.com

- Technology overview

- Ultrasonic sound bites (examples)

- Ultrasonic spectral graphs 


\subsection{Vibration Analysis}

\subsubsection{Introduction}

As all of us who ride or drive an automobile with some regularity know, certain mechanical faults or problems produce symptoms that can be detected by our sense of feel. Vibrations felt in the steering wheel can be an indicator of an out-of-balance wheel or looseness in the steering linkage. Transmission gear problems can be felt on the shift linkage. Looseness in exhaust system components can sometimes be felt as vibrations in the floorboard. The common thread with all these problems is that degeneration of some mechanical device beyond permissible operational design limitations has manifested itself by the generation of abnormal levels of vibration. What is vibration and what do we mean by levels of vibration? The dictionary defines vibration as "a periodic motion of the particles of an elastic body or medium in alternately opposite directions from the position of equilibrium when that equilibrium has been disturbed or the state of being vibrated or in vibratory motion as in (1) oscillation or (2) a quivering or trembling motion."

The key elements to take away from this definition are vibration is motion, and this motion is cyclic around a position of equilibrium. How many times have you touched a machine to see if it was running? You are able to tell by touch if the motor is running because of vibration generated by motion of rotational machine components and the transmittal of these forces to the machine housing. Many parts of the machine are rotating and each one of these parts is generating its own distinctive pattern and level of vibration. The level and frequency of these vibrations are different and the human touch is not sensitive enough to discern these differences. This is where vibration detection instrumentation and signature analysis software can provide us the necessary sensitivity. Sensors are used to quantify the magnitude of vibration or how rough or smooth the machine is running. This is expressed as vibration amplitude. This magnitude of vibration is expressed as:

- Displacement - The total distance traveled by the vibrating part from one extreme limit of travel to the other extreme limit of travel. This distance is also called the "peak-to-peak displacement."

- Velocity - A measurement of the speed at which a machine or machine component is moving as it undergoes oscillating motion.

- Acceleration - The rate of change of velocity. Recognizing that vibrational forces are cyclic, both the magnitude of displacement and velocity change from a neutral or minimum value to some maximum. Acceleration is a value representing the maximum rate that velocity (speed of the displacement) is increasing.

Various transducers are available that will sense and provide an electrical output reflective of the vibrational displacement, velocity, or acceleration. The specific unit of measure to best evaluate the machine condition will be

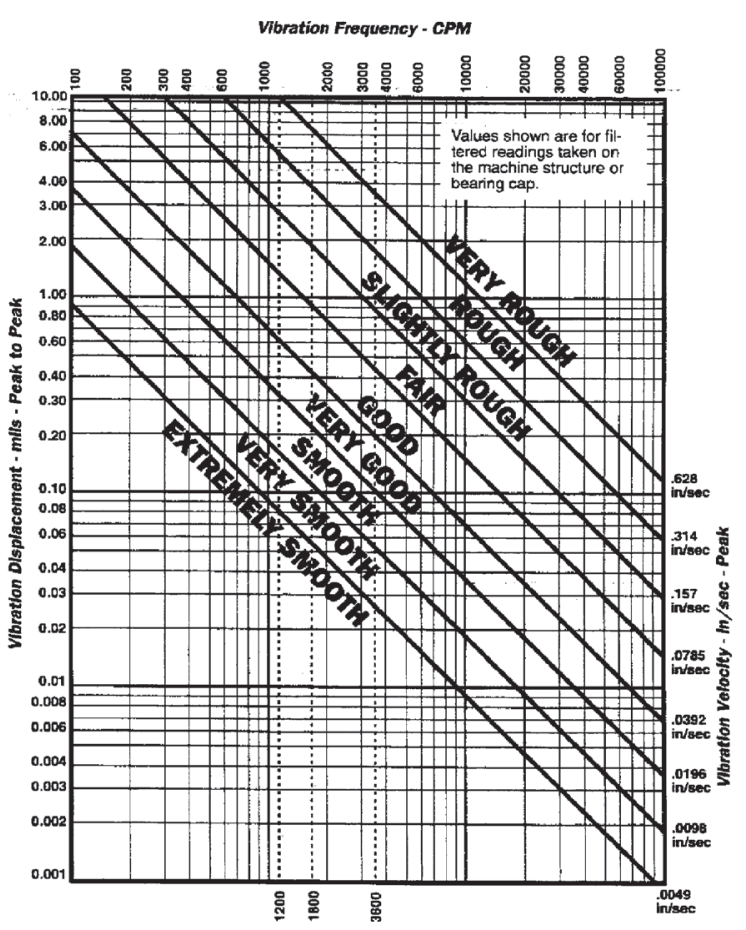

Figure 6.5.1. Vibration severity chart 
dependent on the machine speed and design. Several guidelines have been published to provide assistance in determination of the relative running condition of a machine. An example is seen in Figure 6.5.1. It should be said that the values defined in this guideline, or similar guidelines, are not absolute vibration limits above which the machine will fail and below which the machine will run indefinitely. It is impossible to establish absolute vibration limits. However, in setting up a predictive maintenance program, it is necessary to establish some severity criteria or limits above which action will be taken. Such charts are not intended to be used for establishing vibration acceptance criteria for rebuilt or newly installed machines. They are to be used to evaluate the general or overall condition of machines that are already installed and operating in service. For those, setting up a predictive maintenance program, lacking experience or historical data, similar charts can serve as an excellent guide to get started.

As indicated earlier, many vibration signals are generated at one time. Once a magnitude of vibration exceeds some predetermined value, vibration signature analysis can be used in defining the machine location that is the source of the vibration and in need of repair or replacement. By using analysis equipment and

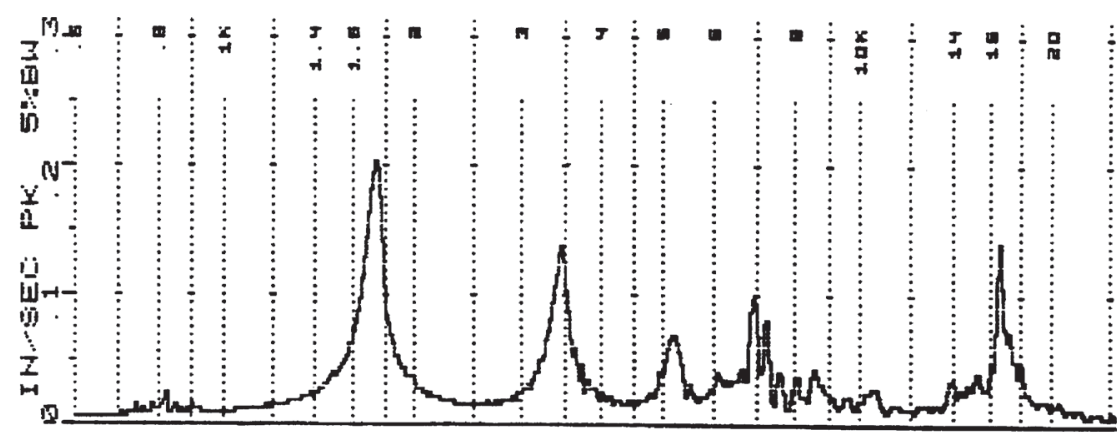

Figure 6.5.2. FFT - Example of graph breaking down vibration level at different frequencies software, the individual vibration signals are separated and displayed in a manner that defines the magnitude of vibration and frequency (Figure 6.5.2). With the understanding of machine design and operation, an individual schooled in vibration signature analysis can interpret this information to define the machine problem to a component level.

\subsubsection{Types of Equipment}

Depending on the application, a wide variety of hardware options exist in the world of vibration. Although not complicated, actual hardware requirements depend on several factors. The speed of the machine, on-line monitoring versus off-line data collection, analysis needs, signal output requirements, etc., will affect the type of equipment options available. Regardless of the approach, any vibration program will require a sensing device (transducer) to measure the existing vibration and translate this information into some electronic signal. Transducers are relatively small in size (see Figure 6.5.3) and can be permanently mounted or affixed to the monitoring location periodically during data collection.

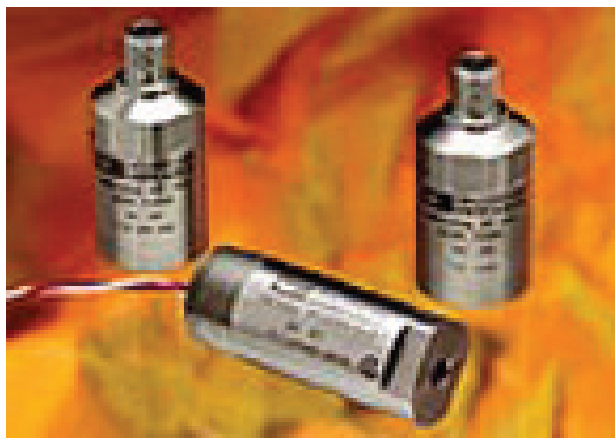

Figure 6.5.3. Typical vibration transducers

In some cases, the actual translation of the vibration to an electrical signal occurs in a handheld monitoring device. A metal probe attached to a handheld instrument is held against a point of interest and the instrument translates the motions felt on the probe to some sort of electrical signal. Other portable devices use a transducer and handheld data-collection device. Both styles will provide 


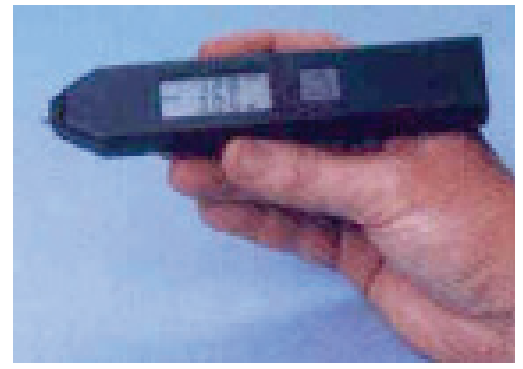

Examples of typical hand-held vibration sensing meters. Note readout providing immediate level indication.
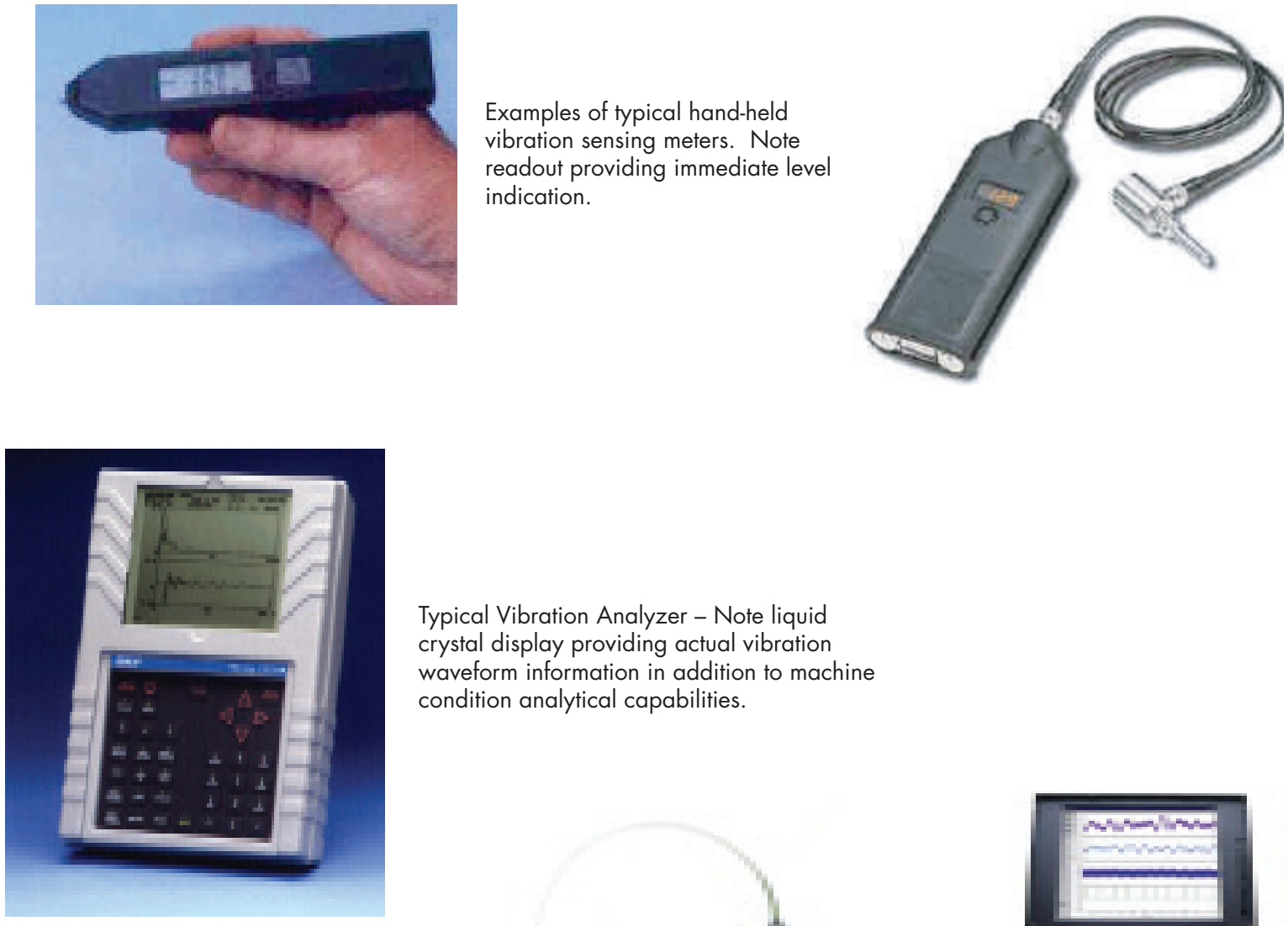

Typical Vibration Analyzer - Note liquid crystal display providing actual vibration waveform information in addition to machine condition analytical capabilities.

some sort of display where the vibration magnitude is defined. Styles and equipment size vary greatly, but equipment is designed to be portable.

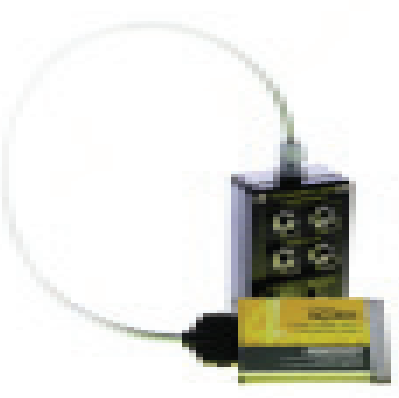

Some signal acquisition and analysis equipment interface a PC directly with the sensors.

In addition to instruments designed to measure vibration magnitude, many manufacturers provide instrumentation that will perform signal analysis as well. Some equipment is a stand-alone design and performs analysis in the field independent of computer interface while other equipment designs interface tranducers directly with a PC where analysis software is utilized to interpret the signal data.

\subsubsection{System Applications}

Vibration monitoring and analysis can be used to discover and diagnose a wide variety of problems related to rotating equipment. The following list provides some generally accepted abnormal equipment conditions/faults where this predictive maintenance technology can be of use in defining existing problems:

- Unbalance

- Eccentric rotors

- Misalignment

- Resonance problems
- Mechanical looseness/weakness

- Rotor rub

- Sleeve-bearing problems

- Rolling element bearing problems 
- Flow-induced vibration problems

- Gear problems

- Electrical problems

- Belt drive problems.

Analyzing equipment to determine the presence of these problems is not a simple and easily performed procedure. Properly performed and evaluated vibration signature analysis requires highly trained and skilled individuals, knowledgeable in both the technology and the equipment being tested. Determination of some of the problems listed is less straightforward than other problems and may require many hours of experience by the technician to properly diagnosis the condition.

\subsubsection{Equipment Cost/Payback}

As indicated earlier, the styles, types, and capabilities of vibration monitoring equipment vary greatly. Naturally, equipment cost follows this variance. Transducers can cost under $\$ 100$. The expected cost for vibration metering devices capable of defining magnitude with no analysis capability is approximately $\$ 1,000$. The cost goes up from there. A high-end vibration analyzer with software and all the accessories can exceed $\$ 30,000$. A typical industrial site can expect to recover the cost of the high-end equipment investment within 2 years. Sites with a minimal number of rotating equipment, low-cost equipment installations, and/or no production-related concerns may find it uneconomically advantageous to purchase a $\$ 30,000$ vibration analysis system. These facilities may be wise to establish an internal program of vibration monitoring using a low-cost vibration-metering device and then employ the services of an outside contractor to conduct periodic surveys. These services generally range in cost from $\$ 600$ to $\$ 1,200$ per day.

\subsubsection{Training Availability}

Training for vibration analysis is available through a variety of system manufacturers and vendors. Additional training and certification is available through the Vibration Institute (see Resources section for contact information) from where certification for Levels I - IV is available.

\subsubsection{Case Studies}

\section{Vibration Analysis on Pump}

Vibration analysis on a 200-hp motor/pump combination resulted in determination of improperly sized shaft bearings on both the pump end and the motor end. Repair costs were less than $\$ 2,700$. Continued operation would have led to failure and a replacement cost exceeding $\$ 10,000$.

\subsubsection{References/Resources}

The references and resources provided below are by no means all-inclusive. The listed organizations are not endorsed by the authors of this guide and are provided for your information only. To locate additional resources, the authors of this guide recommend contacting relevant trade groups, databases, and the world-wide web. 


\subsubsection{Training Equipment Resources}

Wilcoxon Research, Inc.

Gaithersburg, MD

Telephone: (301) 330-8811 or 1-800-945-2696

Web site: www.wilcoxon.com

Computational Systems, Inc./

Emerson Process Management

Web address: www.compsys.com

\subsubsection{Service Companies}

Industrial Research Technology

Bethlehem, PA - Pittsburgh, PA -

Cleveland, $\mathrm{OH}$ - Detroit, MI - Chicago, IL -

Charleston, SC

Telephone: (610) 867-0101 or

1-800-360-3594

Fax: (610) 867-2341

\subsubsection{Training/Internet Resource Sites}

\section{Vibration Institute}

www.vibinst.org

6262 S. Kingery Highway

Suite 212, Willowbrook, IL 60527

Telephone: (630)654-2254

Fax: (630)654-2271

\section{www.plant-maintenance.com}

- Training material

- Industry links

- Free software

- FFT/CMMS/Inventory control

- Technical articles

- Maintenance-related articles

\section{Engineering Corporation}

U.S. wide

Telephone: 1-800-654-2844 or (206) 842-7656

Web address: www.dliengineering.com

Commtest, Inc.

Knoxville, TN

Telephone: 1-877-582-2946

Web address: www.commtest.com

Computational Systems, Inc./

Emerson Process Management

835 Innovation Drive

Knoxville, TN 37932

Telephone: (865) 675-2110

Fax: (865) 218-1401 www.reliabilityweb.com

- Training material

- Industry links

- Free software

- FFT/CMMS/Inventory control

- Technical articles

- Maintenance-related articles

www.maintenance-news.com

- Industry links

- Technical articles

- Maintenance-related articles 


\subsection{Motor Analysis}

\subsubsection{Introduction}

When it comes to motor condition analysis, infrared (IR) and vibration will not provide all the answers required to properly characterize motor condition. Over the past several years, motor condition analysis techniques have evolved from simple testing into testing techniques that more accurately define a motor's condition. Motor faults or conditions like winding short-circuits, open coils, improper torque settings, as well as many mechanically-related problems can be diagnosed using motor analysis techniques. Use of these predictive maintenance techniques and technologies to evaluate winding insulation and motor condition has not grown as rapidly as other predictive techniques. Motor analysis equipment remains fairly expensive and proper analysis requires a high degree of skill and knowledge. Recent advances in equipment portability and an increase in the number of vendors providing contracted testing services continue to advance predictive motor analysis techniques. Currently, more than 20 different types of motor tests exist, depending on how the individual tests are defined and grouped. The section below provides an overview of two commonly used tests.

\subsubsection{Motor Analysis Test}

\subsubsection{Electrical Surge Comparison}

In addition to ground wall insulation resistance, one of the primary concerns related to motor condition is winding insulation. Surge comparison testing can be used to identify turn-to-turn and phase-to-phase insulation deterioration, as well as a reversal or open circuit in the connection of one or more coils or coil groups. Recent advances in the portability of test devices now allow this test technique to be used in troubleshooting and predictive maintenance. Because of differences in insulation thickness, motor winding insulation tends to be more susceptible to failure from the inherent stresses existing within the motor environment than ground wall insulation. Surge comparison testing identifies insulation deterioration by applying a high frequency transient surge to equal parts of a winding and comparing the resulting voltage waveforms. Differences seen in the resulting waveforms are indicative insulation or coil deterioration. A properly trained test technician can use these differences to properly diagnose the type and severity of the fault. In addition to utilization of this motor analysis technique in a predictive maintenance program, it can also be used to identify improper motor repair practices or improper operating conditions (speeds, temperature, load).

Surge comparison testing is a moderately complex and expensive predictive maintenance technique. As with most predictive maintenance techniques, the greatest saving opportunities do not come directly from preventing a catastrophic failure of a component (i.e., motor) but rather the less tangible cost saving benefits. Reduced downtimes, ability to schedule maintenance, increased production, decreased overtime, and decreased inventory cost are just a few of the advantages of being able to predict an upcoming motor failure.

\subsubsection{Motor Current Signature Analysis}

Another useful tool in the motor predictive maintenance arsenal is motor current signature analysis (MCSA). MCSA provides a non-intrusive method for detecting mechanical and electrical problems in motor-driven rotating equipment. The technology is based on the principle that a 
conventional electric motor driving a mechanical load acts as a transducer. The motor (acting as a transducer) senses mechanical load variations and converts them into electric current variations that are transmitted along the motor power cables. These current signatures are reflective of a machine's condition and closely resemble signatures produced using vibration monitoring. These current signals are recorded and processed by software to produce a visual representation of the existing frequencies against current amplitude. Analysis of these variations can provide an indication of machine condition, which may be trended over time to provide an early warning of machine deterioration or process alteration.

Motor current signature analysis is one of the moderately complex and expensive predictive techniques. The complexity stems in large part from the relatively subjective nature of interpreting the spectra, and the limited number of industry-wide historical or comparative spectra available for specific applications. This type of analysis is typically limited to mission critical applications and/or those with life/health/safety implications.

\subsubsection{System Applications}

- Stem packing degradation

- Incorrect torque switch settings

- Degraded stem or gear case lubrication

- Worn gear tooth wear

- Restricted valve stem travel

- Obstructions in the valve seat area

- Disengagement of the motor pinion gear
- Improper seal/packing installation

- Improper bearing or gear installation

- Inaccurate shaft alignment or rotor balancing

- Insulation deterioration

- Turn-to-turn shorting

- Phase-to-phase shorting

- Short circuits

- Reversed or open coils.

\subsubsection{Equipment Cost/Payback}

As indicated earlier, motor analysis equipment is still costly and generally requires a high degree of training and experience to properly diagnosis equipment problems. A facility with a large number of motors critical to process throughput may find that ownership of this technology and adequately trained personnel more than pays for itself in reduced downtime, overtime cost, and motor inventory needs. Smaller facilities may find utilization of one of the many contracted service providers valuable in defining and maintaining the health of the motors within their facility. As with most predictive maintenance contract services, cost will range from $\$ 600$ to $\$ 1,200$ per day for on-site support. Finding a single motor problem whose failure would result in facility downtime can quickly offset the cost of these services.

\subsubsection{Training Availability}

Training for motor analysis is usually highly specialized and typically available through a variety of system manufacturers and vendors. 


\subsubsection{References/Resources}

The references and resources provided below are by no means all-inclusive. The listed organizations are not endorsed by the authors of this guide and are provided for your information only. To locate additional resources, the authors of this guide recommend contacting relevant trade groups, databases, and the world-wide web.

\subsubsection{Equipment Resources}

Computational Systems, Inc./

Emerson ProcessManagement

835 Innovation Drive

Knoxville, TN 37932

Telephone: (865) 675-2110

Fax: (865) 218-1401

Chauvin Arnoux ${ }^{\circledR}$, Inc. d.b.a. $\mathrm{AEMC}^{\circledR}$ Instruments 200 Foxborough Boulevard Foxborough, MA 02035

Telephone: (508) 698-2115 or (800) 343-1391

Fax: (508) 698-2118

Email: sales@aemc.com

\subsubsection{Service Companies}

Industrial Technology Research Bethlehem, PA - Pittsburgh, PA Cleveland, $\mathrm{OH}$ - Detroit, MI - Chicago, IL Charleston, SC - Hamilton, ONT Telephone: (610) 867-0101 or (800) 360-3594 Fax: (610) 867-2341

\subsubsection{Internet Site Resources}

www.mt-online.com

- Technology overview

- Technology vendors

- Industry articles

\author{
AVO International \\ 4651 S. Westmoreland Road \\ Dallas, TX 75237-1017 \\ Telephone: (800) 723-2861 \\ Fax: (214) 333-3533 \\ Baker Instrument Company \\ 4812 McMurry Avenue \\ Fort Collins, CO 80525 \\ Telephone: (970) 282-1200 or (800) 752-8272 \\ Fax: (970) 282-1010
}




\subsection{Performance Trending}

\subsubsection{Introduction}

In addition to the general preventive maintenance we perform, or have performed on our vehicles, many of us log and trend important parametric information related to the health of our vehicles and use this information to determine maintenance needs. We calculate and trend our cars mileage per gallon of gas. We track engine temperature and oil pressure. We track oil usage. This information is then used to define when vehicle maintenance is required. Maintenance activities such as tune-ups, thermostat replacement, cooling system flushes, belt replacements, oil seal replacements, etc., may all be originally stimulated by vehicle parametric information we trend.

Using this performance trending approach can also be a valuable tool in maintaining the health and operational performance of the components in our facilities/plants. By logging and trending the differential pressure across a supply or discharge filter in the HVAC system, we can determine when filter replacement is required, rather than changing the filter out at some pre-defined interval (preventive maintenance). Logging and trending temperature data can monitor the performance of many heat exchangers. This information can be used to assist in the scheduling of tube cleaning. It may also serve as an indication that flow control valves are not working properly or chemical control measures are inadequate. Perhaps a decrease in heat exchanger performance, as seen by a change in delta-temperature, is due to biological fouling at our cooling loop pump suction. An increase in boiler stack temperature might be an indication of tube scaling. We may need to perform tube cleaning and adjust our chemistry control measures. Changes in combustion efficiency may be indicative of improperly operating oxygen trim control, fuel flow control, air box leakage, or tube scaling.

The key idea of performance trending is that much of the equipment installed in our facilities is already provided with instrumentation that can be used to assist in determination of the health/ condition of the related component. Where the instruments are not present, installation of a pressure, temperature, or current sensing data loggers can be relatively straight forward and rather inexpensive. A particular good resource to better understand portable meters or data loggers and their vendors is the report titled Portable Data Loggers Diagnostic Tools for Energy-Efficient Building Operations (PECI 1999).

\subsubsection{How to Establish a Performance Trending Program}

One of the first steps of any predictive maintenance program is to know what equipment exists in your facility. First, generate a master equipment list, then prioritize the equipment on the list to define which pieces of equipment are critical to your facility's operation, important to personnel safety, or can have a significant budget impact (either through failure or inefficient operation).

Evaluate what parametric data should/could be easily collected from installed or portable instrumentation to provide information related to the condition/performance of the equipment on the master list based on your equipment prioritization.

Determine what, if any, of the defined data are already collected. Evaluate if any related parametric information is currently being tracked and if that information provides information regarding the condition or efficiency of a component or system. Terminate the collection of information not useful in the evaluation of a component's condition/efficiency unless required by other administrative requirements. 
Define and install instrumentation not currently available to monitor a critical component's condition/efficiency.

Log the information at some frequency defined by plant engineering or operational staff. For example, the frequency may be every 4 hours while operating or may simply be a single reading after reaching steady-state conditions, depending on the data evaluation needs.

Provide collected data to individual with knowledge and background necessary to properly trend and evaluate it.

\subsubsection{System Applications}

Generally, any plant component with installed, or easily installed, instrumentation useful in evaluating the components condition, operation, or efficiency can be trended. Information can also be obtained using portable instrumentation, (e.g., an infrared thermometer or a variety of stand-alone data logging devices). Some general applications might be:

- Heat exchangers

- Filters

- Pumps

- HVAC equipment

- Compressors

- Diesel/gasoline engines

- Boilers.

\subsubsection{Equipment Cost/Payback}

The cost to establish an effective trending program is minimal and can provide one of the largest returns on dollars expended. Most plants have much of the instrumentation needed to gain the parametric information already installed. Today's instrumentation offers many cost-effective opportunities to gather information without having to incur the expense of running conduit with power and signal cabling. The information gatherers are generally already on the payroll and in many cases, already gathering the needed information to be trended. For the most part, establishing a trending program would require little more than using the information already gathered and currently collecting dust. When portable data-logging systems are purchased, the payback for the little extra money spent is quickly recovered in increased machine efficiency and decreased energy cost.

\subsubsection{Training Availability}

Training for performance trending is very application-specific. Most trending is done via preinstalled system sensors, an existing building automation system and/or the use of portable data loggers. All of these systems will function differently with education and training typically available through equipment vendors or distributors. 


\subsubsection{Case Studies}

Operational Efficiency Opportunity Using Data Logger Data to Validate Boiler Operation (FEMP 2007)

Objective: Use data logger (5-minute run-time, time-series data) to validate proper boiler operation.

Situation: Federal facility with boiler heating/process loads. End-use run-time data logger installed. Data reported are from peak-season loading conditions.

Findings: Reviewing the 5-minute run-time data (data collected with stand-alone magnetic field enabled logger placed near boiler combustion-air blower motor) reveals excessive cycling of boiler; Figure 6.7.1 presents these data. A bar in the figure rising from 0 to 1 indicates the boiler cycling "on," the bar returning from 1 to 0 indicates the boiler cycling "off." Therefore, each bar in the graph represents one on/off cycle.

\section{Boiler Frequency Cycle Indicator}

"1" represents boiler-on event, "0" represents boiler-off event

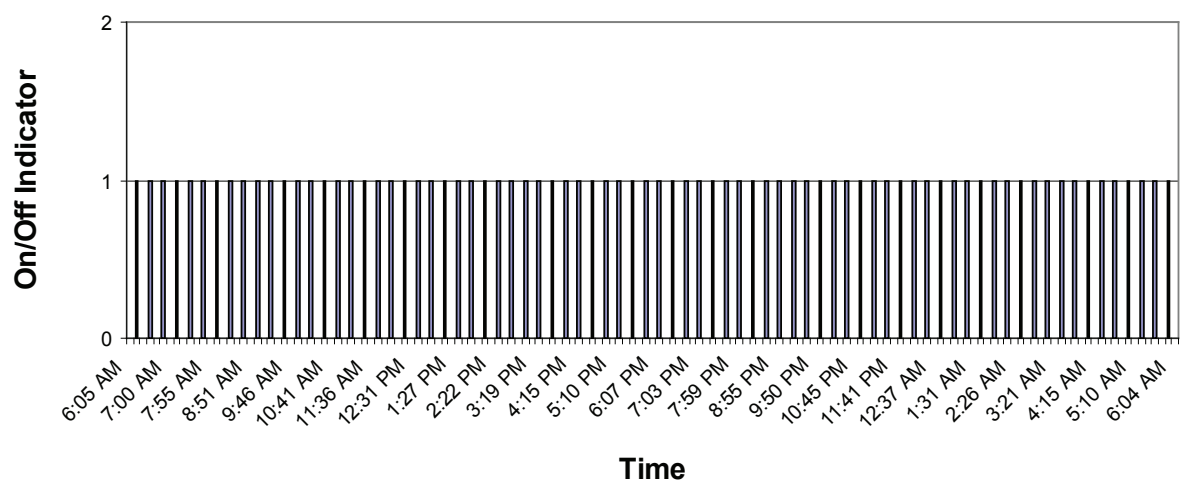

Figure 6.7.1. Boiler Cycling Frequency Data

Outcome: Processing these data reveals an average of 6.5 on/off cycles per hour - far in excess of the recommended 1-2, depending on load conditions. Further exploration uncovered gross boiler over-sizing due to partial decommissioning of building/process loads. The outcome recommendation includes installation of smaller, properly sized, and more efficient boiler to carry load.

\subsection{References}

FEMP. 2007. Metering Best Practices Guide: A Guide to Achieving Utility Resource Efficiency. DOE/EE0323. U.S. Department of Energy, Federal Energy Management Program, Washington, D.C.

NASA. 2000. Reliability Centered Maintenance Guide for Facilities and Collateral Equipment. National Aeronautics and Space Administration, Washington, D.C.

PECI. 1999. Portable Data Loggers Diagnostic Tools for Energy-Efficient Building Operations. Prepared for the U.S. EPA and U.S. DOE by Portland Energy Conservation, Incorporated, Portland, Oregon. 



\section{Chapter 7 Commissioning Existing Buildings}

\subsection{Introduction}

Commissioning of existing buildings is quickly becoming one of the most important topics in the building management arena. In the Federal Sector, commissioning has taken on new importance with the enactment of EISA 2007, whereby Federal facilities are required to be assessed for commissioning measures. In general, commissioning is the process of ensuring that a building performs according to its design intent and the needs of its owners and occupants (Anderson 1997). While additional research is needed to further pinpoint the costs and resulting benefits of commissioning new and existing buildings, numerous case studies have demonstrated resulting O\&M-related energy efficiency improvements on the order of 5\% to 30\% covering a wide range of building uses. The resulting simple payback periods are typically less than 2 years and often less than 0.5 year.

Ideally, the building commissioning process begins during the planning stages of a new building design or new equipment installation. The fact is that the vast majority of buildings have never been commissioned. Even today, with mounting evidence of resulting expected benefits, very few new buildings undergo a complete commissioning process. Instead, new buildings are typically turned over to the building operating staff with operating problems in place, incomplete documentation, and minimal operator training for building-specific equipment. These same problems occur with major equipment installations. Then, during building and equipment operations phases, the overall efficiency of mechanical systems degrades as sensors drift, short-term adjustments are made, tenant needs change, and so on. Even after adjustments are made, perhaps through a one-time recommissioning effort, performance degradation is continuous.

Commissioning of existing buildings (and more specifically the energy-consuming mechanical/ electrical systems within them and control systems that monitor them) is critical to ensure energyefficient operation. Additional benefits include extended equipment life, increased tenant satisfaction through improved space comfort, improved indoor air quality, and fewer O\&M emergency calls.

Table 7.1.1 below (adapted from FEMP 2006) provides guidance on commissioning types and their suitability for different facility situations.

Table 7.1.1. Commissioning type consideration by facility condition

\begin{tabular}{|l|l|}
\hline \multicolumn{2}{|c|}{ What Type of Commissioning Should I Choose? } \\
\hline My Building is... & Consider... \\
\hline ...new or going to be undergoing major renovation. & $\begin{array}{l}\text { Commissioning - ideal for new construction or major renovation, } \\
\text { and best implemented through all phases of the construction } \\
\text { project. }\end{array}$ \\
\hline $\begin{array}{l}\text {...old and expensive to operate and experiencing a } \\
\text { lot of equipment failures. }\end{array}$ & $\begin{array}{l}\text { Retro-commissioning - ideal for older facilities that have never } \\
\text { been through a commissioning process. }\end{array}$ \\
\hline $\begin{array}{l}\text {...relatively new and was commissioned during } \\
\text { construction, but energy use has been increasing. }\end{array}$ & $\begin{array}{l}\text { Re-commissioning - ideal to "tune-up" buildings that have already } \\
\text { been commissioned, bring them back to their original design intent } \\
\text { and operational efficiency. }\end{array}$ \\
\hline $\begin{array}{l}\text {...large and complex, has a metering system and a } \\
\text { preventive maintenance program, but still has high } \\
\text { energy use and tenant complaints. }\end{array}$ & $\begin{array}{l}\text { Continuous Commissioning - ideal for facilities with building } \\
\text { automation system (BAS), advanced metering systems, and well-run } \\
\text { O\&M organizations. }\end{array}$ \\
\hline
\end{tabular}

O\&M Best Practices Guide, Release 3.0 


\subsection{Definitions}

There are a number of commissioning approaches that can be applied to building mechanical/ electrical equipment and systems.

New Building Commissioning: New building commissioning $(\mathrm{Cx})$ is a means to ensuring through design reviews, functional testing, system documentation, and operator training that systems and equipment in new buildings are operating properly.

Recommissioning: Recommissioning $(\mathrm{RCx})$, which is sometimes referred to as "retrocommissioning," is the practice of commissioning existing buildings - testing and adjusting the building systems to meet the original design intent and/or optimize the systems to satisfy current operational needs. RCx relies on building and equipment documentation, along with functional testing to optimize performance.

Continuous Commissioning ${ }^{\mathrm{TM}}$ : Continuous commissioning ${ }^{\mathrm{TM}}$ refers to a commissioning approach that is integrated into a facility's standard O\&M program. As such, activities in support of the continuous commissioning ${ }^{\mathrm{TM}}$ effort are completed on a regular basis, compared to recommissioning approaches that tend to be distinct events. The continuous commissioning ${ }^{\mathrm{TM}}$ (CC) approach developed by the Energy Sciences Laboratory at Texas A\&M University is a formalized continuous commissioning ${ }^{\mathrm{TM}}$ approach and is defined as "an ongoing process to resolve operating problems, improve comfort, optimize energy use and to identify retrofits for existing commercial and institutional buildings and central plant facilities" (Texas A\&M 2002). Continuous commissioning ${ }^{\mathrm{TM}}$ is the most costly existing building commissioning approach due to necessary allocations of staff and equipment; however, the higher costs can work to identify equipment inefficiencies as they occur, allowing for quick remediation, greater energy and cost savings, and better building services. By definition, continuous commissioning ${ }^{\mathrm{TM}}$ works to ensure more stable building operations over time than the recommissioning approaches.

Value Recommissioning: Value recommissioning ( $\mathrm{VCx})$ is the lowest cost option that focuses on the most common opportunities, ideally incorporating them into daily operating procedures. $\mathrm{VCx}$ is the least comprehensive and requires the least specialized skill set. VCx concentrates on the most common opportunities that typically carry the shortest payback periods. Therefore, VCx is best applied in buildings where resources for structured recommissioning or continuous commissioning ${ }^{\mathrm{TM}}$ programs are not available. In addition to realizing highly cost-effective energy savings, tracking benefits (i.e., energy savings, cost savings, and reduced occupant complaints) of VCx activities can be helpful in developing justifications for funding requests of the more robust commissioning approaches. 


\begin{tabular}{|c|c|c|c|c|}
\hline \multicolumn{5}{|c|}{ Summary of Commissioning Approaches } \\
\hline $\begin{array}{l}\text { Commissioning } \\
\text { Approach }\end{array}$ & Primary Objectives & Relative Costs & Benefits & Best Applications \\
\hline $\begin{array}{l}\text { New building or } \\
\text { new equipment } \\
\text { commissioning }\end{array}$ & $\begin{array}{l}\text { Ensure new equipment } \\
\text { is correctly installed } \\
\text { and operating correctly. }\end{array}$ & $\begin{array}{l}\text { Costs vary by size of } \\
\text { building and complexity } \\
\text { of systems: } \$ 0.50 \text { to } \\
\$ 3.00 \text { per square foot } \\
\text { (Welker 2003). }\end{array}$ & $\begin{array}{l}\text { Owners know equipment } \\
\text { operates correctly and as } \\
\text { intended at acceptance. } \\
\text { Resulting documentation } \\
\text { and training helps establish } \\
\text { correct building operations } \\
\text { and are useful to future } \\
\text { recommissioning activities. }\end{array}$ & $\begin{array}{l}\text { The commissioning } \\
\text { process should be } \\
\text { applied to new } \\
\text { buildings and } \\
\text { equipment at the } \\
\text { beginning of the } \\
\text { project-planning phase. }\end{array}$ \\
\hline $\begin{array}{l}\text { Recommissioning } \\
(\mathrm{RCx})\end{array}$ & $\begin{array}{l}\text { Adjust equipment } \\
\text { to provide services } \\
\text { within equipment } \\
\text { specifications while } \\
\text { also meeting current } \\
\text { mission/tenant } \\
\text { operating requirements. }\end{array}$ & $\begin{array}{l}\$ 0.05 \text { to } \$ 0.40 \text { per } \\
\text { square foot. Additional } \\
\text { data are needed to help } \\
\text { pinpoint costs based on } \\
\text { specific building features } \\
\text { and the scope of the } \\
\text { RCx effort. }\end{array}$ & $\begin{array}{l}\text { Verifies and restores } \\
\text { equipment operation in } \\
\text { accordance with original } \\
\text { accordance with original } \\
\text { design intent and/or to } \\
\text { meet current operating } \\
\text { requirements. }\end{array}$ & $\begin{array}{l}\text { Since RCx is a point- } \\
\text { in-time event, best } \\
\text { applications are for } \\
\text { buildings/systems } \\
\text { that have not been } \\
\text { adequately maintained } \\
\text { (recommissioned) } \\
\text { for some period of } \\
\text { time, especially those } \\
\text { systems that have } \\
\text { not been adapted to } \\
\text { accommodate changing } \\
\text { space/tenant needs. }\end{array}$ \\
\hline $\begin{array}{l}\text { Continuous } \\
\text { Commissioning }^{\mathrm{TM}}\end{array}$ & $\begin{array}{l}\text { Integrate } \\
\text { comprehensive } \\
\text { commissioning } \\
\text { approach into on-going } \\
\text { facility O\&M program. }\end{array}$ & $\begin{array}{l}\text { Highest cost option for } \\
\text { existing buildings and } \\
\text { systems. }\end{array}$ & $\begin{array}{l}\text { Identifies and addresses } \\
\text { problems as they occur. } \\
\text { Energy savings persist. } \\
\text { Should generate greatest } \\
\text { energy savings. }\end{array}$ & $\begin{array}{l}\text { Continuous } \\
\text { commissioning }^{\mathrm{TM}} \text { is } \\
\text { the preferred approach } \\
\text { when resources (staffing } \\
\text { and equipment) are } \\
\text { available. }\end{array}$ \\
\hline $\begin{array}{l}\text { Value } \\
\text { Recommissioning } \\
\text { (VCx) }\end{array}$ & $\begin{array}{l}\text { Focus on the most } \\
\text { frequently available- } \\
\text { recommissioning/ } \\
\text { retrocommissioning } \\
\text { opportunities with } \\
\text { highest payback as part } \\
\text { of daily O\&M. }\end{array}$ & $\begin{array}{l}\text { Lowest cost option for } \\
\text { existing buildings and } \\
\text { systems. }\end{array}$ & $\begin{array}{l}\text { Can be completed by } \\
\text { in-house staff. Minimal } \\
\text { up-front or on-going } \\
\text { investment required. }\end{array}$ & $\begin{array}{l}\text { VCx can be applied } \\
\text { in virtually any } \\
\text { building. Can be } \\
\text { used to demonstrate } \\
\text { benefits of larger, more } \\
\text { aggressive existing } \\
\text { building commissioning } \\
\text { program. }\end{array}$ \\
\hline
\end{tabular}




\subsection{Typical Findings from Existing Building Commissioning}

Many case studies of existing building commissioning efforts have been published over the years. A review of case studies for multiple buildings published by Portland Energy Conservation, Inc. (PECI), Texas A\&M University, proceedings from National Building Commissioning Conferences, and FEMP Assessments of Load and Energy Reduction Techniques (ALERT) is useful in identifying measures most typically available in commercial building spaces. The most frequently cited measures/ opportunities are:

- Adjust reset and set-back temperatures and temperature settings - Settings are often adjusted over time based on personal preferences, to compensate for inadequate system operation, or to achieve energy savings. In addition, sensors require periodic recalibration.

- Staging/sequencing of boilers, chillers, and air handling units - Equipment should be operated in the most efficient combination of chillers, boilers, and fans at varying load conditions.

- Adjust and repair dampers and economizers - Malfunctioning or poorly tuned dampers (including seals, actuators, and linkages) and economizers result in (1) increased supply air fan energy in the closed position or require additional air heating and cooling when open too much, (2) undesired building operating conditions due to lack of outside air, and (3) premature equipment degradation and replacement.

- Modify control strategies for standard hours of operation - Motors, pumps, fans, and air handlers often operate on a $24 / 7$ schedule even though not required by either the building tenants or the building operating plan.

- Eliminate simultaneous heating and cooling - Heating and cooling systems for the same space can compete against each other due to improper setpoints.

- Air and water distribution balancing and adjustments - Systems require rebalancing due to drift and changing building/workspace mission and/or tenant requirements.

- Verify controls and control sequencing including enabling and re-enabling automatic controls for setpoints, weekends, and holidays. Verify that overrides are released.

\subsection{Costs and Benefits}

While there are many case studies available on various building commissioning approaches, these case studies do not present costs and measured savings in a uniform way. In addition, there are very few assessments of existing building commissioning efforts containing a "large" building sample from which generalized cost and benefit conclusions can be drawn. This prevents us from being able to pinpoint costs for the various commissioning approaches, especially in 2004 dollars. We are, however, able to draw from the case studies trends in the costs and, in the case of existing building commissioning, the realized energy and/or cost savings.

\subsubsection{New Building Commissioning Costs and Benefits} (Welker 2003)

While O\&M is typically thought of as being limited to existing buildings, it is important for building planners, designers, and O\&M managers to consider O\&M throughout the new building process. One important action is ensuring adequate resources are lined up for the building once it 
is operating. Another highly important action is commissioning the new building. New building commissioning begins during the planning process and runs through final acceptance. The primary goals of new building commissioning efforts are to

- ensure design intent criteria and the owner's requirements are documented and met

- ensure systems and equipment are fully functional and operate in an integrated manner

- provide documentation on systems and equipment that will be

- verify O\&M staff training needs are met.

The cost of new building commissioning varies based on several factors including the building's use, which determines complexity of mechanical systems and size. Typical new building commissioning provider's fees range from $\$ 0.50$ per square foot $\left(/ \mathrm{ft}^{2}\right)$ for "simple" buildings (such as some spaces and classrooms) to $\$ 3.00 / \mathrm{ft}^{2}$ for complex buildings such as hospitals and laboratories. Economies-of-scale do apply. These cost ranges are summarized in Figure 7.4.1.

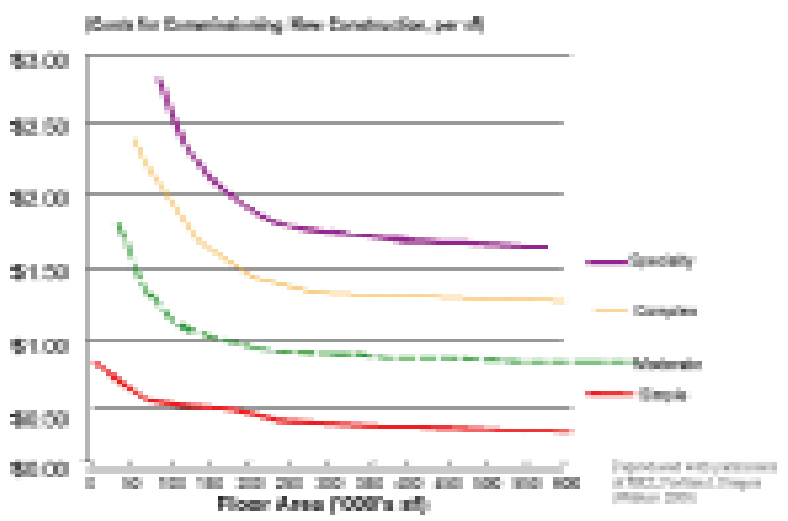

Figure 7.4.1. Construction Phase CX costs

\subsubsection{Existing Building Commissioning Costs and Benefits}

Of the numerous publications reporting or assessing existing building commissioning efforts, three contain significant building samples (see "Summary of Recommissioning Case Study Publications"). These publications, all of which rely on recommissioning efforts from the 1990s, show a range of resulting costs and savings. The reported average cost to recommission is usually in the range of $\$ 0.05 / \mathrm{ft}^{2}$ to $\$ 0.40 / \mathrm{ft}^{2}$. The simple payback period on these efforts is usually less than 2 years and quite frequently less than 0.5 year. Additional reported benefits include reports of improved office comfort, reduced occupant complaints, improved indoor air quality, extended equipment life, reductions in equipment failure, and improved building documentation.

\section{The Cost Effectiveness of Commercial Building Commissioning: A Meta-Analysis of Energy and Non-Energy Impacts in Existing Buildings and New Construction in the United States}

A comprehensive study completed in late 2004 (LBNL 2004) was designed as a "meta-analysis" to compile and synthesize extensive published and unpublished data from buildings commissioning projects undertaken across the United States over the past two decades, establishing the largest available collection of standardized information on commissioning experience. Data were analyzed from 224 buildings across 21 states, representing 30.4 million square feet of commissioned floor area 73 percent in existing buildings and 27 percent in new construction). The goal of this program was to develop a detailed and uniform methodology for characterizing, analyzing, and synthesizing the results. For existing buildings, the analysis found median commissioning costs of $\$ 0.27 / \mathrm{ft}^{2}$, whole-building energy savings of 15 percent, and payback times of 0.7 years. For new construction, median commissioning costs were $\$ 1.00 / \mathrm{ft}^{2}(0.6$ percent of total construction costs), yielding a median payback time of 4.8 years (excluding quantified non-energy impacts). with an average simple payback period of 0.7 year. Average savings varied significantly for the building use types $-\$ 1.26 / \mathrm{ft}^{2} / \mathrm{yr}$ for medical research buildings down to $\$ 0.17 \mathrm{ft}^{2} / \mathrm{yr}$ for school buildings. 


\subsection{Tracking Commissioning Benefits}

As with any investment, it is important to develop metrics for tracking and persistence. In the case of building commissioning, these metrics need to be implemented and tracked on a regular basis for assurance of performance savings. Below is a compilation of commissioning metrics (LBNL 2004) useful for persistence tracking.

\section{Building Characteristics and Demographics}

- Building type (using DOE/CBECS definitions), vintage, location

- Year building commissioned

- Reasons for commissioning, deficiencies identified, measures recommended

\section{Energy utilization intensity (use or savings)}

- Electricity: $\mathrm{kWh} /$ building-year, $12 \mathrm{kWh} / \mathrm{ft}^{2}$-year

- Peak electrical power: $\mathrm{kW} /$ building; $\mathrm{W} / \mathrm{ft}^{2}$

- Fuel: MMBtu/building; kBtu/ft²-year

- Purchased thermal energy: MMBtu/building-year; kBtu/ft²-year

- Total energy: MMBtu/building-year; $\mathrm{kBtu} / \mathrm{ft}^{2}$-year13

- Energy cost: \$/building-year; $\$ / \mathrm{ft}^{2}$-year (based on local or standardized energy prices; nominal [not corrected for inflation] and inflation-corrected to a uniform year's currency)

- Percent energy use savings (total and by fuel)

- Percent total energy cost savings

- Persistence index: Post-commissioning energy use in a given year/pre-commissioning energy use (unit-less ratio)

\section{Commissioning cost}

- $\$$ /building; $\$ / \mathrm{ft}^{2}$ (based on nominal costs or, preferably, inflation-corrected to a uniform year's currency levels. Can be gross value or net, adjusting for the quantified value of non-energy impacts)

- Commissioning cost ratio, for new construction (commissioning cost/total building or renovation construction cost, \%)

- Costs are tabulated separately for the commissioning agent and other parties

- Allocation of costs by source of funds (building owner, utility, research grant, other)

- Total building construction cost (denominator for commissioning cost ratio) 


\section{Cost effectiveness}

- Undiscounted payback time (commissioning cost/annualized energy bill savings). This indicator is preferably normalized to standard energy prices; costs and benefits are inflation corrected to a uniform year's currency levels

\section{Deficiencies and measures}

- Deficiencies/building; Deficiencies/100 kft ${ }^{2}$

- Measures/building; Measures/100 kft²

- Unique codes to identify combinations of deficiencies and measures (described in more depth below) [see Measures Matrix]

\section{Commissioning scope}

- Presence of pre-defined "steps" (yes/no), with different criteria for existing buildings and new construction

\section{Non-energy impacts}

- Type

- Quantified (when possible), \$/building-year; $\$ / \mathrm{ft}^{2}$-year [can be positive or negative] - one time or recurring

\subsection{The Commissioning Process}

A four-step process for existing building commissioning is often recommended (Haasl and Sharp 1999).

Step 1: Planning. The planning step includes developing and agreeing upon the overall commissioning objectives and strategies, assembling the project team, and compiling and perusing building and equipment documentation. Examples of objectives could be a desire to optimize building operations to reduce operating costs, address complaints from occupants regarding air quality or comforts, create a model facility, and improve facility $O \& M$ including reducing emergency trouble calls. Regarding the commissioning team formation, considerations in forming the team could include contracted or in-house staff, level of effort required, desired and necessary qualifications, availability and use of resident knowledge, and available funding resources.

Step 2: Investigation. During this step the site assessment is completed, monitoring and functional test plans are developed and executed, test results are analyzed, a master list of deficiencies is compiled, and recommendations for improvements, including estimates of energy and cost savings, are generated and presented for consideration.

Step 3: Implementation. Accepted recommendations from the investigation step are put into place in the implementation step. Actions include making repairs and improvements, retesting and re-monitoring for results, fine-tuning improvements as needed, and revising estimates energy and cost savings. 
Step 4: Hand-off and Integration. Final documentation of the commissioning effort describing the process, individuals, systems information, and actions taken is developed in this step. Also developed is a plan for future commissioning efforts. Items addressed by the commissioning plan should include recommended procedures for specific building equipment, frequency of testing, analysis of results, periodic reporting, identification of key players, and budget requirements.

\subsection{Commissioning Provider Qualifications}

The question of who should complete the recommissioning effort can be addressed once the recommissioning objectives and budget have been established. Some facilities have the in-house capability to successfully recommission their own equipment, but most do not. Here are some qualifications to consider when selecting a commissioning provider:

- Experience in recommissioning similar types of buildings by use and/or by design

- Experience in recommissioning similar types of building systems

- Experience in providing O\&M training

- Specialized skills to consider include

- Air/water testing and balancing

- Design, installation, and/or troubleshooting of DDCs, pneumatic, and EMCSs

- Demonstrated skills in working with metering and testing equipment/instrumentation.

- Relevant professional licenses and certifications (e.g., professional engineer)

\subsection{The Future of Building Commissioning}

The building commissioning field has grown markedly in the last five years. The data to date have shown tremendous benefits across the board when commissioning has been performed. While much more data are needed in order to fully verify and promote the energy and cost benefits, commissioning intuitively makes great business sense. As the awareness to the energy, cost and operational benefits is raised, we should expect to see the way commissioning is completed to become more effective and reliable and working toward becoming a regular part of the building operations process. Expect some of the following to help move the commissioning process forward.

- Chronicled experiences will lead to better estimates of costs and potential savings.

- Statements of work will become more standardized.

- New functional testing protocols will be developed and made widely available.

- New automated diagnostic technologies will become critical components in establishing continuous commissioning ${ }^{\mathrm{TM}}$ programs.

- Certified commissioning providers. 


\title{
7.9 Case Studies
}

\subsubsection{System Shutdown During Unoccupied Periods}

\author{
(Texas A\&M 2002)
}

The Figure 7.9.1 presents the measured building electricity consumption, excluding chiller consumption, before and after implementation of air-handling units (AHUs) and office equipment turn-off on nights and weekends in the Stephen F. Austin Building in Austin, Texas.

The Stephen F. Austin Building has 470,000 square feet of floor area with 22 dual duct AHUs. During the first phase of implementation, 16 AHUs were turned off from midnight to 4 a.m. weekdays and weekends. During the second phase, 22 AHUs were turned off from 11:00 p.m. to 5 a.m. during weekdays and weekends. During the second phase, all occupants were asked to turn off office equipment when they leave their office. The measured results show that the nighttime whole building electricity use decreased from $1,250 \mathrm{~kW}$ to $900 \mathrm{~kW}$ during the first phase. During the second phase, the nighttime minimum electricity decreased to $800 \mathrm{~kW}$. It was observed that the daily peak electricity consumption after night shutdowns began is significantly lower than the base peak. For example, the lowest peak during the second phase is $1,833 \mathrm{~kW}$, which is $8 \%$ lower than the base peak. The lower electricity peak indicates that some office equipment remained off during the daytime or employees were more conscientious in turning off lights and equipment when they left the office. The annual energy cost saving, including electricity, heating and cooling, was determined to be $\$ 100,000 /$ yr using measured hourly data.

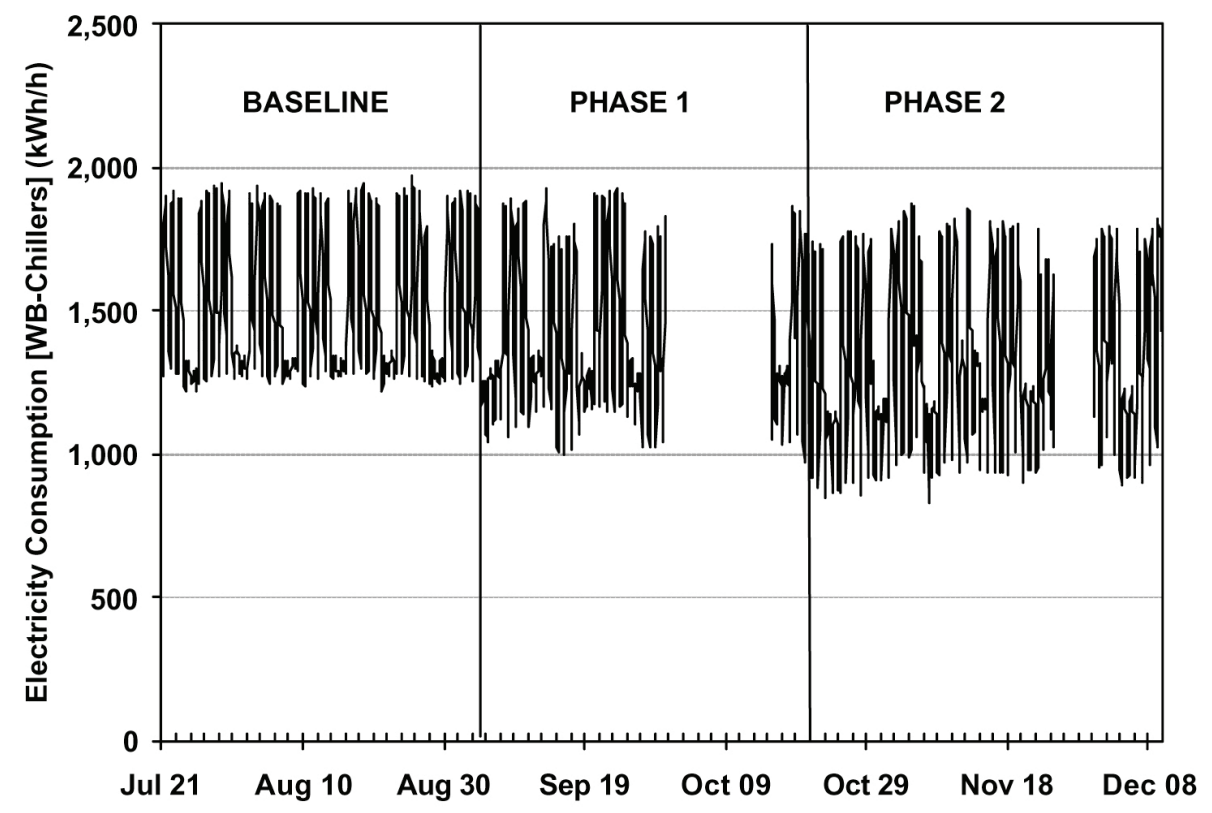

Figure 7.9.1. Whole-building electricity use before and after night shutdown program. Data gaps were periods when data were not available. Average nightime savings is $350 \mathrm{~kW}(1,250 \mathrm{~kW}-900 \mathrm{~kW})$. 


\subsubsection{In-House Recommissioning at a DOE National Laboratory}

The William R. Wiley Environmental Molecular Sciences Laboratory (EMSL) at the Pacific Northwest National Laboratory (PNNL) in Richland, Washington, is a 200,000-square-foot national scientific user facility. In fiscal year (FY) 2000, the energy management team at PNNL recognized an opportunity to improve the performance of the laboratory and reduce energy use and costs through recommissioning. Results: In FY 2002, the estimated resulting annual energy savings of $27 \%$ and annual energy cost savings (avoidance) of $35 \%$, or $\$ 173,735$, versus expected consumption and cost. With a total investment of approximately $\$ 125,000$, this retrocommissioning effort had a simple payback of well less than 1 year.

The energy performance for PNNL's EMSL building is shown in Figure 7.9.2.

The PNNL team followed the basic four-step commissioning approach. During the planning step, the team of in-house staff with experience in equipment operation, energy management, and engineering was assembled and overall objectives and strategies were agreed upon.

In the investigation step, a list of potential energy efficiency measures (EEMs) for the building was developed, the building systems were evaluated, cost estimates for corrective actions were generated, and opportunities prioritized. In developing the list of potential EEMs, the DOE Industrial Assessment Center (www.iac.rutgers.edu/database) served as a starting point.

During the implementation step, the implementation budget was finalized and occupant approvals obtained before changes were put into effect. EEMs deemed easy to complete, measure, and most likely to succeed were the first to be addressed. Results of these initial actions were then used to build-up credibility for the recommissioning approach and gain support to accomplish the full range of EEMs. Completed EEMs were monitored for results with readjustments made as necessary.

For the hand-off and integration step, PNNL has continued the recommissioning effort with activities such as monitoring building energy data, periodic review of operational changes, occupant and operator feedback, and monthly update reports. On-going monitoring of building performance helps to ensure that retrocommissioned building systems continue to operate in their optimized state and energy savings continue to be realized.

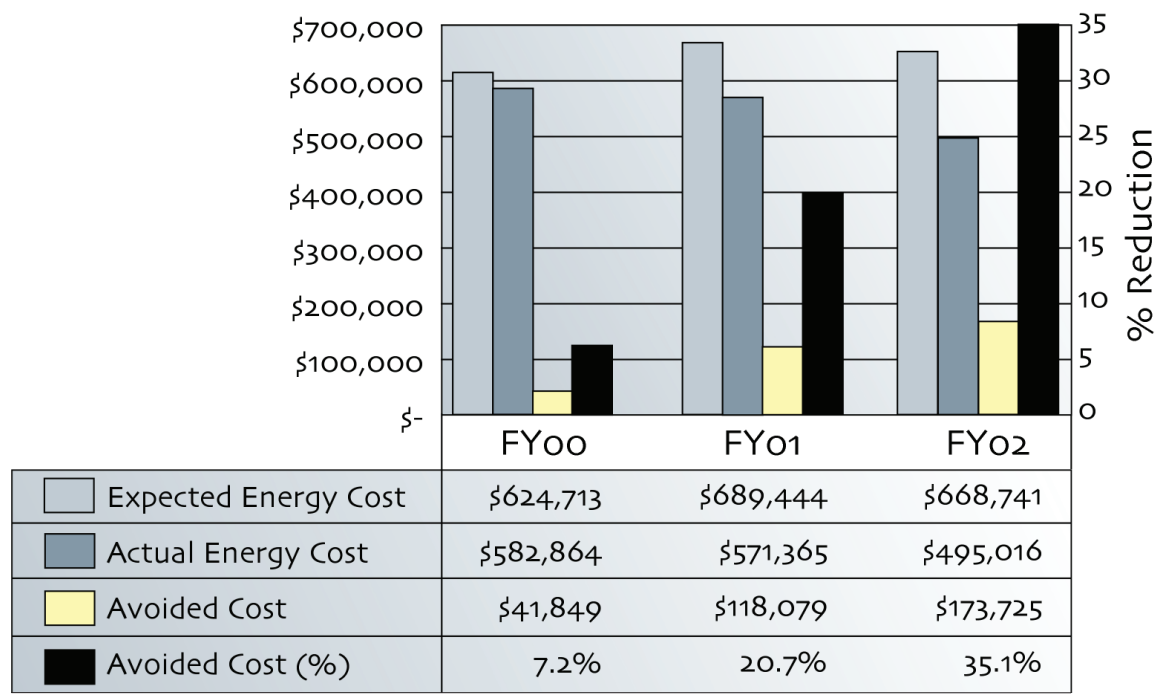

Figure 7.9.2. PNNL EMSL building energy performance by fiscal year (FY) 
Roughly 200 low- and no-cost EEMs were put into place at EMSL. Examples of completed EEMs include

- HVAC systems tuning including modifying chilled water temperature setpoints, ensuring correct operation of heating and cooling valves, optimizing chiller operations, checking and correcting supply fan return dampers, optimizing selected fan heating/cooling strategies, reducing dead band limits on digital controls, and resetting building air flows as appropriate.

- Adjusting temperatures by modifying heat recovery system operational temperatures, modifying supply fan air discharge temperatures, resetting zonal thermostats to better match the conditions of the space (occupied or unoccupied), and applying additional night setbacks.

- Adding holiday schedules to building controls.

- Designating staff members to review operational strategies for facility systems for operational efficiency improvement opportunities.

While the energy and cost savings of the EMSL recommissioning effort are on the high-end, reported benefits of retrocommissioning efforts at other buildings are also impressive. Commissioning of existing buildings is an option that needs to be considered for inclusion in any $O \& M$ program.

\section{Summary of Recommissioning Case Study Publications}

"What Can Commissioning Do for Your Building" (PECl 1997) compiled a database of 175 buildings commissioned between 1993 and 1997. Commissioned buildings were located in the United States and Canada, ranged in size from 12,500 to 2.2 million square feet, ranged in age from 1 (new) to 74 years with a median age of 6 years, and covered a range of end uses including office buildings, retail facilities, hospitals, schools, and laboratories. Data in the case study are compiled by building use and provide the following general findings: costs to commission ranged from $\$ 0.02$ to $\$ 2.88$ per square foot with a median cost per square foot ranging from $\$ 0.09$ to $\$ 0.31$ per square foot. Reported benefits include energy use and energy cost savings, extended equipment life, improved documentation, reduced equipment failure, increased staff training, improved temperature control, improved relative humidity control, reduced occupant complaints, air balancing, and improved indoor air quality (i.e., contaminant control, improved ventilation, and reduced carbon dioxide).

"Commissioning Existing Buildings" (Gregerson 1997) looks at the recommissioning of 44 existing buildings. Commissioning efforts occurred primarily between 1993 and 1996 ran from $\$ 0.05$ to $\$ 0.40$ per square foot with energy savings usually ranging from $5 \%$ to $15 \%$ and paybacks of less than 2 years. This analysis also reports that significant opportunities are often found in buildings with large deferred maintenance, energy intensive buildings, and medical and research facilities.

The "FEMP Continuous Commissioning Guidebook for Federal Energy Managers" (Texas A\&M 2002) provides a summary of results at 28 buildings continuously commissioned as part of the Texas LoanSTAR program. Building uses included hospitals, offices, and dual-use buildings with laboratories and offices or classrooms and offices. Measured annual energy savings averaged $\$ 0.64$ per square foot per year $\left(/ \mathrm{ft}^{2} / \mathrm{yr}\right)$ with an average simple payback period of 0.7 year. Average savings varied significantly for the building use types $-\$ 1.26$ / $\mathrm{ft}^{2} / \mathrm{yr}$ for medical research buildings down to $\$ 0.17 \mathrm{ft}^{2} / \mathrm{yr}$ for school buildings. 


\subsection{Additional Resources}

In addition to the references listed at the end of this chapter, there are many sources of information on existing and new building commissioning via the Internet.

The Portland Energy Conservation, Inc. website (http://www.peci.org) should be your first stop when searching for additional information on existing and new building commissioning. This website offers a wide variety of materials including guidance on the commissioning process, case studies, functional testing guides, links to other websites supporting commissioning activities, and more.

Other potential sources include your state energy office (some offer additional guidance, case studies, and possibly even funding/grants) and your servicing utilities as recommissioning is an excellent way to help meet demand side management initiative goals.

\subsection{References}

FEMP. 2006. Commissioning for Federal Facilities, A Practical guide to Building Commissioning, Re-commissioning, Retro-commissioning, and Continuous Commissioning. Developed by

U.S. Department of Energy and Enviro-Management and Research, Washington, D.C.

Gregerson, J. 1997. Commissioning Existing Buildings. TU-97-3, E Source, Boulder, Colorado.

Haasl, T. and T. Sharp. 1999. A Practical Guide for Commissioning Existing Buildings. ORNL/TM1999/34, Oak Ridge National Laboratory, Oak Ridge, Tennessee.

Lawrence Berkeley National Laboratory (LBNL). 2004. The Cost-Effectivenesss of Commercial-Building Commissioning: A Meta-Analysis of Energy and Non-Energy Impacts in Existing Buildings and New Construction in the United States. LBNL-56637. Can be accessed at http://eetd.lbl.gov/emills/PUBS/PDF/ Cx-Costs-Benefits.pdf.

PECI. 1997. What Can Commissioning Do For Your Building? Portland Energy Conservation, Inc., Federal Energy Management Program, U.S. Department of Energy, Washington, D.C.

Texas A\&M. 2002. Continuous Commissioning Guidebook for Federal Energy Managers. Federal Energy Management Program, U.S. Department of Energy, Washington, D.C. Available URL: https://wwwl.eere.energy.gov/femp/operations_maintenance/om_ccguide.html.

Welker, P. 2003. Building Commissioning. Energy 2003. Available URL: http://www.energy2003.ee.doe.gov/presentations/om/4-welker.pdf. 


\section{Chapter 8 Metering for Operations and Maintenance}

\subsection{Introduction}

Metering and sub-metering of energy and resource use is a critical component of a comprehensive $O \& M$ program. Metering for $O \& M$ and energy/resource efficiency refers to the measurement of quantities of energy delivered, for example, kilowatt-hours of electricity, cubic feet of natural gas, pounds of steam, and gallons of water. Metering may also involve identifying timesof-use for the various energy sources, the instantaneous demand for energy, as well as identify energy use for a collection of buildings, individual buildings, rooms, or specific equipment (e.g., a boiler, chiller, or motor).

Facility resource metering has a variety of applications for the Federal facility energy manager. The necessity to control costs, diagnose equipment malfunction, allocate usage and set resource efficiency goals are all increasingly important reasons for energy and water metering. Furthermore, with the escalating volatility of energy and water rates, these needs are becoming more important.

Historically, the Federal sector has lagged the private sector in metering applications. To this day at Federal sites, it is common to find one "master" meter serving loads representing a few buildings to well in excess of 500 buildings. These mastermetered accounts make it very difficult to manage energy use and are the primary driver for the legislation below.

Energy Policy Act 2005 (EPAct 2005): Section 103 of EPAct 2005 requires that "all Federal buildings shall, for the purposes of efficient use of energy and reduction in the cost of electricity used in such buildings, be metered ... to the maximum extent practicable." This requirement of law is the driving force behind the ongoing efforts of Federal agencies to meter their electric use. The primary metering requirements established in Section 103 of EPAct 2005, Energy Use Management and Accountability, ${ }^{1}$ are summarized by these key points:

- By October 1, 2012, all Federal buildings will be metered for electricity if practicable.

\section{Energy Policy Act of 2005, Public Law 109-58, Section 103}

By October 1, 2012, in accordance with guidelines established by the Secretary under paragraph (2) all Federal buildings shall, for the purposes of efficient use of energy and reduction in the cost of electricity used in such buildings, be metered. Each agency shall use, to the maximum extent practicable, advanced meters or advanced metering devices that provide data at least daily and that measure at least hourly consumption of electricity in the Federal buildings of the agency. Such data shall be incorporated into existing Federal energy tracking systems and made available to Federal facility managers.

- Installed meters will support the efficient use of energy and reduction in cost of electricity used.

- Advanced metering devices that provide interval data on at least a daily basis will be used subject to practicability.

\footnotetext{
${ }_{1}$ The metering requirements of EPAct 2005 amended Section 543 of the National Energy Conservation Policy Act (42 U.S.C. 8253).
} 
- Metered data will be used made available to Federal facility managers.

- Requires Federal agencies to submit to the Department of Energy (DOE) an implementation plan identifying personnel responsible for achieving metering requirements, and any determination by the agency that advanced meters or metering systems are not practicable in their specific situation.

Energy Independence and Security Act of 2007 (EISA 2007): Among other requirements EISA 2007 further strengthens the metering requirements of EPAct 2005 with the following language:

- Not later than October 1, 2016, each agency shall provide for equivalent metering of natural gas and steam, in accordance with guidelines established by the Secretary under paragraph (2).

In addition to energy, gas, and steam metering of water is encouraged to obtain data to support the water intensity reduction goals outlined in EISA 2007.

\subsection{Importance of Metering and the Business Case}

Metering provides the information that when analyzed allows the building operations staff to make informed decisions on how to best operate mechanical/electrical systems and equipment. These decisions will ultimately affect energy costs, equipment costs, and overall building performance.

Outside of single-building sites, there is limited building or equipment sub-metering within the Federal sector. Single building sites are metered for total use by their servicing utility providers, while multi-building sites usually rely on a master meter provided by the utilities at the utilities' points of entry to the site. Sites are billed by their utility providers based on the cumulative usage readings obtained from these utility, or revenue, meters over the billing period, usually about one month. But now consider the application of meters to individual buildings and even energy-intensive equipment that provides facility managers and operators real-time information on how much energy has been or is being used. This type of information can be used to assist in optimizing building and equipment operations, in utility procurements, in building energy budget planning and tracking, and so on.

It is important to keep in mind that meters are not an energy efficiency/energy conservation technology per se; instead, meters and their supporting systems are devices that provide building owners and operators data that can be used to:

- Reduce energy/utility use

- Reduce energy/utility costs

- Improve overall building operations

- Improve equipment operations.

How the metered data are used is critical to a successful metering program. Depending on the type of data collected, it can enable the following practices and functions:

- Verification of utility bills

- Comparison of utility rates

- Proper allocation of costs or billing of reimbursable tenants 
- Demand response or load shedding when purchasing electricity under time-based rates

- Measurement and verification of energy project performance

- Benchmarking building energy use

- Identifying operational efficiency improvement opportunities and retrofit project opportunities

- Usage reporting and tracking in support of establishing and monitoring utility budgets and costs, and in developing annual agency energy reports.

Ultimately, the business case for metering energy/utility use is based on the anticipated benefits to the site. Most of the metered data uses listed above will result in energy cost savings that can be used to justify the cost to purchase, install, and operate the metering system. The degree of cost savings realized depends on the unit cost of the energy/utility being saved and on the effectiveness with which the site analyzes the data and acts upon its findings/recommendations. But other potential benefits should also be considered as part of the metering business case. Examples can include

- Supporting efforts to attain Energy Star and/or LEED-EB (Leadership in Energy and Environmental Design - Existing Buildings) certifications

- Promoting tenant satisfaction by providing information that tenants find useful in managing their operations

- Prolonging equipment life (and reducing capital investment requirements) and improving its reliability by verifying the efficient operation of equipment

- Assessing the impact of utility price fluctuations prior to or as they happen, allowing sites/agencies to address budget shortfalls on a proactive basis.

\subsection{Metering Applications}

The uses for metered data vary from site-to-site and while not all sites have the same uses, some of the more common applications are presented below (Sydlowski 1993).

- Data Recording. Advanced meters can duplicate the conventional metering function of recording total consumption, plus offer enhanced functions such as time-of-use, peak demand, load survey, and power outage recording. For electric metering, advanced meters may also include recording of other electric characteristics, such as voltage, current, and power factor.

- Total Consumption. This is the most basic data recording function, which duplicates the standard kilowatt-hour of electricity $(\mathrm{kWh})$, hundred cubic feet volume (CCF) of gas, pounds (lb) of steam, or gallons (gal) of water consumed between meter readings.

- Time-of-Use Metering. Different rates can be charged for on-peak and off-peak time periods by accumulating the total consumption during operator-defined time windows. The time windows may vary during both time of day and weekday/weekend/holiday.

- Peak Demand Metering. Billing of many larger commercial and industrial customers is based on total consumption and the highest 15-, 30-, or 60-minute demand during the billing period. The peak demand may be reported as a single highest value, highest four values, or highest value during each hour (all peak demand values must be accompanied by an associated time stamp). 
- Load Survey (Profile or Time-Series Data). Energy consumption and conservation impact studies, as well as more complex analysis of system loading, require more detailed demand data. A load survey provides periodic consumption or demand data (in time increments of 1, 5, 15, 30, or 60 minutes).

- Monitoring and Control. A two-way communication link between a central station and customer site provides the opportunity for integrating some other utility functions into the metering functions. Meters can be programmed to detect and report by exception (e.g., report only when a fault is detected) for power outage, leak detection, and tamper detection. The meter can also dispatch control functions, such as remote service disconnect/reconnect, demand-side management (DSM) load control, and load scheduling.

- Load Control. Load control includes DSM control functions such as air conditioner and water heater load-shedding. The DSM load control could be triggered by a fixed algorithm operating independently or real-time central station control.

- Load Scheduling. This includes scheduled start and stop of equipment to minimize or shift load to take maximum advantage of the demand and time-of-use billing rate structures.

- Leak Detection. Continuous monitoring of gas or water usage or pressure can be used to detect leaks.

\subsection{Metering Approaches}

The four predominant levels of resource metering (EPRI 1996) are:

- One-time/spot measurement

- Run-time measurement

- Short-term monitoring

- Long-term monitoring

Each level has its own unique characteristics - no one monitoring approach is useful for all projects. Only long-term monitoring meets requirements set forth in EPAct 2005. A short description of each monitoring level is provided below.

\subsubsection{One-Time/Spot Measurements}

One-time measurements are useful in many "baseline" activities to understand instantaneous energy use, equipment performance, or loading. These measurements become particularly useful in trending equipment performance over time. For example, a spot measurement of a boiler-stack exhaust temperature, trended over time, can be very diagnostic of boiler efficiency.

One-time/Spot Measurement Advantages

- Lowest cost

- Ease of use

- Non-intrusive

- Fast results

One-time/Spot Measurement Disadvantages

- Low accuracy

- Limited application

- Measures single operating parameter

Related to energy performance, one-time measurements are useful when an energy efficiency project has resulted in a finite change in system performance. The amperage of an electric motor or lighting system taken before and after a retrofit can be useful to quantify system savings - assuming similar usage (hours of operation) before and after. 
Equipment useful in making one-time/spot measurements include clamp-on amp probes, contact and non-contact temperature devices, non-intrusive flow measurement devices, and a variety of combustion-efficiency devices. Most of these measurements are obtained and recorded in the field by the analyst.

\subsubsection{Run-Time Measurements}

Run-time measurements are made in situations where hours-of-operation are the critical variable. These measurements are prevalent where an energy efficiency project has impacted the use (i.e., hours of operation) of a device. Appropriate applications for run-time measurements include the run times of fans and pumps, or the operational characteristics of heating, cooling, or lighting systems.
Run-Time Measurement Advantages

- Low cost

- Relatively easy of use

- Non-intrusive

- Useful for constant-load devices

Run-Time Measurement Disadvantages

- Limited application

- Measures single operating parameter

- Requires additional calculations/ assumptions

Because run-time measurements do not capture the energy-use component of the system, these measurements are typically used in conjunction with one-time/spot measurements. Equipment useful in making run-time measurements include a variety of stand-alone (battery-operated) data loggers providing time-series record on run-time. Most of these devices are non-intrusive (i.e., the process or system is not impacted by their use or set-up) and are either optically triggered or take advantage of the electromagnetic characteristics of electrical devices. Run-time measurements are usually obtained in the field by the device, recorded to memory, and then downloaded by the analyst at a later date.

\subsubsection{Short-Term Measurements/ Monitoring}

Short-term monitoring combines both elements of the previous two levels into a time-series record of energy or resource use: magnitude and duration. Typically, short-term monitoring is used to verify performance, initiate trending, or validate energy efficiency improvement. In this level, the term of the monitoring is usually less than one year, and in most cases on the order of weeks to months. In the case of energy efficiency improvement validation, also known as measurement and verification, these measurements may be made for two-weeks prior and post installation of an efficiency improvement project. These data are then, using engineering and statistical methods, extrapolated over the year to report the annual impact.

Equipment useful in short-term monitoring includes a host of portable, stand-alone data loggers capable of multivariate time-series data collection and storage. Most of these data loggers accept a host of sensors including temperature, pressure, voltage, current flow, etc., and have standardized on input communications (e.g., 4 to 20 milliamperes or 0 to 5 volts). These loggers are capable of recording at user-selected intervals from fractions of a second, to hourly, to daily recordings. These systems usually rely on in-field manual downloading or, if available, modem and/or network connections. 


\subsubsection{Long-Term Measurements/ Monitoring}

Long-term monitoring also makes use of time-series recording of energy or resource use, but over a longer duration. Different from short-term use, this level focuses on measurements used in long-term trending or performance verification. The term is typically more than a year and quite often the installation is permanent.

Long-Term Measurement Advantages

- Highest accuracy

- Can quantify magnitude and duration

- Captures most variance

Long-Term Measurement Disadvantages

- High cost

- Most difficult to install/monitor

- Time duration for result availability

Useful applications for this level of monitoring include situations where system use is influenced by variances in weather, occupant behavior, or other operating conditions. Other applications include reimbursable resource allocation, tenant billing activities, or in cases where the persistence of energy or resource savings over time is at issue.

Equipment useful in long-term monitoring included a variety of data loggers, utility-grade meters, or fixed data acquisition systems. In most cases these systems communicate via a network connection/ phone modem to a host computer and/or over the internet.

\subsubsection{The Metering Hierarchy}

Given the above described metering approaches, there is a logical order, or hierarchy, to consider as you look to maximize your metering value while minimizing your metering cost. Figure 8.4.1 presents this concept as a function of level of effort and diagnostic capability that applies to electric metering. This proposed hierarchy starts at the most aggregate level of data collection and processing - the whole-building meter. Assuming access to interval electric data (these are data collected usually at 15-minute intervals), this meter and resulting data can be diagnostic in identifying trends and variance in whole-building performance. In addition, these data can useful in understanding the operation and efficiency of major building systems (e.g., chillers, boilers, air handlers). While the resolution of whole-building data may not be fine enough to identify specific operational or efficiency issues, it can often be used to "frame the question" of what equipment/system is performing inconsistently and in need of further exploration.

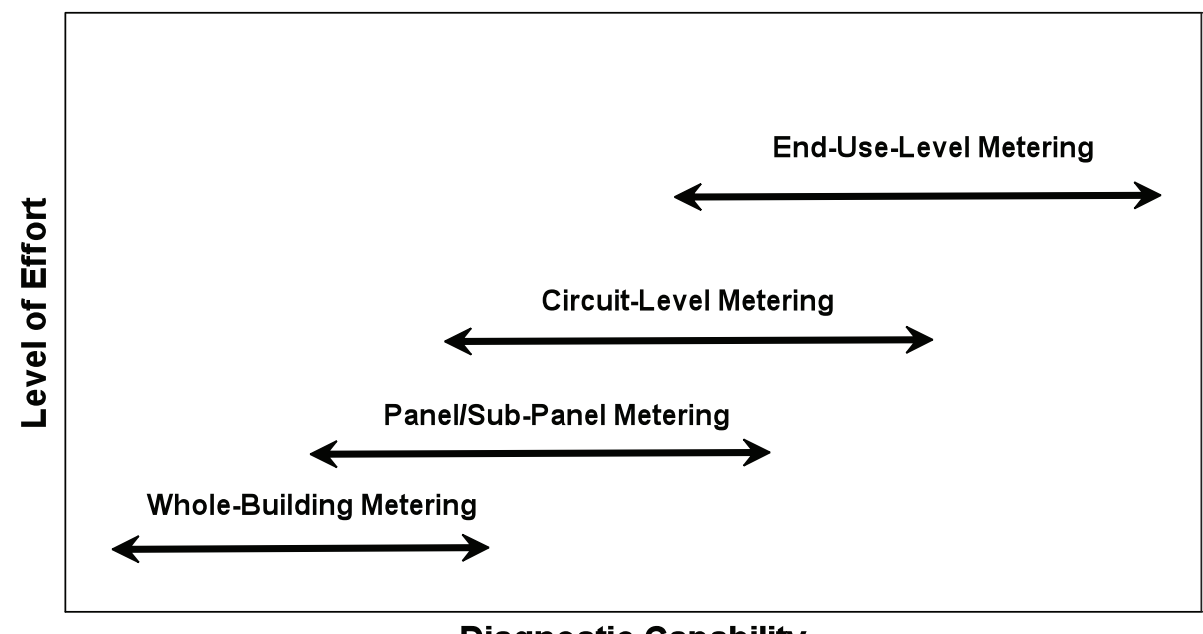

Diagnostic Capability

Figure 8.4.1. Electric metering hierarchy 
If the whole-building meter represents the most aggregate level, the next finer level is at the electrical panel/sub-panel. This second tier in the metering hierarchy focuses on loads connected at a panel (or sub-panel) level as aggregations of specific loads. Examples of panel-level monitoring include lighting panels or motor panels (i.e., motor control centers - MCCs) where hours of operation or efficiency project validation are of interest.

Moving up one more level in the hierarchy, we examine circuit-level monitoring. The focus of metering at this level is within the panel or sub-panel and the monitoring of a specific circuit of interest. This circuit may have specific plug loads of interest such as computers or other peripherals, or may be of interest for power quality or harmonics studies.

The final level in the hierarchy, having the finest data resolution, is the end-use level. End-use monitoring serves to isolate a particular system or equipment type for detailed study. In many cases, the objective of end-use monitoring is equipment performance, whether to identify inefficiency or validate savings estimates. Chillers, boilers, cooling towers, pumps and motors are often end-use metered for performance metrics.

While the above hierarchy presents a step-wise approach to metering and efficiency diagnostics, by no means are we suggesting that all hierarchy steps need be followed sequentially when moving from whole-building to end-use metering. In fact, in some cases there should be enough information to move from the whole-building level directly to end-use level when diagnosing or trending efficiency opportunities. In cases where inefficiency by specific equipment is not so apparent, the additional steps may be beneficial to properly identify the poorly operating equipment.

\subsection{Metering System Components}

There are four necessary components to a viable building-level metering system; the meters, the data-collection system, the data storage/ retrieval system, and the analysis system/capability (AEC 2003; EPRI 1996). Each component is described below.

\subsubsection{Meters}

At the most basic level, all meters provide some output related to resource use - energy, water, natural gas, and steam. Beyond this basic level, more sophisticated meters take advantage of additional capabilities including electrical demand tracking, power quality measurements, and multiple-meter communication for water leak detection applications.

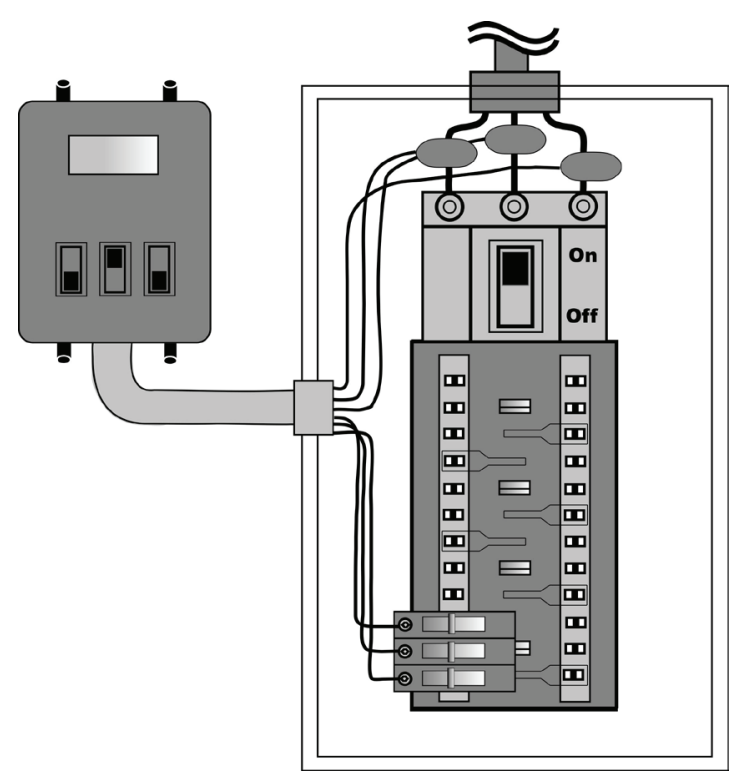

Figure 8.5.1. Typical electrical sub panel (box on left) used in long-term monitoring

For electrical systems, meters can be installed to track whole-building energy use (e.g., utility meters), sub-panel energy use (e.g., a lighting or process circuit), or a specific end use (e.g., a motor or chiller). See Figure 8.5.1 for sub-panel. For water, steam, natural gas, and other flow-related applications, meters are typically in-line installations using positive displacement, insertion turbine, 
or pressure-related techniques. Depending on the need, any of these meters will vary in size, type, output configuration, accuracy, and price. A more complete treatment of utility meters, applications, and evaluation criteria can be found in the FEMP Metering Best Practices Guide (FEMP 2007).

To better understand portable meters or data loggers and their vendors the report titled Portable Data Loggers Diagnostic Tools for Energy-Efficient Building Operations (PECI 1999) is particularly good. A list of vendors of larger, dedicated, whole-building meters can be found in the report titled Advanced Utility Metering (AEC 2003).

\subsubsection{Data Collection}

Modern metering data-collection systems take advantage of recent developments in communications technologies. Over the past 15 years, Automated Meter Reading (AMR) systems have increased in sophistication and reliability, and now represent a very economic means of data collection. When developing the communications portion of your metering program, it is important to consider what existing communications infrastructure you can take advantage of (e.g., building automation system, local area network) to potentially lower the cost of AMR. In addition, if you have a large site with distributed buildings you may find benefit in considering multiple communications technologies (e.g., networks in one area, phone lines in another, and wireless in a third) to gain the necessary communications coverage. Available technologies include:

- Traditional or cellular phone modem: Considered a proven technology, generally available and secure. This mode can be expensive and one needs to be connected to access to real-time data

- Local area networks: A proven technology with increasing availability and always connected. This mode can have IT security concerns/issues.

- Building automation systems: When present provides advantage of accessibility and fast communication. Some systems can have compatibility or data availability issues.

- Radio frequency/wireless networks: With no wires to install, this mode has great logistical and cost advantage. Issues do arise with potential for electrical interference and hardware costs.

- Power line carriers: Excellent use of existing infrastructure and connect-ability. Overall system cost and data transfer rates need to be researched before implementation.

\subsubsection{Data Storage}

The need for, and the duration of, data storage should be carefully considered in the design and implementation of a metering system. A clear understanding of data needs and applications will drive storage decisions. At the most basic level, metered data are easily stored in one of many available database systems. The duration of data storage is a function of data use; long-term end-use studies require longer duration storage, short-term daily comparisons require less. There are a variety of application service providers (ASPs) that can provide data storage and retrieval services on a feebased service.

The specific requirements of the data storage/database system should be decided with assistance from site IT staff or others knowledgeable, or those who will be using the system. Below are concepts and specifications based on work done for the California Energy Commission Public Interest Energy Research Program (PIER) and the Building Technologies Program of the U.S. Department of Energy 
(CEC 2007). A more complete list of data storage software and hardware considerations can be found in the FEMP Metering Best Practices Guide (FEMP 2007).

- Data shall be stored in a structured query language (SQL)-compliant database format or time series format. Minimum requirements are a SQL server or equivalent.

- The database shall allow other application programs to read and access the data with appropriate password protection while the database is running. The database shall not require shutting down in order to access or have data added.

- Trend data shall be archived in a database from field equipment in time intervals no less than once per day.

- All data shall be stored in database file format for direct use by third-party application programs.

- Sufficient data storage capacity will be able to store at least two years of data for all data points. In addition, storage capacity will also allow for compression of one year of data for historic trends and archiving.

- Time stamps shall be collected on all data. The time stamp, depending on system architecture, will be captured at the field controller or system controller and directed to the database archive.

\subsubsection{Data Analysis}

Large-scale analysis of energy data can be time consuming and expensive. In many cases, the manufacturers of metering equipment also provide off-the-shelf or custom software applications to assist these functions. In addition to the meter manufacturers, third-party software vendors, including some ASPs can provide data capture, collection/storage, and analysis services. Analytical services can range from simple use-reporting and tenant billing, to more sophisticated activities of energy use diagnostics and system performance indicators.

\subsection{Metering Economics}

The economic value of metering is directly proportional to the use of the resulting data. The range of potential resource savings related to metering vary with the building, equipment, and the use of the metered data. Economic savings attributed to metering can be as high as 20\%; the higher savings percentages requiring a very proactive use of the metered data.

Metering system installed costs will vary with system, existing infrastructure, and meter type. On average, long-term whole-building type meter installed cost runs between $\$ 1,000$ to $\$ 5,000$ per point or meter. This range is so large because some buildings require extensive rewiring and additional activities related to bringing existing systems up to code. Assuming limited requirements and code issues, an average per meter (electric) installed cost is roughly $\$ 1,500$.

As Federal agencies move toward increased metering, decisions need to be made on the optimal level of metering. In the extreme case, one would have difficulty justifying a meter installation on a small, seldom used, remote storage building. On the other hand, a large, continuously occupied administrative building would make a better case. At issue is where to draw the line, that is, below some set of criteria the economic case for metering becomes marginal. 
EPAct 2005 requires that Federal buildings be metered for electricity "where practicable." The following formula to cost-justify an electric meter (or other utility meters) was presented in DOE (2006):

Where:

$$
\frac{\left[\left(\frac{\text { Installed Cost }}{\text { Desired Simple Payback }}\right)+\text { Annual Cost }\right]}{\% \text { Annual Savings }}=\text { Minimum Annual Electric Bill }
$$

- Installed Cost refers to the total cost to purchase, install, and commission the meter. As previously noted, the cost of a meter application will vary based on a number of factors. Building electric meters are often in the range of $\$ 1,000$ to $\$ 5,000$ completely installed. This broad range reflects the uncertainty of system upgrades that may be associated with electrical code compliance issues.

- Desired Simple Payback represents the number of years it will take the metering system to produce (lead to) cost savings equal to the installed cost. Most agencies prefer a simple payback period of 10 years or less.

- Annual Cost is the total annual cost of the fees and expenses to cover communications, data collection and storage, and data analysis, as well as meter operations and maintenance. The annual cost will vary based on several factors and is typically in the range of $\$ 120 /$ year $(\$ 10)$ month) to $\$ 600 /$ year $(\$ 50 /$ month $)$.

- \% Annual Savings is the estimated cost savings benefits to be realized from the productive use of the metered data. Federal sites are advised to use a minimum of 2 percent annual savings when considering meters for EPAct 2005 compliance.

Using the above formula also requires that there be a reasonable way to estimate the current annual electricity (utility) costs for the building being considered. Except in cases where the buildings already have standard meters, actual usage data to estimate the annual costs will not be available. In these cases, one of the following accepted methods of estimating building energy use should be applied (FEMP 2007):

- Square footage

- Energy-use intensity

- Calibrated software

- Short-term metering

To demonstrate how the metering cost justification formula is used, the following values will be used:

- Installed cost $=\$ 5,000$

- Desired simple payback $=10$ years

- Annual cost $=\$ 25 /$ month $=\$ 300 /$ year

- $\%$ annual savings $=2$ percent 
Sample calculation: (NOTE: The values in this sample are for demonstration purposes only. Sites considering metering applications should use values specific to their site.)

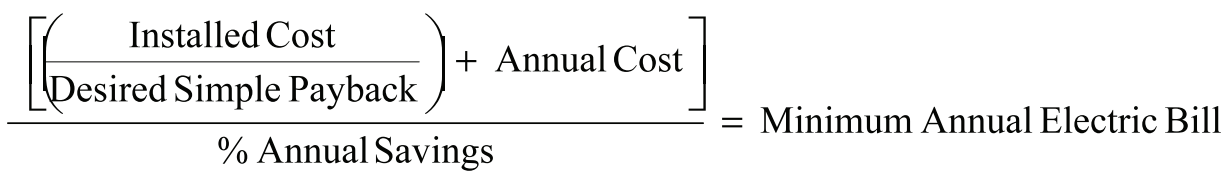

$$
\begin{aligned}
& =[(\$ 5,000) \div(10 \text { years })+\$ 300 / \text { year }] \div(0.02) \\
& =\$ 40,000 \text { minimum annual electric bill }
\end{aligned}
$$

In this example, an electric meter application will be cost-justified if the building's annual electricity use is more than $\$ 40,000$.

As previously mentioned, the results from this equation are sensitive to the input variables.

\subsection{Metering Financing Options}

There are a number of potential financing alternatives available to Federal sites. Factors affecting the financing alternatives available include estimated system cost, agency policies, and utility company support offerings, to name a few. In some cases, sites will be able to finance their metering systems through a combination of approaches, while in other cases they may be limited to single options.

\subsubsection{Metering Financing Hierarchy}

As a way for sites to begin their initial considerations of financing alternatives, the metering financing hierarchy has been developed (Figure 8.7.1). This hierarchy is based on life-cycle costs to the site's facility, utility, or energy management program as many consider life-cycle costs to be the most significant factor in selecting their financing approach. Additional hierarchies may be developed based on factors such as speed of implementation or lowest first/ up-front cost. Note that a lowest first cost approach may allow for faster implementation or a metering program with expanded capabilities.

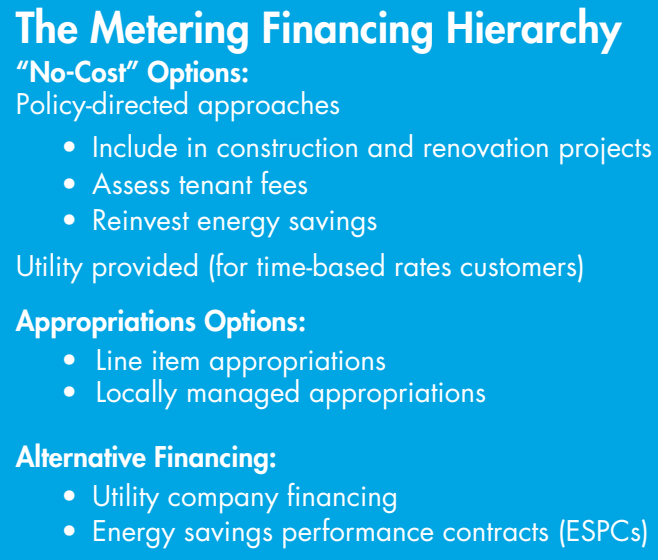

Figure 8.7.1. The metering financing hierarchy

The approaches addressed at the top of the hierarchy are the so-called "no cost" options. This is not to imply that the meters are free: instead, the costs to purchase and install the meters are covered in part or in total by programs other than the site facilities, utilities, or energy program.

The appropriations approaches are next in this hierarchy's order. While the costs for the metering system are now being incurred by the site or agency facilities programs, agency appropriations are a familiar approach where the total costs of the meters are paid at the time of purchase and installation. 
Alternatively financed approaches appear at the bottom of this hierarchy since the overall lifecycle costs are higher than the appropriations approaches due to added financing charges. This is not to imply that these approaches are any less likely to succeed than the other options. Site metering opportunities at some sites may benefit from alternative financing as a way expand the metering system or add capabilities beyond the EPAct 2005 requirements.

Specific to alternatively financed approaches and as described in the document titled: Approaches for the Application of Advanced Meters and Metering Systems at Federal Facilities through Alternatively Financed Contracts (LBNL 2005), there are at least five potential approaches to using alternatively financed projects to achieve the benefits of advanced meters and metering systems. Each of these approaches is briefly described below with more detail provided in the above mentioned report:

1. Install as part of other energy conservation measures (ECMs) or the $M \& V$ effort of the project - the meters installed as part of other ECMs (such as peak load management) or the $M \& V$ plan of an ESPC or the performance assurance plan of a UESC (either as required for $M \& V$ or augmented by additional facility funds) can be used to achieve the benefits of advanced metering.

2. Install using project savings - a portion of savings from other ECMs can be used to install and use advanced metering. This approach has been used in a relatively large, complex facility with significant potential for additional supply side savings opportunities.

3. Install as ECM with stipulated savings - This approach has also been used in a relatively large facility with significant potential for follow-on savings.

4. Install as an ECM with stipulated initial savings and follow-on share of savings - This approach is an extension of approach 3 with the application of the Award Fee Plan incentive concept, which allows a sharing of subsequent savings from actions taken on opportunities identified by the metering system.

5. Install in support of retro-commissioning ECM - the cost-effective use of retro-commissioning of relatively large and complex buildings has been repeatedly demonstrated by Texas A\&M University.

Advanced metering technologies are unique energy conservation measures because their primary benefit is to help identify energy saving opportunities. The problem is resulting energy savings are often difficult to quantify prior to installation and use. Thus, installation through alternative financing for several of the identified approaches does rely on stipulating savings, which is contrary to FEMP M\&V guidance.

Critical to the success of advanced metering technologies is the availability of staff that are motivated and trained to use the data. This includes the ability to gather, analyze, direct, and implement changes that work to optimize performance and energy efficiency. Remember, metering by itself does not save energy; instead, metering should be viewed as a technology that enables optimized performance and energy efficiency. The strategies summarized all require dedicated staff capable of affecting changes as a result of the analysis of metered data. These staff can be in-house, with an energy services company, or even a Resource Efficiency Manager. ${ }^{2}$

\footnotetext{
${ }^{2}$ See http://www.energy.wsu.edu/projects/rem/ for information on Resource Efficiency Managers.
} 


\subsection{Steps in Meter Planning}

The development of a metering plan is highly dependent on a site's needs, its mission, existing metering equipment, and available infrastructure. When it comes to metering, one size does not fit all. Below are some very general guidelines identifying the steps and actions necessary for a quality metering program. These guidelines summarize information found in FEMP (2006), AEC (2002), EPRI (1996), and Sydlowski (1993) where more detailed information can be found.

Whichever approach a site uses in its planning effort, there are key elements that should be addressed for all utility metering programs (FEMP 2006):

- Establish program goals and objectives

- Identify needs to support selected analysis approaches

- Develop and apply evaluation criteria

- Implementation, design, and installation

- Performance validation and persistence

Figure 8.8.1 provides a more detailed overview of the planning process.

\subsubsection{Establish Program Goals and Objectives}

The critical first step for all metering programs is to establish the site's overall metering objective. While the ultimate goal of the metering program is to reduce utility use and/or costs, how this is done will depend on how the metered data are used. Some of the more typical uses include cost allocation among tenants, bill verification, demand management, and energy use diagnostics. Examples of possible objectives might be:

- To fully enable energy bill allocation throughout an entire facility.

- To effectively manage electric loads to minimize costs under a time-based rate schedule.

- To identify system-specific operational efficiency opportunities.

\subsubsection{Identify Needs to Support Selected Analysis Approaches}

The information obtained in this step is used to ensure that the necessary data are obtained and its analysis is supported. Inclusive is the survey of any existing metering components that are operational and in use as they may support the new program's goals and objectives.

- Data needs serves as the starting point for this portion of the plan's development. What specific types of data are needed to support the program's goals and objectives. For example, allocation electricity costs based on actual use will require

(at a minimum) $\mathrm{kWh}$ and $\mathrm{kW}$ data at the building level or

for portions of the buildings occupied by different tenants.

- Analysis methodologies are a critical component of a site's metering program. Data by itself is not of much use without some analysis to determine what it means. 
- Equipment needs are based on the data requirements and the analysis methodologies identified, and should identify what types of metering/ monitoring equipment and hardware/software tools would be most appropriate to provide that data and its communication and storage.

- Survey existing metering systems. Many multiple building sites have some level of building metering or sub-metering in place.

- Staffing resources needed to operate the metering system when in place are also critical to a successful metering program.

- Security requirements vary widely across the Federal sector. In general, information technology (IT) staff should be asked to participate in the development of the metering program planning efforts at the very beginning of the process.

\subsubsection{Develop and Apply Evaluation Criteria}

Meters should be applied where they will lead to a costeffective reduction in utility use and/or costs. Determining which buildings can be metered cost-effectively requires that criteria be established and applied that take into account the life-cycle costs to meter and the benefits to be realized. The primary variables that impact the cost-effectiveness of meters are:

- The annual utility cost of the building being metered

- The cost to purchase and install the meter and associated hardware

- Expected savings resulting from the productive use of data, typically in the range of 2 percent to 10 percent, but sometimes higher depending on how the metered data are used

- Site economic criteria - usually payback period.

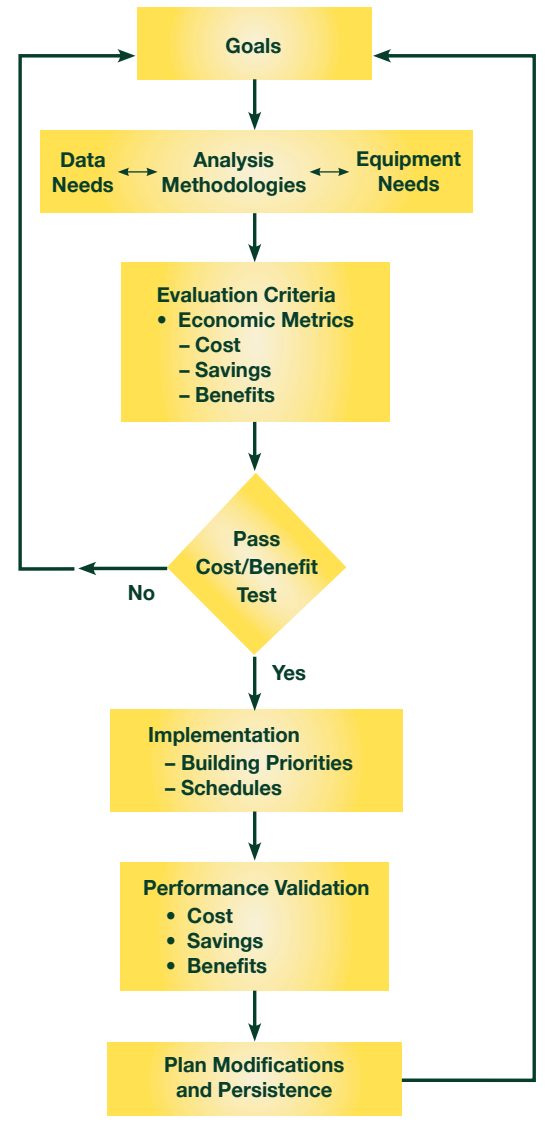

Figure 8.8.1. Development process for meter system planning 


\subsubsection{Implementation, Design, and Installation}

The planning process up to this point has been largely analytical. Based on the goals, objectives, analysis needs, and application of evaluation criteria, there is now enough information to design the actual metering system. Elements of the implementation, design, and installation steps include the following sub-elements discussed below:

- System financing, or how much funds are available and how will these funds be obtained, needs to be addressed early in the design process and revisited once cost estimates based on actual designs are completed.

- Prioritization of buildings and/or utilities to be metered. There may be a need or a greater benefit to metering some buildings and/or some utilities before others.

- The design of the metering system hardware application needs to:

- Satisfy functional requirements

- Define a system architecture

- Develop equipment specifications

- Review and refine the cost estimate to purchase and install the metering system.

\subsubsection{Performance Validation and Persistence}

Once the metering system is up and running, the overall program focus shifts to making sure:

- Accurate data are obtained and put to timely productive use

- The metering system continues to operate effectively and reliably.

\subsection{Case Study - General Services Administration's Kastenmeier Federal Courthouse}

In 2005, the operations staff at the Kastenmeier Federal Courthouse in Madison, Wisconsin, agreed to serve as a pilot site for the demonstration of the newly developed web-enabled WholeBuilding Energy Diagnostician (WBE). The WBE was originally developed by the Pacific Northwest National Laboratory (PNNL) with funding from the Department of Energy's Building Technologies Program. In an effort to make the tool more affordable and more widely available to the Federal sector, DOE's Federal Energy Management Program (FEMP) funded the development of a web-enabled version of the WBE. The WBE module installed at the Kastenmeier Federal Courthouse was a commercialized version of the tool.

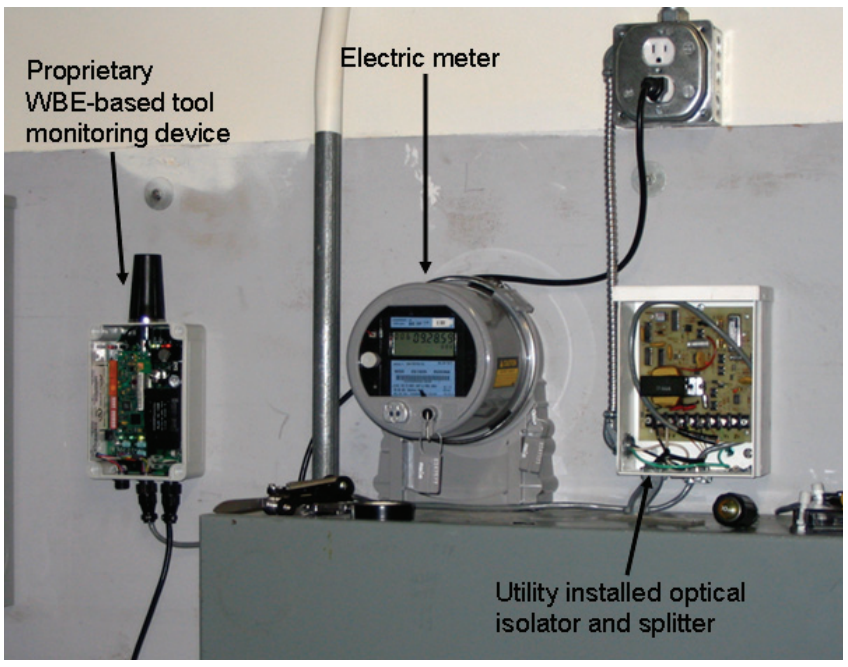

Figure 8.9.1. Installed wireless monitoring system for WBEbased system

Photo courtesy of NorthWrite, Inc., Minneapolis, MN. 
The WBE module tracks energy uses at the building level - in this case, the total electric and natural gas use. The values of expected energy consumption are generated by empirical models of the building, which are automatically developed by the WBE. In general, the model uses time of week, outdoor air dry-bulb temperature, and relative humidity as independent variables. The WBE then graphically provides building operators alarms for unexpected usage to identify major changes in energy consumption (PNNL 2005).

As part of the demonstration project, NorthWrite, Inc., partnered with FEMP to make the webenabled WBE module available to the Madison Courthouse as part of an overall suite of operations and management tools. The Madison Courthouse is a 100,000-square-foot building in Madison, Wisconsin. The building spaces include court rooms, chambers for the judges, jury rooms, holding cells, and offices for the Clerk of Courts, Bankruptcy Courts and U.S. marshals. Daily building occupancy includes approximately 120 full-time employees plus daily visitors.

The one-year demonstration started in May 2005 with the installation of the electric pulse meter and a monitor device, which reads pulse outputs from the meter and sends them wirelessly to a network operations center, needed to support the web-enabled WBE (Figure 8.9.1). A gas pulse meter was installed in July 2005. Summary of costs to purchase, install, and operate the metering system at the Kastenmeier Federal Courthouse is as follows:

- $\$ 1,000$ to purchase and install the electric and gas meters (approximately $\$ 500$ each)

- $\$ 3,500$ to install the proprietary WBE-based tool hardware

- $\$ 2,500$ to train agency staff on the use of the commercial web-based suite of tools (which included the WBE-based tool as well as additional site maintenance management functionality)

- $\$ 100$ per month for the monitor service

- $\$ 250$ per month to subscribe to the WBE-based tool and commercial maintenance management services suite of tools.

The reports and graphics generated by the WBE module are reviewed daily by the building mechanic as part of the morning startup, with an emphasis on verifying that peak usages do not vary unexpectedly (Figures 8.9.2 and 8.9.3). These daily reviews of the data have been helpful in diagnosing:

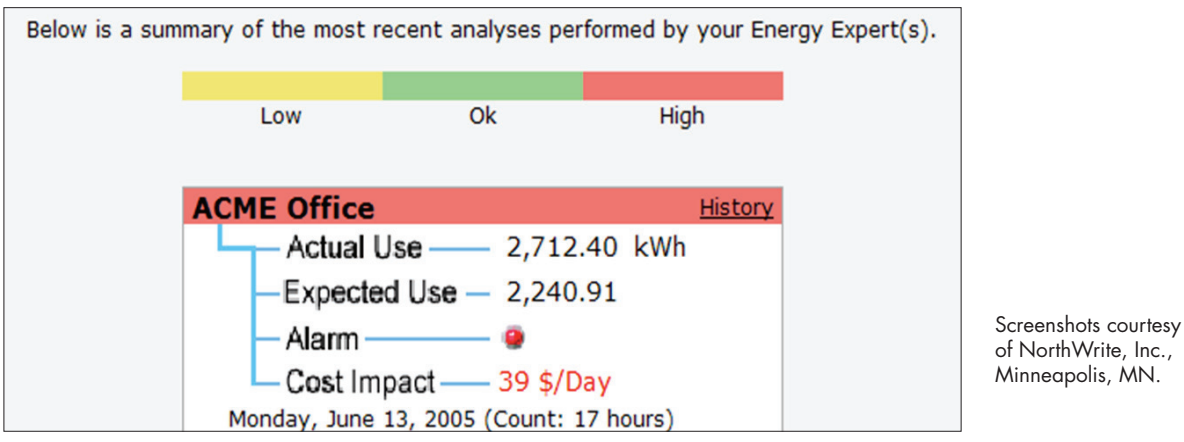

Figure 8.9.2. Sample screen capture for a generic building showing an alarm or high-energy using condition. Included is an estimated cost impact associated with the higher than expected electricity use. 


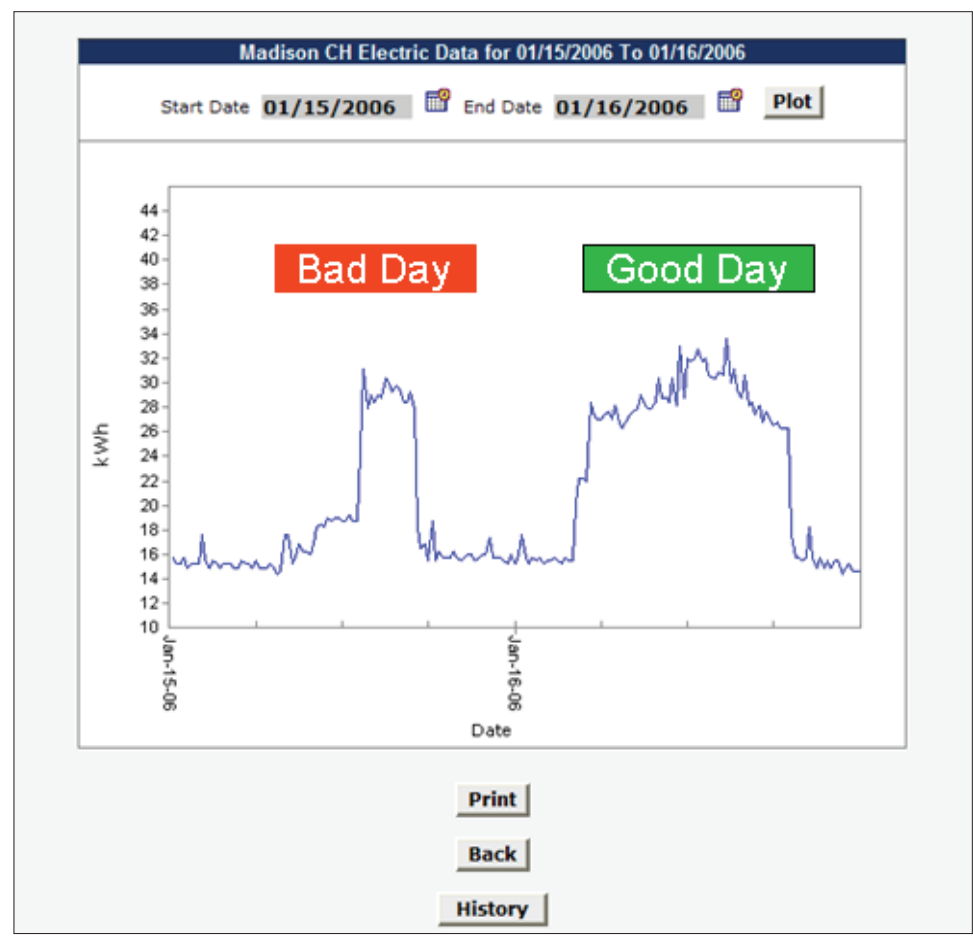

Figure 8.9.3. Data from the monitoring device provides a comparison of 2 days of electricity use for Sunday, January 15, 2006, and Monday, January 16, 2006. Figure shows unexpected off-hour usage on the 15th, while electricity consumption on the 16th was as expected.

- Incomplete reprogramming of schedules on the building automation system (BAS) following a time change

- Improper boiler sequencing operations

- An air-handler operating 24/7 instead of on the schedule as programmed by the BAS

- Belt slippage due to wear on a large horsepower motor

- Refrigerant leaks in rooftop compressors.

The WBE module also lets the General Services Administration (GSA) staff observe the effects of variable-speed drives and direct-expansion cooling operations, including occasional spikes in electrical consumption, and verify that energy-intensive IT downloads are completed during offhours.

Since this is a web-based system, the GSA regional energy office in Chicago is able to access and review the system data. This second set of eyes works to alert the Madison staff of other possible emerging trends.

\section{Lessons Learned:}

- Metered data were instrumental in identifying high or abnormal energy use, and assisted in diagnosing inefficient equipment and systems operations at the Kastenmeier Federal Courthouse.

- The ability to view data at multiple, including remote, locations allowed for expanded assessment capabilities.

- Metering natural gas consumption, while not required by EPAct 2005, proved beneficial. Metering natural gas consumption is now required by EISA 2007. 


\subsection{References}

AEC. 2003. Advanced Utility Metering. Under contract NREL/SR-710-33539, Architectural Energy

Corporation, Boulder, Colorado.

California Energy Commission (CEC) 2007. Continuous Performance Monitoring Systems, Specification Guide for Performance Monitoring Systems. Sacramento, California. Available at: http://cbs.lbl.gov/ performance-monitoring/specifications.

EISA 2007. Energy Independence and Security Act of 2007. Public Law 110-140. Signed December 19, 2007.

EPAct 2005. Energy Policy Act of 2005. Public Law 109-58, as amended, 119 Stat. 624 et seq.

EPRI. 1996. End-Use Performance Monitoring Handbook. EPRI TR-106960, Electric Power Research Institute, Palo Alto, California.

FEMP. 2007. Metering Best Practices: A Guide to Achieving Utility Resource Efficiency. DOE/EE-0323. Available at: http://wwwl.eere.energy.gov/femp/pdfs/mbpg.pdf.

FEMP. 2006. Guidance for Electric Metering in Federal Buildings. DOE/EE-0312. Available at: http://wwwl.eere.energy.gov/femp/pdfs/adv_metering.pdf.

LBNL. 2005. Approaches for the Application of Advanced Meters and Metering Systems at Federal Facilities through Alternatively Financed Contracts. Lawrence Berkely National Laboratory, Berkely, California. Available at: http://ateam.lbl.gov/mv.

Pacific Northwest National Laboratory (PNNL). 2005. Whole-Building Energy (WBE) Module. Richland, Washington. Available at: http://www.buildingsystemsprogram.pnl.gov/fdd/wbd/wbemain.stm.

PECI. 1999. Portable Data Loggers Diagnostic Tools for Energy-Efficient Building Operations. Prepared for the U.S. EPA and U.S. DOE by Portland Energy Conservation, Incorporated, Portland, Oregon.

Sydlowski, R.F. 1993. Advanced Metering Techniques. PNL-8487, Pacific Northwest National Laboratory, Richland, Washington. 


\section{Chapter 9 O\&M Ideas for Major Equipment Types}

\subsection{Introduction}

At the heart of all O\&M lies the equipment. Across the Federal sector, this equipment varies greatly in age, size, type, model, fuel used, condition, etc. While it is well beyond the scope of this guide to study all equipment types, we tried to focus our efforts on the more common types prevalent in the Federal sector. The objectives of this chapter are the following:

- Present general equipment descriptions and operating principles for the major equipment types.

- Discuss the key maintenance components of that equipment.

- Highlight important safety issues.

- Point out cost and energy efficiency issues.

- Highlight any water-related efficiency impacts issues.

- Provide recommended general O\&M activities in the form of checklists.

- Where possible, provide case studies.

The checklists provided at the end of each section were complied from a number of resources. These are not presented to replace activities specifically recommended by your equipment vendors or manufacturers. In most cases, these checklists represent industry standard best practices for the given equipment. They are presented here to supplement existing OEMM procedures, or to merely serve as reminders of activities that should be taking place. The recommendations in this guide are designed to supplement those of the manufacturer, or, as is all too often the case, provide guidance for systems and equipment for which technical documentation has been lost. As a rule, this guide will first defer to the manufacturer's recommendations on equipment operations and maintenance.

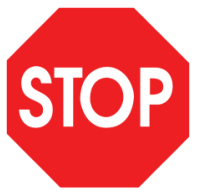

\section{Actions and activities recommended in this guide should only be attempted by trained and certified personnel. If such personnel are not available, the actions recommended here should not be initiated.}

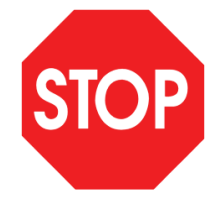

\subsubsection{Lock and Tag}

Lock and tag (also referred to as lockout-tagout) is a widely accepted safety procedure designed to ensure equipment being serviced is not energized while being worked on. The system works by physically locking the potential hazard (usually an electric switch, flow valve, etc.) in position such that system activation is not possible. In addition to the lock, a tag is attached to the device indicating that work is being completed and the system should not be energized.

When multiple staff are working on different parts of a larger system, the locked device is secured with a folding scissors clamp (Figure 9.1.1) that has many lock holes capable of holding it closed. In this situation, each staff member applies their own lock to the scissor clamp; therefore, the locked-out device cannot be activated until all staff have removed their lock from the clamp. 


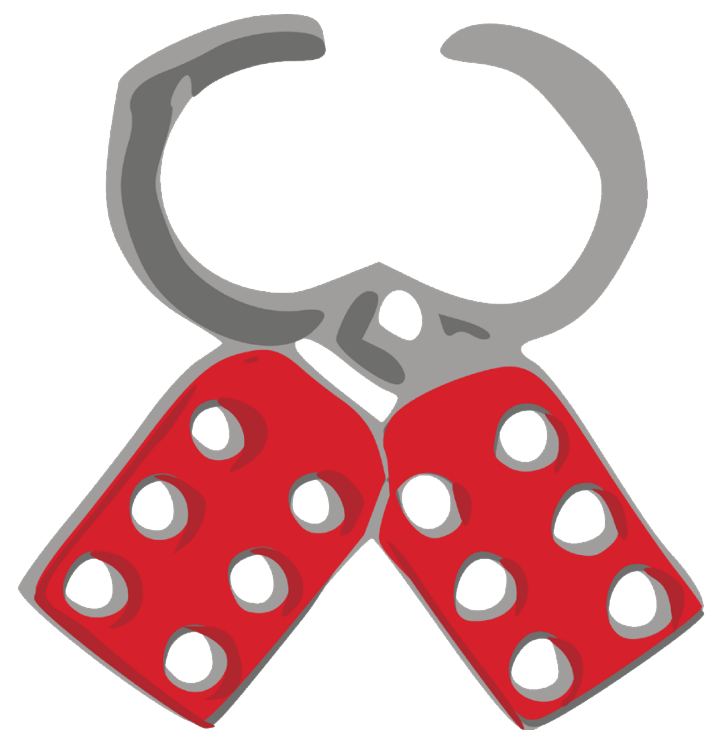

Figure 9.1.1. Typical folding lock and tag scissor clamp. This clamp allows for locks for up to 6 different facility staff.

There are well-accepted conventions for lock-and-tag in the United States, these include:

- No two keys or locks should ever be the same.

- A staff member's lock and tag must not be removed by anyone other than the individual who installed the lock and tag unless removal is accomplished under the direction of the employer.

- Lock and tag devices shall indicate the identity of the employee applying the device(s).

- Tag devices shall warn against hazardous conditions if the machine or equipment is energized and shall include directions such as: Do Not Start. Do Not Open. Do Not Close. Do Not Energize. Do Not Operate.

- Tags must be securely attached to energy-isolating devices so that they cannot be inadvertently or accidentally detached during use.

- Employer procedures and training for lock and tag use and removal must have been developed, documented, and incorporated into the employer's energy control program.

The Occupational Safety and Health Administration's (OSHA) standard on the Control of Hazardous Energy (Lockout-Tagout), found in CFR 1910.147, spells out the steps employers must take to prevent accidents associated with hazardous energy. The standard addresses practices and procedures necessary to disable machinery and prevent the release of potentially hazardous energy while maintenance or service is performed. 


\subsection{Boilers}

\subsubsection{Introduction}

Boilers are fuel-burning appliances that produce either hot water or steam that gets circulated through piping for heating or process uses.

Boiler systems are major financial investments, yet the methods for protecting these investments vary widely. Proper maintenance and operation of boilers systems is important with regard to efficiency and reliability. Without this attention, boilers can be very dangerous (NBBPVI 2001b).

\subsubsection{Types of Boilers (Niles and Rosaler 1998)}

Boiler designs can be classified in three main divisions - fire-tube boilers, water-tube boilers, and electric boilers.

\subsubsection{Fire-Tube Boilers}

Fire-tube boilers rely on hot gases circulating through the boiler inside tubes that are submerged in water (Figure 9.2.1). These gases usually make several passes through these tubes, thereby transferring their heat through the tube walls causing the water to boil on the other side. Fire-tube boilers are

Boiler horsepower: As defined, $34.5 \mathrm{lb}$ of steam at $212^{\circ} \mathrm{F}$ could do the same work (lifting weight) as one horse. In terms of Btu output1 bhp equals 33,475 Btu/hr. generally available in the range 20 through 800 boiler horsepower (bhp) and in pressures up to 150 psi.

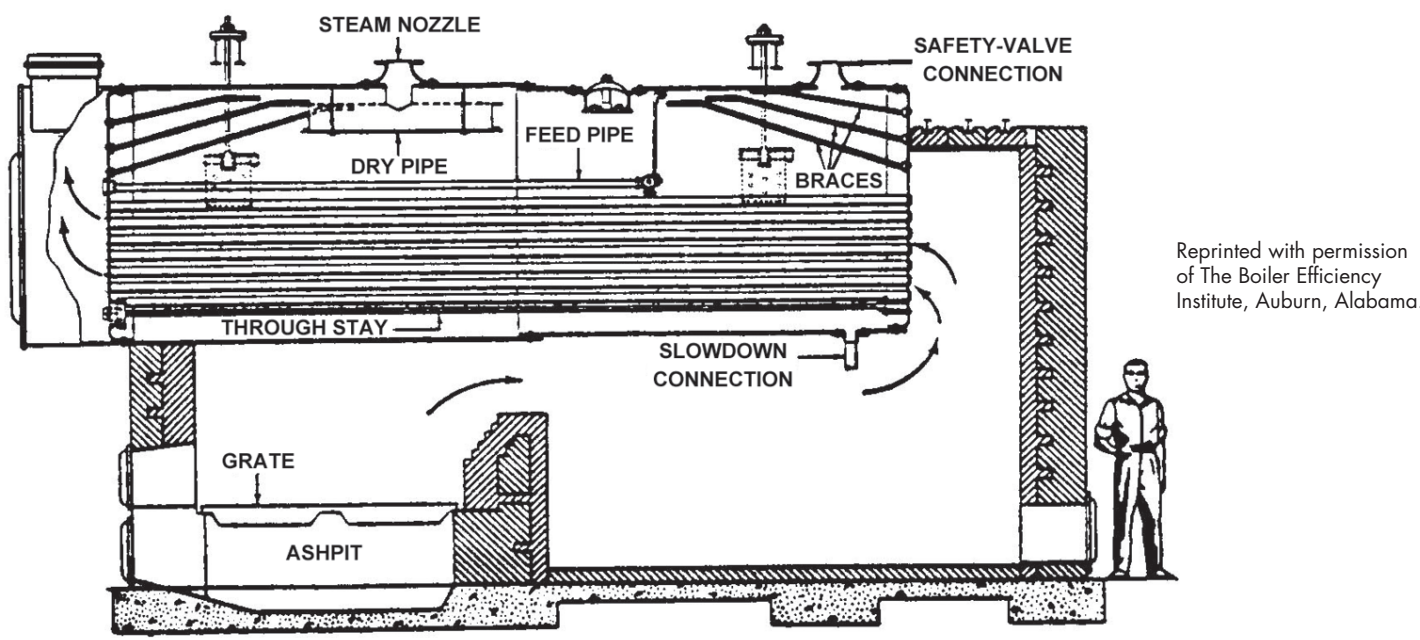

Figure 9.2.1. Horizontal return fire-tube boiler (hot gases pass through tube submerged in water).

\subsubsection{Water-Tube Boilers}

Most high-pressure and large boilers are of this type (Figure 9.2.2). It is important to note that the small tubes in the water-tube boiler can withstand high pressure better than the large vessels of a fire-tube boiler. In the water-tube boiler, gases flow over water-filled tubes. These water-filled tubes are in turn connected to large containers called drums. 


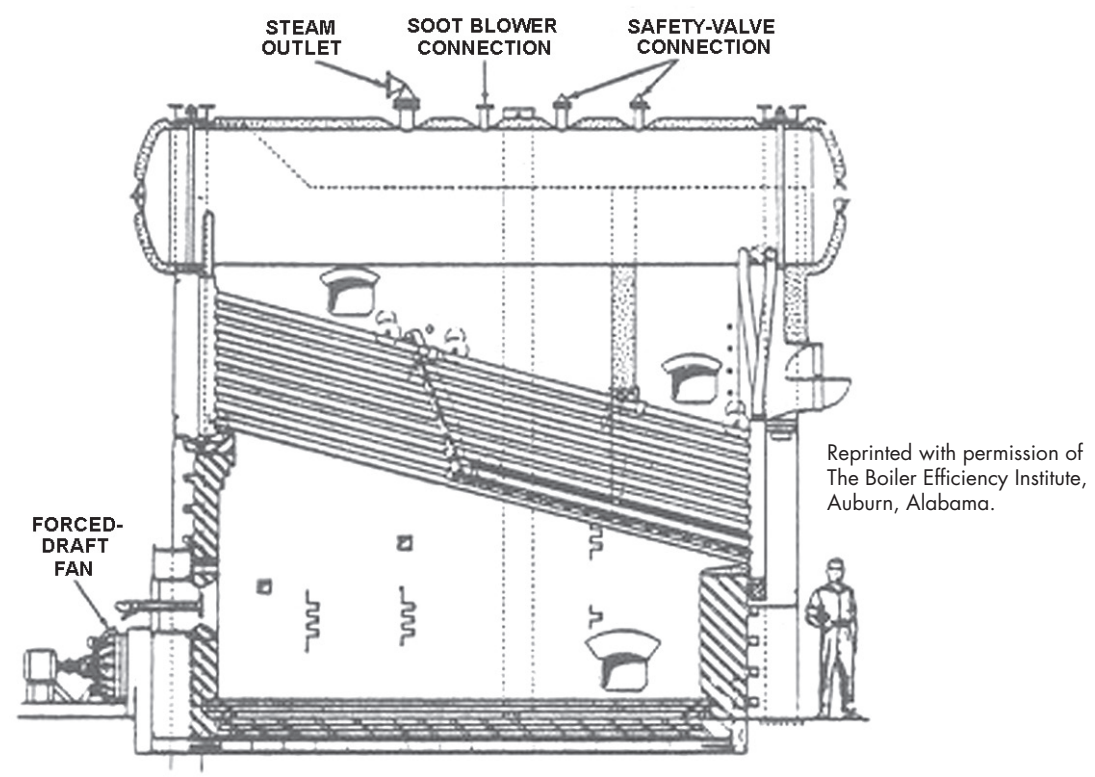

Figure 9.2.2. Longitudinal-drum water-tube boiler (water passes through tubes surrounded by hot gases).

Water-tube boilers are available in sizes ranging from smaller residential type to very large utility class boilers. Boiler pressures range from 15 psi through pressures exceeding 3,500 psi.

\subsubsection{Electric Boilers}

Electric boilers (Figure 9.2.3) are very efficient sources of hot water or steam, which are available in ratings from 5 to over $50,000 \mathrm{~kW}$. They can provide sufficient heat for any HVAC requirement in applications ranging from humidification to primary heat sources.

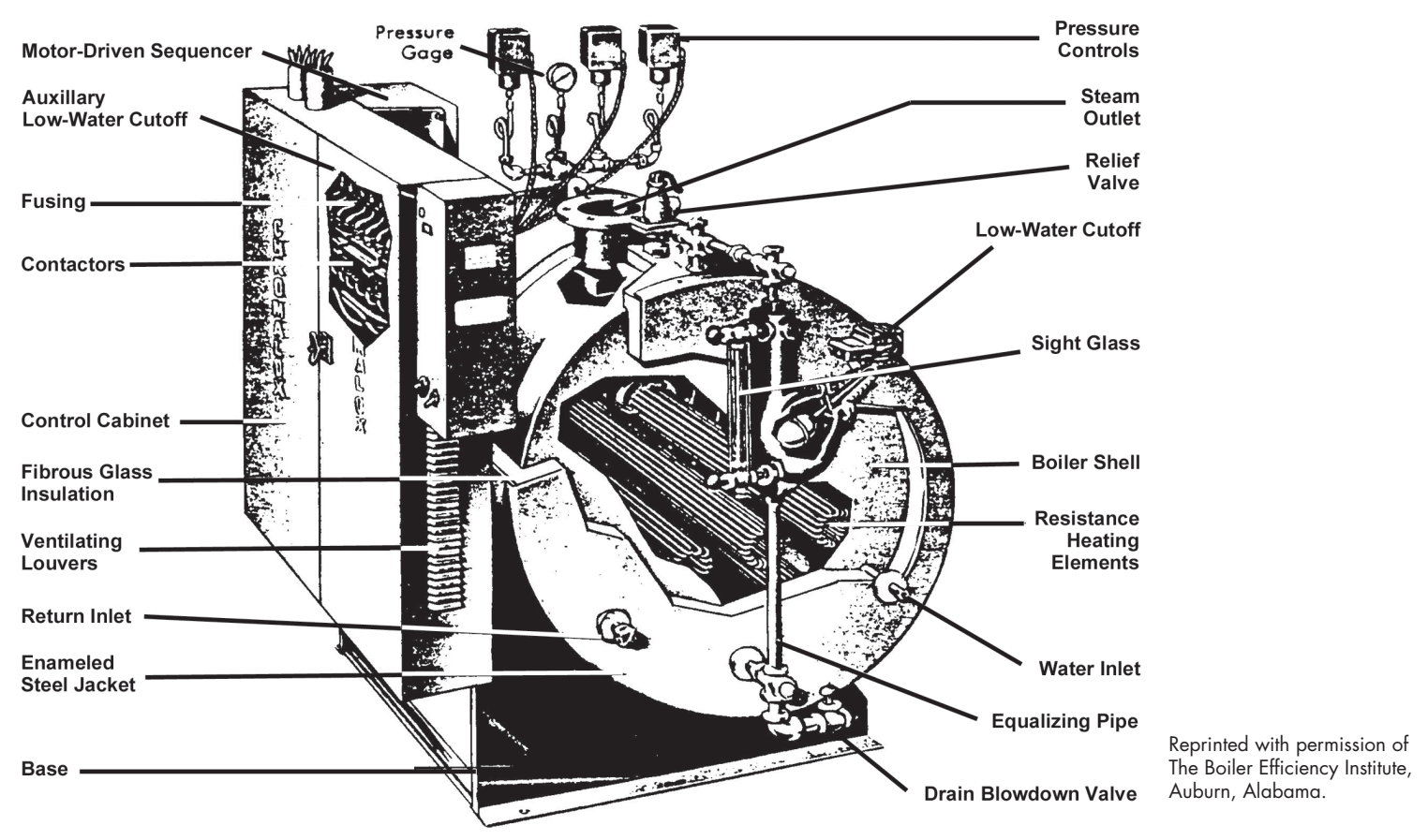

Figure 9.2.3. Electric boiler 


\subsubsection{Key Components (Nakonezny 2001)}

\subsubsection{Critical Components}

In general, the critical components are those whose failure will directly affect the reliability of the boiler. The critical components can be prioritized by the impact they have on safety, reliability, and performance. These critical pressure parts include:

- Drums - The steam drum is the single most expensive component in the boiler. Consequently, any maintenance program must address the steam drum, as well as any other drums, in the convection passes of the

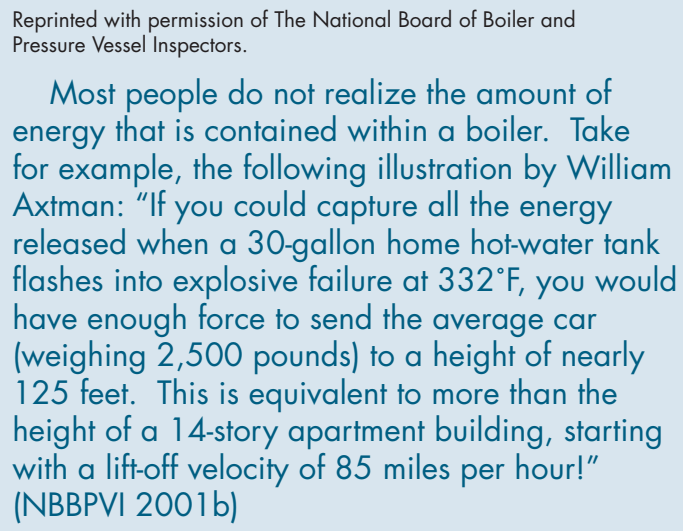
energy that is contained within a boiler. Take for example, the following illustration by William Axtman: "If you could capture all the energy released when a 30-gallon home hot-water tank flashes into explosive failure at $332^{\circ} \mathrm{F}$, you would have enough force to send the average car (weighing 2,500 pounds) to a height of nearly 125 feet. This is equivalent to more than the height of a 14-story apartment building, starting with a lift-off velocity of 85 miles per hour!" (NBBPVI 2001b)

boiler. In general, problems in the drums are associated with corrosion. In some instances, where drums have rolled tubes, rolling may produce excessive stresses that can lead to damage in the ligament areas. Problems in the drums normally lead to indications that are seen on the surfaces - either inside diameter (ID) or outside diameter (OD).

Assessment: Inspection and testing focuses on detecting surface indications. The preferred nondestructive examination (NDE) method is wet fluorescent magnetic particle testing (WFMT). Because WFMT uses fluorescent particles that are examined under ultraviolet light, it is more sensitive than dry powder type-magnetic particle testing (MT) and it is faster than liquid dye penetrant testing (PT) methods. WFMT should include the major welds, selected attachment welds, and at least some of the ligaments. If locations of corrosion are found, then ultrasonic thickness testing (UTT) may be performed to assess thinning due to metal loss. In rare instances, metallographic replication may be performed.

- Headers - Boilers designed for temperatures above $900^{\circ} \mathrm{F}\left(482^{\circ} \mathrm{C}\right)$ can have superheater outlet headers that are subject to creep - the plastic deformation (strain) of the header from longterm exposure to temperature and stress. For high temperature headers, tests can include metallographic replication and ultrasonic angle beam shear wave inspections of higher stress weld locations. However, industrial boilers are more typically designed for temperatures less than $900^{\circ} \mathrm{F}\left(482^{\circ} \mathrm{C}\right)$ such that failure is not normally related to creep. Lower temperature headers are subject to corrosion or possible erosion. Additionally, cycles of thermal expansion and mechanical loading may lead to fatigue damage.

Assessment: NDE should include testing of the welds by MT or WFMT. In addition, it is advisable to perform internal inspection with a video probe to assess water side cleanliness, to note any buildup of deposits or maintenance debris that could obstruct flow, and to determine if corrosion is a problem. Inspected headers should include some of the water circuit headers as well as superheater headers. If a location of corrosion is seen, then UTT to quantify remaining wall thickness is advisable. 
- Tubing - By far, the greatest number of forced outages in all types of boilers are caused by tube failures. Failure mechanisms vary greatly from the long term to the short term. Superheater tubes operating at sufficient temperature can fail long term (over many years) due to normal life expenditure. For these tubes with predicted finite life, Babcock \& Wilcox (B\&W) offers the NOTIS $^{\circledR}$ test and remaining life analysis. However, most tubes in the industrial boiler do not have a finite life due to their temperature of operation under normal conditions. Tubes are more likely to fail because of abnormal deterioration such as water/steam-side deposits retarding heat transfer, flow obstructions, tube corrosion (ID and/or OD), fatigue, and tube erosion.

Assessment: Tubing is one of the components where visual examination is of great importance because many tube damage mechanisms lead to visual signs such as distortion, discoloration, swelling, or surface damage. The primary NDE method for obtaining data used in tube assessment is contact UTT for tube thickness measurements. Contact UTT is done on accessible tube surfaces by placing the UT transducer onto the tube using a couplant, a gel or fluid that transmits the UT sound into the tube. Variations on standard contact UTT have been developed due to access limitations. Examples are internal rotating inspection system (IRIS)-based techniques in which the UT signal is reflected from a high rpm rotating mirror to scan tubes from the ID especially in the area adjacent to drums; and B\&W's immersion UT where a multiple transducer probe is inserted into boiler bank tubes from the steam drum to provide measurements at four orthogonal points. These systems can be advantageous in the assessment of pitting.

\section{- Piping}

- Main Steam - For lower temperature systems, the piping is subject to the same damage as noted for the boiler headers. In addition, the piping supports may experience deterioration and become damaged from excessive or cyclical system loads.

Assessment: The NDE method of choice for testing of external weld surfaces is WFMT. MT and PT are sometimes used if lighting or pipe geometry make WFMT impractical. Nondrainable sections, such as sagging horizontal runs, are subject to internal corrosion and pitting. These areas should be examined by internal video probe and/or UTT measurements. Volumetric inspection (i.e., ultrasonic shear wave) of selected piping welds may be included in the NDE; however, concerns for weld integrity associated with the growth of subsurface cracks is a problem associated with creep of high-temperature piping and is not a concern on most industrial installations.

- Feedwater - A piping system often overlooked is feedwater piping. Depending upon the operating parameters of the feedwater system, the flow rates, and the piping geometry, the pipe may be prone to corrosion or flow assisted corrosion (FAC). This is also referred to as erosion-corrosion. If susceptible, the pipe may experience material loss from internal surfaces near bends, pumps, injection points, and flow transitions. Ingress of air into the system can lead to corrosion and pitting. Out-of-service corrosion can occur if the boiler is idle for long periods.

Assessment: Internal visual inspection with a video probe is recommended if access allows. NDE can include MT, PT, or WFMT at selected welds. UTT should be done in any location where FAC is suspected to ensure there is not significant piping wall loss. 
- Deaerators - Overlooked for many years in condition assessment and maintenance inspection programs, deaerators have been known to fail catastrophically in both industrial and utility plants. The damage mechanism is corrosion of shell welds, which occurs on the ID surfaces.

Assessment: Deaerators' welds should have a thorough visual inspection. All internal welds and selected external attachment welds should be tested by WFMT.

\subsubsection{Other Components (Williamson-Thermoflo Company 2001)}

\section{- Air openings}

Assessment: Verify that combustion and ventilation air openings to the boiler room and/ or building are open and unobstructed. Check operation and wiring of automatic combustion air dampers, if used. Verify that boiler vent discharge and air intake are clean and free of obstructions.

\section{- Flue gas vent system}

Assessment: Visually inspect entire flue gas venting system for blockage, deterioration, or leakage. Repair any joints that show signs of leakage in accordance with vent manufacturer's instructions. Verify that masonry chimneys are lined, lining is in good condition, and there are not openings into the chimney.

\section{- Pilot and main burner flames}

Assessment: Visually inspect pilot burner and main burner flames.

- Proper pilot flame

- Blue flame.

- Inner cone engulfing thermocouple.

- Thermocouple glowing cherry red.

- Improper pilot flame

- Overfired - Large flame lifting or blowing past thermocouple.

- Underfired - Small flame. Inner cone not engulfing thermocouple.

- Lack of primary air - Yellow flame tip.

- Incorrectly heated thermocouple.

- Check burner flames-Main burner

- Proper main burner flame

- Yellow-orange streaks may appear (caused by dust)

- Improper main burner flame

- Overfired - Large flames.

- Underfired - Small flames.

- Lack of primary air - Yellow tipping on flames (sooting will occur). 


\section{- Boiler heating surfaces}

Assessment: Use a bright light to inspect the boiler flue collector and heating surfaces. If the vent pipe or boiler interior surfaces show evidence of soot, clean boiler heating surfaces. Remove the flue collector and clean the boiler, if necessary, after closer inspection of boiler heating surfaces. If there is evidence of rusty scale deposits on boiler surfaces, check the water piping and control system to make sure the boiler return water temperature is properly maintained. Reconnect vent and draft diverter. Check inside and around boiler for evidence of any leaks from the boiler. If found, locate source of leaks and repair.

\section{- Burners and base}

Assessment: Inspect burners and all other components in the boiler base. If burners must be cleaned, raise the rear of each burner to release from support slot, slide forward, and remove. Then brush and vacuum the burners thoroughly, making sure all ports are free of debris. Carefully replace all burners, making sure burner with pilot bracket is replaced in its original position and all burners are upright (ports up). Inspect the base insulation.

\subsubsection{Safety Issues (NBBPVI 2001c)}

Boiler safety is a key objective of the National Board of Boiler and Pressure Vessel Inspectors. This organization tracks and reports on boiler safety and "incidents" related to boilers and pressure vessels that occur each year. Figure 9.2.4 details the 1999 boiler incidents by major category. It is important to note that the number one incident category resulting in injury was poor maintenance/operator error. Furthermore, statistics tracking loss-of-life incidents reported that in 1999, three of seven boiler-related deaths were attributed to poor maintenance/operator error. The point of relaying this information is to suggest that through proper maintenance and operator training these incidents may be reduced.

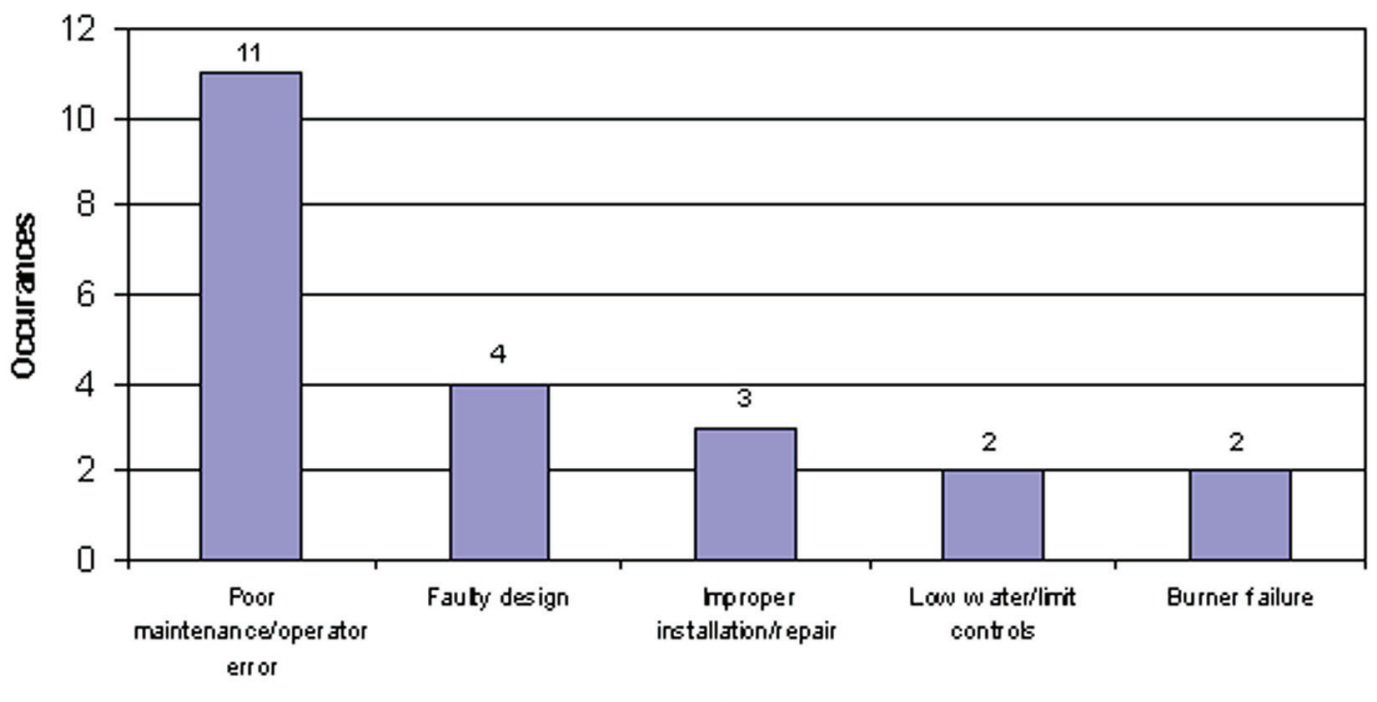

Incidents

Figure 9.2.4. Adapted from 1999 National Board of Boiler and Pressure Vessel Inspectors incident report summary.
At atmospheric pressure, $1 \mathrm{ft}^{3}$ of water converted to steam expands to occupy $1,600 \mathrm{ft}^{3}$ of space. If this expansion takes place in a vented tank, after create a vacuum with an external force on the tank of $\mathbf{9 0 0}$ tons! Boiler operators must understand this concept (NTT 1996). which the vent is closed, the condensing steam will 
Boiler inspections should be performed at regular intervals by certified boiler inspectors. Inspections should include verification and function of all safety systems and procedures as well as operator certification review.

\subsubsection{Cost and Energy/Water Efficiency (Dyer and Maples 1988)}

\subsubsection{Efficiency, Safety, and Life of the Equipment}

It is impossible to change the efficiency without changing the safety of the operation and the resultant life of the equipment, which in turn affects maintenance cost. An example to illustrate this relation between efficiency, safety, and life of the equipment is shown in Figure 9.2.5. The temperature distribution in an efficiently operated boiler is shown as the solid line. If fouling develops on the water side due to poor water quality control, it will result in a temperature increase of the hot gases on the fire side as shown by the dashed line. This fouling will result in an increase in stack temperature, thus decreasing the efficiency of the boiler. A metal failure will also change the life of the boiler, since fouling material will allow corrosion to occur, leading to increased maintenance cost and decreased equipment reliability and safety.

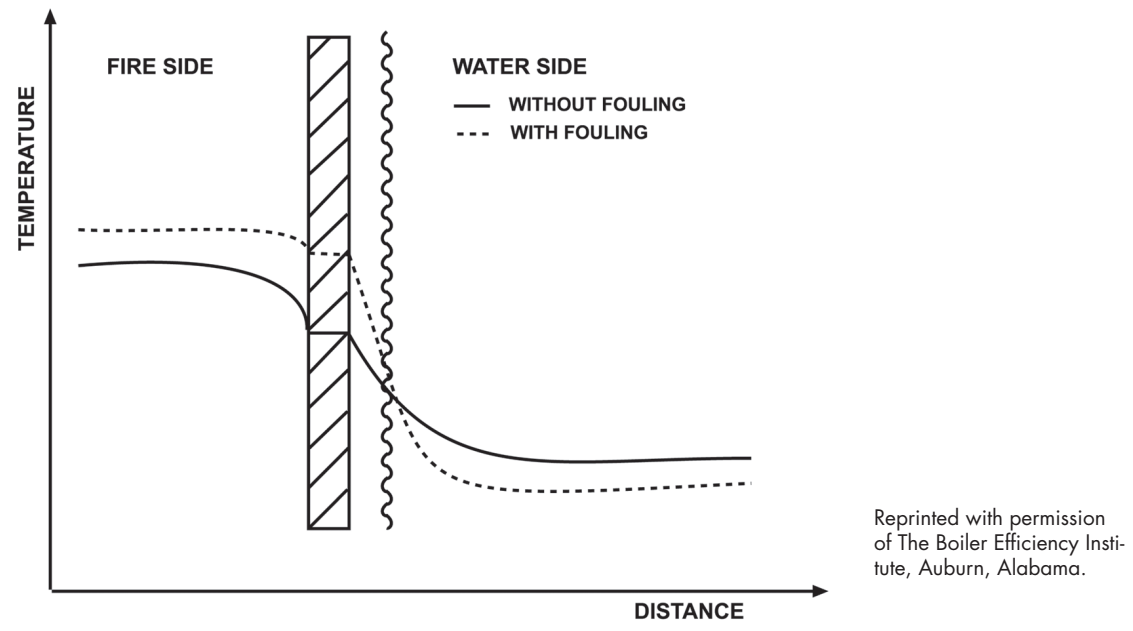

Figure 9.2.5. Effect of fouling on water side

\subsubsection{Boiler Energy Best Practices}

In a study conducted by the Boiler Efficiency Institute in Auburn, Alabama, researchers have developed eleven ways to improve boiler efficiency with important reasons behind each action.

- Reduce excess air - Excess air means there is more air for combustion than is required. The extra air is heated up and thrown away. The most important parameter affecting combustion efficiency is the air/fuel ratio.

- Symptom - The oxygen in the air that is not used for combustion is discharged in the flue gas; therefore, a simple measurement of oxygen level in the exhaust gas tells us how much air is being used. Note: It is worth mentioning the other side of the spectrum. The so called "deficient air" must be avoided as well because (1) it decreases efficiency, (2) allows deposit of soot on the fire side, and (3) the flue gases are potentially explosive. 
- Action Required - Determine the combustion efficiency using dedicated or portable combustion analysis equipment. Adjustments for better burning include:

- Cleaning

- New tips/orifices

- Damper repair

- Control repair

- Refractory repair

- Fuel pressure

- Furnace pressure
- Swirl at burner inlet

- Atomizing pressure

- Fuel temperature

- Burner position

- Bed thickness

- Ratio under/overfire air

- Undergrate air distribution.

- Install waste heat recovery - The magnitude of the stack loss for boilers without recovery is about $18 \%$ on gas-fired and about $12 \%$ for oil- and coal-fired boilers. A major problem with heat recovery in flue gas is corrosion. If flue gas is cooled, drops of acid condense at the acid dew temperature. As the temperature of the flue gas is dropped further, the water dew point is reached at which water condenses. The water mixes with the acid and reduces the severity of the corrosion problem.

- Symptom - Flue gas temperature is the indicator that determines whether an economizer or air heater is needed. It must be remembered that many factors cause high flue gas temperature (e.g., fouled water side or fire side surfaces, excess air).

- Action Required - If flue gas temperature exceeds minimum allowable temperature by $50^{\circ} \mathrm{F}$ or more, a conventional economizer may be economically feasible. An unconventional recovery device should be considered if the low-temperature waste heat saved can be used to heating water or air. Cautionary Note: A high flue gas temperature may be a sign of poor heat transfer resulting from scale or soot deposits. Boilers should be cleaned and tuned before considering the installation of a waste heat recovery system.

- Reduce scale and soot deposits - Scale or deposits serve as an insulator, resulting in more heat from the flame going up the stack rather than to the water due to these deposits. Any scale formation has a tremendous potential to decrease the heat transfer.

- Symptom - The best indirect indicator for scale or

Scale deposits on the water side and soot deposits on the fire side of a boiler not only act as insulators that reduce efficiency, but also cause damage to the tube structure due to overheating and corrosion. deposit build-up is the flue gas temperature. If at the same load and excess air the flue gas temperature rises with time, the effect is probably due to scale or deposits.

- Action Required - Soot is caused primarily by incomplete combustion. This is probably due to deficient air, a fouled burner, a defective burner, etc. Adjust excess air. Make repairs as necessary to eliminate smoke and carbon monoxide.

Scale formation is due to poor water quality. First, the water must be soft as it enters the boiler. Sufficient chemical must be fed in the boiler to control hardness. 
- Reduce blowdown - Blowdown results in the energy in the hot water being lost to the sewer unless energy recovery equipment is used. There are two types of blowdown. Mud blow is designed to remove the heavy sludge that accumulates at the bottom of the boiler. Continuous or skimming blow is designed to remove light solids that are dissolved in the water.

- Symptom - Observe the closeness of the various water quality parameters to the tolerances stipulated for the boiler per manufacturer specifications and check a sample of mud blowdown to ensure blowdown is only used for that purpose. Check the water quality in the boiler using standards chemical tests.

- Action Required - Conduct proper pre-treatment of the water by ensuring makeup is softened. Perform a "mud test" each time a mud blowdown is executed to reduce it to a minimum. A test should be conducted to see how high total dissolved solids (TDS) in the boiler can be carried without carryover.

- Recover waste heat from blowdown - Blowdown contains energy, which can be captured by a waste heat recovery system.

- Symptom and Action Required - Any boiler with a significant makeup (say 5\%) is a candidate for blowdown waste heat recovery.

\section{- Stop dynamic operation on applicable boilers}

Typical uses for waste heat include:

- Heating of combustion air

- Makeup water heating

- Boiler feedwater heating

- Appropriate process water heating

- Domestic water heating.

- Symptom - Any boiler which either stays off a significant amount of time or continuously varies in firing rate can be changed to improve efficiency.

- Action Required - For boilers which operate on and off, it may be possible to reduce the firing rate by changing burner tips. Another point to consider is whether more boilers are being used than necessary.

- Reduce line pressure - Line pressure sets the steam temperature for saturated steam.

- Symptom and Action Required - Any steam line that is being operated at a pressure higher than the process requirements offers a potential to save energy by reducing steam line pressure to a minimum required pressure determined by engineering studies of the systems for different seasons of the year.

- Operate boilers at peak efficiency - Plants having two or more boilers can save energy by load management such that each boiler is operated to obtain combined peak efficiency.

- Symptom and Action Required - Improved efficiency can be obtained by proper load selection, if operators determine firing schedule by those boilers, which operate "smoothly."

- Preheat combustion air - Since the boiler and stack release heat, which rises to the top of the boiler room, the air ducts can be arranged so the boiler is able to draw the hot air down back to the boiler.

- Symptom - Measure vertical temperature in the boiler room to indicate magnitude of stratification of the air.

- Action Required - Modify the air circulation so the boiler intake for outside air is able to draw from the top of the boiler room. 
Reprinted with permission of the National Board of Boiler and Pressure Vessel Inspectors

\section{General Requirements for a Safe and Efficient Boiler Room}

1. Keep the boiler room clean and clear of all unnecessary items. The boiler room should not be considered an all-purpose storage area. The burner requires proper air circulation in order to prevent incomplete fuel combustion. Use boiler operating log sheets, maintenance records, and the production of carbon monoxide. The boiler room is for the boiler!

2. Ensure that all personnel who operate or maintain the boiler room are properly trained on all equipment, controls, safety devices, and up-to-date operating procedures.

3. Before start-up, ensure that the boiler room is free of all potentially dangerous situations, like flammable materials, mechanical, or physical damage to the boiler or related equipment. Clear intakes and exhaust vents; check for deterioration and possible leaks.

4. Ensure a thorough inspection by a properly qualified inspector.

5. After any extensive repair or new installation of equipment, make sure a qualified boiler inspector re-inspects the entire system.

6. Monitor all new equipment closely until safety and efficiency are demonstrated.

7. Use boiler operating log sheets, maintenance records, and manufacturer's recommendations to establish a preventive maintenance schedule based on operating conditions, past maintenance, repair, and replacement that were performed on the equipment.

8. Establish a checklist for proper startup and shutdown of boilers and all related equipment according to manufacturer's recommendations.

9. Observe equipment extensively before allowing an automating operation system to be used with minimal supervision.

10. Establish a periodic preventive maintenance and safety program that follows manufacturer's recommendations.

- Switch from steam to air atomization - The energy to produce the air is a tiny fraction of the energy in the fuel, while the energy in the steam is usually $1 \%$ or more of the energy in the fuel.

- Symptom - Any steam-atomized burner is a candidate for retrofit.

- Action Required - Check economics to see if satisfactory return on investment is available.

\subsubsection{Maintenance of Boilers (NBBPVI 2001a)}

A boiler efficiency improvement program must include two aspects: (1) action to bring the boiler to peak efficiency and (2) action to maintain the efficiency at the maximum level. Good maintenance and efficiency start with having a working knowledge of the components associated with the boiler, keeping records, etc., and end with cleaning heat transfer surfaces, adjusting the air-to-fuel ratio, etc (NBBPVI 2001a). Sample steam/hot-water boiler maintenance, testing and inspection logs, as well as water quality testing log can be found can be found at the end of this section following the maintenance checklists.

\subsubsection{Diagnostic Tools}

- Combustion analyzer - A combustion analyzer samples, analyzes, and reports the combustion efficiency of most types of combustion equipment including boilers, furnaces, and water heaters. When properly maintained and calibrated, these devices provide an accurate measure of combustion efficiency from which efficiency corrections can be made. Combustion analyzers come in a variety of styles from portable units to dedicated units. 
- Thermography - An infrared thermometer or camera allows for an accurate, non-contact assessment of temperature. Applications for boilers include insulation assessments on boilers, steam, and condensate-return piping. Other applications include motor/bearing temperature assessments on feedwater pumps and draft fan systems. More information on thermography can be found in Chapter 6.

\subsubsection{Available Software Tools}

\section{- Steam System Tool Suite}

Description: If you consider potential steam system improvements in your plant, the results could be worthwhile. In fact, in many facilities, steam system improvements can save $10 \%$ to $20 \%$ in fuel costs.

To help you tap into potential savings in your facility, DOE offers a suite of tools for evaluating and identifying steam system improvements. The tools suggest a range of ways to save steam energy and boost productivity. They also compare your system against identified best practices and the selfevaluations of similar facilities.

\section{- Steam System Scoping Tool}

This tool is designed to help steam system energy managers and operations personnel to perform initial self-assessments of their steam systems. This tool will profile and grade steam system operations and management. This tool will help you to evaluate your steam system operations against best practices.

- Steam System Assessment Tool (SSAT) Version 3

SSAT allows steam analysts to develop approximate models of real steam systems. Using these models, you can apply SSAT to quantify the magnitude — energy, cost, and emissions-savings—of key potential steam improvement opportunities. SSAT contains the key features of typical steam systems.

New to Version 3 includes a set of templates for measurement in both English and metric units. The new templates correct all known problems with Version 2, such as an update to the User Calculations sheet, which allows better access to Microsoft Excel functionality. Version 3 is also now compatible with Microsoft Vista and Microsoft Excel 2007.

\section{- 3E Plus ${ }^{\circledR}$ Version 4.0}

The program calculates the most economical thickness of industrial insulation for user input operating conditions. You can make calculations using the built-in thermal performance relationships of generic insulation materials or supply conductivity data for other materials.

Availability: To download the Steam System Tool Suite and learn more about DOE Qualified Specialists and training opportunities, visit the Industrial Technology Program Web site: wwwl.eere.energy.gov/industry/bestpractices. 


\subsubsection{Relevant Operational/Energy Efficiency Measures}

There are many operational/energy efficiency measures that could be presented for proper boiler operation and control. The following section focuses on the most prevalent $O \& M$ recommendations having the greatest energy impacts at Federal facilities. These recommendations are also some of the most easily implemented for boiler operators and O\&M staff/contractors.

\subsubsection{Boiler Measure \#1: Boiler Loading, Sequencing, Scheduling, and Control}

The degree to which a boiler is loaded can be determined by the boiler's firing rate. Some boiler manufacturers produce boilers that operate at a single firing rate, but most manufacturers' boilers can operate over a wide range of firing rates. The firing rate dictates the amount of heat that is produced by the boiler and consequently, modulates to meet the heating requirements of a given system or process. In traditional commercial buildings, the hot water or steam demands will be considerably greater in the winter months, gradually decreasing in the spring/fall months and finally hitting its low point during the summer. A boiler will handle this changing demand by increasing or decreasing the boiler's firing rate. Meeting these changing loads introduces challenges to boiler operators to meet the given loads while loading, sequencing and scheduling the boilers properly.

Any gas-fired boiler that cycles on and off regularly or has a firing rate that continually changes over short periods can be altered to improve the boiler's efficiency. Frequent boiler cycling is usually a sign of insufficient building and/or process loading. Possible solutions to this problem (Dyer 1991) include adjusting the boiler's high and low pressure limits (or differential) farther apart and thus keeping the boiler on and off for longer periods of

\section{O\&M Tip:} Load management measures, including optimal matching of boiler size and boiler load, can save as much as $50 \%$ of a boiler's fuel use. time. The second option is replacement with a properly sized boiler.

The efficiency penalty associated with low-firing stem from the operational characteristic of the boiler. Typically, a boiler has its highest efficiency at high fire and near full load. This efficiency usually decreases with decreasing load.

The efficiency penalty related to the boiler cycle consists of a pre-purge, a firing interval, and a post-purge, followed by an idle (off) period. While necessary to ensure a safe burn cycle, the pre- and post-purge cycles result in heat loss up the exhaust stack. Short cycling results in excessive heat loss. Table 9.2.1 indicates the energy loss resulting from this type of cycling (Dyer 1991).

Table 9.2.1. Boiler cycling energy loss

\begin{tabular}{|c|c|}
\hline Number of Cycles/Hour & Percentage of Energy Loss \\
\hline 2 & 2 \\
\hline 5 & 8 \\
10 & 30 \\
\hline $\begin{array}{l}\text { Based on equal time between on and off, purge } 1 \text { minute, stack temp }=400^{\circ} \mathrm{F} \text {, airflow } \\
\text { through boiler with fan off }=10 \% \text { of fan forced airflow. }\end{array}$ \\
\hline
\end{tabular}




\section{Opportunity Identification}

Boiler operators should record in the daily log if the boiler is cycling frequently. If excessive cycling is observed, operators should consider the options given above to correct the problem.

Boiler operators should also record in the daily log the firing rate to meet the given hot water or steam load. If the boiler's firing rate continuously cycles over short periods of time and with fairly small variations in load - this should be noted. Seasonal variations in firing rate should be noted with an eye for sporadic firing over time. Corrections in firing rates require knowledge of boiler controls and should only be made by qualified staff.

\section{Diagnostic Equipment}

Data Loggers. The diagnostic test equipment to consider for assessing boiler cycling includes many types of electric data logging equipment. These data loggers can be configured to record the time-series electrical energy delivered to the boiler's purge fan as either an amperage or wattage measurement. These data could then be used to identify cycling frequency and hours of operation.

Other data logging options include a variety of stand-alone data loggers that record run-time of electric devices and are activated by sensing the magnetic field generated during electric motor operation. As above, these loggers develop a times-series record of on-time which is then used to identify cycling frequency and hours of operation.

\section{Energy Savings and Economics}

Estimated Annual Energy Savings. Using Table 9.2.1 the annual energy savings, which could be realized by eliminating or reducing cycling losses, can be estimated as follows:

Energy Savings $=\left[\left(\frac{B L \times R F C}{E F F \times\left(1-\frac{E L_{1}}{100}\right)}\right)-\left(\frac{B L \times R F C}{E F F \times\left(1-\frac{E L_{2}}{100}\right)}\right)\right] \times H$

Annual Energy Savings $=\sum_{i=1}^{n}$ Energy Savings

where:

$\mathrm{BL}=$ current boiler load or firing rate, $\% / 100$

$\mathrm{RFC}=$ rated fuel consumption at full load, MMBtu/hr

$\mathrm{EFF}=$ boiler efficiency, \%/100

$\mathrm{EL}_{1}=$ current energy loss due to cycling, \%

$\mathrm{EL}_{2}=$ tuned energy loss due to cycling, \%

$\mathrm{H}=$ hours the boiler operates at the given cycling rate, hours 
Estimated Annual Cost Savings. The annual cost savings, which could be realized by eliminating or reducing cycling losses, can be estimated as follows:

\section{Annual Cost Savings = Annual Energy Savings $\times F C$}

where: $\mathrm{FC}=$ fuel cost, $\$ / \mathrm{MMBtu}$

\section{Boiler Loading Energy Savings and Economics Example}

Example Synopsis: A boiler's high pressure set point was increased to reduce the cycling losses of a given boiler. Before the change was implemented, the boiler cycled on and off 5 times per hour, during low load conditions. With the new set point, the boiler only cycles on and off 2 times per hour. The boiler operates at this low load condition approximately 2,500 hours per year, and has a firing rate at this reduced loading of $20 \%$. The rated fuel consumption at full load is $10 \mathrm{MMBtu} / \mathrm{hr}$, with an efficiency of $82 \%$. The average fuel cost for the boiler is $\$ 9.00 / \mathrm{MMBtu}$.

The annual energy savings can be estimated as:

$$
\begin{gathered}
\text { Energy Savings }=\left[\left(\frac{0.2 \times 10}{0.82 \times\left(1-\frac{8}{100}\right)}\right)-\left(\frac{0.2 \times 10}{0.82 \times\left(1-\frac{2}{100}\right)}\right)\right] \times 2,500 \\
\text { Energy Savings }=405.78 \text { MMBtulyr }
\end{gathered}
$$

The annual cost savings can be estimated as:

$$
\begin{gathered}
\text { Annual Cost Savings }=(405.78 \text { MMBtu/yr }) \times(\$ 9.00 / M M B t u) \\
\text { Annual Cost Savings }=\$ 3,652 / y r
\end{gathered}
$$

An associated energy conservation measure that should be considered, in relation to boiler sequencing and control, relates to the number of boilers that operate to meet a given process or building load. The more boilers that operate to meet a given load, results in lower firing rates for each boiler. Boiler manufacturers should be contacted to acquire information on how well each boiler performs at a given firing rate, and the boilers should be operated accordingly to load the boilers as efficiently as possible. The site should also make every possible effort to reduce the number of boilers operating at a given time.

\section{Operation and Maintenance - Persistence}

Most boilers require daily attention including aspects of logging boiler functions, temperatures and pressures. Boiler operators need to continuously monitor the boiler's operation to ensure proper operation, efficiency and safety. For ideas on persistence actions see the Boiler Operations and Maintenance Checklist at the end of this section. 


\subsubsection{Boiler Measure \#2: Boiler Combustion Efficiency}

The boiler combustion process is affected by many variables including the temperature, pressure, and humidity of ambient air; the composition of the fuel and the rate of fuel and air supply to the process. It is important to note that the theoretical representation of the combustion process is just that - theoretical. It is important to consider all of the real-world inefficiencies and how the fuel and air actually come together when making combustion efficiency estimates.

O\&M Tip:

A comprehensive tune-up with precision testing equipment to detect and correct excess air losses, smoking, unburned fuel losses, sooting, and high stack temperatures can result in boiler fuel savings of $2 \%$ to $20 \%$.

\section{Opportunity Identification}

The efficiency of the combustion process is typically measured through the percent oxygen $\left(\mathrm{O}_{2}\right)$ in the exhaust gas. The amount of oxygen (or excess air as it is often referred to) in the exhaust gas is defined as the amount of air, above that which is theoretically required for complete combustion. It is imperative that boilers are operated with some excess air to ensure complete and safe combustion. Yet, the amount of excess air needs to be controlled so to minimize the losses associated with the heat that is expelled in the exhaust gases. Table 9.2.2 summarizes the typical optimum excess air requirements of conventional boilers (Doty and Turner 2009).

Table 9.2.2. Optimum excess air

\begin{tabular}{|llcc|}
\hline Fuel Type & Firing Method & $\begin{array}{c}\text { Optimum } \\
\text { Excess Air (\%) }\end{array}$ & $\begin{array}{c}\text { Equivalent } \mathrm{O}_{2} \\
\text { (by volume) }\end{array}$ \\
\hline Natural gas & Natural draft & 20 to 30 & 4 to 5 \\
\hline Natural gas & Forced draft & 5 to 10 & 1 to 2 \\
\hline Natural gas & Low excess air & 0.4 to 0.2 & 0.1 to 0.5 \\
\hline No. 2 oil & Rotary cup & 15 to 20 & 3 to 4 \\
\hline No. 2 oil & Air-atomized & 10 to 15 & 2 to 3 \\
\hline No. 2 oil & Steam-atomized & 10 to 15 & 2 to 3 \\
\hline No. 6 oil & Steam-atomized & 10 to 15 & 2 to 3 \\
\hline
\end{tabular}

The tuned combustion efficiency values specific to the subject boiler are typically published by the manufacturer. These values, usually published as easy to use charts, will display the optimum combustion efficiency compared to the boiler load or firing rate. Using this information, site personnel can determine the maximum combustion efficiency at the average load of the subject boiler.

If the boiler has large variances in load (firing rate) throughout the year, and the given boiler combustion efficiency varies significantly with load (firing rate), the equation referenced below can be calculated for each season, with the appropriate efficiency and fuel consumption for the given season.

Tuning the Boiler. The boiler can be tuned by adjusting the air to fuel ratio linkages feeding the boiler burner. Experienced boiler operators will need to adjust the air to fuel linkages accordingly to increase or decrease the given ratios to achieve the optimum excess air and resulting combustion efficiency. 
Diagnostic Equipment. To accurately measure combustion efficiency, excess air and a host of other diagnostic parameters, a combustion analyzer is recommended. These devices, made by a number of different manufacturers, are typically portable, handheld devices that are quick and easy to use. Most modern combustion analyzers will measure and calculate the following:

- Combustion air ambient temperature, $\mathrm{T}_{\mathrm{a}}$

- Stack temperature of the boiler, $\mathrm{T}_{\mathrm{s}}$

- Percent excess air, \%

- Percent $\mathrm{O}_{2}, \%$

- Percent $\mathrm{CO}_{2}, \%$

- Percent CO, \%

- Nitric Oxide, NX ppm

- Combustion efficiency, EF

A typical combustion analyzer is shown below in Figure 9.2.6. The probe seen in the picture is inserted in a hole in the exhaust stack of the boiler. If the boiler has a heat recovery system in the boiler exhaust stack, such as an economizer, the probe should be inserted above the heat recovery system. Figure 9.2.7 provides example locations for measurement of stack temperature and combustion air temperature readings (Combustion Analysis Basics 2004).

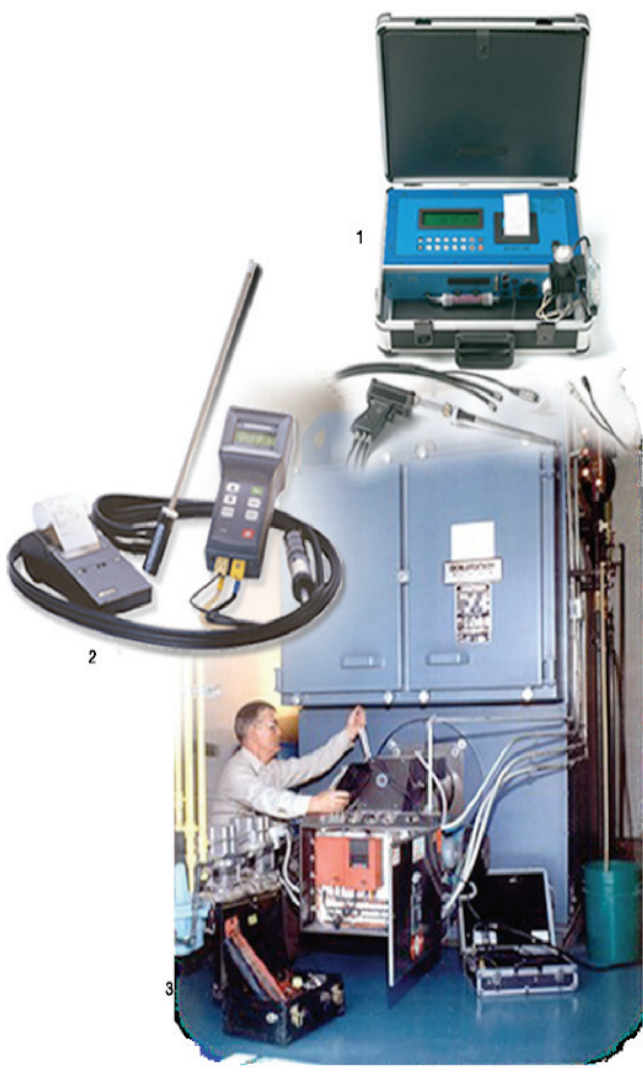

Figure 9.2.6. Combustion analyzer
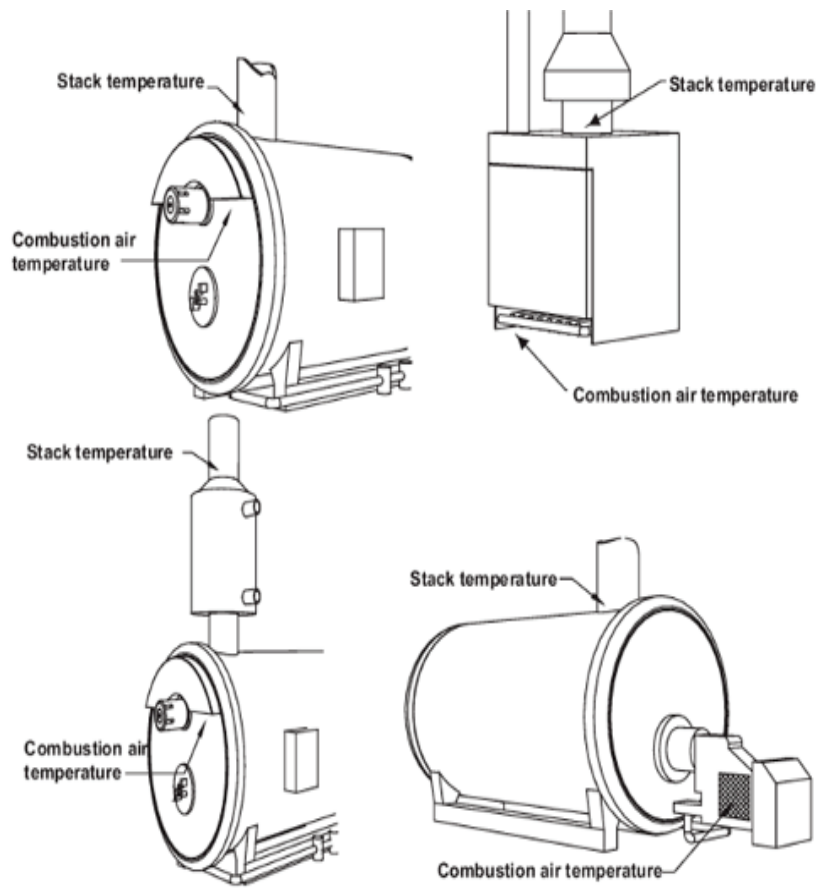

Figure 9.2.7. Example locations - combustion analysis 


\section{Energy Savings and Economics}

Estimated Annual Energy Savings. The annual energy savings, which could be realized by improving combustion efficiency, can be estimated as follows:

$$
\text { Annual Energy Savings }=\left[1-\left(\frac{E F F_{1}}{E F F_{2}}\right)\right] \times A F C
$$

where

$\mathrm{EFF}_{1}=$ current combustion efficiency, \%

$\mathrm{EFF}_{2}=$ tuned combustion efficiency, \%

$\mathrm{AFC}=$ annual fuel consumption, MMBtu/yr

Estimated Annual Cost Savings. The annual cost savings, which could be realized by improving combustion efficiency, can be estimated as follows:

\section{Annual Cost Savings = Annual Energy Savings $\times$ FC}

where $\mathrm{FC}=$ fuel cost, $\$ / \mathrm{MMBtu}$

\section{Combustion Efficiency Energy Savings and Economics Example}

Example Synopsis: A boiler has an annual fuel consumption of 5,000 MMBtu/yr. A combustion efficiency test reveals an excess air ratio of $28.1 \%$, an excess oxygen ratio of $5 \%$, a flue gas temperature of $400^{\circ} \mathrm{F}$, and a $79.5 \%$ combustion efficiency. The boiler manufacturer's specification sheets indicate that the boiler can safely operate at a $9.5 \%$ excess air ratio, which would reduce the flue gas temperature to $300^{\circ} \mathrm{F}$ and increase the combustion efficiency to $83.1 \%$. The average fuel cost for the boiler is $\$ 9.00 / \mathrm{MMBtu}$.

The annual energy savings can be estimated as:

$$
\begin{aligned}
& \text { Annual Energy Savings }=\left[1-\left(\frac{79.5}{83.1}\right)\right] \times 5,000 \\
& \text { Annual Energy Savings }=216.61 \mathrm{MMBtu} / \mathrm{yr}
\end{aligned}
$$

The annual cost savings can be estimated as:

$$
\begin{gathered}
\text { Annual Cost Savings }=(216.61 \mathrm{MMBtu} / \mathrm{yr})(\$ 9.00 / \mathrm{MMBt \imath} \\
\text { Annual Cost Savings }=\$ 1,949 / y r
\end{gathered}
$$

\section{Operation and Maintenance - Persistence}

Combustion analysis measurements should be taken regularly to ensure efficient boiler operation all year. Depending on use, boilers should be tuned at least annually; high use boilers at least twice annually. 
Boilers that have highly variable loads throughout the year should consider the installation of online oxygen analyzers. These analyzers will monitor the $\mathrm{O}_{2}$ in the exhaust gas and provide feedback to the linkages controlling the air to fuel ratios into the boilers burner (DOE 2002). This type of control usually offers significant savings by continuously changing the air to fuel linkages and maintaining optimum combustion efficiencies at all times. It should be noted that even if the boiler has an oxygen "trim" system, the boiler operators should periodically test the boilers with handheld combustion analyzers to ensure the automated controls are calibrated and operating properly.

\subsubsection{Boiler Measure \#3: Trending Boiler Stack Temperature}

Trending the boiler stack temperature ensures the minimum amount of heat is expelled with the boiler's exhaust gases. This essentially minimizes the total thermal mass flowing with the exhaust air out of the boiler. A lower boiler stack temperature means more of the heat is going into the water or steam serving the process load or HVAC system in the building.

The stack temperature of the boiler can be optimized and maintained by making sure all heat transfer surfaces (both on the fire-side and on the water side) are clean. This is accomplished through an effective water treatment program (water side affect) and a fire-side cleaning program.

A final method of stack-gas temperature optimization can be accomplished through the use of a heat recovery system such as an economizer. An economizer places an air to water heat exchanger in the exhaust stack that uses the heat in the exhaust gases to preheat the feed water into the boiler.

\subsubsection{Opportunity Identification}

This section will focus on maintaining an effective water side maintenance/cleaning, and fire side cleaning program as these are no-low cost measures to implement, that should be part of the Operations and Maintenance program for the building.

Fire side Cleaning and Maintenance Program. Fire side cleaning consists of manually cleaning the particulates that accumulate on the fire side of the boiler. Reducing the residue on the fire side of the boiler increases the amount of heat that gets absorbed into the water, and helps maintain proper emissions from the boiler. Some particulate accumulation is normal for continuously operating boilers, but excessive fire side residue can be an indication of failed internal components that are expelling unburned fuel into the combustion chamber, causing excess sooting. Excess sooting can also be the result of incomplete combustion due to inadequate excess air.

Water side Cleaning and Maintenance Program. Hot water boilers are usually closed loop systems, therefore the boiler water is treated before it enters the boiler and piping, and does not require any additional chemicals or daily water treatment tests. Steam boilers on the other hand, lose steam due to a variety of circumstances and therefore require additional water to maintain consistent water levels. Boiler water-side maintenance for steam

O\&M Tip: Every $40^{\circ} \mathrm{F}$ reduction in net stack temperature (outlet temperature minus inlet combustion air temperature) is estimated to save $1 \%$ to $2 \%$ of a boiler's fuel use. boilers consists of maintaining "soft water" for the feed-water and eliminating as much dissolved oxygen as possible. The first requires daily chemical monitoring and treatment of the feed-water. The presence of "hard-water" can create a "scale" buildup on the pipes. Once built up, the scale acts as an insulator and inhibits heat transfer into the boiler water. This creates excess heat in the combustion chamber that gets vented with the exhaust gases rather than absorbing into the process water. 
Scale formation on the water side of the boiler is due to poor water quality, as such, water must be treated before it enters the boiler. Table 9.2.3 presents the chemical limits recommended for BoilerWater Concentrations (Doty and Turner 2009).

The table columns highlight the limits according to the American Boiler Manufacturers Association (ABMA) for total solids, alkalinity, suspended solids, and silica. For each column heading the ABMA value represents the target limit while the column headed "Possible" represents the upper limit.

Table 9.2.3. Recommended limits for boiler-water concentrations

\begin{tabular}{|l|c|c|c|c|c|c|c|}
\hline $\begin{array}{c}\text { Drum Pressure } \\
\text { (psig) }\end{array}$ & \multicolumn{2}{|c|}{ Total Solids } & \multicolumn{2}{c|}{ Alkalinity } & \multicolumn{2}{c|}{ Suspended Solids } & Silica \\
\hline ABMA & Possible & ABMA & Possible & ABMA & Possible & ABMA \\
\hline to 300 & 3,500 & 6,000 & 700 & 1,000 & 300 & 250 & 125 \\
\hline 301 to 450 & 3,000 & 5,000 & 600 & 900 & 250 & 200 & 90 \\
\hline 451 to 600 & 2,500 & 4,000 & 500 & 500 & 150 & 100 & 50 \\
\hline 601 to 750 & 2,000 & 2,500 & 400 & 400 & 100 & 50 & 35 \\
\hline 751 to 900 & 1,500 & -- & 300 & 300 & 60 & - & 20 \\
\hline 901 to 1,000 & 1,250 & -- & 250 & 250 & 40 & -- & 8 \\
\hline 1,001 to 1,500 & 1,000 & -- & 200 & 200 & 20 & -- & 2 \\
\hline
\end{tabular}

The second water-side maintenance activity requires an operational de-aerator to remove excess oxygen. Excess oxygen in the feed-water piping can lead to oxygen pitting and ultimately corrosion which can cause pipe failure. As seen in Figures 9.2.8 through 9.2.13, proper de-aerator operation is essential to prevent oxygen pitting which can cause catastrophic failures in steam systems (Eckerlin 2006).

\section{Diagnostic Equipment}

Diagnostic equipment consists of a boiler-stack thermometer and water treatment test equipment necessary to properly analyze the boiler water. Local water treatment companies should be contacted to determine the appropriate additives and controlling agents needed for the particular water compositions that are unique to the given community or region.

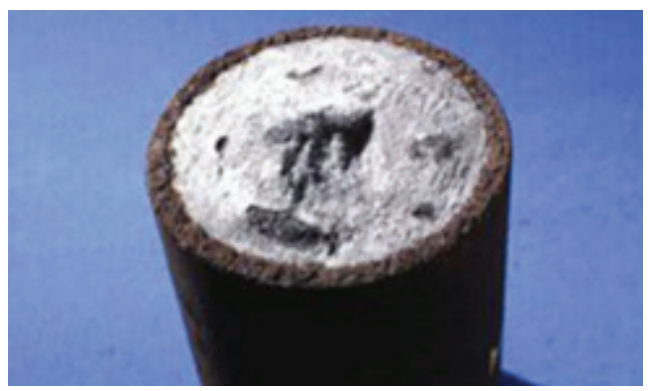

Figure 9.2.8. Boiler tube - scale deposit

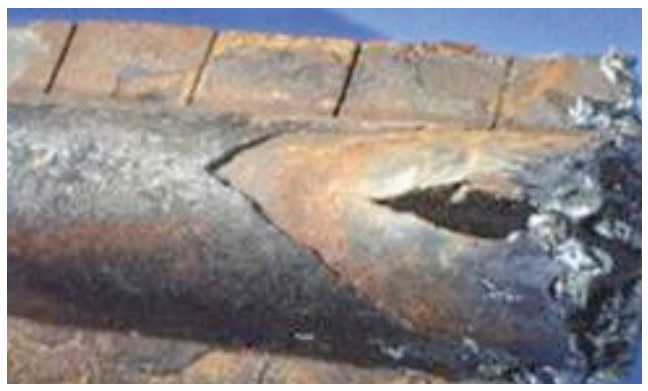

Figure 9.2.9. Boiler tube - failure (rupture) 


\section{Energy Savings and Economics}

Figure 9.2.14 presents energy loss percentage as a function of scale thickness. This information is very useful in estimating the resulting energy loss from scale build-up.

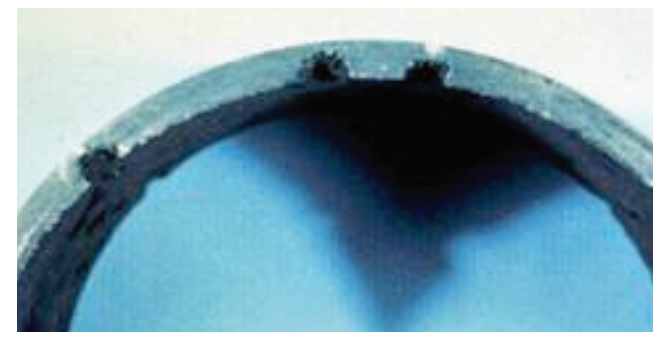

Figure 9.2.10. Feed-water pipe - oxygen pitting

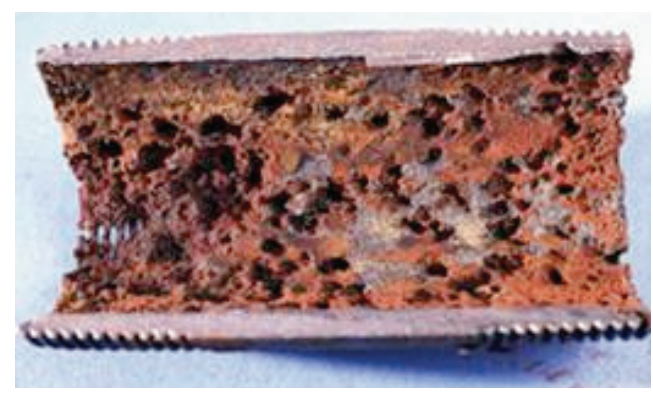

Figure 9.2.12. Condensate pipe - oxygen pitting

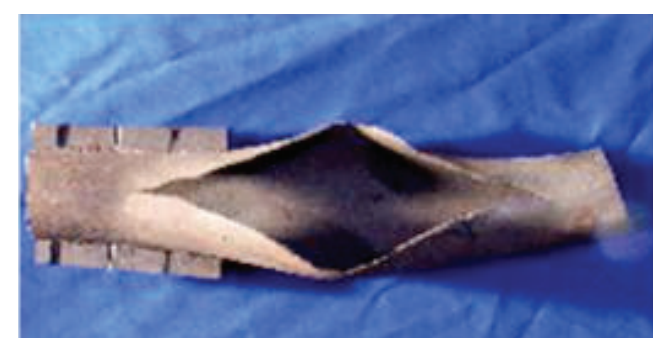

Figure 9.2.11. Boiler tube - failure (rupture)

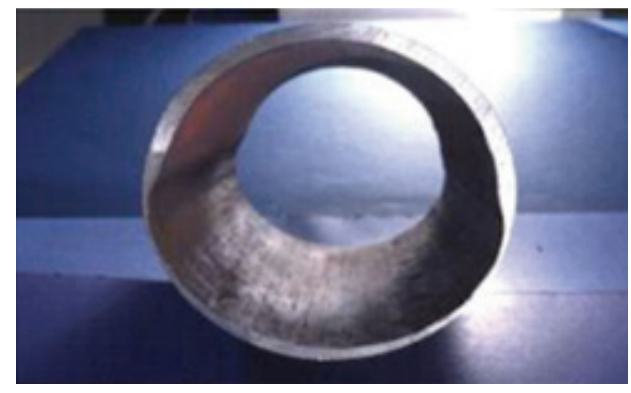

Figure 9.2.13. Condensate pipe - acidic corrosion

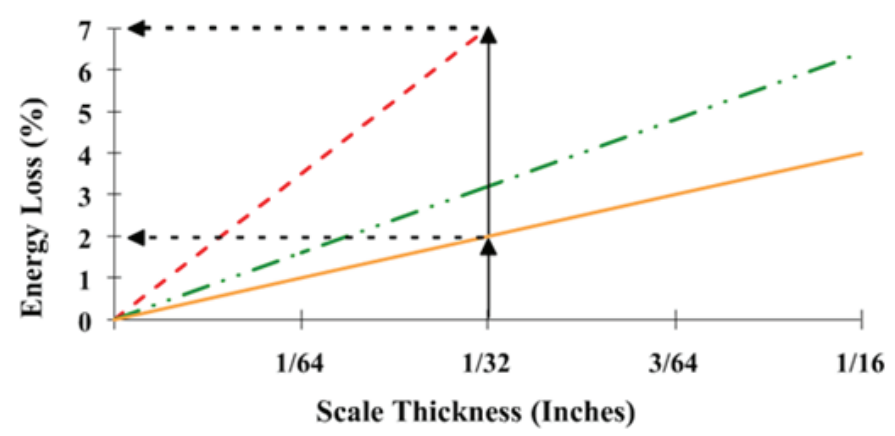

- Iron \& Silica - - High Iron Content

"Normal" Scale

Figure 9.2.14. Boiler energy losses versus scale thickness

\section{Estimated Annual Energy Savings}

The annual energy savings, which could be realized by removing scale from the water side of the boiler, can be estimated as follows:

$$
\text { Annual Energy Savings }=\left[\left(\frac{B L \times R F C}{E F F \times\left(1-\frac{E L_{1}}{100}\right)}\right)-\left(\frac{B L \times R F C}{E F F \times\left(1-\frac{E L_{2}}{100}\right)}\right)\right] \times H
$$


where

$\mathrm{BL}=$ current boiler load or firing rate, $\% / 100$

$\mathrm{RFC}=$ rated fuel consumption at full load, MMBtu/hr

$\mathrm{EFF}=$ boiler efficiency, \%/100

$\mathrm{EL}_{1}=$ current energy loss due to scale buildup, \%

$\mathrm{EL}_{2}=$ tuned energy loss with out scale buildup, \%

$\mathrm{H}=$ hours the boiler operates at the given cycling rate, hours

\section{Estimated Annual Cost Savings}

The annual cost savings, which could be realized by removing scale from the water side of the boiler, can be estimated as follows:

\section{Annual Cost Savings $=$ Annual Energy Savings $\times F C$}

where

$\mathrm{FC}=$ fuel cost, $\$ / \mathrm{MMBtu}$

\section{Boiler Tube Cleaning Energy Savings and Economics Example}

Example Synopsis: After visually inspecting the water side of a water tube boiler, normal scale $3 / 64$ inch thick was found on the inner surface of the tubes resulting in an estimated $3 \%$ efficiency penalty (see Figure 9.2.14). On-site O\&M personnel are going to manually remove the scale. The boiler currently operates 4,000 hrs per year, at an average firing rate of $50 \%$, with a boiler efficiency of $82 \%$ and a rated fuel consumption at full load of $10 \mathrm{MMBtu} / \mathrm{hr}$. The average fuel cost for the boiler is $\$ 9.00 /$ MMBtu.

The annual energy savings can be estimated as:

$$
\begin{gathered}
\text { Annual Energy Savings }=\left[\left(\frac{0.5 \times 10}{0.82 \times\left(1-\frac{3}{100}\right)}\right)-\left(\frac{0.5 \times 10}{0.82 \times\left(1-\frac{0}{100}\right)}\right)\right] \times 2,000 \\
\text { Annual Energy Savings }=377.17 \mathrm{MMBtu} / \mathrm{yr}
\end{gathered}
$$

The annual cost savings can be estimated as:

$$
\begin{gathered}
\text { Annual Cost Savings }=(377.17 \text { MMBtu/yr })(\$ 9.00 / M M B t u) \\
\text { Annual Cost Savings }=\$ 3,394 / y r
\end{gathered}
$$




\section{Operation and Maintenance - Persistence}

- Boiler operators should record the results of the boiler water-chemistry tests daily. The waterchemistry tests should be recorded and benchmarked to determine the necessary treatment.

- Boiler operators should complete daily records of the de-aerator's operation to ensure continuous and proper operation.

- Boiler operators should take daily logs of stack temperature for trending purposes as this is a highly diagnostic indication of boiler heat-transfer-surface condition. An increasing stack temperature can be indicative of reduced heat transfer.

- The fire side of the boiler should be cleaned once a year, and is usually mandated by local emission regulatory committee.

The Boiler Operations and Maintenance Checklist, sample boiler maintenance log, and water quality test report form are provided at the end of this section for review and consideration.

\subsubsection{Boiler Rules of Thumb}

In the report, Wise Rules for Industrial Energy Efficiency, the EPA develops a comprehensive list of rules-of-thumb relating to boiler efficiency improvements. Some of these rules are presented below (EPA 2003):

- Boiler Rule 1. Effective boiler load management techniques, such as operating on high fire settings or installing smaller boilers, can save over 7\% of a typical facility's total energy use with an average simple payback of less than 2 years.

- Boiler Rule 2. Load management measures, including optimal matching of boiler size and boiler load, can save as much as $50 \%$ of a boiler's fuel use.

- Boiler Rule 3. An upgraded boiler maintenance program including optimizing air-to-fuel ratio, burner maintenance, and tube cleaning, can save about $2 \%$ of a facility's total energy use with an average simply payback of 5 months.

- Boiler Rule 4. A comprehensive tune-up with precision testing equipment to detect and correct excess air losses, smoking, unburned fuel losses, sooting, and high stack temperatures can result in boiler fuel savings of $2 \%$ to $20 \%$.

- Boiler Rule 5. A 3\% decrease in flue gas $\mathrm{O}_{2}$ typically produces boiler fuel savings of $2 \%$.

- Boiler Rule 6. Every $40^{\circ} \mathrm{F}$ reduction in net stack temperature (outlet temperature minus inlet combustion air temperature is estimated to save $1 \%$ to $2 \%$ of a boiler's fuel use.

- Boiler Rule 7. Removing a 1/32 inch deposit on boiler heat transfer surfaces can decrease a boiler's fuel use by $2 \%$; removal of a $1 / 8$ inch deposit can decrease boiler fuel use by over $8 \%$.

- Boiler Rule 8. For every $11^{\circ} \mathrm{F}$ that the entering feedwater temperature is increased, the boiler's fuel use is reduced by $1 \%$. 


\subsubsection{Boiler Water-Use Best Practices}

Boilers and steam generators are not only used in comfort heating applications, they are also used in institutional kitchens, or in facilities where large amounts of process steam are used. These systems use varying amounts of water depending on the size of the system, the amount of steam used, and the amount of condensate returned.

To maintain optimal equipment performance and minimized water use, the following guidelines are suggested:

- Install meters on boiler system make up lines to track system water use and trend.

- Install meters on make-up lines to recirculating closed water loop heating systems so that leaks can be easily detected.

- Boiler blowdown is the periodic or continuous removal of water from a boiler to remove accumulated dissolved solids and/or sludges and is a common mechanism to reduce contaminant build-up. Proper control of blowdown is critical to boiler operation. Insufficient blowdown may lead to efficiency reducing deposits on heat transfer surfaces. Excessive blowdown wastes water, energy, and chemicals. The American Society of Mechanical Engineers (ASME 1994) has developed a consensus on operating practices for boiler feedwater and blowdown that is related to operating pressure, which applies for both steam purity and deposition control.

- Consider obtaining the services of a water treatment specialist to prevent system scale, corrosion and optimize cycles of concentration. Treatment programs should include periodic checks of boiler water chemistry and automated chemical delivery to optimize performance and minimize water use.

- Develop and implement a routine inspection and maintenance program to check steam traps and steam lines for leaks. Repair leaks as soon as possible.

- Develop and implement a boiler tuning program to be completed a minimum of once per operating year.

- Provide proper insulation on piping and on the central storage tank.

- Develop and implement a routine inspection and maintenance program on condensate pumps.

- Regularly clean and inspect boiler water and fire tubes. Reducing scale buildup will improve heat transfer and the energy efficiency of the system.

- Employ an expansion tank to temper boiler blowdown drainage rather than cold water mixing.

- Maintain your condensate return system. By recycling condensate for reuse, water supply, chemical use, and operating costs for this equipment can be reduced by up to 70 percent. A condensate return system also helps lower energy costs as the condensate water is already hot and needs less heating to produce steam than water from other make-up sources.

- Install an automatic blowdown system based on boiler water quality to better manage the treatment of boiler make-up water. 


\subsubsection{Case Studies}

\section{Combustion Efficiency of a Natural Gas Boiler (OIT 2001)}

A study of combustion efficiency of a $300 \mathrm{hp}$ natural-gas-fired heating boiler was completed. Flue gas measurements were taken and found a temperature of $400^{\circ} \mathrm{F}$ and a percentage of oxygen of $6.2 \%$. An efficient, well-tuned boiler of this type and size should have a percent oxygen reading of about $2 \%$ - corresponding to about 10\% excess air. This extra oxygen in the flue gas translates into excess air (and its heat) traveling out of the boiler system - a waste of energy.

The calculated savings from bringing this boiler to the recommended oxygen/excess air level was about $\$ 730$ per year. The cost to implement this action included the purchase of an inexpensive combustion analyzer costing $\$ 500$. Thus, the cost savings of $\$ 730$ would pay for the implementation cost of $\$ 500$ in about 8 months. Added to these savings is the ability to tune other boilers at the site with this same analyzer.

\subsubsection{Boiler Checklist, Sample Boiler Maintenance Log, and Water Quality Test}

\begin{tabular}{|c|c|c|c|c|c|}
\hline \multirow[b]{2}{*}{ Description } & \multirow[b]{2}{*}{ Comments } & \multicolumn{4}{|c|}{ Maintenance Frequency } \\
\hline & & Daily & Weekly & Monthly & Annually \\
\hline Boiler use/sequencing & Turn off/sequence unnecessary boilers & $\mathrm{X}$ & & & \\
\hline Overall visual inspection & $\begin{array}{l}\text { Complete overall visual inspection to } \\
\text { be sure all equipment is operating and } \\
\text { safety systems are in place }\end{array}$ & $\mathrm{X}$ & & & \\
\hline $\begin{array}{l}\text { Follow manufacturer's } \\
\text { recommended procedures in } \\
\text { lubricating all components }\end{array}$ & $\begin{array}{l}\text { Compare temperatures with tests } \\
\text { performed after annual cleaning }\end{array}$ & $\mathrm{X}$ & & & \\
\hline Check steam pressure & $\begin{array}{l}\text { Is variation in steam pressure as } \\
\text { expected under different loads? Wet } \\
\text { steam may be produced if the pressure } \\
\text { drops too fast }\end{array}$ & $\mathrm{X}$ & & & \\
\hline Check unstable water level & $\begin{array}{l}\text { Unstable levels can be a sign of } \\
\text { contaminates in feedwater, overloading } \\
\text { of boiler, equipment malfunction }\end{array}$ & $\mathrm{X}$ & & & \\
\hline Check burner & $\begin{array}{l}\text { Check for proper control and } \\
\text { cleanliness }\end{array}$ & $\mathrm{X}$ & & & \\
\hline Check motor condition & Check for proper function temperatures & $\mathrm{X}$ & & & \\
\hline $\begin{array}{l}\text { Check air temperatures in } \\
\text { boiler room }\end{array}$ & $\begin{array}{l}\text { Temperatures should not exceed or } \\
\text { drop below design limits }\end{array}$ & $\mathrm{X}$ & & & \\
\hline Boiler blowdown & $\begin{array}{l}\text { Verify the bottom, surface and water } \\
\text { column blow downs are occurring and } \\
\text { are effective }\end{array}$ & $\mathrm{X}$ & & & \\
\hline
\end{tabular}


Boiler Checklist (contd)

\begin{tabular}{|c|c|c|c|c|c|}
\hline \multirow{2}{*}{ Description } & \multirow{2}{*}{ Comments } & \multicolumn{4}{|c|}{ Maintenance Frequency } \\
\hline & & Daily & Weekly & Monthly & Annually \\
\hline Boiler logs & $\begin{array}{l}\text { Keep daily logs on: } \\
\text { - Type and amount of fuel used } \\
\text { - Flue gas temperature } \\
\text { - Makeup water volume } \\
\text { - Steam pressure, temperature, and } \\
\text { amount generated } \\
\text { Look for variations as a method of fault } \\
\text { detection }\end{array}$ & $\mathrm{X}$ & & & \\
\hline Check oil filter assemblies & $\begin{array}{l}\text { Check and clean/replace oil filters and } \\
\text { strainers }\end{array}$ & $\mathrm{X}$ & & & \\
\hline Inspect oil heaters & $\begin{array}{l}\text { Check to ensure that oil is at proper } \\
\text { temperature prior to burning }\end{array}$ & $\mathrm{X}$ & & & \\
\hline $\begin{array}{l}\text { Check boiler water } \\
\text { treatment }\end{array}$ & $\begin{array}{l}\text { Confirm water treatment system is } \\
\text { functioning properly }\end{array}$ & $\mathrm{X}$ & & & \\
\hline $\begin{array}{l}\text { Check flue gas temperatures } \\
\text { and composition }\end{array}$ & $\begin{array}{l}\text { Measure flue gas composition and } \\
\text { temperatures at selected firing positions } \\
\text { - recommended } \mathrm{O}_{2} \% \text { and } \mathrm{CO}_{2} \%\end{array}$ & & $\mathrm{X}$ & & \\
\hline & $\begin{array}{lll}\text { Fuel } & \mathrm{O}_{2} \% & \mathrm{CO}_{2} \% \\
\text { Natural gas } & 1.5 & 10 \\
\text { No. 2 fuel oil } & 2.0 & 11.5 \\
\text { No. 6 fuel oil } & 2.5 & 12.5\end{array}$ & & & & \\
\hline & $\begin{array}{l}\text { Note: percentages may vary due to fuel } \\
\text { composition variations }\end{array}$ & & & & \\
\hline Check all relief valves & Check for leaks & & $\mathrm{X}$ & & \\
\hline Check water level control & $\begin{array}{l}\text { Stop feedwater pump and allow } \\
\text { control to stop fuel flow to burner. } \\
\text { Do not allow water level to drop below } \\
\text { recommended level. }\end{array}$ & & $\mathrm{X}$ & & \\
\hline $\begin{array}{l}\text { Check pilot and burner } \\
\text { assemblies }\end{array}$ & $\begin{array}{l}\text { Clean pilot and burner following } \\
\text { manufacturer's guidelines. Examine for } \\
\text { mineral or corrosion buildup. }\end{array}$ & & $\mathrm{X}$ & & \\
\hline $\begin{array}{l}\text { Check boiler operating } \\
\text { characteristics }\end{array}$ & $\begin{array}{l}\text { Stop fuel flow and observe flame failure. } \\
\text { Start boiler and observe characteristics } \\
\text { of flame. }\end{array}$ & & $\mathrm{X}$ & & \\
\hline $\begin{array}{l}\text { Inspect system for water/ } \\
\text { steam leaks and leakage } \\
\text { opportunities }\end{array}$ & $\begin{array}{l}\text { Look for: leaks, defective valves and } \\
\text { traps, corroded piping, condition of } \\
\text { insulation }\end{array}$ & & $\mathrm{X}$ & & \\
\hline $\begin{array}{l}\text { Inspect all linkages on } \\
\text { combustion air dampers and } \\
\text { fuel valves }\end{array}$ & Check for proper setting and tightness & & $\mathrm{X}$ & & \\
\hline Inspect boiler for air leaks & Check damper seals & & $\mathrm{X}$ & & \\
\hline $\begin{array}{l}\text { Check blowdown and water } \\
\text { treatment procedures }\end{array}$ & $\begin{array}{l}\text { Determine if blowdown is adequate to } \\
\text { prevent solids buildup }\end{array}$ & & & $\mathrm{X}$ & \\
\hline Flue gases & $\begin{array}{l}\text { Measure and compare last month's } \\
\text { readings flue gas composition over } \\
\text { entire firing range }\end{array}$ & & & $\mathrm{X}$ & \\
\hline
\end{tabular}


Boiler Checklist (contd)

\begin{tabular}{|c|c|c|c|c|c|}
\hline \multirow{2}{*}{ Description } & \multirow{2}{*}{ Comments } & \multicolumn{4}{|c|}{ Maintenance Frequency } \\
\hline & & Daily & Weekly & Monthly & Annually \\
\hline Combustion air supply & $\begin{array}{l}\text { Check combustion air inlet to boiler } \\
\text { room and boiler to make sure openings } \\
\text { are adequate and clean }\end{array}$ & & & $\mathrm{X}$ & \\
\hline Check fuel system & $\begin{array}{l}\text { Check pressure gauge, pumps, filters } \\
\text { and transfer lines. Clean filters as } \\
\text { required. }\end{array}$ & & & $\mathrm{X}$ & \\
\hline $\begin{array}{l}\text { Check belts and packing } \\
\text { glands }\end{array}$ & $\begin{array}{l}\text { Check belts for proper tension. Check } \\
\text { packing glands for compression leakage. }\end{array}$ & & & $\mathrm{X}$ & \\
\hline Check for air leaks & $\begin{array}{l}\text { Check for air leaks around access } \\
\text { openings and flame scanner assembly. }\end{array}$ & & & $\mathrm{X}$ & \\
\hline Check all blower belts & $\begin{array}{l}\text { Check for tightness and minimum } \\
\text { slippage. }\end{array}$ & & & $\mathrm{X}$ & \\
\hline Check all gaskets & $\begin{array}{l}\text { Check gaskets for tight sealing, replace } \\
\text { if do not provide tight seal }\end{array}$ & & & $\mathrm{X}$ & \\
\hline Inspect boiler insulation & $\begin{array}{l}\text { Inspect all boiler insulation and casings } \\
\text { for hot spots }\end{array}$ & & & $\mathrm{X}$ & \\
\hline Steam control valves & $\begin{array}{l}\text { Calibrate steam control valves as } \\
\text { specified by manufacturer }\end{array}$ & & & $\mathrm{X}$ & \\
\hline Pressure reducing/regulating & Check for proper operation valves & & & $\mathrm{X}$ & \\
\hline Perform water quality test & $\begin{array}{l}\text { Check water quality for proper } \\
\text { chemical balance }\end{array}$ & & & $\mathrm{X}$ & \\
\hline Clean water side surfaces & $\begin{array}{l}\text { Follow manufacturer's recommendation } \\
\text { on cleaning and preparing water side } \\
\text { surfaces }\end{array}$ & & & & $\mathrm{X}$ \\
\hline Clean fire side & $\begin{array}{l}\text { Follow manufacturer's recommendation } \\
\text { on cleaning and preparing fire side } \\
\text { surfaces }\end{array}$ & & & & $X$ \\
\hline $\begin{array}{l}\text { Inspect and repair } \\
\text { refractories on fire side }\end{array}$ & $\begin{array}{l}\text { Use recommended material and } \\
\text { procedures }\end{array}$ & & & & $\mathrm{X}$ \\
\hline Relief valve & Remove and recondition or replace & & & & $\mathrm{X}$ \\
\hline Feedwater system & $\begin{array}{l}\text { Clean and recondition feedwater } \\
\text { pumps. Clean condensate receivers and } \\
\text { deaeration system }\end{array}$ & & & & $\mathrm{X}$ \\
\hline Fuel system & $\begin{array}{l}\text { Clean and recondition system pumps, } \\
\text { filters, pilot, oil preheaters, oil storage } \\
\text { tanks, etc. }\end{array}$ & & & & $\mathrm{X}$ \\
\hline Electrical systems & $\begin{array}{l}\text { Clean all electrical terminals. Check } \\
\text { electronic controls and replace any } \\
\text { defective parts. }\end{array}$ & & & & $\mathrm{X}$ \\
\hline $\begin{array}{l}\text { Hydraulic and pneumatic } \\
\text { valves }\end{array}$ & Check operation and repair as necessary & & & & $\mathrm{X}$ \\
\hline Flue gases & $\begin{array}{l}\text { Make adjustments to give optimal flue } \\
\text { gas composition. Record composition, } \\
\text { firing position, and temperature. }\end{array}$ & & & & $X$ \\
\hline Eddy current test & $\begin{array}{l}\text { As required, conduct eddy current test } \\
\text { to assess tube wall thickness }\end{array}$ & & & & $\mathrm{X}$ \\
\hline
\end{tabular}




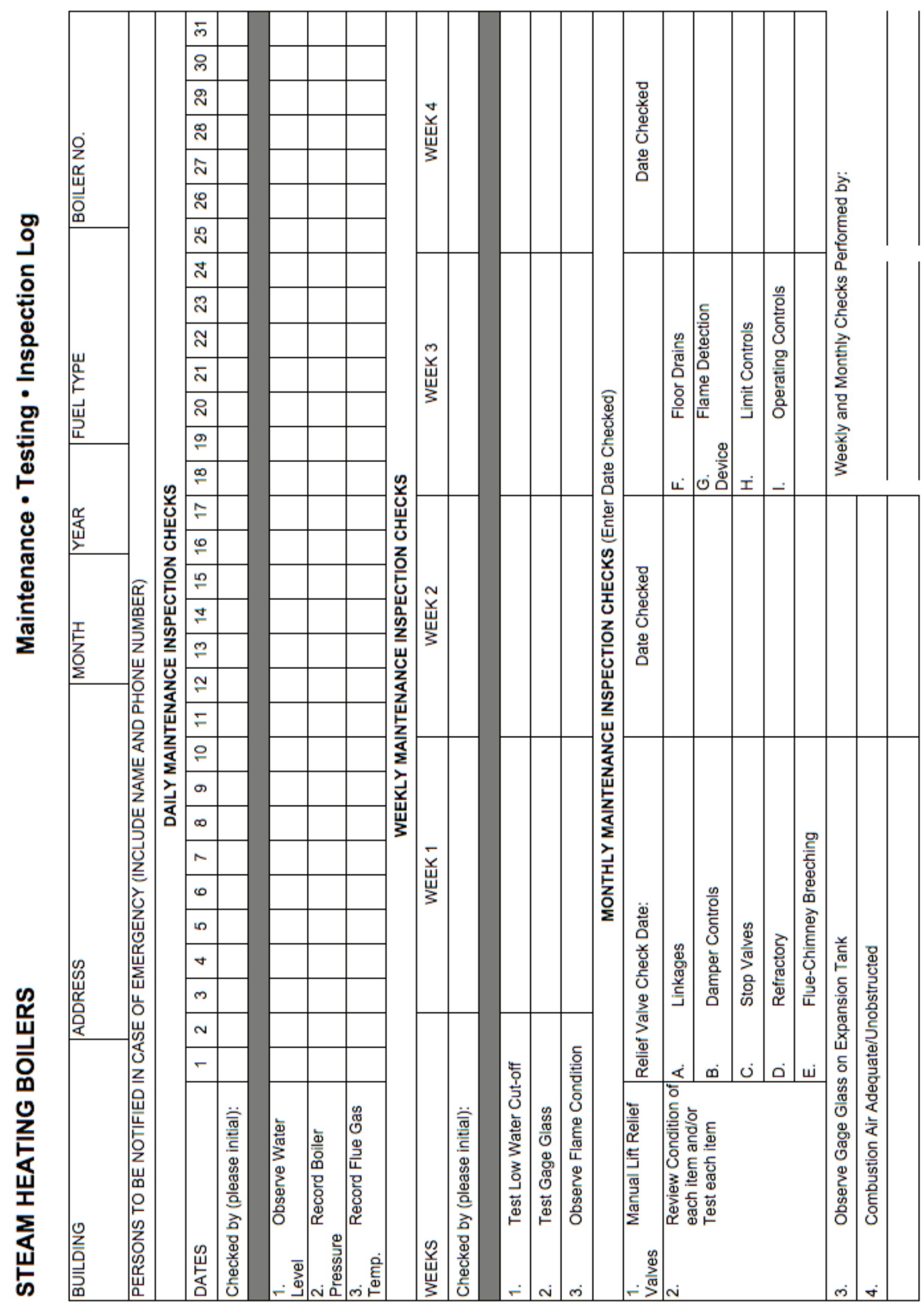


Boilers Checklist (contd)

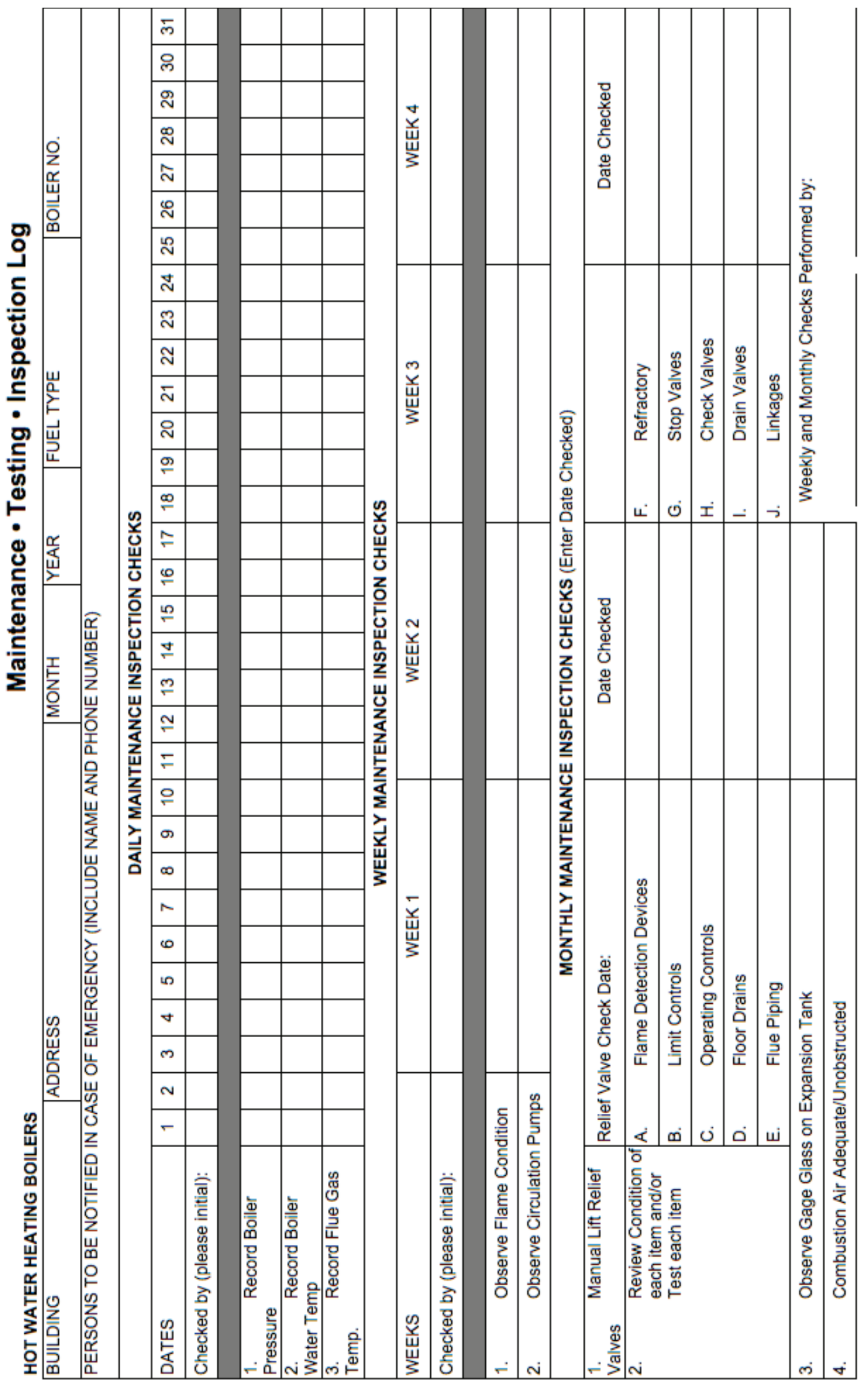




\begin{tabular}{|c|c|c|c|c|c|c|c|c|c|c|c|c|c|c|}
\hline \multicolumn{15}{|c|}{ Sample Water Quality Test Form } \\
\hline \multirow[t]{2}{*}{ Date } & \multirow{2}{*}{ 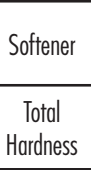 } & \multicolumn{3}{|c|}{ Feedwater } & \multicolumn{6}{|c|}{ Boiler Water Test } & \multicolumn{2}{|c|}{ Condensate } & $\begin{array}{l}\text { Lbs products } \\
\text { fed/day }\end{array}$ & \multirow[t]{2}{*}{$\begin{array}{l}\text { Operator } \\
\text { Initials }\end{array}$} \\
\hline & & $\begin{array}{l}\text { TDS or } \\
\text { Cond. }\end{array}$ & $\begin{array}{c}\text { Total } \\
\text { Hardness }\end{array}$ & pH & Bir. No. & 0-Alk & $\begin{array}{l}\text { TDS or } \\
\text { Cond. }\end{array}$ & $\mathrm{SiO}_{2}$ & $\mathrm{SO}_{3}$ & Poly or $\mathrm{PO}_{4}$ & pH & $\begin{array}{l}\text { TDS or } \\
\text { Cond. }\end{array}$ & & \\
\hline & & & & & & & & & & & & & & \\
\hline & & & & & & & & & & & & & & \\
\hline & & & & & & & & & & & & & & \\
\hline & & & & & & & & & & & & & & \\
\hline & & & & & & & & & & & & & & \\
\hline & & & & & & & & & & & & & & \\
\hline & & & & & & & & & & & & & & \\
\hline & & & & & & & & & & & & & & \\
\hline & & & & & & & & & & & & & & \\
\hline & & & & & & & & & & & & & & \\
\hline & & & & & & & & & & & & & & \\
\hline & & & & & & & & & & & & & & \\
\hline & & & & & & & & & & & & & & \\
\hline & & & & & & & & & & & & & & \\
\hline & & & & & & & & & & & & & & \\
\hline & & & & & & & & & & & & & & \\
\hline & & & & & & & & & & & & & & \\
\hline & & & & & & & & & & & & & & \\
\hline & & & & & & & & & & & & & & \\
\hline & & & & & & & & & & & & & & \\
\hline & & & & & & & & & & & & & & \\
\hline & & & & & & & & & & & & & & \\
\hline & & & & & & & & & & & & & & \\
\hline & & & & & & & & & & & & & & \\
\hline & & & & & & & & & & & & & & \\
\hline & & & & & & & & & & & & & & \\
\hline & & & & & & & & & & & & & & \\
\hline & & & & & & & & & & & & & & \\
\hline & & & & & & & & & & & & & & \\
\hline & & & & & & & & & & & & & & \\
\hline & & & & & & & & & & & & & & \\
\hline & & & & & & & & & & & & & & \\
\hline & & & & & & & & & & & & & & \\
\hline & & & & & & & & & & & & & & \\
\hline & & & & & & & & & & & & & & \\
\hline & & & & & & & & & & & & & & \\
\hline & & & & & & & & & & & & & & \\
\hline & & & & & & & & & & & & & & \\
\hline & & & & & & & & & & & & & & \\
\hline
\end{tabular}




\subsubsection{References}

ASME 1994. Consensus Operating Practic es for Control of Feedwater/Boiler Water Chemistry in Modern Industrial Boilers, American Society of Mechanical Engineers, New York, New York.

Combustion Analysis Basics. 2004. An Overview of Measurements, Methods and Calculations Used in Combustion Analysis. TSI Incorporated, Shoreview, Minnesota.

DOE. 2002. “Improve Your Boiler's Combustion Efficiency, Tip Sheet \#4.” In Energy Tips, DOE/ GO 102002-1 506, Office of Industrial Technologies, U.S. Department of Energy, Washington, D.C.

DOE. 2009. 2009 Buildings Energy Data Book. Prepared by Oak Ridge National Laboratory for the Office of Energy Efficiency and Renewable Energy, U.S. Department of Energy, Washington, D.C. Available at: http://buildingsdatabook.eren.doe.gov/.

Doty, S. and Turner WC. 2009. Energy Management Handbook. Seventh Edition, Fairmont Press, Lilburn, Georgia.

Dyer D. 1991. Maples, Glennon Boiler Efficiency Improvement, Boiler Efficiency Institute, Auburn, Alabama, Fifth Edition.

Dyer, D.F. and G. Maples. 1988. Boiler Efficiency Improvement. Boiler Efficiency Institute, Auburn, Alabama.

Eckerlin H. 2006. "Measuring and Improving Combustion Efficiency." In National IAC Webcast Lecture Series 2006, Lecture 2. U.S. Department of Energy, Industrial Assessment Center at North Carolina University, USDOE SAVE ENERGY NOW. Available URL: http://iac.rutgers.edu/lectures2006/arch_lectures.php.

EPA. 2003. Wise Rules for Industrial Energy Efficiency - A Tool Kit For Estimating Energy Savings and Greenhouse Gas Emissions Reductions. EPA 231-R-98-014, U.S. Environmental Protection Agency, Washington, D.C.

EPA. 2006. Heating and Cooling System Upgrades. U.S. Environmental Protection Agency, Washington, D.C. Available URL: http://www.energystar.gov.

Nakoneczny, G.J. July 1, 2001. Boiler Fitness Survey for Condition Assessment of Industrial Boilers, BR-1635, Babcock \& Wilcox Company, Charlotte, North Carolina.

Niles, R.G. and R.C. Rosaler. 1998. HVAC Systems and Components Handbook. Second Edition. McGraw-Hill, New York.

NTT. 1996. Boilers: An Operators Workshop. National Technology Transfer, Inc. Englewood, Colorado.

OIT. 2001. Modern Industrial Assessments: A Training Manual. Industrial Assessment Manual from the Office of Productivity and Energy Assessment at the State University of New Jersey, Rutgers, for the U.S. Department of Energy Office of Industrial Technology. 
The National Board of Boiler and Pressure Vessel Inspectors (NBBPVI). April 15, 2001a. School Boiler Maintenance Programs: How Safe are The Children. National Board BULLETIN, Fall 1997, Columbus, Ohio. [On-line report]. Available URL: http://www.nationalboard.org/Publications/Bulletin/ FA97.pdf.

The National Board of Boiler and Pressure Vessel Inspectors (NBBPVI). April 15, 2001b. Is preventive maintenance cost effective? National Board BULLETIN, Summer 2000, Columbus, Ohio. [Online report]. Available URL: http://www.nationalboard.org/Publications/Bulletin/SU00.pdf.

The National Board of Boiler and Pressure Vessel Inspectors (NBBPVI). April 15, 2001c. 1999 Incident Report. National Board BULLETIN, Summer 2000, Columbus, Ohio. [Online report]. Available URL: http://www.nationalboard.org/Publications/Bulletin/SU00.pdf.

Williamson-Thermoflo Company. July 12, 2001. GSA Gas Fired Steam Boilers: Boiler Manual. Part Number 550-110-738/0600, Williamson-Thermoflo, Milwaukee, Wisconsin. [Online report]. Available URL: http://www.williamson-thermoflo.com/pdf_files/550-110-738.pdf. 


\subsection{Steam Traps}

\subsubsection{Introduction}

Steam traps are automatic valves that release condensed steam (condensate) from a steam space while preventing the loss of live steam. They also remove non-condensable gases from the steam space. Steam traps are designed to maintain steam energy efficiency for performing specific tasks such as heating a building or maintaining heat for process. Once steam has transferred heat through a process and becomes hot water, it is removed by the trap from the steam side as condensate and either returned to the boiler via condensate return lines or discharged to the atmosphere, which is a wasteful practice (Gorelik and Bandes 2001).

\subsubsection{Types of Steam Traps (DOE 2001a)}

Steam traps are commonly classified by the physical process causing them to open and close. The three major categories of steam traps are 1) mechanical, 2) thermostatic, and 3) thermodynamic. In addition, some steam traps combine characteristics of more than one of these basic categories.

\subsubsection{Mechanical Steam Trap}

The operation of a mechanical steam trap is driven by the difference in density between condensate and steam. The denser condensate rests on the bottom of any vessel containing the two fluids. As additional condensate is generated, its level in the vessel will rise. This action is transmitted to a valve via either a "free float" or a float and connecting levers in a mechanical steam trap. One common type of mechanical steam trap is the inverted bucket trap shown in Figure 9.3.1. Steam entering the submerged bucket causes it to rise upward and seal the valve against the valve seat. As the steam condenses inside the bucket or if condensate is predominately entering the bucket, the weight of the bucket will cause it to sink and pull the valve away from the valve seat. Any air or other non-condensable gases entering the bucket will cause it to float and the valve to close. Thus, the top of the bucket has a small hole to allow non-condensable gases to escape. The hole must be relatively small to avoid excessive steam loss.

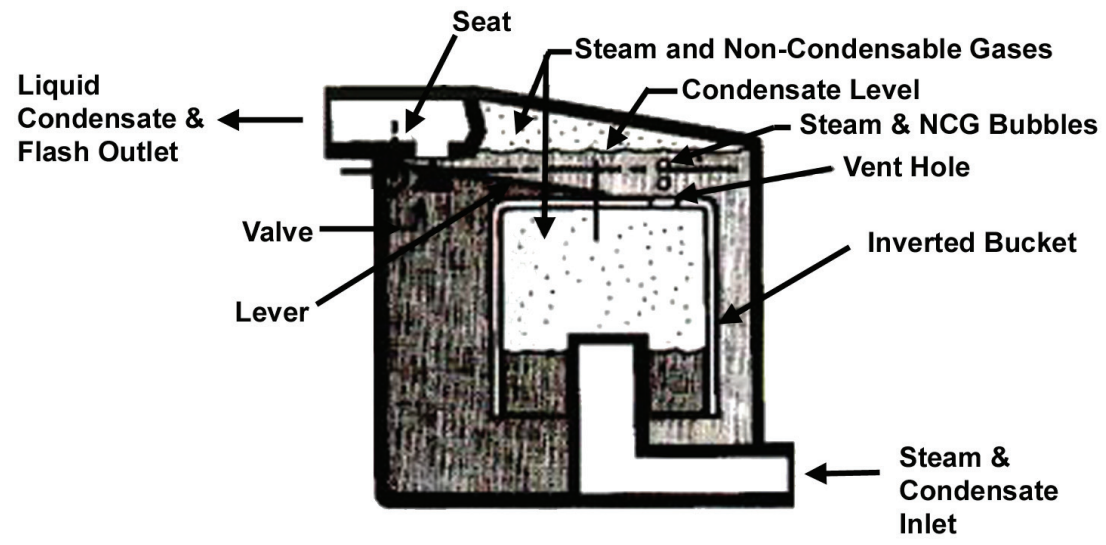

Figure 9.3.1. Inverted bucket steam trap 


\subsubsection{Thermostatic Steam Trap}

As the name implies, the operation of a thermostatic steam trap is driven by the difference in temperature between steam and sub-cooled condensate. Valve actuation is achieved via expansion and contraction of a bimetallic element or a liquid-filled bellows. Bimetallic and bellows thermostatic traps are shown in Figures 9.3.2 and 9.3.3. Although both types of thermostatic traps close when exposure to steam expands the bimetallic element or bellows, there are important differences in design and operating characteristics. Upstream pressure works to open the valve in a bimetallic trap, while expansion of the bimetallic element works in the opposite direction. Note that changes in the downstream pressure will affect the temperature at which the valve opens or closes. In addition, the nonlinear relationship between steam pressure and temperature requires careful design of the bimetallic element for proper response at different operating pressures. Upstream and downstream pressures have the opposite affect in a bellows trap; an increase in upstream pressure tends to close the valve and vice versa. While higher temperatures still work to close the valve, the relationship between temperature and bellows expansion can be made to vary significantly by changing the fluid inside the bellows. Using water within the bellows results in nearly identical expansion as steam temperature and pressure increase, because pressure inside and outside the bellows is nearly balanced.

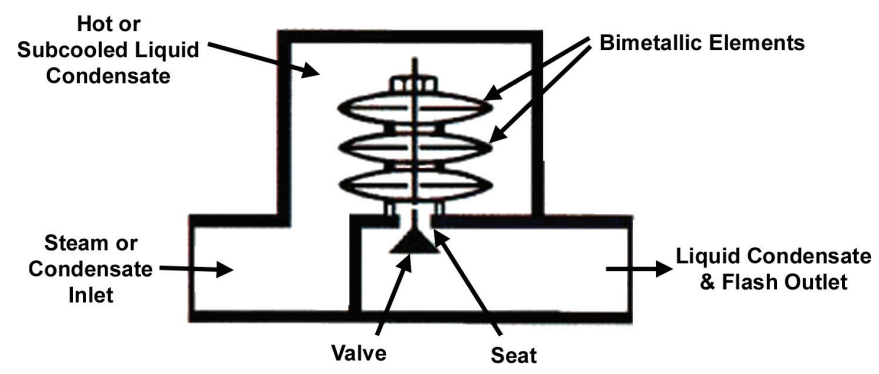

Figure 9.3.2. Bimetallic steam trap

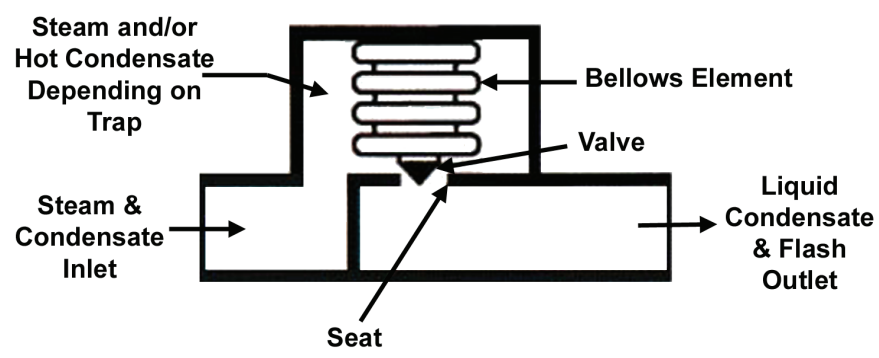

Figure 9.3.3. Bellows steam trap

In contrast to the inverted bucket trap, both types of thermostatic traps allow rapid purging of air at startup. The inverted bucket trap relies on fluid density differences to actuate its valve. Therefore, it cannot distinguish between air and steam and must purge air (and some steam) through a small hole. A thermostatic trap, on the other hand, relies on temperature differences to actuate its valve. Until warmed by steam, its valve will remain wide open, allowing the air to easily leave. After the trap warms up, its valve will close, and no continuous loss of steam through a purge hole occurs. Recognition of this deficiency with inverted bucket traps or other simple mechanical traps led to the development of float and thermostatic traps. The condensate release valve is driven by the level of condensate inside the trap, while an air release valve is driven by the temperature of the trap. A float and thermostatic trap, shown in Figure 9.3.4, has a 


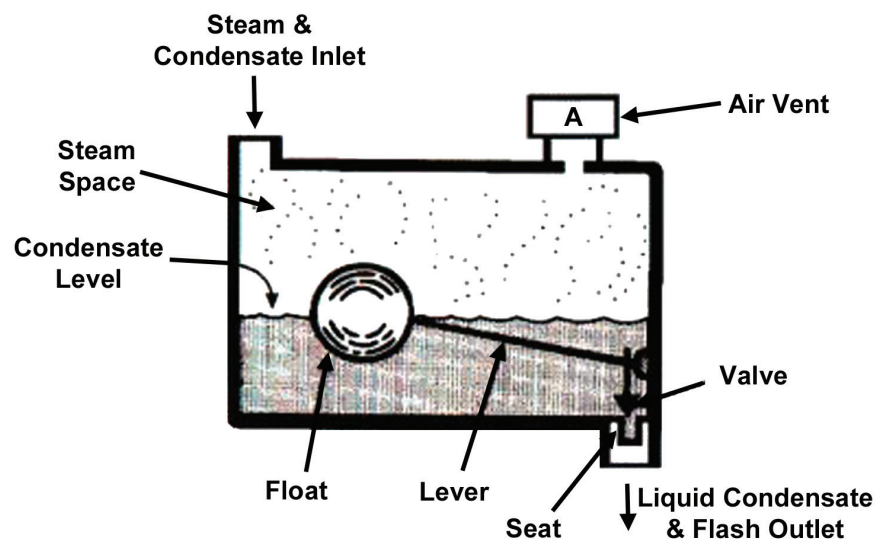

Figure 9.3.4. Float and thermostatic steam trap

float that controls the condensate valve and a thermostatic element. When condensate enters the trap, the float raises allowing condensate to exit. The thermostatic element opens only if there is a temperature drop around the element caused by air or other non-condensable gases.

\subsubsection{Thermodynamic Steam Traps}

Thermodynamic trap valves are driven by differences in the pressure applied by steam and condensate, with the presence of steam or condensate within the trap being affected by the design of the trap and its impact on local flow velocity and pressure. Disc, piston, and lever designs are three types of thermodynamic traps with similar operating principles; a disc trap is shown in Figure 9.3.5. When sub-cooled condensate enters the trap, the increase in pressure lifts the disc off its valve seat and allows the condensate to flow into the chamber and out of the trap. The narrow inlet port results in a localized increase in velocity and decrease in pressure as the condensate flows through the trap, following the first law of thermodynamics and the Bernoulli equation. As the condensate entering the trap increases in temperature, it will eventually flash to steam because of the localized pressure drop just described. This increases the velocity and decreases the pressure even further, causing the disc to snap close against the seating surface. The moderate pressure of the flash steam on top of the disc acts on the entire disc surface, creating a greater force than the higher pressure steam and condensate at the inlet, which acts on a much smaller portion on the opposite side of the disc. Eventually, the disc chamber will cool, the flash steam will condense, and inlet condensate will again have adequate pressure to lift the disc and repeat the cycle.

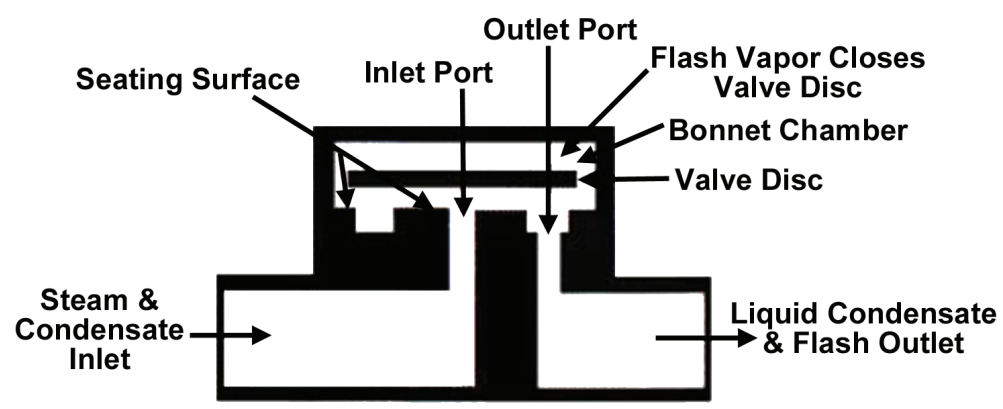

Figure 9.3.5. Disc steam trap 


\subsubsection{Other Steam Traps}

Another type of steam trap is the fixed orifice steam trap. Fixed orifice traps contain a set orifice in the trap body and continually discharge condensate. They are said to be self-regulating. As the rate of condensation decreases, the condensate temperature will increase, causing a throttling in the orifice and reducing capacity due to steam flashing on the downstream side. An increased load will decrease flashing and the orifice capacity will become greater (Gorelik and Bandes 2001). Orifice steam traps function best in situations with relatively constant steam loads. In situations where steam loads vary, the orifice trap either is allowing steam to escape or condensate to back up into the system. Varying loads, such as those found in most steam heating systems, are usually not good candidates for orifice steam traps. Before an orifice trap is specified, a careful analysis of appropriateness is recommended - preferably done by someone not selling orifice steam traps!

\subsubsection{Safety Issues}

When steam traps cause a backup of condensate in a steam main, the condensate is carried along with the steam. It lowers steam quality and increases the potential for water hammer. Not only will energy be wasted, equipment can be destroyed. Water hammer occurs as slugs of water are picked up at high speeds in a poorly designed steam main, in pipe coils, or where there is a lift after a steam trap. In some systems, the flow may be at 120 feet per second, which is about $82 \mathrm{mph}$. As the slug of condensate is carried along the steam line, it reaches an obstruction, such as a bend or a valve, where it is suddenly stopped. The effect of this impact can be catastrophic. It is important to note that the damaging effect of water hammer is due to steam velocity, not steam pressure. It can be as damaging in low-pressure systems as it can in high. This can actually produce a safety hazard, as the force of water hammer can blow out a valve or a strainer. Condensate in a steam system can be very destructive. It can cause valves to become wiredrawn (worn or ground) and unable to hold temperatures as required. Little beads of water in a steam line can eventually cut any small orifices the steam normally passes through.

Wiredrawing will eventually cut enough of the metal in a valve seat that it prevents adequate closure, producing leakage in the system (Gorelik and Bandes 2001).

\subsubsection{Cost and Energy Efficiency (DOE 2001a)}

Monitoring and evaluation equipment does not save any energy directly, but identifies traps that have failed and whether failure has occurred in an open or closed position. Traps failing in an open position allow steam to pass continuously, as long as the system is energized. The rate of energy loss can be estimated based on the size of the orifice and system steam pressure using the relationship illustrated in Figure 9.3.6. This figure is derived
The use of Figure 9.3.6 is illustrated via the following example. Inspection and observation of a trap led to the judgment that it had failed in the fully open position and was blowing steam. Manufacturer data indicated that the actual orifice diameter was $3 / 8$ inch. The trap operated at 60 psia and was energized for $50 \%$ of the year. Boiler efficiency was estimated to be $75 \%$. Calculation of annual energy loss for this example is illustrated below.

Estimating steam loss using Figure 9.3.6.

Assume: 3/8-inch diameter orifice steam trap, 50\% blocked, 60 psia saturated steam system, steam system energized $4,380 \mathrm{~h} / \mathrm{yr}$ ( $50 \%$ of year), $75 \%$ boiler efficiency.

- Using Figure 9.3.6 for 3/8-inch orifice and 60 psia steam, steam loss $=2,500$ million Btu/yr.

- Assuming trap is $50 \%$ blocked, annual steam loss estimate = 1,250 million Btu/yr.

- Assuming steam system is energized $50 \%$ of the year, energy loss $=625$ million Btu/yr.

- Assuming a fuel value of $\$ 5.00$ per million cubic feet (1 million Błu boiler input).

Annual fuel loss including boiler losses $=[(625$ million Btu $/ \mathrm{yr}) /(75 \%$ efficiency $)$ $(\$ 5.00 /$ million Btu $)]=\$ 4,165 / \mathrm{yr}$. 


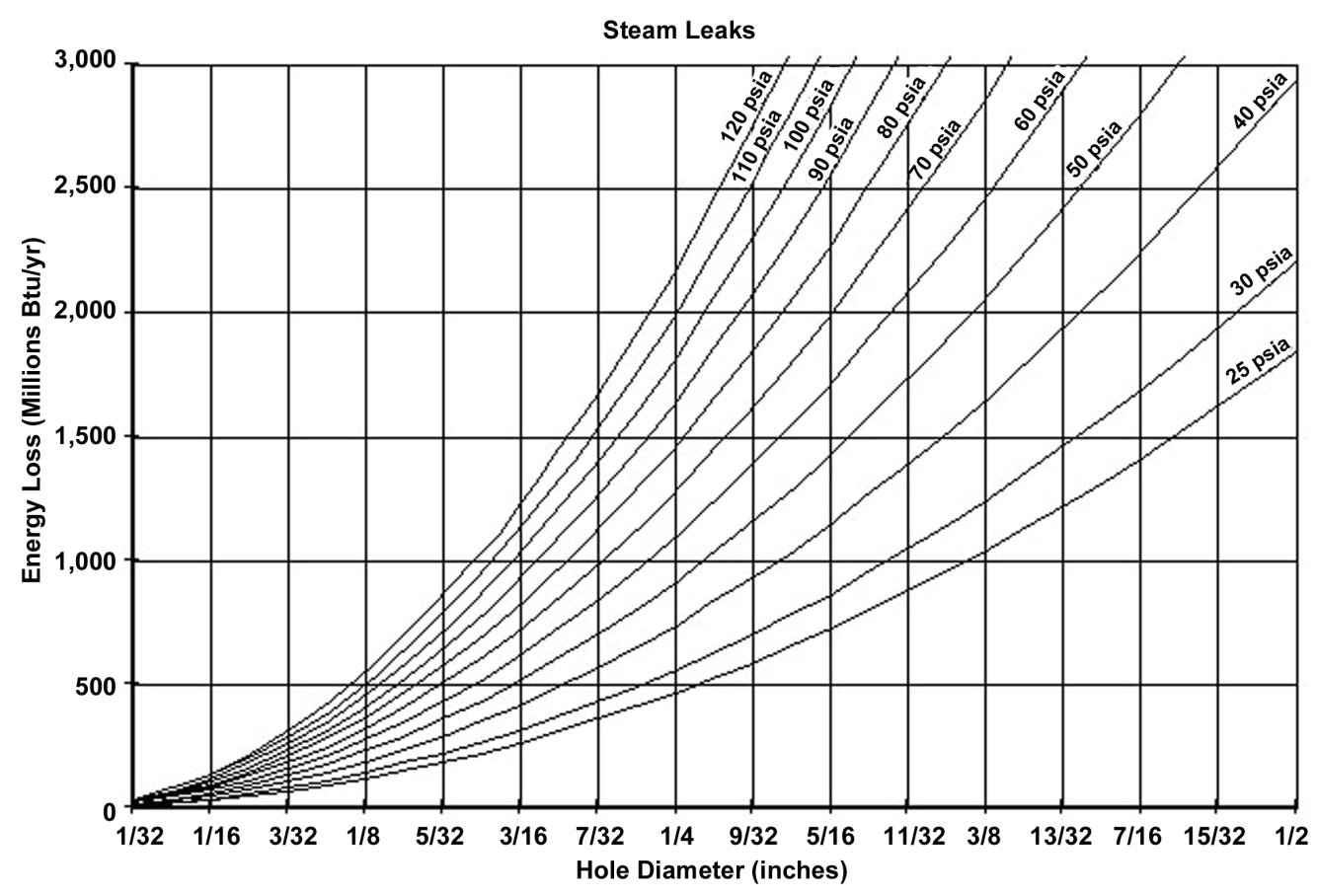

Figure 9.3.6. Energy loss from leaking steam traps.

from Grashof's equation for steam discharge through an orifice (Avallone and Baumeister 1986) and assumes the trap is energized (leaks) the entire year, all steam leak energy is lost, and that makeup water is available at an average temperature of $60^{\circ} \mathrm{F}$. Boiler losses are not included in Figure 9.3.6, so must be accounted for separately. Thus, adjustments from the raw estimate read from this figure must be made to account for less than full-time steam supply and for boiler losses.

The maximum steam loss rate occurs when a trap fails with its valve stuck in a fully opened position. While this failure mode is relatively common, the actual orifice size could be any fraction of the fully opened position. Therefore, judgment must be applied to estimate the orifice size associated with a specific malfunctioning trap. Lacking better data, assuming a trap has failed with an orifice size equivalent to one-half of its fully-opened condition is probably prudent.

\subsubsection{Other Costs}

Where condensate is not returned to the boiler, water losses will be proportional to the energy losses noted above. Feedwater treatment costs (i.e., chemical to treat makeup water) will also be proportionately increased. In turn, an increase in make-up water increases the blowdown requirement and associated energy and water losses. Even where condensate is returned to the boiler, steam bypassing a trap may not condense prior to arriving at the deaerator, where it may be vented along with the non-condensable gases. Steam losses also represent a loss in steam-heating capacity, which could result in an inability to maintain the indoor design temperature on winter days or reduce production capacity in process heating applications. Traps that fail closed do not result in energy or water losses, but can also result in significant capacity reduction (as the condensate takes up pipe cross-sectional area that otherwise would be available for steam flow). Of generally more critical concern is the physical damage that can result from the irregular movement of condensate in a twophase system, a problem commonly referred to as "water hammer." 


\subsubsection{Maintenance of Steam Traps}

Considering that many Federal sites have hundreds if not thousands of traps, and that one malfunctioning steam trap can cost thousands of dollars in wasted steam per year, steam trap maintenance should receive a constant and dedicated effort.

Excluding design problems, two of the most common causes of trap failure are oversizing and dirt.

- Oversizing causes traps to work too hard. In some cases, this can result in blowing of live steam. As an example, an inverted bucket trap can lose its prime due to an abrupt change in pressure. This will cause the bucket to sink, forcing the valve open.

- Dirt is always being created in a steam system. Excessive build-up can cause plugging or prevent a valve from closing. Dirt is generally produced from pipe scale or from over-treating of chemicals in a boiler.

\subsubsection{Characteristics of Steam Trap Failure (Gorelik and Bandes 2001)}

\section{- Mechanical Steam Trap (Inverted Bucket} Steam Trap) - Inverted bucket traps have a "bucket" that rises or falls as steam and/ or condensate enters the trap body. When steam is in the body, the bucket rises closing a valve. As condensate enters, the bucket sinks down, opening a valve and allowing the condensate to drain. Inverted bucket traps are ideally suited for water-hammer conditions but may be subject to freezing in low temperature climates if not insulated. Usually, when this trap fails, it fails open. Either the bucket loses its prime and sinks or impurities in the system may prevent the valve from closing.

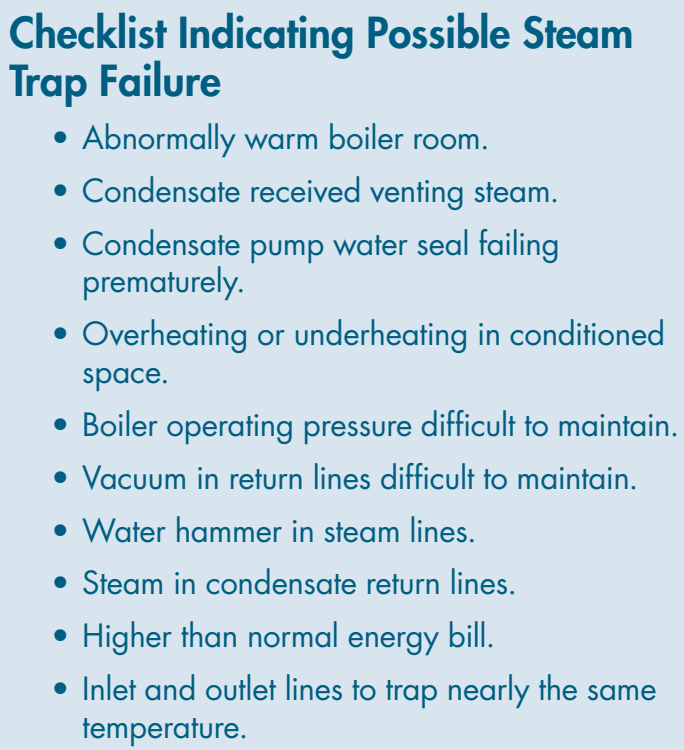

- Water hammer in steam lines.

- Steam in condensate return lines.

- Higher than normal energy bill.

- Inlet and outlet lines to trap nearly the same temperature.

- Thermostatic Steam Trap (Bimetallic and Bellows Steam Traps) - Thermostatic traps have, as the main operating element, a metallic corrugated bellows that is filled with an alcohol mixture that has a boiling point lower than that of water. The bellows will contract when in contact with condensate and expand when steam is present. Should a heavy condensate load occur, such as in start-up, the bellows will remain in a contracted state, allowing condensate to flow continuously. As steam builds up, the bellows will close. Therefore, there will be moments when this trap will act as a "continuous flow" type while at other times, it will act intermittently as it opens and closes to condensate and steam, or it may remain totally closed. These traps adjust automatically to variations of steam pressure but may be damaged in the presence of water hammer. They can fail open should the bellows become damaged or due to particulates in the valve hole, preventing adequate closing. There can be times when the tray becomes plugged and will fail closed. 
- Thermodynamic Steam Trap (Disc Steam Trap) - Thermodynamic traps have a disc that rises and falls depending on the variations in pressure between steam and condensate. Steam will tend to keep the disc down or closed. As condensate builds up, it reduces the pressure in the upper chamber and allows the disc to move up for condensate discharge. This trap is a good general type trap where steam pressures remain constant. It can handle superheat and "water hammer" but is not recommended for process, since it has a tendency to air-bind and does not handle pressure fluctuations well. A thermodynamic trap usually fails open. There are other conditions that may indicate steam wastage, such as "motor boating," in which the disc begins to wear and fluctuates rapidly, allowing steam to leak through.

- Other Steam Traps (Thermostatic and Float Steam Trap and Orifice Steam Trap) - Float and thermostatic traps consist of a ball float and a thermostatic bellows element. As condensate flows through the body, the float rises or falls, opening the valve according to the flow rate. The thermostatic element discharges air from the steam lines. They are good in heavy and light loads and on high and low pressure, but are not recommended where water hammer is a possibility. When these traps fail, they usually fail closed. However, the ball float may become damaged and sink down, failing in the open position. The thermostatic element may also fail and cause a "fail open" condition.

For the case of fixed orifice traps, there is the possibility that on light loads these traps will pass live steam. There is also a tendency to waterlog under wide load variations. They can become clogged due to particulate buildup in the orifice and at times impurities can cause erosion and damage the orifice size, causing a blow-by of steam.

\section{General Requirements for Safe and Efficient Operation of Steam Traps}

(Climate Technology Initiative 2001)

1. Every operating area should have a program to routinely check steam traps for proper operation. Testing frequency depends on local experiences but should at least occur yearly.

2. All traps should be numbered and locations mapped for easier testing and record-keeping. Trap supply and return lines should be noted to simplify isolation and repair.

3. Maintenance and operational personnel should be adequately trained in trap testing techniques. Where ultrasonic testing is needed, specially trained personnel should be used.

4. High maintenance priority should be given to the repair or maintenance of failed traps. Attention to such a timely maintenance procedure can reduce failures to $3 \%$ to $5 \%$ or less. A failed open trap can mean steam losses of 50 to $100 \mathrm{lb} / \mathrm{hr}$.

5. All traps in closed systems should have atmospheric vents so that trap operation can be visually checked. If trap headers are not equipped with these, they should be modified.

6. Proper trap design should be selected for each specific application. Inverted bucket traps may be preferred over thermostatic and thermodynamic-type traps for certain applications.

7. It is important to be able to observe the discharge from traps through the header. Although several different techniques can be used, the most foolproof method for testing traps is observation. Without proper training, ultrasonic, acoustical, and pyrometric test methods can lead to erroneous conclusions.

8. Traps should be properly sized for the expected condensate load. Improper sizing can cause steam losses, freezing, and mechanical failures.

9. Condensate collection systems should be properly designed to minimize frozen and/or premature trap failures. Condensate piping should be sized to accommodate $10 \%$ of the traps failing to open. 


\subsubsection{Performance Assessment}

\section{Methods}

Steam trap performance assessment is basically concerned with answering the following two questions: 1) Is the trap working correctly or not? 2) If not, has the trap failed in the open or closed position? Traps that fail open result in a loss of steam and its energy. Where condensate is not returned, the water is lost as well. The result is significant economic loss, directly via increased boiler plant costs, and potentially indirectly, via decreased steam heating capacity. Traps that fail closed do not result in energy or water losses, but can result in significantly reduced heating capacity and/or damage to steam heating equipment.

There are three basic methods for evaluating a steam trap that are commonly discussed in the literature: sight, sound, and temperature. Because of the challenges associated with steam trap assessment, at least two of the three methods should be used to increase the chances of correctly identifying the condition of a steam trap.

\section{Sight Method}

The sight method is usually based on a visual observation of the fluid downstream of the trap. This is possible if there is no condensate recovery system or if test valves have been installed to allow a momentary discharge of the downstream fluid from the condensate recovery system. In either case, the steam trap evaluator must be able to distinguish between "flash" steam, which is characteristic of a properly working trap, and "live" steam, which is characteristic of a trap that has failed open and is leaking or blowing a significant amount of steam. Flash steam is created when a portion of the condensate flashes to vapor upon expansion to atmospheric pressure. Flash steam is characterized by a relatively lazy, billowy plume. Live steam, on the other hand, will form a much sharper, higher velocity plume that may not be immediately visible as it exits the test valve or steam trap. The difference between live steam and flash steam is illustrated in Figure 9.3.7.
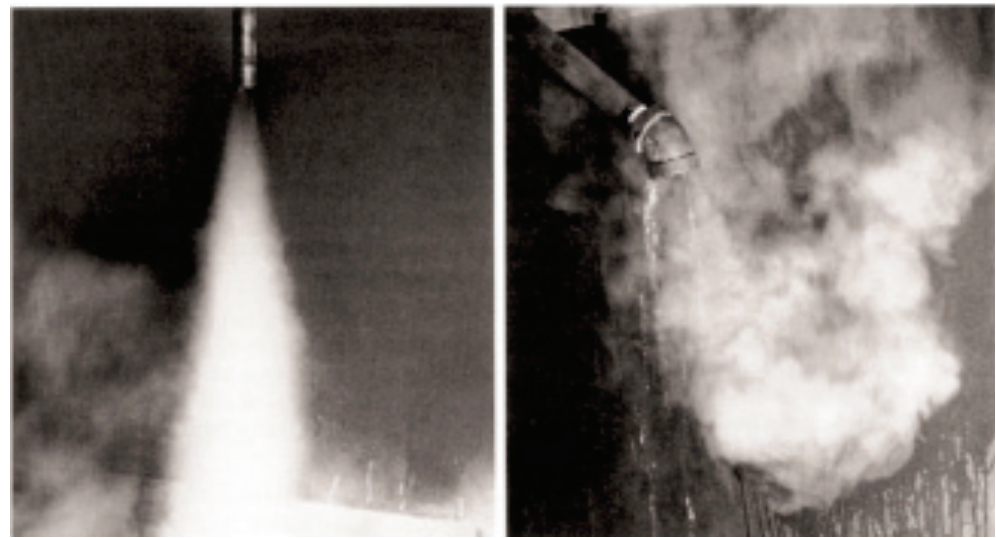

Figure 9.3.7. Live steam (left) versus flash steam (right)

Sight glasses can also be used for a visual observation, but have some drawbacks that must be overcome or avoided. First, steam and condensate are both expected to exist upstream and downstream of the trap (live steam on the upstream side and flash steam on the downstream side). Second, the view through a sight glass tends to deteriorate over time because of internal or external fouling. Third, both steam and condensate will appear as clear fluids within the pipe. In response to the first and third concerns, sight glasses have been developed with internal features that allow the proportion of steam and condensate to be identified. 


\section{Sound Method}

Mechanisms within steam traps and the flow of steam and condensate through steam traps generate sonic (audible to the human ear) and supersonic sounds. Proper listening equipment, coupled with the knowledge of normal and abnormal sounds, can yield reliable assessments of steam trap working condition. Listening devices range from a screwdriver or simple mechanic's stethoscope that allow listening to sonic sounds to more sophisticated electronic devices that allow "listening" to sonic or sonic and ultrasonic sounds at selected frequencies. The most sophisticated devices compare measured sounds with the expected sounds of working and non-working traps to render a judgment on trap condition.

\section{Temperature Method}

Measuring the temperature of the steam trap is generally regarded as the least reliable of the three basic evaluation techniques. Saturated steam and condensate exist at the same temperature, of course, so it's not possible to distinguish between the two based on temperature. Still, temperature measurement provides important information for evaluation purposes. A cold trap (i.e., one that is significantly cooler than the expected saturated steam temperature) indicates that the trap is flooded with condensate, assuming the trap is in service. A flooded trap could mean several things, but barring measurement during startup, when flooding can be expected, generally indicates a problem that needs to be addressed. Downstream temperature measurement may also yield useful clues in certain circumstances. For example, the temperature downstream of a trap should drop off relatively quickly if the trap is working properly (mostly condensate immediately past the trap). On the other hand, the temperature downstream of the trap will be nearly constant if significant steam is getting past the trap. Care must be taken not to use this technique where other traps could affect downstream conditions, however. Temperature measurement methods, like sound measurement, vary tremendously in the degree of sophistication. At the low-end, spitting on the trap and watching the sizzle provides a general indication of temperature. For the more genteel, a squirt bottle filled with water will serve the same purpose. Alternatively, a glove-covered hand can provide a similar level of accuracy. More sophisticated are various types of temperature sensitive crayons or tapes designed to change color in different temperature ranges. Thermometers, thermocouples, and other devices requiring contact with the trap offer better precision. Finally, non-contact (i.e., infrared) temperature measuring devices (sensing thermometers and cameras) provide the precision of thermometers and thermocouples without requiring physical contact. Non-contact temperature measurement makes it easier to evaluate traps that are relatively difficult or dangerous to access closely.

\section{Automated Diagnostics}

In recent years a number of manufacturers have devised self-diagnosing steam trap routines. In most cases these are based on absence or presence of condensate in the trap as measured by either temperature and/or conductivity. These systems can be connected to an energy management and control system to notify facilities staff of condition or failure. While the remote and self diagnosing aspects of these systems is quite attractive, the vendor should make the facility manager aware that once the sensing element is compromised, the system may be outputting incorrect information and thus lead to a false sense of security. While these systems hold great promise, the user needs to be aware that they are another item that needs to be maintained for proper function. 
Recommended time schedule for testing steam traps

- Process steam traps: Every 3 months

- High pressure steam traps: Every 6 months

- Low to medium pressure steam traps: Every 6 months

At an absolute minimum, all steam traps should be surveyed and tested at least once per year

- Building heating steam traps: Twice a heating season

\subsubsection{Diagnostic Equipment}

- Thermography - An infrared thermometer or camera allows for an accurate, non-contact assessment of temperature. Applications for steam traps include testing for proper function and insulation assessments around the traps. More information on thermography can be found in Chapter 6.

- Ultrasonic analyzer - Steam traps emit very distinct sound patterns; each trap type is said to have a particular signature. These sounds are not audible to the unaided ear. Using an ultrasonic detector, the analyst is able to isolate the frequency of sound being emitted by the steam trap, compare it to trended sound signatures, and make an assessment. Changes in these ultrasonic wave emissions are indicative of changes in steam trap function. More information on ultrasonic analysis can be found in Chapter 6 .

\subsubsection{Relevant Operational/Energy Efficiency Measures}

There are many operational/energy efficiency measures that could be presented for proper steam trap operation and control. The following section focuses on the most prevalent O\&M recommendations having the greatest energy impacts at Federal facilities. These recommendations are also some of the most easily implemented for boiler operators and O\&M contractors.

Steam Trap Measure: Cost Evaluation of Failed Steam Trap

Table 9.3.1 below can be used to approximate the energy loss from a failed-open steam trap (DOE 2006).

Table 9.3.1. Steam trap discharge rate

\begin{tabular}{|c|c|c|c|c|}
\hline \multirow{2}{*}{$\begin{array}{c}\text { Trap Orifice } \\
\text { Diameter (in.) }\end{array}$} & \multicolumn{4}{|c|}{ Steam Loss (lb/hr) } \\
\cline { 2 - 5 } & 15 & 100 & 150 & 300 \\
\hline & 0.85 & 3.3 & 4.8 & - \\
\hline $1 / 32$ & 3.40 & 13.2 & 18.9 & 36.2 \\
\hline $1 / 16$ & 13.7 & 52.8 & 75.8 & 145 \\
\hline $1 / 8$ & 30.7 & 119 & 170 & 326 \\
\hline $3 / 16$ & 54.7 & 211 & 303 & 579 \\
\hline $1 / 4$ & 123 & 475 & 682 & 1,303 \\
\hline $3 / 8$ & & & & \\
\hline
\end{tabular}


Estimated Annual Energy Savings. The annual energy savings, which could be realized by repairing a failed steam trap, can be estimated as follows (DOE 2006).

where

$$
\text { Annual Energy Savings }=\frac{D R \times H}{1,000}
$$

$\mathrm{DR}=$ discharge rate of steam, $\mathrm{lb} / \mathrm{hr}$

$\mathrm{H}=$ annual hours of operation, hours

Estimated Annual Cost Savings. The annual cost savings, which could be realized by repairing a failed steam trap, can be estimated as follows:

$$
\text { Annual Cost Savings = Annual Energy Savings } \times \text { FCS }
$$

where

FCS $=$ average fuel cost of steam, $\$ / 1,000 \mathrm{lb}$ of steam

It should be noted that this cost savings calculation assumes on-site personnel have benchmarked the fuel cost of steam production. This will display how much the site is paying to produce steam, on a $\$ / 1,000 \mathrm{lb}$ of steam basis.

\section{Steam Trap Replacement Energy Savings and Economics Example}

\section{Example Synopsis}

A steam system audit reveals a failed steam trap in a steam line pressurized to $100 \mathrm{psig}$. The steam trap has an orifice diameter of $1 / 8$ of an inch and results in a loss rate of $52.8 \mathrm{lb} / \mathrm{hr}$ (see Table 9.3.1). The line is energized $8,000 \mathrm{hrs} / \mathrm{yr}$ and the current fuel costs are $\$ 10 / 1,000 \mathrm{lb}$ of steam.

The annual energy savings can be estimated as:

$$
\begin{gathered}
\text { Annual Energy Savings }=\frac{52.8 \times 8,000}{1,000} \\
\text { Annual Energy Savings }=422.4(1,000 \mathrm{lb} / \mathrm{yr})
\end{gathered}
$$

The annual cost savings can be estimated as:

$$
\begin{gathered}
\text { Annual Cost Savings }=(422.4(1,000 \text { lb/yr }))(\$ 10.00 / 1,000 l b) \\
\text { Annual Cost Savings }=\$ 4,224 / y r
\end{gathered}
$$




\subsubsection{Steam Trap Water-Use Best Practices}

The predominant impact steam traps have on water use relates to proper function. A steam trap that is failed open coupled to distribution system with a leaky or non-existent condensate return will be losing water, via condensed steam, at a significant rate. Whether failed open or closed an improperly functioning steam trap impacts the entire system by introducing inefficiency. Any inefficiency results in a less-than-optimal operation leading to increased resource use - water is one of those resources.

\subsubsection{Case Studies}

\section{Event at a Major Research Government Facility (DOE 2001b)}

On October 10, 1986, a condensate-induced water hammer at a major research government facility injured four steamfitters-two of them fatally. One of the steamfitters attempted to activate an 8-inch steam line located in a manhole. He noticed that there was no steam in either the steam line or the steam trap assembly and concluded that the steam trap had failed. Steam traps are devices designed to automatically remove condensate (liquid) from steam piping while the steam system is operating in a steady state. Without shutting off the steam supply, he and another steamfitter replaced the trap and left.

Later the first steamfitter, his supervisor, and two other steamfitters returned and found the line held a large amount of condensate. They cracked open a gate valve to drain the condensate into an 8 -inch main. They cracked the valve open enough to allow water to pass, but this was too far open to control the sudden movement of steam into the main after all the condensate had been removed. A series of powerful water hammer surges caused the gaskets on two blind flanges in the manhole to fail, releasing hot condensate and steam into the manhole. A photograph of one failed gasket is shown in Figure 9.3.8. All four steamfitters suffered external burns and steam inhalation. Two of them died as a result.

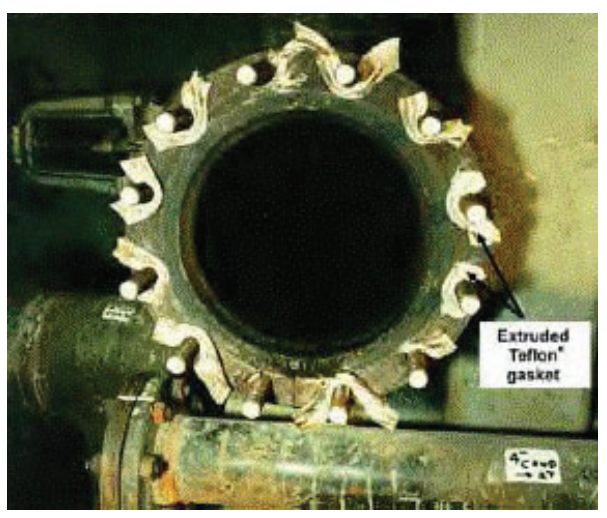

Figure 9.3.8. Failed gasket on blind flange

A Type A Accident Investigation Board determined that the probable cause of the event was a lack of procedures and training, resulting in operational error. Operators had used an in-line gate valve to remove condensate from a steam line under pressure instead of drains installed for that purpose.

The board also cited several management problems. There had been no Operational Readiness Review prior to system activation. Laboratory personnel had not witnessed all the hydrostatic and pressure testing, nor had all test results been submitted, as required by the contract. Documentation for design changes was inadequate. 


\section{Event at a Georgia Hospital (DOE 2001c)}

In June 1991, a valve gasket blew out in a steam system at a Georgia hospital. Operators isolated that section of the line and replaced the gasket. The section was closed for 2 weeks, allowing condensate to accumulate in the line. After the repair was completed, an operator opened the steam valve at the upstream end of the section. He drove to the other end and started to open the downstream steam valve. He did not open the blow-off valve to remove condensate before he opened the steam valve. Water hammer ruptured the valve before it was $20 \%$ open, releasing steam and condensate and killing the operator.

Investigators determined that about 1,900 pounds of water had accumulated at the low point in the line adjacent to the repaired valve, where a steam trap had been disconnected. Because the line was cold, the incoming steam condensed quickly, lowering the system pressure and accelerating the steam flow into the section. This swept the accumulated water toward the downstream valve and may have produced a relatively small steam-propelled water slug impact before the operator arrived. About 600 pounds of steam condensed in the cold section of the pipe before equilibrium was reached.

When the downstream valve was opened, the steam on the downstream side rapidly condensed into water on the upstream side. This flow picked up a 75 cubic foot slug of water about 400 feet downstream of the valve. The slug sealed off a steam pocket and accelerated until it hit the valve, causing it to rupture.

Investigators concluded that the accident could have been prevented if the operator had allowed the pipe to warm up first and if he had used the blow-off valve to remove condensate before opening the downstream valve.

\section{Maintenance of Steam Traps}

A steam trap assessment of three VA hospitals located in Providence, RI, Brockton, MA, and West Roxbury, MA was conducted with help of FEMP's SAVEnergy Program. The facilities are served by 15,40 , and 80 psig steam lines. The Providence system alone includes approximately 1,100 steam traps.

The assessment targeted steam trap performance and the value of steam losses from malfunctioning traps. The malfunctioning traps were designated for either repair or replacement. Included in this assessment was a training program on steam trap testing.

The cost of the initial steam trap audit was $\$ 25,000$ for the three facilities. Estimated energy savings totaled $\$ 104,000$. The cost of repair and replacement traps was about $\$ 10,000$. Thus, the cost savings of $\$ 104,000$ would pay for the implementation cost of $\$ 35,000$ in about 4 months. 


\subsubsection{Steam Traps Checklist}

\begin{tabular}{|c|c|c|c|c|c|}
\hline \multirow{2}{*}{ Description } & \multirow{2}{*}{ Comments } & \multicolumn{4}{|c|}{ Maintenance Frequency } \\
\hline & & Daily & Weekly & Monthly & Annually \\
\hline Test steam traps & $\begin{array}{l}\text { Daily/weekly test recommended for } \\
\text { high-pressure traps ( } 250 \text { psig or more) }\end{array}$ & $\mathrm{X}$ & & & \\
\hline Test steam traps & $\begin{array}{l}\text { Weekly/monthly test recommended } \\
\text { for medium-pressure traps }(30-250 \\
\text { psig) }\end{array}$ & & $\mathrm{X}$ & & \\
\hline Test steam traps & $\begin{array}{l}\text { Monthly/annually test recommended } \\
\text { for low-pressure traps }\end{array}$ & & & $\mathrm{X}$ & \\
\hline Repair/replace steam traps & $\begin{array}{l}\text { When testing shows problems. } \\
\text { Typically, traps should be replaced } \\
\text { every } 3-4 \text { years. }\end{array}$ & & & $\mathrm{X}$ & \\
\hline Replace steam traps & $\begin{array}{l}\text { When replacing, take the time to } \\
\text { make sure traps are sized properly. }\end{array}$ & & & & $\mathrm{X}$ \\
\hline
\end{tabular}

\subsubsection{References}

Avallone, E.A. and T. Baumeister, editors. 1986. Marks' Standard Handbook for Mechanical Engineers. 9th ed. McGraw-Hill, New York.

Climate Technology Initiative. April 7, 2001. Steam Systems. CTI Energy Efficiency Workshop, September 19-26, 1999, Yakkaichi, Japan. Reprinted with permission of the Climate Technology Initiative.

DOE. 2006. "Inspect and Repair Steam Traps, Steam Tip Sheet 1." In Energy Tips, DOE/GO102006-2248, Industrial Technologies Program, U.S. Department of Energy, Washington, D.C.

Gorelik, B. and A. Bandes. August 15, 2001. Inspect Steam Traps for Efficient System. [Online report]. Available URL: http://www.maintenanceresources.com/Referencelibrary/SteamTraps/Inspect.htm. Reprinted with permission of Mr. Bruce Gorelik.

U.S. Department of Energy (DOE). March 30, 2001a. Steam Trap Performance Assessment. Federal Technology Alert.

U.S. Department of Energy (DOE). March 30, 2001b. 1986 Event at Brookhaven National Laboratory. NFS Safety Notes, Issue No. 98-02, November 1998, Office of Operating Experience Analysis and Feedback, Office of Nuclear and Facility Safety [Online report]. Available URL: http://tis.eh.doe.gov/ web/oeaf/lessons_learned/ons/sn9802.html.

U.S. Department of Energy (DOE). March 30, 2001c. 1991 Event at a Georgia Hospital. NFS Safety Notes, Issue No. 98-02, November 1998, Office of Operating Experience Analysis and Feedback, Office of Nuclear and Facility Safety [Online report]. Available URL: http://tis.eh.doe.gov/web/oeaf/ lessons_learned/ons/sn9802.html. 


\subsection{Chillers}

\subsubsection{Introduction}

A chiller can be generally classified as a refrigeration system that cools water. Similar to an air conditioner, a chiller uses either a vapor-compression or absorption cycle to cool. Once cooled, chilled water has a variety of applications from space cooling to process uses.

\subsubsection{Types of Chillers}

\subsubsection{Mechanical Compression Chiller (Dyer and Maples 1995)}

The refrigeration cycle of a simple mechanical compression system is shown in Figure 9.4.1. The mechanical compression cycle has four basic components through which the refrigerant passes: (1) the evaporator, (2) the compressor, (3) the condenser, and (4) the expansion valve. The evaporator operates at a low pressure (and low temperature) and the condenser operates at high pressure (and temperature).

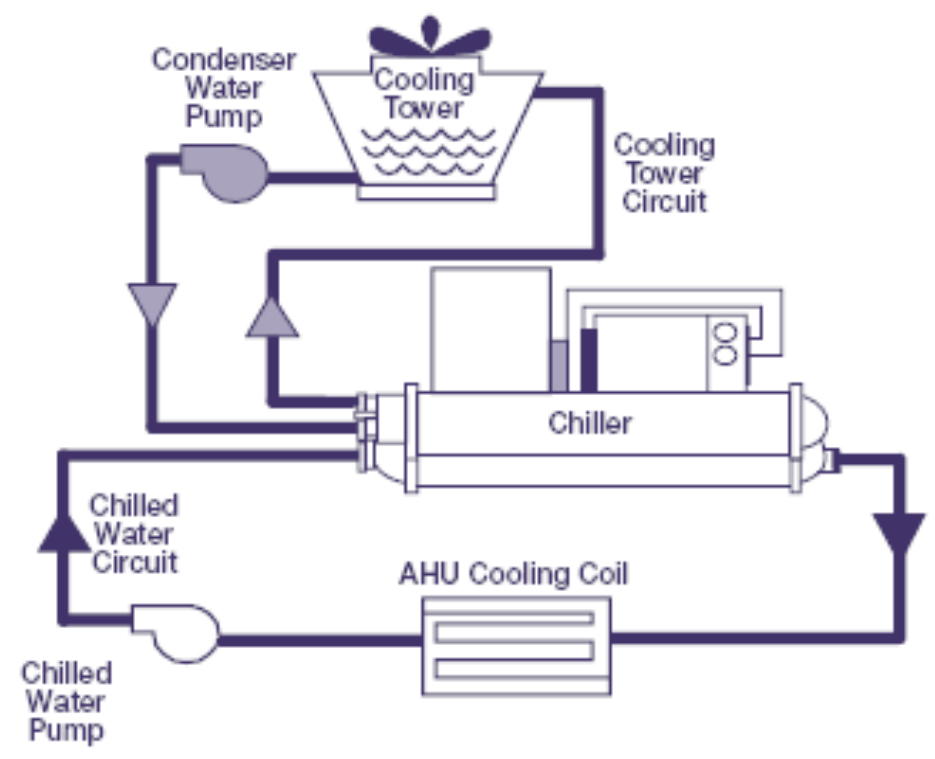

Figure 9.4.1. Typical chiller plant

The chiller cycle begins in the evaporator coils located in the chiller where the liquid refrigerant flows over the evaporator tube bundles and evaporates, absorbing heat from the chilled water circulating through the tube bundle. The refrigerant vapor, which is somewhat cooler than the chilled water temperature, is drawn out of the evaporator by the compressor. The compressor "pumps" the refrigerant vapor to the condenser by raising the refrigerant pressure (and thus, temperature). The refrigerant condenses on the cooling water coils of the condenser giving up its heat to the cooling water. The high-pressure liquid refrigerant from the condenser then passes through the expansion device that reduces the refrigerant pressure (and temperature) to that of the evaporator. The refrigerant again flows over the chilled water coils absorbing more heat and completing the cycle. Mechanical compression chillers are generally classified by compressor type: reciprocating, centrifugal, and screw (Dyer and Maples 1995). 
- Reciprocating - This is a positive displacement machine that maintains fairly constant volumetric flow over a wide range of pressure ratios. They are almost exclusively driven by fixed speed electric motors.

- Centrifugal - This type of compressor raises the refrigerant pressure by imparting momentum to the refrigerant with a spinning impeller, then stagnating the flow in a diffuser section around the impeller tip. They are noted for high capacity with compact design. Typical capacities range from 100 to 10,000 tons.

- Screw - The screw or helical compressor is a positive displacement machine that has a nearly constant flow performance characteristic. The machine essentially consists of two mating helically grooved rotors, a male (lobes) and a female (gullies), in a stationary housing. As the helical rotors rotate, the gas is compressed by direct volume reduction between the two rotors.

\subsubsection{Absorption Chiller (Dyer and Maples 1995)}

The absorption and the mechanical compression cycles have the evaporation and condensation of a refrigerant in common. In both cycles, the refrigerant evaporates at low pressure (and low temperature) to absorb heat and then condenses at higher pressure (and higher temperature) to reject heat to the atmosphere. Both cycles require energy to raise the temperature of the refrigerant for the heat rejection process. In the mechanical compression cycle, the energy is supplied in the form of work to the compressor whereas in the absorption cycle, heat is added (usually steam) to raise the refrigerant temperature.

The absorption cycle requires two working fluids: a refrigerant and an absorbent. Of the many combinations of refrigerant and absorbent that have been tried, only lithium bromide-water and ammonia-water cycles are commonly used today.

\subsubsection{Key Components (Dyer and Maples 1995)}

\subsubsection{Mechanical Compression Chillers}

- Evaporator - Component in which liquid refrigerant flows over a tube bundle and evaporates, absorbing heat from the chilled water circulating through the tube bundle.

- Compressor - "Pumps" the refrigerant vapor to the condenser by raising the refrigerant pressure (and thus, temperature).

- Condenser - Component in which refrigerant condenses on a set of cooling water coils giving up its heat to the cooling water.

- Expansion Valve - The high-pressure liquid refrigerant coming from the condenser passes through this expansion device, reducing the refrigerant's pressure (and temperature) to that of the evaporator.

\subsubsection{Absorption Chiller}

The absorption cycle is made up of four basic components:

- Evaporator - Where evaporation of the liquid refrigerant takes place.

- Absorber - Where concentrated absorbent is sprayed through the vapor space and over condensing water coils. Since the absorbent has a strong attraction for the refrigerant, the refrigerant is absorbed with the help of the cooling water coils. 
- Generator - Where the dilute solution flows over the generator tubes and is heated by the steam or hot water.

- Condenser - Where the refrigerant vapor from the generator releases its heat of vaporization to the cooling water as it condenses over the condenser water tube bundle.

\subsubsection{Safety Issues (TARAP 2001)}

Large chillers are most commonly located in mechanical equipment rooms within the building they are air conditioning. If a hazardous refrigerant is used (e.g., ammonia), the equipment room must meet additional requirements typically including minimum ventilation airflows and vapor concentration monitoring.

In many urban code jurisdictions, the use of ammonia as a refrigerant is prohibited outright. For large chillers, the refrigerant charge is too large to allow hydrocarbon refrigerants in chillers located in a mechanical equipment room.

\subsubsection{Cost and Energy Efficiency (Dyer and Maples 1995)}

The following steps describe ways to improve chiller performance, therefore, reducing its operating costs:

- Raise chilled water temperature - The energy input required for any liquid chiller (mechanical compression or absorption) increases as the temperature lift between the evaporator and the condenser increases. Raising the chilled water temperature will cause a corresponding increase in the evaporator temperature and thus, decrease the required temperature lift.

- Reduce condenser water temperature - The effect of reducing condenser water temperature is very similar to that of raising the chilled water temperature, namely reducing the temperature lift that must be supplied by the chiller.

On a centrifugal chiller, if the chilled water temperature is raised by $2^{\circ} \mathrm{F}$ to $3^{\circ} \mathrm{F}$, the system efficiency can increase by as much as $3 \%$ to $5 \%$.

- Reducing scale or fouling - The heat transfer surfaces in chillers tends to collect various mineral and sludge deposits from the water that is circulated through them. Any buildup insulates the tubes in the heat exchanger causing a decrease in heat exchanger efficiency and thus, requiring a large temperature difference between the water and the refrigerant.

- Purge air from condenser - Air trapped in the condenser causes an increased pressure at the compressor discharge. This results in increased compressor horsepower. The result has the same effect as scale buildup in the condenser.

- Maintain adequate condenser water flow - Most chillers include a filter in the condenser water line to remove material picked up in the cooling tower. Blockage in this filter at higher loads will cause an increase in condenser refrigerant temperature due to poor heat transfer.

- Reducing auxiliary power requirements - The total energy cost of producing chilled water is not limited to the cost of operating the chiller itself. Cooling tower fans, condenser water circulating pumps, and chilled water circulating pumps must also be included. Reduce these requirements as much as possible. 
- Use variable speed drive on centrifugal chillers - Centrifugal chillers are typically driven by fixed speed electric motors. Practical capacity reduction may be achieved with speed reductions, which in turn requires a combination of speed control and prerotation vanes.

- Compressor changeouts - In many installations, energy saving measures have reduced demand to the point that existing chillers are tremendously oversized, forcing the chiller to operate at greatly reduced loads even during peak demand times. This causes a number of problems including surging and poor efficiency. Replacing the compressor and motor drive to more closely match the observed load can alleviate these problems.

- Use free cooling - Cooling is often required even when outside temperatures drop below the minimum condenser water temperature. If outside air temperature is low enough, the chiller should be shut off and outside air used. If cooling cannot be done with outside air, a chiller bypass can be used to produce chilled water without the use of a chiller.

- Operate chillers at peak efficiency - Plants having two or more chillers can save energy by load management such that each chiller is operated to obtain combined peak efficiency. An example of this is the use of a combination of reciprocating and centrifugal compressor chillers.

- Heat recovery systems - Heat recovery systems extract heat from the chilled liquid and reject some of that heat, plus the energy of compression, to warm water circuit for reheat and cooling.

- Use absorption chilling for peak shaving - In installations where the electricity demand curve is dominated by the demand for chilled water, absorption chillers can be used to reduce the overall electricity demand.

- Replace absorption chillers with electric drive centrifugals - Typical absorption chillers require approximately $1.6 \mathrm{Btu}$ of thermal energy delivered to the chiller to remove $1 \mathrm{Btu}$ of energy from the chilled water. Modern electric drive centrifugal chillers require only $0.2 \mathrm{Btu}$ of electrical energy to remove $1 \mathrm{Btu}$ of energy from the chilled water $(0.7 \mathrm{kw} / \mathrm{ton})$.

- Thermal storage - The storage of ice for later use is an increasing attractive option since cooling is required virtually year-round in many large buildings across the country. Because of utility demand charges, it is more economical to provide the cooling source during non-air conditioning periods and tap it when air conditioning is needed, especially peak periods.

\subsubsection{Maintenance of Chillers (Trade Press Publishing Corporation 2001)}

Similar to boilers, effective maintenance of chillers requires two activities: first, bring the chiller to peak efficiency and second, maintain that peak efficiency. There are some basic steps facility professionals can take to make sure their building's chillers are being maintained properly. Among them are:

- Inspecting the chiller as recommended by the chiller manufacturer. Typically, this should be done at least quarterly.

- Routine inspection for refrigerant leaks.

- Checking compressor operating pressures.

- Checking all oil levels and pressures.

- Examining all motor voltages and amps. 
- Checking all electrical starters, contactors, and relays.

- Checking all hot gas and unloader operations.

- Using superheat and subcooling temperature readings to obtain a chiller's maximum efficiency.

- Taking discharge line temperature readings.

A sample chiller operations log useful for recording relevant operational efficiency metrics is provide at the end of this section following the chiller maintenance checklist.

\subsubsection{Diagnostic Tools}

- Thermography - An infrared thermometer or camera allows for an accurate, non-contact assessment of temperature. Applications for chillers include insulation assessments on chilled water piping as well as motor/bearing temperature assessments on compressors and pumping systems. More information on thermography can be found in Chapter 6 .

- Ultrasonic analyzer - Most rotating equipment and many fluid systems emit sound patterns in the ultrasonic frequency spectrum. Changes in these ultrasonic wave emissions are indicative of changes in equipment condition. Analyzer applications for chillers include compressors, chilled water pumping systems (e.g., bearing wear) and refrigerant leak detection. More information on ultrasonic analysis can be found in Chapter 6 .

\subsubsection{Available Software Tool}

\section{Chilled Water System Analysis Tool (CWSAT) Version 2.3}

Description: The DOE Chilled Water System Analysis Tool (CWSAT) is a software tool that is available at no charge to help optimize the performance of industrial chilled water systems. The tool allows the user to propose changes to existing equipment including chillers, pumps, and towers, and calculates how much energy and money the plant can save by implementing these changes.

The CWSAT uses inputs of the chilled water system equipment and operating parameters to calculate the system's energy consumption. The level of input detail is customized to the knowledge of the user. When specific equipment details are not known, catalog and default data are available in the CWSAT and can be readily utilized. The CWSAT allows users to analyze the impacts of implementing many system improvement measures by changing input data and comparing the revised system's energy consumption to the user's originally inputted system.

The tool can quickly calculate the potential energy savings opportunities that exist from measures such as increasing the chilled water temperature, decreasing the condenser water temperature, replacing the chillers, applying variable speed control to the circulation pump motors, and upgrading the tower motor controls to 2 -speed or variable speed. Depending on the characteristics of the specific chilled water system being analyzed, the tool can examine additional system specific cost reduction measures. These measures include replacing the chiller refrigerant, installing a variable speed drive on centrifugal compressors, using free cooling, and sequencing chiller operation to minimize energy consumption.

Availability: To download CWSAT and learn more about training opportunities, visit the Industrial Technology Program Web site: wwwl.eere.energy.gov/industry/bestpractices. 


\subsubsection{Relevant Operational/Energy Efficiency Measures}

There are a number of operational/energy efficiency measures that could be presented for proper chiller operation and control. The following section focuses on the most prevalent O\&M recommendations having the greatest energy impacts at Federal facilities.

Chiller Measure \#1: Chilled Water Temperature Control

Chillers are typically set to have a chilled water output temperature in the range of $42^{\circ} \mathrm{F}$ to $45^{\circ} \mathrm{F}$. If the maximum cooling load on the chillers cause the chiller to operate at less than full load, the chiller operator could possibly increase the chilled water temperature and still meet the cooling loads of the building while saving energy.

O\&M Tip: Increasing chiller water temperature by $1^{\circ} \mathrm{F}$ reduces chiller energy use by $1.7 \%$ and $1.2 \%$ for centrifugal and reciprocating compressors, respectively.

Likewise, the energy input required for any chiller (mechanical compression or absorption) increases as the temperature lift between the evaporator and the condenser increases. Raising the chilled water temperature will cause a corresponding increase in the evaporator temperature and thus, decrease the required temperature lift. A decrease in temperature lift equates to a decrease in energy use.

\section{Opportunity Identification}

The basic chilled water control strategies for chillers using microprocessor-based controllers are presented below:

Return Temperature. A chiller controlled by return-water temperature will rely on preset operational instructions based on the return temperature. For example, if the return water temperature increases, indicating an increasing load, the chiller is preprogrammed to respond with greater capacity and thereby mitigating the increased load.

Supply Temperature. A chiller controlled by the supply-water temperature functions with a set of water temperatures pre-programmed based on chiller loading. For example, as a space or process calls for greater capacity (i.e., a space temperature is increasing with solar loading) the chiller response is proportional to the call for added capacity.

Constant Return. If the chiller is controlled to have a constant return water temperature, the chiller will modulate chilled water supply temperatures to achieve a certain return water temperature over a range of chiller loads. In this case, the chiller operator specifies the desired chilled water return temperature, and the chiller modulates the chilled water supply temperature accordingly to meet this temperature.

Outside Air. Water cooled chillers that are located indoors, usually require an outdoor temperature sensor wired into the chiller's control panel. Most chiller manufacturers provide outside air temperature sensors that are specific to their chillers, and easily be integrated into the chiller control panel. In this case, the chiller reads the outdoor wet-bulb temperatures and modulates the chilled water temperature based on predefined outdoor air temperatures and chilled-water set-points. 
Zone Temperature. Some chillers come equipped with temperature sensors that read interior zone temperatures, or they have controls that can be integrated into the building automation system (BAS). In this case, the operators can apply chilled water reset strategies based on the interior zone temperatures. In each case, the chiller will usually step up the chilled water temperature to that of the reset value, even if the compressor is in the "off" cycle.

Chilled water reset strategies usually reset the chilled water temperature over a range of about $10^{\circ} \mathrm{F}$ (Webster 2003). Chiller operators should contact their local chiller manufacturers for information on setting appropriate chilled water temperatures. Manufacturers can provide guidance on chilled water modulation at partial loads, and outside air temperatures for the particular chiller.

Regardless of the control strategy used to modulate chilled water temperatures, the operators should always keep in mind the impacts on the entire chilled water system. Care should be taken to optimize the entire system, rather than just applying chilled water reset strategies blindly (Webster 2003).

It is also important to consider the implications on cooling coils and their ability to regulate the indoor relative humidity ratios within the building, at higher chilled water temperatures. As the chilled water temperatures are increased, the energy/facility managers should closely monitor indoor relative humidity $(\mathrm{RH})$ levels to make sure they are staying in the 55\% to $60 \% \mathrm{RH}$ range.

\section{Diagnostic Equipment}

Opportunities with chillers rely on the use of the chiller controller and/or the BAS for diagnosis. There are situations where neither the controller nor the BAS are available or programmed properly for use. In these cases, portable data loggers for evaluating temperatures are most appropriate. In addition, chiller and chilled water distribution systems usually have temperature and pressure devices hard-mounted to the system. These devices, provided they are accurate, can be used in system diagnostics.

\section{Energy Savings and Economics}

Recognizing that the system efficiency can increase by as much as $2 \%$ to $5 \%$ by raising the chilled water supply temperature by $2^{\circ} \mathrm{F}$ to $3^{\circ} \mathrm{F}$, the annual energy savings, which could be realized, can be estimated as follows:

$$
\begin{gathered}
\text { Energy Savings }=(C E U \times H)-\left[C E U \times H\left(1-\frac{E S}{100}\right)\right] \\
\text { Annual Energy Savings }=\sum_{i=1}^{n} \text { Energy Savings }
\end{gathered}
$$

where

$$
\begin{aligned}
& \text { CEU = chiller energy use, } \mathrm{kW} \\
& \mathrm{H}=\text { hours of operation at a given load, } \mathrm{h} \\
& \mathrm{ES}=\text { energy savings, } \%
\end{aligned}
$$




\section{Estimated Annual Cost Savings}

The annual cost savings, which could be realized by increasing chilled water temperatures, can be estimated as follows:

\section{Annual Cost Savings $=$ Annual Energy Savings $\times$ ER}

where ER = electric energy rate, $\$ / \mathrm{kWh}$

It should be noted that this cost savings calculation does not account for an electric peak demand reduction. If the facility has a peak demand charge, and the chiller operates everyday with on operational schedule that is coincident with the facilities peak demand, then this calculation could underestimates the cost savings.

\section{Chilled Water Supply Temperature Energy Savings and Economics Example}

Example Synopsis: A water cooled centrifugal chiller currently has a constant $42^{\circ} \mathrm{F}$ supply temperature. After inspection it was determined that the temperature controls can allow modulation up to $45^{\circ} \mathrm{F}$ during low load periods with an estimated energy savings of $2.25 \%$. The operators estimate that the chiller can operate at $45^{\circ} \mathrm{F}$ for 3,000 hrs per year, and the chiller has an electrical load of $300 \mathrm{~kW}$ when operating at these low load conditions. The average electric rate is $\$ 0.10 / \mathrm{kWh}$.

The annual energy savings can be estimated as:

$$
\begin{gathered}
\text { Energy Savings }=(300 \times 3,000)-\left[300 \times 3,000\left(1-\frac{2.25}{100}\right)\right] \\
\text { Annual Energy Savings }=20,250 \mathrm{kWh} / \mathrm{yr}
\end{gathered}
$$

The annual cost savings can be estimated as:

$$
\begin{gathered}
\text { Annual Cost Savings }=(20,250 \mathrm{kWh} / \mathrm{yr})(\$ 0.10 / \mathrm{kWh}) \\
\text { Annual Cost Savings }=\$ 2,025 / y r
\end{gathered}
$$

Chiller Measure \#2: Condenser Water Temperature Control

The effect of reducing condenser water temperature (watercooled chillers only) is very similar to that of raising the chilled water temperature on the supply side, namely reducing the temperature lift that must be supplied by the chiller. These temperatures can be reset downward as outdoor wet-bulb temperatures decrease and during lowload conditions (Webster 2003).

\section{O\&M Tip:}

For each $1^{\circ} \mathrm{F}$ decrease in condenser cooling water temperature, until optimal water temperature is reached, there is a corresponding percentage decrease in chiller energy use.

It is important to note that the chiller operators need to make sure that the chiller is capable of handling lowered condenser water temperatures. Some chillers are not designed to handle lower condenser water temperatures and can encounter compressor oil return problems. As a default, site personnel should always check with their local chiller manufacturers before lowering the condenser water temperatures. 


\section{Opportunity Identification}

Most chillers reach their maximum operating efficiency at the designed peak load. However, chillers operate at the part-load condition most of the time. Resetting the condenser water temperature normally decreases the temperature lift between the evaporator and the condenser, thus increasing the chiller operating efficiency. Therefore, to reset the condenser water temperature to the lowest possible temperature will allow the cooling tower to generate cooler condenser water whenever possible. Note that although lowering the condenser water temperature will reduce chiller energy, it may increase cooling tower energy consumption because the tower fan may have to run longer to achieve the lower condenser water temperature. In addition, some older chillers have condensing water temperature limitations. Consult the chiller manufacturer to establish appropriate guidelines for lowering the condenser water temperature.

\section{Diagnostic Equipment}

Opportunities with chillers rely on the use of the chiller controller and/or the BAS for diagnosis. There are situations where neither the controller not the BAS are available or programmed properly for use. In these cases, portable data loggers for evaluating temperatures are most appropriate. In addition, chiller and chilled water distribution systems usually have temperature and pressure devices hard-mounted to the system. These devices, provided they are accurate, can be used in system diagnostics.

\section{Estimated Annual Energy Savings}

Lowering the condenser water temperature $2^{\circ} \mathrm{F}$ to $3^{\circ} \mathrm{F}$ can increase system efficiency by as much as $2 \%$ to $3 \%$. The annual energy savings, which could be realized by reducing condenser temperatures, can be estimated as follows:

$$
\begin{aligned}
& \text { Energy Savings }=(C E U \times H)-\left[C E U \times H\left(1-\frac{E S}{100}\right)\right] \\
& \text { Annual Energy Savings }=\sum_{i=1}^{n} \text { Energy Savings }
\end{aligned}
$$

where

$\mathrm{CEU}=$ chiller energy use, $\mathrm{kW}$

$\mathrm{H}=$ hours of operation at a given load, $\mathrm{h}$

$\mathrm{ES}=$ energy savings, \%

\section{Estimated Annual Cost Savings}

The annual cost savings, which could be realized by reducing condenser temperatures, can be estimated as follows:

Annual Cost Savings = Annual Energy Savings $\times$ ER

where ER = electric energy rate, $\$ / \mathrm{kWh}$ 
It should be noted that this cost savings calculation does not account for an electric peak demand reduction. If the facility has a peak demand charge, and the chiller operates everyday with on operational schedule that is coincident with the facilities peak demand, then this estimate slightly underestimates the cost savings.

\section{Condenser Temperature Reset Energy Savings and Economics Example}

Example Synopsis: A water cooled centrifugal chiller currently has an entering condenser temperature of $55^{\circ} \mathrm{F}$. After inspection it was determined that the temperature controls can allow modulation down to $52^{\circ} \mathrm{F}$ during low load periods. The operators estimate that the chiller can operate at $52^{\circ} \mathrm{F}$ for 3,000 hrs per year, and the chiller has an electrical load of $300 \mathrm{~kW}$ when operating at these low load conditions. The average electric rate is $\$ 0.10 / \mathrm{kWh}$.

The annual energy savings can be estimated as:

$$
\begin{gathered}
\text { Energy Savings }=(300 \times 3,000)-\left[300 \times 3,000\left(1-\frac{3}{100}\right)\right] \\
\text { Annual Energy Savings }=27,000 \mathrm{kWh} / \mathrm{yr}
\end{gathered}
$$

The annual cost savings can be estimated as:

$$
\text { Annual Cost Savings }=(27,000 \mathrm{kWh} / \mathrm{yr})(\$ 0.10 / \mathrm{kWh})
$$

$$
\text { Annual Cost Savings }=\$ 2,700 / y r
$$

\subsubsection{Chiller Water-Use Best Practices}

The predominant impact chillers have on water use relates to proper function. An inefficient chiller will require longer hours of operation to satisfy the load. It is these additional hours that result in greater water use though evaporation at the cooling tower and any leaks in the system. Any

\begin{tabular}{|c|c|c|c|c|c|}
\hline \multirow{2}{*}{ Description } & \multirow{2}{*}{ Comments } & \multicolumn{4}{|c|}{ Maintenance Frequency } \\
\hline & & Daily & Weekly & $\begin{array}{l}\text { Semi- } \\
\text { Annually }\end{array}$ & Annually \\
\hline Chiller use/sequencing & Turn off/sequence unnecessary chillers & $\mathrm{X}$ & & & \\
\hline Overall visual inspection & $\begin{array}{l}\text { Complete overall visual inspection to } \\
\text { be sure all equipment is operating and } \\
\text { safety systems are in place }\end{array}$ & $\mathrm{X}$ & & & \\
\hline Check setpoints & $\begin{array}{l}\text { Check all setpoints for proper setting } \\
\text { and function }\end{array}$ & $X$ & & & \\
\hline Evaporator and condenser & $\begin{array}{l}\text { Assess evaporator and condenser coil } \\
\text { fouling as required }\end{array}$ & & $X$ & & \\
\hline $\begin{array}{l}\text { Compressor motor } \\
\text { temperature }\end{array}$ & $\begin{array}{l}\text { Check temperature per manufacturer's } \\
\text { specifications }\end{array}$ & & $X$ & & \\
\hline
\end{tabular}
inefficiency results in a less-than-optimal operation leading to increased resource use - water is one of those resources.

\subsubsection{Chillers Checklist}




\section{Chiller Checklist (contd)}

\begin{tabular}{|c|c|c|c|c|c|}
\hline \multirow{2}{*}{ Description } & \multirow{2}{*}{ Comments } & \multicolumn{4}{|c|}{ Maintenance Frequency } \\
\hline & & Daily & Weekly & $\begin{array}{l}\text { Semi- } \\
\text { Annually }\end{array}$ & Annually \\
\hline Perform water quality test & $\begin{array}{l}\text { Check water quality for proper } \\
\text { chemical balance }\end{array}$ & & $\mathrm{X}$ & & \\
\hline Leak testing & $\begin{array}{l}\text { Conduct leak testing on all compressor } \\
\text { fittings, oil pump joints and fittings, } \\
\text { and relief valves }\end{array}$ & & $\mathrm{X}$ & & \\
\hline Check all insulation & $\begin{array}{l}\text { Check insulation for condition and } \\
\text { appropriateness }\end{array}$ & & $\mathrm{X}$ & & \\
\hline Control operation & $\begin{array}{l}\text { Verify proper control function } \\
\text { including: } \\
\text { - Hot gas bypass } \\
\text { - Liquid injection }\end{array}$ & & $\mathrm{X}$ & & \\
\hline $\begin{array}{l}\text { Check vane control } \\
\text { settings }\end{array}$ & $\begin{array}{l}\text { Check settings per manufacturer's } \\
\text { specification }\end{array}$ & & & $\mathrm{X}$ & \\
\hline $\begin{array}{l}\text { Verify motor load limit } \\
\text { control }\end{array}$ & $\begin{array}{l}\text { Check settings per manufacturer's } \\
\text { specification }\end{array}$ & & & $\mathrm{X}$ & \\
\hline $\begin{array}{l}\text { Verify load balance } \\
\text { operation }\end{array}$ & $\begin{array}{l}\text { Check settings per manufacturer's } \\
\text { specification }\end{array}$ & & & $\mathrm{X}$ & \\
\hline $\begin{array}{l}\text { Check chilled water reset } \\
\text { settings and function }\end{array}$ & $\begin{array}{l}\text { Check settings per manufacturer's } \\
\text { specification }\end{array}$ & & & $\mathrm{X}$ & \\
\hline $\begin{array}{l}\text { Check chiller lockout } \\
\text { setpoint }\end{array}$ & $\begin{array}{l}\text { Check settings per manufacturer's } \\
\text { specification }\end{array}$ & & & & $\mathrm{X}$ \\
\hline Clean condenser tubes & $\begin{array}{l}\text { Clean tubes at least annually as part of } \\
\text { shutdown procedure }\end{array}$ & & & & $\mathrm{X}$ \\
\hline $\begin{array}{l}\text { Eddy current test } \\
\text { condenser tubes }\end{array}$ & $\begin{array}{l}\text { As required, conduct eddy current test } \\
\text { to assess tube wall thickness }\end{array}$ & & & & $\mathrm{X}$ \\
\hline Clean evaporator tubes & $\begin{array}{l}\text { Clean tubes at least annually as part of } \\
\text { shutdown procedure }\end{array}$ & & & & $\mathrm{X}$ \\
\hline $\begin{array}{l}\text { Eddy current test } \\
\text { evaporator tubes }\end{array}$ & $\begin{array}{l}\text { As required, conduct eddy current test } \\
\text { to assess tube wall thickness }\end{array}$ & & & & $\mathrm{X}$ \\
\hline $\begin{array}{l}\text { Compressor motor and } \\
\text { assembly }\end{array}$ & $\begin{array}{l}\text { - Check all alignments to specification } \\
\text { - Check all seals, provide lubrication } \\
\text { where necessary }\end{array}$ & & & & $\mathrm{X}$ \\
\hline Compressor oil system & $\begin{array}{l}\text { - Conduct analysis on oil and filter } \\
\text { - Change as required } \\
\text { - Check oil pump and seals } \\
\text { - Check oil heater and thermostat } \\
\text { - Check all strainers, valves, etc. }\end{array}$ & & & & $\mathrm{X}$ \\
\hline Electrical connections & $\begin{array}{l}\text { Check all electrical connections/ } \\
\text { terminals for contact and tightness }\end{array}$ & & & & $\mathrm{X}$ \\
\hline Water flows & $\begin{array}{l}\text { Assess proper water flow in evaporator } \\
\text { and condenser }\end{array}$ & & & & $\mathrm{X}$ \\
\hline $\begin{array}{l}\text { Check refrigerant level } \\
\text { and condition }\end{array}$ & $\begin{array}{l}\text { Add refrigerant as required. Record } \\
\text { amounts and address leakage issues. }\end{array}$ & & & & $\mathrm{X}$ \\
\hline
\end{tabular}




\subsubsection{Sample Chiller Operation Log}

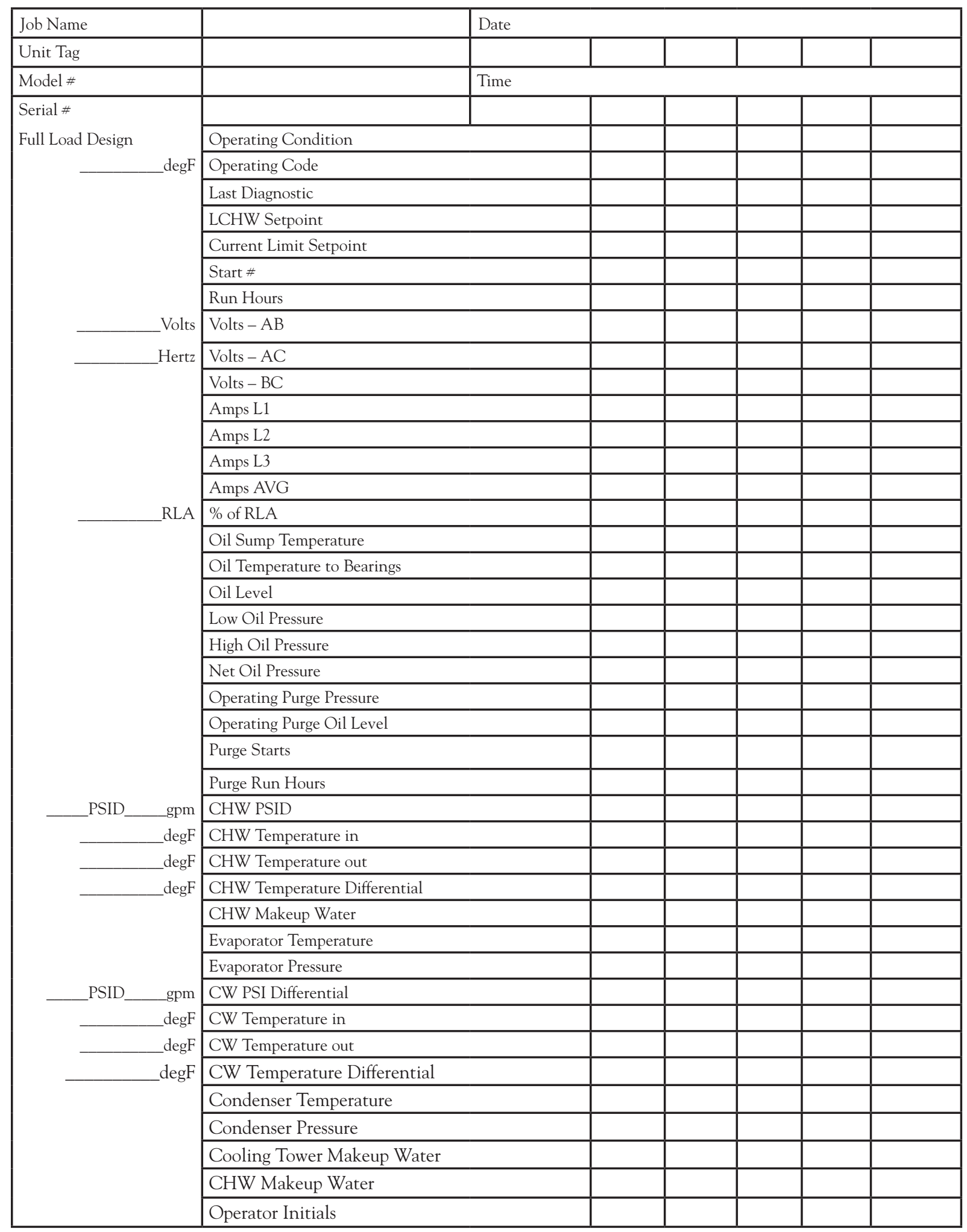




\subsubsection{References}

Dyer, D.F. and G. Maples. 1995. HVAC Efficiency Improvement. Boiler Efficiency Institute, Auburn, Alabama.

The Alliance for Responsible Atmospheric Policy (TARAP). August 3, 2001. Arthur D. Little Report, Section 7 Chiller. [Online report]. Available URL: http://www.arap.org/adlittle/7.html.

Trade Press Publishing Corporation. August 6, 2001. Energy Decisions, May 2000, Chiller Preventive Maintenance Checklist. [Online]. Available URL: http://www.facilitiesnet.com/fn/NS/ NS3nOeb.html | ticket $=1234567890123456789112925988$.

Webster T. 2003. Chiller Controls-Related Energy Saving Opportunities in Federal Facilities. LBNL 47649, prepared by the University of California for Lawrence Berkeley National Laboratory, Berkeley, California. 


\subsection{Cooling Towers}

\subsubsection{Introduction}

A cooling tower (Figure 9.5.1) is a specialized heat exchanger in which two fluids (air and water) are brought into direct contact with each other to affect the transfer of heat. In a "spray-filled" tower, this is accomplished by spraying a flowing mass of water into a rain-like pattern, through which an upward moving mass flow of cool air is induced by the action of a fan (Marley Cooling Technologies 2001a).

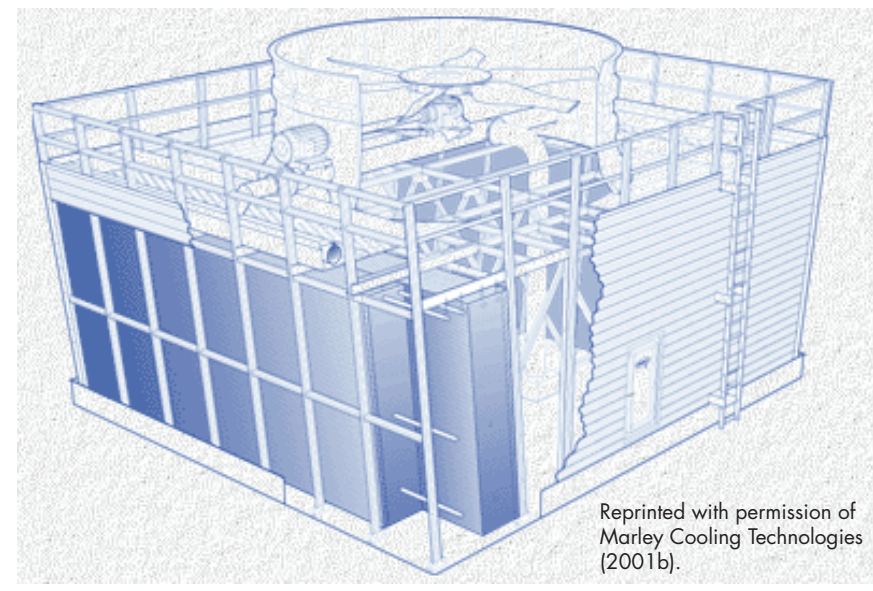

Figure 9.5.1. Cooling tower

\subsubsection{Types of Cooling Towers}

There are two basic types of cooling towers, direct or open and indirect or closed.

1. Direct or open cooling tower (Figure 9.5.2)

This type of system exposes the cooling water directly to the atmosphere. The warm cooling is sprayed over a fill in the cooling tower to increase the contact area, and air is blown through the fill. The majority of heat removed from the cooling water is due to evaporation. The remaining cooled water drops into a collection basin and is recirculated to the chiller (WSUCEEP 2001).

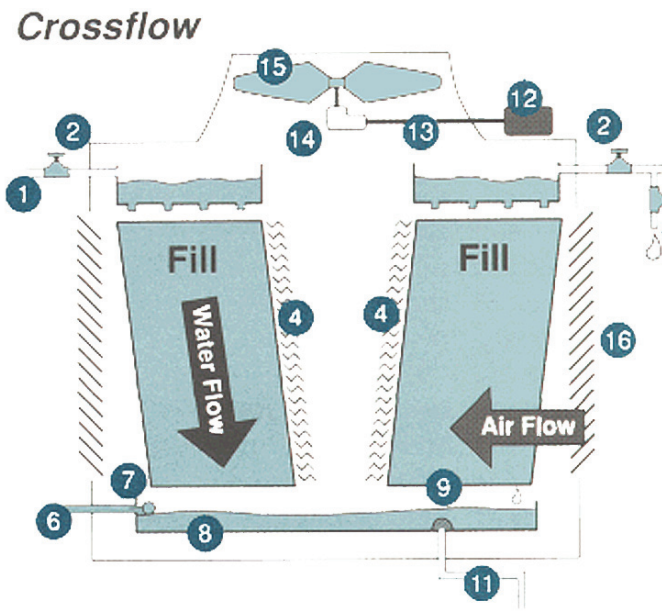

Figure 9.5.2. Direct or open cooling tower

1. Hot water from chiller

2. Flow control valve

3. Distribution pipes and nozzles

(10) 4. Draft eliminators

5. Centrifugal blower

6. Make-up water infeed

7. Float valve

8. Collection basin

9. Strainer

Note: Items 3 and 5 not shown in Figure 9.5.2.

Reprinted with permission of Washington State University Cooperative Extension Energy Program.
10. Bleed water

11. Cooled water to chiller

12. Fan drive

13. Drive shaft

14. Gear box

15. Propeller fan

16. Air intake louvers 
2. Indirect or closed cooling tower

An indirect or closed cooling tower circulates the water through tubes located in the tower. In this type of tower, the cooling water does not come in contact with the outside air and represents a "closed" system.

\subsubsection{Key Components}

A cooling tower is a collection of systems that work together. Following is an overview of how these systems operate.

Hot water from a chilled water system is delivered to the top of the cooling tower by the condenser pump through distribution piping. The hot water is sprayed through nozzles onto the heat transfer media (fill) inside the cooling tower. Some towers feed the nozzles through pressurized piping; others use a water distribution basin and feed the nozzles through gravity.

A cold-water collection basin at the base of the tower gathers cool water after it has passed through the heat transfer media. The cool water is pumped back to the condenser to complete the cooling water loop.

Cooling towers use evaporation to release waste heat from a HVAC system. Hot water flowing from the condenser is slowed down and spread out in the heat transfer media (fill). A portion of the hot water is evaporated in the fill area, which cools the bulk water. Cooling tower fill is typically arranged in packs of thin corrugated plastic sheets or, alternately, as splash bars supported in a grid pattern.

Large volumes of air flowing through the heat transfer media help increase the rate of evaporation and cooling capacity of the tower. This airflow is generated by fans powered by electric motors. The cooling tower fan size and airflow rate are selected for the desired cooling at the design conditions of hot water, cold water, water flow rate, and wet bulb air temperature.

HVAC cooling tower fans may be propeller type or squirrel cage blowers, depending on the tower design. Small fans may be connected directly to the driving motor, but most designs require an intermediate speed reduction provided by a power belt or reduction gears. The fan and drive system operates in conjunction with a starter and control unit that provides start/stop and speed control.

As cooling air moves through the fill, small droplets of cooling water become entrained and can exit the cooling tower as carry-over or drift. Devices called drift eliminators are used to remove carryover water droplets. Cooling tower drift becomes an annoyance when the droplets fall on people and surfaces downwind from the cooling tower. Efficient drift eliminators remove virtually all of the entrained cooling water droplets from the air stream (Suptic 1998).

\subsubsection{Safety Issues}

Warm water in the cooling system is a natural habitat for microorganisms. Chemical treatment is required to eliminate this biological growth. Several acceptable biocides are available from water treatment companies for this purpose. Cooling towers must be thoroughly cleaned on a periodic basis to minimize bacterial growth. Unclean cooling towers promote growth of potentially infectious bacteria, including Legionella Pneumophilia (Suptic 1998). 
Legionella may be found in water droplets from cooling towers, which may become airborne and become a serious health hazard if inhaled by a human. The lung is a warm and moist environment, which presents perfect conditions for the growth of such a disease. Common symptoms on patients with legionnaires disease are cough, chills, and fever. In addition, muscle aches, headache, tiredness, loss of appetite, and, occasionally, diarrhea can also be present. Laboratory tests may show decreased function of the kidneys. Chest x-rays often show pneumonia.

\subsubsection{Cost and Energy Efficiency}

An improperly maintained cooling tower will produce warmer cooling water, resulting in higher condenser temperatures than a properly maintained cooling tower. This reduces the efficiency of the chiller, wastes energy, and increases cost. The chiller will consume $2.5 \%$ to $3.5 \%$ more energy for each degree increase in the condenser temperature.

For example, if a 100 -ton chiller costs $\$ 20,000$ in energy to operate each year, it will cost you an additional $\$ 500$ to $\$ 700$ per year for every degree increase in condenser temperature. Thus, for a $5^{\circ} \mathrm{F}$ to $10^{\circ} \mathrm{F}$ increase, you can expect to pay $\$ 2,500$ to $\$ 7,000$ a year in additional electricity costs. In addition, a poorly maintained cooling tower will have a shorter operating life, is more likely to need costly repairs, and is less reliable (WSUCEEP 2001).

\subsubsection{Maintenance of Cooling Towers}

Cooling tower maintenance must be an ongoing endeavor. Lapses in regular maintenance can result in system degradation, loss of efficiency, and potentially serious health issues.

\section{General Requirements for Safe and Efficient Cooling Towers Provide:}

(Suptic 1998)

1. Safe access around the cooling tower, including all points where inspection and maintenance activities occur.

2. Fall protection around inspection and maintenance surfaces, such as the top of the cooling tower.

3. Lockout of fan motor and circulating pumps during inspection and maintenance.

4. Protection of workers from exposure to biological and chemical hazards within the cooling water system.

5. Cooling tower location must prevent cooling tower discharge air from entering the fresh air intake ducts of any building.

6. When starting the tower, inspect and remove any accumulated debris.

7. Balance waterflow following the tower manufacturer's procedure to ensure even distribution of hot water to all areas of the fill. Poorly distributed water can lead to air bypass through the fill and loss of tower performance.

8. Follow your water treating company's recommendations regarding chemical addition during startup and continued operation of the cooling system. Galvanized steel cooling towers require special passivation procedures during the first weeks of operation to prevent "white rust."

9. Before starting the fan motor, check the tightness and alignment of drive belts, tightness of mechanical holddown bolts, oil level in gear reducer drive systems, and alignment of couplings. Rotate the fan by hand and ensure that blades clear all points of the fan shroud.

10. The motor control system is designed to start and stop the fan to maintain return cold water temperature. The fan motor must start and stop no more frequently than four to five times per hour to prevent motor overheating.

11. Blowdown water rate from the cooling tower should be adjusted to maintain between two to four concentrations of dissolved solids. 


\subsubsection{Common Causes of Cooling Towers Poor Performance}

- Scale Deposits - When water evaporates from the cooling tower, it leaves scale deposits on the surface of the fill from the minerals that were dissolved in the water. Scale build-up acts as a barrier to heat transfer from the water to the air. Excessive scale build-up is a sign of water treatment problems.

- Clogged Spray Nozzles - Algae and sediment that collect in the water basin as well as excessive solids that get into the cooling water can clog the spray nozzles. This causes uneven water distribution over the fill, resulting in uneven airflow through the fill and reduced heat transfer surface area. This problem is a sign of water treatment problems and clogged strainers.

- Poor AirFlow - Poor airflow through the tower reduces the amount of heat transfer from the water to the air. Poor airflow can be caused by debris at the inlets or outlets of the tower or in the fill. Other causes of poor airflow are loose fan and motor mountings, poor motor and fan alignment, poor gear box maintenance, improper fan pitch, damage to fan blades, or excessive vibration. Reduced airflow due to poor fan performance can ultimately lead to motor or fan failure.

- Poor Pump Performance - An indirect cooling tower uses a cooling tower pump. Proper water flow is important to achieve optimum heat transfer. Loose connections, failing bearings, cavitation, clogged strainers, excessive vibration, and non-design operating conditions result in reduced water flow, reduced efficiency, and premature equipment failure (WSUCEEP 2001).

\subsubsection{Diagnostic Tools}

- Thermography - An infrared thermometer or camera allows for an accurate, non-contact assessment of temperature. Applications for cooling towers include bearing and electrical contact assessments on motor and fan systems as well as hot spots on belt and other drive systems. More information on thermography can be found in Chapter 6 .

- Ultrasonic analyzer - Electric motor and fan systems emit very distinct sound patterns around bearings and drives (direct or belt). In most cases, these sounds are not audible to the unaided ear, or are drown-out by other equipment noises. Using an ultrasonic detector, the analyst is able to isolate the frequency of sound being emitted by the bearing or drive. Changes in these ultrasonic wave emissions are indicative of changes in equipment condition-some of these changes can be a precursor to component degradation and failure. More information on ultrasonic analysis can be found in Chapter 6 .

\subsubsection{Cooling Tower Water-Use Best Practices}

As discussed, cooling towers regulate temperature by dissipating heat from recirculating water used to cool chillers, air-conditioning equipment, or other process equipment. Heat is rejected from the tower primarily through evaporation. Therefore, by design, cooling towers consume significant amounts of water. The thermal efficiency and longevity of the cooling tower and equipment used to cool depend on the proper management of water recirculated through the tower (FEMP 2008). 
Water leaves a cooling tower system in any one of four ways:

1. Evaporation: This is the primary function of the tower and is the method that transfers heat from the cooling tower system to the environment. The quantity of evaporation is not a subject for water efficiency efforts (although improving the energy efficiency of the systems you are cooling will reduce the evaporative load on your tower). Evaporative losses relate to the specifics of the system and environment. In rough terms, for every $10^{\circ} \mathrm{F}$ of water temperature drop across the tower, there is an evaporative loss of approximately 1 percent, equating, on average, to 2.5 to $4.0 \mathrm{gpm}$ per 100 tons of capacity.

2. Blowdown or Bleed-off: When water evaporates from the tower leaves behind dissolved and suspended substances. If left unchecked, these chemicals will lead to basin water with increasing concentrations of total dissolved solids (TDS). If the concentration gets too high, the solids can come out of solution and cause scale to form within the system and/or the dissolved solids can lead to corrosion problems. Additional problems may arise by creating conditions conducive to biofouling. To mediate this problem, a certain amount of water is removed from the cooling tower - this water is referred to as blowdown or bleed off. As this water is being removed, the same quantity is being reintroduced and is called make up. Carefully monitoring and controlling the quantity of blowdown and make up provides the most significant opportunity to conserve water in cooling tower operations.

3. Drift: A comparatively small quantity of water may be carried from the tower not as vapor but as mist or small droplets. Drift loss is small compared to evaporation and blow-down, and is controlled with baffles and drift eliminators. While estimates of drift losses range well below $1 \%$ of tower flow rate, on larger towers these losses can add up.

4. Basin Leaks/Overflows: Properly operated towers should not have leaks or overflows.

In addition to carefully controlling tower operation, other water efficiency opportunities arise from using alternate sources of make-up water. Sometimes water from other equipment within a facility can be recycled and reused for cooling tower make-up with little or no pre-treatment, including the following:

- Air handler condensate (water that collects when warm, moist air passes over the cooling coils in air handler units). This reuse is particularly appropriate because the condensate has a low mineral content, and typically is generated in greatest quantities when cooling tower loads are the highest.

- Water used in a once through cooling system.

- Pretreated effluent from other processes, provided that any chemicals used are compatible with the cooling tower system.

- High-quality municipal wastewater effluent or recycled water (where available). 


\subsubsection{Operations and Maintenance Opportunities}

- From an operational perspective, the blowdown losses represent the most significant water conservation opportunity. To maximize efficiency potential, calculate and understand your "cycles of concentration." Check the ratio of conductivity of blowdown and make-up water. Work with your cooling tower water treatment specialist to maximize the cycles of concentration. Many systems operate at 2 to 4 cycles of concentration, while 6 cycles or more may be possible. Increasing your cycles from 3 to 6 will reduce cooling tower make-up water by 20 percent, and cooling tower blowdown by 50 percent. The actual number of cycles you can carry will depend on your make-up water quality and cooling tower water treatment regimen. Depending on your make-up water, treatment programs may include corrosion and scaling inhibitors, along with biological fouling inhibitors.

- Install a conductivity controller to automatically control your blowdown. Working with your water treatment specialist, determine the maximum cycles of concentration you can safely achieve, and the resulting conductivity (typically measured as microSiemens per centimeter, $\mathrm{uS} / \mathrm{cm}$ ). A conductivity controller can continuously measure the conductivity of the cooling tower water and discharge water only when the conductivity set point is exceeded.

- Install flow meters on make-up and blowdown lines. Check the ratio of make-up flow to blowdown flow. Then check the ratio of conductivity of blowdown water and the make-up water (you can use a handheld conductivity meter if your tower is not equipped with permanent meters). These ratios should match your target cycles of concentration. If both ratios are not about the same, check the tower for leaks or other unauthorized draw-off. If you are not maintaining target cycles of concentration, check system components, including conductivity controller, make-up water fill valve, and blowdown valve.

- Read conductivity and flow meters regularly to quickly identify problems. Keep a log of makeup and blowdown quantities, conductivity, and cycles of concentration. Monitor trends to spot deterioration in performance.

- Consider using acid treatment such as sulfuric, hydrochloric, or ascorbic acid, where appropriate. When added to recirculating water, acid can improve the efficiency of a cooling system by controlling the scale buildup potential from mineral deposits. Acid treatment lowers the $\mathrm{pH}$ of the water, and is effective in converting a portion of the alkalinity (bicarbonate and carbonate), a primary constituent of scale formation, into more readily soluble forms. Make sure that workers are fully trained in the proper handling of acids. Also note that acid overdoses can severely damage a cooling system. The use a timer or continuous $\mathrm{pH}$ monitoring via instrumentation should be employed. Additionally, it is important to add acid at a point where the flow of water promotes rapid mixing and distribution. Be aware that lowering $\mathrm{pH}$ may mean you may have to add a corrosion inhibitor.

- Select your water treatment vendor with care. Tell vendors that water efficiency is a high priority and ask them to estimate the quantities and costs of treatment chemicals, volumes of blowdown water and the expected cycles of concentration ratio. Keep in mind that some vendors may be reluctant to improve water efficiency because it means the facility will purchase fewer chemicals. In some cases, saving on chemicals can outweigh the savings on water costs. Vendors should be selected based on "cost to treat 1,000 gallons make-up water" and highest "recommended system water cycle of concentration." 
- Consider measuring the amount of water lost to evaporation. Some water utilities will provide a credit to the sewer charges for evaporative losses, measured as the difference between metered make-up water minus metered blowdown water.

- Consider a comprehensive air handler coil maintenance program. As coils become dirty or fouled, there is increased load on the chilled water system in order to maintain conditioned air set point temperatures. Increased load on the chilled water system not only has an associated increase in electrical consumption, it also increases the load on the evaporative cooling process which uses more water.

\subsubsection{Retrofit Opportunities}

- Install a sidestream filtration system that is composed of a rapid sand filter or high-efficiency cartridge filter to cleanse the water. These systems draw water from the sump, filter out sediments and return the filtered water to the tower, enabling the system to operate more efficiently with less water and chemicals. Sidestream filtration is particularly helpful if your system is subject to dusty atmospheric conditions. Sidestream filtration can turn a troublesome system into a more trouble-free system.

- Install a make-up water softening system when hardness (calcium and magnesium) is the limiting factor on your cycles of concentration. Water softening removes hardness using an ion exchange resin, and can allow you to operate at higher cycles of concentration.

- Install covers to block sunlight penetration. Reducing the amount of sunlight on tower surfaces can significantly reduce biological growth such as algae.

- Consider alternative water treatment options such as ozonation or ionization, to reduce water and chemical usage. Be careful to consider the life-cycle cost impact of such systems.

- Install automated chemical feed systems on large cooling tower systems (over 100 ton). The automated feed system should control blowdown/bleed-off by conductivity and then add chemicals based on make-up water flow. These systems minimize water and chemical use while optimizing control against scale, corrosion, and biological growth. 


\subsubsection{Cooling Towers Checklist}

\begin{tabular}{|c|c|c|c|c|c|}
\hline \multirow{2}{*}{ Description } & \multirow{2}{*}{ Comments } & \multicolumn{4}{|c|}{ Maintenance Frequency } \\
\hline & & Daily & Weekly & Monthly & Annually \\
\hline $\begin{array}{l}\text { Cooling tower use/ } \\
\text { sequencing }\end{array}$ & $\begin{array}{l}\text { Turn off/sequence unnecessary cooling } \\
\text { towers }\end{array}$ & $\mathrm{X}$ & & & \\
\hline $\begin{array}{l}\text { Overall visual } \\
\text { inspection }\end{array}$ & $\begin{array}{l}\text { Complete overall visual inspection to be } \\
\text { sure all equipment is operating and safety } \\
\text { systems are in place }\end{array}$ & $\mathrm{X}$ & & & \\
\hline Inspect for clogging & Make sure water is flowing in tower & $\mathrm{X}$ & & & \\
\hline Fan motor condition & $\begin{array}{l}\text { Check the condition of the fan motor } \\
\text { through temperature or vibration analysis } \\
\text { and compare to baseline values }\end{array}$ & & $\mathrm{X}$ & & \\
\hline Clean suction screen & Physically clean screen of all debris & & $\mathrm{X}$ & & \\
\hline Test water samples & $\begin{array}{l}\text { Test for proper concentrations of } \\
\text { dissolved solids, and chemistry. Adjust } \\
\text { blowdown and chemicals as necessary. }\end{array}$ & & $\mathrm{X}$ & & \\
\hline Operate make-up water & $\begin{array}{l}\text { Operate switch manually to ensure proper } \\
\text { float switch operation }\end{array}$ & & $\mathrm{X}$ & & \\
\hline Vibration & $\begin{array}{l}\text { Check for excessive vibration in motors, } \\
\text { fans, and pumps }\end{array}$ & & $\mathrm{X}$ & & \\
\hline Check tower structure & $\begin{array}{l}\text { Check for loose fill, connections, leaks, } \\
\text { etc. }\end{array}$ & & $\mathrm{X}$ & & \\
\hline Check belts and pulleys & Adjust all belts and pulleys & & $\mathrm{X}$ & & \\
\hline Check lubrication & $\begin{array}{l}\text { Assure that all bearings are lubricated per } \\
\text { the manufacture's recommendation }\end{array}$ & & & $\mathrm{X}$ & \\
\hline $\begin{array}{l}\text { Check motor supports } \\
\text { and fan blades }\end{array}$ & $\begin{array}{l}\text { Check for excessive wear and secure } \\
\text { fastening }\end{array}$ & & & $\mathrm{X}$ & \\
\hline Motor alignment & $\begin{array}{l}\text { Aligning the motor coupling allows for } \\
\text { efficient torque transfer }\end{array}$ & & & $\mathrm{X}$ & \\
\hline $\begin{array}{l}\text { Check drift } \\
\text { eliminators, louvers, } \\
\text { and fill }\end{array}$ & $\begin{array}{l}\text { Look for proper positioning and scale } \\
\text { build up }\end{array}$ & & & $\mathrm{X}$ & \\
\hline Clean tower & $\begin{array}{l}\text { Remove all dust, scale, and algae from } \\
\text { tower basin, fill, and spray nozzles }\end{array}$ & & & & $\mathrm{X}$ \\
\hline Check bearings & $\begin{array}{l}\text { Inspect bearings and drive belts for wear. } \\
\text { Adjust, repair, or replace as necessary. }\end{array}$ & & & & $\mathrm{X}$ \\
\hline Motor condition & $\begin{array}{l}\text { Checking the condition of the motor } \\
\text { through temperature or vibration analysis } \\
\text { assures long life }\end{array}$ & & & & $\mathrm{X}$ \\
\hline
\end{tabular}




\subsubsection{References}

FEMP 2008. Federal Energy Management Program - Water Best Management Practices. Available on line at URL: http://wwwl.eere.energy.gov/femp/water/water_bmp.htm.

Marley Cooling Technologies. July 6, 2001a. Cooling Information Index. Reprinted with permission of Marley Cooling Technologies. http:// www.trane.com/commercial/library/vol34_2/admapn018en_0105.pdf.

Marley Cooling Technologies. September 2, 2002b. Sigma F Series. [Online report]. Available URL: http://www.marleyct.com/sigmafseries.htm. Reprinted with permission of Marley Cooling Technologies.

Suptic, D.M. April 13, 2001. A Guide to Trouble-Free Cooling Towers: A basic understanding of cooling tower operation and maintenance will help keep a cooling water system running in top condition, year after year, June 1998, RSES Journal. [Online report]. Available URL: http://www.pace-incorporated.com/ maint1.htm. Reprinted with permission of RSES Journal.

Washington State University Cooperative Extension Energy Program (WSUCEEP). April 24, 2001. Optimizing Cooling Tower Performance, WSUEEP98013 [Online report]. Reprinted with permission of Washington State University Cooperative Extension Energy Program. 


\subsection{Energy Management/Building Automation Systems}

\subsubsection{Introduction}

The objective of an energy management/building automation system (also know as an energy management and control system [EMCS]) is to achieve an optimal level of control of occupant comfort while minimizing energy use. These control systems are the integrating component to fans, pumps, heating/cooling equipment, dampers, mixing boxes, and thermostats. Monitoring and optimizing temperature, pressure, humidity, and flow rates are key functions of modern building control systems.

\subsubsection{System Types}

At the crudest level of energy management and control is the manual operation of energy using devices; the toggling on and off of basic comfort and lighting systems based on need. The earliest forms of energy management involved simple time clock- and thermostat-based systems; indeed, many of these systems are still being used. Typically, these systems are wired directly to the enduse equipment and mostly function autonomously from other system components. Progressing with technology and the increasing economic availability of microprocessor-based systems, energy management has quickly moved to its current state of computer based, digitally controlled systems.

Direct digital control (DDC) systems function by measuring particular system variables (temperature, for instance), processing those variables (comparing a measured temperature to a desired setpoint), and then signaling a terminal device (air damper/mixing box) to respond. With the advent of DDC systems, terminal devices are now able to respond quicker and with more accuracy to a given input. This increased response is a function of the DDC system capability to control devices in a nonlinear fashion. Control that once relied on linear "hunting" to arrive at the desired setpoint now is accomplished through sophisticated algorithms making use of proportional and integral (PI) control strategies to arrive at the setpoint quicker and with more accuracy.

\subsubsection{Key Components}

The hardware making up modern control systems have three necessary elements: sensors, controllers, and the controlled devices.

- Sensors - There is an increasing variety and level of sophistication of sensors available for use with modern control systems. Some of the more common include: temperature, humidity, pressure, flow rate, and power. Sensors are now available that track indoor air quality, lighting level, and fire/smoke.

- Controllers - The function of the controller is to compare a signal received from the sensor to a desired setpoint, and then send out a corresponding signal to the controlled device for action. Controllers may be very simple such as a thermostat where the sensor and controller are usually co-located, to very sophisticated microprocessor based systems capable of powerful analysis routines.

- Controlled devices - The controlled device is the terminal device receiving the signal from the controller. Amongst others, typical controlled devices include: air dampers, mixing boxes, control valves, and in some cases, fans, pumps, and motors. 


\subsubsection{Safety Issues}

The introduction of outdoor air is the primary means for dilution of potentially harmful contaminants. Because an EMCS has the capability to control ventilation rates and outdoor-air volumes, certain health and safety precautions need to be taken to ensure proper operation and air quality. Regular checks of contaminant levels, humidity levels, and proper system operation are recommended.

A modern EMCS is capable of other control functions including fire detection and fire suppression systems. As these systems take on other roles, roles that now include responsibilities for personal safety, their operations and maintenance must be given the highest priority.

\subsubsection{Cost and Efficiency}

Simply installing an EMCS does not guarantee that a building will save energy. Proper installation and commissioning are prerequisites for optimal operation and realizing potential savings. While it is beyond the scope of this guide to detail all the possible EMCS savings strategies, some of the more common functions are presented below.

- Scheduling - An EMCS has the ability to schedule the HVAC system for night setback, holiday/weekend schedules (with override control), optimal start/stop, and morning warm-up/ cool-down functions.

- Resets - Controlling and resetting temperatures of supply air, mixed air, hot water, and chilled water optimize the overall systems for efficiency.

- Economizers - Controlling economizer functions with an EMCS helps to assure proper integration and function with other system components. Strategies include typical air-side functions (i.e., economizer use tied to inside setpoints and outside temperatures) and night-time ventilation (purge) operations.

- Advanced functionality - A more sophisticated EMCS has expended capabilities including chiller/boiler staging, variable speed drive control, zoned and occupancy-based lighting control, and electrical demand limiting.

\subsubsection{Maintenance}

The ability of an EMCS to efficiently control energy use in a building is a direct function of the data provided to the EMCS. The old adage 'garbage in - garbage out' could not hold more truth than in an EMCS making decisions based on a host of sensor inputs.

For a number of reasons, the calibration of sensors is an often overlooked activity. In many ways, sensors fall into the same category as steam traps: if it doesn't 'look' broken - don't fix it. Unfortunately, as with steam traps, sensors out of calibration can lead to enormous energy penalties. Furthermore, as with steam traps, these penalties can go undetected for years without a proactive maintenance program. 
The following is a list of sensors and actuators that will most need calibration (PECI 1997):

- Outside air temperature

- Mixed air temperature

- Return air temperature

- Discharge or supply air temperature

- Coil face discharge air temperatures

- Chilled water supply temperature

- Condenser entering water temperature

- Heating water supply temperature

- Wet bulb temperature or RH sensors

- Space temperature sensors

\section{Are You Calibrated?}

Answer the following questions to determine if your system or equipment needs calibration (PECI 1997):

1. Are you sure your sensors and actuators were calibrated when originally installed?

2. Have your sensors or actuators been calibrated since?

3. Have temperature complaints come from areas that ought to be comfortable?

4. Are any systems performing erratically?

5. Are there areas or equipment that repeatedly have comfort or operational problems?

- Economizer and related dampers

- Cooling and heating coil valves

- Static pressure transmitters

- Air and water flow rates

- Terminal unit dampers and flows.

Sensor and actuator calibration should be an integral part of all maintenance programs.

\subsubsection{Diagnostic Equipment}

- Calibration - All energy management systems rely on sensors for proper feedback to adjust to efficient conditions. The accuracy with which these conditions are reached is a direct function of the accuracy of the sensor providing the feedback. Proper and persistent calibration activities are a requirement for efficient conditions.

\subsubsection{Relevant Operational/Energy Efficiency Measures}

There are many operational/energy efficiency measures that could be presented for proper EMCS/BAS operation and control. The following section focuses on the most prevalent O\&M recommendations having the greatest energy impacts at Federal facilities.

EMCS Measure \#1: HVAC Scheduling, Temperature/Pressure Setpoints

Site energy/facility managers should have a goal of matching HVAC scheduling to the actual tenant schedules within all buildings. The building operators should closely monitor tenant schedules and adjust the HVAC schedules accordingly to meet changing schedules throughout the year. 
The construction of the building, including the types of windows, insulation, and overall orientation, contributes to its ability to retain conditioned air. This coupled with the internal heating and cooling loads in the building will dictate when the HVAC system should be cycled during the day.

\section{Direct Digital Control (DDC) Optimal Start/Stop}

Most DDC systems have optimal start-stop programs with software algorithms that assess indoor and outdoor temperatures and, based on adaptive learning, the DDC system will activate the building's HVAC system at different times each day. This technology is one of the most energyefficient HVAC control programs available and should be utilized whenever possible. Other DDC systems have the ability to program preset start-stop times for the building's HVAC system. In this case, the building operators should try to start the HVAC system as close to the tenants arrival as possible. The operators should also consider applying different start times based on average outdoor air temperatures versus times of extreme outdoor air temperatures.

\section{DDC Holiday Scheduling}

If the building has a DDC control system, it will typically come equipped with a holiday scheduling feature. Building operators should utilize this feature to turn off the building's HVAC system during unoccupied periods and holidays. In addition to unoccupied periods and holidays, many DoD facilities, such as barracks, training facilities, and mess halls, will go unoccupied for periods of time when troops are deployed, therefore they should have scheduling adjusted accordingly. It should be noted that if the building is located in a humid climate, the HVAC system should be put into standby mode and turned on to maintain the humidity limits and unoccupied setback temperatures within the facility.

Building operators should periodically review their DDC codes to make sure the HVAC schedules matches the tenant schedules as closely as possible. If the building operators have to implement overrides to handle extreme weather conditions or special occupancy circumstances, these overrides should be recorded and removed as soon as possible.

In buildings with electromechanical and pneumatic controls, the building operators should at a minimum apply a start-stop schedule based on historic data relating to the amount of time it takes to condition the building. In general, when the HVAC system is turned off, the building operators need to ensure that all of the HVAC fans and pumps are turned off. Although it might be necessary to continuously operate the building chillers and boilers, the building's fans and pumps can be turned off when the HVAC system is not operating.

\section{Temperature and Pressure Setpoints}

Temperature setpoints in buildings can typically be programmed using the proportional integral (PI) control loop. If the PI control loop is used, the site must ensure that the throttling range is not too small (DDC Online 2006b). The throttling range relates to the gap between the heating setpoint and cooling setpoint. The larger this gap is, the less energy the site will use to condition the interior air. Guidelines on indoor temperature setpoints for energy efficiency target the heating season setpoint at between $68^{\circ} \mathrm{F}-72^{\circ} \mathrm{F}$ and the cooling season setpoint at between $72^{\circ} \mathrm{F}-78^{\circ} \mathrm{F}$. The optimal seasonal setpoint (balancing thermal comfort with energy efficiency) will be a function of type of activity taking place in the space and the ambient relative humidity. 
While some facilities target $68^{\circ} \mathrm{F}$ heating and $78^{\circ} \mathrm{F}$ cooling setpoints, they are not operated at these temperatures because of occupant complaints. Regardless of the chosen setpoints, facility managers should strive to have the largest throttling range (or dead-band gap) between the two setpoints. This ensures that the HVAC system will not slightly overcool the building, causing the building to immediately go into heating mode, and then slightly overheat the building, causing it to go back into cooling mode. This type of constant cycling is inefficient, hard on equipment, and causes the building to constantly "hunt" for the right temperature.

As previously mentioned, the building operators should also implement a nighttime or unoccupied setback temperature. The unoccupied setback for heating should be $5^{\circ} \mathrm{F}$ to $10^{\circ} \mathrm{F}$ cooler than the occupied setpoint, and the unoccupied setback for cooling should be $5^{\circ} \mathrm{F}$ to $10^{\circ} \mathrm{F}$ warmer than the occupied setpoint. In humid climates, the underlying activator of the system should be the relative humidity ratios. As long as these ratios are met, the interior temperatures should be allowed to float over the preset unoccupied setpoints.

The temperature setpoint methodology is also valid for electromechanical and pneumatic controls. The only difference may be in the allowable control points - two are typical with electromechanical systems.

\section{Pressure Setpoints}

Based on energy and O\&M audits of a variety of Federal facilities, many air-side static pressure setpoints fall in range of the 1.9" water column (w.c.) to 2.6" w.c. This is far higher than necessary where most variable air volume (VAV) systems are intended to operate in the 1" to 1.5 " w.c. range (Lundstrom 2006). If this type of operation is encountered, the site should investigate the system to make sure the VAV fans are operating and controlling properly. These high static pressure readings can sometimes be caused by site staff looking to make a quick fix when one of the fans is not operating or controlling properly. This could also be caused by a failed static pressure sensor, failed inlet vane controls, slipping belts or breached ductwork. In any case, the building operator should determine the design air-side static pressure setpoint for the particular air-handling unit to ensure the current operation is as close to this value as possible. The operator should identify the location of the static pressure gauges - they should be installed about $2 / 3$ of the way down the longest stretch of ductwork.

In DDC control systems, some HVAC operators encourage unoccupied pressure setpoint reductions to be implemented in conjunction with the unoccupied temperature setpoint changes. This offers greater energy savings in VAV systems by allowing for a larger dead-band temperature range and less air to be circulated through the building. 
As staff perform certain maintenance tasks to prepare equipment for heating or cooling seasons, they should also review and adjust operational strategies seasonally.

EMCS Measure \#2: HVAC Tune-Up and Maintenance

Some of the most important HVAC tune-up and maintenance activities a site should consider are related to the following: valves, filters, coil cleanings, sensor calibration, damper operation, belt system checks, system override correction, and air/water flow analysis.

\section{Valves}

Control valves in HVAC systems are used to control the amount of hot or chilled water that circulates through heating or cooling coils. While a necessary component, control valves are notorious for failing. Unfortunately, when a control valve failure occurs, it often goes unnoticed by site staff because it is difficult to assess visually. Common control valve problems/malfunctions include valves that have been manually overridden in the open position, valves stuck in a fixed position, valves that are leaking, and valves that are incorrectly wired - usually backwards.

One method of valve diagnosis starts with the DDC system. Through the DDC system, an operator will determine if a particular heating coil is hot (i.e., is being supplied with hot water). This will be evident through the system reported as a temperature at the coil. Next, the operator will make sure the zone served by this coil is actually calling for heat; this is represented in the system as a request for service. If the zone is not calling for heat, yet the coil is hot, the operator should examine the control valve for either leakage or manual override. This same procedure holds true for cooling coils.

Another method of valve diagnosis again makes use of the DDC system. In this scenario, the operator uses the system to fully close both the heating and cooling valves or he can manually override them. Once done, the operator then reviews the air temperatures on either side of the heating/cooling coils for which there should not be more than a $2^{\circ} \mathrm{F}$ to $4^{\circ} \mathrm{F}$ temperature difference between the two temperature sensors. If the temperature difference exceeds this range, the operator should consider either control valve or temperature sensor malfunction.

\section{Sensor Calibration}

The HVAC temperature, pressure, relative humidity and $\mathrm{CO}_{2}$ sensors within a building have certain calibration limits that they operate within. The accuracy of a given sensor is primarily a function of the sensor type, with accuracy of all sensors usually degrading over time. Accordingly, as a general maintenance function, sensor assessment and calibration should be a routine function. Refer to manufacturer's data for the recommendations of assessment and calibration.

As with valves, damper operation can be verified using a DDC control system. Through this system, a facility manager can activate the damper to the fully open and then fully closed position while a colleague in the field verifies this function. If a particular damper is not actuating as it should, the linkages and actuator should be examined for proper connection and operation. During this process, field staff should also verify that all moving parts are properly lubricated and seals are in good shape. 
Because economizers are dampers that interact with outside air, buildings where these are installed should receive special attention. In addition to the above procedure, economizer dampers should be checked at a higher frequency to ensure proper modulation, sealing, and sensor calibration. The temperature and/or humidity (i.e., enthalpy) sensor used to control the economizers should be part of a routine calibration schedule.

\section{Belt-Driven System}

Belt-driven systems are common in HVAC fan systems. Belt drives are common because they are simple and allow for driven equipment speed control, which is accomplished through the adjustment of pulley size. While belt-drive systems are generally considered to be efficient, certain belts are more efficient than others. Standard belt drives typically use V-belts that have a trapezoidal cross section, and operate by wedging themselves into the pulley. These V-belts have initial efficiencies on the order of $95 \%$ to $98 \%$, which can degrade by as much as $5 \%$ over the life of the system, if the belts are not periodically re tensioned (DOE 2005b).

If the fans currently have standard V-belts, retrofit options for consideration include cogged-Vbelts or synchronous belts and drives. In both cases, efficiency gains on the order of $2 \%$ to $5 \%$ are possible, depending on the existing belt and its condition. It should be noted that cogged-V-belts do not require a pulley change as part of the retrofit while the synchronous belt retrofit does.

\section{System Overrides}

System overrides that are programmed into the buildings DDC systems should be periodically checked. System overrides are sometimes necessary to handle extreme weather conditions, occupancy conditions, or special events. As these are programmed, a special note should be made of what was over-ridden, for what purpose, and when it can be reset. The site should implement a continuous override inspection program to look at all of the overrides that have been programmed into the DDC system and to make sure they are removed as soon as possible.

\section{Simultaneous Heating and Cooling}

In dry climates that do not have a need to simultaneously heat and cool the air to control the relative humidity, it is generally advised that the heating should be disabled whenever the cooling system is activated and vice versa. In pneumatic and electromechanical systems, the building operator may have to manually override the heating and cooling system to accomplish this.

With DDC systems installed in areas not requiring dehumidification the system should be programmed to lock out the hot-water pumps during high ambient conditions (e.g., outdoor air temperatures above $70^{\circ} \mathrm{F}$ ) and lock out the chilled water pumps during low ambient conditions (e.g., outdoor air temperatures below $60^{\circ} \mathrm{F}$ to $55^{\circ} \mathrm{F}$ ). This will ensure that only the necessary service is provided and eliminate the wasteful practice of unnecessary simultaneous heating and cooling.

Where simultaneous heating and cooling is required (e.g., in humid climatic regions) to remove the moisture from the conditioned air, and then to heat the air back up to the required setpoint temperatures, building operators should check for proper operation. As noted above, checks should be made to ensure temperature dead-band setting is far enough apart that it does not cause the HVAC system to continuously "hunt." 


\subsubsection{Case Studies}

\section{Benefit of O\&M Controls Assessments (PECI 1999)}

A 250,000 square-foot office building in downtown Nashville, Tennessee, was renovated in 1993. The renovation included installing a DDC energy management control system to control the variable air volume (VAV) HVAC system and lighting and a variable frequency drive (VFD) for the chilled water system. The building was not commissioned as part of the renovation. An O\&M assessment was performed 3 years later because the building was experiencing problems and energy bills seemed higher then expected. As a result of the assessment, a total of 32 O\&M related problems including a major indoor air quality (IAQ) deficiency were identified. It was also determined that the majority of these problems had been present since the renovation. Annual energy savings from the recommended O\&M improvements and repairs are estimated at $\$ 9,300$. The simple payback for both the assessment and implementation is under 7 months.

\section{GSA/FEMP Pre-Cooling Strategy at the Philadelphia Custom House (FEMP 2007)}

FEMP performed a study of prospective load management and demand response approaches for the General Services Administration's (GSA) Philadelphia Custom House in early 2005 (Figure 9.6.1). GSA adopted the key recommendation and, through a few targeted operational changes and almost no capital cost, saved nearly $\$ 70,000$ in demand payments in 2005-2006 and more than $\$ 100,000$ (almost 15 percent of the facility's annual electricity bill) in 2006-2007.

GSA pays more than $\$ 28$ per kilowatt $(\mathrm{kW})$ - two to three times the national norm-in demand charges for the 570,000 square foot Custom House, and is also subject to a demand "ratchet" such that 80 percent of

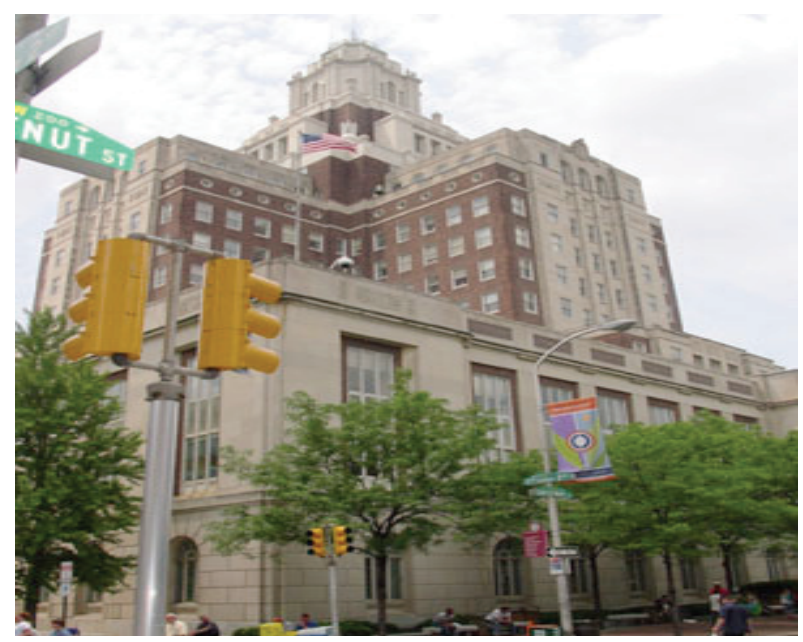

Figure 9.6.1. General Services Administration's Custom House, Philadelphia, PA its summer peak power draw (i.e., its highest single 30-minute interval reading between June and September) becomes its minimum billed demand for each of the next eight months (October through May).

Since the Custom House generally experiences a summer peak of about 2,000 kW, this means that GSA is obligated to pay for at least $1,600 \mathrm{~kW}$ during these off-peak months. However, the facility is a conventional Federal office building with a low load factor, and barely reaches peaks of $1,000 \mathrm{~kW}$ from December to March. At more than $\$ 28$ per $\mathrm{kW}$, the Custom House regularly pays its utility (PECO Energy) over $\$ 15,000$ per month during those four months (as well as additional sums in the "shoulder" months of October, November, April, and May) for power it does not even draw. 
With this in mind, GSA requested that FEMP conduct a study on the potential to cost-effectively reduce its peak demand. The central component of FEMP's recommendation was a "precooling" strategy where GSA would turn on its chilled water plant very early in the morning (as opposed to the usual 6 A.M.) on hot summer days. In addition, FEMP recommended that the chilled water valves in the building's roughly one thousand perimeter induction units be tripped to a "fail-open" position during these early morning hours so that the facility would actually be somewhat overcooled. The idea was to utilize the circa 1934 building's substantial mass as a thermal storage medium, which could then absorb heat and provide cool-temperature radiation throughout the day, mitigating the customary afternoon power peak.

GSA adopted this strategy, and working with their operations and maintenance contractor developed a multi-part plan to reduce the building's peak through early morning pre-cooling and afternoon "demand-limiting." The key elements are:

- If the outside air exceeds $70^{\circ} \mathrm{F}$ at 2 A.M., one of the facility's two 650 -ton chillers is turned on and programmed to produce $42^{\circ} \mathrm{F}$ chilled water;

- All induction unit chilled water valves are set to a full-open position during the early morning;

- At 9 A.M., the chilled water temperature is raised to $46^{\circ} \mathrm{F}$ and induction unit control reverts to the tenants (the units have no re-heat coils but the unit controls can be set towards "warmer" to reduce or eliminate the flow of chilled water through them);

- If demand reaches $1,500 \mathrm{~kW}$ and is still rising by 12 noon, the chilled water temperature is raised again, to $48^{\circ} \mathrm{F}$;

- Only one of the two 650-ton chillers is allowed to operate at any given time.

In the beginning of summer 2005, the team executed the strategy manually, using control system overrides for chiller operation and bleeding the air out of the pneumatic lines to open the induction unit valves. Once the team gained confidence in this strategy, the building's controls contractor was called in to help automate it within the energy management control system (installed in 2003 as part of a Super Energy Savings Performance Contract).

As a result, the operations team was able to keep the facility's peak demand down to $1,766 \mathrm{~kW}$ over the summer (defined by the PECO tariff as June though September), as opposed to the 2,050 kW or higher that would likely have been reached. GSA benefited directly from the reduced demand in the summer, saving an estimated $\$ 26,000$ (see Table 9.6.1) in those four months alone. 
Table 9.6.1. Custom House demand reduction and savings 2005-2006

\begin{tabular}{|c|c|c|c|c|c|}
\hline Month & $\begin{array}{c}\text { Expected Peak } \\
(\mathrm{kW})^{*}\end{array}$ & $\begin{array}{c}\text { Actual Peak } \\
(\mathrm{kW})^{*}\end{array}$ & $\begin{array}{c}\text { Billed Peak } \\
\qquad(\mathrm{kW})^{* *}\end{array}$ & $\begin{array}{c}\text { Peak } \\
\text { Reduction } \\
(\mathrm{kW})\end{array}$ & kW Value \\
\hline June 2005 & 1,900 & 1,766 & 1,766 & 134 & $\$ 3,410$ \\
\hline July 2005 & 2,050 & 1,692 & 1,692 & 358 & $\$ 9,109$ \\
\hline August 2005 & 2,050 & 1,692 & 1,697 & 353 & $\$ 8,982$ \\
\hline September 2005 & 1,900 & 1,711 & 1,711 & 189 & $\$ 4,809$ \\
\hline October 2005 & 1,640 & 1,640 & 1,604 & 36 & $\$ 916$ \\
\hline November 2005 & 1,640 & 1,448 & 1,448 & 192 & $\$ 4,885$ \\
\hline December 2005 & 1,640 & 1,015 & 1,413 & 227 & $\$ 5,776$ \\
\hline January 2006 & 1,640 & 992 & 1,413 & 227 & $\$ 6,134$ \\
\hline February 2006 & 1,640 & 961 & 1,413 & 227 & $\$ 6,134$ \\
\hline March 2006 & 1,640 & 953 & 1,413 & 227 & $\$ 6,134$ \\
\hline April 2006 & 1,640 & 1,393 & 1,413 & 227 & $\$ 6,134$ \\
\hline May 2006 & 1,850 & 1,646 & 1,646 & 204 & $\$ 5,512$ \\
\hline Total Savings & & & & & $\$ 67,934$ \\
\hline
\end{tabular}

GSA reaped even greater savings from the reduced ratchet charges during the winter months. The ratchet clause set the minimum demand charge for the October through May bills at 1,413 kW ( 80 percent of the $1,766 \mathrm{~kW}$ summer peak). While the previous four summers' average peak was $2,080 \mathrm{~kW}$, FEMP conservatively estimated that 2,050 kW would have been 2005's peak draw (this is a conservative estimate because the summer of 2005 was an unusually hot one in the mid-Atlantic). Since 80 percent of 2,050 is 1,640, this figure was used to estimate the ratchet savings - i.e., to represent what the billed peak would have been without the pre-cooling. The $227 \mathrm{~kW}$ reduction $(1640$ - 1413) translated to more than $\$ 30,000$ in savings for the five months of December through April; additional ratchet relief in October, November, and May made for a total (including the $\$ 26,000$ in direct summer months' savings) of roughly $\$ 68,000$.

In sum, the Custom House's pre-cooling thermal storage experiment has been an enormous success. The GSA avoided almost $\$ 70,000$ in demand charges during the first year (2005-6). GSA concluded at a "lessons learned" meeting that the GSA should "declare summer 2005's usage was only 0.5 percent higher, despite the fact that it had 4.3 percent more cooling degree days." Moreover, a regression plotting the four previous summers' $\mathrm{kWh}$ consumption against the number of cooling degree days in each revealed that summer 2005's actual consumption was 2 percent less than what the model predicted. The facility's summer 2006 usage fell a remarkable 7.5 percent below the regression's prediction. 


\subsubsection{Building Controls Checklist}

\begin{tabular}{|c|c|c|c|c|c|}
\hline \multirow{2}{*}{ Description } & \multirow{2}{*}{ Comments } & \multicolumn{4}{|c|}{ Maintenance Frequency } \\
\hline & & Daily & Weekly & $\begin{array}{l}\text { Semi- } \\
\text { Annually }\end{array}$ & Annually \\
\hline $\begin{array}{l}\text { Overall visual } \\
\text { inspection }\end{array}$ & $\begin{array}{l}\text { Complete overall visual inspection to be } \\
\text { sure all equipment is operating and safety } \\
\text { systems are in place }\end{array}$ & $\mathrm{X}$ & & & \\
\hline $\begin{array}{l}\text { Verify control } \\
\text { schedules }\end{array}$ & $\begin{array}{l}\text { Verify in control software that schedules are } \\
\text { accurate for season, occupancy, etc. }\end{array}$ & $\mathrm{X}$ & & & \\
\hline Verify setpoints & $\begin{array}{l}\text { Verify in control software that setpoints are } \\
\text { accurate for season, occupancy, etc. }\end{array}$ & $\mathrm{X}$ & & & \\
\hline Time clocks & Reset after every power outage & $\mathrm{X}$ & & & \\
\hline Check all gauges & $\begin{array}{l}\text { Check all gauges to make sure readings are } \\
\text { as expected }\end{array}$ & & $\mathrm{X}$ & & \\
\hline $\begin{array}{l}\text { Control tubing } \\
\text { (pneumatic system) }\end{array}$ & Check all control tubing for leaks & & $\mathrm{X}$ & & \\
\hline $\begin{array}{l}\text { Check outside air } \\
\text { volumes }\end{array}$ & $\begin{array}{l}\text { Calculated the amount of outside air } \\
\text { introduced and compare to requirements }\end{array}$ & & $\mathrm{X}$ & & \\
\hline Check setpoints & $\begin{array}{l}\text { Check setpoints and review rational for } \\
\text { setting }\end{array}$ & & $\mathrm{X}$ & & \\
\hline Check schedules & $\begin{array}{l}\text { Check schedules and review rational for } \\
\text { setting }\end{array}$ & & $\mathrm{X}$ & & \\
\hline Check deadbands & $\begin{array}{l}\text { Assure that all deadbands are accurate and } \\
\text { the only simultaneous heating and cooling } \\
\text { is by design }\end{array}$ & & $\mathrm{X}$ & & \\
\hline Check sensors & $\begin{array}{l}\text { Conduct thorough check of all sensors - } \\
\text { temperature, pressure, humidity, flow, etc. } \\
\text { - for expected values }\end{array}$ & & & $\mathrm{X}$ & \\
\hline Time clocks & Check for accuracy and clean & & & $\mathrm{X}$ & \\
\hline Calibrate sensors & $\begin{array}{l}\text { Calibrate all sensors: temperature, pressure, } \\
\text { humidity, flow, etc. }\end{array}$ & & & & $\mathrm{X}$ \\
\hline
\end{tabular}




\subsubsection{References}

DDC Online. 2006a. Introduction to Direct Digital Control Systems. Chapter 1, Direct Digital Controls Online. Available URL: http://www.ddc-online.org/.

DDC Online. 2006b. Control Response. Chapter 2, Direct Digital Controls Online. Available URL: http://www.ddc-online.org/.

DOE. 2005b. "Replace V-Belts with Cogged or Synchronous Belt Drives." In Motor Systems Tip Sheet \#5, DOE/GO-102005-2060, U.S. Department of Energy, Office of Energy Efficiency and Renewable Energy, Washington, D.C.

FEMP 2007. GSA's Cool Coup at the Philadelphia Custom House. FEMP Focus, Fall 2007. U.S. Department of Energy, Federal Energy Management Program. Washington D.C.

Lundstrom C. 2006. Top Recommissioning Measures to Maintain Efficiency. EMC Engineers Inc., Energy.

PECI. 1997. Energy Management Systems: A Practical Guide. Portland Energy Conservation, Inc., Portland, Oregon.

PECI. 1999. Operations and Maintenance Assessments. Portland Energy Conservation, Inc. Published by the U.S. Environmental Protection Agency and the U.S. Department of Energy. 


\subsection{Air Handling Systems}

\subsubsection{Introduction}

The components of most air handling systems include fans, ductwork, damper assemblies, heating and cooling coils (or elements), and associated sensors.

\subsubsection{Types of Air Handling Systems}

Most air handling systems fall into two broad categories, constant-volume (CV) and variable-airvolume (VAV). The following descriptions provide an overview of generic system types commonly found in larger commercial and institutional buildings (Better Bricks 2008).

Constant Air Volume. Constant air volume systems provide a constant airflow rate to the zone. The control variable is the temperature of the air supplied to the zone. These systems can be configured for single-zone or multi-zone systems and may be configured as a single duct or two duct (dual duct) system.

Variable Air Volume. VAV systems provide comfort by changing the volume of air delivered to a zone based on temperature needs and controlled by static pressure measured in the duct system. Most VAV systems are single duct systems and provide cooling and ventilation - when necessary, air is heated often at the terminal unit.

\subsubsection{Key Components}

- Fans - This topic will be addressed in Section 9.8

- Coils - Coils provide the mechanism for heat transfer between the air stream and the heatexchange fluid (usually water, steam or refrigerant). These coils are made of tubes that carry the fluid and are surrounded by rows of thin fins designed to increase the heat-transfer surface area. For maximum heat transfer, it is imperative to keep these coils clean and free of obstructions.

- Filters - With the goal of efficient heat transfer and good air quality, filters are used to prevent particulate matter or other contaminants from entering (or re-circulating) though an air handling system. Filters are classified by ASHRAE Standard 52.2 and rated by their Minimum Efficiency Reporting Value (MERV). By design, the airflow through a filter bank should be as uniform across the entire filter surface area and, depending on the filter type and design, in the range of 400 to 600 feet per minute (fpm). Filters are a required maintenance item and should be changed based on system use and contaminant loading.

- Dampers - To control and direct the flow of air through the system, dampers are installed at the inlet, the outlet, or internal to the air handling system. There are a variety of damper types and configurations. Dampers are a notorious source of energy waste via leakage, malfunction, or being disabled. Due to their typical location and challenges associated with proper assessment, damper assemblies are often not addressed in standard maintenance practices.

- Ducts - The ducts found in most commercial facilities are usually made of galvanized steel and are insulated to reduce heat transfer and prevent condensation. Duct connections from section to section, or at the terminal apparatus, need to be done according local code requirements and should be checked annually for integrity. 


\subsubsection{Cost and Energy Efficiency}

Many air handling system efficiency measures relate to how the system is controlled and are covered in Section 9.6 Energy Management and Building Automation Systems. Additional measures for consideration are presented below.

- Filters - Air filters play a critical role in maintaining indoor air quality and protecting the downstream components of the system from dirt that reduces equipment efficiency. In the worse case, dirty filters can result in supply air bypassing the filter and depositing dirt on the heating/ cooling coils rather than on the filter. This results in dirty coils, poor heat transfer, and general inefficiency. In addition to the efficiency penalty, cleaning a dirty coil is far more difficult and labor intensive than replacing filters (DOE 2005).

As a rule, sites should routinely change filters based on either the pressure drop across the filter, calendar scheduling, or visual inspection. Scheduled intervals should be between 1 and 6 months, depending on the dirt loading from indoor and outdoor air. Measuring the pressure drop across the filter is the most reliable way to assess filter condition. In facilities with regular and predictable dirt loading, measuring the pressure drop across the filter can be used to establish the proper filter-changing interval; thereafter, filter changes can be routinely scheduled. Refer to manufacturer's data for the recommendations of pressure drop across specific filters.

- Coil Cleaning - Hot water and chilled water coils in HVAC systems tend to accumulate dirt and debris, similarly to HVAC filters. As dirt and debris accumulates, it inhibits the heat transferred from the working fluid to the air stream, thus reducing the efficiency of the HVAC system. Much like HVAC filters, the scheduled intervals between cleanings is a function of the dirt loading across the coil and is primarily a function of how much dirt is in the ambient air and what has bypassed the filter. Based on the site's periodic inspections, the given facility should develop appropriate cleaning schedules for all of the hot water and chilled water coils. Figure 9.7.1 presents a cooling coil in great need of maintenance.

- Damper Operation - There are a number of potential faults HVAC dampers may be subject to. These include dampers stuck open or closed, dampers manually positioned (i.e., mechanically fixed in a position using wire, boards, etc.), dampers with missing vanes, or dampers operating with poor seals. Figure 9.7.2 shows one all too common solution to a damper issue - something not recommended by this guide's authors.

\subsubsection{Maintenance}

Proper maintenance for air handling systems includes scheduled filter replacement, coil cleaning, duct integrity evaluation, damper cleanliness and function.

\subsubsection{Diagnostic Tools}

The combination of a facility's building automation system and occupant interaction can be very diagnostic of an air handling systems function. Repeated cold/warm complaint calls, validated through the BAS sensor readings, can be indicative of a poorly performing system in need of maintenance. 


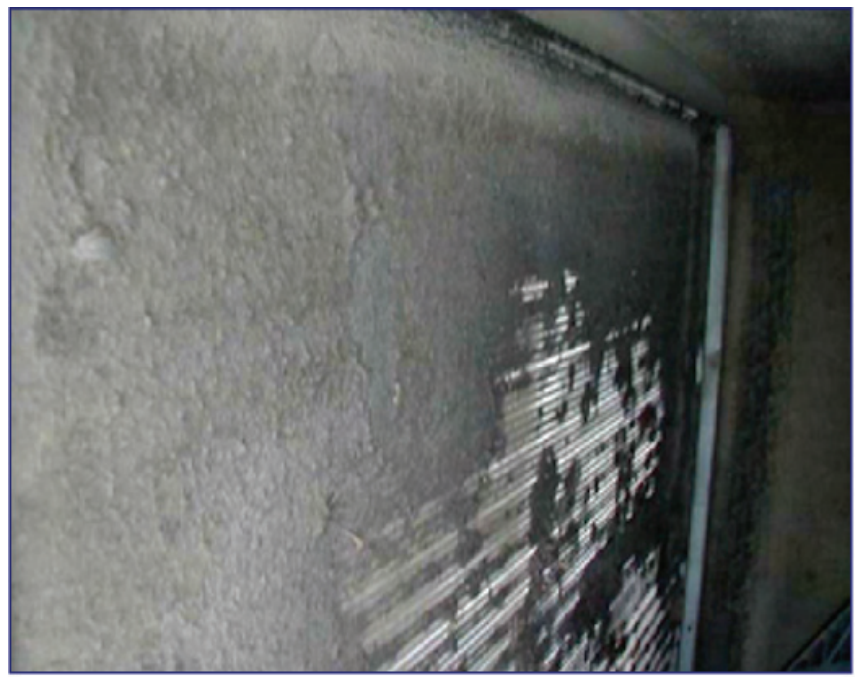

Figure 9.7.1. Cooling coil requiring cleaning

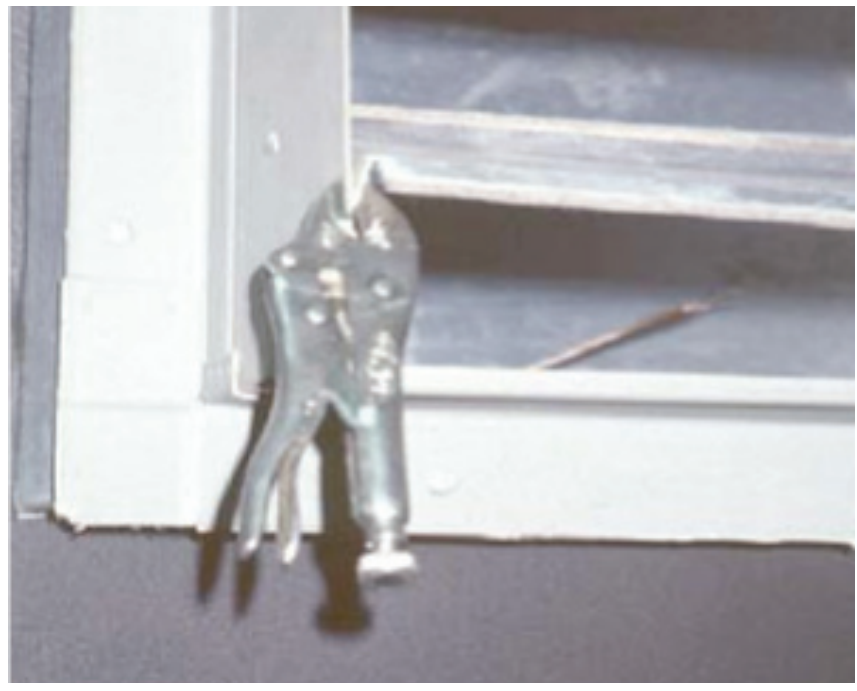

Figure 9.7.2. Damper quick fix - not recommended

\subsubsection{Case Study}

Retro-Commissioning of Air-Handling System at the Ronald V. Dellums Federal Building (QuEST 2004)

During a Building Tune-Up (BTU) Program audit at the Ronald V. Dellums Federal Building in Oakland, program engineers identified several simple ways to improve energy efficiency in its air handling systems yielding more than $\$ 65,000$ in annual savings.

The 1.1 million square foot office building was the focus of a thorough retro-commissioning (R-Cx) audit provided as part of the Oakland Energy Partnership (OEP) Program. The audit team found that energy costs could be cut by improving placement of key air stream sensors, addressing air damper problems, and reducing pressure setpoints. 


\section{An Efficient Building Can Reduce Costs Even More.}

Although the building was completed in 1994 and has an energy use intensity of $54 \mathrm{kBtu} / \mathrm{sqft}$ yr, well below the average $70 \mathrm{kBtu} / \mathrm{sqft}$-yr for typical office buildings in Oakland, the tune-up team managed to find numerous cost-effective savings measures.

One of the findings of the program was that poor sensor locations in the air handlers have been wasting over $\$ 27,000$ per year. By simply moving sensors to locations that are more representative of the air stream of interest, the existing control algorithms work as they were originally intended.

In another case, air was flowing through the ducts in the reverse direction of the intended design. Functional testing showed that under certain conditions, air from one hot deck supply fan was flowing up the common supply shaft and back feeding through the other fan. The R-Cx team recommended controlling both $5^{\text {th }}$ floor $\&$ penthouse fans in unison to prevent this problem. Expert analysis required to identify this problem was paid for by the BTU program and building owners paid relatively little to implement the measures.

The investigation phase of the project included analysis of trended data logs and extensive functional testing of the HVAC equipment. A total of 12 operational deficiencies were observed in the air handling systems. The problems with the greatest potential for energy savings were thoroughly analyzed and corrective measures were recommended. The project team also made specific recommendations on how to improve the operation and comfort of the facility on other nonenergy related issues.

\section{Improvements Save Energy and Increase Comfort.}

Identification, documentation and implementation of non-energy measures can often improve occupant comfort, reduce operator workload and generally improve the operation of the facility. Examples of such measures at the Ronald V. Dellums Federal Building included:

- Cleaning and calibrating airflow-monitoring stations on supply and return fans. This corrective measure allowed proper tracking of the return fans speed, which helped maintain the proper pressurization within the building.

- Adding an "auto-zero" calibration feature to the VAV box control programs. This ensured that each occupant received the correct airflow in the work area.

- Adjusting the valve actuators and positioners serving the chilled water coils to reduce hunting and increase coil capacity. 
9.7.6 Air Handling System Checklists (Better Bricks 2008)

\begin{tabular}{|c|c|c|c|c|c|}
\hline \multirow{2}{*}{ Description } & \multirow{2}{*}{ Comments } & \multicolumn{4}{|c|}{ Maintenance Frequency } \\
\hline & & Daily & Weekly & Monthly & Annually \\
\hline $\begin{array}{l}\text { Overall visual } \\
\text { inspection }\end{array}$ & $\begin{array}{l}\text { Complete overall visual inspection to be } \\
\text { sure all equipment is operating and safety } \\
\text { systems are in place }\end{array}$ & $\mathrm{X}$ & & & \\
\hline Filters & $\begin{array}{l}\text { Check filter condition according to system } \\
\text { type and manufacturer's recommendations }\end{array}$ & & & $\mathrm{X}$ & \\
\hline System integrity & $\begin{array}{l}\text { Inspect for leakage due to major } \\
\text { connections and access doors not being } \\
\text { properly closed. }\end{array}$ & & & $\mathrm{X}$ & \\
\hline Dampers & $\begin{array}{l}\text { Inspect damper actuator and linkage for } \\
\text { proper operation by cycling fully opened to } \\
\text { fully closed. }\end{array}$ & & & $\mathrm{X}$ & \\
\hline Filter assemblies & $\begin{array}{l}\text { Inspect filter rack for integrity. Inspect local } \\
\text { pressure differential gauge, tubing, and pilot } \\
\text { tubes for condition }\end{array}$ & & & & $\mathrm{X}$ \\
\hline Coils & $\begin{array}{l}\text { Inspect coil fins for physical damage, and } \\
\text { comb out any bent fins. Clean coils if } \\
\text { significant dirt is present and hampering } \\
\text { coil performance }\end{array}$ & & & & $\mathrm{X}$ \\
\hline
\end{tabular}

\subsubsection{References}

Department of Energy (DOE). 2005. Actions You Can Take to Reduce Cooling Costs. PNNL-SA-45361; U.S. Department of Energy, Federal Energy Management Program, Washington, D.C.

Better Bricks. 2008. Bottom Line Thinking on Energy - Building Operations. Northwest Energy Efficiency Alliance. Available at URL: http://www.betterbricks.com.

QuEST 2004. Retro-Commissioning Process Finds Energy Cost Savings in Air Handling Systems. QuEST - Building Tune-Up Program. Quantum Energy Services \& Technologies, Inc., Berkeley, California. 


\subsection{Fans}

\subsubsection{Introduction}

The American Society of Heating, Refrigerating, and Air-Conditioning Engineers (ASHRAE) defines a fan as an "air pump that creates a pressure difference and causes airflow. The impeller does the work on the air, imparting to it both static and kinetic energy, varying proportion depending on the fan type" (ASHRAE 1992).

\subsubsection{Types of Fans (Bodman and Shelton 1995)}

The two general types of fans are axial-flow and centrifugal. With axial-flow fans, the air passes through the fan parallel to the drive shaft. With centrifugal fans, the air makes a right angle turn from the fan inlet to outlet.

\subsubsection{Axial Fan}

Axial-flow fans can be subdivided based on construction and performance characteristics.

- Propeller fan - The basic design of propeller fans enhances maintenance to remove dust and dirt accumulations. The fan normally consists of a "flat" frame or housing for mounting, a propellershaped blade, and a drive motor. It may be direct drive (Figure 9.8.1) with the wheel mounted on the motor shaft or belt driven (Figure 9.8.2) with the wheel mounted on its own shaft and bearings.
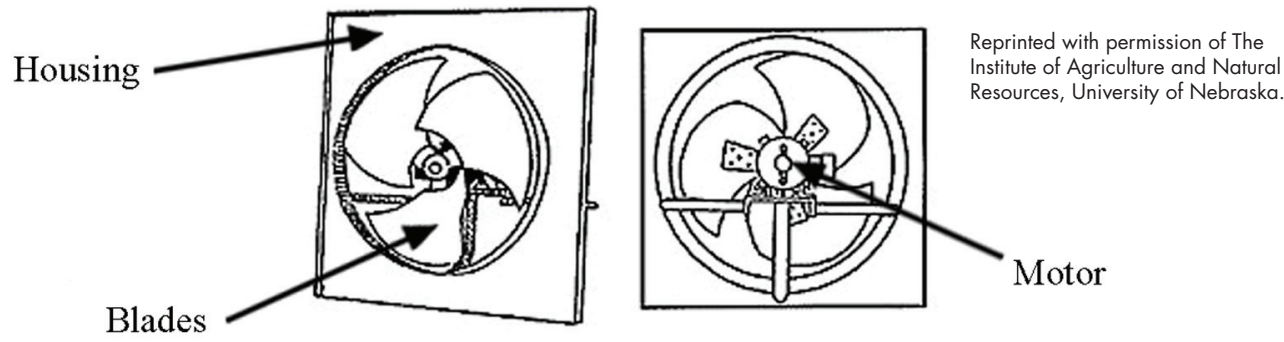

Figure 9.8.1. Propeller direct-drive fan (front and rear view).
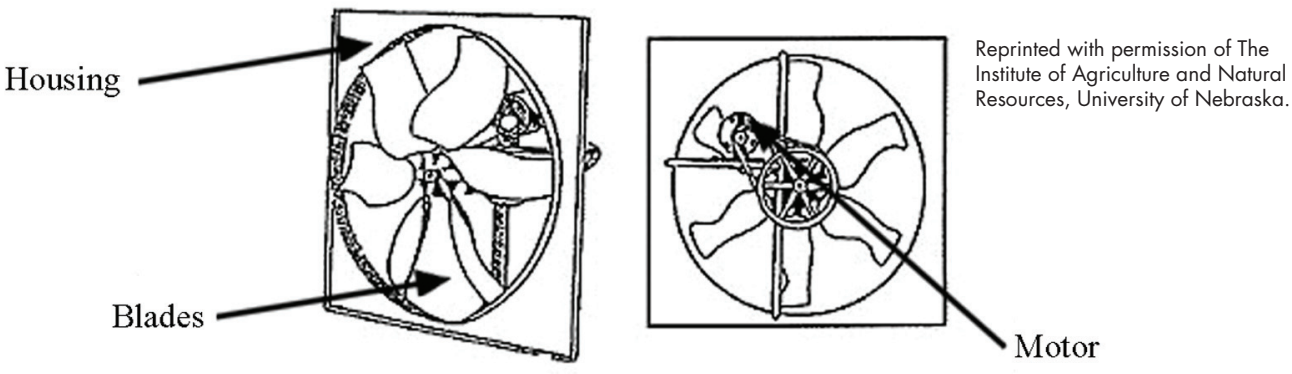

Figure 9.8.2. Propeller belt-drive fan (front and rear view). 
- Tube-axial fans - A tube-axial fan (Figure 9.8.3) consists of a tube-shaped housing, a propellershaped blade, and a drive motor. Vane-axial fans (Figure 9.8.4) are a variation of tube-axial fans, and are similar in design and application. The major difference is that air straightening vanes are added either in front of or behind the blades. This results in a slightly more efficient fan, capable of somewhat greater static pressures and airflow rates.

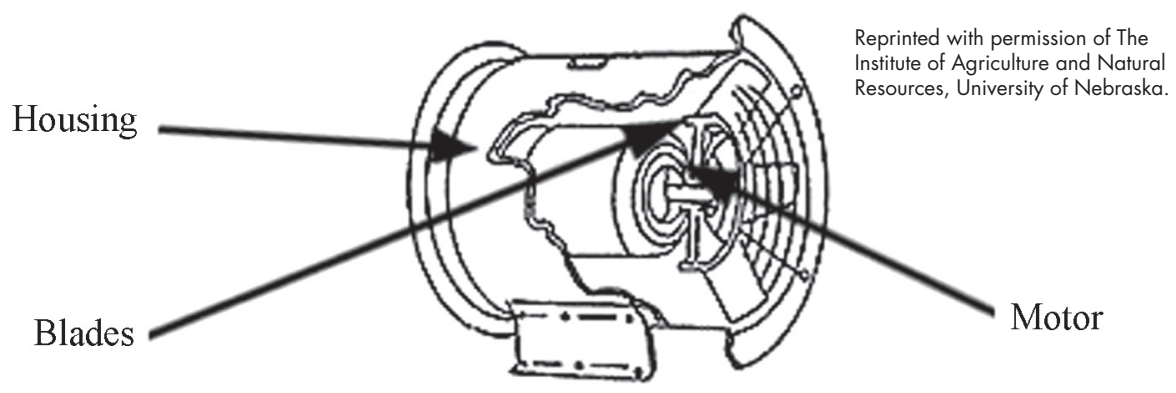

Figure 9.8.3. Tube-axial fan

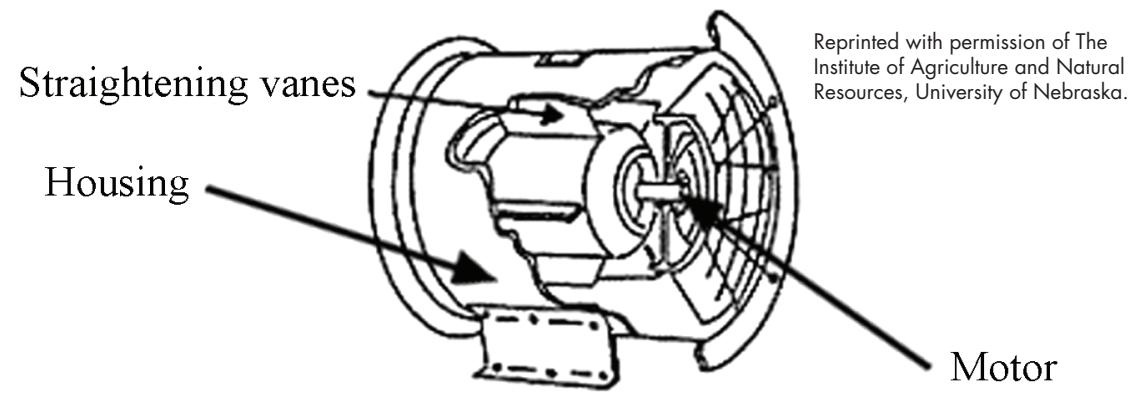

Figure 9.8.4. Vane axial fan

\subsubsection{Centrifugal Fans}

Often called "squirrel cage" fans, centrifugal fans have an entirely different design (Figure 9.8.5). These fans operate on the principle of "throwing" air away from the blade tips. The blades can be forward curved, straight, or backward curved. Centrifugal fans with backward curved blades are generally more efficient than the other two blade configurations. This design is most often used for aeration applications

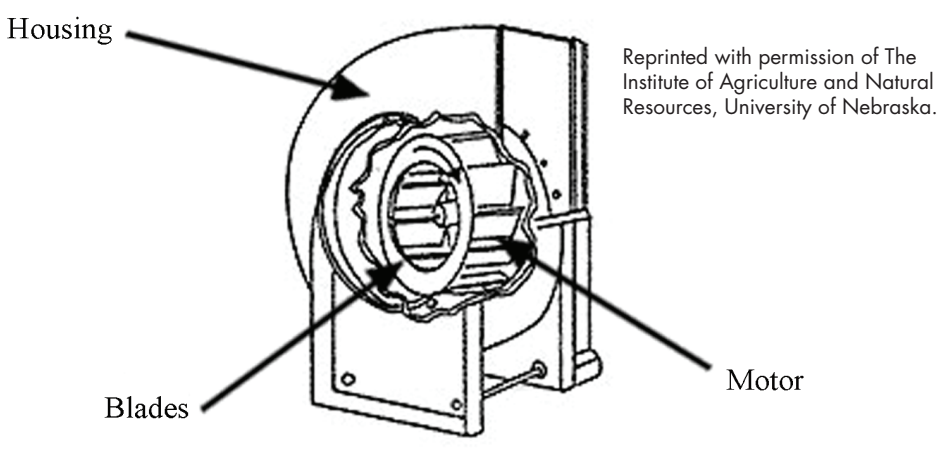

Figure 9.8.5. Centrifugal fan where high airflow rates and high static pressures are required. Centrifugal fans with forward curved blades have somewhat lower static pressure capabilities but tend to be quieter than the other blade designs. Furnace fans typically use a forward curved blade. An advantage of the straight blade design is that with proper design it can be used to handle dirty air or convey materials. Centrifugal fans are generally less expensive than axial fans and simpler in construction, but generally do not achieve the same efficiency. 


\subsubsection{Key Components}

- Impeller or rotor - A series of radial blades are attached to a hub. The assembly of the hub and blades is called impeller or rotor. As the impeller rotates, it creates a pressure difference and causes airflow.

- Motor - Drives the blades so they turn. It may be direct drive with the wheel mounted on the motor shaft or belt driven with the wheel mounted on its own shaft and bearings. It is important to note that fans may also be driven by other sources of motive power such as an internal combustion engine, or steam or gas turbine.

- Housing - Encloses and protects the motor and impeller.

\subsubsection{Safety Issues}

Continuously moving fresh air through a confined space is the most effective means of controlling pollutant levels and ensuring good air quality. Ventilation dilutes and displaces air contaminants, assures that an adequate oxygen supply is maintained during entry, and exhausts contaminants created by entry activities such as welding, oxygen-fuel cutting, or abrasive blasting (North Carolina State University 2001).

\subsubsection{Cost and Energy Efficiency}

In certain situations, fans can provide an effective alternative to costly air conditioning. Fans cool people by circulating or ventilating air. Circulating air speeds up the evaporation of perspiration from the skin so we feel cooler. Ventilating replaces hot, stuffy, indoor air with cooler, fresh, outdoor air. Research shows moving air with a fan has the same affect on personal comfort as lowering the temperature by over $5^{\circ} \mathrm{F}$. This happens because air movement created by the fan speeds up the rate at which our body loses heat, so we feel cooler. Opening and closing windows or doors helps the fan move indoor air outside and outdoor air inside, increasing the efficiency of the fan. When it is hot outside, close windows and doors to the outside. In the morning or evening, when outdoor air is cooler, place the fan in front of a window or door and open windows on the opposite side of the room. This draws cooler air through the living area (EPCOR 2001).

In many applications, fan control represents a significant opportunity for increased efficiency and reduced cost. A simple and low-cost means of flow control relies on dampers, either before or after the fan. Dampers add resistance to accomplish reduced flow, while increasing pressure. This increased pressure results in increased energy use for the flow level required. Alternatives to damper flow control methods include physical reductions in fan speed though the use of belts and pulleys or variable speed controllers.

\subsubsection{Maintenance of Fans}

Typically, fans provide years of trouble-free operation with relatively minimal maintenance. However, this high reliability can lead to a false sense of security resulting in maintenance neglect and eventual failure. Due to their prominence within HVAC and other process systems (without the fan operating, the system shuts down), fans need to remain high on the maintenance activity list.

Most fan maintenance activities center on cleaning housings and fan blades, lubricating and checking seals, adjusting belts, checking bearings and structural members, and tracking vibration. 


\subsubsection{Diagnostic Tools}

- Ultrasonic analyzer - Air moving systems emit very distinct sound patterns around bearings and fan blades. In most cases, these sounds are not audible to the unaided ear or are drown-out by other equipment noises. Using an ultrasonic detector, the analyst is able to isolate the frequency of sound being emitted by the bearing or blades. Changes in these ultrasonic wave emissions are indicative of changes in equipment condition-some of these changes can be a precursor to component degradation and failure. More information on ultrasonic analysis can be found in Chapter 6.

- Vibration analyzer - Within air moving systems, there are many moving parts, most in rotational motion. These parts generate a distinct pattern and level of vibration. Using a vibration analyzer and signature analysis software, the analyst can discern the vibration amplitude of the point on the equipment being monitored. This amplitude is then compared with trended readings. Changes in these readings are indicative of changes in equipment condition. More information on vibration analysis can be found in Chapter 6 .

\subsubsection{Available Software Tools}

\section{Fan System Assessment Tool (FSAT)}

Description: Experience has shown that greater energy savings can be achieved through system optimization than through component optimization. The DOE Fan System Assessment Tool (FSAT) helps users quantify energy consumption and energy savings opportunities in industrial fan systems. By reducing the engineering time associated with analyzing fan systems it now becomes easier to understand the economic and energy significance of changes in both system equipment and operating practices.

FSAT helps users quantify the difference between rated performance and installed performance due to such things as:

- High duct velocity

- Discharge dampers locked in position

- Obstructed inlets

- Incorrectly sized fans

- Poor duct geometry

- Degraded impellers.

FSAT is simple and quick to use, and requires only basic information about fans and the motors that drive them. With FSAT, users can calculate the amount of energy used by a fan system; determine system efficiency; and quantify the savings potential of an upgraded system. The tool also provides a prescreening filter to identify fan systems that are likely to offer optimization opportunities based on the system's control, production and maintenance, and effect.

FSAT estimates the work done by the fan system and compares that to the estimated energy input into the system. Using generic typical performance characteristics for fans and motors, indications of potential savings (in energy and dollars) are developed. 
Availability: To download the Fan System Assessment Tool and learn more about DOE Qualified Specialists and training opportunities, visit the Industrial Technology Program Web site: www.eere. energy.gov/industry/bestpractices.

\subsubsection{Relevant Operational/Energy Efficiency Measures}

There are a number of operational/energy efficiency measures that could be presented for proper fan operation and control. This section focuses on the most prevalent $O \& M$ recommendations having the greatest energy impacts at Federal facilities and includes (DOE 2003, UNEP 2006):

Oversized Fans: A common problem in many facilities is the purchase of oversized fans for their service requirements. These oversized fans will not operate at the most efficient point and in extreme cases these fans may operate in an unstable manner because of the point of operation on the fan airflow pressure curve. Oversized fans generate excess flow energy, resulting in high airflow noise and increased stress on the fan and the system. Consequently, oversized fans not only cost more to purchase and to operate, they create avoidable system performance problems. Possible solutions include, amongst other replacing the fan, replacing the motor, or introducing a variable speed drive motor.

\section{Fan System Operational-Efficiency Considerations} (UNEP 2006)

- Use smooth, well-rounded air inlet cones for fan air intake

- Avoid poor flow distribution at the fan inlet

- Minimize fan inlet and outlet obstructions

- Clean screens, filters and fan blades regularly

- Minimize fan speed

- Use low slip or flat belts for power transmission

- Check belt tension regularly

- Use variable speed drives for large variable fan loads

- Use energy-efficient motors for continuous or near continuous operation

- Eliminate leaks in ductwork

- Minimize bends in ductwork

- Turn fans and blowers off when not needed

- Reduce the fan speed by pulley diameter modifications in case of oversized motors

- Adopt inlet guide vanes in place of discharge damper control

- Reduce transmission losses by using energy-efficient flat belts or cogged raw-edged V-belts instead of conventional V-belt systems

- Ensure proper alignment between drive and driven system

- Ensure proper power supply quality to the motor drive

- Regularly check for vibration trend to predict any incipient failures like bearing damage, misalignments, unbalance, foundation looseness.

System Resistance: The fan operates at a point where the system resistance curve and the fan curve intersects. The system resistance has a major role in determining the performance and efficiency of a fan. The system resistance also changes depending on the process. For example, the formation of the coatings/erosion of the lining in the ducts, changes the system resistance marginally. In some cases, the change of equipment, or duct modifications, drastically shift the operating point, resulting in lower efficiency. In such cases, to maintain the efficiency as before, the fan has to be changed. Hence, the system resistance has to be periodically checked, more so when modifications are introduced and action taken accordingly, for efficient operation of the fan. 
Fan Maintenance: Regular maintenance of fans is important to maintain their performance levels. Maintenance activities include:

- Periodic inspection of all system components

- Bearing lubrication and replacement

- Belt tightening and replacement

- Motor repair or replacement

- Fan cleaning

Fan Control: Normally, an installed fan operates at a constant speed. But some situations may require a speed change; for example, more airflow may be needed from the fan when a new run of duct is added, or less airflow may be needed if the fan is oversized. There are several ways to reduce or control the airflow of fans. These are summarized in Table 9.8.1.

Table 9.8.1. Fan-flow control comparison (adapted from DOE 2003)

\begin{tabular}{|c|c|c|}
\hline Type of Fan Flow Control & Advantages & Disadvantages \\
\hline $\begin{array}{l}\text { Pulley change: reduces the motor/drive } \\
\text { pulley size }\end{array}$ & $\begin{array}{l}\text { Permanent speed decrease } \\
\text { Real energy reduction }\end{array}$ & $\begin{array}{l}\text { Fan must be able to handle capacity } \\
\text { change } \\
\text { Fan must be driven by V-belt system or } \\
\text { motor }\end{array}$ \\
\hline $\begin{array}{l}\text { Dampers: reduce the amount of flow } \\
\text { and increases the upstream pressure, } \\
\text { which reduces fan output }\end{array}$ & $\begin{array}{l}\text { - Inexpensive } \\
\text { - Easy to install }\end{array}$ & $\begin{array}{l}\text { - Provide a limited amount of } \\
\text { adjustment } \\
\text { - Reduce the flow but not the energy } \\
\text { consumption } \\
\text { - Higher operating and maintenance } \\
\text { costs }\end{array}$ \\
\hline $\begin{array}{l}\text { Inlet guide vanes: create swirls in the } \\
\text { fan direction thereby lessening the } \\
\text { angle between incoming air and fan } \\
\text { blades, and thus lowering fan load, } \\
\text { pressure and airflow }\end{array}$ & $\begin{array}{l}\text { Improve fan efficiency because } \\
\text { both fan load and delivered } \\
\text { airflow are reduced } \\
\text { - Cost-effective at airflows between } \\
80-100 \% \text { of full flow }\end{array}$ & $\begin{array}{l}\text { Less efficient at airflows lower than } \\
80 \% \text { of full flow }\end{array}$ \\
\hline $\begin{array}{l}\text { Variable Speed Drive (VSD): } \\
\text { reducing the speed of motor of the fan } \\
\text { to meet reduced flow requirements } \\
\text { - Mechanical VSDs: hydraulic } \\
\text { clutches, fluid couplings, and } \\
\text { adjustable belts and pulleys } \\
\text { - Electrical VSDs: eddy current } \\
\text { clutches, wound rotor motor } \\
\text { controllers, and variable frequency } \\
\text { drives (VFDs: change motor's } \\
\text { rotational speed by adjusting } \\
\text { electrical frequency of power } \\
\text { supplied) }\end{array}$ & $\begin{array}{l}\text { - Most improved and efficient flow } \\
\text { control } \\
\text { - Allow fan speed adjustments over } \\
\text { a continuous range } \\
\text { For VFDs specifically: } \\
\text { - Effective and easy flow control } \\
\text { - Improve fan operating efficiency } \\
\text { over a wide range of operating } \\
\text { conditions } \\
\text { - Can be retrofitted to existing } \\
\text { motor's compactness } \\
\text { - No fouling problems } \\
\text { lowering overall system flow }\end{array}$ & $\begin{array}{l}\text { Mechanical VSDs can have fouling } \\
\text { problems } \\
\text { - Investment costs can be a barrier }\end{array}$ \\
\hline
\end{tabular}




\subsubsection{Case Studies}

\section{Blower for an Industrial Application}

The operation of a centrifugal fan by damper control is energy inefficient because part of the energy supplied to the fan is lost across damper. The damper control has to be minimized by suitably optimizing the capacity of the fan to suit the requirement. One of the best methods to optimize the capacity of the fan is by reducing the rpm of the fan and operate the blower with more damper opening.

Previous Status. An air blower was operated with 30\% damper opening. The blower was belt-driven. The pressure required for the process was 0.0853 psi. The pressure rise of the blower was 0.1423 psi and the pressure drop across the damper was 0.0569 psi. This indicates an excess capacity/ static head available in the blower.

Energy Saving Project. The rpm of the blower was reduced by $20 \%$ by suitably changing the pulley. After the reduction in rpm, the damper was operated with $60 \%$ to $70 \%$ opening.

The replacement of the pulley was taken up during a non-working day. No difficulties were encountered on implementation of the project.

Financial Analysis. The reduction in rpm of the blower and minimizing the damper control resulted in reduction of power consumption by $1.2 \mathrm{~kW}$. The implementation of this project resulted in an annual savings of approximately $\$ 720$. The investment made was approximately $\$ 210$, which was paid back in under 4 months (Confederation of Indian Industry 2001). 


\subsubsection{Fans Checklist}

\begin{tabular}{|c|c|c|c|c|c|}
\hline \multirow{2}{*}{ Description } & \multirow{2}{*}{ Comments } & \multicolumn{4}{|c|}{ Maintenance Frequency } \\
\hline & & Daily & Weekly & Monthly & Annually \\
\hline $\begin{array}{l}\text { System use/ } \\
\text { sequencing }\end{array}$ & Turn off/sequence unnecessary equipment & $X$ & & & \\
\hline $\begin{array}{l}\text { Overall visual } \\
\text { inspection }\end{array}$ & $\begin{array}{l}\text { Complete overall visual inspection to be } \\
\text { sure all equipment is operating and safety } \\
\text { systems are in place }\end{array}$ & $\mathrm{X}$ & & & \\
\hline Observe belts & Verify proper belt tension and alignment & & & $\mathrm{X}$ & \\
\hline Inspect pulley wheels & Clean and lubricate where required & & & $\mathrm{X}$ & \\
\hline Inspect dampers & $\begin{array}{l}\text { Confirm proper and complete closure } \\
\text { control; outside air dampers should be } \\
\text { airtight when closed }\end{array}$ & & & $X$ & \\
\hline $\begin{array}{l}\text { Observe actuator/ } \\
\text { linkage control }\end{array}$ & $\begin{array}{l}\text { Verify operation, clean, lubricate, adjust as } \\
\text { needed }\end{array}$ & & & $\mathrm{X}$ & \\
\hline Check fan blades & $\begin{array}{l}\text { Validate proper rotation and clean when } \\
\text { necessary }\end{array}$ & & & $\mathrm{X}$ & \\
\hline Filters & $\begin{array}{l}\text { Check for gaps, replace when dirty - } \\
\text { monthly }\end{array}$ & & & $\mathrm{X}$ & \\
\hline $\begin{array}{l}\text { Check for air quality } \\
\text { anomalies }\end{array}$ & $\begin{array}{l}\text { Inspect for moisture/growth on walls, } \\
\text { ceilings, carpets, and in/outside of duct- } \\
\text { work. Check for musty smells and listen to } \\
\text { complaints. }\end{array}$ & & & $\mathrm{X}$ & \\
\hline Check wiring & Verify all electrical connections are tight & & & & $\mathrm{X}$ \\
\hline Inspect ductwork & $\begin{array}{l}\text { Check and refasten loose connections, } \\
\text { repair all leaks }\end{array}$ & & & & $\mathrm{X}$ \\
\hline Coils & $\begin{array}{l}\text { Confirm that filters have been kept clean, } \\
\text { as necessary }\end{array}$ & & & & $\mathrm{X}$ \\
\hline Insulation & $\begin{array}{l}\text { Inspect, repair, replace all compromised } \\
\text { duct insulation }\end{array}$ & & & & $\mathrm{X}$ \\
\hline
\end{tabular}




\subsubsection{References}

American Society of Heating, Refrigerating, and Air-Conditioning Engineers (ASHRAE). 1992. ASHRAE HVAC Systems and Equipment, I-P ed, ASHRAE Handbook, Atlanta, Georgia.

Bodman, G.R. and D.P. Shelton. July 2, 2001. Ventilation Fans: Types and Sizes. Institute of Agriculture and Natural Resources, University of Nebraska Cooperative Extension, University of Nebraska, May 1995 [Online report]. Available URL: http://www.ianr.unl.edu/pubs/farmbuildings/ g1243.htm. Reprinted with permission of the Institute of Agriculture and Natural Resources, University of Nebraska.

Confederation of Indian Industry. August 2, 2001. Reduction of Gasifier Air Blower Speed. Energy Efficiency, Green Business Centre. Reprinted with permission of the Confederation of Indian Industry.

EPCOR. August 17, 2001. Cooling with Fans [Online]. Available URL: http://www.epcor-group.com/ Residential/Efficiency.htm. Reprinted with permission of EPCOR.

General Services Administration. 1995. Public Buildings Maintenance Guides and Time Standards. Publication 5850, Public Building Service, Office of Real Property Management and Safety.

North Carolina State University. August 16, 2001. Confined Space Ventilation. Appendix D, Health $\&$ Safety Manual, Environmental Health \& Safety Center [Online report]. Available URL:

http://www2.ncsu.edu/ncsu/ehs/www99/right/handsMan/confined/Appx-D.pdf. Reprinted with permission of North Carolina State University.

UNEP, 2006. Energy Efficiency Guide for Industry, 2006. United Nations Environmental Program. Washington D.C.

U.S. Department of Energy (U.S. DOE) 2003. Improving Fan System Performance - A Sourcebook for Industry. Available on-line at URL: wwwl.eere.energy.gov/industry/bestpractices/pdfs/fan_sourcebook.pdf. 


\subsection{Pumps}

\subsubsection{Introduction}

Keeping pumps operating successfully for long periods of time requires careful pump design selection, proper installation, careful operation, the ability to observe changes in performance over time, and in the event of a failure, the capacity to thoroughly investigate the cause of the failure and take measures to prevent the problem from recurring. Pumps that are properly sized and dynamically balanced, that sit on stable foundations with good shaft alignment and with proper lubrication, that operators start, run, and stop carefully, and that maintenance personnel observe for the appearance of unhealthy trends which could begin acting on and causing damage to, usually never experience a catastrophic failure (Piotrowski 2001).

\subsubsection{Types of Pumps}

The family of pumps comprehends a large number of types based on application and capabilities.

The two major groups of pumps are dynamic and positive displacement.

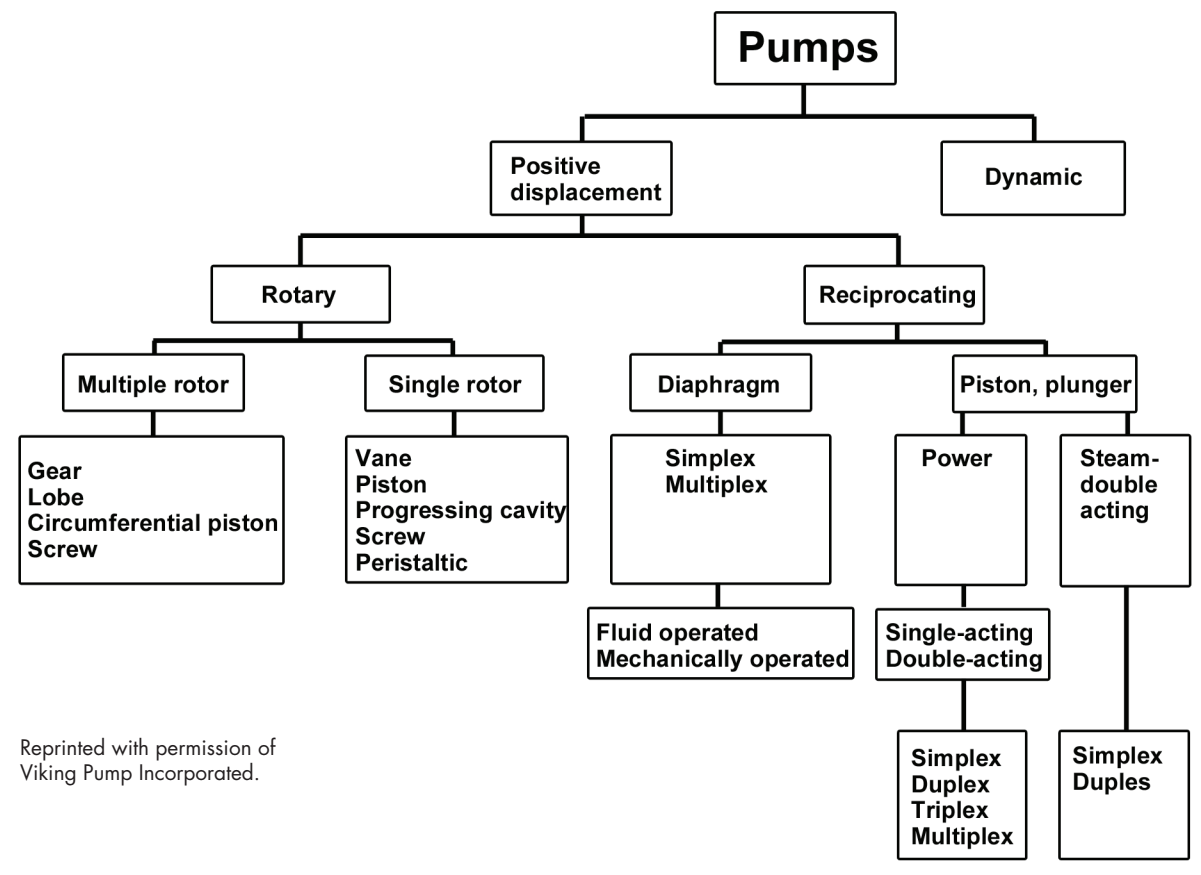

Figure 9.9.1. Technology tree for pumps. 


\subsubsection{Dynamic Pump (Centrifugal Pump) (Pump World 2001a)}

Centrifugal pumps are classified into three general categories:

- Radial flow - a centrifugal pump in which the pressure is developed wholly by centrifugal force.

- Mixed flow - a centrifugal pump in which the pressure is developed partly by centrifugal force and partly by the lift of the vanes of the impeller on the liquid.

- Axial flow - a centrifugal pump in which the pressure is developed by the propelling or lifting action of the vanes of the impeller on the liquid.

\subsubsection{Positive Displacement Pump (Pump World 2001c)}

A positive displacement pump (Figure 9.9.2) has an expanding cavity on the suction side of the pump and a decreasing cavity on the discharge side. Liquid is allowed to flow into the pump as the cavity on the suction side expands and the liquid is forced out of the discharge as the cavity collapses. This principle applies to all types of positive displacement pumps whether the pump is a rotary lobe, gear within a gear, piston, diaphragm, screw, progressing cavity, etc.

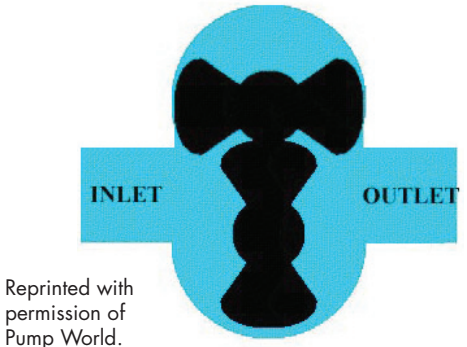

Figure 9.9.2. Rotary lobe pump

A positive displacement pump, unlike a centrifugal pump, will produce the same flow at a given rpm no matter what the discharge pressure is. A positive displacement pump cannot be operated against a closed valve on the discharge side of the pump, i.e., it does not have a shut-off head like a centrifugal pump does. If a positive displacement pump is allowed to operate against a closed discharge valve, it will continue to produce flow which will increase the pressure in the discharge line until either the line bursts or the pump is severely damaged or both (Pump World 2001d).

For purposes of this guide, positive displacement pumps (Figure 9.9.3) are classified into two general categories and then subdivided into four categories each:

Positive Displacement Pumps
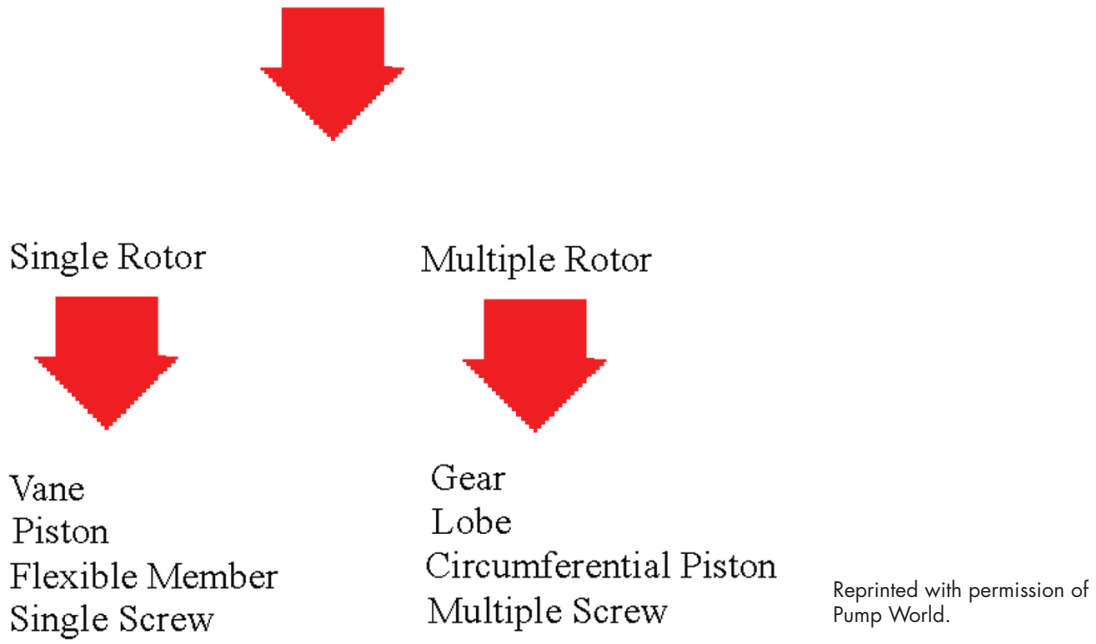

Figure 9.9.3. Positive displacement pumps. 


\subsubsection{Key Components}

\subsubsection{Centrifugal Pump (Pump World 2001b)}

The two main components of a centrifugal pump (Figure 9.9.4) are the impeller and the volute.

The impeller produces liquid velocity and the volute forces the liquid to discharge from the pump converting velocity to pressure. This is accomplished by offsetting the impeller in the volute and by maintaining a close clearance between the impeller and the volute at the cut-water. Please note the impeller rotation. A centrifugal pump impeller slings the liquid out of the volute.

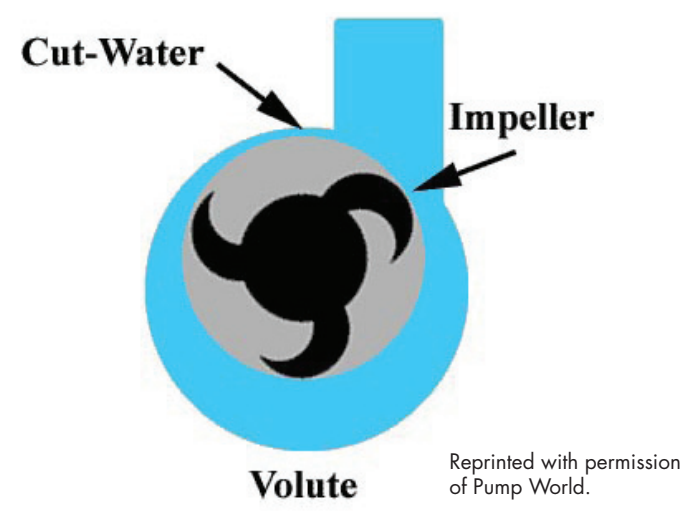

Figure 9.9.4. Centrifugal pump.

\subsubsection{Positive Displacement Pumps}

- Single Rotor (Pump World 2001d)

- Vane - The vane(s) may be blades, buckets, rollers, or slippers that cooperate with a dam to draw fluid into and out of the pump chamber.

- Piston - Fluid is drawn in and out of the pump chamber by a piston(s) reciprocating within a cylinder(s) and operating port valves.

- Flexible Member - Pumping and sealing depends on the elasticity of a flexible member(s) that may be a tube, vane, or a liner.

- Single Screw - Fluid is carried between rotor screw threads as they mesh with internal threads on the stator.

- Multiple Rotor (Pump World 2001d)

- Gear - Fluid is carried between gear teeth and is expelled by the meshing of the gears that cooperate to provide continuous sealing between the pump inlet and outlet.

- Lobe - Fluid is carried between rotor lobes that cooperate to provide continuous sealing between the pump inlet and outlet.

- Circumferential Piston - Fluid is carried in spaces between piston surfaces not requiring contacts between rotor surfaces.

- Multiple Screw - Fluid is carried between rotor screw threads as they mesh. 
- Relief Valves (Pump World 2001e)

Note: A relief valve (Figure 9.9.5) on the discharge side of a positive displacement pump is an absolute must for safety!

- Internal Relief Valve - Pump manufacturers normally have an option to supply an internal relief valve. These relief valves will temporarily relieve the pressure on the discharge side of a pump operating against a closed valve. They are normally not full ported, i.e., cannot bypass all the flow produced by the pump. These internal relief valves should be used for pump protection against a temporary closing of a valve.

- External Relief Valve - An external relief valve (RV) installed in the discharge line with a return line back to the supply tank is highly recommended to provide complete protection against an unexpected over pressure situation.

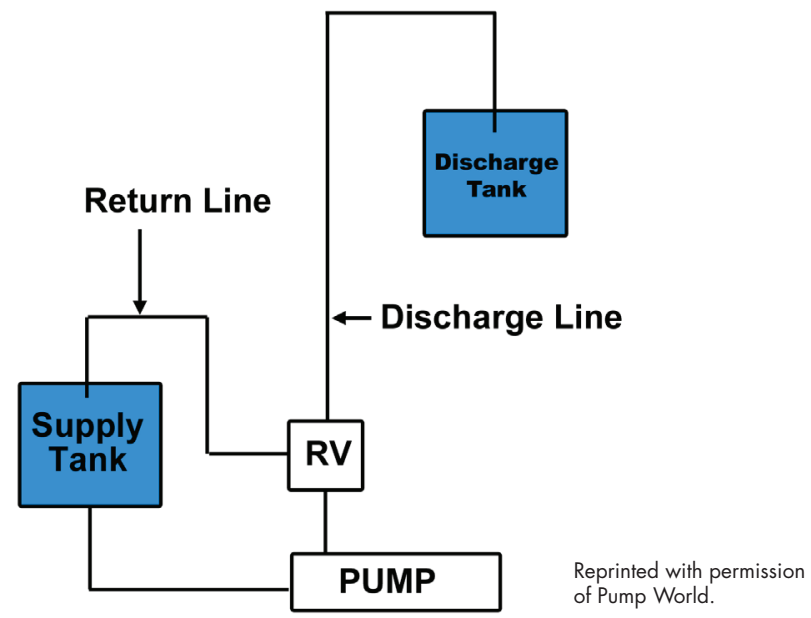

Figure 9.9.5. Schematic of pump and relief valve.

\subsubsection{Safety Issues (Pompe Spec Incorporated 2001)}

Some important safety tips related to maintenance actions for pumps:

- Safety apparel

- Insulated work gloves when handling hot bearings or using bearing heater.

- Heavy work gloves when handling parts with sharp edges, especially impellers.

- Safety glasses (with side shields) for eye protection, especially in machine shop area.

- Steel-toed shoes for foot protection when handling parts, heavy tools, etc.

- Safe operating procedures

- Coupling guards: Never operate a pump without coupling guard properly installed.

- Flanged connections:

- Never force piping to make connection with pump.

- Insure proper size, material, and number of fasteners are installed.

- Beware of corroded fasteners. 
- When operating pump:

- Do not operate below minimum rated flow, or with suction/discharge valves closed.

- Do not open vent or drain valves, or remove plugs while system is pressurized.

- Maintenance safety

- Always lock out power.

- Ensure pump is isolated from system and pressure is relieved before any disassembly of pump, removal of plugs, or disconnecting piping.

- Pump and components are heavy. Failure to properly lift and support equipment could result in serious injury.

- Observe proper decontamination procedures. Know and follow company safety regulations.

- Never apply heat to remove impeller.

\subsubsection{Cost and Energy Efficiency}

Pumps frequently are asked to operate far off their best efficiency point, or are perched atop unstable base-plates, or are run under moderate to severe misalignment conditions, or, having been lubricated at the factory, are not given another drop of lubricant until the bearings seize and vibrate to the point where bolts come loose. When the unit finally stops pumping, new parts are thrown on the machine and the deterioration process starts all over again, with no conjecture as to why the failure occurred.

Proper maintenance is vital to achieving top pump efficiency expected life. Additionally, because pumps are a vital part of many HVAC and process applications, their efficiency

The following are measures that can improve pump efficiency: (OIT 1995)

- Shut down unnecessary pumps.

- Restore internal clearances if performance has changed.

- Trim or change impellers if head is larger than necessary.

- Control by throttle instead of running wide-open or bypassing flow.

- Replace oversized pumps.

- Use multiple pumps instead of one large one.

- Use a small booster pump.

- Change the speed of a pump for the most efficient match of horsepower requirements with output.

directly affects the efficiency of other system

components. For example, an improperly sized pump can impact critical flow rates to equipment whose efficiency is based on these flow rates-a chiller is a good example of this.

\subsubsection{Maintenance of Pumps}

(General Services Administration 1995)

The importance of pumps to the daily operation of buildings and processes necessitates a proactive maintenance program. Most pump maintenance activities center on checking packing and mechanical seals for leakage, performing preventive/predictive maintenance activities on bearings, assuring proper alignment, and validating proper motor condition and function.
The heart beats an average of 75 times per minute, or about 4,500 times per hour. While the body is resting, the heart pumps 2.5 ounces of blood per beat. This amount does not seem like much, but it sums up to almost 5 liters of blood pumped per minute by the heart, or about 7,200 liters per day. The amount of blood delivered by the heart can vary depending upon the body's need. During periods of great activity, such as exercising, the body demands higher amounts of blood, rich in oxygen and nutrients, increasing the heart's output by nearly five times. 


\section{Large Horsepower (25 horsepower and above) Pump Efficiency Survey (OIT 1995)}

Actions are given in decreasing potential for efficiency improvement:

1. Excessive pump maintenance - this is often associated with one of the following:

- Oversized pumps that are heavily throttled.

- Pumps in cavitation.

- Badly worn pumps.

- Pumps that are misapplied for the present operation.

2. Any pump system with large flow or pressure variations. When normal flows or pressures are less than $75 \%$ of their maximum, energy is probably being wasted from excessive throttling, large bypass flows, or operation of unneeded pumps.

3. Bypassed flow, either from a control system or deadhead protection orifices, is wasted energy.

4. Throttled control valves. The pressure drop across a control valve represents wasted energy, that is proportional to the pressure drop and flow.

5. Fixed throttle operation. Pumps throttled at a constant head and flow indicate excess capacity.

6. Noisy pumps or valves. A noisy pump generally indicates cavitation from heavy throttling or excess flow. Noisy control valves or bypass valves usually mean a higher pressure drop with a corresponding high energy loss.

7. A multiple pump system. Energy is commonly lost from bypassing excess capacity, running unneeded pumps, maintaining excess pressure, or having as large flow increment between pumps.

8. Changes from design conditions. Changes in plant operating conditions (expansions, shutdowns, etc.) can cause pumps that were previously well applied to operate at reduced efficiency.

9. A low-flow, high-pressure user. Such users may require operation of the entire system at high pressure.

10. Pumps with known overcapacity. Overcapacity wastes energy because more flow is pumped at a higher pressure than required.

\subsubsection{Diagnostic Tools}

- Thermography - An infrared thermometer or camera allows for an accurate, non-contact assessment of temperature. Applications for pumps include assessments on bearing assemblies at the impeller housing and motor system connections. More information on thermography can be found in Chapter 6.

- Ultrasonic analyzer - Fluid pumping systems emit very distinct sound patterns around bearings and impellers. In most cases, these sounds are not audible to the unaided ear, or are drown-out by other equipment noises. Using an ultrasonic detector, the analyst is able to isolate the frequency of sound being emitted by the bearing or impeller. Changes in these ultrasonic wave emissions are indicative of changes in equipment condition-some of these changes can be a precursor to component degradation and failure. More information on ultrasonic analysis can be found in Chapter 6.

- Vibration analyzer - Within a fluid pump, there are many moving parts; some in rotational motion and some in linear motion. In either case, these parts generate a distinct pattern and level of vibration. Using a vibration analyzer and signature analysis software, the analyst can discern the vibration amplitude of the point on the equipment being monitored. This amplitude is then compared with trended readings. Changes in these readings are indicative of changes in equipment condition. More information on vibration analysis can be found in Chapter 6 . 


\subsubsection{Available Software Tools}

\section{Pumping System Assessment Tool (PSAT)}

Description: The Pumping System Assessment Tool (PSAT) software uses data that is typically available or easily obtained in the field (e.g., pump head, flow rate, and motor power) to estimate potential energy and dollar savings in industrial pump systems. The software, developed by the DOE Industrial Technologies Program (ITP), is available at no cost for evaluating industrial pump systems.

Use the PSAT prescreening filter to identify areas that are likely to offer the greatest savings. Look for symptoms associated with inefficient energy consumption:

- Throttle-valve control for the system

- Cavitation noise or damage in the system

- Continuous pump operation to support a batch process

- Constant number of parallel pumps supporting a process with changing demands

- Bypass or recirculation line normally open

- High system maintenance

- Systems that have undergone change in function.

PSAT assesses current pump system operating efficiency by comparing field measurements of the power delivered to the motor with the fluid work (flow and head) required by the application. It estimates a system's achievable efficiency based on pump efficiencies (from Hydraulic Institute standards) and performance characteristics of pumps and motors (based on the MotorMaster+ database, see Section 9.10.8). Subsequent comparison of the actual and achievable efficiencies distinguishes systems with lower levels of opportunity from those that warrant additional engineering analysis.

Availability: To download the PSAT and learn more about DOE Qualified Specialists and training opportunities, visit the Industrial Technology Program Web site: wwwl.eere.energy.gov/ industry/bestpractices.

\subsubsection{Relevant Operational/Energy Efficiency Measures}

There are a number of operational/energy efficiency measures that could be presented for proper pump operation and control. This section focuses on the most prevalent $O \& M$ recommendations having the greatest energy impacts at Federal facilities and includes (DOE 2001, DOE 2004, BEE 2004):

- Pump Selection

- Controlling the flow rate by speed variation

- Eliminating flow control valve

- Eliminating by-pass control

- Impeller trimming 


\section{Pump Selection}

In selecting a pump, facility managers try to match the system curve supplied by the user with a pump curve that satisfies these needs as closely as possible. The pump operating point is the point where the pump curve and the system resistance curve intersect. However, it is impossible for one operating point to meet all desired operating conditions. For example, when the discharge valve is throttled to control flow, the system resistance curve shifts so does the operating point - this to a lessthan efficient point of operation.

The efficiency of a pump is affected when the selected pump is oversized. This is because flow of oversized pumps must be controlled with different methods, such as a throttle valve or a by-pass line. These devices provide additional resistance by increasing the friction. As a result the system curve shifts and intersects the pump curve at a different point, a point of lower efficiency. In other words, the pump efficiency is reduced because the output flow is reduced but power consumption is not. Inefficiencies of oversized pumps can be overcome by, for example, the installation of variable speed drives, two-speed drives, operating the pump at a lower rpm, or installing a smaller impeller or trimmed impeller (BEE 2004).

\section{Controlling flow rate by speed variation}

A centrifugal pump's rotating impeller generates head. The impeller's peripheral velocity is directly related to shaft rotational speed. Therefore varying the rotational speed has a direct effect on the performance of the pump. The pump performance parameters (flow rate, head, power) will change with varying rotating speeds. To safely control a pump at different speeds it is therefore important to understand the relationships between the two. The equations that explain these relationships are known as the "Affinity Laws" these are:

- Flow rate $(\mathrm{Q})$ is directly proportional to the rotating speed

- Head $(\mathrm{H})$ is proportional to the square of the rotating speed

- Power $(\mathrm{P})$ is proportional to the cube of the rotating speed

As can be seen from the above laws, doubling the rotating speed of the centrifugal pump will increase the power consumption by 8 times. Conversely a small reduction in speed will result in a very large reduction in power consumption. This forms the basis for energy conservation in centrifugal pumps with varying flow requirements. It is relevant to note that flow control by speed regulation is always more efficient than by a control valve. This is because valves reduce the flow, but not the energy consumed by pumps. In addition to energy savings, other benefits could include:

- Increased bearing life - this is because bearings carry the hydraulic forces on the impeller (created by the pressure profile inside the pump casing), which are reduced approximately with the square of speed. For a pump, bearing life is proportional to the seventh power of speed.

- Vibration and noise are reduced and seal life is increased, provided that the duty point remains within the allowable operating range. 


\section{Using variable speed drive (VSD)}

Controlling the pump speed is the most efficient way to control the flow, because when the pump's speed is reduced, the power consumption is also reduced. The most commonly used method to reduce pump speed is Variable Speed Drive (VSD). VSDs allow pump speed adjustments over a continuous range, avoiding the need to jump from speed to speed as with multiple-speed pumps. VSDs control pump speeds use two types of systems:

- Mechanical VSDs include hydraulic clutches, fluid couplings, and adjustable belts and pulleys.

- Electrical VSDs include eddy current clutches, wound-rotor motor controllers, and variable frequency drives (VFDs). VFDs are the most popular and adjust the electrical frequency of the power supplied to a motor to change the motor's rotational speed.

For many systems, VFDs offer a means to improve the pump operating efficiency under different operating conditions. When a VFD reduced the RPM of a pump, the head/flow and power curves move down and to the left, and the efficiency curve also shifts to the left. The major advantages of VSD application in addition to energy saving are (DOE, 2004):

- Improved process control because VSDs can correct small variations in flow more quickly.

- Improved system reliability because wear of pumps, bearings and seals is reduced.

- Reduction of capital \& maintenance cost because control valves, by-pass lines, and conventional starters are no longer needed.

- Soft starter capability: VSDs allow the motor the motor to have a lower startup current.

\section{Eliminating flow control valve}

Another method to control the flow by closing or opening the discharge valve (this is also known as "throttling" the valves). While this method reduces the flow, it does not reduce the power consumed, as the total head (static head) increases. This method increases vibration and corrosion and thereby increases maintenance costs of pumps and potentially reduces their lifetimes. VSDs are always a better solution from an energy efficiency perspective.

\section{Eliminating by-pass control}

The flow can also be reduced by installing a by-pass control system, in which the discharge of the pump is divided into two flows going into two separate pipelines. One of the pipelines delivers the fluid to the delivery point, while the second pipeline returns the fluid to the source. In other words, part of the fluid is pumped around for no reason, and thus is energy inefficient. Because of this inefficiency, this option should therefore be avoided.

\section{Impeller trimming}

Changing the impeller diameter gives a proportional change in the impeller's peripheral velocity. Similar to the affinity laws, the following equations apply to the impeller diameter:

- Flow rate $(\mathrm{Q})$ is proportional to the diameter

- Head $(\mathrm{H})$ is proportional to the square of the diameter

- Power $(\mathrm{P})$ is proportional to the cube of the diameter 
Changing the impeller diameter is an energy efficient way to control the pump flow rate.

However, for this option, the following should be considered:

- This option cannot be used where varying flow patterns exist.

- The impeller should not be trimmed more than $25 \%$ of the original impeller size, otherwise it leads to vibration due to cavitation and therefore decrease the pump efficiency.

- The balance of the pump has to been maintained, i.e. the impeller trimming should be the same on all sides.

Changing the impeller itself is a better option than trimming the impeller, but is also more expensive and sometimes the next smaller impeller is too small.

\subsubsection{Pump System Water-Use Best Practices}

The predominant impact pumps have on water use relates to proper function and no leakage. A pump operating at too high of a pressure can lead to leak formation and/or leakage increase. As part of the daily maintenance activity, pressure verification and leakage survey should be completed and documented.

\subsubsection{Case Study (DOE 2001)}

\section{Pump Optimization for Sewage Pumping Station}

The town of Trumbull, CT was looking for a way to increase the operating performance of one of its ten sewage-pumping stations. The station consisted of two identical sewage-handling pumps (each with a 40-hp direct drive motor) vertically mounted below ground, handling 340,000 gallons of raw sewage per day. The system used one pump to handle the entire flow under normal operation, and used the second pump only in extreme conditions (heavy rainfall). To meet normal loads, each pump rarely operated more than 5 minutes at a time. The control system required two continuously running compressors. A constant pump speed of 1,320 rpm was obtained using a wound rotor and variable resistance circuit motor control system. The pumping system experienced frequent breakdowns, occasional flooding, and sewage spills.

After a thorough systems analysis, engineers installed an additional 10-hp pump with direct on-line motor starters and a passive level control system with float switches, replacing the old active control system. The new pump handles the same volume as the original 40-hp pumps during normal periods, but runs for longer periods of time. The lower outflow rate reduces friction and shock losses in the piping system, which lowers the required head pressure (and thus, the energy consumption).

In addition, the existing pump speed control was eliminated and the motors were wired for direct on-line start. Without the speed control, the motors powering the existing pumps run at $1,750 \mathrm{rpm}$ instead of $1,320 \mathrm{rpm}$, so their impellers were trimmed to a smaller diameter. The existing pumps are still used for the infrequent peak flows that the new smaller pump cannot handle. Energy consumption was further reduced through the elimination of the two compressors for the active control system and the two circulating pumps for the old motor control system. The installed cost of all the added measures was $\$ 11,000$. 
Results. In addition to the annual 17,650 kWh of electricity savings from modifying the pump unit, significant energy savings also resulted from changes made to other energy use sources in the station (Figure 9.9.6). Annual energy consumption of the active level control $(7,300 \mathrm{kWh} /$ year $)$ and the cooling water pumps $(1,750 \mathrm{kWh} /$ year $)$ was entirely eliminated. In all, over $26,000 \mathrm{kWh}$ is being saved annually, a reduction of almost $38 \%$, resulting in $\$ 2,200$ in annual energy savings.

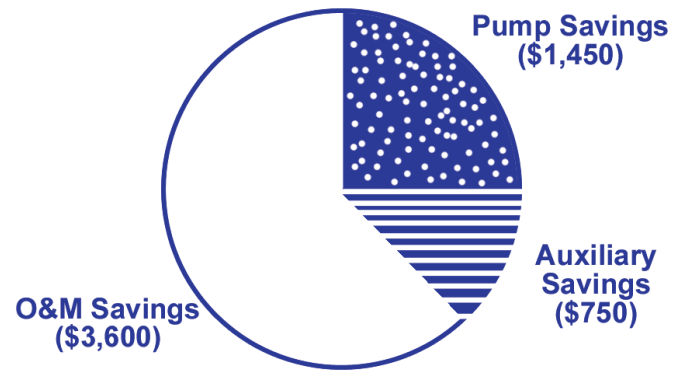

Figure 9.9.6. Pump system energy use and savings.

This project also produced maintenance savings of $\$ 3,600$. Maintenance staff no longer needs to replace two mechanical seals each year. Other benefits of the project savings include extended equipment life due to reduced starting and stopping of the equipment, increased system capacity, and decreased noise. Most of the same measures can be utilized at the town's other pumping stations, as well.

The total annual savings from the project, due to lower energy costs as well as reduced maintenance and supplies, is $\$ 5,800$ (Figure 9.9.7), which is roughly half of the total retrofit cost of $\$ 11,000$.

Lessons Learned. Several key conclusions from Trumbull's experience are relevant for virtually any pumping systems project:

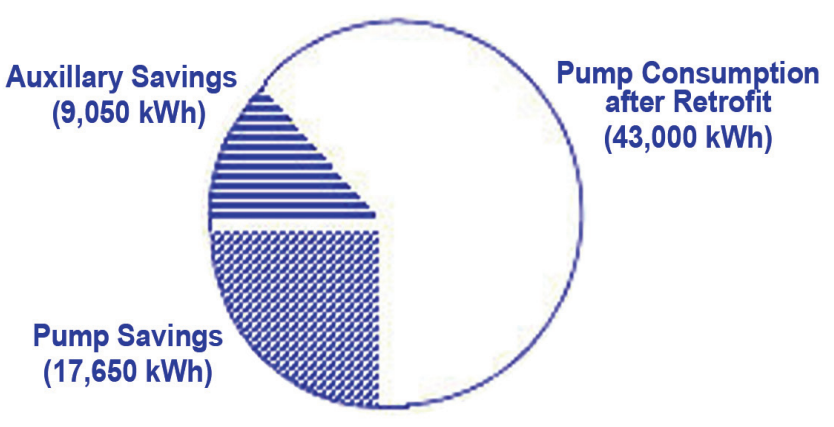

Figure 9.9.7. Retrofit cost savings ( $\$ 5,800$ annually).

- Proper pump selection and careful attention to equipment operating schedules can yield substantial energy savings.

- In systems with static head, stepping of pump sizes for variable flow rate applications can decrease energy consumption.

- A "systems" approach can identify energy and cost savings opportunities beyond the pumps themselves. 


\subsubsection{Pumps Checklist}

\begin{tabular}{|c|c|c|c|c|c|}
\hline \multirow{2}{*}{ Description } & \multirow{2}{*}{ Comments } & \multicolumn{4}{|c|}{ Maintenance Frequency } \\
\hline & & Daily & Weekly & Monthly & Annually \\
\hline Pump use/sequencing & Turn off/sequence unnecessary pumps & $X$ & & & \\
\hline $\begin{array}{l}\text { Overall visual } \\
\text { inspection }\end{array}$ & $\begin{array}{l}\text { Complete overall visual inspection to be } \\
\text { sure all equipment is operating and safety } \\
\text { systems are in place }\end{array}$ & $\mathrm{X}$ & & & \\
\hline Check lubrication & $\begin{array}{l}\text { Assure that all bearings are lubricated per } \\
\text { the manufacture's recommendation }\end{array}$ & & & $X$ & \\
\hline Check packing & $\begin{array}{l}\text { Check packing for wear and repack as } \\
\text { necessary. Consider replacing packing with } \\
\text { mechanical seals. }\end{array}$ & & & $\mathrm{X}$ & \\
\hline $\begin{array}{l}\text { Motor/pump } \\
\text { alignment }\end{array}$ & $\begin{array}{l}\text { Aligning the pump/motor coupling allows } \\
\text { for efficient torque transfer to the pump }\end{array}$ & & & $\mathrm{X}$ & \\
\hline Check mountings & Check and secure all pump mountings & & & $\mathrm{X}$ & \\
\hline Check bearings & $\begin{array}{l}\text { Inspect bearings and drive belts for wear. } \\
\text { Adjust, repair, or replace as necessary. }\end{array}$ & & & & $\mathrm{X}$ \\
\hline Motor condition & $\begin{array}{l}\text { Checking the condition of the motor } \\
\text { through temperature or vibration analysis } \\
\text { assures long life }\end{array}$ & & & & $\mathrm{X}$ \\
\hline
\end{tabular}




\subsubsection{References}

Bureau of Energy Efficiency, Ministry of Power, India. 2004. Pumps and Pumping Systems. In: Energy Efficiency in Electrical Utilities, Chapter 6.

General Services Administration. 1995. Public Buildings Maintenance Guides and Time Standards. Publication 5850, Public Building Service, Office of Real Property Management and Safety.

OIT. 1995. Modern Industrial Assessments: A Training Manual. Industrial Assessment Manual from the Office of Productivity and Energy Assessment at the State University of New Jersey, Rutgers, for the U.S. Department of Energy Office of Industrial Technology.

Piotrowski, J. April 2, 2001. Pro-Active Maintenance for Pumps. Archives, February 2001, Pump-Zone.com [Report online]. Available URL: http://www.pump-zone.com. Reprinted with permission of Pump \& Systems Magazine.

Pompe Spec Incorporated. July 13, 2001. Safety Tips. Resources [Online]. Available URL: http://www.pompespec.com/frameset_e.html?ressources_e.html wbodypompespec. Reprinted with permission of Pompe Spec Incorporated.

Pump World [Online]. Available URL: http://www.pumpworld.com/contents.htm. Reprinted with permission of the Pump World.

U.S. Department of Energy (DOE). May 4, 2001. Case Study: Pump Optimization for Sewage Pumping Station. Federal Management Energy Program [Online report]. Available URL: http://www.eere. energy.gov/femp/technologies/eep_centrifugal_pump.cfm.

Viking Pump, Incorporated. May 25, 2001. Rotary Pump Family Tree. PumpSchool.com [Online]. Available URL: http://www.pumpschool.com/intro/pdtree.htm. Reprinted with permission of Viking Pump, Incorporated.

U.S. Department of Energy (DOE) 2001. Office of Industrial Technologies. Pump Life Cycle Costs: A guide to LCC analysis for pumping systems. DOE/GO-102001-1190. 2001. Available URL: http://wwwl.eere.energy.gov/industry/bestpractices/techpubs_motors.html.

U.S. Department of Energy (US DOE) 2004. Office of Industrial Technologies. Variable Speed Pumping - A Guide to Successful Applications. Executive Summary. 2004. http://wwwl.eere.energy.gov/ industry/bestpractices/techpubs_motors.html. 


\subsection{Motors}

\subsubsection{Introduction}

Motor systems consume about $70 \%$ of all the electric energy used in the manufacturing sector of the United States. To date, most public and private programs to improve motor system energy efficiency have focused on the motor component. This is primarily due to the complexity associated with motor-driven equipment and the system as a whole. The electric motor itself, however, is only the core component of a much broader system of electrical and mechanical equipment that provides a service (e.g., refrigeration, compression, or fluid movement).

Numerous studies have shown that opportunities for efficiency improvement and performance optimization are actually much greater in the other components of the system-the controller, the mechanical system coupling, the driven equipment, and the interaction with the process operation. Despite these significant system-level opportunities, most efficiency improvement activities or programs have focused on the motor component or other individual components (Nadel et al. 2001).

\subsubsection{Types of Motors}

\subsubsection{DC Motors (Naves 2001a)}

Direct-current (DC) motors (Figure 9.10.1) are often used in variable speed applications. The DC motor can be designed to run at any speed within the limits imposed by centrifugal forces and commutation considerations. Many machine tools also use DC motors because of the ease with which speed can be adjusted.

All DC motors, other than the relatively small brushless types, use a commutator assembly on the rotor. This requires periodic maintenance and is partly responsible for the added cost of a DC motor when compared to an alternate-current $(\mathrm{AC})$ squirrel-cage induction motor of the same power. The speed adjustment flexibility often justifies the extra cost (Apogee Interactive 2001a).

\subsubsection{AC Motors}

(Naves 2001b)

As in the DC motor case, an AC motor (Figure 9.10.2) has a current passed through the coil, generating a torque on the coil. The design of an AC motor is considerably more involved than the design of a DC motor. The magnetic field is produced by an electromagnet powered by the same $\mathrm{AC}$ voltage as the motor coil. The coils that produce the magnetic field are traditionally called the "field coils" while the coils and the solid core that rotates is called the "armature."

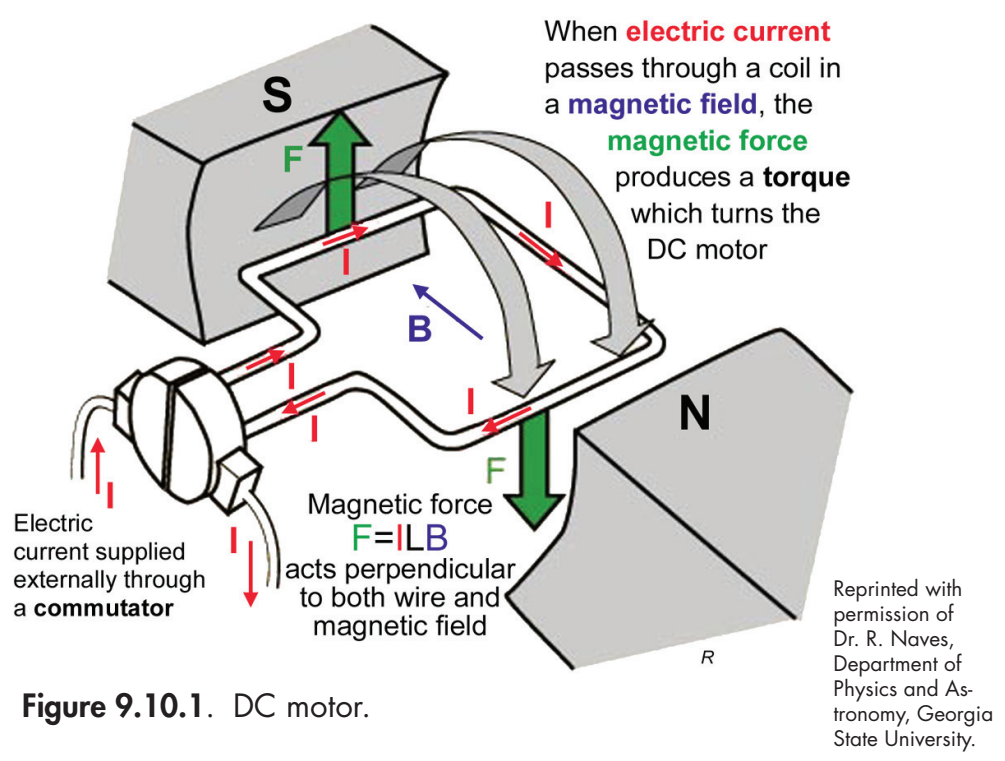


- Induction motor (VPISU 2001) - The induction motor is a three-phase AC motor and is the most widely used machine. Its characteristic features are:

- Simple and rugged construction.

- Low cost and minimum maintenance.

- High reliability and sufficiently high efficiency.

- Needs no extra starting motor and need not be synchronized.

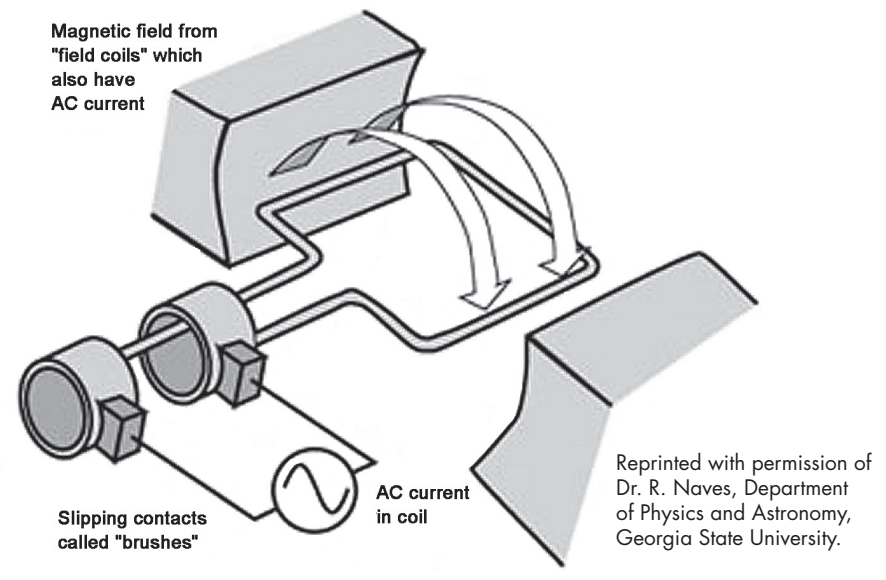

Figure 9.10.2. $A C$ motor

An induction motor operates on the principle of induction. The rotor receives power due to induction from stator rather than direct conduction of electrical power. When a three-phase voltage is applied to the stator winding, a rotating magnetic field of constant magnitude is produced. This rotating field is produced by the contributions of space-displaced phase windings carrying appropriate time displaced currents. The rotating field induces an electromotive force (emf).

- Synchronous motor (Apogee Interactive 2001b) - The most obvious characteristic of a synchronous motor is its strict synchronism with the power line frequency. The reason the industrial user is likely to prefer a synchronous motor is its higher efficiency and the opportunity for the user to adjust the motor's power factor.

A specially designed motor controller performs these operations in the proper sequence and at the proper times during the starting process.

\subsubsection{Key Components}

\subsubsection{DC Motor (The World Book Encyclopedia 1986)}

- Field pole - The purpose of this component is to create a steady magnetic field in the motor. For the case of a small DC motor (Figure 9.10.3), a permanent magnet, field magnet, composes the field structure. However, for larger or more complex motors, one or more electromagnets, which receive electricity from an outside power source, is/are the field structure. 
- Armature - When current goes through the armature, it becomes an electromagnet. The armature, cylindrical in shape, is linked to a drive shaft in order to drive the load. For the case of a small DC motor, the armature rotates in the magnetic field established by the poles, until the north and south poles of the magnets change location with respect to the armature. Once this happens, the current is reversed to switch the south and north poles of the armature.

- Commutator - This component is found mainly in DC motors. Its purpose is to overturn the direction of the electric current in the armature. The commutator also aids in the transmission of current between the armature and the power source.

\subsubsection{AC Motor}

- Rotor

- Induction motor (VPISU 2001) - Two types of rotors are used in induction motors: squirrel-cage rotor and wound rotor. (Figure 9.10.4)

A squirrel-cage rotor consists of thick conducting bars embedded in parallel slots. These bars are short-circuited at both ends by means of short-circuiting rings. A wound rotor has three-phase, double-layer, distributed winding. It is wound for as many poles as the stator. The three phases are wired internally and

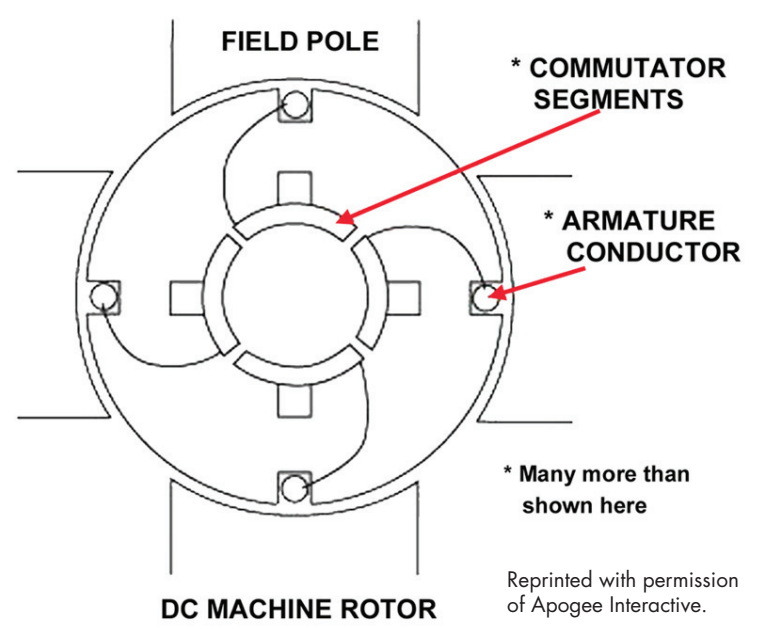

Figure 9.10.3. Parts of a direct current motor the other ends are connected to slip-rings mounted on a shaft with brushes resting on them.

- Synchronous motor - The main difference between the synchronous motor and the induction motor is that the rotor of the synchronous motor travels at the same speed as the rotating magnetic field. This is possible because the magnetic field of the rotor is no longer induced. The rotor either has permanent magnets or DC-excited currents, which are forced to lock into a certain position when confronted with another magnetic field.

- Stator (VPISU 2001)

- Induction motor - The stator is made up of a number of stampings with slots to carry three-phase windings. It is wound for a definite number of poles. The windings are geometrically spaced 120 degrees apart.

- Synchronous motor - The stator produces a rotating magnetic field that is proportional to the frequency supplied.

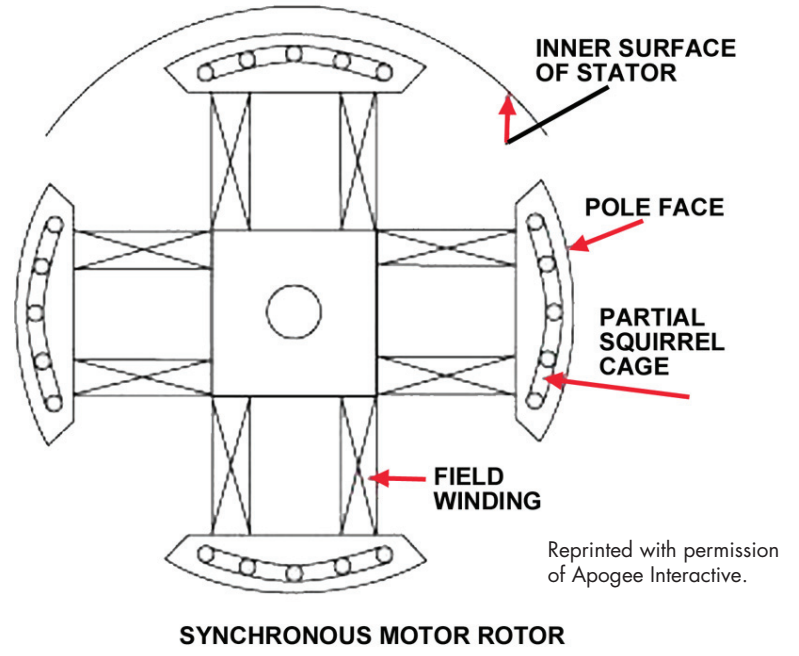

Figure 9.10.4. Parts of an alternating current motor 


\subsubsection{Safety Issues (Operators and Consulting Services Incorporated 2001)}

Electric motors are a major driving force in many industries. Their compact size and versatile application potentials make them a necessity. Motors are chosen many times because of the low vibration characteristics in driving equipment because of the potential extended life of the driven equipment. The higher rpm and small size of a motor will also make it a perfect fit for many applications.

Motors can be purchased for varying application areas such as for operating in a potentially gaseous or explosive area. When purchasing a motor, be sure to check the classification of the area, you may have a motor that does not meet the classification it is presently in! For example, a relatively new line of motors is being manufactured with special external coatings that resist the elements. These were developed because of the chemical plant setting in which highly corrosive atmospheres were deteriorating steel housings. They are, for the most part, the same motors but have an epoxy or equivalent coating.

\subsubsection{Cost and Energy Efficiency (DOE 2001)}

An electric motor performs efficiently only when it is maintained and used properly. Electric motor efficiencies vary with motor load; the efficiency of a constant speed motor decreases as motor load decreases. Below are some general guidelines for efficient operations of electric motors.

- Turn off unneeded motors - Locate motors that operate needlessly, even for a portion of the time they are on and turn them off. For example, there may be multiple HVAC circulation pumps operating when demand falls, cooling tower fans operating when target temperatures are met, ceiling fans on in unoccupied spaces, exhaust fans operating after ventilation needs are met, and escalators operating after closing.

- Reduce motor system usage - The efficiency of mechanical systems affects the run-time of motors. For example, reducing solar load on a building will reduce the amount of time the air handler motors would need to operate.

- Sizing motors is important - Do not assume an existing motor is properly sized for its load, especially when replacing motors. Many motors operate most efficiently at $75 \%$ to $85 \%$ of full load rating. Under-sizing or over-sizing reduces efficiency. For large motors, facility managers may want to seek professional help in determining the proper sizes and actual loadings of existing motors. There are several ways to estimate actual motor loading: the kilowatt technique, the amperage ratio technique, and the less reliable slip technique. All three are supported in the MotorMaster+ software.

- Replacement of motors versus rewinding - Instead of rewinding small motors, consider replacement with an energy-efficient version. For larger motors, if motor rewinding offers the lowest life-cycle cost, select a rewind facility with high quality standards to ensure that motor efficiency is not adversely affected. For sizes of $10 \mathrm{hp}$ or less, new motors are generally cheaper than rewinding. Most standard efficiency motors under $100 \mathrm{hp}$ will be cost-effective to scrap when they fail, provided they have sufficient run-time and are replaced with energyefficient models. 


\subsubsection{Maintenance of Motors}

Electric motors fail for a variety of reasons. Certain components of motors degrade with time and operating stress. Electrical insulation weakens over time with exposure to voltage unbalance, over and under-voltage, voltage disturbances, and temperature. Contact between moving surfaces causes wear. Wear is affected by dirt, moisture, and corrosive fumes and is greatly accelerated when lubricant is misapplied, becomes overheated or contaminated, or is not replaced at regular intervals. When any components are degraded beyond the point of economical repair, the motor's economic life is ended.

\section{Strategies to Reduce Motor System Usage}

- Reduce loads on HVAC systems.

- Improve building shell.

- Manage restorations better.

- Improve HVAC conditions.

- Check refrigerant charge.

- Reduce refrigeration loads.

- Improve insulation.

- Add strip curtains on doors.

- Calibrate control setpoints.

- Check refrigerant charge.

- Check ventilation systems for excessive air.

- Re-sheave fan if air is excessive.

Downsize motors, if possible.

- Improve compressed air systems.

- Locate and repair compressed air leaks.

- Check air tool fittings for physical damage.

- Turn off air to tools when not in use.

- Repair duct leaks.

The best safeguard against thermal damage is avoiding conditions that contribute to overheating. These include dirt, under and over-voltage, voltage unbalance, harmonics, high ambient temperature, poor ventilation, and overload operation (even within the service factor). Bearing failures account for nearly one-half of all motor failures. If not detected in time, the failing bearing can cause overheating and damage insulation, or can fail catastrophically and do irreparable mechanical damage to the motor.

Preventative and predictive maintenance programs for motors are effective practices in manufacturing plants. These maintenance procedures involve a sequence of steps plant personnel use to prolong motor life or foresee a motor failure. The technicians use a series of diagnostics such as motor temperature and motor vibration as key pieces of information in learning about the motors. One way a technician can use these diagnostics is to compare the vibration signature found in the motor with the failure mode to determine the cause of the failure. Often failures occur well before the expected design life span of the motor and studies have shown that mechanical failures are the prime cause of premature electrical failures. Preventative maintenance takes steps to improve motor performance and to extend its life. Common preventative tasks include routine lubrication, allowing adequate ventilation, and ensuring the motor is not undergoing any type of unbalanced voltage situation.

The goal of predictive maintenance programs is to reduce maintenance costs by detecting problems early, which allows for better maintenance planning and less unexpected failures. Predictive maintenance programs for motors observe the temperatures, vibrations, and other data to determine a time for an overhaul or replacement of the motor (Barnish et al. 2001).

Consult each motor's instructions for maintenance guidelines. Motors are not all the same. Be careful not to think that what is good for one is good for all. For example, some motors require a periodic greasing of the bearings and some do not (Operators and Consulting Services Incorporated 2001). 


\section{General Requirements for Safe and Efficiency Motor Operation} (DOE 2001)

1. Motors, properly selected and installed, are capable of operating for many years with a reasonably small amount of maintenance.

2. Before servicing a motor and motor-operated equipment, disconnect the power supply from motors and accessories. Use safe working practices during servicing of the equipment.

3. Clean motor surfaces and ventilation openings periodically, preferably with a vacuum cleaner. Heavy accumulations of dust and lint will result in overheating and premature motor failure.

4. Facility managers should inventory all motors in their facilities, beginning with the largest and those with the longest run-times. This inventory enables facility managers to make informed choices about replacement either before or after motor failure. Field testing motors prior to failure enables the facility manager to properly size replacements to match the actual driven load. The software mentioned below can help with this inventory.

\subsubsection{Diagnostic Equipment}

- Thermography - An infrared thermometer or camera allows for an accurate, non-contact assessment of temperature. Applications for motors include bearing and electrical contact assessments on motor systems and motor control centers. More information on thermography can be found in Chapter 6.

- Ultrasonic analyzer - Electric motor systems emit very distinct sound patterns around bearings. In most cases, these sounds are not audible to the unaided ear or are drown-out by other equipment noises. Using an ultrasonic detector, the analyst is able to isolate the frequency of sound being emitted by the bearing. Changes in these ultrasonic wave emissions are indicative of changes in equipment condition-some of these changes can be a precursor to component degradation and failure. More information on ultrasonic analysis can be found in Chapter 6 .

- Vibration analyzer - The rotational motion within electric motors generates distinct patterns and levels of vibration. Using a vibration analyzer and signature analysis software, the analyst can discern the vibration amplitude of the point on the motor being monitored. This amplitude is then compared with trended readings. Changes in these readings are indicative of changes in equipment condition. More information on vibration analysis can be found in Chapter 6.

- Other motor analysis - Motor faults or conditions including winding short-circuits, open coils, improper torque settings, as well as many mechanical problems can be diagnosed using a variety of motor analysis techniques. These techniques are usually very specialized to specific motor types and expected faults. More information on motor analysis techniques can be found in Chapter 6 .

\subsubsection{Available Software Tools}

\section{MotorMaster+ Version 4.0 for Motor Replace/Rewind Decisions}

Description: Developed by the DOE Industrial Technologies Program, this software tool handles everything from calculating the simple payback on a single motor purchase to comprehensive, integrated motor system management. 
MotorMaster+ allows users to create or import an inventory of in-plant operating and spare motors. Motor load, efficiency at the load point, annual energy use, and annual operating costs can be determined after taking field measurements. The software quickly identifies inefficient or oversized facility motors and computes the savings that can be achieved by replacing older, standard efficiency motors with premium efficiency models. The software runs on local or wide-area networks for access by multiple users.

Some of MotorMaster+ features include:

- Expanded list of more than 17,000 motors from 14 manufacturers, including National Electrical Manufacturers Association (NEMA) Premium ${ }^{\circledR}$ efficiency medium-voltage ( $>600$ volt) motors.

- Improved predictive maintenance testing-facilitates rapid data entry, sorting by condition, and rewind/replace recommendations.

- Technical data to help optimize drive systems, such as data on motor part-load efficiency and power factor; full-load speed; and locked-rotor, breakdown, and full-load torque.

- Motor purchasing information, including list prices, warranty periods, catalog numbers, motor weights, and manufacturer addresses.

- Capability to calculate energy savings, dollar savings, simple payback, cash flows, and the aftertaxes rate of return-on-investment for energy programs - taking into account such variables as load factor, motor efficiency, purchase price, energy costs, hours of operation, and utility rebates.

Availability: To download the MotorMaster+ and learn more about DOE Qualified Specialists and training opportunities, visit the Industrial Technology Program Web site: wwwl.eere.energy.gov/ industry/bestpractices.

\subsubsection{Relevant Operational/Energy Efficient Measures}

There are a number of operational/energy efficiency measures that could be presented for proper motor operation and control. This section focuses on the most prevalent O\&M recommendations having the greatest energy impacts at Federal facilities and includes (DOE 2003, UNEP 2006):

Replace standard motors with energy efficient motors. High efficiency motors have been designed specifically to increase operating efficiency compared to standard motors. Design improvements focus on reducing intrinsic motor losses and include the use of lower-loss silicon steel, a longer core (to increase active material), thicker wires (to reduce resistance), thinner laminations, smaller air gap between stator and rotor, copper instead of aluminum bars in the rotor, superior bearings and a smaller fan, etc.

Energy efficient motors cover a wide range of ratings and the full load and efficiencies are 3\% to $7 \%$ higher compared with standard motors.. As a result of the modifications to improve performance, the costs of energy efficient motors are higher than those of standard motors. The higher cost will often be paid back rapidly through reduced operating costs, particularly in new applications or endof-life motor replacements. But replacing existing motors that have not reached the end of their useful life with energy efficient motors may not always be financially feasible, and therefore it is recommended to only replace these with energy efficiency motors when they fail. 
Sizing to variable load. Industrial motors frequently operate under varying load conditions due to process requirements. A common practice in this situation is to select a motor based on the highest anticipated load. But this makes the motor more expensive as the motor would operate at full capacity for short periods only, and it carries the risk of motor under-loading.

An alternative is to select the motor rating based on the load duration curve of a particular application. This means that the selected motor rating is slightly lower than the highest anticipated load and would occasionally overload for a short period of time. This is possible as manufacturers design motors with a service factor (usually $15 \%$ above the rated load) to ensure that running motors above the rated load once in a while will not cause significant damage.

The biggest risk is overheating of the motor, which adversely affects the motor life and efficiency and increases operating costs. A criteria in selecting the motor rating is therefore that the weighted average temperature rise over the actual operating cycle should not be greater than the temperature rise under continuous full-load operation (100\%). Overheating can occur with:

- Extreme load changes, such as frequent starts / stops, or high initial loads

- Frequent and/or long periods of overloading

- Limited ability for the motor to cool down, for example at high altitudes, in hot environments or when motors are enclosed or dirty

Improving power quality. Motor performance is affected considerably by the quality of input power, which is determined by the actual volts and frequency compared to rated values. Fluctuation in voltage and frequency much larger than the accepted values has detrimental impacts on motor performance.

Voltage unbalance can be even more detrimental to motor performance and occurs when the voltages in the three phases of a three-phase motor are not equal. This is usually caused by the supply different voltages to each of the three phases. It can also result from the use of different cable sizes in the distribution system.

The voltage of each phase in a three-phase system should be of equal magnitude, symmetrical, and separated by $120^{\circ}$. Phase balance should be within $1 \%$ to avoid de-rating of the motor and voiding of manufacturers' warranties. Several factors can affect voltage balance: single-phase loads on any one phase, different cable sizing, or faulty circuits. An unbalanced system increases distribution system losses and reduces motor efficiency.

Voltage unbalance can be minimized by:

- Balancing any single phase loads equally among all the three phases

- Segregating any single phase loads which disturb the load balance and feed them from a separate line/transformer

Improving maintenance. Most motor cores are manufactured from silicon steel or de-carbonized cold-rolled steel, the electrical properties of which do not change measurably with age. However, poor maintenance can cause deterioration in motor efficiency over time and lead to unreliable operation. For example, improper lubrication can cause increased friction in both the motor and associated drive transmission equipment. Resistance losses in the motor, which rise with temperature, would increase. 
Ambient conditions can also have a detrimental effect on motor performance. For example, extreme temperatures, high dust loading, corrosive atmosphere, and humidity can impair insulation properties; mechanical stresses due to load cycling can lead to misalignment.

Appropriate maintenance is needed to maintain motor performance. A checklist of good maintenance practices would include:

- Inspect motors regularly for wear in bearings and housings (to reduce frictional losses) and for dirt/dust in motor ventilating ducts (to ensure proper heat dissipation.

- Check load conditions to ensure that the motor is not over or under loaded. A change in motor load from the last test indicates a change in the driven load, the cause of which should be understood

- Lubricate appropriately. Manufacturers generally give recommendations for how and when to lubricate their motors. Inadequate lubrication can cause problems, as noted above. Overlubrication can also create problems, e.g. excess oil or grease from the motor bearings can enter the motor and saturate the motor insulation, causing premature failure or creating a fire risk

- Check periodically for proper alignment of the motor and the driven equipment. Improper alignment can cause shafts and bearings to wear quickly, resulting in damage to both the motor and the driven equipment

- Ensure that supply wiring and terminal box are properly sized and installed. Inspect regularly the connections at the motor and starter to be sure that they are clean and tight

- Provide adequate ventilation and keep motor cooling ducts clean to help dissipate heat to reduce excessive losses. The life of the insulation in the motor would also be longer: for every $10^{\circ} \mathrm{C}$ increase in motor operating temperature over the recommended peak, the time before rewinding would be needed is estimated to be halved.

Multi-speed motors. Motors can be wound such that two speeds, in the ratio of 2:1, can be obtained. Motors can also be wound with two separate windings, each giving two operating speeds and thus a total of four speeds. Multi-speed motors can be designed for applications involving constant torque, variable torque, or for constant output power. Multi-speed motors are suitable for applications that require limited speed control (two or four fixed speeds instead of continuously variable speed). These motors tend to be very economical as their efficiency is lower compared to single-speed motors.

Variable speed drives (VSDs). VSDs are also called adjustable speed drives and can change the speed of a motor and are available in a range from several $\mathrm{kW}$ to $750 \mathrm{~kW}$. They are designed to operate standard induction motors and can therefore be easily installed in an existing system.

When loads vary, VSDs or two-speed motors can often reduce electrical energy consumption in centrifugal pumping and fan applications by $50 \%$ or more. The basic drive consists of the inverter itself which converts the $60 \mathrm{~Hz}$ incoming power to a variable frequency and variable voltage. The variable frequency will control the motor speed. 


\subsubsection{Electric Motors Checklist}

\begin{tabular}{|c|c|c|c|c|c|}
\hline \multirow{2}{*}{ Description } & \multirow{2}{*}{ Comments } & \multicolumn{4}{|c|}{ Maintenance Frequency } \\
\hline & & Daily & Weekly & Monthly & Annually \\
\hline $\begin{array}{l}\text { Motor use/ } \\
\text { sequencing }\end{array}$ & Turn off/sequence unnecessary motors & $\mathrm{X}$ & & & \\
\hline $\begin{array}{l}\text { Overall visual } \\
\text { inspection }\end{array}$ & $\begin{array}{l}\text { Complete overall visual inspection to be } \\
\text { sure all equipment is operating and safety } \\
\text { systems are in place }\end{array}$ & $\mathrm{X}$ & & & \\
\hline Motor condition & $\begin{array}{l}\text { Check the condition of the motor through } \\
\text { temperature or vibration analysis and } \\
\text { compare to baseline values }\end{array}$ & & $\mathrm{X}$ & & \\
\hline Check lubrication & $\begin{array}{l}\text { Assure that all bearings are lubricated per } \\
\text { the manufacture's recommendation }\end{array}$ & & & $\mathrm{X}$ & \\
\hline Check packing & $\begin{array}{l}\text { Check packing for wear and repack as } \\
\text { necessary. Consider replacing packing with } \\
\text { mechanical seals. }\end{array}$ & & & $\mathrm{X}$ & \\
\hline Motor alignment & $\begin{array}{l}\text { Aligning the motor coupling allows for } \\
\text { efficient torque transfer to the pump }\end{array}$ & & & $\mathrm{X}$ & \\
\hline Check mountings & Check and secure all motor mountings & & & $\mathrm{X}$ & \\
\hline $\begin{array}{l}\text { Check terminal } \\
\text { tightness }\end{array}$ & Tighten connection terminals as necessary & & & $\mathrm{X}$ & \\
\hline Cleaning & $\begin{array}{l}\text { Remove dust and dirt from motor to } \\
\text { facilitate cooling }\end{array}$ & & & $\mathrm{X}$ & \\
\hline Check bearings & $\begin{array}{l}\text { Inspect bearings and drive belts for wear. } \\
\text { Adjust, repair, or replace as necessary. }\end{array}$ & & & & $\mathrm{X}$ \\
\hline Motor condition & $\begin{array}{l}\text { Checking the condition of the motor } \\
\text { through temperature or vibration analysis } \\
\text { assures long life }\end{array}$ & & & & $\mathrm{X}$ \\
\hline $\begin{array}{l}\text { Check for balanced } \\
\text { three-phase power }\end{array}$ & $\begin{array}{l}\text { Unbalanced power can shorten the motor } \\
\text { life through excessive heat build up }\end{array}$ & & & & $\mathrm{X}$ \\
\hline $\begin{array}{l}\text { Check for over- } \\
\text { voltage or under- } \\
\text { voltage conditions }\end{array}$ & $\begin{array}{l}\text { Over- or under-voltage situations can } \\
\text { shorten the motor life through excessive } \\
\text { heat build up }\end{array}$ & & & & $\mathrm{X}$ \\
\hline
\end{tabular}




\subsubsection{References}

Apogee Interactive. July 5, 2001a. Characteristics of Direct Current Motors. Electrical Systems. Reprinted with permission of Apogee Interactive, www.apogee.net.

Apogee Interactive. July 5, 2001b. Characteristics of a Synchronous Motor. Electrical Systems Reprinted with permission of Apogee Interactive, www.apogee.net.

Barnish, T.J., M.R. Muller, and D.J. Kasten. June 14, 2001. Motor Maintenance: A Survey of Techniques and Results. Presented at the 1997 ACEEE Summer Study on Energy Efficiency in Industry, July 8-11, 1997, Saratoga Springs, New York, Office of Industrial Productivity and Energy Assessment, Confederation of Indian Industry. July 15, 2001. Replacement with Correct Size Combustion Air Blower in Kiln. Case Studies. Reprinted with permission of Confederation of Indian Industry.

Nadel, S.R., N. Elliott, M. Shepard, S. Greenberg, G. Katz, and A.T. de Almeida. Forthcoming (2001). Energy-Efficient Motor Systems: A Handbook on Technology, Program, and Policy Opportunities. Second Edition. American Council for an Energy-Efficient Economy. Washington, D.C.

Naves, R. July 8, 2001a. DC Motor. Electricity and Magnetism, HyperPhysics, Department of Physics and Astronomy, Georgia State University [Online]. Available URL: http://hyperphysics.phyastr.gsu.edu/hbase/magnetic/motdc.html\#c1. Reprinted with permission Dr. R. Naves, Department of Physics and Astronomy, Georgia State University.

Naves, R. July 8, 2001b. AC Motor. Electricity and Magnetism, HyperPhysics, Department of Physics and Astronomy, Georgia State University [Online]. Available URL: http://hyperphysics. phy-astr.gsu.edu/hbase/magnetic/motorac.html. Reprinted with permission Dr. R. Naves, Department of Physics and Astronomy, Georgia State University.

Operators and Consulting Services Incorporated. May 30, 2001. Electric Motors. Oilfield Machinery Maintenance Online [Online]. Available URL: http://www.oilmachineryforum.com/electric.htm.

Reprinted with permission of Operators and Consulting Services Incorporated.

The World Book Encyclopedia. 1986. Motors. Volume 13, World Book, Inc.

UNEP, 2006. Energy Efficiency Guide for Industry, 2006. United Nations Environmental Program. Washington, D.C.

U.S. Department of Energy (DOE). 2001. Greening Federal Facilities: An Energy, Environmental, and Economic Resource Guide for Federal Facility Managers and Designers. 2nd ed., Part V Energy Systems, 5.7 Electric Motors and Drives, Federal Management Energy Program [Online report]. Available URL: http://www.nrel.gov/docs/fy0losti/29267.pdf.

U.S. Department of Energy (DOE). 2003. Fact Sheet: Determining Motor Load and Efficiency. Available URL: http://www1.eere.energy.gov/industry/bestpractices/pdfs/10097517.pdf.

Virginia Polytechnic Institute and State University and Iowa State University (VPISU). July 14, 2001. Induction Motor, Powerlearn Program funded by the National Science Foundations and the Electric Power Research Institute [Online]. Reprinted with permission of Virginia Polytechnic Institute and State University. 


\subsection{Air Compressors}

\subsubsection{Introduction}

Compressed air, along with gas, electricity, and water, is essential to most modern industrial and commercial operations. It runs tools and machinery, provides power for material handling systems, and ensures clean, breathable air in contaminated environments. It is used by virtually every industrial segment from aircraft and automobiles to dairies, fish farming, and textiles.

A plant's expense for its compressed air is often thought of only in terms of the cost of the equipment. Energy costs, however, represent as much as $70 \%$ of the total expense in producing compressed air. As electricity rates escalate across the nation and the cost of maintenance and repair increases, selecting the most efficient and reliable compressor becomes critical (Kaeser Compressors 2001a).

\subsubsection{Types of Air Compressors (Dyer and Maples 1992)}

The two general types of air compressors are positive displacement and centrifugal.

\subsubsection{Positive Displacement}

- Rotary screw compressor - The main element of the rotary screw compressor (Figure 9.11.1) is made up of two close clearance helical-lobe rotors that turn in synchronous mesh. As the rotors revolve, the gas is forced into a decreasing inter-lobe cavity until it reaches the discharge port. In lubricated units, the male rotor drives the female and oil is injected into the cylinder serving as a lubricant, coolant, and as an oil seal to reduce back slippage. On non-lubricated types, timing gears are used to drive the rotors and multistaging is necessary to prevent gas temperatures from going too high.

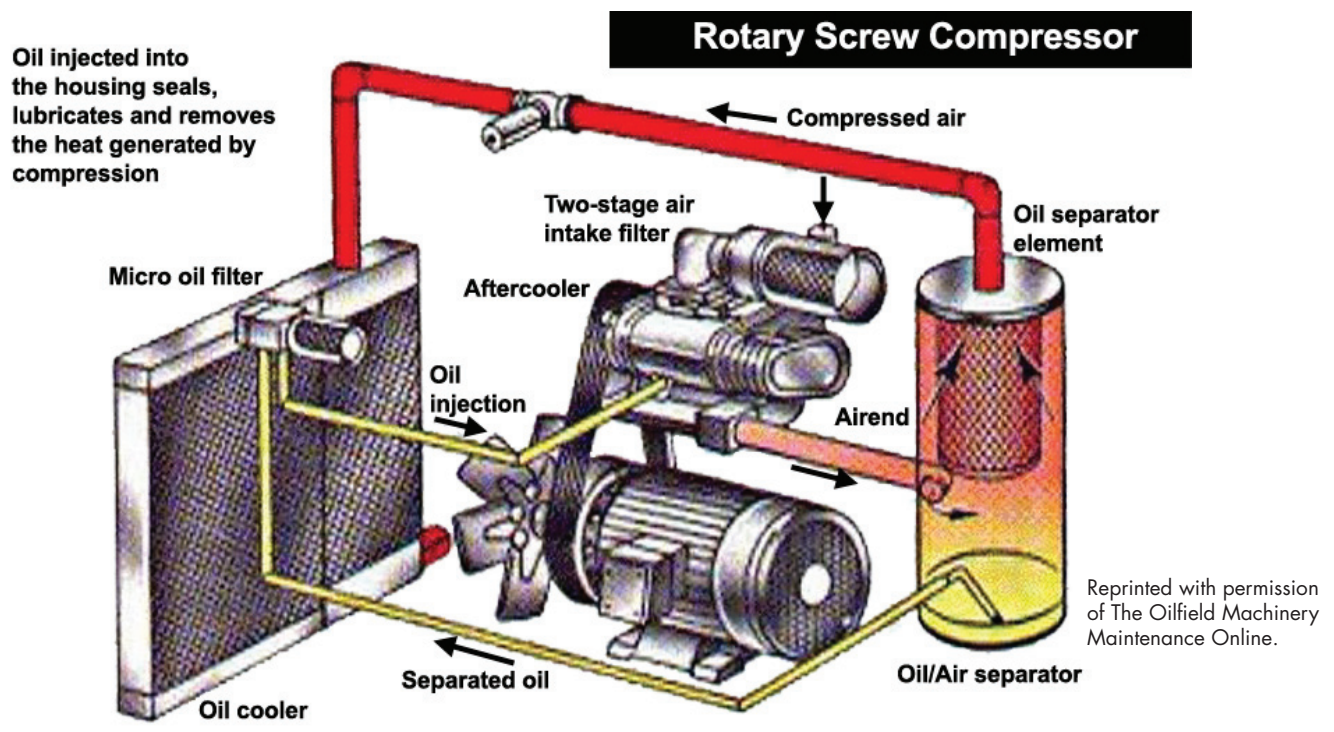

Figure 9.11.1. Rotary screw compressor 
- Reciprocating compressor - A reciprocating compressor (Figure 9.11.2) is made up of a cylinder and a piston. Compression is accomplished by the change in volume as the piston moves toward the "top" end of the cylinder. This compression may be oil-lubricated or, in some cases, it may require little or no lubrication (oil-free) in the cylinder.

The cylinder in the reciprocating machines may be air cooled or water cooled. Water cooling is used on the larger units. This cooling action is very important to increase compressor life and to keep maintenance and repairs low.

Multiple stage compressors have a minimum of two pistons. The first compresses the gas to an intermediate pressure. Intercooling of the gas before entering the second stage usually follows the first stage compression. Two stage units allow for more efficient and cooler operating compressors, which increases compressor life.

\subsubsection{Centrifugal Compressor}

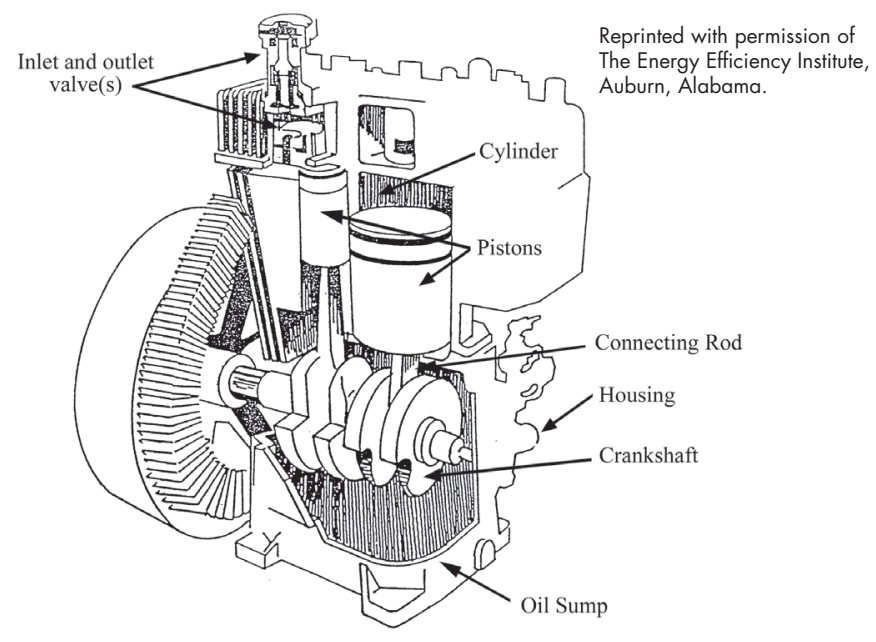

Figure 9.11.2. Typical single acting two-stage compressor

The compression action is accomplished when the gas enters the center of rotation and is accelerated as it flows in an outward direction. This gas velocity is then transferred into a pressure rise. Part of the pressure rise occurs in the rotor and part in a stationary element called the diffuser. The rotating element can have either forward curved blades, radial blades, or backward blades.

The centrifugal compressor will usually have more than one stage of compression with intercooling between each stage. One of the drawbacks of this machine is its inability to deliver part-load flow at overall efficiencies as high as other types of compressors. Many people consider the centrifugal machine a base-load machine.

\subsubsection{Key Components (Dyer and Maples 1992)}

- Positive Displacement Air Compressor

- Cylinder - Chamber where the compression process takes place by the change in its volume as the piston moves up and down.

- Piston - Component located inside the cylinder directly responsible for the compression of air.

- Crankshaft - Converts rotational motion generated by the motor to unidirectional motion for the piston.

- Connecting rod - Connects the crankshaft with the piston.

- Inlet and exhaust valves - Control the amount of air going in and out of the cylinder. 
- Rotary Screw Compressor

- Helical-lobe rotors - The main elements of this type of compressor where two close clearance helical-lobe rotors turn in synchronous mesh. As the rotors revolve, the gas is forced into a decreasing "inter-lobe cavity until it reaches the discharge port (Figure 9.11.3).

- Centrifugal Compressor

- Rotating Impeller - Imparts velocity to the air, which is converted to pressure.

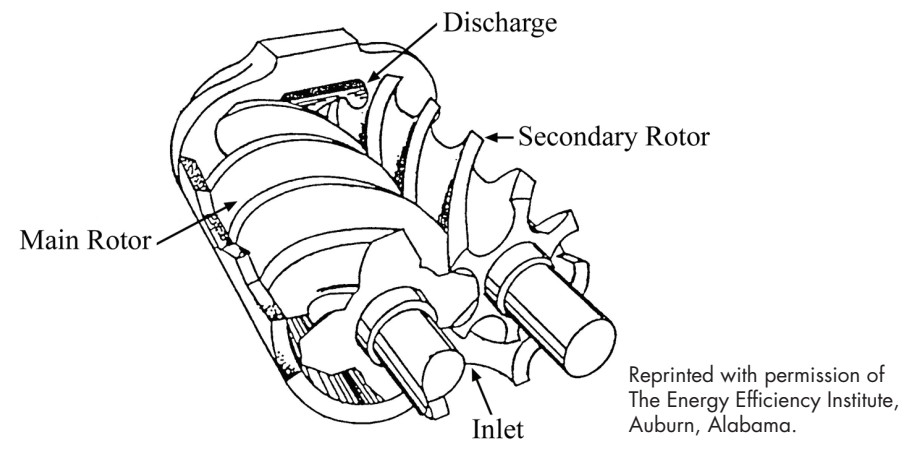

Figure 9.11.3. Helical-lobe rotors

\subsubsection{Safety Issues (UFEHS 2001)}

\subsubsection{General Safety Requirements for Compressed Air}

All components of compressed air systems should be inspected regularly by qualified and trained employees. Maintenance superintendents should check with state and/or insurance companies to determine if they require their own inspection of this equipment. Operators need to be aware of the following:

- Air receivers - The maximum allowable working pressures of air receivers should never be exceeded except when being tested. Only hydrostatically tested and approved tanks shall be used as air receivers.

- Each air receiver shall be equipped with at least one pressure gauge and an ASME safety valve of the proper design.

- A safety (spring loaded) release valve shall be installed to prevent the receiver from exceeding the maximum allowable working pressure.

- Air distribution lines

- Air lines should be made of high quality materials, fitted with secure connections.

- Hoses should be checked to make sure they are properly connected to pipe outlets before use.

- Air lines should be inspected frequently for defects and any defective equipment repaired or replaced immediately.

- Compressed air lines should be identified as to maximum working pressures (psi) by tagging or marking pipeline outlets. 
- Pressure regulation devices

- Valves, gauges, and other regulating devices should be installed on compressor equipment in such a way that cannot be made inoperative.

- Air tank safety valves should be set no less than 15 psi or $10 \%$ (whichever is greater) above the operating pressure of the compressor but never higher than the maximum allowable working pressure of the air receiver.

- Air compressor operation

- Air compressor equipment should be operated only by authorized and trained personnel.

- The air intake should be from a clean, outside, fresh air source. Screens or filters can be used to clean the air.

- Air compressors should never be operated at speeds faster than the manufacturers recommendation.

- Moving parts, such as compressor flywheels, pulleys, and belts that could be hazardous should be effectively guarded.

\subsubsection{Cost and Energy Efficiency (Kaeser Compressors 2001b)}

It takes 7 to $8 \mathrm{hp}$ of electricity to produce $1 \mathrm{hp}$ worth of air force. Yet, this high-energy cost quite often is overlooked. Depending on plant location and local power costs, the annual cost of electrical power can be equal to-or as much as two times greater than-the initial cost of the air compressor. Over a 10-year operating period, a 100-hp compressed air system that you bought for $\$ 40,000$ will accumulate up to $\$ 800,000$ in electrical power costs. Following a few simple steps can significantly reduce energy costs by as much as $35 \%$.

\subsubsection{Identify the Electrical Cost of Compressed Air}

To judge the magnitude of the opportunities that exist to save electrical power costs in your compressed air system, it is important to identify the electrical cost of compressed air. The chart below shows the relationship between compressor hp and energy cost. In addition, consider the following:

- Direct cost of pressure - Every 10 psig increase of pressure in a plant system requires about $5 \%$ more power to produce. For example: A 520 cubicfeet-per-minute (cfm) compressor, delivering air at 110 pounds per-square-inch-gage (psig), requires about 100 horsepower ( $\mathrm{hp}$ ). However, at 100 psig, only $95 \mathrm{hp}$ is required. Potential power cost savings (at 10 cents per $\mathrm{kWh}$; 8,760 hr/year) is $\$ 3,750 /$ year.

- Indirect cost of pressure - System pressure affects air consumption on the use or demand side. The air system will automatically use more air at higher pressures. If there is no resulting increase in productivity, air is wasted. Increased air consumption

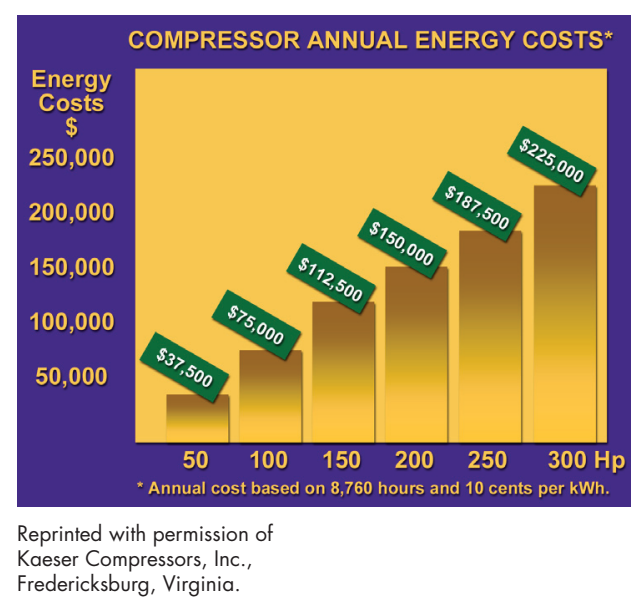


caused by higher than needed pressure is called artificial demand. A system using $520 \mathrm{cfm}$ at 110 psig inlet pressure will consume only $400 \mathrm{cfm}$ at $80 \mathrm{psig}$. The potential power cost savings $(520 \mathrm{cfm}-400 \mathrm{cfm}=120 \mathrm{cfm}$, resulting in $24 \mathrm{hp}$, at 10 cents $/ \mathrm{kWh} ; 8,760 \mathrm{hr} /$ year $)$ is $\$ 18,000 /$ year. Note: Also remember that the leakage rate is significantly reduced at lower pressures, further reducing power costs.

- The cost of wasted air volume - Each cubic feet per meter of air volume wasted can be translated into extra compressor horsepower and is an identifiable cost. As shown by Chart 1, if this waste is recovered, the result will be $\$ 750 /$ hp per year in lower energy costs.

- Select the most efficient demand side - The magnitude of the above is solely dependent on the ability of the compressor control to translate reduced airflow into lower electrical power consumption.

The chart below shows the relationship between the full load power required for a compressor at various air demands and common control types. It becomes apparent that the on line-off line control (dual control) is superior to other controls in translating savings in air consumption into real power savings. Looking at our example of reducing air consumption from $520 \mathrm{cfm}$ to $400 \mathrm{cfm}(77 \%)$, the compressor operating on

\section{General Notes on Air Compressors (OIT 1995)}

- Screw air compressors use $40 \%$ to $100 \%$ of rated power unloaded.

- Reciprocating air compressors are more efficient, but also more expensive.

- About $90 \%$ of energy becomes heat.

- Rule of thumb: roughly $20 \mathrm{hp}$ per $100 \mathrm{cfm}$ at 100 psi.

- Use low-pressure blowers versus compressed air whenever possible.

- Second, third, weekend shifts may have low compressed air needs that could be served by a smaller compressor.

- Outside air is cooler, denser, easier to compress than warm inside air.

- Friction can be reduced by using synthetic lubricants.

- Older compressors are driven by older less efficient motors. dual control requires $83 \%$ of full load power. That is $12 \%$ less energy than when operated on modulation control. If the air consumption drops to 50\%, the difference (dual versus modulation) in energy consumption is increased even further, to $24 \%$.

\subsubsection{Waste Heat Recovered from Compressors can be Used for Heating (Kaeser Compressors 2001c)}

The heat generated by air compressors can be used effectively within a plant for space heating and/or process water heating. Considerable energy savings result in short payback periods.

- Process heating - Heated water is available from units equipped with water-cooled oil coolers and after-coolers. Generally, these units can effectively discharge the water at temperatures between $130^{\circ} \mathrm{F}$ and $160^{\circ} \mathrm{F}$.

- Space heating - Is essentially accomplished by ducting the heated cooling air from the compressor package to an area that requires heating. If ductwork is used, be careful not to exceed the manufacturer's maximum back-pressure allowance.

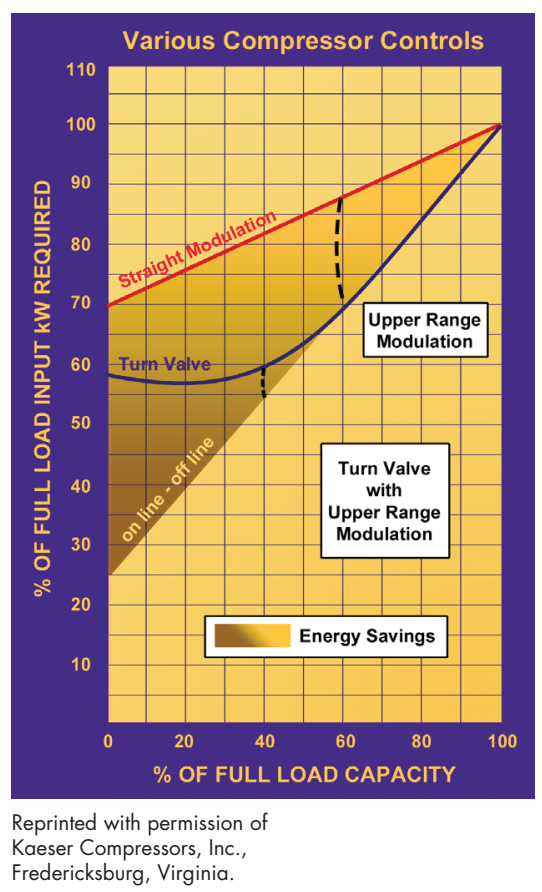


When space heating is used in the winter, arrangements should be made in the ductwork to return some of the heated air to the compressor room in order to maintain a $60^{\circ} \mathrm{F}$ room temperature. This ensures that the air discharged is at comfortable levels.

\subsubsection{Use of Flow Controllers}

Most compressed air systems operate at artificially high pressures to compensate for flow fluctuations and downstream pressure drops caused by lack of "real" storage and improperly designed piping systems. Even if additional compressor capacity is available, the time delay caused by bringing the necessary compressor(s) on-line would cause unacceptable pressure drop.

Operating at these artificially high pressures requires up to $25 \%$ more compressor capacity than actually needed. This $25 \%$ in wasted operating cost can be eliminated by reduced leakage and elimination of artificial demand.

A flow controller separates the supply side (compressors, dryers, and filters) from the demand side (distribution system). It creates "real" storage within the receiver tank(s) by accumulating compressed air without delivering it downstream. The air pressure only increases upstream of the air receiver, while the flow controller delivers the needed flow downstream at a constant, lower system pressure. This reduces the actual flow demand by virtually eliminating artificial demand and substantially reducing leakage.

\subsubsection{Importance of Maintenance to Energy Savings}

- Leaks are expensive. Statistics show that the average system wastes between 25\% and 35\% to leaks. In a compressed air system of $1,000 \mathrm{cfm}, 30 \%$ leaks equals $300 \mathrm{cfm}$. That translates into savings of $60 \mathrm{hp}$ or $\$ 45,000$ annually.

- A formalized program of leak monitoring and repair is essential to control costs. As a start, monitor all the flow needed during off periods.

- Equip maintenance personnel with proper leak detection equipment and train them on how to use it. Establish a routine for regular leak inspections. Involve both maintenance and production personnel.

- Establish accountability of air usage as part of the production expense. Use flow controllers and sequencers to reduce system pressure and compressed air consumption.

- A well-maintained compressor not only serves you better with less downtime and repairs, but will save you electrical power costs too.

\subsubsection{Leak Evaluation Procedure}

Leaks can be a significant source of wasted energy in an industrial compressed air system, sometimes wasting 20 to $30 \%$ of a compressor's output. A typical plant that has not been well maintained will likely have a leak rate equal to 20 percent of total compressed air production capacity. On the other hand, proactive leak detection and repair can reduce leaks to less than 10 percent of compressor output (DOE 1998, UNEP 2006).

In addition to being a source of wasted energy, leaks can also contribute to other operating losses. Leaks cause a drop in system pressure, which can make air tools function less efficiently, adversely affecting production. In addition, by forcing the equipment to run longer, leaks shorten the life of 
almost all system equipment (including the compressor package itself). Increased running time can also lead to additional maintenance requirements and increased unscheduled downtime. Finally, leaks can lead to adding unnecessary compressor capacity.

While leakage can come from any part of the system, the most common problem areas are:

- Couplings, hoses, tubes, and fittings

- Pressure regulators

- Open condensate traps and shut-off valves

- Pipe joints, disconnects, and thread sealants.

Leakage rates are a function of the supply pressure and increase with higher system pressures.

For compressors that have start/stop or load/unload controls, there is an easy way to estimate the amount of leakage in the system. This method involves starting the compressor when there are no demands on the system (when all the air-operated, end-use equipment is turned off). A number of measurements are taken to determine the average time it takes to load and unload the compressor. The compressor will load and unload because the air leaks will cause the compressor to cycle on and off as the pressure drops from air escaping through the leaks. Total leakage (percentage) can be calculated as follows (DOE 1998):

Leakage Percentage $(\%)=\{(T \times 100) /(T+t)\}$

where: $\quad \mathrm{T}=$ on-loading time in minutes

$\mathrm{t}=$ off-loading time in minutes

Leakage will be expressed in terms of the percentage of compressor capacity lost. The percentage lost to leakage should be less than 10 percent in a well-maintained system. Poorly maintained systems can have losses as high as 20 to 30 percent of air capacity and power.

9.11.6 Maintenance of Air Compressors (Oil Machinery Maintenance Online 2001)

Maintenance of your compressed air system is of great importance and is often left undone or half done. Neglect of an air system will ultimately "poison" the entire downstream air system and cause problems. Clean dry air supplies start at the air compressor package. The small amount of time you spend maintaining the system is well worth the trouble.

\subsubsection{General Requirements for a Safe and Efficient Air Compressor}

- Always turn power off before servicing.

- Compressor oil and oil cleanliness:

- Change the oil according to manufacturer's recommendations.

- Use a high-quality oil and keep the level where it's supposed to be.

- Sample the oil every month. 
- Condensate control

- Drain fluid traps regularly or automatically.

- Drain receiving tanks regularly or automatically.

- Service air-drying systems according to manufacturer's recommendations.

\section{Common Causes of Air Compressor Poor Performance (Kaeser Compressors 2001d) \\ Problem \\ Remedial Action}

Low pressure at point Leaks in distribution piping

of use

Clogged filter elements

Fouled dryer heat exchanger

Low pressure at compressor discharge

Low pressure at For systems with modulating load compressor discharge controls, improper adjustment of air capacity control

Worn or broken valves

Improper air pressure switch setting

Water in lines

Failed condensate traps

Failed or undersized compressed air dryer

Liquid oil in air lines Faulty air/oil separation

Dirt, rust, or scale in air lines

Excessive service to load/hour ratio

Improper pressure switch setting

Elevated compressor Restricted airflow temperature

In the absence of liquid water, normal aging of the air lines

System idling too much
Check lines, connections, and valves for leaks; clean or replace filter elements

Clean heat exchanger

Follow manufacturer's recommendation for adjustment of control

Check valves and repair or replace as required

Follow manufacturer's recommendations for setting air pressure switch

Clean, repair, or replace the trap

Repair or replace dryer

Check air/oil separation system; change separator element

Install filters at point of use

For multiple compressor systems, consider sequencing controls to minimize compressor idle time; adjust idle time according to manufacturer's recommendations

Readjust according to manufacturer's recommendations

Clean cooler exterior and check inlet filter mats

Check water flow, pressure, and quality; clean heat exchanger as needed

Check compressor oil level; add oil as required

Remove restriction; replace parts as required

Excessive ambient temperatures
Improper ventilation to compressor; check with manufacturer to determine maximum operating temperature 
- Keep air inlet filters clean.

- Keep motor belts tight.

- Minimize system leaks.

\subsubsection{Diagnostic Tools}

- Ultrasonic analyzer - Compressed gas systems emit very distinct sound patterns around leakage areas. In most cases, these sounds are not audible to the unaided ear or are drown-out by other equipment noises. Using an ultrasonic detector, the analyst is able to isolate the frequency of sound being emitted by the air or gas leak. The ultrasonic detector represents an accurate and cost-effective means to locate leaks in air/gas systems. More information on ultrasonic analysis can be found in Chapter 6 .

- Vibration analyzer - Within a compressor, there are many moving parts; some in rotational motion and some in linear motion. In either case, these parts generate a distinct pattern and level of vibration. Using a vibration analyzer and signature analysis software, the analyst can discern the vibration amplitude of the point on the equipment being monitored. This amplitude is then compared with trended readings. Changes in these readings are indicative of changes in equipment condition. More information on vibration analysis can be found in Chapter 6 .

\subsubsection{Available Software Tools}

\section{AIRMaster+ Improves Compressed Air System Performance Software}

Description: AIRMaster+, developed by the DOE Industrial Technologies Program (ITP), provides a systematic approach for assessing the supply-side performance of compressed air systems. Using plant-specific data, the software effectively evaluates supply-side operational costs for various equipment configurations and system profiles. It provides useful estimates of the potential savings to be gained from selected energy-efficiency measures and calculates the associated simple payback periods.

AIRMaster+ includes a database of generic or industry-standard compressors and creates an inventory specific to your actual, in-plant air compressors. Based on user-provided data, the software simulates existing and modified compressed air system operations. It can model part-load system operations for an unlimited number of rotary screw, reciprocating, and centrifugal air compressors operating simultaneously with independent control strategies and schedules.

Powerful software features facilitate development of 24-hour metered airflow or power data load profiles for each compressor; calculation of life-cycle costs; input of seasonal electric energy and demand charges; and tracking of maintenance histories for systems and components.

AIRMaster+ also includes LogTool, companion software that serves as a data importation and analysis aid. The tool helps users import data that is exported from different types of data loggers; select logger data channels and modify their properties (e.g., name, type, units, etc.); view data values for one or more logger channels; display trend plots with one or two Y axes; display scatter plots; and display day type plots in the format that is needed for AIRMaster+.

Availability: To download AIRMaster+ and learn more about DOE Qualified Specialists and training opportunities, visit the Industrial Technology Program Web site: www.eere.energy.gov/industry/ bestpractices. 


\subsubsection{Relevant Operational/Energy Efficiency Measures}

There are many operational/energy efficiency measures that could be presented for proper compressed air operation and control. The following section focuses on the most prevalent O\&M recommendations having the greatest energy impacts at Federal facilities. These recommendations are also some of the most easily implemented for boiler operators and O\&M contractors.

Compressed Air Measure: Cost Evaluation of Compressed Air Leakage

Table 9.11.4 below can be used to approximate the flow rate in $\mathrm{cfm}$ of compressed air leaks as a function of orifice size and line pressure (DOE 2000).

Table 9.11.4. Steam trap discharge rate

\begin{tabular}{|c|c|c|c|c|c|c|}
\hline Leakage Rates for Different Supply Pressures and Approximate Orifice Sizes (cfm) \\
\hline Pressure (psig) & \multicolumn{7}{|c|}{ Orifice Diameter (in.) } \\
\cline { 2 - 7 } & $1 / 64$ & $1 / 32$ & $1 / 16$ & $1 / 8$ & $1 / 4$ & $3 / 8$ \\
\hline 70 & 0.29 & 1.16 & 4.66 & 18.62 & 74.40 & 167.80 \\
\hline 80 & 0.32 & 1.26 & 5.24 & 20.76 & 83.10 & 187.20 \\
\hline 90 & 0.36 & 1.46 & 5.72 & 23.10 & 92.00 & 206.60 \\
\hline 100 & 0.40 & 1.55 & 6.31 & 25.22 & 100.90 & 227.00 \\
\hline 125 & 0.48 & 1.94 & 7.66 & 30.65 & 122.20 & 275.50 \\
\hline
\end{tabular}

Estimated Annual Energy Savings. The annual energy savings, which could be realized by fixing a compressed air leak, can be estimated as follows:

where

$$
\text { Annual Energy Savings }=N \times L R \times E U \times H \times C
$$

$$
\begin{aligned}
& \mathrm{N}=\text { number of leaks, no units } \\
& \mathrm{LR}=\text { leakage rate, } \mathrm{cfm} \text { (from the table above) } \\
& \mathrm{EU}=\text { compressor energy use, } \mathrm{kW} / \mathrm{cfm} \\
& \mathrm{H}=\text { annual hours of operation, hours } \\
& \mathrm{C}=\text { orifice edge coefficient, no units }
\end{aligned}
$$

Estimated Annual Cost Savings. The annual cost savings, which could be realized by fixing a compressed air leak, can be estimated as follows:

$$
\text { Annual Cost Savings = Annual Energy Savings } \times \text { ER }
$$

where $\quad E R=$ average annual electricity rate, $\$ / \mathrm{kWh}$ 
It should be noted that this cost savings calculation doesn't account for an electric peak demand reduction. If the facility has a peak demand charge, and the compressor operates everyday with an operational schedule that is coincident with the facility's peak demand, then this estimate slightly underestimates the cost savings.

\section{Compressed Air Leaks Energy Savings and Economics}

\section{Example Synopsis}

A compressed air system audit reveals 5 air leaks, all with an estimated orifice diameter of 1/16 of an inch. The leaks are located in a line pressurized to 100 psig. The energy use of the compressor is $18 \mathrm{~kW} / 100 \mathrm{cfm}$, and is operated $8,760 \mathrm{hrs}$ per year. The electrical rate is approximately $\$ 0.10$ per kWh. (Assumed sharp edged orifice, multiplier equals 0.61)

The annual energy savings can be estimated as:

$$
\begin{aligned}
& \text { Annual Energy Savings }=5 \times 6.31 \times 0.18 \times 0.61 \times 8,670 \\
& \text { Annual Energy Savings }=30,346.30 \mathrm{kWh} / \mathrm{yr}
\end{aligned}
$$

The annual cost savings can be estimated as:

$$
\begin{gathered}
\text { Annual Energy Savings }=(30,346.30 \mathrm{kWh} / \mathrm{yr})(\$ 0.10 / \mathrm{kWh}) \\
\text { Annual Energy Savings }=\$ 3,034 / \mathrm{yr}
\end{gathered}
$$

\section{Compressed Air Systems Rules of Thumb (EPA 2003)}

- Compressed Air Rule 1. Efficiency improvements can reduce compressed air system energy use by $20 \%$ to $50 \%$.

- Compressed Air Rule 2. Efficiency improvements to compressed air systems can save approximately one-half percent of a facility's total energy use.

- Compressed Air Rule 3. Repairing air leaks can reduce compressed air system energy use by 30\% or more.

- Compressed Air Rule 4. Repairing air leaks can reduce a facility's total energy use by about onehalf percent, with an average simple payback of 3 months.

- Compressed Air Rule 5. It takes approximately 2.5 to $5.0 \mathrm{kWh}$ to compress $1,000 \mathrm{ft}^{3}$ of air to 100 psi. Each psi reduction in compressed air loss from the distribution system (at 100 psi), reduces a compressor's energy use by more than one-half percent. 
In the absence of calculating the cost of a compressed air leak, Table 9.11 .5 can be used as a rough cost estimate for compressed air leakage cost (DOE 2003)

Table 9.11.5. Compressed air leaks - cost per year assuming $\$ 0.05 / \mathrm{kWh}$

\begin{tabular}{|c|c|}
\hline Size (in.) & $\begin{array}{c}\text { Cost Per Year } \\
(\$ / y \mathbf{r})\end{array}$ \\
\hline $1 / 16$ & $\$ 523$ \\
\hline $1 / 8$ & $\$ 2,095$ \\
\hline $1 / 4$ & $\$ 8,382$ \\
\hline
\end{tabular}

\subsubsection{Air Compressor Water-Use Best Practices}

In some instances larger air compressors will be water cooled using the practice of "single-pass" or "once-through cooling." Single-pass or once through cooling systems provide an opportunity for significant water savings. In these systems, water is circulated only once through the compressor and then is disposed of to drain. To remove the same heat load, single-pass systems use 40 times more water than a cooling tower operated at 5 cycles of concentration. To maximize water savings, single-pass cooling equipment should be either modified to recirculate water or if possible, should be eliminated altogether. Possible options to minimize water usage include (FEMP 2008):

- Eliminate single pass cooling by modifying equipment to operate on a closed loop that recirculates the water instead of discharging it.

- If modification of equipment to a closed loop system is not feasible, add an automatic control to shut off the entire system during unoccupied night or weekend hours. This option should only be considered where shutdown would have no adverse impact on indoor air quality.

- Installation of a chiller or cooling tower is also an economical alternative. Excess cooling capacity may already exist within the building that can be utilized.

- Find another use for the single-pass effluent, in boiler make-up supply or landscape irrigation, and implement. Note some equipment effluent may be contaminated such as degreasers and hydraulic equipment. This effluent must not be used in boilers.

\subsubsection{Case Study}

\section{Air Compressor Leakage (OIT 1995)}

The cost of compressed air leaks is the energy cost to compress the volume of the lost air from atmospheric pressure to the compressor operating pressure. The amount of lost air depends on the line pressure, the compressed air temperature and the point of the leak, the air temperature at the compressor inlet, and the estimated area of the leak.

A study of a 75-hp compressor that operates 8,520 hours per year was shown to have a leakage rate of $24 \%$. The majority of these leaks were due to open, unused lines. The compressor, a singlestage screw type, provides compressed air at 115 psi, is $91.5 \%$ efficient, and operates with electricity costing \$14.05 per million Btu. 
The study identified eight major leaks ranging in size from $1 / 16$ to $1 / 8$ inches in diameter. The calculated total annual cost of these leaks was $\$ 5,730$.

Correcting the leaks in this system involved the following:

- Replacement of couplings and/r hoses.

- Replacement of seals around filters.

- Repairing breaks in compressed-air lines.

The total cost of the repairs was $\$ 460$. Thus, the cost savings of $\$ 5,730$ would pay for the implementation cost of $\$ 460$ in about a month.

\subsubsection{Air Compressors Checklist}

\begin{tabular}{|c|c|c|c|c|c|}
\hline \multirow[b]{2}{*}{ Description } & \multirow[b]{2}{*}{ Comments } & \multicolumn{4}{|c|}{ Maintenance Frequency } \\
\hline & & Daily & Weekly & Monthly & Annually \\
\hline $\begin{array}{l}\text { Compressor use/ } \\
\text { sequencing }\end{array}$ & Turn off/sequence unnecessary compressors & $\mathrm{X}$ & & & \\
\hline $\begin{array}{l}\text { Overall visual } \\
\text { inspection }\end{array}$ & $\begin{array}{l}\text { Complete overall visual inspection to be sure } \\
\text { all equipment is operating and safety systems } \\
\text { are in place }\end{array}$ & $\mathrm{X}$ & & & \\
\hline Leakage assessment & Look for and report any system leakages & $\mathrm{X}$ & & & \\
\hline $\begin{array}{l}\text { Compressor } \\
\text { operation }\end{array}$ & $\begin{array}{l}\text { Monitor operation for run time and } \\
\text { temperature variance from trended norms }\end{array}$ & $\mathrm{X}$ & & & \\
\hline Dryers & Dryers should be observed for proper function & $\mathrm{X}$ & & & \\
\hline $\begin{array}{l}\text { Compressor } \\
\text { ventilation }\end{array}$ & $\begin{array}{l}\text { Make sure proper ventilation is available for } \\
\text { compressor and inlet }\end{array}$ & $\mathrm{X}$ & & & \\
\hline $\begin{array}{l}\text { Compressor } \\
\text { lubricant }\end{array}$ & $\begin{array}{l}\text { Note level, color, and pressure. Compare } \\
\text { with trended values. }\end{array}$ & $\mathrm{X}$ & & & \\
\hline Condensate drain & $\begin{array}{l}\text { Drain condensate from tank, legs, and/or } \\
\text { traps }\end{array}$ & $\mathrm{X}$ & & & \\
\hline $\begin{array}{l}\text { Operating } \\
\text { temperature }\end{array}$ & $\begin{array}{l}\text { Verify operating temperature is per } \\
\text { manufacturer specification }\end{array}$ & $\mathrm{X}$ & & & \\
\hline $\begin{array}{l}\text { Pressure relief } \\
\text { valves }\end{array}$ & $\begin{array}{l}\text { Verify all pressure relief valves are } \\
\text { functioning properly }\end{array}$ & & $\mathrm{X}$ & & \\
\hline Check belt tension & $\begin{array}{l}\text { Check belt tension and alignment for proper } \\
\text { settings }\end{array}$ & & $\mathrm{X}$ & & \\
\hline Intake filter pads & $\begin{array}{l}\text { Clean or replace intake filter pads as } \\
\text { necessary }\end{array}$ & & $\mathrm{X}$ & & \\
\hline $\begin{array}{l}\text { Air-consuming } \\
\text { device check }\end{array}$ & $\begin{array}{l}\text { All air-consuming devices need to be } \\
\text { inspected on a regular basis for leakage. } \\
\text { Leakage typically occurs in: } \\
\text { - Worn/cracked/frayed hoses } \\
\text { - Sticking air valves } \\
\text { - Cylinder packing }\end{array}$ & & $\mathrm{X}$ & & \\
\hline Drain traps & Clean out debris and check operation & & $\mathrm{X}$ & & \\
\hline Motor bearings & $\begin{array}{l}\text { Lubricate motor bearings to manufacturer's } \\
\text { specification }\end{array}$ & & & $\mathrm{X}$ & \\
\hline
\end{tabular}


Chiller Checklist (contd)

\begin{tabular}{|c|c|c|c|c|c|}
\hline \multirow{2}{*}{ Description } & \multirow{2}{*}{ Comments } & \multicolumn{4}{|c|}{ Maintenance Frequency } \\
\hline & & Daily & Weekly & Monthly & Annually \\
\hline System oil & $\begin{array}{l}\text { Depending on use and compressor size, } \\
\text { develop periodic oil sampling to monitor } \\
\text { moisture, particulate levels, and other } \\
\text { contamination. Replace oil as required. }\end{array}$ & & & $\mathrm{X}$ & \\
\hline Couplings & $\begin{array}{l}\text { Inspect all couplings for proper function and } \\
\text { alignment }\end{array}$ & & & & $\mathrm{X}$ \\
\hline Shaft seals & Check all seals for leakage or wear & & & & $\mathrm{X}$ \\
\hline Air line filters & $\begin{array}{l}\text { Replace particulate and lubricant removal } \\
\text { elements when pressure drop exceeds } 2-3 \text { psid }\end{array}$ & & & & $\mathrm{X}$ \\
\hline Check mountings & Check and secure all compressor mountings & & & & $\mathrm{X}$ \\
\hline
\end{tabular}

\subsubsection{References}

DOE. 1998. Improving Compressed Air System Performance: A Sourcebook for Industry. Industrial Technologies Program, U.S. Department of Energy, Washington, D.C.

DOE. 2003. Improving Compressed Air System Performance. DOE/GO-102003-1822, Industrial Technologies Program, U.S. Department of Energy, Washington D.C.

Dyer, D.F. and G. Maples. 1992. Electrical Efficiency Improvement. Energy Efficiency Institute, Auburn.

EPA. 2003. Wise Rules for Industrial Energy Efficiency - A Tool Kit For Estimating Energy Savings and Greenhouse Gas Emissions Reductions. EPA 231-R-98-014, U.S. Environmental Protection Agency, Washington, D.C.

FEMP 2008. Federal Energy Management Program - Water Best Management Practices. Available on line at URL: http://wwwl.eere.energy.gov/femp/program/waterefficiency_bmp.html.

Kaeser Compressors, Inc. July 29, 2001a. Getting the Most for Your Money: Types of Compressors. Air Compressor Guide [Online Report]. Available URL: http://www.maintenanceresources.com/ Referencelibrary/AirCompressors/kaeserpage 1.htm.

Kaeser Compressors, Inc. July 29, 2001b. Evaluating Compressor Efficiency. Air Compressor Guide [Online Report]. Available URL: http://www.maintenanceresources.com/Referencelibrary/AirCompressors/ kaeserpage7.htm.

Kaeser Compressors, Inc. July 29, 2001c. Waste Heat Recovery and the Importance of Maintenance. Air Compressor Guide [Online Report]. Available URL: http://www.maintenanceresources.com/ Referencelibrary/AirCompressors/kaeserpage9.htm. 
Kaeser Compressors, Inc. July 29, 2001d. Getting the Most for Your Money: Troubleshooting. Air Compressor Guide [Online Report]. Available URL: http://www.maintenanceresources.com/

Referencelibrary/AirCompressors/kaeserpage5.htm.

Oil Machinery Maintenance Online. July 16, 2001. Air Compressors [Online]. Available URL: http://www.oilmachineryforum.com/air.htm.

OIT. 1995. Modern Industrial Assessments: A Training Manual. Industrial Assessment Manual from the Office of Productivity and Energy Assessment at the State University of New Jersey, Rutgers, for the U.S. Department of Energy Office of Industrial Technology.

University of Florida Environmental Health and Safety (UFEHS). July 26, 2001. Compressed Air Safety: General safety requirements for compressed air [Online]. Available URL: http://www.ehs.ufl.edu/ General/Shop/comp_air.htm.

UNEP, 2006. Energy Efficiency Guide for Industry, 2006. United Nations Environmental Program. Washington, D.C. 


\subsection{Lighting}

\subsubsection{Introduction}

Recent studies reveal that over $20 \%$ of the nation's electricity consumption is related to various types of lighting products and systems. Advanced energy saving technologies are readily available to reduce both the connected load and energy consumption, but are only effective if they are properly installed, calibrated, and maintained. Improvements in lighting efficiencies are so rapid that it can be cost-effective to implement upgrades, retrofits or redesigns to lighting systems that are only 5 to 10 years old. In addition to everyday maintenance and operation of lighting systems, this section discusses the important issues of commissioning and regular reevaluation of system components with a view toward upgrades.

\subsubsection{Systems and Components}

A lighting system consists of light sources, the ballasts or other devices that regulate the power that drives electric lights, the luminaire housing with components that hold the sources and direct and shield the light, and lighting controls that manipulate the time or intensity of lighting systems.

\subsubsection{Light Sources}

Natural light sources include the sun and daylight (light from the sky). The electric light sources most common to Federal buildings include incandescent/halogen, fluorescent, high intensity discharge, and light emitting diodes. Characteristics common to light sources include their output, efficiency, life, color, and distribution.

A. Daylight/Sunlight - Daylight is an acceptable and desirable light source for building interiors. It uses the light from the sky, or occasionally sunlight reflected off building surfaces. Direct sunlight should generally be shielded, preferably before it hits the windows to reduce glare and thermal gains. In particular, direct sun penetration should be kept out of work environments. Interior window blinds are almost always needed to control sky glare and sun penetration, even when overhangs or light shelves exist.

B. Electrical Lamps - The lamp is the source of electric light, the device that converts electric power into visible light. Selecting the lamp types is at the heart of a high-quality lighting plan, and central to visual performance, energy conservation, and the appearance of a space. Various light sources have different characteristics, but the basic performance principles include the following:

- Lumen output - the amount of light emitted by a lamp

- Efficacy - the efficiency of lamps in producing light, measured in lumens of light per watt of energy

- Rated lamp life - expected lamp life typically reported in hours

- Lamp lumen depreciation - the loss of light output over time, usually reported as a percentage

- Color temperature (CCT) and color rendering (CRI) - a numerical value related to the appearance of the light and the objects illuminated 
Fluorescent lamps generate their light by using electricity to excite a conductive vapor of mercury and an inert gas.

The resultant ultraviolet light strikes a phosphor coating on the inside of the tube, causing it to glow. The elements used in the phosphor coating control the lamp's color.

\section{T12 lamps - Linear}

fluorescent lamps with a $1-1 / 2$ inch diameter $(12 / 8$ of an inch). They are now considered obsolete for most new applications. These were the standard fluorescent lamps until T8 lamps came on the market in the 1980s.

T8 lamps - Linear fluorescent lamps with a 1 inch diameter ( $8 / 8$ of an inch). These are the workhorse of the commercial lighting industry and have become the standard for offices and general applications. Since they are $22 \%$ more efficient than T12s, it is generally always costeffective to retrofit or replace fixtures that use T12 lamps in existing applications even before the existing T12 lamps burn out. The rare exception might be individual fixtures that are rarely used. However, it will be more efficient to replace or upgrade these at the same time to avoid costly individual replacements at a later date. T8 lamps use the same socket as T12, but not the same ballast. There is a wide range of T8 design options and good color rendition. The most commonly used T8 lamp is 4-feet-long and 32-watts (F32T8).

High performance or premium T8 lamps - High performance T8s are marketed under the tradenames Ultra (GE), Advantage (Philips), or Super T8 (Sylvania). These T8 lamps provide higher efficacy, higher maintained lumens, and are available in extended life versions with a $20 \%$ increase in lamp life. The improved performance is achieved in different ways by different products. Some products have reduced wattages (28 to 30 watts) while achieving the same lumen output as a standard T8. Others have increased lumen output $(3,100$ lumens) without increasing the wattage. The increased lumen output results in a brighter lamp and potentially more glare. This can be prevented by using the lower wattage version, or by coupling a 3,100 lumen lamp with a reduced output ballast $(.77 \mathrm{BF})$. Premium T8s have a higher initial cost, but the increased energy efficiency and life make them the recommended light source for most commercial fluorescent installations including Federal projects. 
T5 lamps - Linear fluorescent lamps with a diameter of 5/8 of an inch. These cannot replace T8 lamps because they have different characteristics and different lengths (metric), socket configurations and ballasts. T5s are smaller lamps than T8s, but have similar efficacy (lumens per watts). Their smaller diameter allows for shallower fixtures and greater reflector control, but also increases the brightness, limiting their use to heavily shielded or indirect fixtures.

T5HO (high output) - T5 lamps with approximately the same maintained lumens as two standard T8 lamps but less efficient, with about 7\% to 10\% fewer lumens per watt. This development allows the designer to potentially reduce the number of fixtures, lamps, and ballasts in an application, making it less expensive to maintain. However, the intense brightness of T5HOs limits their use to primarily indirect luminaires to avoid glare. Also, using one-lamp rather than two-lamp luminaires eliminates the potential for two-level switching. Analysis is required to demonstrate the benefits of using T5HO lamps to offset their lower efficacy and higher cost.

\section{Compact fluorescent lamps (CFLs)}

- Fluorescent lamps with a single base and bent-tube construction. Originally designed for the retrofitting of standard incandescents, the first CFLs had a screwtype base. While screw base lamps are still available, commercial applications typically use lamps with a 4-pin base. This prevents the future replacement of a screw-based CFL with a much less efficient incandescent lamp. CFL lamps have a wide range of sizes and attractive colors, and can be used in most Federal applications that formerly used incandescent.

High Intensity Discharge (HID) lamps also use a gas-filled tube to generate light, but use an arc current and vaporized metals at relatively high temperatures and pressures. There are two main types in current use metal halide $(\mathrm{MH})$ and high-pressure sodium (HPS) - and their characteristics are determined by the gas. MH provides a white light with a CRI of 65-95, while HPS emits a yellowish light with a CRI of 22 to 65. Historically, HID lamps were relegated to outdoor or service areas, but advances in color, configurations, and efficacy have made them more attractive for commercial and interior use. 
Electrodeless lamps (also called induction lamps) most commonly use radio frequency to ionize mercury vapor at low-pressures, resulting in exciting the phosphors inside the envelope to create a glow, similar to fluorescent technology. The three major lamp manufacturers each produce a distinctive lamp design, the small reflector "Genura" lamp by GE, the globe-shaped "QL" by Philips, and the high-output donut-shaped "Icetron" by Sylvania.

Incandescent/Halogen lamps generate their light by heating a tungsten filament until it glows, in the presence of an inert gas such as argon or nitrogen. A halogen lamp is a form of incandescent lamp that introduces traces of halogen gas and a quartz envelope to burn hotter and prolong the filament life. Consequently, they are whiter $(3000 \mathrm{~K}$ rather than $2700 \mathrm{~K})$ and are slightly more energy efficient than standard incandescents. Halogen should be used in lieu of standard incandescent, and low voltage should be considered for the tighter, more focused beam. However, whenever possible, the use of more efficient CFL or ceramic metal halide sources should be explored. Since incandescent/halogen lamp types are very inefficient (roughly five times less efficient than fluorescent), they should be used sparingly, or the project will not meet the energy code. See the suggested uses below.

Light Emitting Diodes (LEDs) are made of an advanced semi-conductor material that emits visible light when current passes through it. Different conductor materials are used, each emitting a distinctive wavelength of light. LEDs come in red, amber, blue, green, and a cool white. LEDs are beginning to see extensive use in a variety of applications including street/ parking lot lighting, supermarket refrigerated display case lighting, and other display lighting applications.

\subsubsection{Ballasts, Transformers, and Power Packs}

Electrical devices are needed to provide the necessary high starting voltage, and then limit and regulate the current to the lamp during operations. All gas discharge lamps, like fluorescent and high intensity discharge (HID), require ballasts (incandescent lamps do not). Ballasts typically are designed to efficiently operate a specific lamp type, so lamps and ballasts are chosen together. The final ballast product selection is usually done by

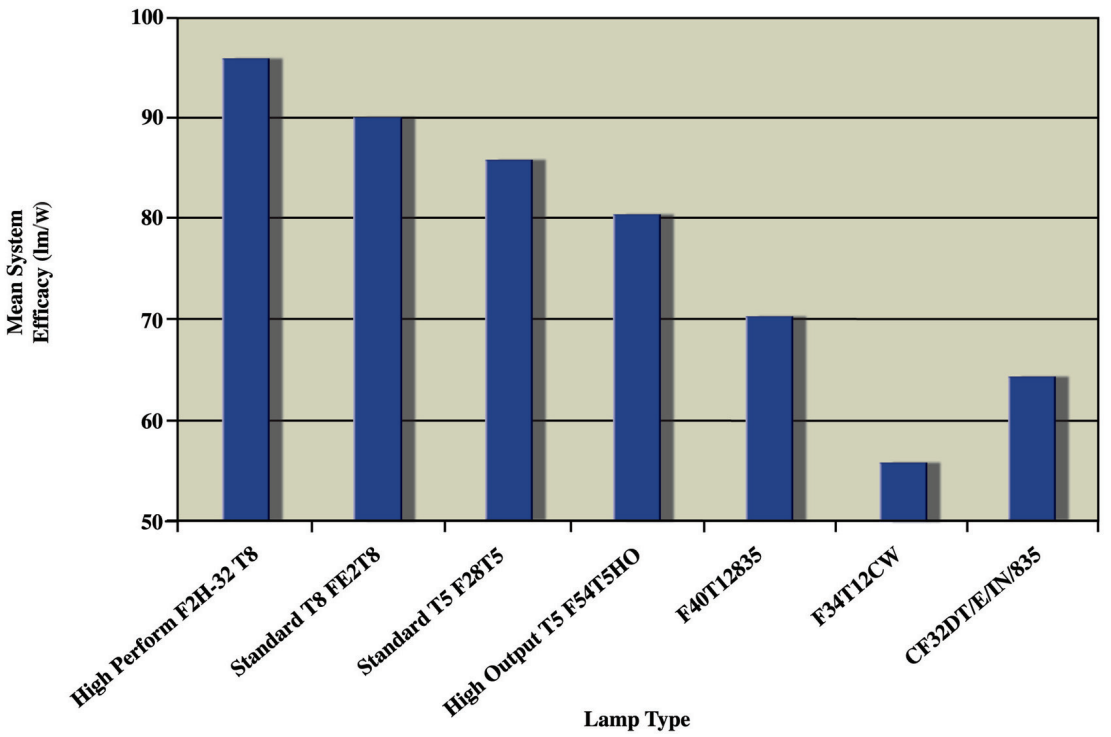

Figure 9.12.1. Fluorescent lamp/ballast efficacy the fixture manufacturer, in response to the lighting designer's minimum performance requirements. In specifying or evaluating ballasts, the basic performance criteria to consider include the following:

- Ballast Factor (BF) - proportion of potential light output. Not a measure of efficiency.

- Lamp-Ballast System Efficacy - Mean lumens of lamps divided by input wattage of ballast. Best measure to evaluate system efficiency. 
- Power Factor $(\mathrm{PF})$ - Not lower than 0.90

- Total Harmonic Distortion (THD) - Not higher than 20\%

- Minimum Starting Temperature - appropriate for application

- Voltage requirements - matching supply voltage, or multi-voltage taps

- Maximum distance between lamp and remotely located ballast - check with manufacturer.

\subsubsection{Luminaire Housing}

A luminaire is the entire lighting assembly that includes a light source, a ballast to control the power, and a housing with components necessary for light distribution and shielding of the source.

Aspects of the luminaire housing related to building operations and maintenance include:

- Sturdy construction, not easily moved or damaged or vandalized.

- Materials that maintain their initial characteristics, like reflectance or shininess (specularity) or cleanliness.

- Features that make installation, wiring, and leveling easy.

- Features that make maintenance easy, like hinges, fasteners, self-tapping screws, safety chains, no rough edges, easy access to ballasts and wiring, ease of cleaning.

Luminaires are most often classified by the light source and the distribution of the light. Once the most appropriate distribution is selected for a particular application, then luminaires within that classification can be compared for glare control, efficiency, and overall performance.

- Direct $90 \%$ to $100 \%$ downlight

- Semi-direct $60 \%$ to $90 \%$ downlight, $10 \%$ to $40 \%$ uplight

- General diffuse $40 \%$ to $60 \%$ up and downlight

- Semi-indirect $60 \%$ to $90 \%$ uplight, $10 \%$ to $40 \%$ downlight

- Indirect $90 \%$ to $100 \%$ uplight

Cleaning classification - The recommended cleaning schedules for luminaires depends on the openness of the fixture design, the distribution characteristics mentioned above, and the dirtiness of the environment.

These conditions are components of the "luminaire dirt depreciation" (LDD) factor (see recoverable light losses, Section 9.12.4.1). The capacity for a luminaire to retain dirt or dust falls into two categories:

- Open/Unventilated - Luminaires that are open on the bottom, with or without louvers or baffles, and a housing that has no top ventilation apertures that would provide a steady path for air to move through the fixture.

- All Other - Luminaires that do not meet the description above, such as bare lamps, strip fixtures, enclosed or lensed fixtures, or any fixtures with top openings for ventilation. 


\subsubsection{Lighting Control Devices}

There is seldom just one way to accomplish the desired control of lighting, and a variety of equipment is available to the lighting designer. (Minimum lighting controls are required by code see Energy Codes, Section 9.12.4.4.) A comprehensive strategy uses several of these control devices in concert, responding to project-specific usage patterns:

- Manual controls

- Switches and switching patterns

- Manual dimmers
- Automatic controls

- Occupancy sensors

- Daylight sensors

- Pre-set controls

- Time controls

- Centralized control management

Manual Controls - Manual controls allow the users to select the lighting levels best suited to their immediate needs. Task lights located in workstations should have manual controls. Spaces with variable activities, such as training rooms, multi-purpose rooms, or conference centers, generally require manual controls to enable the users to tailor the light for each different activity. Allowing the users to select a "pre-set" lighting scene will generally reduce consumption. With manual controls, occupancy satisfaction is achieved, but the reduction in energy use is unpredictable since it requires individuals to turn off their lights. For effective use, the controls need to be intuitive and labeled. Note that even with manual controls, the energy standard still requires automatic shutoff when spaces are not occupied.

Switches. Switching strategies can be used in combinations to offer multiple levels of illumination, and multiple mixes of available light sources. In its simplest application, open work areas can have several zones of luminaires, so partially occupied rooms do not need to burn all the lights. Three-way switches are typically used in multi-entry and multi-zoned rooms to facilitate people moving from zone to zone. Automatic switches, (or Sentry-type switches that reset to the off position) are appropriate for use with manual-on/automatic-off occupancy sensors. Another strategy is bi-level switching - two (or more) light levels within a space can be attained with multi-lamp luminaires, factory pre-wired for easy connection to separate switches, which allows one lamp in each fixture to be turned off, effectively "dimming" the lights. When several light sources - e.g., overhead luminaries, wall washers, down lights - are present, each type should be switched separately.

Manual dimmers. Manual dimming is most useful to respond to specific user needs - dimming the conference room lights for AV presentations, raising the light level for the cleaning crew, changing the mood in a cultural space. Manual dimmers can be wall box sliders or hand-held remote controls. Both incandescent and fluorescent light sources are dimmable, and both use less energy when dimmed, although the energy saved is not always proportional to the decrease in light. Incandescent lamps can be readily dimmed, but fluorescent need specialized electronic dimming ballasts.

Automatic Controls - Automatic controls provide benefits in user comfort and energy conservation. Automatic controls can deliver reliable energy savings without occupant participation, and when well designed, without their notice. In addition, they can make adjustments to light levels throughout the day, or in response to specific needs. For safety reasons, lighting controls should be specified to default to full-on when control equipment fails. Recommissioning is valuable for determining that all the controls operate and save energy as intended. 


\section{Automatic controls advantages, disadvantages, and appropriate uses Advantages:}

- Sufficient energy conservation possible

- Energy savings are more predictable

- Allows a comprehensive daylighting strategy

- Subtle changes in light levels can be accomplished without occupant participation

- Flexible for accommodating changes in use or occupancy over the moderate/long-term

\section{Disadvantages:}

- Controls must be very reliable and predictable for user acceptance

- May require expertise and/or training of maintenance personnel

- Commissioning is required and adjustments may be necessary when layouts change

- Moderate to high initial cost (\$0.20/ $/ \mathrm{tt}^{2}$ for scheduling, higher for daylighting)

\section{Appropriate Uses:}

- Dimming of electric lighting to support a daylighting strategy

- Rooms with periods of no occupancy during the day (for occupancy sensors) or have regular operating hours (time clocks)

- Support spaces and outdoor areas with predictable needs

Occupancy Sensors. Occupancy sensors turn off the lights when they detect that no occupants are present. The occupancy sensor includes a motion sensor, a control unit, and a relay for switching the lights. The sensor and control unit are connected to the luminaire by low voltage wiring, with a transformer stepping down the current. There are three commonly used types of occupancy sensors, defined by how they detect motion: ultrasonic, passive infrared and dualtechnology.

- Ultrasonic sensors (US) utilize a quartz crystal that emits high frequency ultrasonic waves throughout the room. Shifts to the frequency of the wave (called Doppler effect) indicate that there is motion/occupancy in the space. US cover the area in a continuous manner, and there are no blind spots in the coverage, e.g., a desk behind a partition. While this makes them effective at detecting occupancy, it also makes them more vulnerable to "false-on" readings caused by traffic in adjacent corridors and air currents. Therefore, they can be most effectively used in combination with manual-on switches (see below), particularly in daylighted spaces. Manual-on prevents false-ons and saves energy

Figure 9.12.2. Wall-box occupancy sensor uses hidden internal dip-switches to set manual-on, auto-off. by avoiding unnecessary automatic activation when daylight or spill-light is sufficient for the activity. 


\section{HID lamp advantages, disadvantages, and appropriate uses}

\section{Advantages:}

- High lumen output - up to 1,000 wattage lamps available

- Medium to high efficacy - MH: 51 to 85 lumens per watt; HPS: 60 to 115 lumens per watt

- Long lamp life - MH: 10,000 to 20,000 hours; HPS: 10,000 to 24,000 + hours

- Insensitivity to ambient temperatures

- $50 \%$ and $100 \%$ bi-level switching ballasts available

\section{Disadvantages:}

- Lamps have a warm-up period before reaching full output/color

- If power is interrupted, lamps must cool off before restriking (hence unreliable dimming and unacceptability for emergency lighting). Some HPS lamps are available with instant restrike.

- Inappropriate for many control strategies like daylight harvesting, occupancy sensors, or frequent switching.

\section{Appropriate Uses:}

- Metal halide lamps come in a wide range of shapes and colors, and are suitable for most lighting applications where continuous operation is required. "Ceramic" metal halide technology provides colors in the 80 to $98 \mathrm{CRI}$ range with a warm color temperature of $3000 \mathrm{~K}$.

- Metal halide PAR and small tubular lamps provide an energy-efficient substitute for many types incandescent/ halogen reflector and tubular lamps

- High-pressure sodium (HPS) lamps are most often used in roadway and other outdoor applications. Lamp life is very long $(30,000+$ hours), but the CRI is low (about 22 to 30$)$. Improved whiter HPS lamps are available with a CRI of 65, but as color improves, efficacy and life are significantly reduced.

- Not a point source if narrow beam distribution is required

\section{Electrodeless lamp advantages, disadvantages, and appropriate uses}

\section{Advantages:}

- Very long life (100,000 hours) due to lack of electrodes to deteriorate

- Good maintained lumen output over life

- Low to high light output available (1,100 to 12,000 lumens per lamp)

- Medium to high efficacy (40 to 60 lumens/watt)

\section{Disadvantages:}

- Not interchangeable with other lamps and ballasts. No competition.

- Only one manufacturer per lamp style (donut, reflector, globe)

- Limited to diffuse distribution

- Limited wattages and lumen output for each style

- Requires magnetic core, which has shorter life than the lamp

\section{Appropriate Uses:}

- Locations where maintenance is expensive or difficult

- Replacement reflector lamp for incandescent floodlight in high ceilings

- Locations where high lumen output and diffuse distribution is desirable (indirect kiosks in high ceilings)

- More information is available from the manufacturers and the Advanced Lighting Guidelines. 


\section{Incandescent/Halogen lamp advantages, disadvantages, and appropriate uses}

\section{Advantages:}

- Excellent color rendering and a warm appearance

- Can be focused for use in reflector lamps

- Compact size

- No ballast required

- Easily dimmed

- Minimal ultra-violet emissions for conservation of light sensitive materials

\section{Disadvantages:}

- Low efficacy - Halogen is the best at 13 to 21 lumens per watt.

- Shorter lamp life than alternatives - Halogen is the best at 3,000 to 6,000 hours

- Lamp can get very hot

- Low voltage transformers may be required for halogen lights

- Point source is glary if not shielded.

\section{Appropriate Uses:}

- Historic settings when CFL lamps cannot be used

- Applications in which color rendering is extremely important (art work, limited retail)

- Displays where the narrowest beam control is necessary

\section{LED Lamp advantages, disadvantages, and appropriate uses}

\section{Advantages:}

- Impact resistant

- Operate best at cooler temperatures so good for outdoor applications

- Small size

- Low to medium efficacy, depending on the color. Red is highest, followed by amber, green, white, and blue. A more efficient white light can be created by combining red, green, and blue LEDs. White LEDs are currently about 30 lumens per watt, but efficacies are expected to increase steadily.

- Monochromatic color for exit signs, signals, and special effects

- Effective for rapid or frequent switching applications

\section{Disadvantages:}

- Rapid lumen depreciation: White LEDs may last 12,000 hours or longer, but "useful life" is only 6,000 hours, the point at which point light output has reduced $50 \%$.

- Monochromatic color

- Heat buildup

- Cost

- White LEDs are still bluish and provide low lumens per watt, similar to incandescent. Both conditions are expected to improve rapidly over the next 15 years.

\section{Appropriate Uses:}

- Currently used primarily in exit signage, traffic signaling, and certain special effects

- Excellent for projecting words or an image - as in walk/don't walk signs or exit signs. FEMP recommends them for these uses.

- LED sources may have the greatest potential for technical improvements and new applications in the next 15 years. 
- Passive infrared sensors (PIR) respond to the infrared heat energy of occupants, detecting motion at the "human" wavelength. They operate on a line-of-sight basis and do not detect occupants behind partitions or around corners. They also are less likely to detect motion as the distance increases. Therefore, they are useful when a room is small or it is desirable to control only a portion of a space. PIR are more susceptible to false-off readings than false-ons, so tend to be more annoying to occupants than ultrasonic sensors.

- Dual-technology sensors combine two technologies to prevent both false-offs and false-ons. The most common one uses both ultrasonic and passive infrared sensing to detect occupancy. The sensor usually requires that both US and PIR sense occupancy before turning on. The lights will remain on as long as either technology detects someone. High quality occupancy sensors use the dual technology, since it is more reliable than each of the separate technologies used independently. Dual-technology sensors cost more than sensors using either US or PIR alone.

Other occupancy sensor features to consider include:

- Mounting location - Ceiling, high-wall or corner, or wall box. Room size and layout are the major determinants. Ceiling-mounted sensors are the most versatile because their view is less obstructed. Wall box sensors take the place of the room's wall switch, and they are economical and easy to retrofit. Wall box sensors are appropriate for small, unobstructed spaces.

- On-Off settings - Occupancy sensors can automatically turn on (auto-on) and then automatically turn off (auto-off). Or, they can require the user to turn them on (manual-on) and then automatically turn off. Manual-on sensors save more energy because the lights do not turn on when the user does not need them. Auto-on sensors are useful in applications where the users are not familiar with the layout and switch locations, or where finding a switch would be inconvenient.

- Sensitivity - Most sensors can be adjusted for the desired degree of activity that will trigger a sensor response. The time-delay (i.e., the time elapsed between the moment a sensor stops sensing an occupant and the time it turns off) can also be selected. The setting can range from 30 seconds to 30 minutes, and the choice becomes a balance between energy conservation, user tolerance, and lamp life. We suggest no less than 15 minutes if controlling instant start ballasts.

- Multiple level control - Occupancy sensors are effective for multiple level switching in spaces where full off is not acceptable, but occupancy is not continuous. By using a two- or three-level ballast, or multi-lamp fixtures with lamps wired separately, the lowest level may be allowed to operate at most hours, but when occupancy is sensed, the light level increases. This is a useful energy saving strategy in areas where safety or security requires some light at all times, such as certain enclosed stairs, security corridors, restrooms, etc. Of the two strategies, multi-level ballasts have the advantage of keeping the lamp warm, reducing early burn-outs caused by frequent switching.

Daylight Controls. Daylight controls are photoelectric devices that turn off or dim the lights in response to the natural illumination available. Depending on the availability of daylight, the hours of operation and the space function, photoelectrically-controlled lighting can save $10 \%$ to $60 \%$ of a building's lighting energy. This can translate into even more savings since daylight availability coincides with the hours of the day when peak demand charges apply.

Smooth and continuous dimming is the preferred strategy for automated daylighting controls in offices or other work areas, since it is not distracting to the workers. The photosensor adjusts the light level based on the amount of natural light sensed by sending a signal to the dimming ballast. The less 
expensive dimming ballasts with minimum settings of $20 \%$ of full output are appropriate for daylight dimming (EPRI 1997). The two strategies, "closed-loop" and "open loop," are based on photosensor locations, and the correct sensor location is essential. In a "closed loop" system, the sensor is located above a horizontal surface to detect the light reflecting off that surface from both electric and daylight sources. Since the sensor is reading reflected light, the reflective characteristics of the surface should remain constant. Consequently, sensors are located over a circulation area, rather than a workstation where the reflectivity of the worker's clothes or desktop contents might change. In an "openloop" system, the sensor is located near the window in such a way to only detect daylight. In both systems, the sensor must not pick

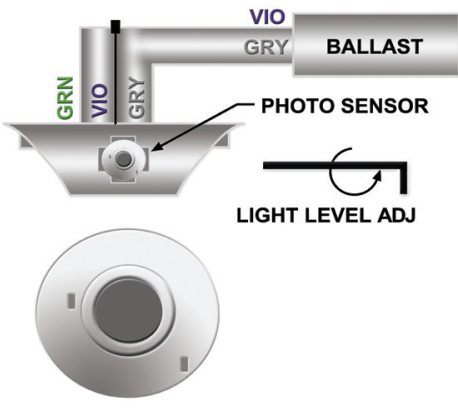

Figure 9.12.3. Photosensor and fluorescent dimming ballast for continuous daylight dimming. up the direct illumination from the electric lights. Sensors can control more than one dimming ballast but the luminaires being controlled must all have a similar orientation to the natural light. For example, trees in front of several windows define a separate lighting "zone." Time-delay settings are used to slow down the response to rapid changes in natural lighting conditions, providing more steady lighting.

Switching the lights off when sufficient natural lighting is present is a less expensive strategy, but not as acceptable to the occupants. This approach is most commonly found in outdoor applications - controlling parking lot lighting for example. In buildings, a stepped approach to daylight switching is sometimes employed, in which only some lamps are switched off in multi-lamp luminaires.

Alternately, daylight switching is used in rooms where continuous occupancy is not common, such as corridors, cafeterias, atria, or copy rooms.

Pre-set Controls. Switching, dimming, or a combination of the two functions can be automatically preprogrammed so that the user can select an appropriate lighting environment ("scene") at the touch of a button. Each scene uses a different combination of the luminaires in the room (sometimes dimmed) to provide the most appropriate light for one of several planned activities in that room. A "pre-set controller" and wiring plan organizes this. For example, the occupant of a conference room could select one pre-set scene from a five-button "scene selector" wall-mounted in the room, labeled "Conference," "Presentation," "Slide Viewing," "Cleaning," and "Off." This allows multiple lighting systems to be installed to meet the varying needs of separate activities, but prevents them from all being used at full intensity for every activity. A pre-set scene should be included for the cleaning crew, which should use the most energy-efficient lights that will allow them to do their work.

Time Controls. Time clocks are devices that can be programmed to turn lights on or off at designated times. These are a useful alternative to photoelectric sensors in applications with very predictable usage, such as in parking lots. Simple timers are another option, turning the lights on for a specified period of time, although there are limited applications where this is appropriate, e.g., library stacks. A time-controlled "sweep" strategy is sometimes effective. After normal hours of occupancy, most of the lighting is turned off (swept off), but if any occupants remain, they can override the command in just their space. Override controls can be wall switches located within the space or be activated by telephone or computer. These systems typically flash the lights prior to turnoff, to give any remaining occupants ample time to take action. There is usually more than one sweep operation scheduled after hours until all lights are turned off. 
Centralized Control Management. Automated Building Management Systems (BMS) are becoming more common in medium- and large-sized facilities to control HVAC, electrical, water, and fire systems. Incorporating lighting controls is a natural step in efficient management, and centralized lighting control systems are available that can interface with building maintenance systems while providing data on lighting operation. However, in some cases, centralized systems are not appropriate for some functions, such as managing the dimming controls. The technological advance that may change this is DALI (digital addressable lighting interface), a communication protocol that allows an entire lighting system to be managed with computer software. This is promising for situations that require sophisticated control and flexibility for lighting reconfiguration. The DALI system is being designed based on an international standard so that various system components are compatible.

\subsubsection{Safety Issues}

In dealing with lighting equipment, the greatest concern is electrical shock, followed by injury from falls from high mounting locations, ladders and lifts, and handling of hazardous waste.

\subsubsection{Electrical and Equipment Safety}

- All electrical equipment should be properly grounded, including luminaires, ballasts, starters, capacitors and controls, and be in accordance with the National Electric $\operatorname{Code}^{\circledR}\left(\mathrm{NEC}^{\circledR}\right)$.

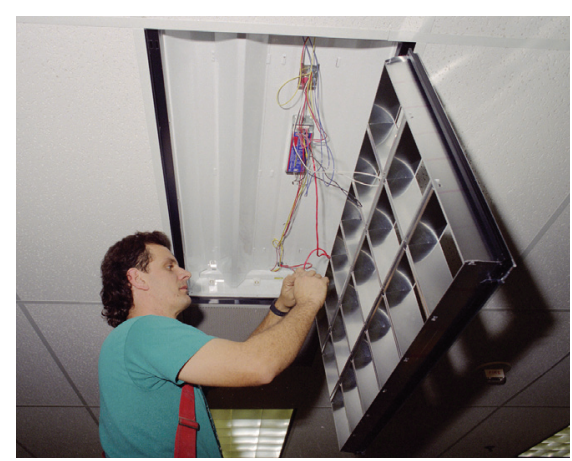

Figure 9.12.4. Repair and rewiring must be done by a licensed electrician.

- Although maintenance personnel may handle routine maintenance such as changing lamps or cleaning luminaires, all trouble-shooting and repair must be handled by licensed electricians. All personnel must be properly trained and equipped.

- All maintenance personnel shall be provided with and instructed in the use of proper tools and equipment such as protective hand tools, fall protection such as safety belts or harnesses, hard hats, goggles, gloves, and testing tools.

- All maintenance of lighting equipment must follow the lockout/tagout standard in OSHA 1910.147 - The Control of Hazardous Energy. This standard applies to the control of energy during servicing and/or maintenance of machines and equipment. Employers must utilize procedures "for affixing appropriate lockout devices or tagout devices to energy isolating devices, and to otherwise disable machines or equipment to prevent unexpected energization, start-up or release of stored energy. The employer must be able to demonstrate that the tag-out device provides an equivalent level of safety to the lock-out device in that particular situation." Consult the OSHA website for the U.S. Department of Labor at www.osha.gov.

- Special precautions should be taken near high voltages and lighting components such as HID capacitors that may retain their electric change after the system has been de-energized. See OHSA.

- All forms of lifts, scaffolds, and ladders must meet OSHA standards for construction and use. Portable scaffolds, telescoping scaffolds, and personnel lifts are typically safer than ladders, by providing a firmer footing and space for tools, replacement items, and cleaning materials. Ladders used for lighting maintenance should not be made from materials that conduct electricity, such as aluminum. Stilts are sometimes used for maintenance of low ceilings or low-mounted luminaires. 


\subsubsection{Hazardous Materials Handling}

- Breakage of mercury-containing lamps - Mercury vapor is most hazardous when lamps are operable. When a fluorescent or metal halide lamp containing mercury gas is broken, the following safety procedure is recommended. Clear the areas for 10 minutes; turn off AC so that mercury vapor does not spread; flush the area with fresh air: use an N95 respirator mask and goggles and gloves to sweep the particles into a glass jar. Double wrap in a paper bag. Dispose of as hazardous waste. Clean area and clothes. Discard gloves.

- Hazardous waste lamps are classified by the U.S. Environmental Protection Agency (EPA) as those failing the EPA Toxicity Characteristic Leaching Procedure (TCLP) for landfills, and include fluorescent, high pressure sodium, metal halide, mercury vapor, and neon lamps (if they contain mercury). The EPA revised their rules about mercury-containing lamps in 2000, allowing the following three options:

- Mercury-containing lamps must pass the TCLP test

- Must be treated as hazardous waste in storage, handling, collection, and transportation

- Must be managed under the universal waste rule (40 CFR 273), i.e., recycled.

- The universal waste rule allows for disposal of hazardous lamps in small quantities. However, since the Federal government disposes of such high volumes of waste, this practice should not be followed. Recycling costs about $\$ 0.35$ to $\$ 1.50$ per 4 -foot lamp depending on quantity and adjunct services. See www.lamprecycle.org for lamp disposal regulations and lists of recyclers. Hazardous waste landfill costs are about $\$ 0.25$ to $\$ 0.50$ per 4 -foot lamp, not counting storage, collection, and transportation fees - costs that are generally more expensive than for recycling. Different states, (e.g., CA, CT, FL, ME, MI, PA, RI, VT) have more stringent regulations and do not even allow low-mercury lamps (i.e., lamps passing the TCLP test) in landfills.

- Magnetic ballasts with PCBs in the capacitors can still be found in older installations, even though they were banned from being manufactured or distributed after 1978. All ballasts produced after that date are clearly labeled "No PCBs." PCBs are classified by the EPA as a hazardous waste under the Toxic Substances Control Act of 1976 (TSCA) section of their regulations, which requires disposal of the capacitor in a Federally-approved incinerator. Ballasts that are not leaking can be recycled. Whether or not the ballast is leaking fluid, the building manager should use a qualified disposal contractor who is aware of all PCB-related hazards.

- The building manager and the waste or recycling contractor must keep proper documentation and chain of possession records. Auditing the contractor and reviewing the contractor's closure plan (for transition of materials if the contractor goes out of business) is recommended prior to signing a contract and every few years afterwards. 


\subsubsection{Energy Efficiency, Savings, and Cost}

Ways to maintain performance and improve system efficiency through planned maintenance, response to complaints, retrofit, and redesign are described in this section.

\subsubsection{Planned versus Reactive Maintenance}

Lighting systems are intentionally overdesigned to account for losses in light output that will occur over time. Thus, the initial light levels are higher than needed, in order to ensure that the maintained light levels do not fall below design recommendations over time. The determination of overdesign depends on light loss factors (LLF) that include assumptions for cleaning and relamping fixtures at regular intervals, that is, a program of planned lighting maintenance.

$$
\text { Luminaires required }=\frac{\text { Lighted area } \mathrm{x} \text { desired maintained illuminance }}{\text { Initial lamp lumens } \mathrm{x} \text { luminaire utilization efficiency } \mathrm{x} \text { LLF }}
$$

Planned maintenance can improve the LLF, reducing the number of luminaires required. Reactive maintenance, i.e., replacing lamps or ballasts when they fail, will not keep illumination at the desired levels. Following a planned maintenance program is essential to the success of any lighting system.

A planned maintenance program can reduce the degree of overdesign, resulting in significant reductions in first cost of equipment and in energy consumption. It can also improve safety, security, and the visual appearance of the spaces.

A proactive, planned maintenance program includes the following:

- Cleaning of lamps, luminaries, and room surfaces at regular intervals

- Group relamping on a scheduled basis of all luminaires in an area, with spot relamping in between. One cleaning can be performed in conjunction with relamping

- Inspection and repair of lighting equipment at regular intervals

- Inspection and re-calibration of lighting controls at regular intervals

- Re-evaluation of lighting system and potential upgrades. An upgrade may replace a group relamping cycle.

Recoverable light loss factors (LLF) are those that can be fully or partially returned to initial performance by proper maintenance. They include the following:

- Lamp Burnouts (LBO). "Rated Lamp Life" is provided by the manufacturer and represents the point in time when 50\% of a group of lamps have burned out under controlled testing with lamps switched on 12-hour intervals. These are useful in determining exactly when group relamping interval is most economical (typically at about $70 \%$ to $80 \%$ of rated lamp life for fluorescent, see Figure 9.12.5). Extended life fluorescent lamps are available with 20\% to 50\% longer rated life. Frequent switching of fluorescent lamps (more than five on-off cycles per day) may greatly reduce lamp life, unless the cathodes are protected by a "programmed -start" ballast. 
- Lamp Lumen Depreciation (LLD). Lamp lumen depreciation presents the decrease in light output of a lamp over time. Lamp catalogues provide both "initial lumens" and "mean lumens," the former measured after 100 hours, and the latter occurring at $40 \%$ of the rated lamp life. New, high performance T8 lamps retain more of their lumen output than other sources (about 92\%), while HPS retains only about 70\% and metal halide about 65\%. Mercury Vapor and LEDs have the greatest fall off in light output, so although they have longer rated lives, it makes more sense to consider replacing them before the end of their "useful" life.

- Luminaire Dirt Depreciation (LDD). Dirt and dust that settles on lamps and luminaire not only reduce the output but can also change the distribution of a luminaire (Levin 2002). The LDD factor used in lighting calculations depends on

- The type of luminaire (open but unventilated, and all others)

- The cleanliness of the environment

- The anticipated cleaning schedule

- See the IESNA RP-36-03 cleaning curves and equations to determine the best cleaning schedule. In a clean environment, some enclosed and ventilated luminaires can be cleaned every 24 to 30 months, resulting in less than 10\% light loss (i.e., a LDD of 0.9). An open luminaire without ventilation would have to be cleaned every 12 months to keep the light loss at the same level. In a "dirty" environment, luminaires require cleaning every 6 months to a year to keep light losses above 20\% (i.e., a LDD of 0.8).

- Room Surface Dirt Depreciation (RSDD). The reflective characteristics of the interior finishes can have a large impact on the efficiency of the lighting system and the quality and comfort of the light provided. Light levels can be better maintained by regular cleaning of the work surfaces. In existing facilities, light output, comfort, and lighting quality can be improved by repainting the walls a lighter color.

Non-recoverable light loss factors include:

- Ballast losses (the difference between rated lamp wattage and the actual input wattage)

- Supply voltage variations

- Ambient temperature of luminaire and surrounds

- Luminaire surface deterioration - Permanent deterioration of luminaire surfaces can be minimized by the wise specification of finishes for luminaire interiors and reflectors.

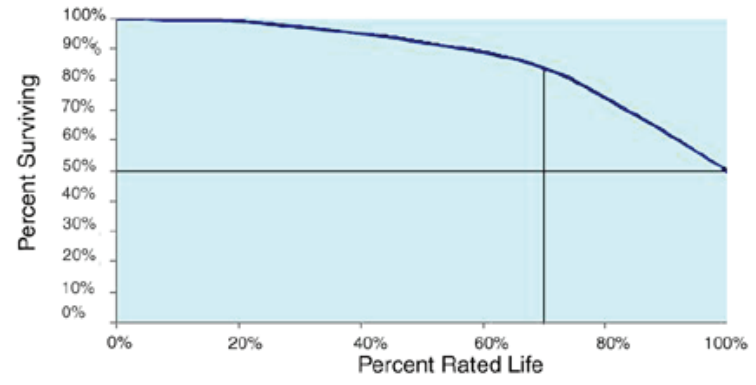

Figure 9.12.5. Fluorescent lamp mortality curve 


\subsubsection{Response to Complaints}

Perhaps the greatest cause of lighting energy waste is controls that do not reduce energy consumption because they have failed or are improperly calibrated, or lighting controls that have been over-ridden or disabled rather than calibrated correctly. For example, an employee complains that the daylight dimming is too abrupt, or results in light levels that are too low. Rather than investigating the problem and fixing it, or providing the employee with an additional task light, either the staff cuts the control wires so the lights will not dim, or sets the sensor settings so high that the lights will not dim, or the employee puts tape over the light sensor so that the lights will not dim. While it is possible that a control system has been poorly designed and can never be calibrated well enough to satisfy the occupants, every effort should be made to work with the control manufacturer and the system designer to achieve the proper balance between energy savings and user acceptance. The easy way out of disabling the offending system can have a vast impact on the energy savings, and may even impact on cooling loads that were designed on the basis of reduced lighting consumption.

\subsubsection{Retrofit versus Redesign}

Retrofit is typically described as replacement of components (lamps, ballasts, reflectors, lenses, even luminaires) in the same housing or location as the original lighting equipment. Redesign is typically described as new luminaires in some new locations. On the surface, retrofit may appear to be the cheapest and easiest path, but in fact is not always the most cost-effective strategy. Retrofit may not be the best solution if:

- Existing lighting quality is poor

- Existing light levels are too low or contrast between bright and dark areas is too high

- Existing lighting does not light walls or work partitions

- Existing luminaire locations produce illumination that is not uniform

- Existing luminaire spacing is too wide and/or partial height partitions obstruct the light.

- Luminaire spacing or locations are inappropriate for current or proposed use or furniture layouts

- Existing room surfaces or furniture are dark in color

- Retrofit options will narrow the distribution of light or lessen the light levels on vertical surfaces.

If "retrofit" still seems like the best option, consult the IESNA Guidelines for Upgrading Lighting Systems in Commercial and Institutional Spaces (LEM-3-07), available at www.iesna.org.

Otherwise, consider redesigning the lighting layouts and reconsidering the types of luminaires if any of the existing conditions make the space unsuitable for retrofit. The trend of improvements in lighting technologies can create cost-effective opportunities for upgrading the lighting in Federal facilities, even if they have been upgraded in the last 5 to 10 years. For example, high performance T8 lamps and ballasts could save 10\% to $15 \%$ over standard T8s installed only 8 years ago.

- At the very least, higher performance lamps should be considered for the next scheduled group relamping.

- Upgrade lamps (and ballasts) instead of group relamping 


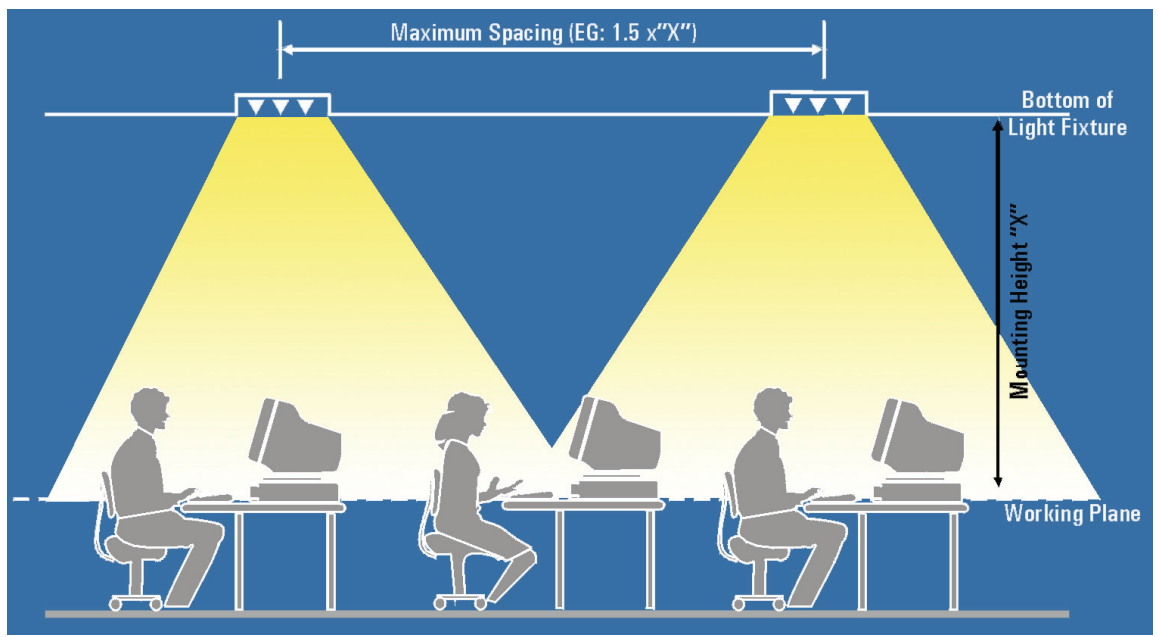

Uniform light distribution following maximum spacing criterion.

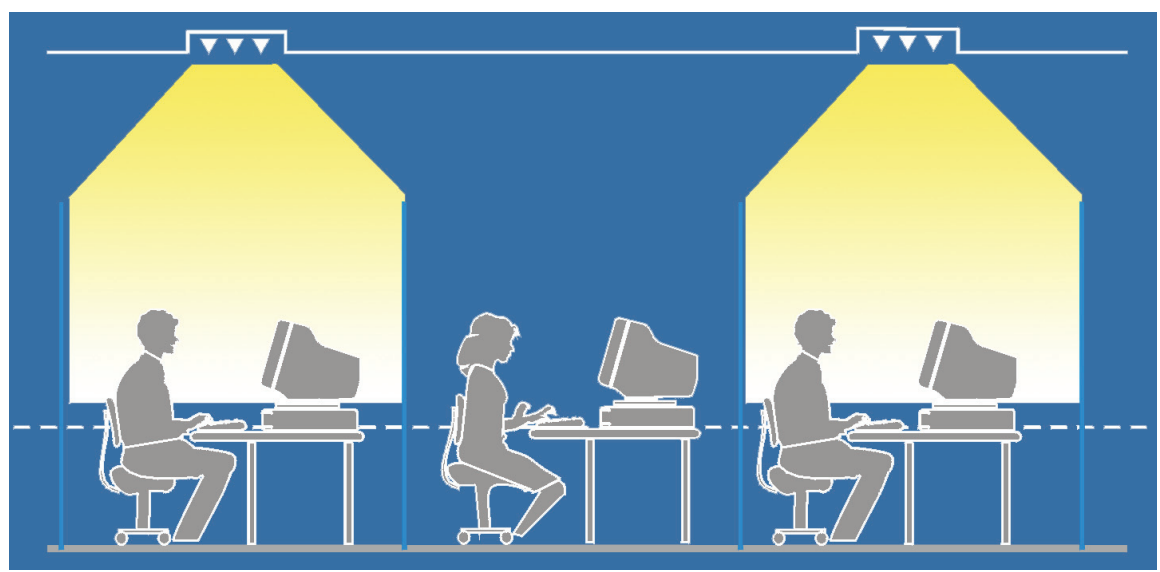

Spacing criterion does not account for partial height partitions.

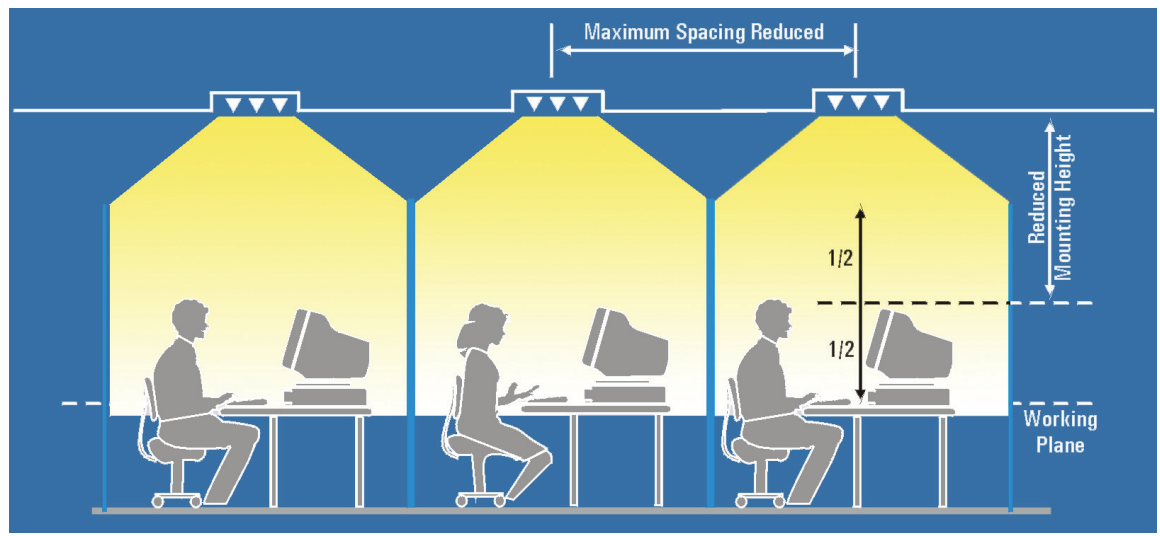

Adjusted spacing criterion and mounting height to accommodate partitions.

Figure 9.12.6. Lighting uniformity and fixture spacing criteria. 
When considering a retrofit or redesign, it is important to keep in mind the importance of the quality of the lighting in a space. Lighting quality is just as important, and oftentimes more so than quantity of illumination. The IESNA Handbook, Ninth Edition, Chapter 10, contains lighting design guides for a wide range of space functions. These outline the most important qualitative needs, as well as the recommended light levels for each function.

- Uniformity - There should not be a wide range of differences between the highest and lowest brightness in the space. The existence of partial height furniture partitions may significantly reduce uniformity, requiring a closer spacing or wider distribution of luminaires. Avoid harsh shadows or patterns (see Figure 9.12.6).

- Spacing Criterion - Manufacturers provide the maximum spacing between luminaires that will maintain acceptable uniformity. However, this "spacing criterion" assumes that a room is unobstructed. If a room has partial height furniture partitions, tall files, or other obstructions, the spacing criterion should be reduced by a factor of 0.75 to 0.85 .

- Lighting Walls and Ceilings - The perception of occupants that the lighting is too bright, comfortable, or too dim is based more on the brightness of the room surfaces and vertical partitions than that of the task or desktop. A lighting system should be designed to distribute light to the walls and ceilings as well as the task. A light colored room can increase light levels as much as $20 \%$ over a dark colored room. Cleaning the wall surfaces improves efficiency, especially in a "dirty" environment, but repainting a wall with a lighter color will show much greater improvement.

- Glare - Excessive contrasts in light cause glare. It most often occurs when a bright light source (including windows) interfere with the viewing of less bright objects. Existing conditions of glare can be mitigated, or glare prevented in retrofits, by some of the following recommendations:

- Shield the lamp from view with baffles, louvers, lenses, or diffusing overlays. Use only semispecular or white painted louvers and reflectors.

- Increase the reflectances of room surfaces by using lighter colored paints and fabrics in a matte or eggshell finish.

- Use low output (high-efficiency) lamps in the field of view. T5HO lamps are very bright and best used in indirect applications.

- Decrease the contrast between fixtures and ceilings by adding uplight or selecting luminaires with an uplight component.

- Color - For almost any task, color discrimination aids visibility. Light sources are typically described by their "correlated color temperature (CCT)" and their color rendering index (CRI). For most workplaces, use fluorescent lamps in the 80 to 85 CRI range, and metal halide lamps at 80 and higher. For most workspaces, CCT between 3500 and 4100 are acceptable. For reference, 3000 Kelvin CCT is warm, $3500 \mathrm{~K}$ is neutral, and $4100 \mathrm{~K}$ and higher become increasingly cool in appearance. Sunlight is in the 4000 to $6000 \mathrm{~K}$ range, and daylight is in the 5000 to $10,000 \mathrm{~K}$ range. 


\subsubsection{Energy Codes}

The current energy code applicable to all Federal buildings is 10 CFR 434 ("Energy Code for New Federal Commercial and Multi-Family High Rise Residential Buildings"). This code is similar in requirements to the ANSI/ASHRAE/IESNA 90.1-2001 standard for commercial buildings (ANSI/ ASHRAE/IESNA 2001). It is expected to be upgraded to reference the current standard, which has limits on connected load up to $30 \%$ more stringent. This will have a big impact on major renovations in Federal facilities. The lighting portion of the energy code has three components - determination of a whole project interior lighting power allowance, determination of an exterior power allowance, and mandatory requirements for lighting controls and exterior lamp efficiencies.

\subsubsection{Maintenance Procedures}

\subsubsection{Commissioning}

"Commissioning" is defined as the entire process of quality assurance of a lighting system that begins with proper design and specifications, and concludes with calibration, fine tuning, aiming, documentation, monitoring, and verification and that the system operates and saves energy as intended, and is acceptable to the occupants. Even if a lighting system was carefully commissioned prior to occupancy, certain components of it should be recommissioned at intervals ranging from 2 to 5 years to ensure that it is operating as intended. In addition, as tasks or occupants change within the building, lighting controls and even some light levels may need adjustment. The specific lighting related recommendations below pertain equally to commissioning or recommissioning - to the initial design, or to any retrofit, upgrade, or redesign of the lighting system.

\section{Lighting Efficiency Considerations} (UNEP 2006)

- Reduce excessive illumination levels to standard levels using switching, delamping, etc. (Know the electrical effects before doing delamping.)

- Aggressively control lighting with clock timers, delay timers, photocells, and/or occupancy sensors.

- Install efficient alternatives to incandescent lighting, mercury vapor lighting, etc. Efficiency (lumens/watt) of various technologies range from best to worst approximately as follows: low pressure sodium, high pressure sodium, metal halide, fluorescent, mercury vapor, incandescent.

- Select ballasts and lamps carefully with high power factor and long-term efficiency in mind obsolete fluorescent systems to Compact fluorescents and electronic ballasts.

- Consider lowering the fixtures to enable using less of them.

- Consider day lighting, skylights.

- Consider painting the walls a lighter color and using less lighting fixtures or lower wattages.

- Use task lighting and reduce background illumination.

- Re-evaluate exterior lighting strategy, type,and control. Control it aggressively.

- Change exit signs from incandescent to LED.

- A commissioning plan contains the following elements: design intent, design features, calibration levels, methods of verification, documentation requirements, schedules, and checklists.

- Establish schedules for relamping, cleaning, recalibration, and reevaluation of the lighting system.

- Intervals for recommissioning should be based on the type of equipment. See lighting controls below. 
- Specify that the ballasts and lighting controls be factory pre-set to the greatest extent possible. This shall not remove the responsibility from the contractor for field calibration if it is needed. Specify calibration levels to the extent they can be known prior to installation.

- Aiming - Some lighting equipment is sensitive to orientation, such as spotlight, wall washers, and occupancy sensors. A "pre-aiming diagram" can be specified or requested prior to installation, so that the contractor can make reasonable adjustments to the equipment during the initial installation.

- Calibration - If calibration settings were not specified initially, the facility manager should contact the manufacturer of control equipment directly for assistance.

- Ensure that the commissioning is complete PRIOR to building occupancy. Even a few days of an improperly calibrated control device can turn occupants against the system, resulting in huge energy waste.

\subsubsection{Common Causes of Poor Performance}

Some maintenance items such as swirling lamps or inoperable ballasts are obviously in need of immediate attention and repair (see troubleshooting below).

Of more serious concern are systems that are improperly calibrated or not being maintained on a planned basis resulting in energy waste and/or poor lighting quality. These hidden factors include:

- Dirt accumulation on luminaires or room surfaces that has significantly reduced light output.

- Older lamps that have not burned out but output fewer lumens than the system design assumptions.

- Lamps that are still operating, but have passed their "useful" life, such as metal halides and LEDs.

- Dimming or stepped ballasts that are miswired or failed by defaulting to full output.

- Controls that were never properly calibrated or have fallen out of correct calibration.

- Controls or power packs that have failed and defaulted to continuous on.

- Motion sensors or light sensors that have been disabled by the occupants.

- Controls that have been overridden or disabled (rather than recalibrated) by the building staff in response to complaints.

\subsubsection{Cleaning}

The intent of cleaning lamps, luminaries, and room surfaces is to return them to their original condition recovering any interim losses in light output. It is important to use the proper cleaning compounds and strategies, so that luminaire surfaces are not damaged. Different surfaces require different cleaning compounds. In lieu of manufacturer's instructions, the following represents some guidance. 
- Never clean lamps that are operational or still hot.

- Use very mild soaps and cleaners, followed by a clean rinse on most surfaces. Silver films require the mildest $0.5 \%$ solution and a soft damp cloth. Avoid strong alkaline cleaners or abrasives cleaners.

- Glass cleaners may be used on porcelain or glass but the latter requires an additional clear rinse.

- To avoid static charge on plastics, use anti-static cleaning compounds. Do not dry-wipe plastic after a rinse, as this will create an electrostatic charge. Drip-drying creates streaks. Vacuuming is the best method for drying plastics.

\subsubsection{Lamp and Ballast Troubleshooting}

The most common problems associated with lamps and ballasts are:

- Lamps will not light or start erratically or slowly.

- Premature failure or lamp life shorter than expected.

- Deposits, discoloration, dark spots, or streaks of the lamps.

- Blinking, swirling, fluttering, spiraling, unexpected dimming.

- Light output or color degradation sooner that expected.

- Blistering/bulging on the bulb.

- Lamp cycling on and off.

- Ballast noise.

The Illuminating Engineering Society of North America (IESNA) and the interNational Association of Lighting Management Companies (NALMCO) have developed a joint publication titled Recommended Practice for Planned Indoor Lighting Maintenance (IESNA/NALMCO RP-36-03). It contains troubleshooting guidance for incandescent, fluorescent, and HID lamps and ballasts. This material is excerpted from troubleshooting guides originally published in Illuminations, a NALMCO publication. It is available electronically or as a publication at www.iesna.org. 


\subsubsection{Lighting Controls Calibration and Troubleshooting}

\section{Calibration}

Evaluate lighting controls annually to determine if they are in need of recalibration see Figure 9.12.7. Seek advice from manufacturers of controls. Document all settings and dates of recalibration. Seek the optimum balance between energy savings and occupant satisfaction. For some strategies, like daylighting controls, calibrations strategies vary widely by manufacturer.

\begin{tabular}{|c|c|c|}
\hline Control Type & Calibration $^{(a)}$ & Notes \\
\hline Occupancy sensors ceiling-mounted & $\begin{array}{l}\text { Time delay: } 15 \text { minutes } \\
\text { Sensitivity: Medium high }\end{array}$ & 1,2 \\
\hline Wall-box occupancy sensors & $\begin{array}{l}\text { Manual-on Auto-off } \\
\text { Time delay: } 15 \text { minutes } \\
\text { Sensitivity: Medium }\end{array}$ & 1,3 \\
\hline Daylight dimming & $\begin{array}{l}\text { High illuminance before dimming begins } \\
\text { Time delay: } 5 \text { minutes } \\
\text { Fade rate: } 1 \text { minute } \\
\text { Sensitivity: See manufacturer }\end{array}$ & 4 \\
\hline Daylight switching & $\begin{array}{l}\text { Time delay: } 10 \text { minutes } \\
\text { Dead band: } 15 \text { footcandles } \\
\text { Sensitivity: See manufacturer }\end{array}$ & 5 \\
\hline Manual dimming & High end trim at $95 \%$ (incandescent only) & 6 \\
\hline Automatic dimming & $\begin{array}{l}\text { Time delay } \\
\text { Fade rate }\end{array}$ & 7 \\
\hline Pre-set dimming & $\begin{array}{l}\text { Time delay } \\
\text { Fade rate }\end{array}$ & 7 \\
\hline $\begin{array}{l}\text { Automatic timers } \\
\text { Astronomical time clocks }\end{array}$ & $\begin{array}{l}\text { On and off times, differ for weekends, holidays. Multiple } \\
\text { settings depend on space function and occupancy. } \\
\text { Daylight savings }\end{array}$ & 8 \\
\hline \multicolumn{3}{|c|}{$\begin{array}{l}\text { a) Start with these settings and adjust upward and downward as required. (1) Time delays shorter than } 15 \text { minutes are likely to shorten lamp life unless programmed } \\
\text { ballasts are installed. (2) Wire ceiling sensors to an automatic or Sentry-type switch for manual on operation. (3) Ensure that occupancy sensors can be set to manual } \\
\text { "on" without over-riding the automatic off functionality. (4) Set the illuminance level } 20 \% \text { to } 30 \% \text { higher than the designed light level for the electric lighting. Thus, } \\
\text { if } 30 \text { footcandles of electric light is provided, lamps should not start to dim until the daylight and electric light together provide } 36 \text { to } 39 \text { footcandles on the desktop. } \\
\text { (5) Photosensor controlled switching or multi-level switching (sometimes called stepped dimming) is seldom acceptable to occupants in full time work environments. } \\
\text { Set a wide "dead-band" of at least } 15 \text { footcandles to prevent cycling. (6) Slightly reducing the maximum light output of an incandescent lamp extends lamp life. It is } \\
\text { not recommended for halogen lamps and is not effective with fluorescent sources. (7) Settings will depend on specific application. Time delays and fade rates are } \\
\text { not recommended for pre-sets that are controlled by the occupants (rather than part of an automated program or AV sequence) because if the occupants do not see an } \\
\text { immediate response, they often repeatedly turn lights on and off or try other pre-sets. (8) More energy is saved by tailoring the timeclocks more closely to the specific } \\
\text { spaces being controlled and by providing more discrete schedules, i.e., one for Saturday and one for Sunday, rather than the same for the weekend. }\end{array}$} \\
\hline
\end{tabular}

Figure 9.12.7. Calibrations for controls

\section{Troubleshooting}

Occupancy sensors turn lights "on" when they are not needed. Is the sensor responding to movement in the corridor outside the office, currents from the air diffusers, or it is causing the lights to burn even when daylight is sufficient or preferred. Ultrasonic sensors are more prone to false on, but less prone to false offs, because they are more sensitive to subtle movement like occupants typing or writing.

- Start with adjusting (reducing) the sensitivity setting slightly, reducing the sensors sensitivity to motion, without creating a problem with false offs.

- If the occupants are agreeable, setting the sensor to manual "on" operation (if it is connected to, or integral with, a local switch) is the most energy efficient and increases lamp life.

- Mask the sensor so that it does not "see" motion outside the room. 
Occupancy sensors turn lights "off" when occupants are still in the space.

- Check to confirm that sensor is not in test mode.

- Increase the sensitivity setting.

- Increase the time delay, but not longer than 30 minutes.

- Consider replacing infrared sensor with more sensitive ultrasonic sensors.

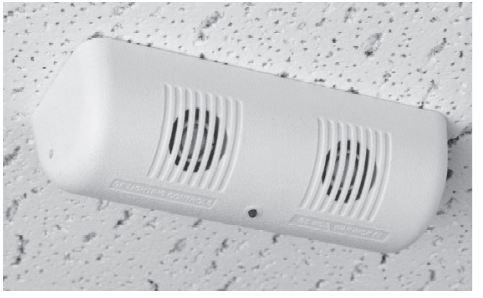

Figure 9.12.8. Ceiling occupancy sensor.

- Evaluate the number and distribution of the existing sensors and verify if the coverage is sufficient. (Partial height partitions and other vertical obstructions must be taken into consideration.)

\section{Daylighting controls dim the lights too much.}

- Verify light levels. If they meet design criteria, the problem may be one of window glare or excessive contrast. Verify that blinds are adequate to control glare. Diffuse shades may be too bright when sun hits them.

- Maximize the "fade rate." Dimming should be smooth and continuous and not perceptible to the occupants. Verify with manufacturer that product has a "continuous" dimming response, not a "threshold" dimming response. The latter is appropriate for spaces like warehouses, but not for offices or spaces with stationary workers.

- Increase time delay to 10 minutes so that lights do not respond to sudden changes like cloud movements near the sun, or people walking under the photosensor.

- Verify that the photocell is properly located over a space that does not change from day to day, like the carpet of aisles between cubicles or an unadorned wall. A photocell over a desktop will respond to the objects on a desk or the occupants clothing, and may dim lights more on days that the occupant wears a white shirt.

- Re-calibrate the photosensor at night and again during hours of daylight. Follow manufacturer's procedure.

\section{Fluorescent lamps flicker when dimming ballasts are at the lowest end of the dimming range.}

- Consult the ballast manufacturer and verify wiring is correct.

- Replace the ballasts.

- If the problem is extensive or attributable to the signal sent by the photosensor, increase the lowest setting, but not higher than 30\%.

\subsubsection{Diagnostic Tools}

Unlike many HVAC systems and components, lighting equipment and systems tend to be fairly stable once installed and commissioned. Diagnostics is, therefore, generally applicable only periodically or when building needs change. However, when initiating any O\&M program or assessment of building energy "health," it is important and can be very profitable to evaluate lighting conditions and equipment. 
Generally, the diagnostics of lighting systems involves the evaluation of the basic characteristics of lighting:

- Quality and quantity of light.

- Equipment types and efficiency, condition, and cleanliness.

- Control condition/settings.

- Energy usage.

For some of these characteristics, visual inspection and physical testing is appropriate and requires no special tools. For others some basic tools can be helpful.

Illuminance (light) meter - Illuminance meters are often referred to as a "light meters" which is a generic term that also includes the meters used by photographers (which is not what is needed for building lighting). Illuminance meters come in many styles at a range of costs. Most will do an adequate job of evaluating basic light levels in building spaces. Light levels should be taken at the spaces where the specific tasks are to be performed such as desktops for office work, hallway floors for egress, etc.

Light levels will change over time as lamps age. However, with modern equipment this is a relatively slight effect and is not typically considered a metric used to make changes to equipment or replace lamps. The most important measurement of light levels is an evaluation when systems are initially installed, equipment changes are made, or an O\&M program is initiated. Light levels that are higher than necessary to provide appropriate lighting or higher than designed are an opportunity for energy savings as light level and kWh usage are directly related.

The required light levels (illuminance) for building areas will depend on the expected tasks. The widely accepted and referenced quality and illuminance recommendations are developed by the Illuminating Engineering Society of North America (IESNA), and can be found in Chapter 10 of the IESNA Handbook, Ninth Edition. The building tenants or other regulatory organizations may also have specific requirements for the activities to be performed in the building.

Energy/lighting/occupancy loggers - Measurements of individual lighting fixtures or panels can provide specific lighting power information that if tracked over time can help identify controls savings opportunities. However, the equipment to support these continuous measurements can be expensive to install and maintain. Less costly options that provide similar useful results are individual lighting loggers than can measure lighting on/off schedules for long periods of time with the capability to download the data to any computer for analysis. This kind of data can identify areas where lighting is left on after hours. Similar occupancy based loggers can specifically identify lighting that remains on when spaces are unoccupied. This information can be used to identify overlit spaces as well as good applications for occupancy sensor controls. These loggers are available from a variety of sources. These can be found on the world-wide web or in the report, Portable Data Loggers Diagnostic Tools for Energy-Efficient Building Operations (PECI 1999).

Flicker checker - For hard-to-reach areas (high ceilings), it is often difficult to determine the type of lighting installed (electronic, magnetic ballast). There is a simple tool available to help determine the characteristics of ballast type (and therefore often lamp type) installed. A common version of this tool is a "flicker checker" used to determine electronic versus electromagnetic ballasts 
available from Sylvania (1-800-544-4828). It operates like a simple toy top and will indicate whether the operating ballast above is a $60 \mathrm{~Hz}$ type or electronic high frequency type. Typically the $60 \mathrm{~Hz}$ type will be operating T12 technology lamps. The high frequency may be operating T12 or T8 technology.

Solar data - When considering the application of daylighting into building spaces, it is important to understand the potential of the building space and the capability of the sun in your area to provide adequate daylight. This involves evaluating the tasks in the space, characterizing the configuration of the space including size and shape of windows or skylights, and assessment of the solar availability in your location. Solar availability data is maintained by the National Oceanographic and Atmospheric Association (NOAA) at www.noaa.gov. Available data includes number of hours of sunshine, number of clear, overcast, and partially cloudy days in a number of cities across the United States based on weather charts. Exterior illumination of sun and daylight can be found for any U.S. latitude through the IESNA daylight availability publication or the ASHRAE handbook. Sun angles can be determined by the Pilkington LOF Sun Angle Calculator, available from www.sbse.org/resources/sac/.

\subsubsection{Economics}

Operations and maintenance activities and equipment represent real costs to a facility and must be evaluated like any other proposed action.

Some potential actions can be evaluated using simple methods to provide appropriate costeffectiveness analysis such as the replacement of incandescent exit signs with reduced-wattage LED signs. The cost of energy saved is easy to calculate based on the wattage difference, 24-hour operation, and local utility rates. The cost of the new exit sign divided by the cost savings provides a simple measure of the time required to pay off the new sign with energy savings (payback period). This is often all that is needed to determine whether the replacement is a good idea.

In other cases, more complicated analysis is required. Large cost items such as more advanced control systems may require longer term investment spanning many years. These types of investment decisions will often require more comprehensive cost analysis that involves more parameters to determine their cost-effectiveness. These often include:

- Installation costs

- Equipment life

- Replacement equipment cost

- Replacement labor

- Interest rate

- Fuel cost

- Fuel escalation rates.

With more advanced resulting analysis metrics such as:

- Return on investment

- Life-cycle cost. 
Software tools are available from many sources to perform this type of analysis. The Federally supported Building Life Cycle Cost (BLCC5) tool for advanced economic analysis is one such tool that is available from the USDOE at www.eere.energy.gov/femp/information/download_blcc.cfm.

\subsubsection{Lighting Checklist}

\begin{tabular}{|c|c|c|}
\hline Description & Comments & Maintenance Frequency \\
\hline Visual inspection & $\begin{array}{l}\text { Inspect fixtures to identify inoperable } \\
\text { or faulty lamps or ballasts. Burned- } \\
\text { out lamps may damage ballasts if not } \\
\text { replaced. }\end{array}$ & Weekly to monthly \\
\hline Visual inspection & $\begin{array}{l}\text { Inspect fixtures and controls to } \\
\text { identify excessive dirt, degraded lenses, } \\
\text { inoperable or ineffective controls. }\end{array}$ & Semi-annually \\
\hline Clean lamps and fixtures & $\begin{array}{l}\text { Lamps and fixture reflective surfaces } \\
\text { should be cleaned periodically for } \\
\text { maximum efficient delivery of light to } \\
\text { the space }\end{array}$ & $\begin{array}{l}6 \text { to } 30 \text { months, depending on space } \\
\text { and luminaire type }\end{array}$ \\
\hline Clean walls and ceilings & $\begin{array}{l}\text { Clean surfaces allow maximum } \\
\text { distribution of light within the space }\end{array}$ & $\begin{array}{l}1 \text { to } 3 \text { years, depending on dirtiness of } \\
\text { environment }\end{array}$ \\
\hline Replace degraded lenses or louvers & $\begin{array}{l}\text { Replace yellowed, stained, or broken } \\
\text { lenses or louvers }\end{array}$ & As identified \\
\hline Repaint walls and replace ceilings & $\begin{array}{l}\text { Lighter colored surfaces will increase } \\
\text { light distribution efficiency within the } \\
\text { space }\end{array}$ & As identified or at tenant change \\
\hline Replace burned out lamps & $\begin{array}{l}\text { For larger facilities consider group } \\
\text { relamping }\end{array}$ & As needed or on group schedule \\
\hline $\begin{array}{l}\text { Evaluate lamps and ballasts for } \\
\text { potential upgrade }\end{array}$ & $\begin{array}{l}\text { Rapid change in technology may } \\
\text { result in significant savings through } \\
\text { relamping or simple retrofit. }\end{array}$ & $\begin{array}{l}\text { Every five years or on group relamping } \\
\text { schedule }\end{array}$ \\
\hline Survey lighting use/illumination levels & $\begin{array}{l}\text { Measure light levels compared to } \\
\text { tasks needs in typical spaces. Identify } \\
\text { areas for reduction or increase in } \\
\text { illuminance }\end{array}$ & Initially and at task/tenant change \\
\hline Survey for daylighting capability & $\begin{array}{l}\text { Identify areas where daylighting } \\
\text { controls could be used }\end{array}$ & One-time analysis or at tenant change \\
\hline Survey for local controls capability & $\begin{array}{l}\text { Identify areas where local automatic } \\
\text { controls could be used }\end{array}$ & Initially and at tasks/tenant change \\
\hline
\end{tabular}




\subsubsection{References}

10 CFR 434. U.S. Department of Energy. "Energy Code for New Federal Commercial and MultiFamily High Rise Residential Buildings." U.S. Code of Federal Regulations.

40 CFR 273. U.S. Environmental Protection Agency. "Standards for Universal Waste Management." U.S. Code of Federal Regulations.

Advanced Lighting Guidelines, New Buildings Institute, 2003, available from www.nbi.org.

ANSI/ASHRAE/IESNA. 2001. Energy Standard for Buildings Except Low-Rise Residential Buildings, ASHRAE/IESNA Standard 90.1-2001 American Society of Heating, Refrigeration and AirConditioning Engineers (ASHRAE).

Daylight Design - Smart and Simple, Electric Power Research Institute (EPRI) TR-109720, 1997, available from www.iesna.org.

DDC Lighting Handbook. 2004. New York City Department of Design and Construction.

IESNA Guidelines for Upgrading Lighting Systems in Commercial and Institutional Spaces (LEM-3-07), available at www.iesna.org.

Levin, R.E., W.E. Bracket, N. Frank, J. Burke. 2002. "Field study of luminaire dirt depreciation." Journal of the IES 31(2):26.

Lighting Controls - Patterns for Design, Electric Power Research Institute (EPRI) TR-107230, 1996, available from www.iesna.org.

PECI. 1999. Portable Data Loggers Diagnostic Tools for Energy-Efficient Building Operations. Prepared for the U.S. Environmental Protection Agency and U.S. Department of Energy by Portland Energy Conservation, Incorporated, Portland, Oregon.

Recommended Practice for Planned Indoor Lighting Maintenance (IESNA/NALMCO RP-36-03). Joint publication of the Illuminating Engineering Society of North America (IESNA) and the interNational Association of Lighting Management Companies (NALMCO), available from www.iesna.org.

Toxic Substances Control Act. 15 USC § Z601 et. seq. (1976).

UNEP, 2006. Energy Efficiency Guide for Industry, 2006. United Nations Environmental Program. Washington, D.C. 



\section{Chapter 10 O\&M Frontiers}

As old a topic as O\&M is, there are a number of new technologies and tools targeting the increased efficiency of O\&M. As with most new technology introduction, these tools are in various stages of commercialization; for up-to-date information on each tool, contact information is provided in this chapter.

As previously mentioned, we are not able to provide a detailed description of all tools and technologies available. What we do provide are some of the more common tools that are currently commercially available. To locate additional resources, the authors recommend contacting relevant trade groups, databases, and the world-wide web.

\subsection{ACRx Handtool/Honeywell HVAC Service Assistant}

Developed by Field Diagnostic Services, Inc., the "HVAC Service Assistant" tool was designed to provide advanced diagnostics for rooftop and packaged HVAC equipment. The tool combines a handheld PDA and multiple pressure/temperature gauges into a single tool that provides expert diagnostic analysis of HVAC equipment to the service technician. This unit automates the detection and diagnosis of problems difficult to identify in compressors, heat exchangers, and expansion valves, as well as calculating the impact of the defect on the efficiency and capacity of the unit - expressing as the potential energy savings that can be achieved through effective implementation of the suggested diagnosis. The product also provides detailed reporting of all activity performed on the unit and can be used to ensure quality of service from the contractor/maintenance staff. Some of the tool features and applications are listed below - for the most current information we suggest contacting the company directly.

\section{Tool features:}

- Automated data collection

- Integrated fault detection

- Calculation and display of system efficiency and capacity

- Detailed Quality of Service and Return on Investment reporting

\section{Tool Applications:}

- Packaged cooling systems including roof-top units

- Split systems/residential and commercial air conditioning

- Cooling and heat side of heat pump systems

- Commissioning and tune-ups of all of the above units

For more information about the HVAC Service Assistant Contact Field Diagnostics at: (267) 583-6330 Ext 10 or dlamb@fielddiagnostics.com http://www.fielddiagnostics.com/serviceassistant.cfm 


\subsection{Decision Support for O\&M (DSOM ${ }^{\circledR}$ )}

The DSOM tool is a condition-based O\&M hardware and software program designed to provide facility staff with intuitive actions to implement efficient, life-cycle asset management. DSOM was developed by researchers at the U.S. Department of Energy's Pacific Northwest National Laboratory (PNNL).

Based on the concept of condition-based management, DSOM focuses on finding the balance between high-production rates, machine stress, and failure. DSOM allows online condition monitoring of equipment and provides early warning signs of degraded performance. DSOM's diagnostic capabilities empower the operations staff to become the first line of maintenance. Moreover, a customized, integrated database, and intuitive access system provide the information all staff need to make informed decisions about how to operate their plant more effectively. Dramatic savings are achievable because DSOM (1) improves process efficiency, (2) cuts maintenance costs, (3) extends equipment life, and (4) reduces energy consumption and associated harmful emissions.

The DSOM technology was developed under government research funding from the U.S. Department of Energy. In 1994, it was installed at the central heating plant of the Marine Corps' Air Ground Combat Center in Twentynine Palms, California. Implementation at Twentynine Palms established proof of principle and verification of value. Recent installations have been completed at Marine Corp Recruiting District Parris Island, the Aberdeen Proving Grounds and a large metropolitan public housing project. Some of the tool features and applications are listed below - for the most current information we suggest contacting the company directly.

\section{Tool features:}

- On-line condition monitoring

- Integrated diagnostics and fault detection

- Real-time notification of degradation and inefficiency

\section{Tool Applications:}

- Heating, ventilation, air conditioning systems

- Central plants

- Single building, campus and multiple building/process facilities

For more information about DSOM

Contact Darrel Hatley (509) 375-2136

www.pnl.gov/dsom/

\subsection{ENFORMA ${ }^{\circledR}$ Portable Diagnostic Solutions}

ENFORMA Building Diagnostics (EBD) utilizes data from an existing building automation system (BAS) to continuously and automatically identify energy inefficiencies and their financial impacts. EBD has automated the manual performance analysis process with algorithms designed to identify problems often undetected by traditional methods and/or BAS monitoring. Some of the tool features and applications are listed below - for the most current information we suggest contacting the company directly. 


\section{Tool features:}

- Automated data collection via existing BAS

- Integrated fault detection

- Automated notification of inefficiencies and accompanying diagnostics

Tool Applications:

- Heating, ventilation, air conditioning systems

- Single building, campus and multiple BAS environments

For more information about ENFORMA

Contact Architectural Energy Corporation at: (303) 444-4149

www.enformadiagnostics.com

\subsection{Performance and Continuous Re-Commissioning Analysis Tool (PACRAT)}

PACRAT is a versatile diagnostic tool developed by Facility Dynamics Engineering to detect problems with HVAC equipment. This tool is designed to provide automated diagnostic capabilities for air handlers, zone distribution systems, chillers, hydronic systems, and whole-building energy use. PACRAT makes use of time-series data collected by existing energy management and control systems (EMCS), utility meters or other data-logging equipment. Once collected, the data are processed making use of an extensive automation of expert rules to assess HVAC system performance (Friedman and Piette 2001). PACRAT is designed to calculate and report deviations from baseline operation and estimate the resulting cost of wasted energy. Some of the tool features and applications are listed below - for the most current information we suggest contacting the company directly.

\section{Tool features:}

- Automated data collection via existing EMCS, utility meters, or data loggers

- Calculates key system parameters, loads, energy use, indoor air quality, etc.

- Diagnoses system problems including poor performance and energy waste.

\section{Tool Applications:}

- Whole building and systems (HVAC) applications

- Single building, multi-building and campus environments

For more information about PACRAT

Contact E. Lon Brightbill (410) 290-0900

www.facilitydynamics.com 


\subsection{Energy Expert}

The Energy Expert is a software application making use of data collected by utility interval meters, an EMCS or other data logging devices, to develop building diagnostics and performance indicators. This application processes the data and then trains itself to create a "smart model" of a building. Once developed, this model compares daily energy use against the model to determine if the facility has over-consumed, under-consumed, or used the expected amount of energy. The Energy Expert provides daily scorecards to show energy use, cost savings, load profiling, etc. Some of the tool features and applications are listed below - for the most current information we suggest contacting the company directly.

\section{Tool features:}

- Automated data collection via existing EMCS, utility meters, or data loggers

- Develops data-based building model for performance comparison and diagnostics

- Provides email/pager notification of anomalies

- Enterprise roll-up of multiple facilities

\section{Tool Applications:}

- Whole building and system applications

- Single building, multi-building and campus environments

For more information about the Energy Expert

Contact Patrick O’Neill (877) 743-4232

www.energyworksite.com

\subsection{Reference}

Friedman, H. and M.A. Piette. 2001. Comparative Guide to Emerging Diagnostic Tools for Large Commercial HVAC Systems. LBNL No. 48629, Lawrence Berkeley National Laboratory, Berkeley, California. 


\section{Chapter 11 Ten Steps to Operational Efficiency}

Step 1: Strive to increase management awareness and appreciation of the operations and maintenance program/department.

- Consider developing a maintenance mission statement and requesting/requiring management sign-off.

- Consider developing a maintenance plan and requesting/requiring management sign-off.

- Begin the development of the OMETA linkages.

- Develop key points of contact within other departments that can participate in the O\&M mission.

Step 2: Commit to begin tracking Operations and Maintenance activities.

- Need to understand where O\&M time is spent.

- Need to understand where O\&M dollars are spent.

- Consider (strongly) purchasing or enhancing a Computerized Maintenance Management System and commit to its implementation and use.

Step 3: Through tracking begin to identify your troubled equipment and systems.

- Make a list of these systems and prioritize them.

Step 4: Commit to addressing at least one of these troubled systems.

- Begin base-lining/tracking this system.

- System operations and history.

- System maintenance and history.

- System costs, time to service, downtime, resulting overtime, etc.

Step 5: Commit to striving for Operational Efficiency of this system.

- Strive to understand how to properly operate this system.

- Define and complete operator training needs.

- Strive to understand how to properly maintain this system.

- Define and complete maintenance training needs.

Step 6: Commit to purchasing or contracting for some form(s) of diagnostic, metering, or monitoring equipment.

Step 7: Commit to trending the collected tracking and diagnostic data. 
- Take to time to understand the data.

- Look for and develop "project opportunities."

- Develop appropriate cost justification metrics.

Step 8: Select, request funding for, and complete first "Operational Efficiency" project.

- Start small, pick a project that will be a winner.

- Carefully document all findings.

- Present success in terms management will understand.

Step 9: Strive to highlight this success - capitalize on visibility opportunities.

- Consider writing an internal success story/case study.

- Submit finding to trade publication or industry conference.

Step 10: Commit to choosing the next piece of equipment...go to Step 3.

- Steps 1 and 2 are ONGOING ACTIVITIES! 


\section{Appendix A}

Glossary of Common Terms 



\section{Appendix A}

\section{Glossary of Common Terms}

Absorption chiller - A refrigeration machine using heat as the power input to generate chilled water.

Adjustable speed drive - A means of changing the speed of a motor in a step-less manner. In the case of an $\mathrm{AC}$ motor, this is accomplished by varying the frequency.

Aerator - A device installed in a faucet or showerhead that adds air to the water flow, thereby maintaining an effective water spray while reducing overall water consumption.

Air changes - Replacement of the total volume of air in a room over a period of time (e.g., 6 air changes per hour).

Ambient temperature - The temperature of the air surrounding an object.

Ballast - A device used to supply the proper voltage and limit the current to operate one or more fluorescent or high-intensity discharge lamps.

Base - A selected period of time with consumption levels or dollar amounts, to which all future usage or costs are compared.

Blackwater - Water discharged from toilets, urinals, and kitchen sinks.

BLCC - Building Life Cycle Costing.

Blowdown - The discharge of water from a boiler or a cooling tower sump that contains a high proportion of total dissolved solids.

British thermal unit (Btu) - The amount of heat required to raise the temperature of one pound of water 1 degree Fahrenheit at or near 39.2 degrees Fahrenheit.

Building commissioning - A systematic process of assuring that a building facility performs in accordance with design intent and the owner's operational needs. Verification and documentation that all building facility systems perform interactively in an efficient manner and that operations and maintenance personnel are well trained.

Building envelope - The exterior surfaces of a building that are exposed to the weather, i.e., walls, roof, windows, doors, etc.

Cavitation - A condition occurring when the inlet pressure at the pump is less than the vapor pressure of the liquid being pumped, causing the liquid to vaporize into bubbles in the suction stream. The bubbles collapse on entering the pump housing with the rotating impeller, preventing the pump from effectively moving the liquid. This creates the very distinct sound of marbles being shaken in a tin can. Each pump has its own characteristic net positive suction head (NPSH) required to prevent this condition.

O\&M Best Practices Guide, Release 3.0 
Cell - The smallest cooling tower subdivision with independent air and water flow. It is enclosed by exterior walls or partition walls. Each cell may have one or more fans and one or more distribution systems.

Chilled Water Reset Schedule - An automated control logic that raises or lowers the supply temperature of the chilled water leaving the chiller, in response to another variable such as outside air temperature.

Celsius (Centigrade) - The temperature at which the freezing point of water is 0 degrees and the boiling point is 100 degrees at sea level.

Centrifugal fan - A device for propelling air by centrifugal action.

cfm - Cubic feet per minute usually refers to the volume of air being moved through an air duct.

Chiller - A refrigeration machine using mechanical energy input to drive a centrifugal compressor to generate chilled water.

Coefficient of performance - Ratio of tons of refrigeration produced to energy required to operate equipment.

Coefficient of utilization - Ratio of lumens on the work surface to total lumens emitted by the lamps.

Coils - Coils are used to heat and cool an airstream by transferring heat from or to another medium. They can be bare-tube type or have an extended fin surface. Coils may use water, steam, refrigerant, or electricity as a source for heat transfer.

Cold deck - A cold air chamber forming a part of an air conditioning system.

Combined wastewater - A facility's total wastewater, both graywater and blackwater.

Compressor - A mechanical device used to compress a gas.

Color rendering index (CRI) - The color appearance of an object under a light source as compared to a reference source.

Condensate - Water obtained by charging the state of water vapor (i.e., steam or moisture in air) from a gas to a liquid usually by cooling.

Condenser - A heat exchanger which removes heat from vapor, changing it to its liquid state. In refrigeration systems, this is the component which rejects heat.

Conduction - Method of heat transfer in which heat moves through a solid.

Convection - Method of heat transfer in which heat moves by motion of a fluid or gas, usually air.

Cooling tower - A device that cools water directly by evaporation.

Damper - A device used to limit the volume of air passing through an air outlet, inlet, or duct. 
Degree days - The degree day for any given day is the difference between 65 degrees and the average daily temperature. For example, if the average temperature is 50 degrees, the degree days is $65-50$ $=15$ degrees days. When accumulated for a season, degree days measure the severity of the entire season.

Demand load - The maximum continuous requirement for electricity measured during a specified amount of time, usually 15 minutes.

Demand factor - The ratio of the maximum demand of a system to the total connected load on the system.

Double bundle chiller - A condenser usually in a refrigeration machine that contains two separate tube bundles allowing the option of rejecting heat to the cooling tower or to another building system requiring heat input.

Dry bulb temperature - The measure of the sensible temperature of air.

Economizer cycle - A method of operating a ventilation system to reduce refrigeration load. Whenever the outside air conditions are more favorable (lower heat content) than return air conditions, outdoor air quantity is increased.

Efficacy - Ratio of usable light to energy input for a lighting fixture or system (lumens per watt)

Energy management system - A microprocessor-based system for controlling equipment and monitoring energy and other operating parameters in a building.

Energy requirement - The total yearly energy used by a building to maintain the selected inside design conditions under the dynamic impact of a typical year's climate. It includes raw fossil fuel consumed in the building and all electricity used for lighting and power. Efficiencies of utilization are applied and all energy is expressed in the common unit of Btu.

Energy utilization index - A reference which expresses the total energy (fossil fuel and electricity) used by a building in a given period (month, year) in terms of Btu's/gross conditioned square feet.

Enthalpy - The total heat content of air expressed in units of Btu/pound. It is the sum of the sensible and latent heat.

Evaporator - A heat exchanger in which a liquid evaporates while absorbing heat.

Evaporation - The act of water or other liquids dissipating or becoming vapor or steam.

Expansion valve - A component of the refrigeration system that regulates the rate of flow of liquid refrigerant into the evaporator.

Fan Coil Unit - A small terminal air handling unit with a fan and coil(s) to heat and/or cool the airstream.

Faucet aerator - Either a device inserted into a faucet head or a type of faucet head that reduces water flow by adding air to the water steam through a series of screens and/or small holes through a disk. An aerator produces a low-flow non-splashing stream of water. 
Fill - The portion of a cooling tower that provides a large air-water interface area for heat transfer allowing a small amount of water to evaporates into the airstream, cooling the remaining water.

Flow restrictors - Washer-like disks that fit inside faucet or shower heads to restrict water flow.

Flushometer valve toilet - Also known as a pressure assisted or pressurized tank toilet, a toilet with the flush valve attached to a pressurized water supply tank. When activated, the flush valve supplies the water to the toilet at the higher flow rate necessary to flush all of the waste through the toilet trap and into the sewer.

Foot candle - Illumination at a distance of one foot from a standard candle.

Gravity flush toilet - A toilet designed with a rubber stopper that releases stored water from the toilet's tank. Gravity flow water then fills the bowl and carries the waste out of the bowl, through the trap and into the sewer.

Graywater - Used water discharged by sinks, showers, bathtubs, clothes washing machines, and the like.

Gross square feet - The total number of square feet contained in a building envelope using the floors as area to be measured.

Heat gain - As applied to HVAC calculations, it is that amount of heat gained by space from all sources including people, lights, machines, sunshine, etc. The total heat gain represents the amount of heat that must be removed from a space to maintain indoor comfort conditions. This is usually expressed in Btu's per hour.

Heat loss - The heat loss from a building when the outdoor temperature is lower than the desired indoor temperature it represents the amount of heat that must be provided to a space to maintain indoor comfort conditions. This is usually expressed in Btu/hour.

Heat pump - A refrigeration machine possessing the capability of reversing the flow so that its output can be either heating or cooling. When used for heating, it extracts heat from a low temperature source.

Heat transmission coefficient - Any one of a number of coefficients used in the calculation of heat transmission by conduction, convection, and radiation through various materials and structures.

Hi-pot (high potential) Testing - Process of applying high voltage to electrical components to verify a lack of leakage current and unsafe conditions.

Horsepower $(\mathrm{hp})$ - British unit of power, $1 \mathrm{hp}=746$ watts or 42,408 Btu's per minute.

Hot deck - A hot air chamber forming part of a multi-zone or dual duct air handling unit.

Humidity, relative - A measurement indicating the moisture content of the air.

IAQ - Indoor Air Quality.

IEQ - Indoor Environmental Quality. 
Impeller - The rotating part of a centrifugal pump, compressor, or fan designed to move a fluid by rotational force. It is usually made up of a disc with multiple vanes attached to it.

Infiltration - The process by which outdoor air leaks into a building by natural forces through cracks around doors and windows.

Latent heat - The quantity of heat required to effect a change in state of a substance.

Life-cycle cost - The cost of the equipment over its entire life including operating costs, maintenance costs, and initial cost.

Low flow toilet - A toilet that uses 3.5 gallons of water per flush.

Load profile - Time distribution of building heating, cooling, and electrical load.

Lumen - Unit of measurement of rate of light flow.

Luminaire - Light fixture designed to produce a specific effect.

Makeup - Water supplied to a system to replace that lost by blowdown, leakage, evaporation, etc. Air supplied to a system to provide for combustion and/or ventilation.

Megger - Electronic tool that generates high voltage used in testing insulation integrity.

Modular - System arrangement whereby the demand for energy (heating, cooling) is met by a series of units sized to meet a portion of the load.

Notched Belt - A belt with teeth (notches) used to mechanically link two or more rotating pulleys. The notches increase grip, help cool the belt and relieve stress as the belt bends around small diameter pulleys. This improves drive efficiency.

Orifice plate - Device inserted in a pipe or duct which causes a pressure drop across it. Depending on orifice size, it can be used to restrict flow or form part of a measuring device.

ORSAT apparatus - A device for measuring the combustion components of boiler or furnace flue gasses.

Piggyback operation - Arrangement of chilled water generation equipment whereby exhaust steam from a steam turbine driven centrifugal chiller is used as the heat source of an absorption chiller.

Plenum - A large duct used as a distributor of air from a furnace.

Potable water - Clean, drinkable water; also known as "white" water.

Power factor - Relationship between KVA and KW. The power factor is one when the KVA equals the KW.

Pressurized tank toilet - A toilet that uses a facility's waterline pressure by pressurizing water held in a vessel within the tank; compressing a pocket of trapped air. The water releases at a force 500 times greater than a conventional gravity toilet. 
Pressure reducing valve - A valve designed to reduce a facility's water consumption by lowering supply-line pressure.

Process Load - A cooling or heating load not related to maintaining occupant comfort, such as file server rooms and specialized diagnostic equipment in the health-care sector. The loads may be intermittent or continuous.

Pump Head - The differential pressure of a fluid generated by a pump between its inlet and outlet. This pressure may be expressed in feet of water or pounds per square inch (psi).

Radiation - The transfer of heat from one body to another by heat waves without heating the air between them.

Refrigerant - A substance producing a refrigerating effect by expanding or vaporizing.

R Value - The resistance to heat flow of insulation.

Seasonal efficiency - Ratio of useful output to energy input for a piece of equipment over an entire heating or cooling season. It can be derived by integrating part load efficiencies against time.

Sensible heat - Heat that results in a temperature change, but no change in state.

Siphonic jet urinal - A urinal that automatically flushes when water, which flows continuously to its tank, reaches a specified preset level.

Source meter - A water meter that records the total waterflow into a facility.

Sub meter - A meter that record energy or water usage by a specific process, a specific part of a building, or a building within a larger facility.

Terminal Unit - The final piece of HVAC equipment in the distribution system capable of modifying the temperature in a conditioned space.

Therm - A unit of gas fuel containing 100,000 Btu's.

Thermography - Process of generating visual images that represent variations in infrared radiance of surfaces and objects.

Ton (of refrigeration) - A means of expressing cooling capacity: 1 ton $=12,000$ Btu/hour cooling (removal of heat).

Transducers - Electronic device that converts energy from one form to another.

Trend Logging - Recording system variables (e.g., temperature, volume, pressure, power) at time intervals to monitor equipment operation and help identify or diagnose problems. Logging is accomplished using portable data loggers, electrical meters, or the resident DDC system.

Two-Way Valve - A valve regulating flow between no flow and full flow. It can either modulate or operate as a two-position valve (open/closed) in response to an external input signal. There is no bypass as is found in a 3-way valve. 
U Value - A coefficient expressing the thermal conductance of a composite structure in Btu's per (square foot) (hour) (degree Fahrenheit difference).

Ultra low flow toilet - A toilet that uses 1.6 gallons or less of water per flush.

Variable speed drive - See "Adjustable speed drive."

Variable frequency drive - See "Adjustable speed drive."

V-Belt - A belt used to mechanically link two or more rotating pulleys. The "V" shape of the belt tracks in a mating groove in the pulley (or sheave).

Veiling reflection - Reflection of light from a task or work surface into the viewer's eyes.

Vapor barrier - A moisture impervious layer designed to prevent moisture migration.

Wet bulb temperature - The lowest temperature attainable by evaporating water in the air without the addition or subtraction of energy.

Xeriscaping - The selection, placement, and care of water-conserving and low-water-demand ground covers, plants, shrubs, and trees in landscaping. 

Appendix B

FEMP Staff Contact List 



\section{Appendix B}

\section{FEMP Staff Contact List}

The U.S. Department of Energy (DOE) Federal Energy Management Program facilitates the Federal Government's implementation of sound, cost-effective energy management and investment practices to enhance the nation's energy security and environmental stewardship.

General Contact Information
EE-2L
1000 Independence Avenue, SW
Washington, DC 20585-0121
202-586-5772
www.femp.energy.gov
Leadership Team
Richard Kidd
Program Manager
202-586-5772
richard.kidd@ee.doe.gov
Jerry Dion
Senior Technology Matrix Manager
202-586-9710
jerry.dion@ee.doe.gov
Brad Gustafson
Supervisor, Applied Technology Services;
Greenhouse Gas Management
202-586-5865
brad.gustafson@ee.doe.gov
Scott Richlen
Supervisor, Decision Support Services
202-586-2078
scott.richlen@ee.doe.gov
Schuyler (Skye) Schell
Supervisor, Project Transaction Services
202-586-9015
schuyler.schell@ee.doe.gov
Arielle Wait
Administrative Support
202-586-5772
arielle.wait@ee.doe.gov
Project Transaction Services
Financing assistance, including ESPCs,
UESCs, and PPAs
Tishisa Braziel
Public Benefit Funds; Enhanced Use
Leases
202-586-7748
tishisa.braziel@ee.doe.gov
Rebecca Dyer
Procurement Policy
202-586-8215
rebecca.dyer@ee.doe.gov

\author{
Nate Folkemer \\ ESPCs \\ 202-287-6033 \\ nathaniel.folkemer@ee.doe.gov \\ Tracy Logan \\ Utility Acquisitions, DOE Rate \\ Interventions, Renewable Power \\ Purchases \\ 202-586-9973 \\ tracy.logan@ee.doe.gov

\section{David McAndrew} \\ Renewable Power Purchases; UESCs; \\ GovEnergy \\ 202-586-7722 \\ david.mcandrew@ee.doe.gov

\section{William Raup \\ ESPCs} \\ 202-586-2214 \\ william.raup@ee.doe.gov
}

\section{Ab Ream \\ Operations and Maintenance; Metering; \\ Commissioning; Energy Audits \\ 202-586-7230 \\ ab.ream@ee.doe.gov}

Applied Technology Services

Technology assistance surrounding energy efficiency and renewable energy

\section{Anne Crawley \\ Renewable Energy \\ 202-586-1505 \\ anne.crawley@ee.doe.gov}

\section{Shawn Herrera}

Metering; Technical Assistance

202-586-1511

shawn.herrera@ee.doe.gov

Boyan Kovacic

Renewable Energy

202-586-4272

boyan.kovacic@ee.doe.gov

Will Lintner

Labs21; Water; Data Centers; New

Technologies; Sustainability

202-586-3120

william.lintner@ee.doe.gov

\section{Mark Reichhardt}

Renewable Power Purchases; Renewable

Energy; Sustainability

202-586-4788

mark.reichhardt@ee.doe.gov

\author{
Amanda Sahl \\ Fleets; Awards; Communications \\ 202-586-1662 \\ amanda.sahl@ee.doe.gov \\ Stephen Walder \\ Energy-Efficient Products \\ 202-586-9209 \\ stephen.walder@ee.doe.gov
}

Decision Support Services

Energy outreach, guidance, training, and education to embrace energy efficiency and renewable energy

\section{David Boomsma}

Budgeting; Planning; Performance

Tracking

202-586-7086

david.boomsma@ee.doe.gov

Teresa Carroll

Schedules and Metrics Tracking

202-586-6477

teresa.carroll@ee.doe.gov

\section{Annie Haskins}

Communications/Outreach; Awards; EERE Information Center

202-586-4536

annie.haskins@ee.doe.gov

Hayes Jones

Communications/Outreach; Awards;

FEMP Focus

202-586-8873

hayes.jones@ee.doe.gov

\section{Joe Konrade}

Peer Review; State Collaboration; Technology Transfer; FEMP Web Site 202-586-8039

joseph.konrade@ee.doe.gov

Cyrus Nasseri

Energy Efficiency Standards; Rule

Making

202-586-9138

cyrus.nasseri@ee.doe.gov

Chris Tremper

Reporting; Guidance; Interagency

Coordination

202-586-7632

chris.tremper@ee.doe.gov

For the most recent contact information please visit http://wwwl .eere.energy.gov/femp/about/contacts.html. 


\section{EDERAL ENERGY MANAGEMENT PROGRAM}

Each Federal agency has a single contact within FEMP. This contact serves as that agency's customer service representative to help identify appropriate resources and resolve concerns related to FEMP services. Representatives also assist in agency planning to meet energy goals.

\begin{tabular}{|c|c|}
\hline Federal Agency/Sub-Agency & FEMP Customer Service Representative \\
\hline Broadcasting Board of Governors & Chris Tremper, 202-586-7632, chris.tremper@ee.doe.gov \\
\hline Department of Agriculture (USDA) & Boyan Kovacic, 202-586-4272, boyan.kovacic@ee.doe.gov \\
\hline Department of Commerce (DOC) & Joe Konrade, 202-586-8039, joseph.konrade@ee.doe.gov \\
\hline Department of Defense (DOD) & Richard Kidd, 202-586-5772, richard.kidd@ee.doe.gov \\
\hline Department of Energy (DOE) & Cyrus Nasseri, 202-586-9138, cyrus.nasseri@ee.doe.gov \\
\hline Department of Health and Human Services (HHS) & David McAndrew, 202-586-7722, david.mcandrew@ee.doe.gov \\
\hline Department of Homeland Security (DHS) & Ab Ream, 202-586-7230, ab.ream@ee.doe.gov \\
\hline Department of Housing and Urban Development (HUD) & Stephen Walder, 202-586-9209, stephen.walder@ee.doe.gov \\
\hline Department of Justice (DOJ) & Tracy Logan, 202-586-9973, tracy.logan@ee.doe.gov \\
\hline Department of Labor (DOL) & Nate Folkemer, 202-287-6033, nathaniel.folkemer@ee.doe.gov \\
\hline Department of State & Mark Reichhardt, 202-586-4788, mark.reichhardt@ee.doe.gov \\
\hline Department of the Interior (DOI) & Joe Konrade, 202-586-8039, joseph.konrade@ee.doe.gov \\
\hline Department of the Treasury & Tishisa Braziel, 202-586-7748, tishisa.braziel@ee.doe.gov \\
\hline Department of Transportation (DOT) & Amanda Sahl, 202-586-1662, amanda.sahl@ee.doe.gov \\
\hline Environmental Protection Agency (EPA) & Mark Reichhardt, 202-586-4788, mark.reichhardt@ee.doe.gov \\
\hline General Services Administration (GSA) & Schuyler (Skye) Schell, 202-586-9015, schuyler.schell@ee.doe.gov \\
\hline National Aeronautics and Space Administration (NASA) & David Boomsma, 202-586-7086, david.boomsma@ee.doe.gov \\
\hline National Archives and Records Administration (NARA) & Rebecca Dyer, 202-586-8215, rebecca.dyer@ee.doe.gov \\
\hline Smithsonian Institution & Teresa Carroll, 202-586-6477, teresa.carroll@ee.doe.gov \\
\hline Social Security Administration (SSA) & Annie Haskins, 202-586-4536, annie.haskins@ee.doe.gov \\
\hline Tennessee Valley Authority (TVA) & Shawn Herrera, 202-586-1511, shawn.herrera@ee.doe.gov \\
\hline U.S. Air Force & Hayes Jones, 202-586-8873, hayes.jones@ee.doe.gov \\
\hline U.S. Army & Anne Crawley, 202-586-1505, anne.crawley@ee.doe.gov \\
\hline U.S. Marine Corps & William Raup, 202-586-2214, william.raup@ee.doe.gov \\
\hline U.S. Navy & Will Lintner , 202-586-3120, william.lintner@ee.doe.gov \\
\hline U.S. Postal Service (USPS) & Brad Gustafson, 202-586-5865, brad.gustafson@ee.doe.gov \\
\hline U.S. Railroad Retirement Board (RRB) & Chris Tremper, 202-586-7632, chris.tremper@ee.doe.gov \\
\hline Veterans Affairs (VA) & Scott Richlen, 202-586-2078, scott.richlen@ee.doe.gov \\
\hline
\end{tabular}


Appendix C

Resources 



\title{
Appendix C
}

\section{Resources for Energy and Facilities Professionals}

The references and resources provided below are by no means all-inclusive. The listed organizations are not endorsed by the authors of this guide and are provided for your information only. To locate additional resources, the authors of this guide recommend contacting relevant trade groups, databases, and the world-wide web.

\section{Organizations}

\author{
American Society for Healthcare Engineering (ASHE) \\ Website: www.ashe.org \\ Description: ASHE serves as an advocate and resource for continuous improvement in healthcare \\ engineering and facilities management and is the largest professional group affiliated with the \\ American Hospital Association. ASHE provides its members with information and education \\ through comprehensive publications and educational programming.
}

\section{American Society of Mechanical Engineers (ASME)}

Website: http://www.asme.org/

Description: The work of ASME is performed by its member-elected Board of Governors and through its 5 councils, 44 boards, and hundreds of committees in 13 regions throughout the world. There are a combined 400 sections and student sections serving ASME's world-wide membership. ASME's vision is to be the premier organization for promoting the art, science, and practice of mechanical engineering throughout the world.

Association for Facilities Engineering (AFE)

Website: http://www.afe.org/

Description: AFE provides education, certification, technical information, and other relevant resources for plant and facility engineering as well as O\&M professionals.

\section{Association of Energy Engineers (AEE)}

Website: www.aeecenter.org

Description: AEE is a comprehensive provider of information serving the fields of energy efficiency, energy services, deregulation, facility management, plant engineering, and environmental compliance.

\section{American Society of Heating, Refrigeration, and Air-Conditioning Engineers (ASHRAE)} Website: www.ashrae.org

Description: ASHRAE fulfills its mission of advancing heating, ventilation, air conditioning, and refrigeration to serve humanity and promote a sustainable world through research, standards writing, publishing, and continuing education. 


\section{Association of Higher Education Facilities Officers}

Website: http://www.appa.org/

Description: APPA (formerly the Association of Physical Plant Administrators) is the association of choice serving educational facilities professionals. An international association dedicated to maintaining, protecting, and promoting the quality of educational facilities, APPA represents more than 1,500 learning institutions serving over 4,700 individuals. APPA's membership includes facilities professionals from public and private, two-year and four-year colleges and universities; medical and law schools; seminaries; public and private K-12 schools and districts; museums and parks; military installations; Federal, state, and city-county governments.

\section{BetterBricks Professional Education \\ Website: www.betterbricks.com}

Description: BetterBricks Professional Education and its partners offer a variety of professional education options at low or no cost throughout the Northwest to improve understanding about the benefits and elements of high-performance building.

\section{Boiler Efficiency Institute \\ Website: www.boilerinstitute.com}

Description: $\mathrm{BEI}$ is the nationally recognized leader in training for optimizing facility systems to minimize costs. Currently BEI is a partnership composed of its two founders: Drs. Glennon Maples and David Dyer and Tom Burch. Collectively, these individuals have written a dozen textbooks, authored five patents, published over fifty scientific papers, and developed numerous computer software packages in their areas of expertise. They have taught more than a thousand workshops involving more than 100,000 people. More than 125,000 facility operation personnel use their textbooks.

\section{Building Commissioning Association (BCA) \\ Website: www.bcxa.org}

Description: BCA promotes building-commissioning practices that maintain high professional standards and fulfill building owners' expectations. The BCA provides information and resources to its members and to the public to increase awareness and promote building commissioning.

\section{Building Operator Certification (BOC) \\ Website: www.theboc.info}

Description: $\mathrm{BOC}$ is a nationally recognized training and certification program for building operators offering improved job skills and more comfortable, energy-efficient facilities. Certification is competency-based and offered at two levels. Level I emphasizes energy-efficient building maintenance practices, while Level II emphasizes equipment troubleshooting and maintenance for energy savings.

\section{Building Owners and Managers Association (BOMA) \\ Website: www.boma.org}

Description: The mission of BOMA International is to enhance the human, intellectual, and physical assets of the commercial real-estate industry through advocacy, education, research, standards, and information. Local associations are in Boise, Portland, Seattle, South Puget Sound, Tri-Cities, and Spokane. 


\section{Energy Facility Contractors Group (EFCOG)}

Website: www.efcog.org

Description: EFCOG promotes excellence in all aspects of the operation, management, and integration of DOE facilities in a safe, environmentally sound, efficient and cost-effective manner through the ongoing exchange of information on lessons learned.

\section{Facilities Net}

Website: http://www.facilitiesnet.com

Description: Organization and wed site for professionals in facility design, construction, and maintenance.

\section{Federal Energy Management Program (FEMP), U.S. Department of Energy (DOE)} Website: wwwl.eere.energy.gov/femp

Description: FEMP helps Federal agencies find innovative solutions to their most difficult energy challenges and address their full range of energy management responsibilities.

\section{Industrial Efficiency Alliance}

Website: www.industrialefficiencyalliance.org

Description: The Industrial Efficiency Alliance and its partners offer business and technical training courses that are designed to equip attendees with the knowledge and tools to improve competitiveness and enhance system performance through increased energy efficiency.

\section{Institute of Asset Management (IAM)}

Website: http://www.iam-uk.org/

Description: An independent organization for professionals dedicated to furthering our knowledge and understanding of Asset Management. In particular, the institute seeks to spread good practice and develop decision support tools and techniques.

Institute of Industrial Engineers (IIE)

Website: http://www.iienet.org/

Description: IIE is the largest professional society dedicated solely to the support of the industrial engineering profession and individuals involved with improving quality and productivity. IIE is an international, nonprofit association that provides leadership for the application, education, training, research, and development of industrial engineering.

\section{International Council for Machinery Lubrication (ICML)}

Website: http://www.lubecouncil.org

Description: A vendor-neutral, not-for-profit organization founded to facilitate growth and development of machine lubrication as a technical field of endeavor. Among its various activities, ICML offers skills-based certification testing for individuals in the fields of machine condition monitoring, lubrication, and oil analysis.

\section{International Facility Management Association (IFMA)}

Website: www.ifma.org

Description: IFMA is a professional association for facility managers. IFMA membership comprises more than 17,500 facility professionals in 56 countries. Their members have a voice in 125 chapters, 15 councils, and one Special Interest Group. 
International Maintenance Institute (IMI)

Website: www.imionline.org

Description: The philosophy of the IMI to professionalize the maintenance function by helping maintenance managers to work smarter through the exchange of ideas and education. The IMI is a goal-driven organization made up of decision making maintenance leaders as well as related sales and service professionals - all dedicated to keeping a nation's infrastructure operating smoothly.

International Training Institute (ITI)

Website: www.sheetmetal-iti.org

Description: ITI has a variety of curricula that teach the students how to operate and service HVAC equipment. This includes the refrigeration system and it components, all types of heating systems (oil, gas, and electric) and their components, as well as the electrical fundamentals required by all of these systems.

\section{International Union of Operating Engineers (IUOE) \\ Website: www.ivoe.org}

Description: IUOE is a progressive, diversified trade union that primarily represents operating engineers who work as heavy-equipment operators; mechanics and surveyors in the construction industry; and stationary engineers who work in operation and maintenance in building and industrial complexes, and in the service industries. Founded in 1896, the IUOE today is the $12^{\text {th }}$ largest union in the AFL-CIO and has 400,000 members in some 170 local unions throughout the United States and Canada. They offer apprenticeships and training to IUOE members.

\section{Lighting Design Lab}

Website: www.lightingdesignlab.com

Description: The Lighting Design Lab in Seattle, WA provides assistance to commercial lighting designers, facility managers, and specification writers that seek the most efficient lighting technologies and strategies.

\section{Machinery Information Management Open Systems Alliance (MIMOSA) \\ Website: http://www.mimosa.org/}

Description: Advocates open exchange of equipment condition related information between condition assessment, process control, and maintenance information systems through published, consensus, conventions and to gain greatest value by combining vital condition information from multiple sources for collective evaluation, reaching accurate determinations of current condition, and projected lifetime and communicating results in a useful, understandable form. MIMOSA is committed to preserving the advantages, effectiveness, and rich detail contained in specialized applications such as vibration, temperature, lubricating oil, and electric motor monitoring and analysis systems within an integrated enterprise information structure.

\section{Maintenance and Reliability Center (MRC)}

Website: http://www.engr.utk.edu/mrc/

Description: A premier institution, headquartered at the University of Tennessee, for education, research, development, information exchange and application of maintenance and reliability engineering. Maintenance and reliability engineering focuses on the use of analysis techniques, advanced predictive and preventive technologies and management systems to identify, manage and eliminate failures that lead to losses in system function. 


\section{Motor Decisions Matter}

Website: www.motorsmatter.org/

Description: A national campaign encouraging the use of sound motor management and planning as a tool to cut motor energy costs and increase productivity. The campaign is sponsored by a consortium of motor industry manufacturers and service centers, trade associations, electric utilities, and government agencies.

\section{National Association of Energy Service Companies (NAESCO) \\ Website: www.naesco.org}

Description: NAESCO is a national trade association which has been promoting the benefits of the widespread use of energy efficiency for over 20 years. On behalf of its membership, NAESCO works to help open new markets for energy services by directly promoting the value of demand reduction to customers through seminars, workshops, training programs, publication of case studies and guidebooks, and the compilation and dissemination of aggregate industry data.

\section{National Association of State Energy Officials (NASEO) \\ Website: www.naseo.org}

Description: NASEO was formed by the states and through an agreement with the National Governors Association in 1986. The organization was created to improve the effectiveness and quality of state energy programs and policies, provide policy input and analysis, share successes among the states, and to be a repository of information on issues of particular concern to the states and their citizens. NASEO is an instrumentality of the states and derives basic funding from the states and the Federal government.

\section{National School Plant Management Association (NSPMA)}

Website: http://nspma.org/

Description: Chartered in 1995, NSPMA was formed in the interest on enhancing and promoting the educational process. Its purpose is to provide for the exchange of information that improves school plant management, maintenance, and care through the promotion of acceptable policies, standards, and practices and to promote the professional advancement of school plant management personnel.

\section{National Sustainable Building Advisor Program (NaSBAP) \\ Website: www.nasbap.org}

Description: NaSBAP offers a training program specifically designed for working professionals wishing to apply sustainable concepts to the buildings they design, develop, and construct—buildings that are energy- and resource-efficient, healthy working and living environments, environmentally responsible, and cost effective. Participants include architects, engineers, tenant and developer representatives, construction and capital project managers, other building industry professionals, and resource conservation specialists.

\section{North Carolina State University Maintenance and Reliability Management Program Web site: http://continuingeducation.ncsu.edu/mrm.html}

Description: North Carolina State University, in partnership with Marshall Institute, offers a threeweek program to develop maintenance and reliability knowledge and sharpen leadership skills for today's increasingly competitive global marketplace. This program will expose you to real-world examples and will provide you with practical knowledge and skills applicable in your plant or facility. 
Northwest Energy Education Institute (NEEI)

Website: www.nweei.org

Description: NEEI is located within the Science Department at Lane Community College, Eugene, Oregon. They have provided energy-efficiency training and development throughout the Northwest since 1998.

\section{Oklahoma Predictive Maintenance Users Group (OPMUG)}

Website: http://www.opmug.net/

Description: Established in 1992 to provide maintenance professionals throughout Oklahoma, and the surrounding states, an opportunity to share and obtain first hand knowledge about predictive maintenance.

\section{Plant Engineering and Maintenance Association of Canada (PEMAC)}

Website: http://www.pemac.org

Description: The national technical association devoted to plant engineering and maintenance, created by and for plant engineering and maintenance people.

\section{Plant Operations Support Program \\ Website: www.ga.wa.gov/plant}

Description: The Plant Operations Support Program is comprised of state agencies, educational facilities, municipalities, and port districts, and acts as a clearinghouse for best practices, organizational standards, and surplus/salvage materials. The consortium includes hundreds of professionals with varied experience and expertise who regularly share solutions and lessons learned.

Professional Thermographers Association

Website: http://www.prothermographer.com

Description: The mission of the Professional Thermographers Association is to provide a platform for non-biased information, professional communication and unity, for individuals and organizations involved in providing, or procuring infrared thermographic services, equipment and support.

\section{Society for Machinery Failure Prevention Technology (MFPT)}

Website: http://www.mfpt.org/

Description: A Division of the Vibration Institute, MFPT acts as a focal point for technological developments that contribute to mechanical failure reduction or prevention.

\section{Society for Maintenance \& Reliability Professionals (SMRP)}

Website: www.smrp.org

Description: An independent, non-profit society by and for practitioners in the Maintenance \& Reliability Profession with nearly 2,000 members strong with global penetration.

Society of Reliability Engineers (SRE)

Website: http://www.sre.org/

Description: SRE is an organization dedicated to all forms of reliability engineering and education. 
U.S. Department of Energy Industrial Technology Program (ITP)

Web site: http://wwwl.eere.energy.gov/industry/

Description: The Industrial Technologies Program (ITP) leads national efforts to improve industrial energy efficiency and environmental performance. ITP is part of the U.S. Department of Energy's Office of Energy Efficiency and Renewable Energy and contributes to its efforts by partnering with U.S. industry in a coordinated program of research and development, validation, and dissemination of energy efficiency technologies and operating practices. ITP works with industry to save energy and money, increase productivity, and reduce environmental impacts by:

- Conducting R\&D on new energy efficient technologies

- Supporting commercialization of emerging technologies

- Providing plants with access to proven technologies, energy assessments, software tools, and other resources

- Promoting energy and carbon management in industry.

\section{U.S. EPA ENERGY STAR}

Website: estar7.energystar.gov/index.cfm?c=business.bus_internet_presentations

Description: ENERGY STAR is a government-backed program helping businesses and individuals protect the environment through superior energy efficiency. ENERGY STAR provides tools and resources that assist facility professionals develop a customized strategy, strengthen communication with decision makers, and gain recognition for their achievements.

\section{Washington State University (WSU) Energy Program}

Website: www.energy.wsu.edu/ten

Description: The WSU Energy Program provides support and information for Resource Efficiency Managers (REMs) or Resource Conservation Managers (RCMs). A REM or RCM is a designated individual acquired by an agency to support its energy and resource efficiency program. The sole focus of the REM or RCM is to bring about reductions in the cost of energy, water, natural gas, fuel oil, refuse disposal, and any other utilities. This is done through improved use practices, greater attention to utility billings and rate structures, and the installation and use of resource-management equipment.

\section{University of California at Davis California Lighting Technology Center (CLTC)}

Web site: http://cltc.ucdavis.edu/content/view/132/208/

Description: The California Lighting Technology Center's (CLTC) mission is to stimulate, facilitate and accelerate the development and commercialization of energy efficient lighting and daylighting technologies. This is accomplished through technology development and demonstrations, as well as offering outreach and education activities in partnership with utilities, lighting manufacturers, end users, builders, designers, researchers, academicians and governmental agencies.

\section{University of Maryland Reliability Engineering Program}

Web site: http://www.enre.umd.edu/

Description: The Reliability Engineering Program at the University of Maryland was approved to offer the MS and $\mathrm{PhD}$ degrees in Reliability Engineering in 1989. It provides a broad range of courses and experiences for its students, designed to prepare them to assist the nation in its ability to produce complex technological systems with ultra-high reliability and availability. 


\section{Publications}

Building Operating Management

www.facilitiesnet.com

Chilton's Industrial Maintenance

and Plant Operation

www.impomag.com

HPAC Engineering

1300 E Ninth Street

Cleveland, $\mathrm{OH}$ 44114-1503

(216) 696-7000

www.hpac.com

Industrial Maintenance and Plant Operation

www.impomag.com

Maintenance Solutions

P.O. Box 5268

Pittsfield, MA 01203-5268

www.facilitiesnet.com

Maintenance Technology

(847) 382-8100/Fax: (847) 304-8603

www.mt-online.com

P/PM Technology

SC Publishing

P.O. Box 2770

Minden, NV 89423-2770

(702) 267-3970

Plant \& Facilities Engineering Digest

Adams/Huecore Publishing, Inc.

29100 Aurora Road, Suite 200

Cleveland, $\mathrm{OH} 44139$

(708) 291-5222

Preventative Maintenance Magazine

Reliability Magazine

www.reliability-magazine.com/ 


\section{Appendix D}

Suggestions for Additions or Revisions 



\section{Appendix D}

\section{Suggestions for Additions or Revisions}

This guide is open to periodic updates and improvement. Readers are encouraged to submit suggestions for additions, deletions, corrections, or where to go for other resources.

In addition, we are interested in what has worked at your Federal site. We want to find other case studies and documentation of your successes.

Please send or fax your information to:

Bill Sandusky

Pacific Northwest National Laboratory (PNNL)

P.O. Box 999, MS K5-08

Richland, WA 99352

email: bill.sandusky@pnl.gov

Fax (509) 375-3614

Additional material to include (please be specific):

Additional References/Resources:

Additional material to include (please be specific): 
Additional References/Resources:

Case study material (feel free to attach additional sheets): 


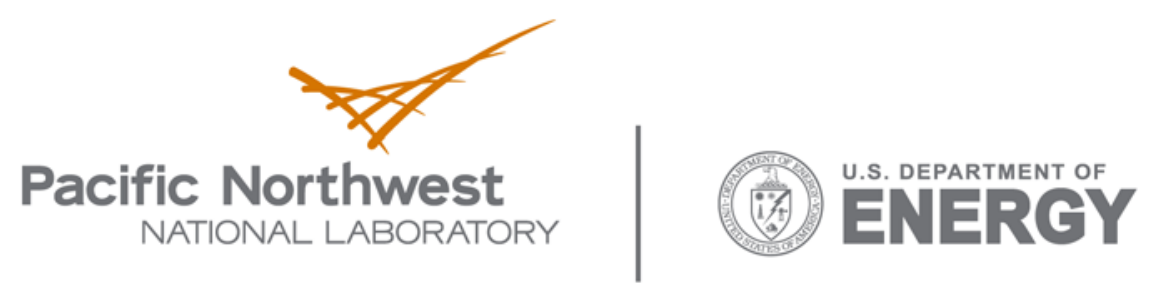

902 Battelle Boulevard

P.O. Box 999

Richland, WA 99352

1-888-375-PNNL (7665)

www.pnl.gov 